\title{
Effects of Grit Roughness and Pitch Oscillations on the LS(1)-0417MOD Airfoil
}

J. M. Janiszewska

R. Reuss Ramsay

M. J. Hoffman

G. M. Gregorek

The Ohio State University

Columbus, Ohio

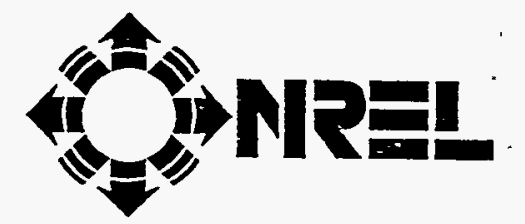

MASTER

National Renewable Energy Laboratory 1617 Cole Boulevard

Golden, Colorado 80401-3393

A national laboratory of the U.S. Department of Energy Managed by Midwest Research Institute for the U.S. Department of Energy under Contract No. DE-AC36-83CH10093 



\section{Effects of Grit Roughness} and Pitch Oscillations on the LS(1)-0417MOD Airfoil

J. M. Janiszewska

R. Reuss Ramsay

M. J. Hoffman

G. M. Gregorek

The Ohio State University

Columbus, Ohio

NREL Technical Monitor:

C. P. Butterfield

\section{MASTER}

National Renewable Energy Laboratory 1617 Cole Boulevard Golden, Colorado 80401-3393

A national laboratory of the U.S. Department of Energy Managed by Midwest Research Institute for the U.S. Department of Energy under contract No. DE-AC36-83CH10093

Prepared under Subcontract No. XF-1-11009-3

January 1996 


\section{NOTICE}

This report was prepared as an account of work sponsored by an agency of the United States government. Neither the United States government nor any agency thereof, nor any of their employees, makes any warranty, express or implied, or assumes any legal liability or responsibility for the accuracy, completeness, or usefulness of any information, apparatus, product, or process disclosed, or represents that its use would not infringe privately owned rights. Reference herein to any specific commercial product, process, or service by trade name, trademark, manufacturer, or otherwise does not necessarily constitute or imply its endorsement, recommendation, or favoring by the United States govemment or any agency thereof. The views and opinions of authors expressed herein do not necessarily state or reflect those of the United States government or any agency thereof.

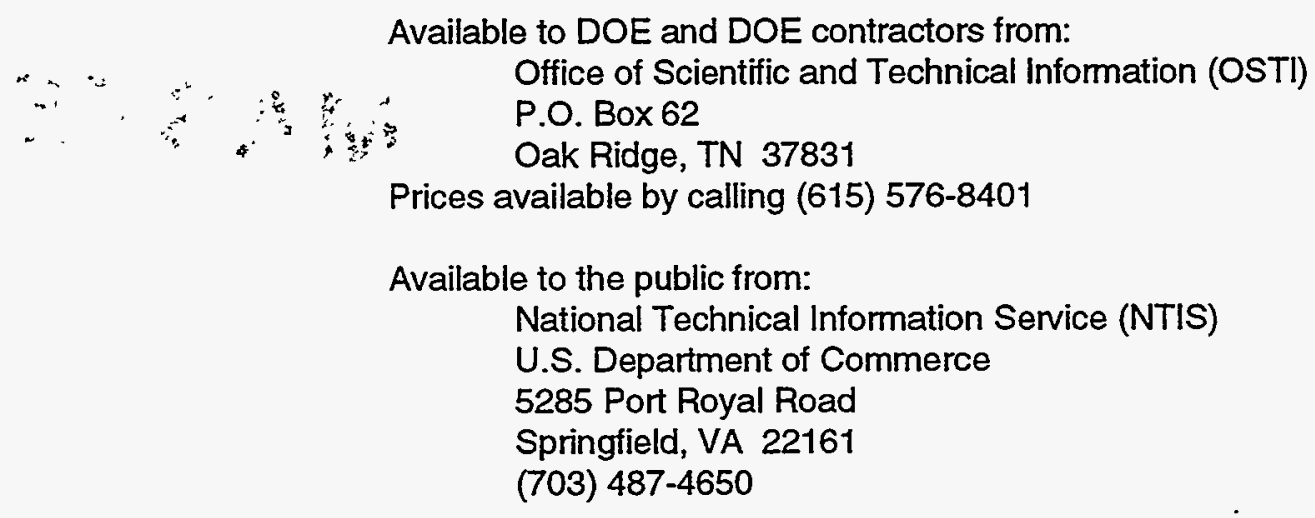




\section{Foreword}

Airfoils for wind turbines have been selected by comparing data from different wind tunnels, tested under different conditions, making it difficult to make accurate comparisons. Most wind tunnel data sets do not contain airfoil performance in stall commonly experienced by turbines operating in the field. Wind turbines commonly experience extreme roughness for which there is very little data. Finally, recent tests have shown that dynamic stall is a common occurrence for most wind turbines operating in yawed, stall or turbulent conditions. Very little dynamic stall data exists for the airfoils of interest to a wind turbine designer. In summary, very little airfoil performance data exists which is appropriate for wind turbine design.

Recognizing the need for a wind turbine airfoil performance data base, the National Renewable Energy Laboratory (NREL), funded by the U.S. Department of Energy, awarded a contract to Ohio State University (OSU) to conduct a wind tunnel test program. Under this program OSU tested a series of popular wind turbine airfoils. A standard test matrix was developed to assure that each airfoil was tested under the same conditions. The test matrix was developed in partnership with industry and is intended to include all of the operating conditions experienced by wind turbines. These conditions include airfoil performance at high angles of attack, rough leading edge (bug simulation), steady and unsteady angles of attack.

Special care has been taken to report as much of the test conditions and raw data as practical so that designers can make their own comparisons and focus on details of the data relevant to their design goals. Some of the airfoil coordinates are proprietary to NREL or an industry partner. To protect the information which defines the exact shape of the airfoil, the coordinates have not been included in the report. Instructions on how to obtain these coordinates may be obtained by contacting C.P. (Sandy) Butterfield at NREL.

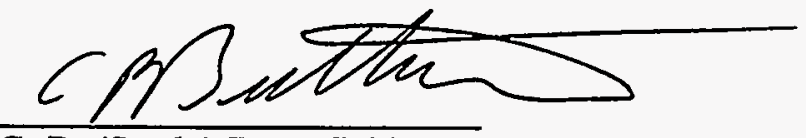

C. P. (Sandy) Butterfield

Wind Technology Division

National Renewable Energy Laboratory

1617 Cole Blvd.

Golden, Colorado, 80401 USA

Internet Address: Sandy_Butterfield@NREL.GOV

Phone 303-384-6902

FAX 303-384-6901 


\section{Preface}

The Ohio State University Aeronautical and Astronautical Research Laboratory is conducting a series of steady state and unsteady wind tunnel tests on a set of airfoils which have been or will be used for horizontal axis wind turbines. The purpose is to investigate the effect of pitch oscillations and leading edge grit roughness on airfoil performance. The study of pitch oscillation effects can help to understand the behavior of horizontal axis wind turbines in yaw. The results of these tests will aid in the development of new airfoil performance codes which account for unsteady behavior and also aid in the design of new airfoils for wind turbines. The application of leading edge grit roughness simulates surface irregularities that occur on wind turbines. These irregularities on the blades are due to the accumulation of insect debris, ice, and/or the aging process and can significantly reduce the power output of the horizontal axis wind turbines. The experimental results from the application of LEGR will help the development of airfoils which are less sensitive to this kind of roughness.

This work was made possible by the efforts and financial support of the National Renewable Energy Laboratory which provided major funding and technical monitoring, the U.S. Department of Energy is credited for its funding of this document through the National Renewable Energy Laboratory under contract number DE-AC36-83CH10093 and KENETECH, U.S. Windpower Incorporated which provided technical assistance. The staff of The Ohio State University Aeronautical and Astronautical Research Laboratory appreciate the contributions made by personnel from both organizations. In addition the authors would like to recognize the efforts of the following student research assistants, Fernando Falasca and Monica Angelats i Coll. 


\section{Summary}

A LS(1)-0417MOD airfoil model was tested in The Ohio State University Aeronautical and Astronautical Research Laboratory $3 \times 5$ subsonic wind tunnel under steady state and unsteady conditions. The test defined baseline conditions for steady state angles of attack from $-20^{\circ}$ to $+40^{\circ}$ and examined unsteady behavior by oscillating the model about its pitch axis for three mean angles, three frequencies, and two amplitudes. For all cases, Reynolds numbers of $0.75,1,1.25$, and 1.5 million were used. In addition, the above conditions were repeated after the application of leading edge grit roughness (LEGR) to determine contamination effects on the airfoil performance.

Steady state results of the LS(1)-0417MOD testing at Reynolds number of 1 million showed a baseline maximum lift coefficient of 1.55 at $15.3^{\circ}$ angle of attack. The application of LEGR reduced the maximum lift coefficient by as much as $27 \%$ and increased the minimum drag coefficient by more than $36 \%$. The zero lift pitching moment of -0.0748 showed a $15 \%$ reduction in magnitude to -0.0634 with LEGR applied.

Data were also obtained for two pitch oscillation amplitudes: $\pm 5.5^{\circ}$ and $\pm 10^{\circ}$. The larger amplitude consistently gave a higher maximum lift coefficient than the smaller amplitude, and both unsteady maximum lift coefficients were greater than the steady state values. Stall is delayed on the airfoil while the angle of attack is increasing, thereby causing an increase in maximum lift coefficient. A hysteresis behavior was exhibited for all the unsteady test cases. The hysteresis loops were larger for the higher reduced frequencies and for the larger amplitude oscillations. As in the steady case, the effect of LEGR in the unsteady case was to reduce the lift coefficient at high angles of attack. In addition, with LEGR, the hysteresis behavior persisted into lower angles of attack than in the clean case. The application of LEGR also increased the size of the hysteresis loops.

In general, the unsteady maximum lift coefficient was from $9 \%$ to $119 \%$ higher than the steady state maximum lift coefficient, and variation in the quarter chord pitching moment coefficient magnitude was from $3 \%$ to $1059 \%$ relative to steady state values at high angles of attack. These findings indicate the importance of considering the unsteady flow behavior occurring in wind turbine operation in order to obtain accurate loads estimates. 


\section{Table of Contents}

Preface iv

Summary

List of Symbols ix

Introduction

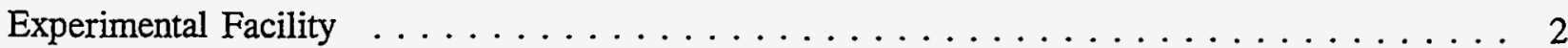

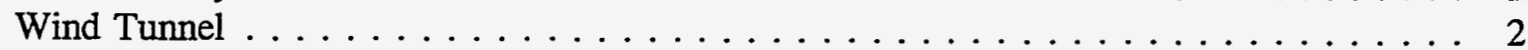

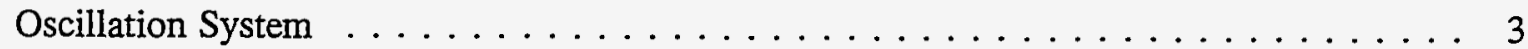

Model Details $\ldots \ldots \ldots \ldots \ldots \ldots \ldots \ldots \ldots \ldots \ldots \ldots \ldots \ldots \ldots$

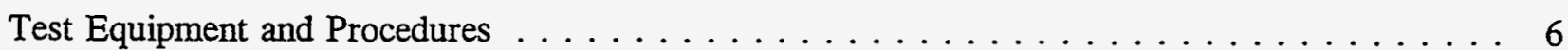

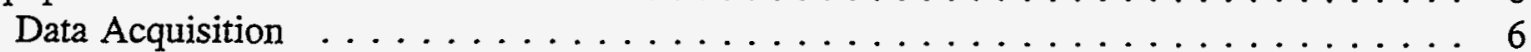

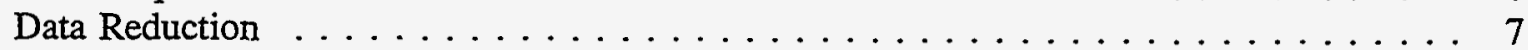

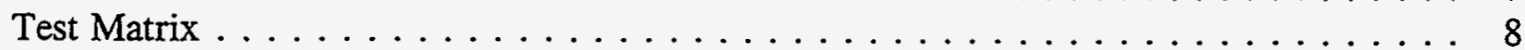

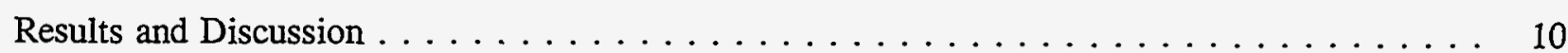

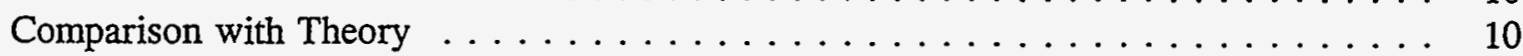

Steady State Data . . . . . . . . . . . . . . . . . . . . . . 11

Unsteady Data . . . . . . . . . . . . . . . . . . . . . 13

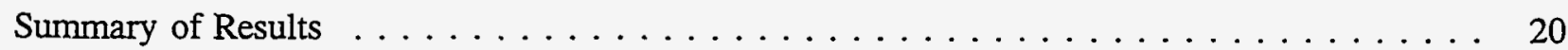

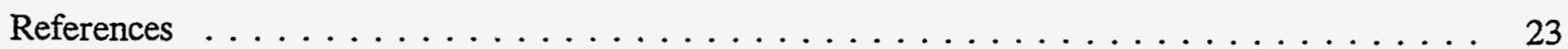

Appendix A: Model and Surface Pressure Tap Coordinates $\ldots \ldots \ldots \ldots \ldots$. . . . . A-1

Appendix B: Steady State Data $\ldots \ldots \ldots \ldots \ldots \ldots \ldots \ldots \ldots \ldots \ldots \ldots$

Appendix $C:$ Unsteady Integrated Coefficients $\ldots \ldots \ldots \ldots \ldots \ldots \ldots \ldots$ 


\section{List of Figures}

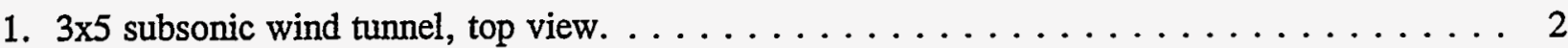

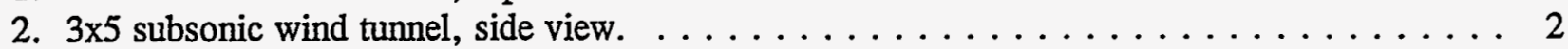

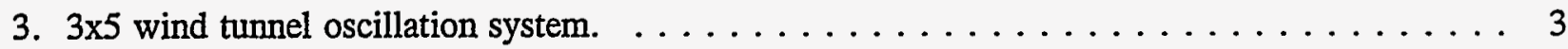

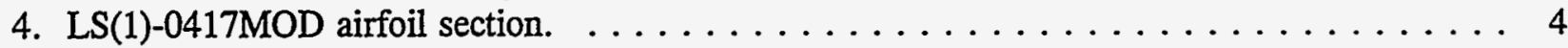

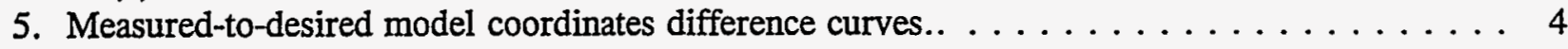

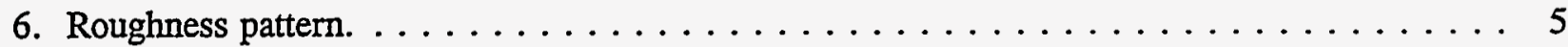

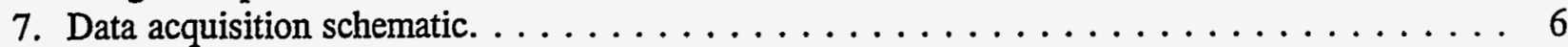

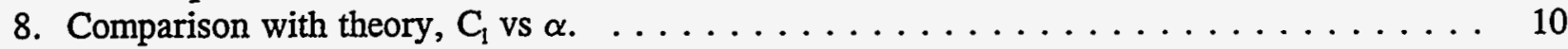

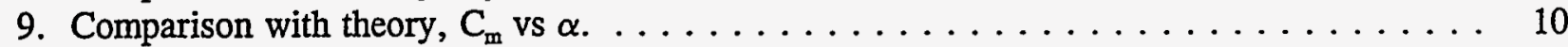

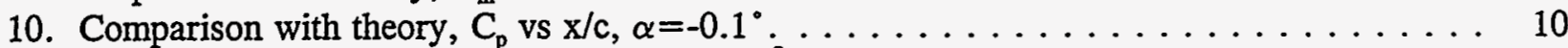

11. Comparison with theory, $\mathrm{C}_{\mathrm{p}} \mathrm{vs} \mathrm{x} / \mathrm{c}, \alpha=8.2^{\circ} \ldots \ldots \ldots \ldots \ldots \ldots \ldots \ldots \ldots$

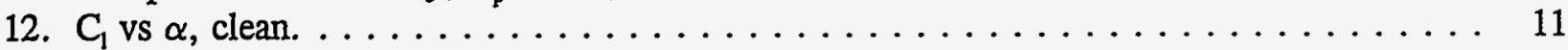

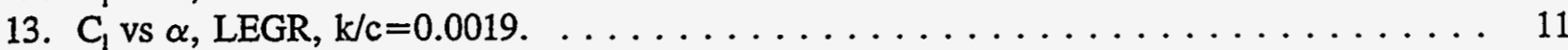

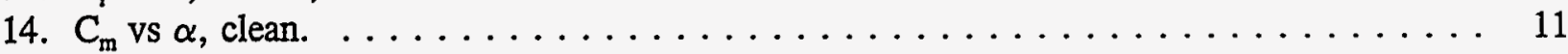

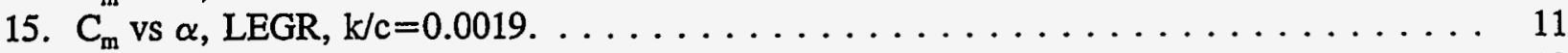

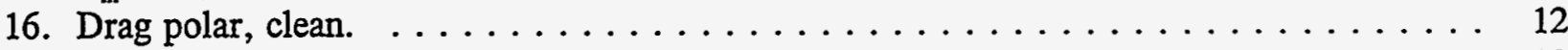

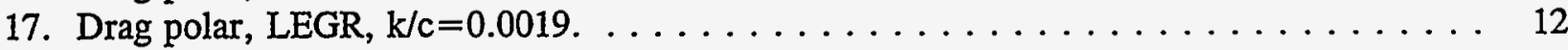

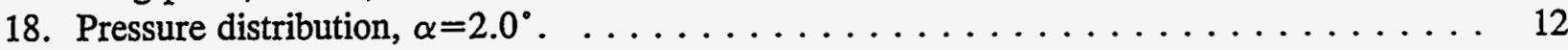

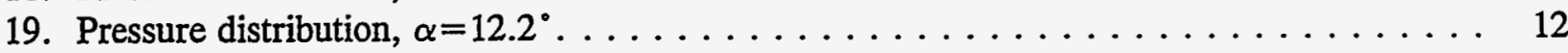

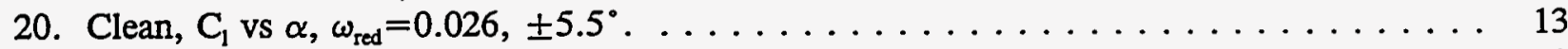

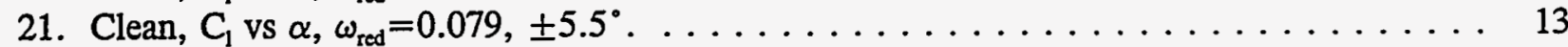

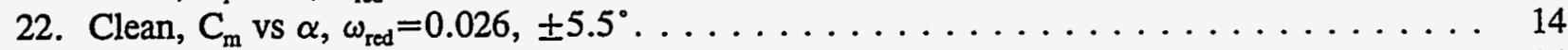

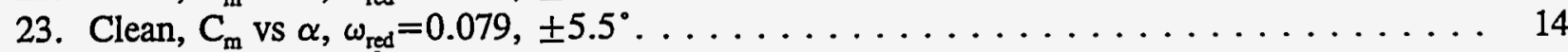

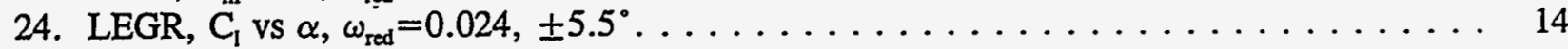

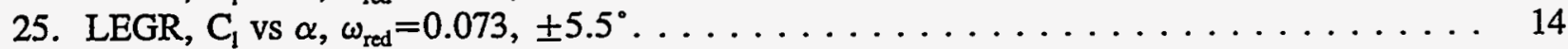

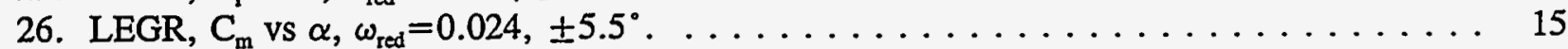

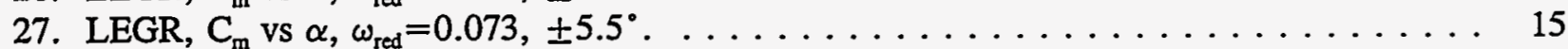

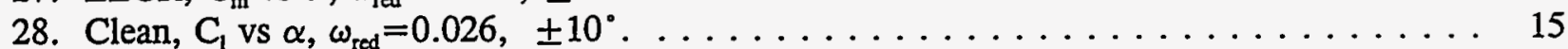

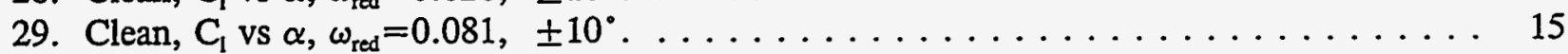

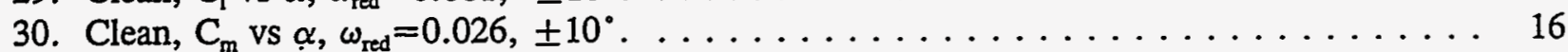

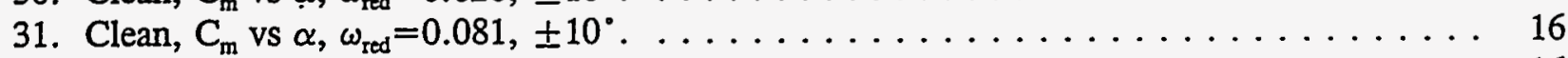

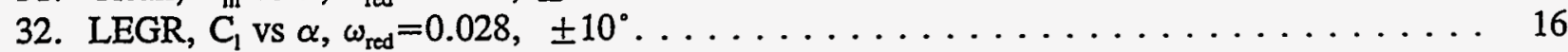

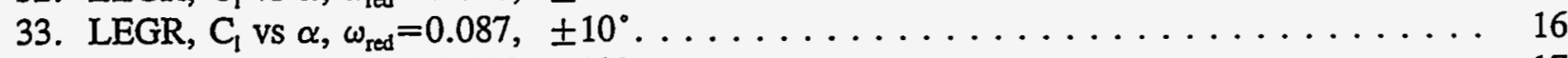

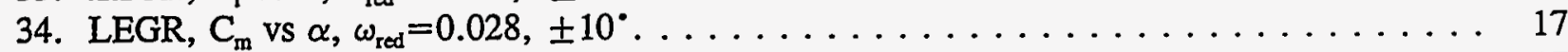

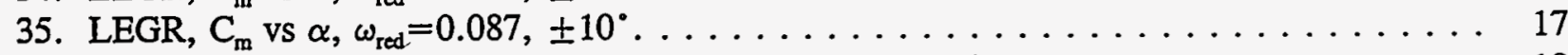

36. Unsteady pressure distribution, clean, $\omega_{\text {red }}=0.053,14 \pm 10^{\circ} \ldots \ldots \ldots \ldots \ldots$

37. Unsteady pressure distribution, LEGR, $\omega_{\text {red }}=0.055,14 \pm 10^{\circ} \ldots \ldots \ldots \ldots \ldots \ldots$

38. Unsteady pressure distribution, clean, $\omega_{\text {red }}=0.052,14 \pm 5.5^{\circ} \ldots \ldots \ldots \ldots \ldots \ldots$

39. Unsteady pressure distribution, clean, $\omega_{\text {red }}=0.053,20 \pm 10^{\circ} \ldots \ldots \ldots \ldots \ldots$ 


\section{List of Tables}

Page

1. LS(1)-0417MOD Aerodynamic Parameters Summary . . . . . . . . . . . . . . . 20

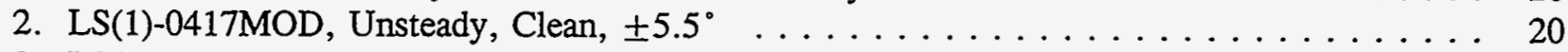

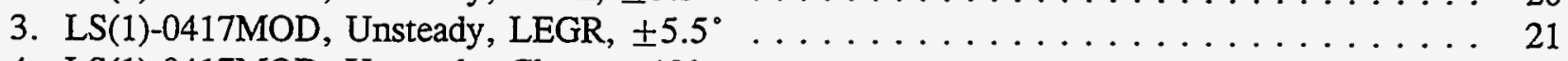

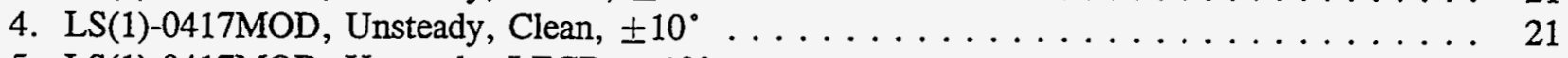

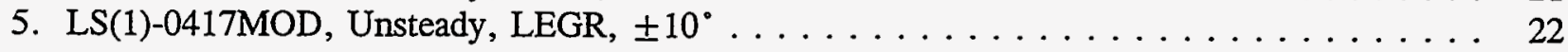




\section{List of Symbols}

\begin{tabular}{|c|c|}
\hline $\mathrm{AOA}$ & Angle of attack \\
\hline $\mathrm{A} / \mathrm{C}$, a.c. & Alternating current \\
\hline c & Model chord length \\
\hline $\mathrm{C}_{\mathrm{d}}$ & Drag coefficient \\
\hline $\mathrm{C}_{\mathrm{dmin}}$ & Minimum drag coefficient \\
\hline $\mathrm{C}_{\mathrm{dp}}$ & Pressure drag coefficient \\
\hline$C_{d w}$ & Wake drag coefficient \\
\hline $\mathrm{C}_{\mathrm{du}}$ & Uncorrected drag coefficient \\
\hline $\mathrm{C}_{1}$ & Lift coefficient \\
\hline $\mathrm{C}_{\operatorname{lmax}}$ & Maximum lift coefficient \\
\hline$C_{1 \text { dec }}$ & Lift coefficient at angle of maximum lift, but with angle of attack decreasing \\
\hline $\mathrm{C}_{\mathrm{lu}}$ & Uncorrected lift coefficient \\
\hline$C_{m}, C_{m} / k$ & Pitching moment coefficient about the quarter chord \\
\hline $\mathrm{C}_{\mathrm{m} \mathrm{dec}}$ & $\begin{array}{l}\text { Pitching moment coefficient at angle of maximum lift, but with angle of attack } \\
\text { decreasing }\end{array}$ \\
\hline $\mathrm{C}_{\mathrm{m} \text { inc }}$ & $\begin{array}{l}\text { Pitching moment coefficient at angle of maximum lift, but with angle of attack } \\
\text { increasing }\end{array}$ \\
\hline $\mathrm{C}_{\mathrm{mo}}$ & Pitching moment coefficient about the quarter chord, at zero lift \\
\hline $\mathrm{C}_{\mathrm{m} / \mathrm{u}}$ & Uncorrected pitching moment coefficient about the quarter chord \\
\hline $\mathrm{C}_{\mathrm{p}}$ & Pressure coefficient, $\left(\mathrm{p}-\mathrm{p}_{\infty}\right) / \mathrm{q}_{\infty}$ \\
\hline $\mathrm{C}_{\mathrm{pmin}}$ & Minimum pressure coefficient \\
\hline $\mathrm{f}$ & Frequency \\
\hline h & Wind tunnel test section height \\
\hline hp, Hp, HP & Horsepower \\
\hline $\mathrm{Hz}$ & Hertz \\
\hline $\mathrm{k}$ & Grit particle size \\
\hline $\mathrm{k} / \mathrm{c}$ & Grit particle size divided by airfoil model chord length \\
\hline $\mathrm{p}$ & Pressure \\
\hline $\mathrm{q}$ & Dynamic pressure \\
\hline $\mathrm{q}_{\mathrm{u}}$ & Uncorrected dynamic pressure \\
\hline $\mathrm{q}_{\mathrm{w}}$ & Dynamic pressure through the model wake \\
\hline$q_{\infty}$ & Free stream dynamic pressure \\
\hline $\operatorname{Re}$ & Reynolds number \\
\hline $\mathrm{Re}_{\mathrm{u}}$ & Uncorrected Reynolds number \\
\hline$t$ & Time \\
\hline $\mathrm{U}_{\infty}$ & Corrected free stream velocity \\
\hline $\mathrm{V}$ & Velocity \\
\hline$V_{u}$ & Uncorrected velocity \\
\hline $\mathrm{x}$ & Axis parallel to model reference line \\
\hline . & Axis perpendicular to model reference line \\
\hline
\end{tabular}




$\begin{array}{ll}\alpha & \text { Angle of attack } \\ \alpha_{\mathrm{dec}} & \text { Decreasing angle of attack } \\ \alpha_{\mathrm{inc}} & \text { Increasing angle of attack } \\ \alpha_{\mathrm{m}} & \text { Median angle of attack } \\ \alpha_{\text {mean }} & \text { Mean angle of attack } \\ \alpha_{\mathrm{u}} & \text { Uncorrected angle of attack } \\ \epsilon & \text { Tunnel solid wall correction scalar } \\ \epsilon_{\mathrm{sb}} & \text { Solid blockage correction scalar } \\ \epsilon_{\mathrm{wb}} & \text { Wake blockage correction scalar } \\ \Lambda & \text { Body-shape factor } \\ \pi & 3.1416 \\ \sigma & \text { Tunnel solid wall correction parameter } \\ \omega_{\text {red }}, \omega_{\text {reduced }} & \text { Reduced frequency, } \pi \mathrm{fc} / \mathrm{U}_{\infty}\end{array}$




\section{Introduction}

Horizontal axis wind turbine rotors experience unsteady aerodynamics due to wind shear when the rotor is yawed, when the rotor blades pass through the support tower wake, and when the wind is gusting. An understanding of this unsteady behavior is necessary to assist in the calculation of rotor performance and loads. The rotors also experience performance degradation caused by surface roughness. These surface irregularities are due to the accumulation of insect debris, ice, and/or the aging process. Wind tunnel studies that examine both the steady and unsteady behavior of airfoils can help define the flow phenomena, and the resultant data can be used to validate analytical computer codes.

An LS(1)-0417MOD airfoil model was tested in The Ohio State University Aeronautical and Astronautical Research Laboratory (OSU/AARL) $3 \times 5$ subsonic wind tunnel $(3 \times 5)$ under steady flow and stationary model conditions, as well as with the model undergoing pitch oscillations. To study the possible extent of performance loss due to surface roughness, a standard grit pattern (LEGR) was used to simulate leading edge contamination. After baseline cases were completed, the LEGR was applied for both steady state and model pitch oscillation cases. The Reynolds numbers for steady state conditions were $0.75,1$, 1.25 , and 1.5 million, while the angle of attack ranged from $-20^{\circ}$ to $+40^{\circ}$. With the model undergoing pitch oscillations, data were acquired at Reynolds numbers of $0.75,1,1.25$, and 1.5 million, at frequencies of $0.6,1.2$, and $1.8 \mathrm{~Hz}$. Two sine wave forcing functions were used; $\pm 5.5^{\circ}$ and $\pm 10^{\circ}$ amplitude, at mean angles of attack of $8^{\circ}, 14^{\circ}$, and $20^{\circ}$. For purposes herein, any reference to unsteady conditions means the airfoil model was in pitch oscillation about the quarter chord. 


\section{Experimental Facility}

\section{Wind Tunnel}

The OSU/AARL $3 \times 5$ was used to conduct tests on the LS(1)-0417MOD airfoil section. Schematics of the top and side views of the tunnel are shown in figures 1 and 2 . This open-circuit tunnel has a velocity range of $0-55 \mathrm{~m} / \mathrm{s}(180-\mathrm{ft} / \mathrm{sec})$ produced by a $2.4-$ meter $(8-\mathrm{ft})$ diameter, six-bladed fan. The fan is belt

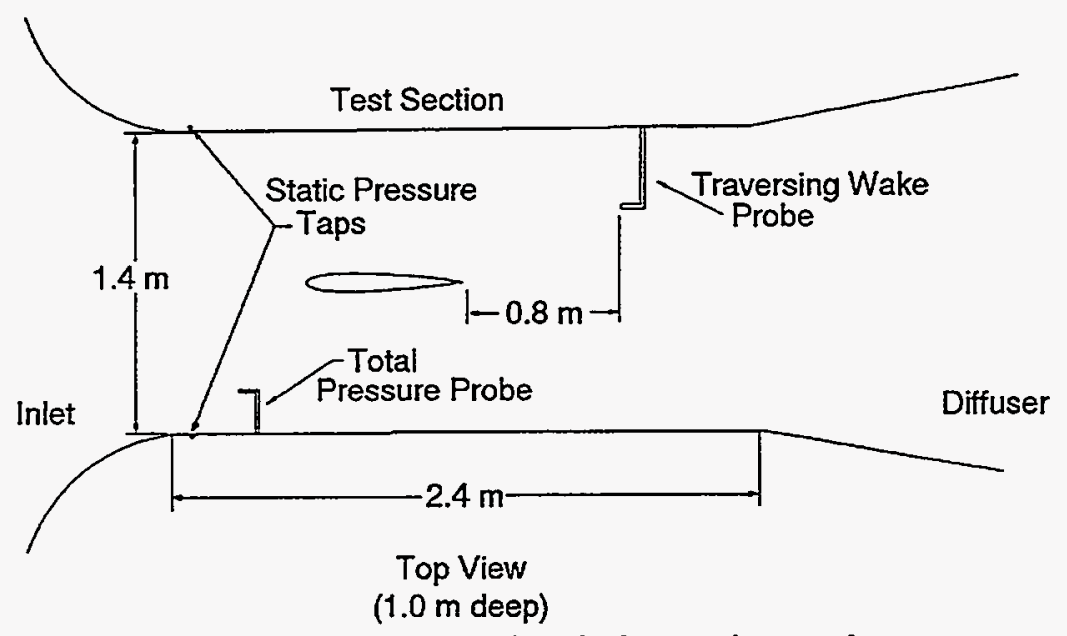

Figure 1. $3 \times 5$ subsonic wind tunnel, top view.

driven by a $93.2-\mathrm{kw}(125-\mathrm{hp})$ three phase a.c. motor connected to a variable frequency motor controller. Nominal test section dimensions are $1.0-\mathrm{m}$ (39-inches) high by $1.4-\mathrm{m}$ ( 55 -inches) wide by $2.4-\mathrm{m}$ (96inches) long. The 457-mm (18-inch) chord airfoil model was mounted vertically in the test section. A

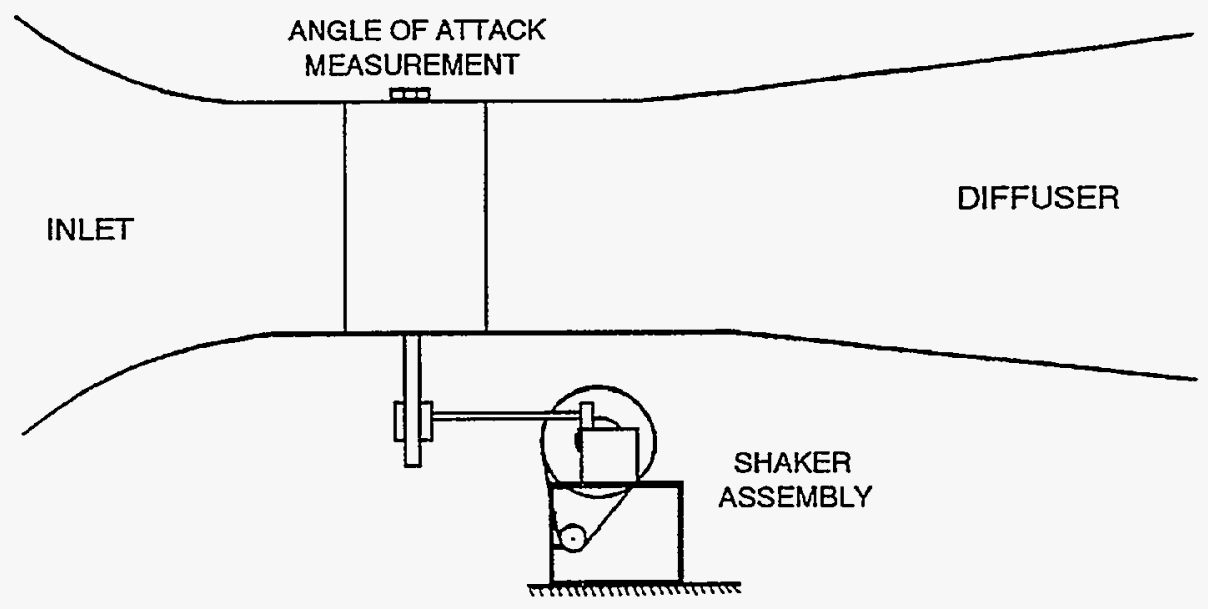

Figure 2. $3 \times 5$ subsonic wind tunnel, side view.

steel tube through the quarter chord of the model attached the model to the tunnel during testing. An angle of attack potentiometer was fastened to the model at the top of the tunnel, as shown in figure 2. The steady state angle of attack was adjusted with a worm gear drive attached to the model strut below the tunnel floor. 


\section{Oscillation System}

Portions of the airfoil model testing required the use of a reliable model pitch oscillation system. The OSU/AARL "shaker" system incorporated a face cam and follower arm attached to the model support tube below the wind tunnel floor, shown in figure 3. The choice of cam governed the type and amplitude of the wave form produced. Sine wave forms with amplitudes of $\pm 5.5^{\circ}$ and $\pm 10^{\circ}$ were used for these tests. The wave form is defined by the equation

$$
\alpha=\alpha_{m}+A \sin (2 \pi f t)
$$

where $\mathrm{A}$ is the respective amplitude. The shaker system was powered by a $5 \mathrm{hp}$ a.c. motor with variable line frequency controller. The useable oscillating frequency range was 0.1 to $2.0 \mathrm{~Hz}$, with three frequencies used for this test: $0.6,1.2$, and $1.8 \mathrm{~Hz}$.

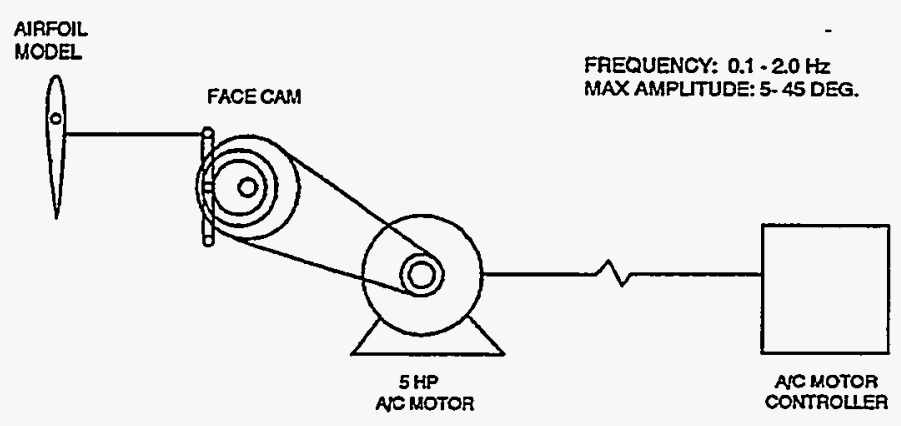

Figure 3. $3 \times 5$ wind tunnel oscillation system. 


\section{Model Details}

A 457-mm (18-inch) constant chord LS(1)-0417MOD airfoil model was designed by OSU/AARL personnel and manufactured by others. Figure 4 shows the airfoil section; while the model measured coordinates are given in Appendix A. The model was manufactured with a carbon composite skin over

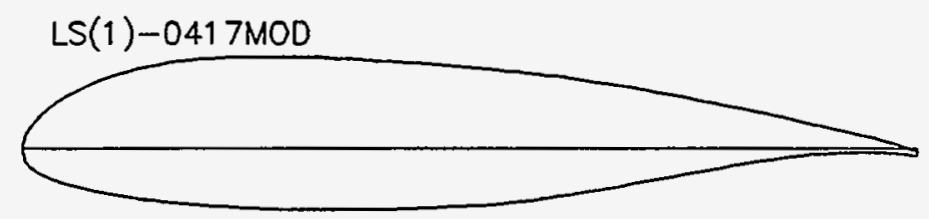

Figure 4. LS(1)-0417MOD airfoil section.

ribs and foam. The main load-bearing member was a $38-\mathrm{mm}$ (1.5-inch) diameter steel tube passed through the model quarter chord station. Ribs and end plates were used to transfer loads from the composite skin to the steel tube. The final surface was hand worked using templates to attain given coordinates within a requested tolerance of $\pm 0.25-\mathrm{mm}( \pm 0.01$-inch). The completed model was measured at three spanwise locations using a Sheffield-Cordax coordinate measurement machine.

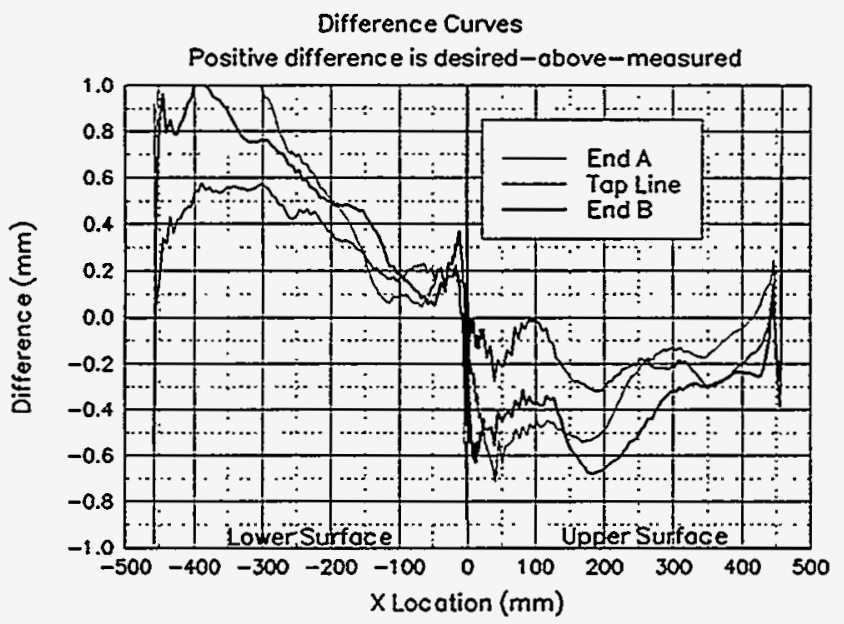

Figure 5. Measured-to-desired model coordinates difference curves..

Measurements were made in English units and later converted to metric. Figure 5 shows the results of comparing measured-to-desired coordinates by calculating differences normal to the profiled surface at three stations on the model. The "spikes" apparent near the trailing edge are due to the numerical methods used and are not real.

To minimize pressure response times, which is important for the unsteady testing, the surface pressure tap lead-out lines had to be as short as possible. Consequently, a compartment was built into the model so pressure scanning modules could be installed inside the model. This compartment was accessed through a panel door fitted flush with the model contour on the lower (pressure) surface.

For test cases involving roughness, a standard, repeatable pattern with grit as roughness elements was desired. The roughness pattern used was jointly developed by OSU/AARL and KENETECH, Windpower 
personnel with a molded insect pattern taken from a wind turbine in the field by personnel at the University of Texas Permian Basin. The particle density was 5 particles per $\mathrm{cm}^{2}$ (32 particles per square inch) in the middle of the pattern, thinning to 1.25 particles per $\mathrm{cm}^{2}$ ( 8 particles per square inch) at the edge of the pattern. Figure 6 shows the pattern. To make a usable template, the pattern was repeatedly cut into a steel sheet 102-mm (4-inch) wide and 91-cm (3-ft) long with holes just large enough for one piece of grit. Based on average particle size from the field specimen, standard \#40 lapidary grit was chosen for the roughness elements, giving $\mathrm{k} / \mathrm{c}=0.0019$ for a $457-\mathrm{mm}$ (18-inch) chord model.

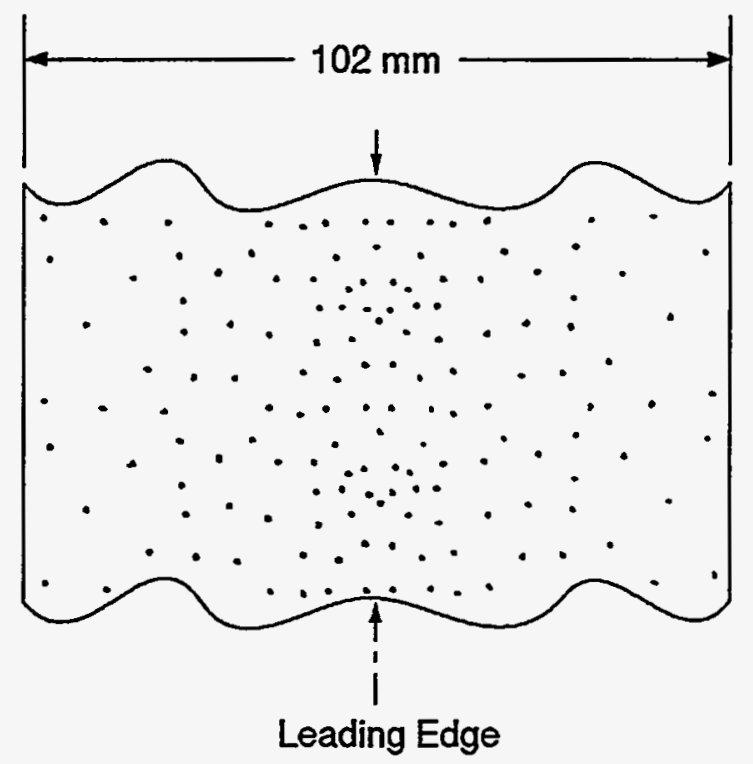

Figure 6. Roughness pattern.

To use the template, 102-mm (4-inch) wide double-tack tape was applied to one side of the template and grit was poured and brushed from the opposite side. The tape was then removed from the template and transferred to the model. This method allowed the same roughness pattern to be replicated for any test. 


\section{Test Equipment and Procedures}

\section{Data Acquisition}

Data were acquired and processed from 52 surface pressure taps, four individual tunnel pressure transducers, an angle of attack potentiometer, a wake probe position potentiometer, and a tunnel thermocouple. The data acquisition system included an IBM PC compatible 80486-based computer connected to a Pressure Systems Incorporated (PSI) data scanning system. The PSI system included a 780B Data Acquisition and Control Unit (DACU), 780B Pressure Calibration Unit (PCU), 81-IFC scanning module interface, two 2.5-psid pressure scanning modules (ESPs), one 20-inch water column range pressure scanning module, and a 30-channel Remotely Addressed Millivolt Module (RAMM-30). Figure 7 shows the data acquisition system schematic.

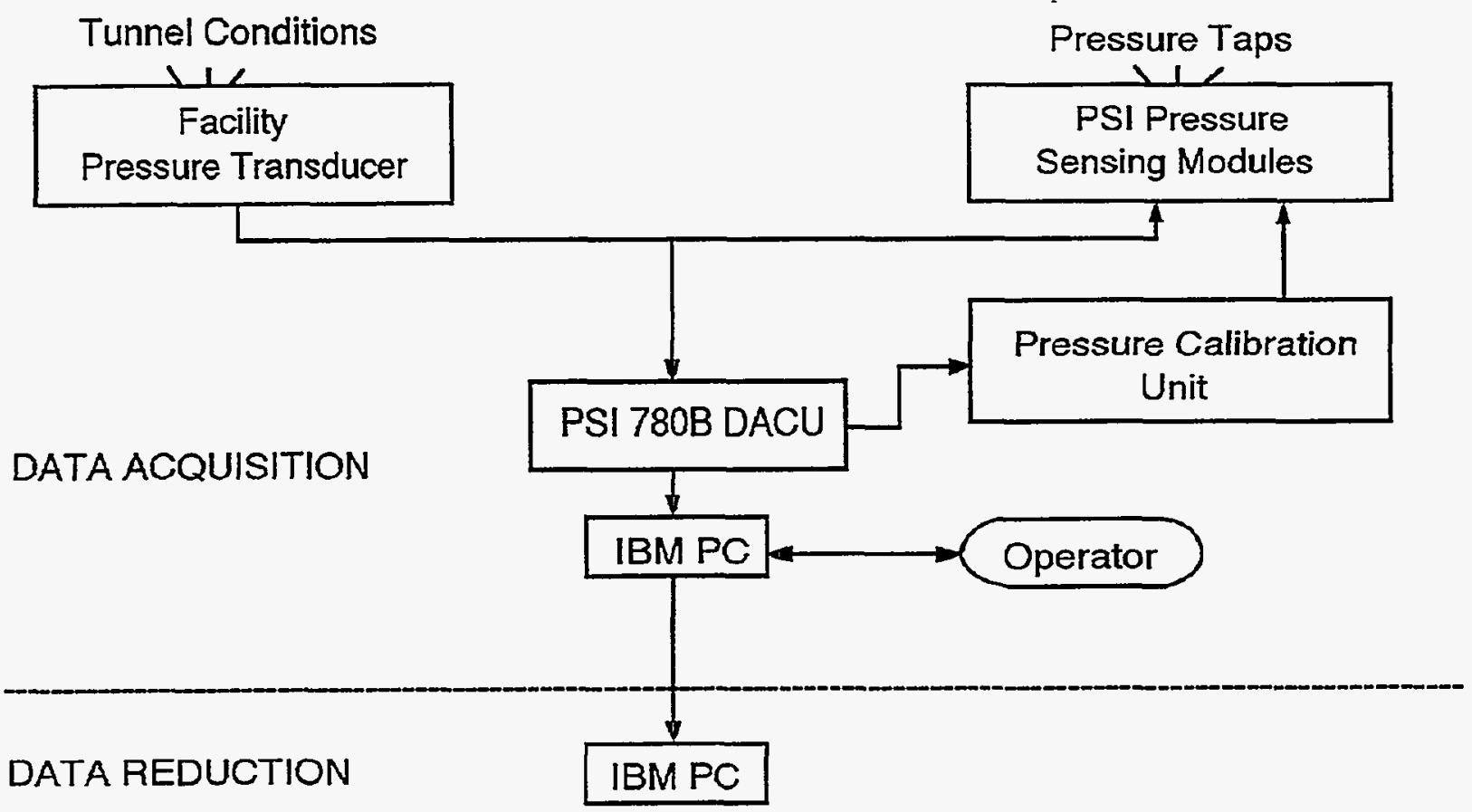

Figure 7. Data acquisition schematic.

Four individual pressure transducers read tunnel total pressure, tunnel north static pressure, tunnel south static pressure, and wake dynamic pressure. Before the test began, these transducers were bench calibrated using a water manometer to determine their sensitivities and offsets. Related values were entered into the data acquisition and reduction program so the transducers could be shunt resistor calibrated before each series of wind tunnel runs.

The rotary angle of attack potentiometer of $0.5 \%$ linearity was regularly calibrated during the tunnel pressure transducers shunt calibration. The angle of attack calibration was accomplished by taking voltage readings at known values of set angle of attack. This calibration method gave angle of attack readings within $\pm 0.25^{\circ}$ over the entire angle range. The wake probe position potentiometer was also a linear potentiometer and it was regularly calibrated during the shunt calibration of the tunnel pressure transducers.

Calibration of the three ESPs was done simultaneously using the DACU and PCU. At operator request, the DACU commanded the PCU to apply known regulated pressures to the ESPs and read the output 
voltages from each integrated pressure sensor. From these values, the DACU calculated the calibration coefficients and stored them internally until the coefficients were requested by the controlling computer. This calibration was done several times during a run set because the ESPs were installed inside the model and their outputs tended to drift with temperature changes during a test sequence. Frequent on-line calibrations minimized the effect.

For steady state cases, the model was set to angle of attack and the tunnel conditions were adjusted. At operator request, pressure measurements from the airfoil surface taps and all other channels of information were acquired and stored by the DACU and subsequently passed to the controlling computer for final processing. The angles of attack were always set in the same progression, from negative to positive values.

For model oscillating cases, the tunnel conditions were set while the model was stationary at the desired mean angle of attack. The "shaker" was started, and after approximately 10 seconds, the model surface pressure and tunnel condition data were acquired. Generally, 120 data scans were acquired over three model oscillation cycles. Since surface pressures were scanned sequentially, the data rate was set so the model rotated through less than $0.50^{\circ}$ during any data burst. Finally, due to the unsteady and complex nature of the pitch oscillation cases, model wake surveys (for drag) were not conducted.

\section{Data Reduction}

The data reduction routine was included as a section of the data acquisition program. This combination of data acquisition and reduction routines allowed data to be reduced on-line during a test. By quickly reducing selected runs, integrity checks could be made to ensure the equipment was working properly and to allow timely decisions about the test matrix.

The ambient pressure was manually input into the computer and updated regularly. This value, along with the measurements from the tunnel pressure transducers and the tunnel thermocouple, were used to calculate tunnel airspeed. As a continuous check of readings, the tunnel total and static pressures were read by both the tunnel individual pressure transducers and the 20 -inch water column ESP.

A typical steady state datum point was derived by acquiring ten data scans of all channels over a 10 second window at each angle of attack and tunnel condition. The reduction portion of the program processed each data scan to coefficient forms $\left(\mathrm{C}_{\mathrm{p}}, \mathrm{C}_{\mathrm{l}}, \mathrm{C}_{\mathrm{m} / \kappa}\right.$, and $\left.\mathrm{C}_{\mathrm{dp}}\right)$ using the measured surface pressure voltages, calibration coefficients, tap locations and wind tunnel conditions. Then, all scan sets for a given condition were ensemble averaged to provide one data set, and that data set was then corrected for the effects of solid tunnel walls. All data were saved in electronic form.

Corrections due to solid tunnel sidewalls were applied to the wind tunnel data. As described by Pope and Harper (1966), tunnel conditions are represented by the following equations:

$$
\begin{gathered}
q=q_{u}(1+2 \epsilon) \\
V=V_{u}(1+\epsilon) \\
R_{e}=R_{e_{u}}(1+\epsilon)
\end{gathered}
$$

Airfoil aerodynamic characteristics are corrected by:

$$
\alpha=\alpha_{u}+\frac{57.3 \sigma}{2 \pi}\left(C_{l_{u}}+4 C_{m \frac{1}{4_{u}}}\right)
$$




$$
\begin{gathered}
C_{l}=C_{l_{u}}(1-\sigma-2 \epsilon) \\
C_{m_{\frac{1}{4}}}=C_{m_{\frac{1}{4}}}(1-2 \epsilon)+\frac{\sigma C_{l}}{4} \\
C_{d}=C_{d_{u}}\left(1-3 \epsilon_{s b}-2 \epsilon_{w b}\right)
\end{gathered}
$$

where

$$
\begin{aligned}
& \sigma=\frac{\pi^{2}}{48}\left(\frac{c}{h}\right)^{2} \\
& \epsilon=\epsilon_{s b}+\epsilon_{w b} \\
& \epsilon_{s b}=\Lambda \sigma \\
& \epsilon_{w b}=\frac{c}{h 4} C_{d_{u}}
\end{aligned}
$$

Model wake data were taken for steady state cases when the wake could be completely traversed. Pressures were acquired from a pitot-static probe, which was connected to measure incompressible dynamic pressure through the wake. These pressure measurements were used to calculate drag coefficient using a form of the Jones equation derived from Schlichting (1979):

$$
C_{d w}=\frac{2}{c} \int \sqrt{\frac{q_{w}}{q_{\infty}}}\left(1-\sqrt{\frac{q_{w}}{q_{\infty}}}\right) d y
$$

This equation assumes that static pressure at the measurement site is the free-stream value. The integration was done automatically except the computer operator chose the end points of the integration from a plot of the wake survey displayed on the computer screen.

For pitch oscillation cases, model surface pressures were reduced to pressure coefficient form with subsequent integrations and angle of attack considerations giving lift, moment, and pressure drag coefficients. The wind tunnel was not calibrated for unsteady model pitch conditions; therefore, the unsteady pressure data were not corrected for any possible effects due to time-dependent pitching or solid tunnel walls. Also, for these cases, the wind tunnel contraction pressures (used for steady state cases) could not be used to calculate instantaneous freestream conditions due to slow response. The tunnel conditions were obtained from a total pressure probe and the average of opposing static pressure taps in the test section entrance, thereby giving near instantaneous flow pressure conditions for the pitching frequencies used.

\section{Test Matrix}

The test was designed to study steady state and unsteady pitch oscillation data. Steady state data were acquired at Reynolds numbers of $0.75,1,1.25$, and 1.5 million with and without LEGR. Refer to the tabular data in Appendix B for the actual Reynolds number for each angle of attack for the steady state data. The angle of attack increment was two degrees when $-20^{\circ}<\alpha<+10^{\circ}$ or $+20^{\circ}<\alpha<+40^{\circ}$ and one degree when $+10^{\circ}<\alpha<+20^{\circ}$. Wake surveys were conducted to find total airfoil drag over an approximate angle of attack range of $-10^{\circ}$ to $+10^{\circ}$. Unsteady data were taken for Reynolds numbers 
of $0.75,1,1.25$, and 1.5 million. Sine wave cams with amplitudes $\pm 5.5^{\circ}$ and $\pm 10^{\circ}$ were used for pitch oscillations, and the mean angles for both of these amplitudes were $8^{\circ}, 14^{\circ}$, and $20^{\circ}$. For all these conditions, the frequencies were varied to $0.6,1.2$, and $1.8 \mathrm{~Hz}$. All data points for the unsteady cases were acquired for both clean and LEGR cases. 


\section{Results and Discussion}

The LS(1)-0417MOD airfoil model was tested under steady state and pitch oscillation conditions. A brief discussion of the results follows, beginning with a comparison of experimental data and computational predictions.

\section{Comparison with Theory}

Present wind tunnel steady state data were compared with the computed predictions made using the North Carolina State Airfoil Analysis Code. This analysis code has proven to be accurate for moderate angles of attack. The analysis was made with specifications set to allow for free transition from laminar to turbulent flow, and the pressure distribution comparisons were matched to the same angle of attack as the wind tunnel cases.

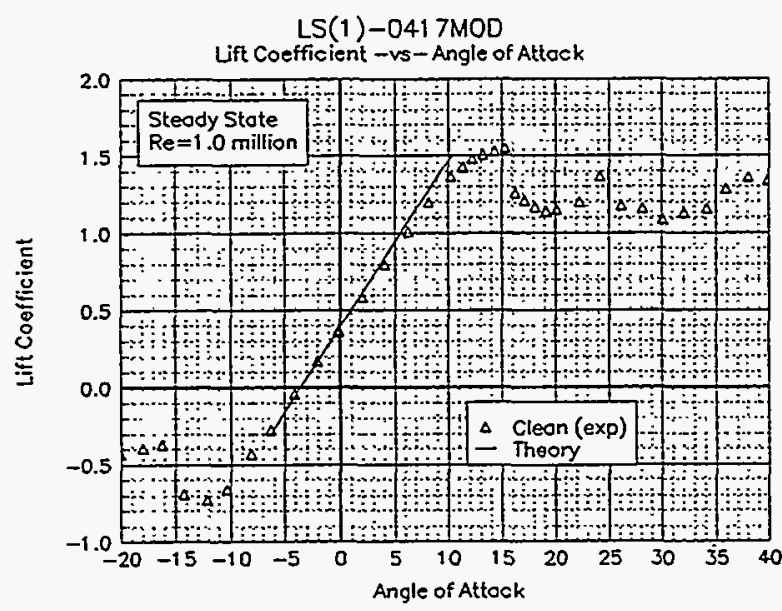

Figure 8. Comparison with theory, $C_{1}$ vs $a$.

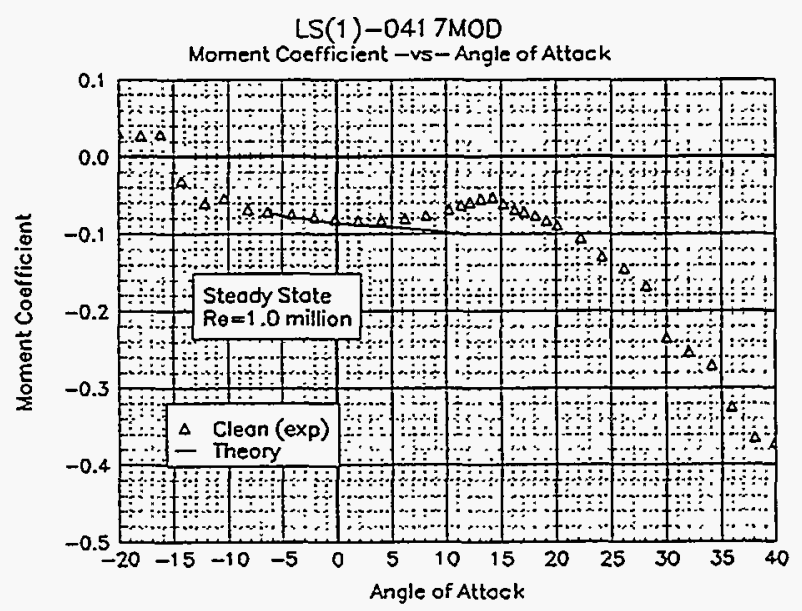

Figure 9. Comparison with theory, $\mathrm{C}_{\mathrm{m}}$ vs $a$.

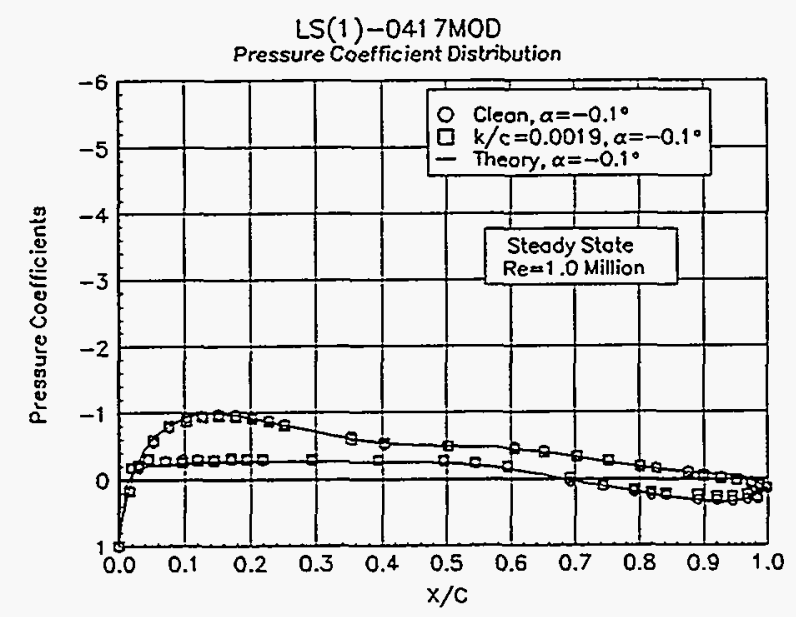

Figure 10. Comparison with theory, $C_{p}$ vs $x / c, a=-0.1^{\circ}$.

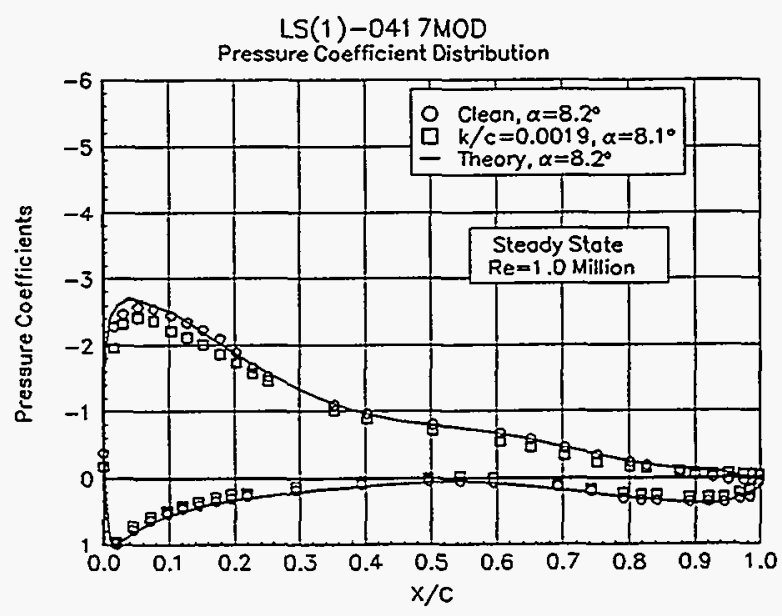

Figure 11. Comparison with theory, $C_{p}$ vs $x / c, a=8.2^{\circ}$.

Figure 8 shows the lift coefficient versus angle of attack for the 1 million Reynolds number case. For moderate angles of attack, where the analysis code is valid, the comparison shows good agreement. The pitching moment about the quarter chord, in figure 9, also shows good agreement for angles of attack 
from $-6^{\circ}$ to $+2^{\circ}$. The pressure distributions shown in figures 10 and 11 , show angles of attack of $-0.1^{\circ}$ and $8.2^{\circ}$, respectively, and include clean and LEGR wind tunnel data as compared to computed, free transition pressure distributions. For the $-0.1^{\circ}$ angle of attack, there is excellent correlation between the experimental and predicted values. For the $8.2^{\circ}$ angle of attack, the agreement is good except there is some discrepancy near the upper (suction) surface leading edge; this can be attributed to the uneven surface around the tap holes.

\section{Steady State Data}

The LS(1)-0417MOD airfoil model was tested at four Reynolds numbers at nominal angles of attack from $-20^{\circ}$ to $+40^{\circ}$. Figures 12 and 13 show lift coefficients for all the test Reynolds numbers both for a clean

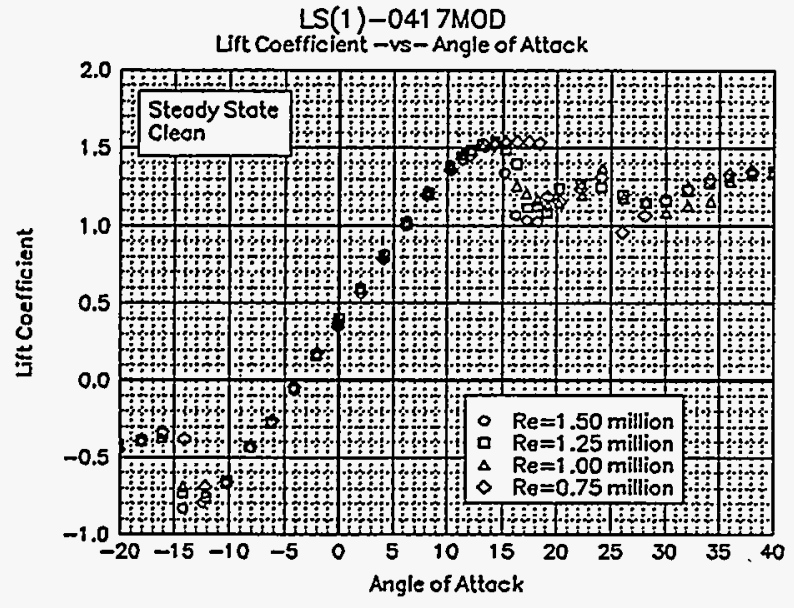

Figure 12. $\mathrm{C}_{1}$ vs $a$, clean.

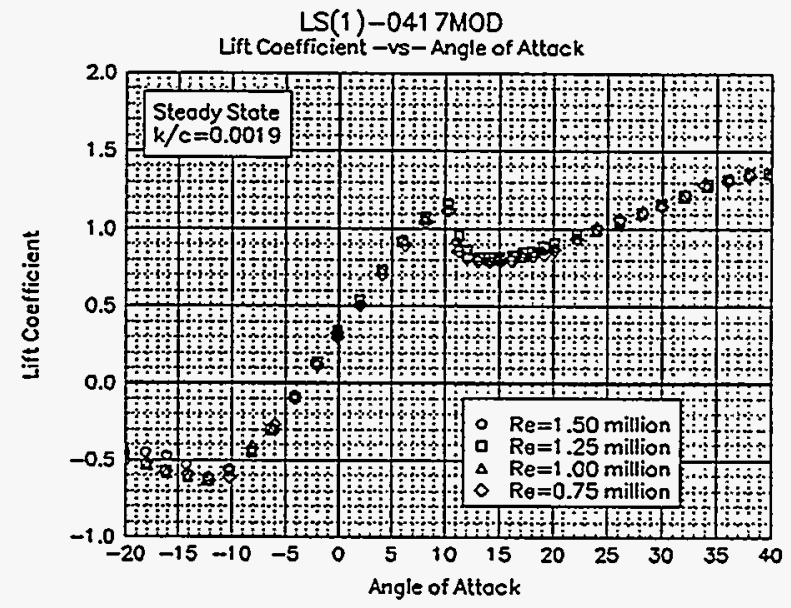

Figure 13. $C_{1}$ vs $a, L E G R, k / c=0.0019$.

model and with LEGR applied, respectively. The maximum positive lift coefficient for the clean cases is about 1.55 and about 1.13 for the LEGR cases, a $27 \%$ reduction. Not only is the lift coefficient lower

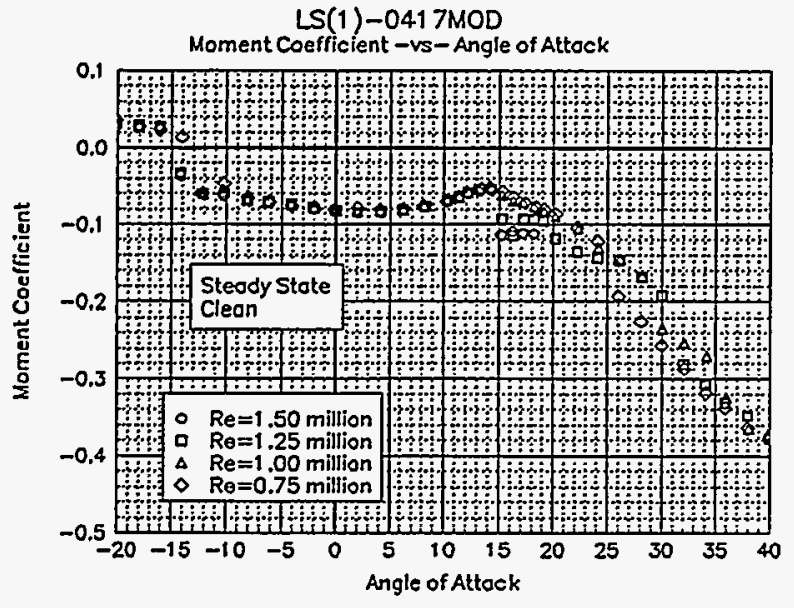

Figure 14. $\mathrm{C}_{\mathrm{m}}$ vs $a$, clean.

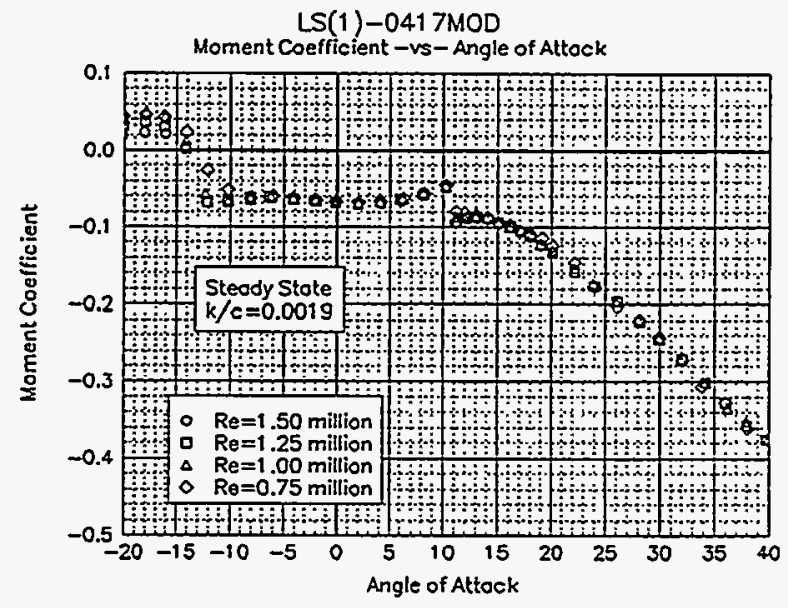

Figure 15. $\mathrm{C}_{\mathrm{m}}$ vs $a, \mathrm{LEGR}, \mathrm{k} / \mathrm{c}=0.0019$.

for the LEGR case, but the stall starts at a significantly lower angle of attack than for the clean case. Finally, the average lift curve slope for clean data is about 0.104 ; it is slightly lower for the LEGR case at 0.096 . The associated average lift coefficients at zero angle of attack are 0.36 for the clean case and 0.31 for the LEGR case. 
Figure 14 shows the pitching moment about the quarter chord for the clean cases and figure 15 shows the same for the LEGR cases. The LEGR data have slightly more positive pitching moment and a flatter curve for angles of attack near zero lift. The pitching moment coefficient about the quarter chord for the 1 million Reynolds number, clean case is -0.0748 and -0.0634 for the LEGR case.

Total wake drag data were obtained for both the clean and LEGR cases over a nominal angle of attack range of $-10^{\circ}$ to $+10^{\circ}$. A pitot-static probe was used to describe the wake profile. This method is

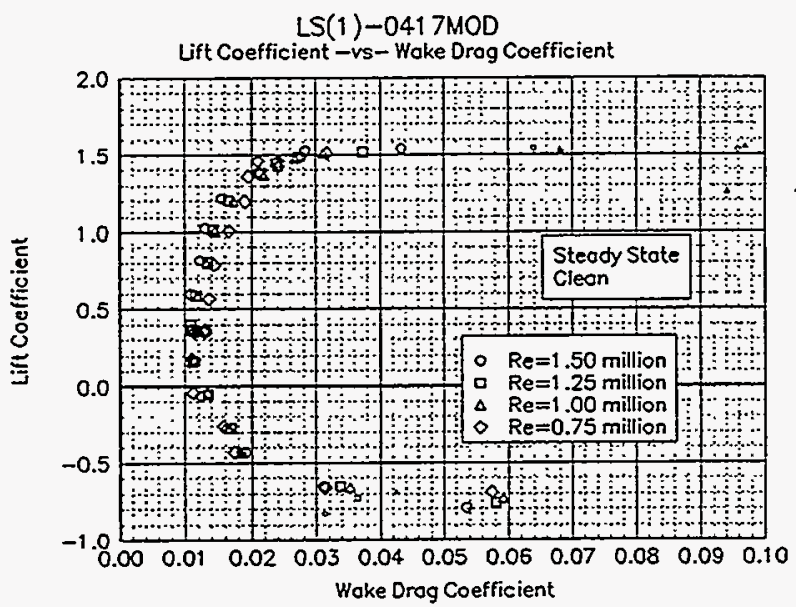

Figure 16. Drag polar, clean.

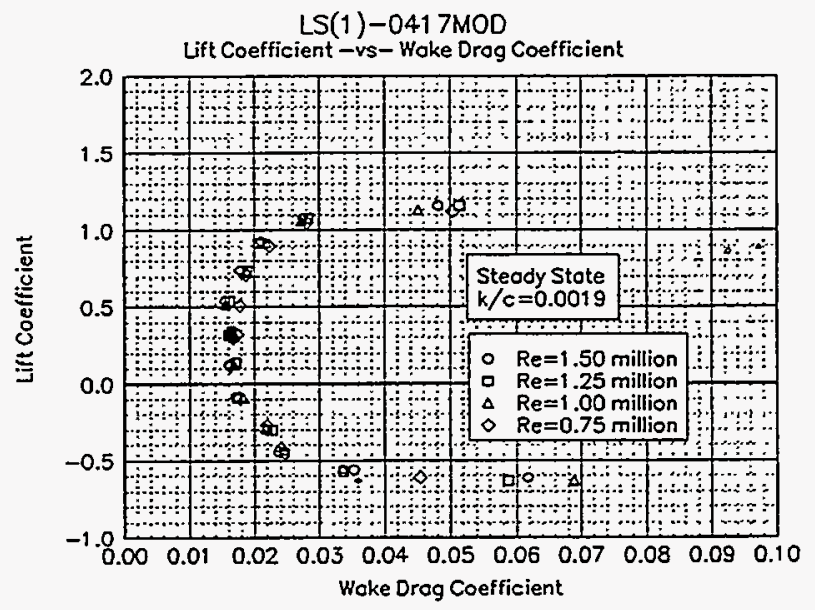

Figure 17. Drag polar, LEGR, $k / c=0.0019$.

reliable when there is relatively low turbulence in the wake flow; therefore, only moderate angles of attack have reliable total drag coefficient data. At angles of attack other than $-10^{\circ}$ to $+10^{\circ}$, surface pressure data were integrated to give $C_{d p}$ and are shown in the drag polars as small symbols. The model clean drag data are shown in figure 16 and the LEGR case is shown in figure 17 . At 1 million Reynolds number, minimum drag coefficient for the clean cases was measured as 0.0115 and 0.0156 for LEGR, a $36 \%$ increase. The general effect of LEGR is to increase drag consistently through most angles of attack.

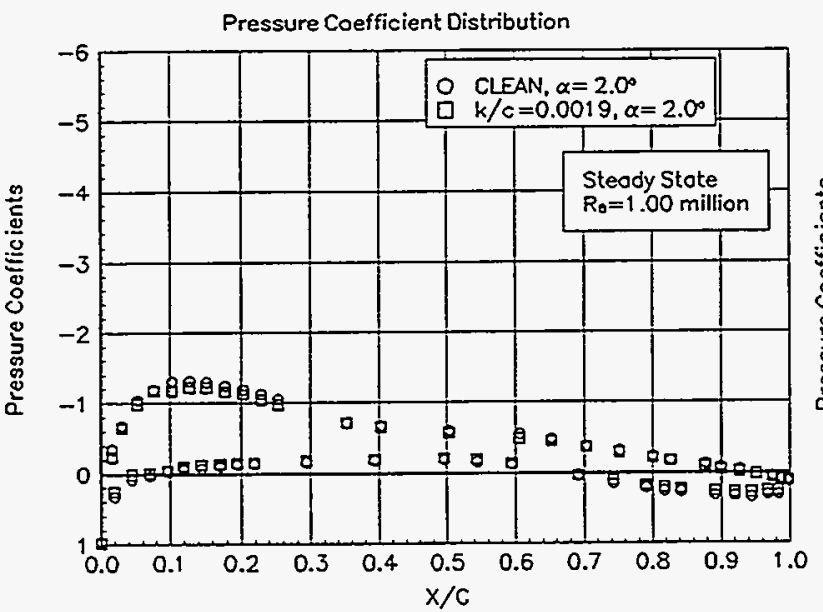

Figure 18. Pressure distribution, $a=2.0^{\circ}$.

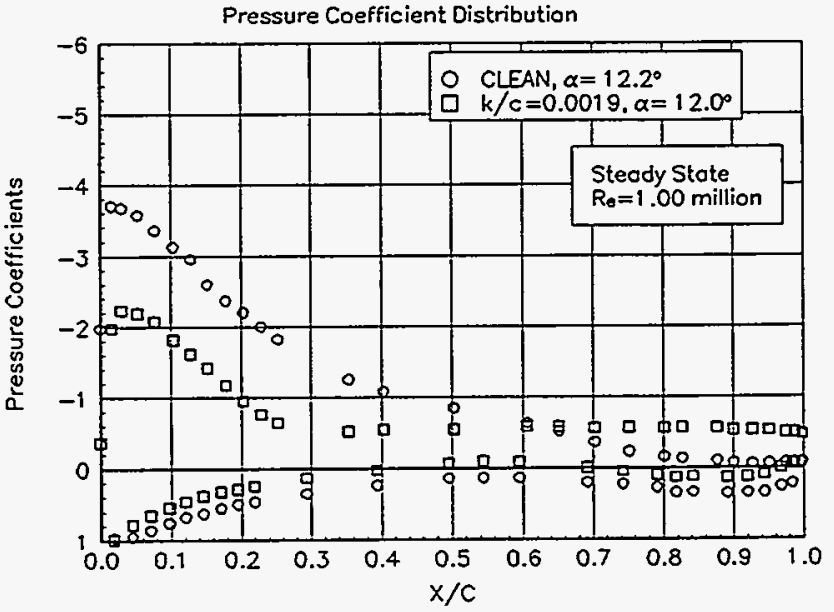

Figure 19. Pressure distribution, $a=12.2^{\circ}$.

Two examples of the surface pressure distributions are shown in figures 18 and 19 for $2.0^{\circ}$ and $12.2^{\circ}$, respectively, at 1 million Reynolds number. At the angles of attack close to zero degrees, the effect of 
LEGR does not appear to significantly affect the pressure distribution compared to the clean case distribution; however, there is an effect apparent in the lift coefficient with values of 0.59 for the clean case and 0.52 for the LEGR case. Another difference between the two cases, which cannot be observed from the pressure distribution, is that the drag increases from 0.0120 for the clean case to 0.0156 for the LEGR case. For the higher angle of attack case, figure 19, the effect of LEGR is to reduce the magnitude of the pressure peak from -3.7 to -2.3 which contributes to a reduction in lift coefficient from 1.48 to 0.87 , a $41 \%$ decrease. The pitching moment is affected at this angle of attack, the clean case is -0.0586 and the LEGR case is -0.0879 .

\section{Unsteady Data}

Unsteady experimental data were obtained for the LS(1)-0417MOD airfoil model undergoing sinusoidal pitch oscillations. As mentioned earlier, no attempt was made to calibrate the wind tunnel for the unsteady oscillating model conditions. The steady state tunnel calibration was used to set flow conditions while the model was stationary at its mean angle of attack. The use of the unsteady data should be limited to comparisons with other models tested in this same facility and can be used to detect possible trends. A comprehensive set of test conditions was used to describe unsteady behavior of an airfoil, including two angle of attack amplitudes, $\pm 5.5^{\circ}$ and $\pm 10^{\circ}$; four Reynolds numbers, $0.75,1,1.25$, and 1.5 million; three pitch oscillation frequencies, $0.6,1.2$, and 1.8 ; and three mean angles of attack, $8^{\circ}$, $14^{\circ}$, and $20^{\circ}$.
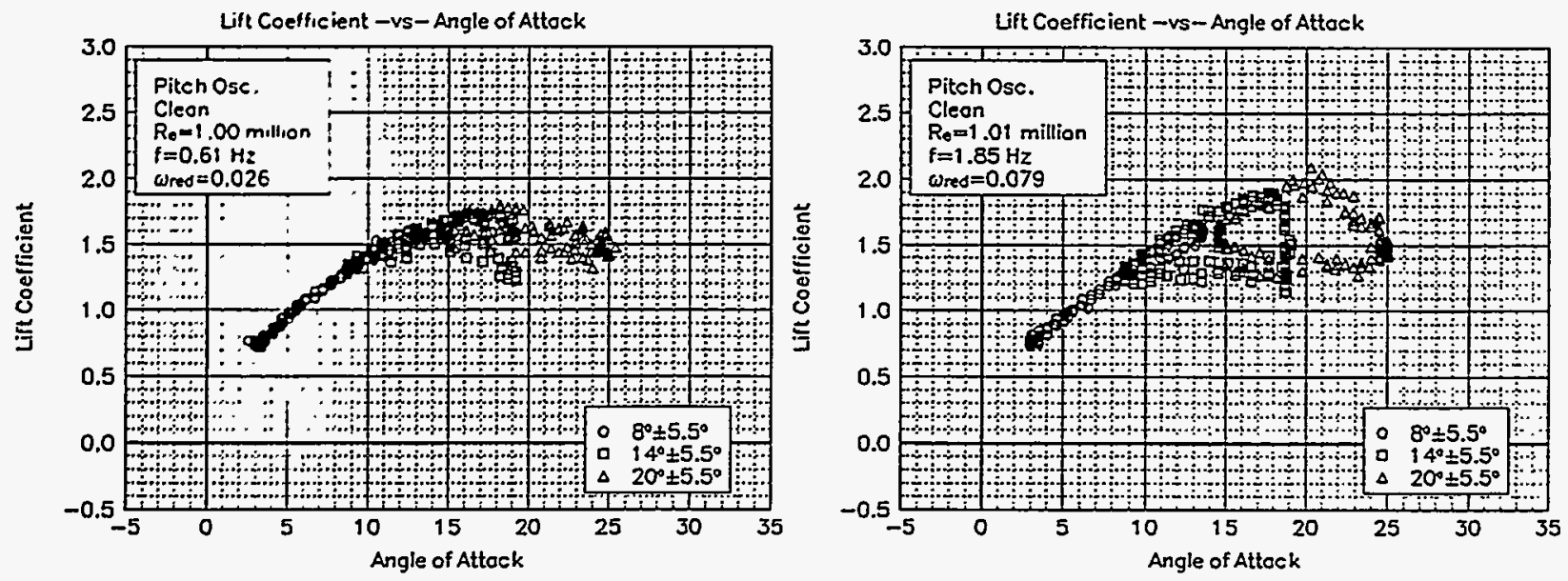

Figure 20. Clean, $C_{1}$ vs $a_{,} \omega_{\text {red }}=0.026, \pm 5.5^{\circ}$.

Figure 21. Clean, $C_{1}$ vs $a, \omega_{\mathrm{red}}=0.079, \pm 5.5^{\circ}$.

Figure 20 shows the lift coefficient versus angle of attack for the $\pm 5.5^{\circ}$ amplitude, model clean case, at reduced frequency of 0.026 and 1 million Reynolds number. Note that all three mean angles of attack are plotted on the same figure. The maximum pre-stall lift coefficient for this case is near 1.73 and occurs when the airfoil is traveling with the angle of attack increasing. In contrast, when the model is traveling through decreasing angles of attack, the stall recovery is delayed and a hysteresis behavior is exhibited in the lift coefficient that can be seen throughout all the unsteady data. In order to obtain some measure of this hysteresis behavior, the lift coefficient on the "return" portion of the curve, at the angle of attack where maximum lift coefficient occurs, can be used. For the case discussed here, the hysteresis or decreasing angle of attack lift coefficient is 1.37 , a $21 \%$ decrease from the 1.73 unsteady maximum value. By comparison, the steady state maximum lift coefficient is 1.55 . At higher reduced frequency of 0.079 , the hysteresis behavior is more pronounced, as seen in figure 21 . In addition to greater hysteresis, the maximum lift coefficient is increased to about 1.90 , is a $23 \%$ increase over the steady state value. The corresponding hysteresis lift coefficient is 1.27 . This difference between steady state 
behavior and unsteady hysteresis behavior is a main reason that unsteady testing should be required for airfoils used in wind turbine applications.
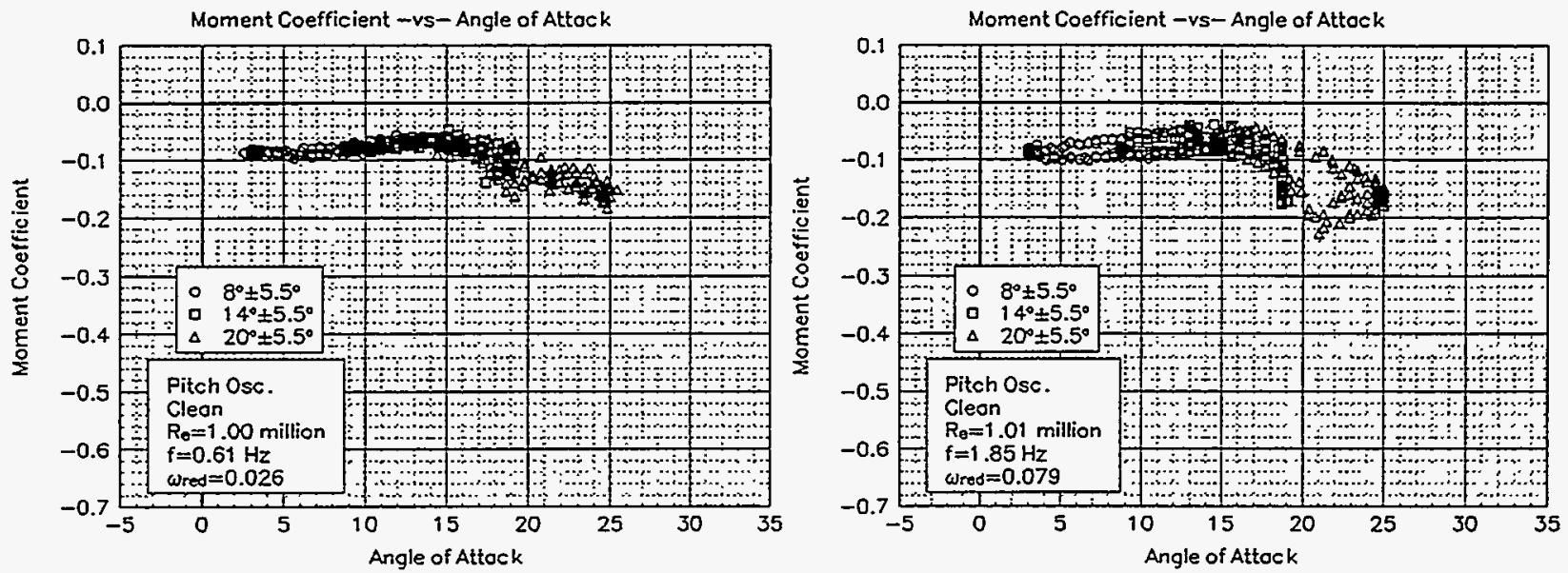

Figure 22. Clean, $\mathrm{C}_{\mathrm{m}}$ vs $a, \omega_{\text {red }}=0.026, \pm 5.5^{\circ}$. Figure 23. Clean, $\mathrm{C}_{\mathrm{m}}$ vs $a, \omega_{\text {red }}=0.079, \pm 5.5^{\circ}$.

The pitching moment in figures 22 and 23 corresponds to the same conditions as the two lift coefficient plots previously discussed. Hysteresis behavior is present but it is not as apparent as in the lift coefficient plots. However, the higher reduced frequency case does show hysteresis more than the lower reduced frequency case. For reference, the steady state maximum lift occurs near $15^{\circ}$ angle of attack and the steady state pitching moment at this maximum lift point is -0.0615 . By comparison, when the airfoil is undergoing pitch oscillation for the lower frequency, pitching moment varies from -0.0932 to -0.0795 (at the angle of attack were maximum lift occurs), a $52 \%$ to $29 \%$ increase in magnitude from the steady state value. Note the angle of attack were the maximum lift coefficient occurs does not necessarily show the "greatest" hysteresis behavior but does give a relative indication of the effect.
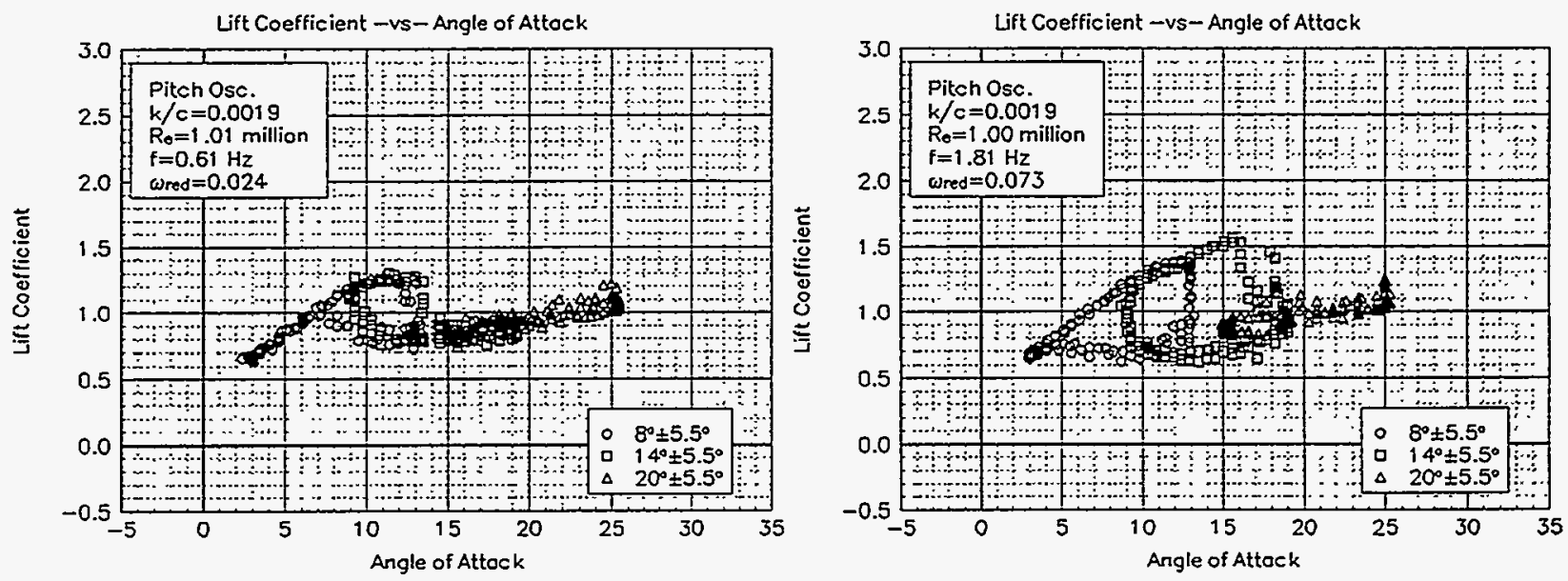

Figure 24. LEGR, $C_{1}$ vs $a, \omega_{\text {red }}=0.024, \pm 5.5^{\circ}$.

Figure 25. LEGR, $C_{1}$ vs $a, \omega_{\text {red }}=0.073, \pm 5.5^{\circ}$.

In comparison to the clean data, the application of LEGR reduces the maximum lift coefficient in the pitch oscillation cases. Lift coefficient versus angle of attack with LEGR applied is shown in figure 24 for the 0.024 reduced frequency case. The 0.073 reduced frequency case is shown in figure 25 . Both plots correspond to the same run conditions described earlier for the clean cases. For the lower reduced frequency, the maximum unsteady lift coefficient is reduced to 1.30 from the corresponding clean case 
of 1.73 , a $25 \%$ decrease. Hysteresis behavior is apparent at this frequency, and the loops are slightly more apparent than in the clean case; the corresponding hysteresis lift coefficient is 0.80 when LEGR is applied. In comparison, the higher frequency, LEGR case has a maximum lift coefficient of 1.57 while the model is increasing in angle of attack and the corresponding decreasing angle of attack lift coefficient is 0.72 . The application of LEGR increased the hysteresis loop size when compared to the clean case at the same run conditions, and the hysteresis loop can be seen at the lower angles of attack for the LEGR case.
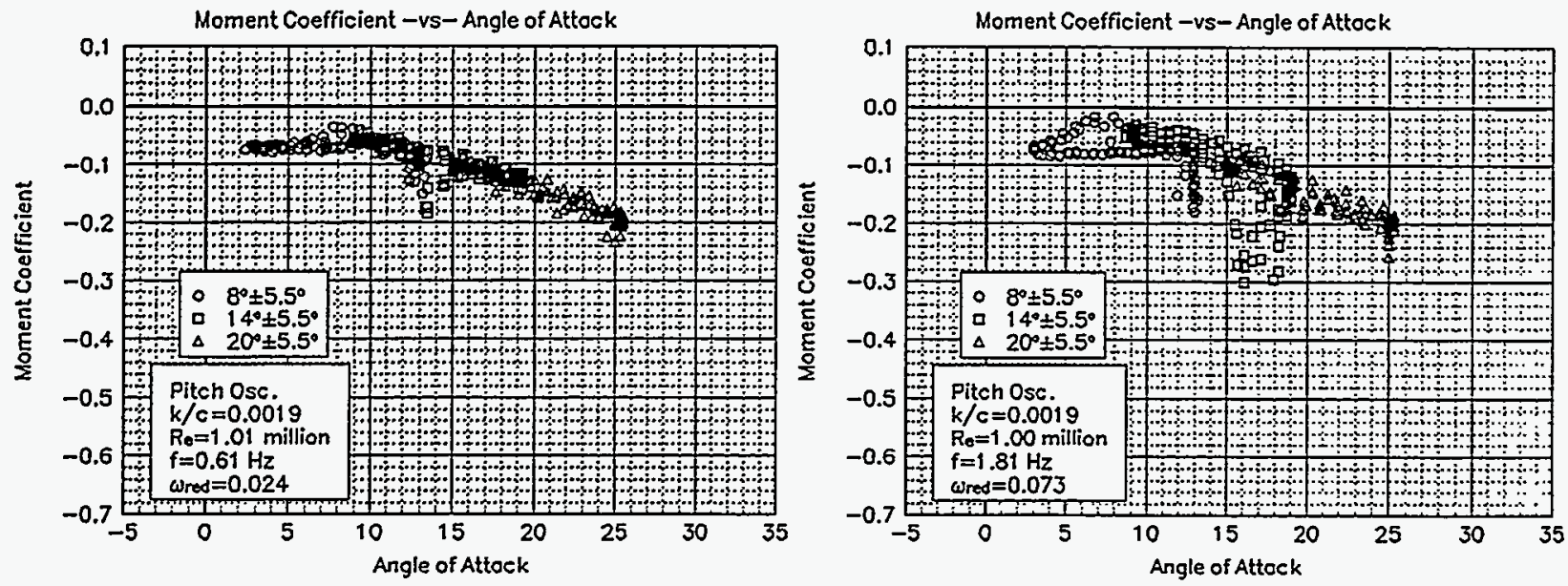

Figure 26. LEGR, $C_{m}$ vs $a, \omega_{\text {red }}=0.024, \pm 5.5^{\circ}$. Figure 27. LEGR, $C_{m}$ vs $a, \omega_{\text {red }}=0.073, \pm 5.5^{\circ}$.

The pitching moment coefficient shown in figure 26 is for 0.024 reduced frequency with LEGR applied. At the angle of unsteady maximum lift, the pitching moment ranges from -0.0652 to -0.0822 ; the steady state LEGR pitching moment is -0.0459 at the steady state stall angle of attack $\left(10.2^{\circ}\right)$. The higher reduced frequency of 0.073 with LEGR applied is shown in figure 27 . As was seen with the lift coefficient, pitching moment hysteresis is also more apparent at the higher reduced frequency than the at lower reduced frequency. Unsteady maximum lift angle of attack for this reduced frequency occurs at $15.6^{\circ}$, and the pitching moment ranges from -0.2166 to -0.0769 at that angle. The effect of LEGR is more visible at the higher frequencies, where the stall is more abrupt and generates a drastic increase in the magnitude of the pitching moment. Throughout the higher angle of attack range, the magnitude
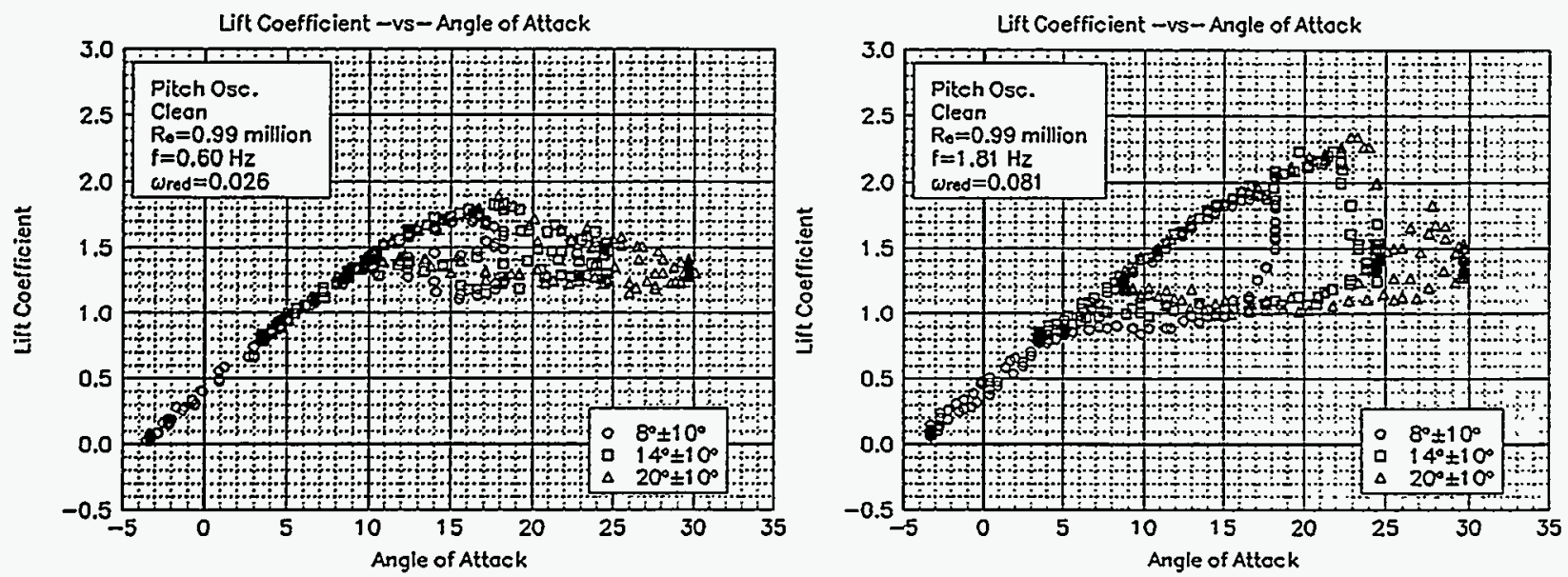

Figure 28. Clean, $C_{1}$ vs $a, \omega_{\text {red }}=0.026, \pm 10^{\circ}$. Figure 29. Clean, $C_{1}$ vs $a, \omega_{\text {red }}=0.081, \pm 10^{\circ}$. of the unsteady pitching moment can be very different from the steady state, clean condition (steady state 
pitching moment at maximum lift is -0.0615). It seems these differences can have an impact on the fatigue life predictions of a wind turbine system.

In addition to the $\pm 5^{\circ}$ unsteady experimental data, $\pm 10^{\circ}$ unsteady data were obtained with and without LEGR. The data were taken at 1 million Reynolds number using the same mean angle and frequencies as the $5.5^{\circ}$ amplitude cases. Figures 28 and 29 show the $\pm 10^{\circ}$, unsteady, clean, lift coefficient for the reduced frequencies of 0.026 and 0.081 , respectively. The maximum lift coefficient for the lower frequency is 1.84 and occurs, as expected, when the airfoil is traveling through increasing angle of attack. The hysteresis lift coefficient (at $18.2^{\circ}$ ) is 1.28 . At the higher reduced frequency, the maximum lift coefficient occurs at a higher angle of attack, $21.8^{\circ}$, and is 2.23 . The corresponding hysteresis lift coefficient is 1.19. The difference between the maximum lift coefficient and the hysteresis lift coefficient indicates a much larger hysteresis response for the higher reduced frequency than for the lower reduced frequency. The steady state, clean, maximum lift coefficient is 1.55 ; therefore, the clean unsteady behavior created lift coefficients up to $44 \%$ higher than the steady state conditions.
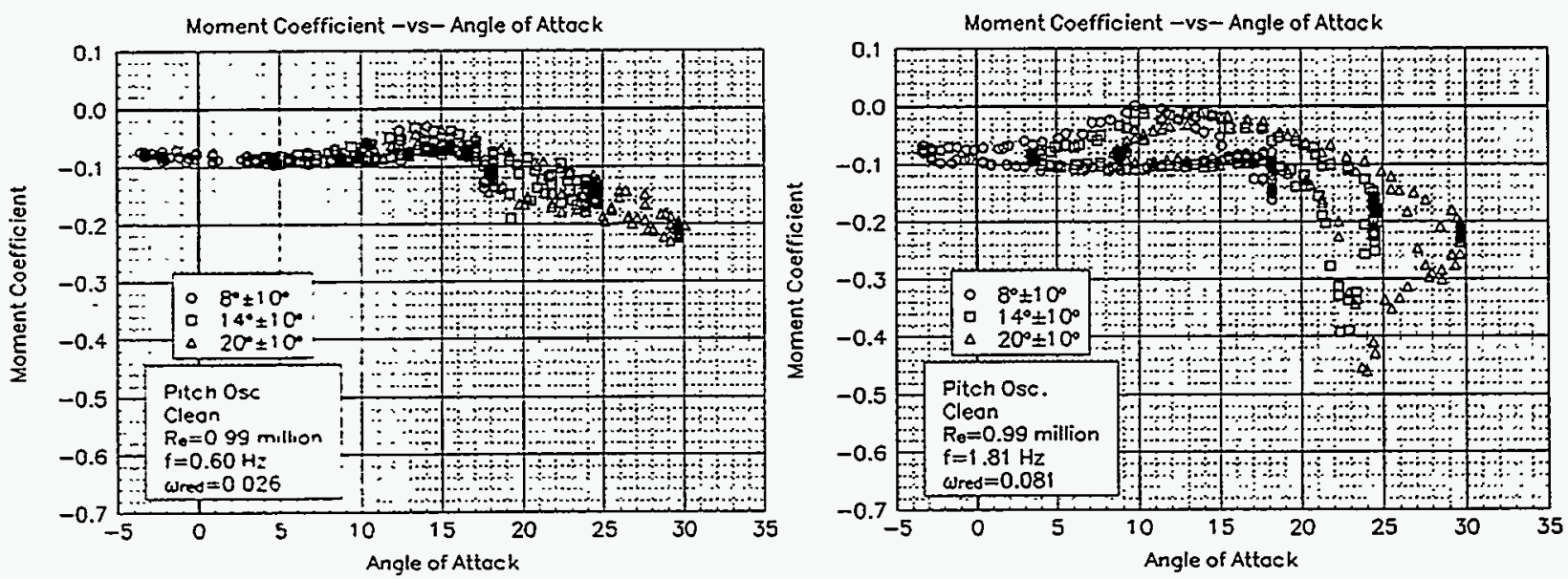

Figure 30. Clean, $\mathrm{C}_{\mathrm{m}}$ vs $a, \omega_{\text {red }}=0.026, \pm 10^{\circ}$.

Figure 31. Clean, $C_{m}$ vs $a, \omega_{\text {red }}=0.081, \pm 10^{\circ}$

The quarter chord pitching moments with the same reduced frequencies as the lift coefficient cases are
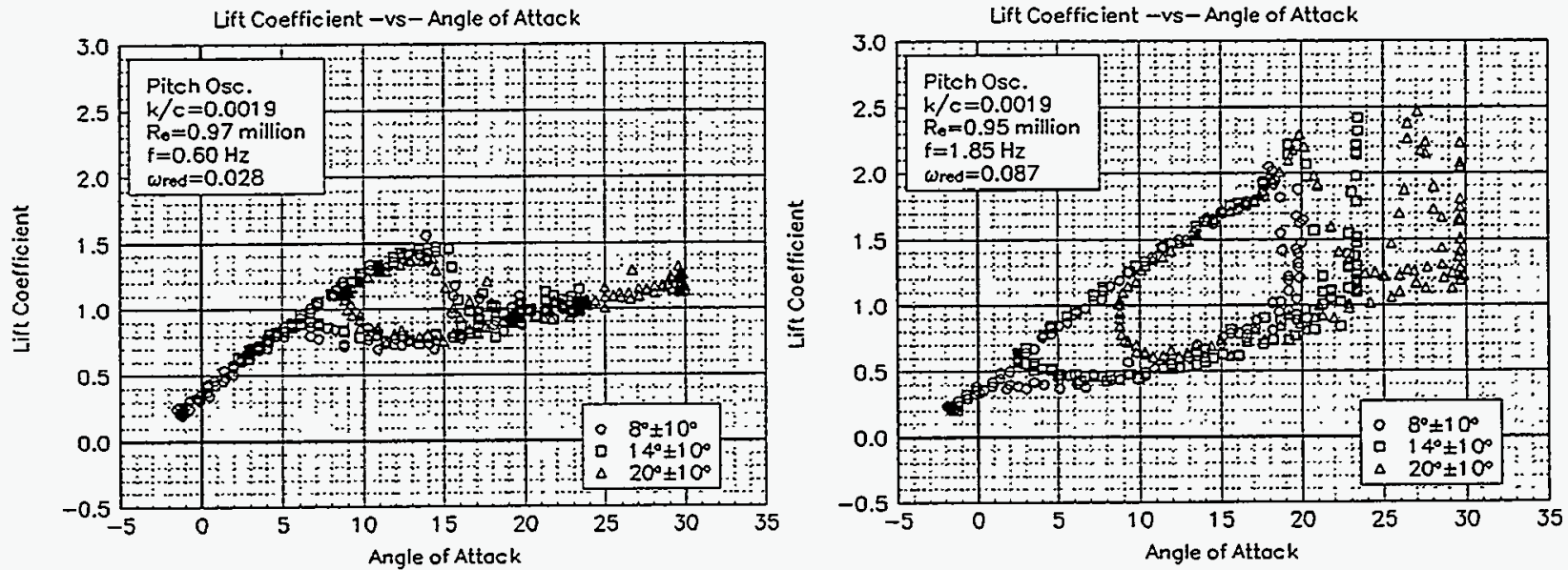

Figure 32. LEGR, $C_{1}$ vs $a, \omega_{\text {red }}=0.028, \pm 10^{\circ}$. Figure 33. LEGR, $C_{1}$ vs $a, \omega_{\text {red }}=0.087, \pm 10^{\circ}$.

shown in figures 30 and 31 . The hysteresis behavior observed in the lift coefficient plots is also reflected in this pitching moment data. Near the maximum lift angle of attack, $18.2^{\circ}$, for the lower frequency, 
the pitching moment coefficient ranges from -0.1250 to -0.0800 ; whereas the 0.081 reduced frequency case has maximum lift near $21.8^{\circ}$ and pitching moment ranges from -0.2270 to -0.1009 . The higher reduced frequency again shows large hysteresis loops for all three mean angles of attack. In comparison, the steady state pitching moment is -0.0615 near the steady state maximum lift coefficient angle of attack of $15.3^{\circ}$.

The application of LEGR degrades the lift performance of the airfoil, as would be expected from the results discussed previously. The LEGR, lift coefficient data for reduced frequencies of 0.028 and 0.087 are shown in figures 32 and 33, respectively. The maximum lift coefficient is reduced to 1.47 from 1.84, for the low frequency clean case. Although there is a reduction, this value is still significantly higher than the LEGR steady state case, which has a maximum lift coefficient of 1.13 at $10.2^{\circ}$ angle of attack. The higher reduced frequency has a maximum lift coefficient of 2.22 , which occurs near $19.2^{\circ}$ angle of attack. The corresponding lift coefficient at $19.2^{\circ}$ for the airfoil traveling with decreasing angle of attack is 0.74 , or one third of the maximum. In the deep stall region for the higher frequencies cases, the lift coefficient data show an abrupt stall and sharp recovery, which is not necessarily evident in the graphs.
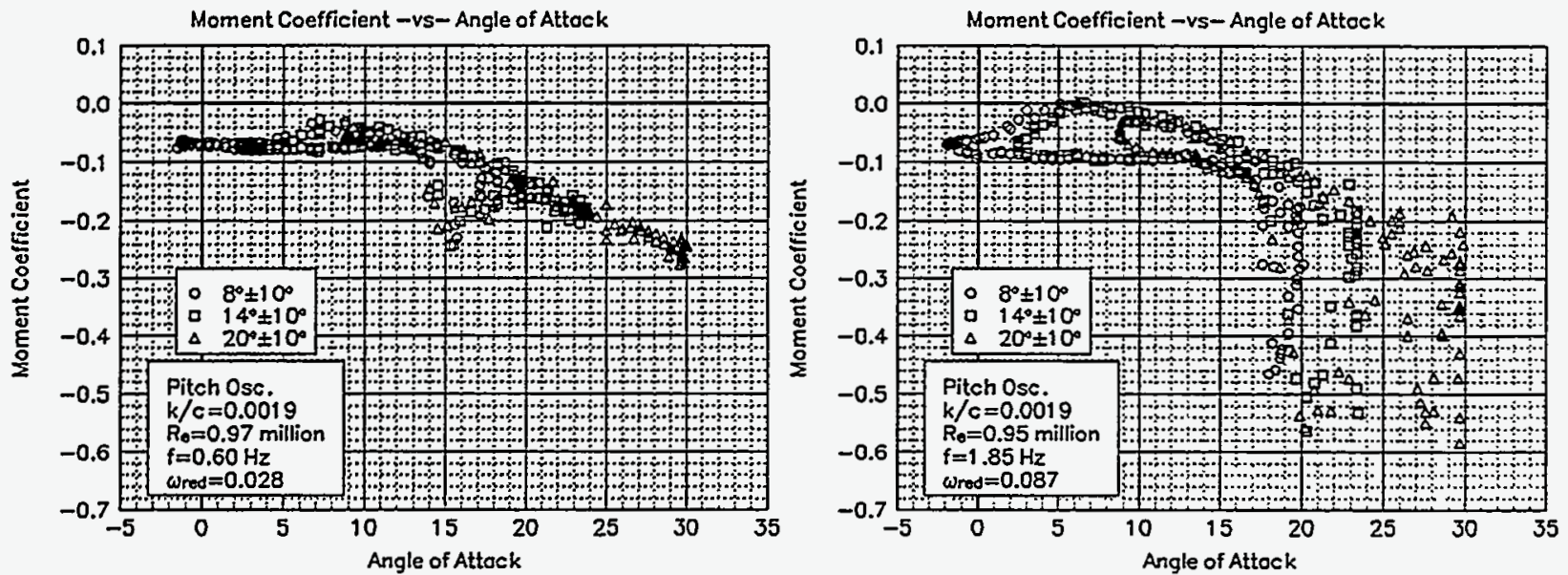

Figure 34. LEGR, $\mathrm{C}_{\mathrm{m}}$ vs $a, \omega_{\mathrm{red}}=0.028, \pm 10^{\circ}$.

Figure 35. LEGR, $\mathrm{C}_{\mathrm{m}}$ vs $a, \omega_{\text {red }}=0.087, \pm 10^{\circ}$.

Figures 34 and 35 show the corresponding pitching moment coefficients for the LEGR case at reduced frequencies of 0.028 and 0.087 . For the 0.028 reduced frequency case, the pitching moment varies from -0.1393 to -0.0715 at $14.5^{\circ}$ (were the maximum lift occurs). The hysteresis behavior is more pronounced for the higher reduced frequency case where the range of pitching moments at the maximum lift angle of $19.2^{\circ}$ is from -0.4247 to -0.1046 . These values are much higher in magnitude than the steady state LEGR value of -0.0459 .

Although all the unsteady data were not discussed here, the previous discussion included typical examples of the wind tunnel data. The remaining cases of the $\pm 5^{\circ}$ and $\pm 10^{\circ}$ oscillation data for all the Reynolds numbers are included in Appendix $C$.

The following four unsteady pressure distributions show examples of the data used to calculate the lift, pressure drag, and pitching moment coefficients. Figure 36 shows the distribution for a clean model with reduced frequency of $0.053,14^{\circ}$ mean angle of attack, and $\pm 10^{\circ}$ pitch oscillation. For plotting clarity, the model pressures were "unwrapped" about the trailing edge. The upper surface pressures are depicted on the right of the surface plot; lower surface values are on the left. The trailing edge is at the midpoint of the $\mathrm{x}$-axis with the leading edge at each extreme. The time scale corresponds to angle of attack. Separation areas are defined by the irregular, "rough" areas in the plot surface. The upper surface 
pressure peaks correspond to the maximum lift locations in the sweeps. For clarification of the irregularities in the pressure distribution, an equally spaced grid was used. The pressure coefficients were linearly interpolated to the specified number of evenly spaced $\mathrm{x}$ positions. For this case, during high angle of attack oscillations, much of the airfoil upper surface separated. The lower surface stays attached through all of the airfoil travel.

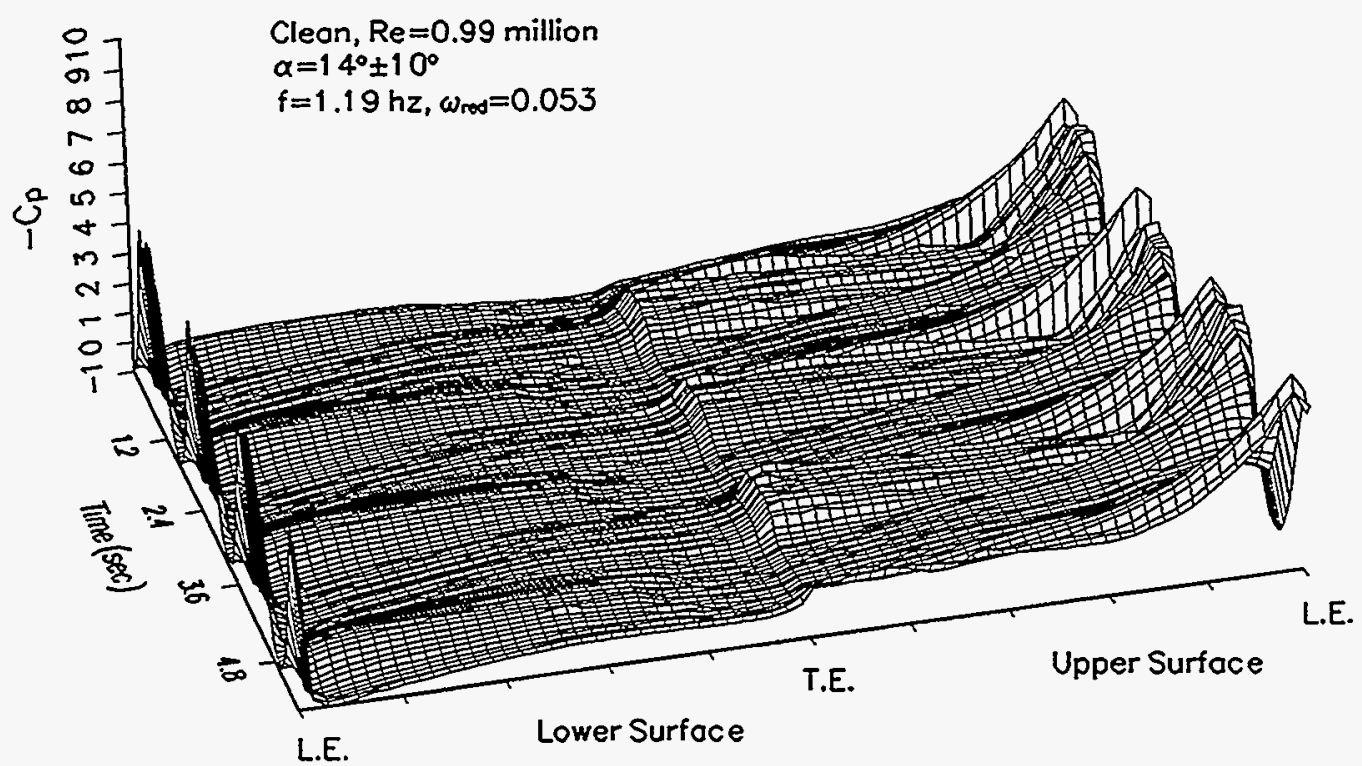

Figure 36. Unsteady pressure distribution, clean, $\omega_{\text {red }}=0.053,14 \pm 10^{\circ}$.

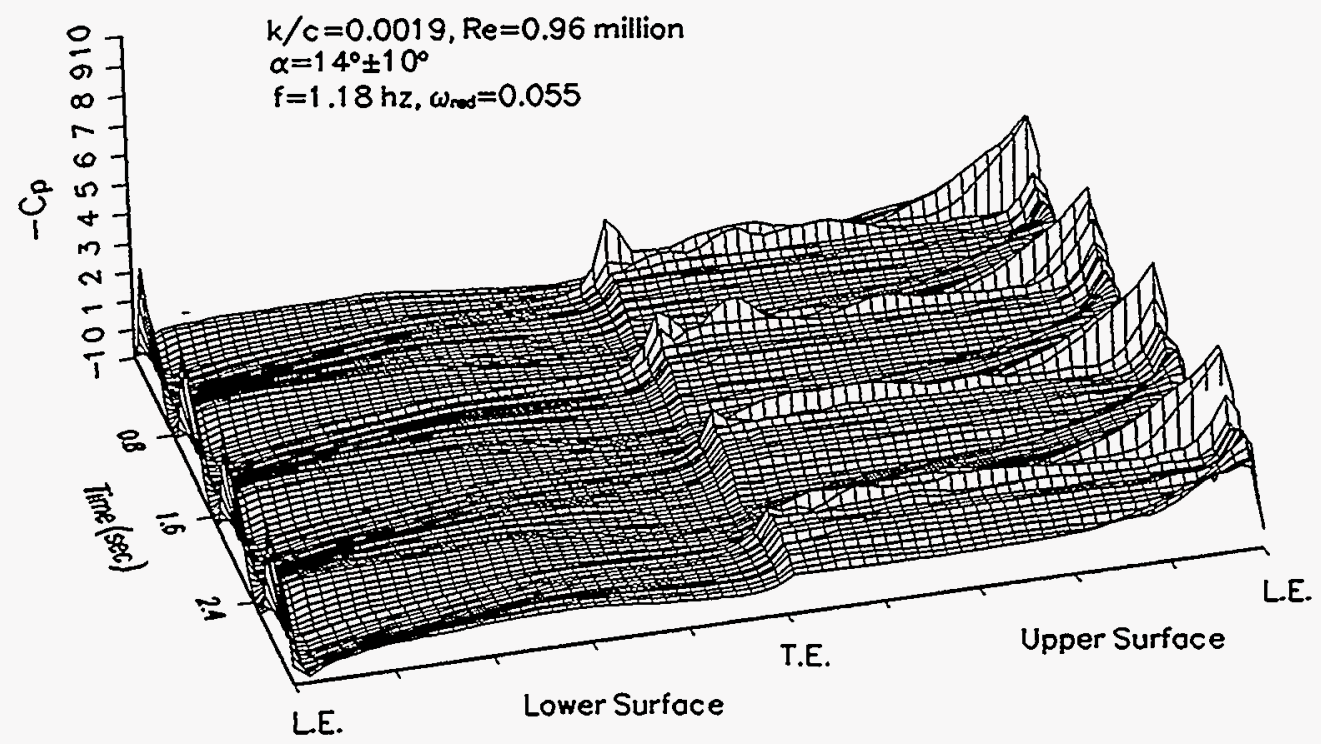

Figure 37. Unsteady pressure distribution, LEGR, $\omega_{\mathrm{red}}=0.055,14 \pm 10^{\circ}$.

Figure 37 shows the LEGR case for the same test conditions as the previous figure. In this case, the pressure peaks were not as high as for the clean case and the stall behavior becomes more noticeable as even more of the upper surface is separated. 
Figure 38 shows the same clean run conditions as above except at a smaller oscillation angle. The structure is similar to the previous graphs; however, there is less flow separation on the upper surface, the consequence of lower angles of attack.

Figure 39 shows clean run conditions for a $\pm 10^{\circ}$ oscillation at a higher Reynolds number and $20^{\circ}$ mean angle of attack. Because of the higher angles of attack, significant portions of the upper surface have separated. The pressure peaks seen emerging at the leading edge have pressure coefficient values up to 5.5 .

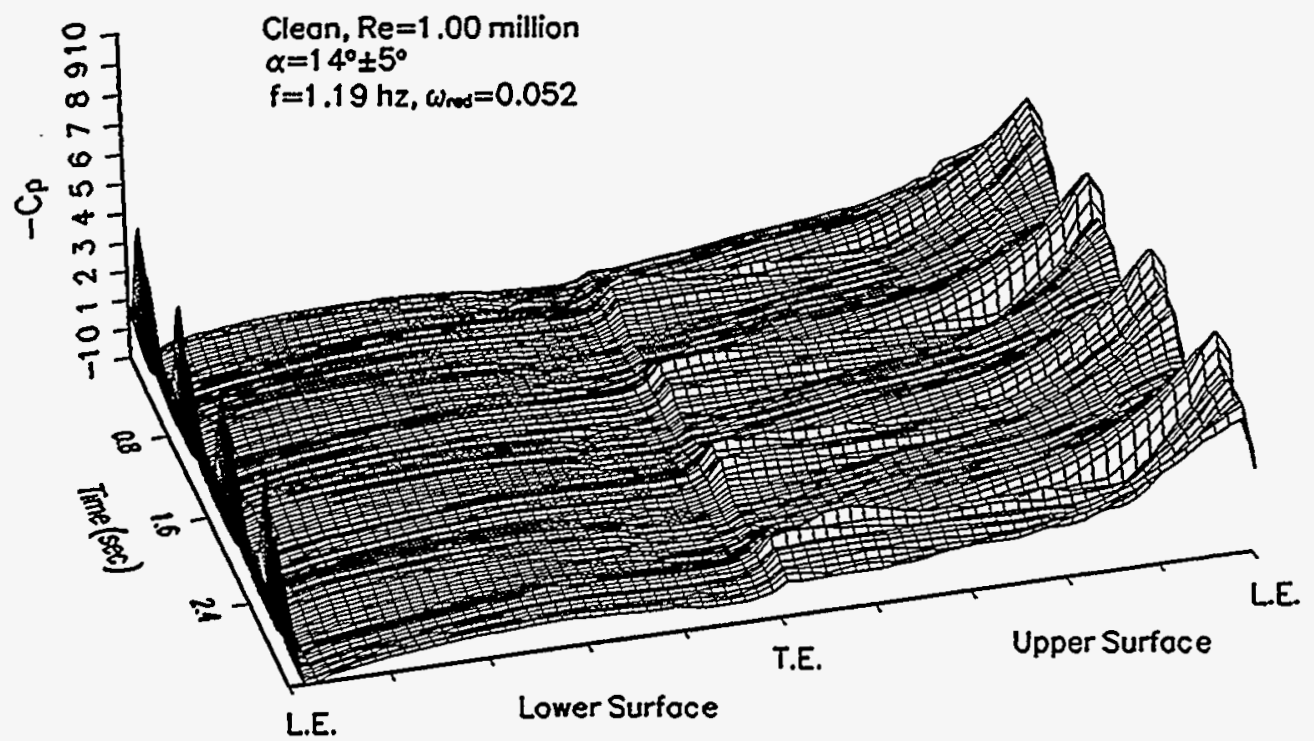

Figure 38. Unsteady pressure distribution, clean, $\omega_{\text {red }}=0.052,14 \pm 5.5^{\circ}$.

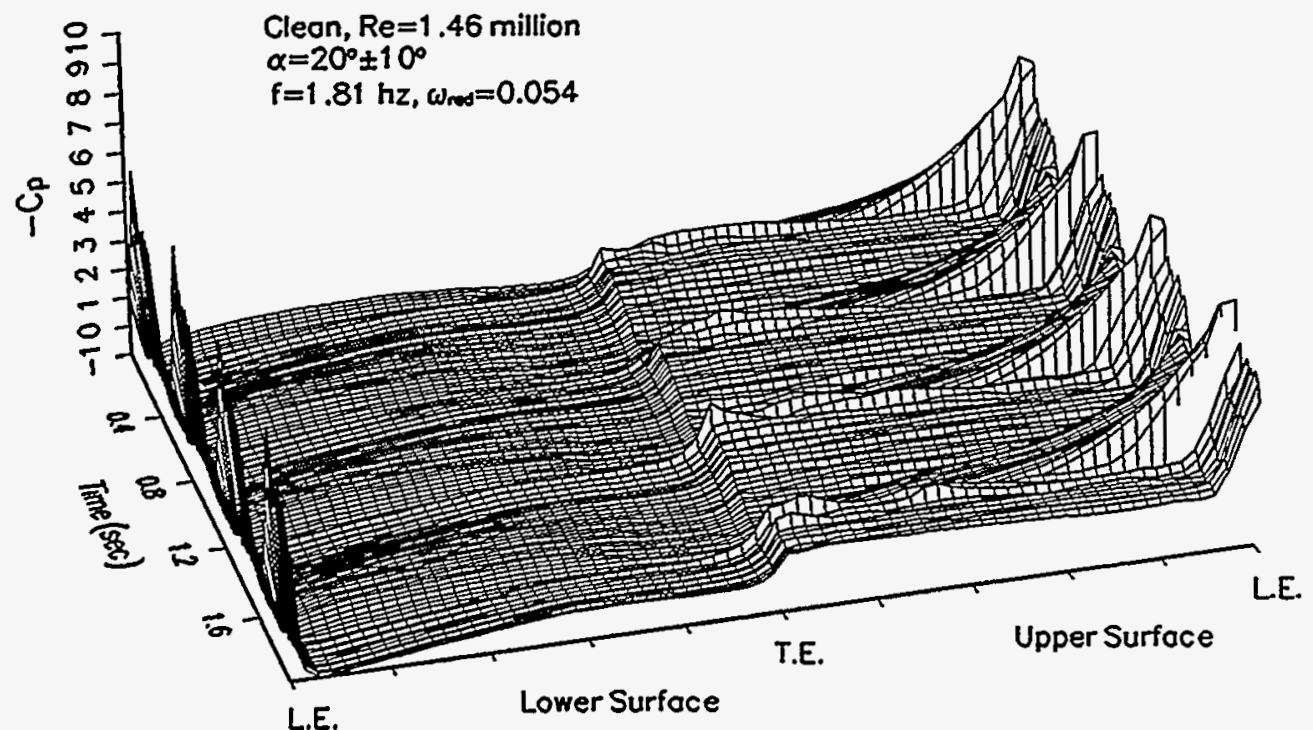

Figure 39. Unsteady pressure distribution, clean, $\omega_{\mathrm{red}}=0.053,20 \pm 10^{\circ}$. 


\section{Summary of Results}

The LS(1)-0417MOD airfoil was tested under steady and pitch oscillation conditions. Baseline tests were made while the model was clean, and then corresponding tests were conducted with LEGR applied.

A summary of the steady state aerodynamic parameters is shown in Table 1. As observed, the application of LEGR reduced the maximum lift of the airfoil up to $27 \%$ and the minimum drag coefficient increased by $36 \%$ to $49 \%$. LEGR also affected the zero lift pitching moment coefficient, reducing the magnitude an average of $15 \%$.

Table 1. LS(1)-0417MOD Aerodynamic Parameters Summary

\begin{tabular}{ccccc}
\hline Grit Pattern & Reynolds no. & $\mathrm{C}_{\operatorname{lmax}}$ & $\mathrm{C}_{\mathrm{dmin}}$ & $\mathrm{C}_{\mathrm{mo}}$ \\
\hline Clean & $0.75 \times 10^{6}$ & $1.54 @ 16.3$ & 0.0110 & -0.0755 \\
$\mathrm{k} / \mathrm{c}=0.0019$ & $0.75 \times 10^{6}$ & $1.12 @ 10.3$ & 0.0163 & -0.0621 \\
Clean & $1.00 \times 10^{6}$ & $1.55 @ 15.3$ & 0.0115 & -0.0748 \\
$\mathrm{k} / \mathrm{c}=0.0019$ & $1.00 \times 10^{6}$ & $1.13 @ 10.2$ & 0.0156 & -0.0634 \\
Clean & $1.25 \times 10^{6}$ & $1.54 @ 14.3$ & 0.0108 & -0.0732 \\
$\mathrm{k} / \mathrm{c}=0.0019$ & $1.25 \times 10^{6}$ & $1.16 @ 10.3$ & 0.0161 & -0.0631 \\
Clean & $1.50 \times 10^{6}$ & $1.54 @ 14.3$ & 0.0109 & -0.0727 \\
$\mathrm{k} / \mathrm{c}=0.0019$ & $1.50 \times 10^{6}$ & $1.16 @ 10.3$ & 0.0155 & -0.0625 \\
\hline
\end{tabular}

Table 2. LS(1)-0417MOD, Unsteady, Clean, $\pm 5.5^{\circ}$

\begin{tabular}{cccccccc}
\hline$\omega_{\text {red }}$ & $\operatorname{Rex} 10^{-6}$ & $\mathrm{f}$ & $\mathrm{C}_{\operatorname{lmax}}$ & $\alpha_{\mathrm{C} \max }$ & $\mathrm{C}_{\mathrm{I} \text { dec }}$ & $\mathrm{C}_{\mathrm{m} \text { inc }}$ & $\mathrm{C}_{\mathrm{m} \text { dec }}$ \\
\hline 0.035 & 0.75 & 0.61 & 1.77 & 17.7 & 1.55 & -0.1250 & -0.0763 \\
0.069 & 0.76 & 1.21 & 1.86 & 17.1 & 1.49 & -0.0847 & -0.0691 \\
0.104 & 0.76 & 1.83 & 1.96 & 18.6 & 1.30 & -0.1478 & -0.0914 \\
\hline 0.026 & 1.00 & 0.61 & 1.73 & 17.0 & 1.37 & -0.0932 & -0.0795 \\
0.052 & 1.00 & 1.19 & 1.84 & 16.6 & 1.47 & -0.0810 & -0.0730 \\
0.079 & 1.01 & 1.85 & 1.90 & 17.7 & 1.27 & -0.0993 & -0.0686 \\
\hline 0.020 & 1.26 & 0.61 & 1.68 & 16.1 & 1.26 & -0.0699 & -0.0604 \\
0.041 & 1.26 & 1.19 & 1.76 & 16.6 & 1.09 & -0.0843 & -0.0645 \\
0.061 & 1.26 & 1.81 & 1.83 & 16.5 & 1.07 & -0.0782 & -0.0619 \\
\hline 0.017 & 1.47 & 0.61 & 1.71 & 17.1 & 1.26 & -0.1374 & -0.1105 \\
0.035 & 1.46 & 1.19 & 1.74 & 16.2 & 1.06 & -0.0799 & -0.0742 \\
0.054 & 1.46 & 1.85 & 1.82 & 16.6 & 1.29 & -0.0782 & -0.0947 \\
\hline
\end{tabular}

The pitch oscillation data can be divided into two groups, the $\pm 5.5^{\circ}$ amplitude and $\pm 10^{\circ}$ amplitude oscillations which show similar trends. For both $\pm 5.5^{\circ}$ and $\pm 10^{\circ}$, the unsteady test conditions and some parameters are listed in Tables $2,3,4$, and 5 . As the reduced frequency, which takes oscillation and tunnel speed into account, is increased, maximum lift coefficient also increases. In addition, the hysteresis behavior becomes increasingly apparent with increased reduced frequency. 
Table 3. LS(1)-0417MOD, Unsteady, LEGR, $\pm 5.5^{\circ}$

\begin{tabular}{cccccccc}
\hline$\omega_{\text {red }}$ & $\operatorname{Rex} 10^{-6}$ & $\mathrm{f}$ & $\mathrm{C}_{\mathrm{lmax}}$ & $\alpha_{\mathrm{Clmax}}$ & $\mathrm{C}_{\mathrm{ldec}}$ & $\mathrm{C}_{\mathrm{m} \text { inc }}$ & $\mathrm{C}_{\mathrm{m} \mathrm{dec}}$ \\
\hline 0.032 & 0.76 & 0.60 & 1.34 & 13.5 & 0.72 & -0.1066 & -0.0713 \\
0.066 & 0.75 & 1.21 & 1.52 & 15.0 & 0.76 & -0.1853 & -0.0783 \\
0.100 & 0.76 & 1.85 & 1.72 & 16.6 & 0.72 & -0.2408 & -0.0800 \\
\hline 0.024 & 1.01 & 0.61 & 1.30 & 11.4 & 0.80 & -0.0652 & -0.0822 \\
0.048 & 1.00 & 1.18 & 1.42 & 14.0 & 0.76 & -0.1343 & -0.0689 \\
0.073 & 1.00 & 1.81 & 1.57 & 15.6 & 0.72 & -0.2166 & -0.0769 \\
\hline 0.019 & 1.25 & 0.61 & 1.29 & 12.4 & 0.80 & -0.0871 & -0.0718 \\
0.039 & 1.25 & 1.21 & 1.43 & 13.9 & 0.77 & -0.1535 & -0.0810 \\
0.059 & 1.25 & 1.83 & 1.50 & 14.8 & 0.76 & -0.1830 & -0.0736 \\
\hline 0.018 & 1.34 & 0.61 & 1.30 & 12.4 & 0.73 & -0.1061 & -0.0808 \\
0.037 & 1.33 & 1.21 & 1.41 & 12.4 & 0.76 & -0.0840 & -0.0782 \\
0.056 & 1.34 & 1.85 & 1.49 & 14.5 & 0.77 & -0.1649 & -0.0700 \\
\hline
\end{tabular}

Table 4. LS(1)-0417MOD, Unsteady, Clean, $\pm 10^{\circ}$

\begin{tabular}{cccccccc}
\hline$\omega_{\text {red }}$ & Rex10-6 & $\mathrm{f}$ & $\mathrm{C}_{\mathrm{lmax}}$ & $\alpha_{\mathrm{Clmax}}$ & $\mathrm{C}_{\mathrm{ldec}}$ & $\mathrm{C}_{\mathrm{m} \text { inc }}$ & $\mathrm{C}_{\mathrm{m} \text { dec }}$ \\
\hline 0.035 & 0.75 & 0.60 & 1.87 & 18.0 & 1.48 & -0.0994 & -0.0717 \\
0.072 & 0.74 & 1.21 & 2.18 & 21.3 & 1.17 & -0.2014 & -0.0927 \\
0.109 & 0.74 & 1.83 & 2.48 & 23.4 & 1.22 & -0.4590 & -0.1363 \\
\hline 0.026 & 0.99 & 0.60 & 1.84 & 18.2 & 1.28 & -0.1250 & -0.0800 \\
0.053 & 0.99 & 1.19 & 2.05 & 19.8 & 1.07 & -0.1770 & -0.0669 \\
0.081 & 0.99 & 1.81 & 2.23 & 21.8 & 1.19 & -0.2770 & -0.1009 \\
\hline 0.021 & 1.24 & 0.61 & 1.77 & 16.8 & 1.27 & -0.0945 & -0.0807 \\
0.042 & 1.23 & 1.19 & 1.92 & 18.2 & 1.21 & -0.0937 & -0.0765 \\
0.065 & 1.23 & 1.85 & 2.14 & 20.8 & 1.01 & -0.1724 & -0.0829 \\
\hline 0.018 & 1.46 & 0.61 & 1.75 & 17.0 & 1.35 & -0.0968 & -0.0918 \\
0.035 & 1.46 & 1.18 & 1.90 & 18.2 & 1.19 & -0.1048 & -0.0839 \\
0.054 & 1.46 & 1.81 & 2.04 & 20.3 & 1.09 & -0.2200 & -0.1002 \\
\hline
\end{tabular}

As expected, the application of LEGR reduces the aerodynamic performance of the airfoil. The maximum lift coefficient is reduced by $12 \%$ to $25 \%$ for the $\pm 5.5^{\circ}$ case and $0 \%$ to $20 \%$ for the $\pm 10^{\circ}$ case. In addition to the following the same trends as the clean, unsteady data discussed previously, LEGR causes the hysteresis behavior to persist into lower angles of attack than in the clean cases. Overall, the unsteady wind tunnel data show hysteresis behavior that becomes more apparent with increased reduced frequency. The maximum unsteady lift coefficient can be up to $54 \%$ higher for the $\pm 5.5^{\circ}$ amplitude and up to $119 \%$ higher for the $\pm 10^{\circ}$ amplitude than the steady state maximum lift coefficient. Variation in the quarter chord pitching moment coefficient can be up to ten times greater than that indicated by steady state results. These findings indicate that it is very important to consider 
the unsteady loading that will occur in wind turbine operation because steady state results can greatly underestimate the forces.

Table 5. LS(1)-0417MOD, Unsteady, LEGR, $\pm 10^{\circ}$

\begin{tabular}{cccccccc}
\hline$\omega_{\text {red }}$ & $\operatorname{Rex} 10^{-6}$ & $\mathrm{f}$ & $\mathrm{C}_{\mathrm{lmax}}$ & $\alpha_{\mathrm{Clmax}}$ & $\mathrm{C}_{1 \text { dec }}$ & $\mathrm{C}_{\mathrm{m} \text { inc }}$ & $\mathrm{C}_{\mathrm{m} \mathrm{dec}}$ \\
\hline 0.037 & 0.74 & 0.60 & 1.55 & 15.6 & 0.77 & -0.1470 & -0.0825 \\
0.074 & 0.73 & 1.19 & 2.00 & 19.2 & 0.76 & -0.4691 & -0.0956 \\
0.115 & 0.72 & 1.83 & 2.45 & 21.3 & 1.51 & -0.5229 & -0.4117 \\
\hline 0.028 & 0.97 & 0.60 & 1.47 & 14.5 & 0.80 & -0.1393 & -0.0715 \\
0.055 & 0.96 & 1.18 & 1.81 & 16.6 & 0.92 & -0.2555 & -0.1136 \\
0.087 & 0.95 & 1.85 & 2.22 & 19.2 & 0.74 & -0.4247 & -0.1046 \\
\hline 0.022 & 1.23 & 0.60 & 1.41 & 13.5 & 0.75 & -0.1048 & -0.0757 \\
0.044 & 1.23 & 1.19 & 1.75 & 16.6 & 0.76 & -0.3621 & -0.0781 \\
0.067 & 1.22 & 1.83 & 2.04 & 17.8 & 0.75 & -0.3243 & -0.0837 \\
\hline 0.018 & 1.46 & 0.60 & 1.41 & 13.5 & 0.75 & -0.1149 & -0.0766 \\
0.037 & 1.46 & 1.21 & 1.63 & 15.6 & 0.71 & -0.2148 & -0.0739 \\
0.057 & 1.45 & 1.83 & 1.86 & 17.2 & 0.84 & -0.3556 & -0.1048 \\
\hline
\end{tabular}




\section{References}

Pope, A.; Harper, J.J. 1966. Low Speed Wind Tunnel Testing. New York, NY: John Wiley \& Sons, Inc.

Schlichting, H. 1979. Boundary Layer Theory. New York, NY: McGraw-Hill Inc.

Smetana, F., Summey, D., et-al. 1975. Light Aircraft Lift, Drag, Moment Prediction - a Review and Analysis. North Carolina State University. NASA CR-2523. 


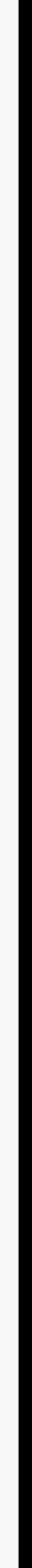


Appendix A: Model and Surface Pressure Tap Coordinates 
A1. LS(1)-0417MOD Measured Model Coordinates, 18-inch Desired Chord . . . . . . . . . A-3

A2. LS(1)-0417MOD Surface Pressure Taps, Non-Dimensional Coordinates A-10 


\begin{tabular}{|c|c|c|c|}
\hline $\begin{array}{l}\text { Chord Station } \\
\text { (in) }\end{array}$ & $\begin{array}{l}\text { Upper Ordinate } \\
\text { (in) }\end{array}$ & $\begin{array}{l}\text { Chord Station } \\
\text { (in) }\end{array}$ & $\begin{array}{l}\text { Lower Ordinate } \\
\text { (in) }\end{array}$ \\
\hline 0.0000 & 0.0000 & 0.0000 & 0.0000 \\
\hline 0.0024 & 0.0405 & 0.0006 & -0.0514 \\
\hline 0.0051 & 0.0627 & 0.0020 & -0.0691 \\
\hline 0.0077 & 0.0782 & 0.0036 & -0.0849 \\
\hline 0.0101 & 0.0922 & 0.0052 & -0.0995 \\
\hline 0.0124 & 0.1034 & 0.0068 & -0.1103 \\
\hline 0.0147 & 0.1138 & 0.0085 & -0.1205 \\
\hline 0.0170 & 0.1239 & 0.0102 & -0.1299 \\
\hline 0.0191 & 0.1329 & 0.0120 & -0.1385 \\
\hline 0.0214 & 0.1415 & 0.0137 & -0.1470 \\
\hline 0.0236 & 0.1494 & 0.0154 & -0.1540 \\
\hline 0.0257 & 0.1573 & 0.0171 & -0.1613 \\
\hline 0.0278 & 0.1643 & 0.0189 & -0.1679 \\
\hline 0.0300 & 0.1714 & 0.0206 & -0.1742 \\
\hline 0.0321 & 0.1781 & 0.0224 & -0.1804 \\
\hline 0.0343 & 0.1846 & 0.0241 & -0.1864 \\
\hline 0.0365 & 0.1912 & 0.0259 & -0.1922 \\
\hline 0.0387 & 0.1974 & 0.0277 & -0.1977 \\
\hline 0.0408 & 0.2033 & 0.0365 & -0.2217 \\
\hline 0.0430 & 0.2094 & 0.0457 & -0.2428 \\
\hline 0.0450 & 0.2148 & 0.0551 & -0.2631 \\
\hline 0.0556 & 0.2414 & 0.0640 & -0.2807 \\
\hline 0.0664 & 0.2662 & 0.0733 & -0.2970 \\
\hline 0.0766 & 0.2874 & 0.0824 & -0.3117 \\
\hline 0.0873 & 0.3083 & 0.0917 & -0.3254 \\
\hline 0.0976 & 0.3270 & 0.1010 & -0.3382 \\
\hline 0.1081 & 0.3454 & 0.1101 & -0.3497 \\
\hline 0.1183 & 0.3623 & 0.1196 & -0.3607 \\
\hline 0.1287 & 0.3787 & 0.1290 & -0.3713 \\
\hline 0.1392 & 0.3945 & 0.1385 & -0.3812 \\
\hline 0.1496 & 0.4100 & 0.1478 & -0.3904 \\
\hline 0.1601 & 0.4250 & 0.1576 & -0.3996 \\
\hline 0.1705 & 0.4395 & 0.1672 & -0.4086 \\
\hline 0.1809 & 0.4535 & 0.1767 & -0.4173 \\
\hline 0.1913 & 0.4674 & 0.1861 & -0.4253 \\
\hline
\end{tabular}




\begin{tabular}{|c|c|c|c|}
\hline \multicolumn{4}{|c|}{$\begin{array}{l}\text { Table A1. LS(1)-0417MOD Measured Model Coordinates, } \\
\text { 18-inch Desired Chord }\end{array}$} \\
\hline $\begin{array}{l}\text { Chord Station } \\
\text { (in) }\end{array}$ & $\begin{array}{l}\text { Upper Ordinate } \\
\text { (in) }\end{array}$ & $\begin{array}{l}\text { Chord Station } \\
\text { (in) }\end{array}$ & $\begin{array}{l}\text { Lower Ordinate } \\
\text { (in) }\end{array}$ \\
\hline 0.2016 & 0.4806 & 0.1956 & -0.4331 \\
\hline 0.2121 & 0.4942 & 0.2054 & -0.4409 \\
\hline 0.2223 & 0.5068 & 0.2148 & -0.4482 \\
\hline 0.2327 & 0.5197 & 0.2246 & -0.4553 \\
\hline 0.2429 & 0.5317 & 0.2342 & -0.4622 \\
\hline 0.2534 & 0.5440 & 0.2436 & -0.4688 \\
\hline 0.2636 & 0.5557 & 0.2528 & -0.4747 \\
\hline 0.2740 & 0.5673 & 0.2627 & -0.4806 \\
\hline 0.2844 & 0.5792 & 0.2729 & -0.4871 \\
\hline 0.2945 & 0.5904 & 0.2820 & -0.4924 \\
\hline 0.3049 & 0.6016 & 0.2920 & -0.4980 \\
\hline 0.3152 & 0.6125 & 0.3017 & -0.5034 \\
\hline 0.3255 & 0.6235 & 0.3116 & -0.5090 \\
\hline 0.3359 & 0.6343 & 0.3210 & -0.5139 \\
\hline 0.3463 & 0.6449 & 0.3308 & -0.5189 \\
\hline 0.3567 & 0.6557 & 0.3412 & -0.5245 \\
\hline 0.3669 & 0.6661 & 0.3504 & -0.5291 \\
\hline 0.3771 & 0.6762 & 0.3606 & -0.5343 \\
\hline 0.3875 & 0.6863 & 0.3704 & -0.5394 \\
\hline 0.3982 & 0.6969 & 0.3800 & -0.5444 \\
\hline 0.4078 & 0.7060 & 0.3892 & -0.5482 \\
\hline 0.4185 & 0.7160 & 0.4002 & -0.5537 \\
\hline 0.4287 & 0.7256 & 0.4096 & -0.5584 \\
\hline 0.4388 & 0.7349 & 0.4189 & -0.5627 \\
\hline 0.4492 & 0.7444 & 0.4291 & -0.5673 \\
\hline 0.4591 & 0.7532 & 0.4391 & -0.5725 \\
\hline 0.4697 & 0.7627 & 0.4481 & -0.5763 \\
\hline 0.4797 & 0.7717 & 0.4582 & -0.5807 \\
\hline 0.4900 & 0.7804 & 0.4686 & -0.5858 \\
\hline 0.5002 & 0.7892 & 0.4775 & -0.5894 \\
\hline 0.5105 & 0.7980 & 0.4879 & -0.5939 \\
\hline 0.5205 & 0.8061 & 0.4981 & -0.5984 \\
\hline 0.5311 & 0.8152 & 0.5078 & -0.6026 \\
\hline 0.5410 & 0.8229 & 0.5179 & -0.6070 \\
\hline 0.5515 & 0.8312 & 0.5279 & -0.6113 \\
\hline
\end{tabular}




\begin{tabular}{|c|c|c|c|}
\hline \multicolumn{4}{|c|}{$\begin{array}{c}\text { Table A1. LS(1)-0417MOD Measured Model Coordinates, } \\
\text { 18-inch Desired Chord }\end{array}$} \\
\hline $\begin{array}{l}\text { Chord Station } \\
\text { (in) }\end{array}$ & $\begin{array}{l}\text { Upper Ordinate } \\
\text { (in) }\end{array}$ & $\begin{array}{l}\text { Chord Station } \\
\text { (in) }\end{array}$ & $\begin{array}{l}\text { Lower Ordinate } \\
\text { (in) }\end{array}$ \\
\hline 0.5621 & 0.8399 & 0.5378 & -0.6156 \\
\hline 0.5714 & 0.8468 & 0.5475 & -0.6196 \\
\hline 0.5825 & 0.8553 & 0.5574 & -0.6236 \\
\hline 0.5925 & 0.8631 & 0.5674 & -0.6278 \\
\hline 0.6027 & 0.8707 & 0.5770 & -0.6316 \\
\hline 0.6130 & 0.8785 & 0.5871 & -0.6355 \\
\hline 0.6233 & 0.8860 & 0.5966 & -0.6391 \\
\hline 0.6339 & 0.8938 & 0.6068 & -0.6431 \\
\hline 0.6435 & 0.9008 & 0.6165 & -0.6468 \\
\hline 0.6538 & 0.9079 & 0.6262 & -0.6504 \\
\hline 0.6640 & 0.9150 & 0.6361 & -0.6540 \\
\hline 0.6741 & 0.9220 & 0.6459 & -0.6575 \\
\hline 0.6842 & 0.9289 & 0.6560 & -0.6611 \\
\hline 0.6944 & 0.9358 & 0.6657 & -0.6645 \\
\hline 0.7047 & 0.9426 & 0.6759 & -0.6680 \\
\hline 0.7148 & 0.9494 & 0.6856 & -0.6713 \\
\hline 0.7251 & 0.9562 & 0.6956 & -0.6747 \\
\hline 0.7354 & 0.9629 & 0.7054 & -0.6779 \\
\hline 0.7457 & 0.9696 & 0.7151 & -0.6811 \\
\hline 0.7560 & 0.9763 & 0.7253 & -0.6843 \\
\hline 0.7660 & 0.9827 & 0.7350 & -0.6875 \\
\hline 0.7764 & 0.9893 & 0.7453 & -0.6908 \\
\hline 0.7866 & 0.9956 & 0.7549 & -0.6938 \\
\hline 0.7968 & 1.0022 & 0.7649 & -0.6969 \\
\hline 0.8071 & 1.0086 & 0.7750 & -0.6999 \\
\hline 0.8176 & 1.0153 & 0.7846 & -0.7031 \\
\hline 0.8274 & 1.0212 & 0.7946 & -0.7062 \\
\hline 0.8376 & 1.0273 & 0.8046 & -0.7093 \\
\hline 0.8478 & 1.0334 & 0.8145 & -0.7123 \\
\hline 0.8581 & 1.0396 & 0.8238 & -0.7151 \\
\hline 0.8682 & 1.0458 & 0.8339 & -0.7179 \\
\hline 0.8781 & 1.0516 & 0.8441 & -0.7207 \\
\hline 0.8884 & 1.0575 & 0.8541 & -0.7238 \\
\hline 0.8986 & 1.0634 & 1.0521 & -0.7772 \\
\hline 0.9090 & 1.0695 & 1.2510 & -0.8252 \\
\hline
\end{tabular}




\begin{tabular}{|c|c|c|c|}
\hline $\begin{array}{l}\text { Chord Station } \\
\text { (in) }\end{array}$ & $\begin{array}{l}\text { Upper Ordinate } \\
\text { (in) }\end{array}$ & $\begin{array}{l}\text { Chord Station } \\
\text { (in) }\end{array}$ & $\begin{array}{l}\text { Lower Ordinate } \\
\text { (in) }\end{array}$ \\
\hline 0.9191 & 1.0754 & 1.4497 & -0.8692 \\
\hline 1.1215 & 1.1831 & 1.6488 & -0.9085 \\
\hline 1.3239 & 1.2774 & 1.8477 & -0.9443 \\
\hline 1.5261 & 1.3611 & 2.0468 & -0.9767 \\
\hline 1.7278 & 1.4344 & 2.2463 & -1.0065 \\
\hline 1.9294 & 1.4990 & 2.4460 & -1.0339 \\
\hline 2.1309 & 1.5558 & 2.6456 & -1.0590 \\
\hline 2.3321 & 1.6057 & 2.8453 & -1.0818 \\
\hline 2.5333 & 1.6489 & 3.0451 & -1.1029 \\
\hline 2.7345 & 1.6859 & 3.2447 & -1.1218 \\
\hline 2.9355 & 1.7184 & 3.4448 & -1.1388 \\
\hline 3.1364 & 1.7461 & 3.6447 & -1.1543 \\
\hline 3.3372 & 1.7697 & 3.8445 & -1.1689 \\
\hline 3.5379 & 1.7890 & 4.0447 & -1.1819 \\
\hline 3.7386 & 1.8051 & 4.2447 & -1.1938 \\
\hline 3.9392 & 1.8180 & 4.4446 & -1.2046 \\
\hline 4.1397 & 1.8276 & 4.6450 & -1.2137 \\
\hline 4.3402 & 1.8349 & 4.8448 & -1.2219 \\
\hline 4.5405 & 1.8401 & 5.0451 & -1.2289 \\
\hline 4.7409 & 1.8427 & 5.2453 & -1.2349 \\
\hline 4.9411 & 1.8433 & 5.4455 & -1.2397 \\
\hline 5.1417 & 1.8417 & 5.6458 & -1.2437 \\
\hline 5.3417 & 1.8383 & 5.8462 & -1.2471 \\
\hline 5.5418 & 1.8333 & 6.0463 & -1.2491 \\
\hline 5.7422 & 1.8268 & 6.2464 & -1.2502 \\
\hline 5.9421 & 1.8192 & 6.4469 & -1.2503 \\
\hline 6.1422 & 1.8102 & 6.6472 & -1.2498 \\
\hline 6.3424 & 1.8002 & 6.8475 & -1.2478 \\
\hline 6.5423 & 1.7893 & 7.0480 & -1.2449 \\
\hline 6.7423 & 1.7781 & 7.2484 & -1.2410 \\
\hline 6.9424 & 1.7665 & 7.4489 & -1.2360 \\
\hline 7.1423 & 1.7547 & 7.6496 & -1.2305 \\
\hline 7.3423 & 1.7423 & 7.8499 & -1.2242 \\
\hline 7.5425 & 1.7295 & 8.0504 & -1.2171 \\
\hline 7.7423 & 1.7163 & 8.2510 & -1.2091 \\
\hline
\end{tabular}




\begin{tabular}{|c|c|c|c|}
\hline \multicolumn{4}{|c|}{$\begin{array}{l}\text { Table A1. LS(1)-0417MOD Measured Model Coordinates, } \\
\text { 18-inch Desired Chord }\end{array}$} \\
\hline $\begin{array}{l}\text { Chord Station } \\
\text { (in) }\end{array}$ & $\begin{array}{l}\text { Upper Ordinate } \\
\text { (in) }\end{array}$ & $\begin{array}{l}\text { Chord Station } \\
\text { (in) }\end{array}$ & $\begin{array}{l}\text { Lower Ordinate } \\
\quad \text { (in) }\end{array}$ \\
\hline 7.9423 & 1.7023 & 8.4515 & -1.2002 \\
\hline 8.1424 & 1.6880 & 8.6519 & -1.1899 \\
\hline 8.3422 & 1.6736 & 8.8526 & -1.1782 \\
\hline 8.5422 & 1.6587 & 9.0532 & -1.1649 \\
\hline 8.7420 & 1.6434 & 9.2540 & -1.1503 \\
\hline 8.9418 & 1.6275 & 9.4547 & -1.1339 \\
\hline 9.1419 & 1.6111 & 9.6552 & -1.1153 \\
\hline 9.3416 & 1.5941 & 9.8561 & -1.0946 \\
\hline 9.5412 & 1.5762 & 10.0570 & -1.0724 \\
\hline 9.7411 & 1.5575 & 10.2579 & -1.0489 \\
\hline 9.9407 & 1.5374 & 10.4589 & -1.0238 \\
\hline 10.1403 & 1.5166 & 10.6599 & -0.9969 \\
\hline 10.3401 & 1.4949 & 10.8609 & -0.9681 \\
\hline 10.5397 & 1.4722 & 11.0622 & -0.9378 \\
\hline 10.7392 & 1.4482 & 11.2636 & -0.9061 \\
\hline 10.9388 & 1.4226 & 11.4646 & -0.8731 \\
\hline 11.1383 & 1.3957 & 11.6665 & -0.8392 \\
\hline 11.3377 & 1.3674 & 11.8677 & -0.8044 \\
\hline 11.5372 & 1.3375 & 12.0691 & -0.7681 \\
\hline 11.7368 & 1.3063 & 12.2709 & -0.7312 \\
\hline 11.9360 & 1.2738 & 12.4726 & -0.6942 \\
\hline 12.1354 & 1.2398 & 12.6741 & -0.6568 \\
\hline 12.3348 & 1.2048 & 12.8759 & -0.6190 \\
\hline 12.5342 & 1.1692 & 13.0777 & -0.5811 \\
\hline 12.7338 & 1.1335 & 13.2792 & -0.5431 \\
\hline 12.9331 & 1.0968 & 13.4811 & -0.5048 \\
\hline 13.1327 & 1.0591 & 13.6829 & -0.4670 \\
\hline 13.3320 & 1.0211 & 13.8845 & -0.4295 \\
\hline 13.5314 & 0.9825 & 14.0865 & -0.3926 \\
\hline 13.7308 & 0.9430 & 14.2882 & -0.3569 \\
\hline 13.9303 & 0.9029 & 14.4897 & -0.3230 \\
\hline 14.1297 & 0.8622 & 14.6916 & -0.2906 \\
\hline 14.3291 & 0.8208 & 14.8932 & -0.2602 \\
\hline 14.5284 & 0.7789 & 15.0947 & -0.2315 \\
\hline 14.7278 & 0.7369 & 15.2963 & -0.2046 \\
\hline
\end{tabular}




\begin{tabular}{|c|c|c|c|}
\hline \multicolumn{4}{|c|}{$\begin{array}{l}\text { Table A1. LS(1)-0417MOD Measured Model Coordinates, } \\
\text { 18-inch Desired Chord }\end{array}$} \\
\hline $\begin{array}{l}\text { Chord Station } \\
\text { (in) }\end{array}$ & $\begin{array}{l}\text { Upper Ordinate } \\
\text { (in) }\end{array}$ & $\begin{array}{l}\text { Chord Station } \\
\text { (in) }\end{array}$ & $\begin{array}{l}\text { Lower Ordinate } \\
\text { (in) }\end{array}$ \\
\hline 14.9270 & 0.6948 & 15.4977 & -0.1787 \\
\hline 15.1266 & 0.6519 & 15.6992 & -0.1546 \\
\hline 15.3258 & 0.6085 & 15.9008 & -0.1329 \\
\hline 15.5250 & 0.5648 & 16.1021 & -0.1151 \\
\hline 15.7246 & 0.5211 & 16.3032 & -0.1008 \\
\hline 15.9236 & 0.4771 & 16.5045 & -0.0899 \\
\hline 16.1229 & 0.4327 & 16.7055 & -0.0829 \\
\hline 16.3222 & 0.3881 & 16.9064 & -0.0800 \\
\hline 16.5213 & 0.3430 & 17.1074 & -0.0816 \\
\hline 16.7204 & 0.2974 & 17.3083 & -0.0886 \\
\hline 16.9198 & 0.2512 & 17.5088 & -0.1011 \\
\hline 17.1188 & 0.2045 & 17.7093 & -0.1198 \\
\hline 17.3175 & 0.1547 & 17.9097 & -0.1450 \\
\hline 17.5160 & 0.1005 & 17.9141 & -0.1455 \\
\hline 17.7142 & 0.0393 & 17.9189 & -0.1460 \\
\hline 17.9089 & -0.0297 & 17.9237 & -0.1465 \\
\hline 17.9134 & -0.0314 & 17.9287 & -0.1470 \\
\hline 17.9186 & -0.0335 & 17.9337 & -0.1475 \\
\hline 17.9236 & -0.0356 & 17.9383 & -0.1479 \\
\hline 17.9283 & -0.0375 & 17.9433 & -0.1484 \\
\hline 17.9330 & -0.0395 & 17.9482 & -0.1488 \\
\hline 17.9380 & -0.0415 & 17.9529 & -0.1492 \\
\hline 17.9431 & -0.0436 & 17.9575 & -0.1494 \\
\hline 17.9477 & -0.0456 & 17.9620 & -0.1496 \\
\hline 17.9523 & -0.0476 & 17.9664 & -0.1497 \\
\hline 17.9570 & -0.0497 & 17.9709 & -0.1496 \\
\hline 17.9622 & -0.0519 & 17.9747 & -0.1493 \\
\hline 17.9670 & -0.0541 & 17.9774 & -0.1485 \\
\hline 17.9713 & -0.0561 & 17.9794 & -0.1475 \\
\hline 17.9758 & -0.0583 & 17.9816 & -0.1459 \\
\hline 17.9805 & -0.0607 & 17.9840 & -0.1434 \\
\hline 17.9843 & -0.0630 & 17.9854 & -0.1389 \\
\hline 17.9869 & -0.0654 & 17.9891 & -0.1319 \\
\hline 17.9893 & -0.0685 & & \\
\hline 17.9909 & -0.0739 & & \\
\hline
\end{tabular}




\begin{tabular}{|c|c|c|c|}
\hline $\begin{array}{l}\text { Chord Station } \\
\text { (in) }\end{array}$ & $\begin{array}{l}\text { Upper Ordinate } \\
\text { (in) }\end{array}$ & $\begin{array}{l}\text { Chord Station } \\
\text { (in) }\end{array}$ & $\begin{array}{l}\text { Lower Ordinate } \\
\text { (in) }\end{array}$ \\
\hline 17.9946 & -0.0824 & & \\
\hline \multicolumn{4}{|c|}{ End of Table A1 } \\
\hline
\end{tabular}




\begin{tabular}{|c|c|c|}
\hline \multicolumn{3}{|c|}{$\begin{array}{l}\text { Table A2. LS(1)-0417MOD Surface Pressure Taps, } \\
\text { Non-Dimensional Coordinates }\end{array}$} \\
\hline Tap Number & Chord Station & Ordinate \\
\hline 1 & 0.9978 & -0.0005 \\
\hline 2 & 0.9839 & -0.0063 \\
\hline 3 & 0.9684 & -0.0049 \\
\hline 4 & 0.9444 & -0.0041 \\
\hline 5 & 0.9202 & -0.0045 \\
\hline 6 & 0.8909 & -0.0064 \\
\hline $7 *$ & 0.8683 & -0.0088 \\
\hline 8 & 0.8422 & -0.0121 \\
\hline 9 & 0.8175 & -0.0158 \\
\hline 10 & 0.7909 & -0.0201 \\
\hline 11 & 0.7427 & -0.0291 \\
\hline 12 & 0.6922 & -0.0386 \\
\hline $13 *$ & 0.6442 & -0.0472 \\
\hline 14 & 0.5950 & -0.0550 \\
\hline 15 & 0.5445 & -0.0612 \\
\hline 16 & 0.4960 & -0.0653 \\
\hline 17 & 0.3942 & -0.0693 \\
\hline 18 & 0.2943 & -0.0689 \\
\hline $19 *$ & 0.2448 & -0.0671 \\
\hline 20 & 0.2193 & -0.0656 \\
\hline 21 & 0.1951 & -0.0640 \\
\hline 22 & 0.1710 & -0.0618 \\
\hline 23 & 0.1447 & -0.0589 \\
\hline 24 & 0.1198 & -0.0556 \\
\hline 25 & 0.0971 & -0.0519 \\
\hline 26 & 0.0714 & -0.0467 \\
\hline 27 & 0.0454 & -0.0400 \\
\hline 28 & 0.0195 & -0.0297 \\
\hline 29 & -0.0001 & 0.0031 \\
\hline 30 & 0.0162 & 0.0319 \\
\hline 31 & 0.0300 & 0.0450 \\
\hline 32 & 0.0530 & 0.0602 \\
\hline 33 & 0.0766 & 0.0717 \\
\hline 34 & 0.1030 & 0.0815 \\
\hline 35 & 0.1284 & 0.0885 \\
\hline 36 & 0.1524 & 0.0934 \\
\hline
\end{tabular}




\begin{tabular}{|c|c|c||}
\hline \multicolumn{3}{||c|}{ Table A2. LS(1)-0417MOD Surface Pressure Taps, } \\
Non-Dimensional Coordinates
\end{tabular}

Taps marked with an * were unusable, because of weak response. 


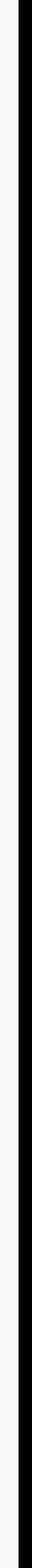




\section{Appendix B: Steady State Data Integrated Coefficients and Pressure Distributions}




\section{List of Tables}

Page

B1. $\mathrm{LS}(1)-0417 \mathrm{MOD}, \mathrm{Clean}, \mathrm{Re}=0.75 \times 10^{6} \ldots \ldots \ldots \ldots \ldots \ldots \ldots \ldots \ldots$

B2. $\mathrm{LS}(1)-0417 \mathrm{MOD}, \mathrm{Clean}, \mathrm{Re}=1.0 \times 10^{6} \ldots \ldots \ldots \ldots \ldots \ldots \ldots \ldots \ldots \ldots$

B3. LS(1)-0417MOD, Clean, $\operatorname{Re}=1.25 \times 10^{6} \ldots \ldots \ldots \ldots \ldots \ldots \ldots \ldots \ldots$

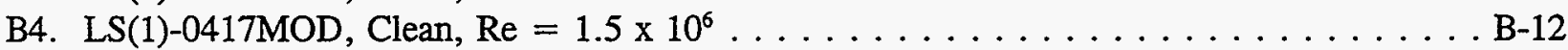

B5. $\mathrm{LS}(1)-0417 \mathrm{MOD}, \mathrm{k} / \mathrm{c}=0.0019, \mathrm{Re}=0.75 \times 10^{6} \ldots \ldots \ldots \ldots \ldots \ldots \ldots$

B6. $\mathrm{LS}(1)-0417 \mathrm{MOD}, \mathrm{k} / \mathrm{c}=0.0019, \mathrm{Re}=1.0 \times 10^{6} \ldots \ldots \ldots \ldots \ldots \ldots \ldots \ldots$

B7. $\mathrm{LS}(1)-0417 \mathrm{MOD}, \mathrm{k} / \mathrm{c}=0.0019, \mathrm{Re}=1.25 \times 10^{6} \ldots \ldots \ldots \ldots \ldots \ldots \ldots \ldots$

B8. $\mathrm{LS}(1)-0417 \mathrm{MOD}, \mathrm{k} / \mathrm{c}=0.0019, \mathrm{Re}=1.5 \times 10^{6} \ldots \ldots \ldots \ldots \ldots \ldots \ldots \ldots$ 


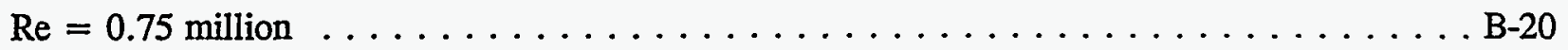

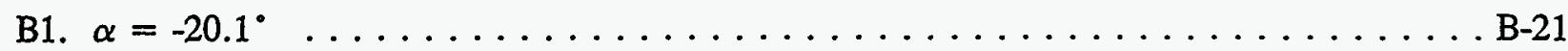

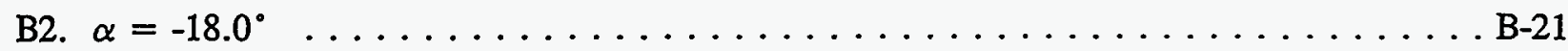

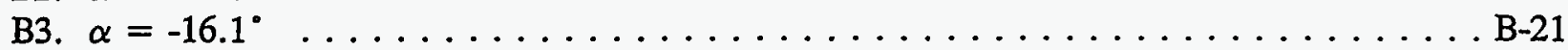

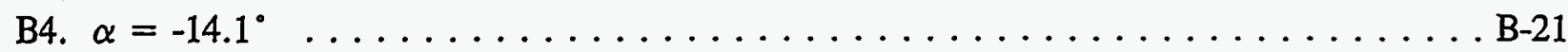

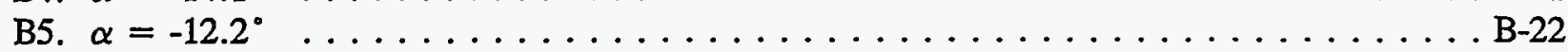

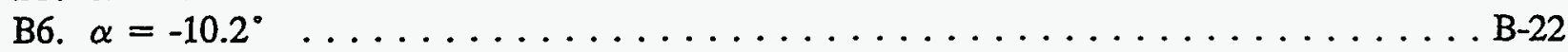

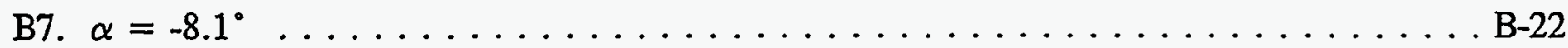

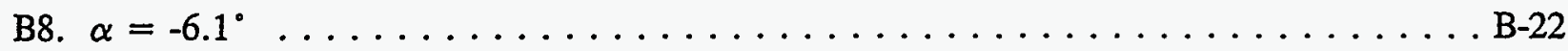

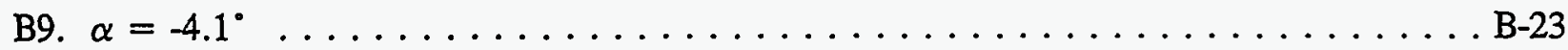

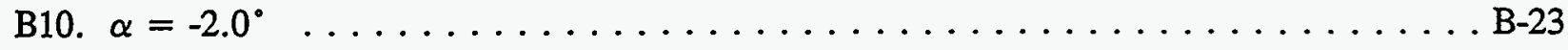

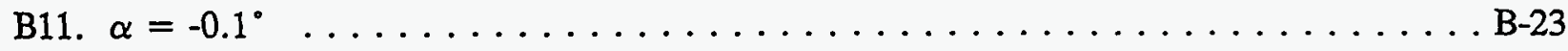

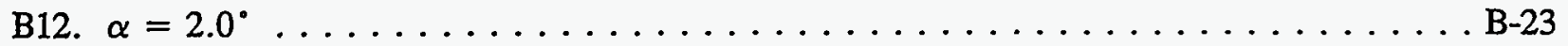

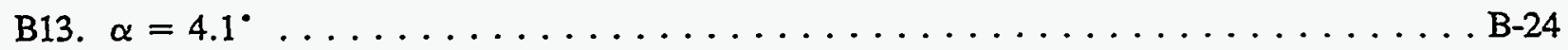

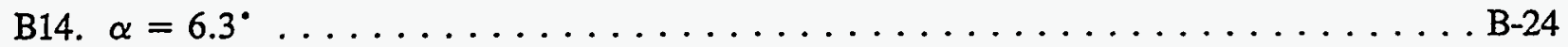

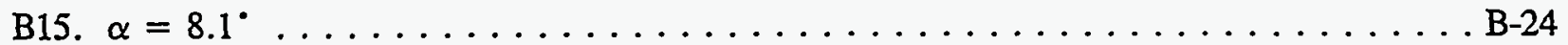

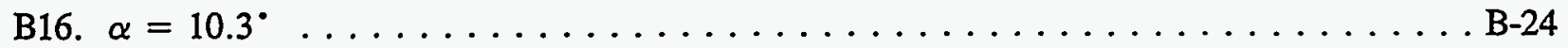

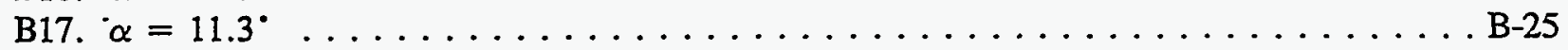

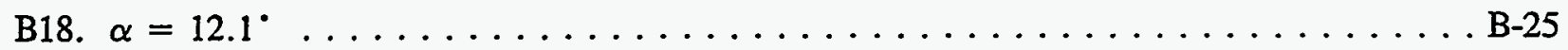

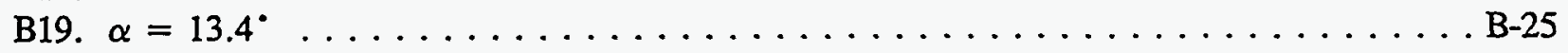

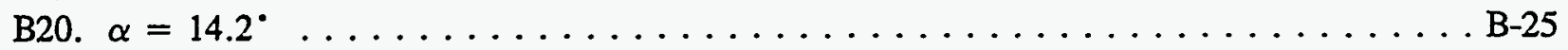

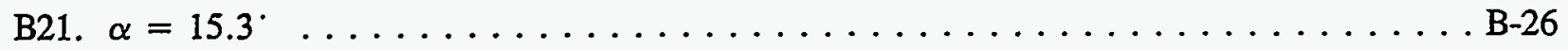

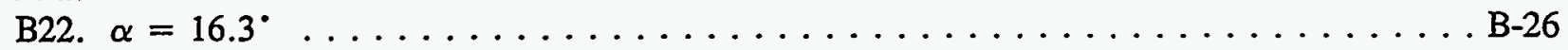

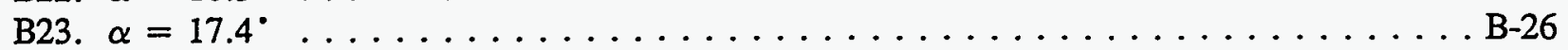

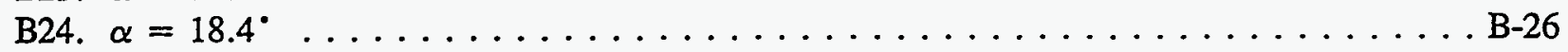

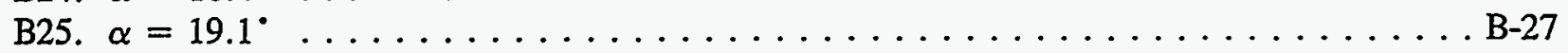

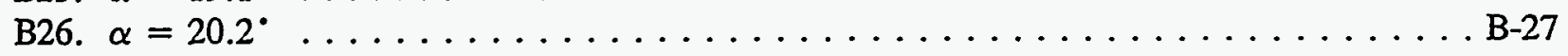

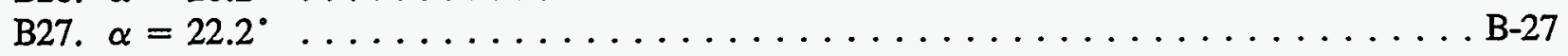

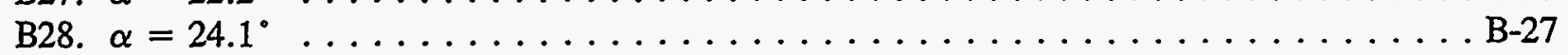

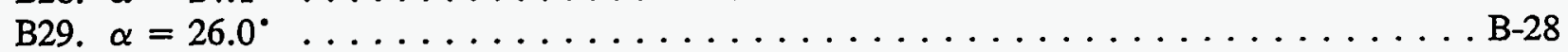

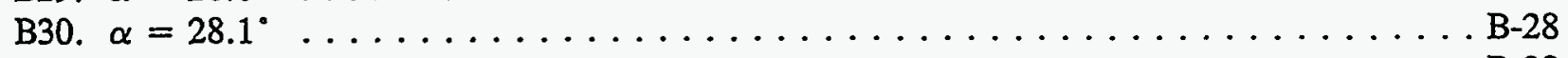

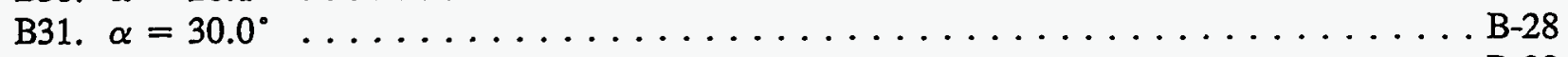

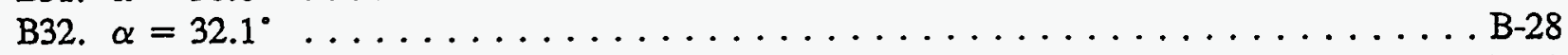

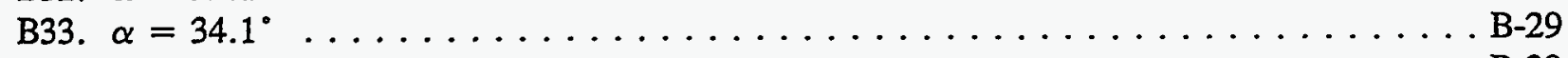

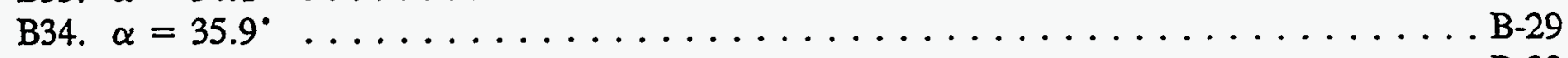

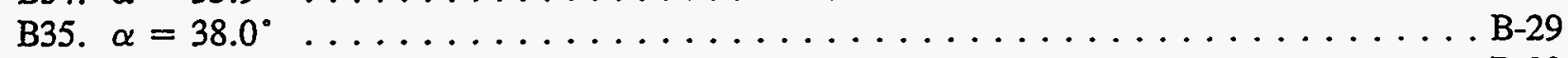

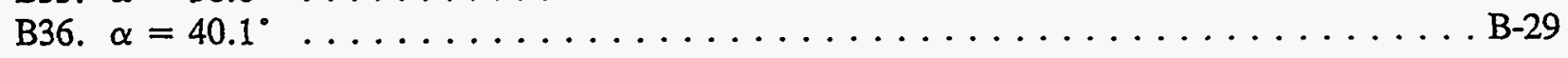

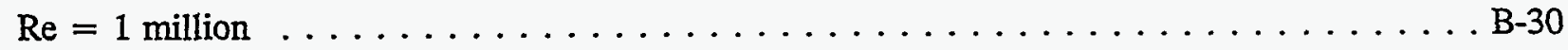

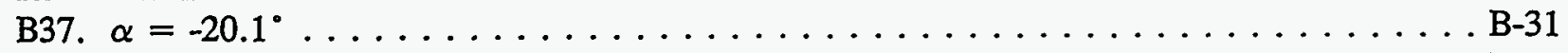

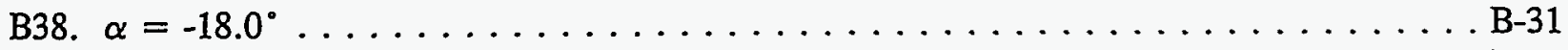

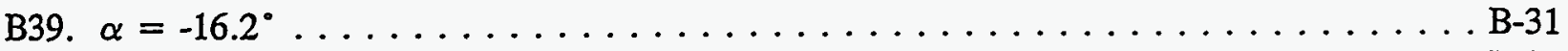

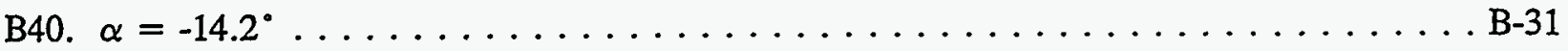

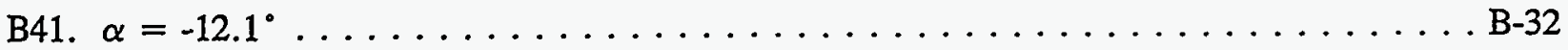

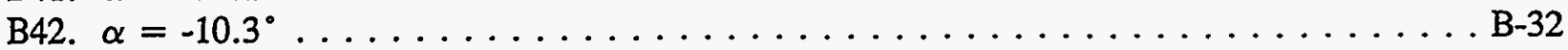

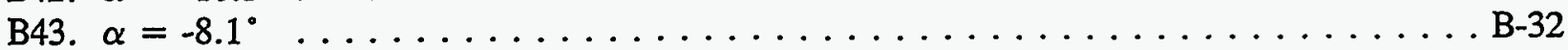


B44. $\alpha=-6.3^{\circ}$

B45. $\alpha=-4.1^{\circ}$

B46. $\alpha=-2.0^{\circ}$

B47. $\alpha=-0.1$

B48. $\alpha=2.0^{\circ}$

B-33

B49. $\alpha=4.1^{\circ}$

B-34

B50. $\alpha=6.3^{\circ}$

B-34

B51. $\alpha=8.2^{\circ}$

B-34

B52. $\alpha=10.3^{\circ}$

B-34

B53. $\alpha=11.4^{\circ}$

B-35

B54. $\alpha=12.2^{\circ}$

B-35

B55. $\alpha=13.2^{\circ}$

B-35

B56. $\alpha=14.3^{\circ}$

B-35

B57. $\alpha=15.3^{\circ}$

B-36

B58. $\alpha=16.3^{\circ}$

B-36

B59. $\alpha=17.2^{\circ}$

B-36

B60. $\alpha=18.2^{\circ}$

B-36

B61. $\alpha=19.2^{\circ}$

B-37

B62. $\alpha=20.2^{\circ}$

B-37

B63. $\alpha=22.3^{\circ}$

B-37

B64. $\alpha=24.2^{\circ}$

B-37

B65. $\alpha=26.2^{\circ}$

B-38

B66. $\alpha=28.2^{\circ}$

B-38

B67. $\alpha=30.1^{\circ}$

B-38

B68. $\alpha=32.1^{\circ}$

B-38

B69. $\alpha=34.2^{\circ}$

B-39

B70. $\alpha=36.0^{\circ}$

B-39

B71. $\alpha=38.1^{\circ}$

B-39

B72. $\alpha=39.9^{\circ}$

B-39

$\operatorname{Re}=1.25$ million

B- 40

B73. $\alpha=-20.1^{\circ}$

B-41

B74. $\alpha=-18.0^{\circ}$

B-41

B75. $\alpha=-16.1^{\circ}$

B- 41

B76. $\alpha=-14.2^{\circ}$

B-41

B77. $\alpha=-12.1^{\circ}$

B-42

B78. $\alpha=-10.2^{\circ}$

B-42

B79. $\alpha=-8.1^{\circ}$

B- 42

B80. $\alpha=-6.2^{\circ}$

B-42

B81. $\alpha=-4.1^{\circ}$

B-43

B82. $\alpha=-2.1^{\circ}$

B-43

B83. $\alpha=0.0^{\circ}$

B-43

B84. $\alpha=2.0^{\circ}$

B-43

B85. $\alpha=4.2^{\circ}$

B-44

B86. $\alpha=6.2^{\circ}$

B-44

B87. $\alpha=8.3^{\circ}$

B- 44

B88. $\alpha=10.3^{\circ}$

B- 44

B89. $\alpha=11.3^{\circ}$

B-45

B90. $\alpha=12.2^{\circ}$

B-45

B91. $\alpha=13.2^{\circ}$

B-45 
B92. $\alpha=14.3^{\circ}$

B93. $\alpha=15.3^{\circ}$

B94. $\alpha=16.3^{\circ}$

B95. $\alpha=17.3^{\circ}$

B96. $\alpha=18.2^{\circ}$

B97. $\alpha=19.1^{\circ}$

B98. $\alpha=20.2^{\circ}$

B99. $\alpha=22.2^{\circ}$

B100. $\alpha=24.1^{\circ}$

B101. $\alpha=26.1^{\circ}$

B102. $\alpha=28.2^{\circ}$

B103. $\alpha=30.1^{\circ}$

B104. $\alpha=32.1^{\circ}$

B105. $\alpha=34.1^{\circ}$

B106. $\alpha=35.9^{\circ}$

B107. $\alpha=38.0^{\circ}$

B108. $\alpha=40.0^{\circ}$

$\operatorname{Re}=1.5$ million

B109. $\alpha=-20.1^{\circ}$

B110. $\alpha=-18.0^{\circ}$

B111. $\alpha=-16.1^{\circ}$

B112. $\alpha=-14.2^{\circ}$

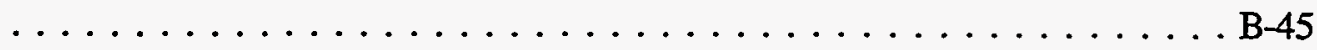

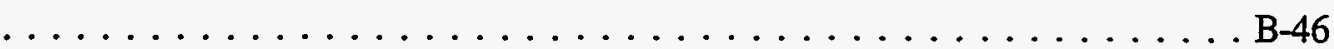

$\ldots \ldots \ldots \ldots \ldots \ldots \ldots \ldots \ldots \ldots \ldots \ldots \ldots \ldots \ldots \ldots \ldots$

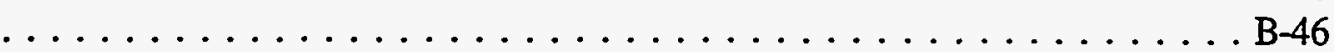

$\ldots \ldots \ldots \ldots \ldots \ldots \ldots \ldots \ldots \ldots \ldots \ldots \ldots \ldots \ldots$

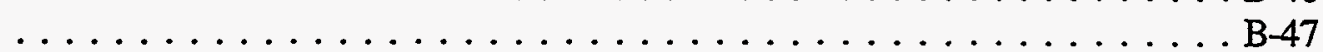

$\ldots \ldots \ldots \ldots \ldots \ldots \ldots \ldots \ldots \ldots \ldots \ldots \ldots \ldots \ldots$

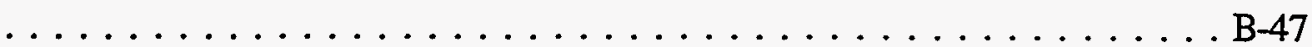

$\ldots \ldots \ldots \ldots \ldots \ldots \ldots \ldots \ldots \ldots \ldots \ldots \ldots \ldots \ldots \ldots \ldots$

$\ldots \ldots \ldots \ldots \ldots \ldots \ldots \ldots \ldots \ldots \ldots \ldots \ldots \ldots \ldots \ldots \ldots$

$\ldots \ldots \ldots \ldots \ldots \ldots \ldots \ldots \ldots \ldots \ldots \ldots \ldots \ldots \ldots \ldots \ldots \ldots \ldots$

$\ldots \ldots \ldots \ldots \ldots \ldots \ldots \ldots \ldots \ldots \ldots \ldots \ldots \ldots \ldots \ldots \ldots \ldots$

$\ldots \ldots \ldots \ldots \ldots \ldots \ldots \ldots \ldots \ldots \ldots \ldots \ldots \ldots \ldots$

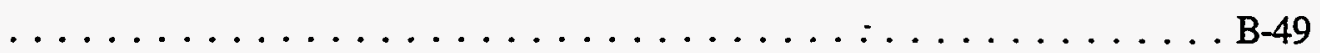

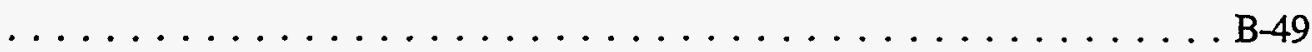

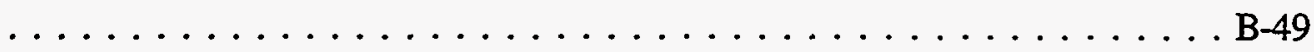

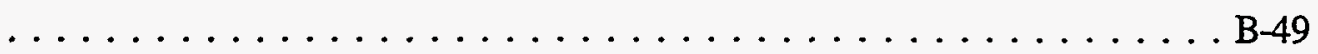

B113. $\alpha=-12.4^{\circ}$

B-50

B114. $\alpha=-10.3^{\circ}$

B-51

B-51

B115. $\alpha=-8.1^{\circ}$

B-51

B-51

B116. $\alpha=-6.2^{\circ}$

B-52

B117. $\alpha=-4.1^{\circ}$

B-52

B-52

B118. $\alpha=-2.0^{\circ}$

B-52

B-53

B119. $\alpha=-0.1^{\circ}$

B-53

B120. $\alpha=2.0^{\circ}$

B121. $\alpha=4.2^{\circ}$

B122. $\alpha=6.3^{\circ}$

B123. $\alpha=8.2^{\circ}$

B124. $\alpha=10.3^{\circ}$

B125. $\alpha=11.4^{\circ}$

B126. $\alpha=12.2^{\circ}$

B127. $\alpha=13.2^{\circ}$

B128. $\alpha=14.3^{\circ}$

B-53

B129. $\alpha=15.2^{\circ}$

B130. $\alpha=16.2^{\circ}$

B131. $\alpha=17.2^{\circ}$

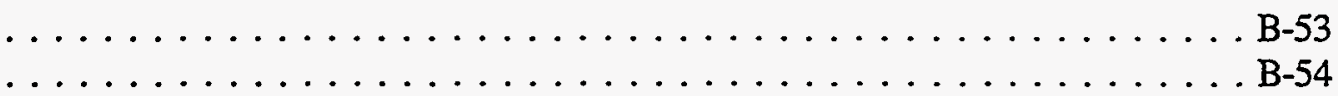

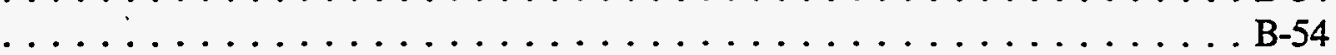

$\ldots \ldots \ldots \ldots \ldots \ldots \ldots \ldots \ldots \ldots \ldots \ldots$ B-54

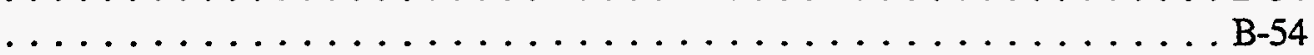

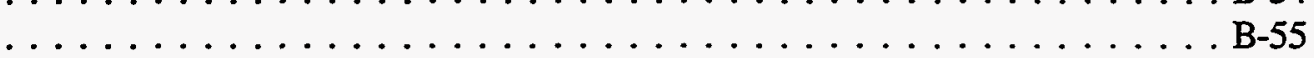

B-55

B-55

B-55

B-56

B132. $\alpha=18.2^{\circ}$

B-56

B-56

B133. $\alpha=19.1^{\circ}$

B-56

B134. $\alpha=20.2^{\circ}$

B-57

B-57 


\begin{tabular}{|c|c|c|c|c|c|c|}
\hline RUN & $\mathrm{AOA}$ & $\mathrm{C}_{1}$ & $\mathrm{C}_{\mathrm{dp}}$ & $\mathrm{C}_{\mathrm{m} / 4}$ & $\operatorname{Re} \times 10^{-6}$ & $\mathrm{C}_{\mathrm{dw}}$ \\
\hline 113 & -20.1 & -0.45 & 0.2805 & 0.0361 & 0.76 & - \\
\hline 112 & -18.0 & -0.39 & 0.2401 & 0.0286 & 0.75 & - \\
\hline 111 & -16.1 & -0.33 & 0.2067 & 0.0233 & 0.76 & - \\
\hline 110 & -14.1 & -0.38 & 0.1594 & 0.0141 & 0.73 & - \\
\hline 109 & -12.2 & -0.69 & 0.0116 & -0.0595 & 0.75 & 0.0574 \\
\hline 108 & -10.2 & -0.66 & 0.0104 & -0.0467 & 0.75 & 0.0314 \\
\hline 107 & -8.1 & -0.43 & 0.0043 & -0.0651 & 0.75 & 0.0175 \\
\hline 106 & -6.1 & -0.26 & -0.0008 & -0.0701 & 0.75 & 0.0158 \\
\hline 105 & -4.1 & -0.04 & -0.0020 & -0.0755 & 0.74 & 0.0112 \\
\hline 104 & -2.0 & 0.18 & -0.0011 & -0.0790 & 0.75 & 0.0110 \\
\hline 103 & -0.1 & 0.35 & 0.0027 & -0.0814 & 0.75 & 0.0113 \\
\hline 114 & -0.1 & 0.35 & 0.0020 & -0.0810 & 0.75 & 0.0129 \\
\hline 140 & -0.1 & 0.37 & 0.0004 & -0.0799 & 0.75 & 0.0130 \\
\hline 115 & 2.0 & 0.57 & 0.0080 & -0.0788 & 0.75 & 0.0136 \\
\hline 116 & 4.1 & 0.79 & 0.0158 & -0.0807 & 0.75 & 0.0144 \\
\hline 117 & 6.3 & 1.01 & 0.0242 & -0.0796 & 0.75 & 0.0166 \\
\hline 118 & 8.1 & 1.20 & 0.0256 & -0.0757 & 0.74 & 0.0190 \\
\hline 119 & 10.3 & 1.36 & 0.0361 & -0.0690 & 0.74 & 0.0195 \\
\hline 120 & 11.3 & 1.43 & 0.0405 & -0.0636 & 0.74 & 0.0241 \\
\hline 121 & 12.1 & 1.46 & 0.0459 & -0.0584 & 0.74 & 0.0241 \\
\hline 122 & 13.4 & 1.51 & 0.0526 & -0.0522 & 0.74 & 0.0317 \\
\hline 123 & 14.2 & 1.52 & 0.0682 & -0.0521 & 0.75 & - \\
\hline 124 & 15.3 & 1.53 & 0.0958 & -0.0567 & 0.75 & -- \\
\hline 125 & 16.3 & 1.54 & 0.1266 & -0.0645 & 0.75 & -- \\
\hline 126 & 17.4 & 1.54 & 0.1545 & -0.0721 & 0.75 & - \\
\hline 127 & 18.4 & 1.53 & 0.1806 & -0.0780 & 0.75 & - \\
\hline 128 & 19.1 & 1.19 & 0.1426 & -0.0799 & 0.75 & - \\
\hline 129 & 20.2 & 1.16 & 0.1627 & -0.0863 & 0.75 & - \\
\hline
\end{tabular}




\begin{tabular}{||c|c|c|c|c|c|c||}
\hline \multicolumn{7}{|c|}{ Table B1. LS(1)-0417MOD, Clean, Re $0.75 \times 10^{6}$} \\
\hline \hline RUN & AOA & $\mathrm{C}_{1}$ & $\mathrm{C}_{\mathrm{dp}}$ & $\mathrm{C}_{\mathrm{m} / 4}$ & $\operatorname{Re} \times 10^{-6}$ & $\mathrm{C}_{\mathrm{dw}}$ \\
\hline 130 & 22.2 & 1.24 & 0.2191 & -0.1039 & 0.74 & - \\
\hline 131 & 24.1 & 1.31 & 0.2759 & -0.1215 & 0.74 & - \\
\hline 132 & 26.0 & 0.96 & 0.5257 & -0.1932 & 0.72 & - \\
\hline 133 & 28.1 & 1.07 & 0.6227 & -0.2249 & 0.75 & - \\
\hline 134 & 30.0 & 1.17 & 0.7195 & -0.2560 & 0.74 & - \\
\hline 135 & 32.1 & 1.24 & 0.8241 & -0.2865 & 0.74 & - \\
\hline 136 & 34.1 & 1.30 & 0.9302 & -0.3179 & 0.75 & - \\
\hline 137 & 35.9 & 1.33 & 1.0116 & -0.3371 & 0.75 & - \\
\hline 138 & 38.0 & 1.35 & 1.1111 & -0.3635 & 0.74 & - \\
\hline 139 & 40.1 & 1.33 & 1.1837 & -0.3750 & 0.75 & - \\
\hline & & & End of Table B1 & & \\
\hline
\end{tabular}




\begin{tabular}{|c|c|c|c|c|c|c|}
\hline \multicolumn{7}{|c|}{ Table B2. LS(1)-0417MOD, Clean, Re $=1.0 \times 10^{6}$} \\
\hline RUN & $\mathrm{AOA}$ & $\mathrm{C}_{1}$ & $\mathrm{C}_{\mathrm{dp}}$ & $\mathrm{C}_{\mathrm{m}^{1 / 4}}$ & $\operatorname{Re} \times 10^{-6}$ & $\mathrm{C}_{\mathrm{dw}}$ \\
\hline 49 & -20.1 & -0.43 & 0.2726 & 0.0309 & 1.00 & - \\
\hline 48 & -18.0 & -0.39 & 0.2387 & 0.0277 & 1.00 & - \\
\hline 47 & -16.2 & -0.37 & 0.2158 & 0.0294 & 1.00 & - \\
\hline 46 & -14.2 & -0.69 & 0.0424 & -0.0315 & 1.00 & - \\
\hline 45 & -12.1 & -0.73 & 0.0041 & -0.0605 & 1.00 & 0.0592 \\
\hline 44 & -10.3 & -0.66 & 0.0030 & -0.0537 & 1.00 & 0.0353 \\
\hline 43 & -8.1 & -0.43 & -0.0002 & -0.0688 & 1.00 & 0.0184 \\
\hline 42 & -6.3 & -0.27 & -0.0035 & -0.0713 & 1.00 & 0.0167 \\
\hline 41 & -4.1 & -0.04 & -0.0034 & -0.0748 & 1.00 & 0.0134 \\
\hline 40 & -2.0 & 0.17 & -0.0025 & -0.0785 & 1.00 & 0.0115 \\
\hline 39 & -0.1 & 0.36 & 0.0010 & -0.0807 & 1.00 & 0.0123 \\
\hline 50 & -0.1 & 0.37 & 0.0004 & -0.0814 & 1.00 & 0.0118 \\
\hline 76 & -0.1 & 0.36 & 0.0007 & -0.0806 & 1.00 & 0.0119 \\
\hline 51 & 2.0 & 0.59 & 0.0065 & -0.0823 & 1.00 & 0.0120 \\
\hline 52 & 4.1 & 0.80 & 0.0148 & -0.0821 & 1.00 & 0.0133 \\
\hline 53 & 6.3 & 1.01 & 0.0220 & -0.0809 & 1.00 & 0.0145 \\
\hline 54 & 8.2 & 1.20 & 0.0253 & -0.0764 & 1.00 & 0.0173 \\
\hline 55 & 10.3 & 1.37 & 0.0353 & -0.0691 & 1.00 & 0.0219 \\
\hline 56 & 11.4 & 1.43 & 0.0391 & -0.0632 & 1.00 & 0.0241 \\
\hline 57 & 12.2 & 1.48 & 0.0427 & -0.0586 & 1.00 & 0.0268 \\
\hline 58 & 13.2 & 1.51 & 0.0554 & -0.0543 & 1.00 & 0.0312 \\
\hline 59 & 14.3 & 1.53 & 0.0680 & -0.0524 & 1.00 & - \\
\hline 60 & 15.3 & 1.55 & 0.0970 & -0.0615 & 1.00 & - \\
\hline 61 & 16.3 & 1.26 & 0.0941 & -0.0688 & 1.02 & -- \\
\hline 62 & 17.2 & 1.21 & 0.1069 & -0.0714 & 1.02 & - \\
\hline 63 & 18.2 & 1.17 & 0.1269 & -0.0768 & 1.00 & - \\
\hline 64 & 19.2 & 1.14 & 0.1462 & -0.0834 & 1.00 & - \\
\hline 65 & 20.2 & 1.15 & 0.1678 & -0.0893 & 1.00 & -- \\
\hline
\end{tabular}




\begin{tabular}{|c|c|c|c|c|c|c||}
\hline \multicolumn{7}{|c|}{ Table B2. LS(1)-0417MOD, Clean, Re $=1.0 \times 10^{6}$} \\
\hline \hline RUN & AOA & $C_{l}$ & $C_{d p}$ & $C_{m^{1} /}$ & $\operatorname{Re} \times 10^{-6}$ & $C_{d w}$ \\
\hline 66 & 22.3 & 1.20 & 0.2214 & -0.1054 & 0.99 & - \\
\hline 67 & 24.2 & 1.37 & 0.3034 & -0.1296 & 0.99 & - \\
\hline 68 & 26.2 & 1.18 & 0.3305 & -0.1444 & 0.99 & - \\
\hline 69 & 28.2 & 1.16 & 0.3973 & -0.1670 & 0.97 & - \\
\hline 70 & 30.1 & 1.09 & 0.6750 & -0.2343 & 0.98 & - \\
\hline 71 & 32.1 & 1.13 & 0.7535 & -0.2530 & 0.97 & - \\
\hline 72 & 34.2 & 1.16 & 0.8307 & -0.2700 & 0.98 & - \\
\hline 73 & 36.0 & 1.29 & 0.9879 & -0.3243 & 0.99 & - \\
\hline 74 & 38.1 & 1.36 & 1.1175 & -0.3645 & 0.98 & - \\
\hline 75 & 39.9 & 1.34 & 1.1750 & -0.3715 & 0.98 & - \\
\hline & & & End of Table B2 & & \\
\hline
\end{tabular}




\begin{tabular}{|c|c|c|c|c|c|c|}
\hline RUN & $\mathrm{AOA}$ & $\mathrm{C}_{1}$ & $\mathrm{C}_{\mathrm{dp}}$ & $\mathrm{C}_{\mathrm{m}^{1 / 4}}$ & $\operatorname{Re} \times 10^{-6}$ & $\mathrm{C}_{\mathrm{dw}}$ \\
\hline 11 & -20.1 & -0.42 & 0.2700 & 0.0319 & 1.24 & - \\
\hline 10 & -18.0 & -0.39 & 0.2380 & 0.0297 & 1.25 & - \\
\hline 9 & -16.1 & -0.35 & 0.2106 & 0.0271 & 1.25 & - \\
\hline 8 & -14.2 & -0.73 & 0.0364 & -0.0335 & 1.26 & - \\
\hline 7 & -12.1 & -0.76 & 0.0006 & -0.0596 & 1.25 & 0.0581 \\
\hline 6 & -10.2 & -0.65 & 0.0015 & -0.0586 & 1.26 & 0.0338 \\
\hline 5 & -8.1 & -0.43 & -0.0016 & -0.0678 & 1.25 & 0.0185 \\
\hline 4 & -6.2 & -0.27 & -0.0029 & -0.0701 & 1.25 & 0.0169 \\
\hline 3 & -4.1 & -0.05 & -0.0040 & -0.0732 & 1.25 & 0.0135 \\
\hline 2 & -2.1 & 0.16 & -0.0028 & -0.0774 & 1.25 & 0.0112 \\
\hline 12 & -0.1 & 0.37 & 0.0000 & -0.0813 & 1.25 & 0.0108 \\
\hline 38 & -0.1 & 0.37 & 0.0007 & -0.0812 & 1.25 & 0.0110 \\
\hline 1 & 0.0 & 0.40 & -0.0004 & -0.0820 & 1.26 & 0.0109 \\
\hline 13 & 2.0 & 0.59 & 0.0068 & -0.0837 & 1.25 & 0.0117 \\
\hline 14 & 4.2 & 0.81 & 0.0143 & -0.0824 & 1.25 & 0.0135 \\
\hline 15 & 6.2 & 1.02 & 0.0198 & -0.0811 & 1.25 & 0.0143 \\
\hline 16 & 8.3 & 1.21 & 0.0271 & -0.0760 & 1.25 & 0.0165 \\
\hline 17 & 10.3 & 1.38 & 0.0327 & -0.0688 & 1.24 & 0.0215 \\
\hline 18 & 11.3 & 1.45 & 0.0385 & -0.0644 & 1.25 & 0.0238 \\
\hline 19 & 12.2 & 1.49 & 0.0390 & -0.0578 & 1.25 & 0.0272 \\
\hline 20 & 13.2 & 1.52 & 0.0514 & -0.0542 & 1.25 & 0.0374 \\
\hline 21 & 14.3 & 1.54 & 0.0640 & -0.0530 & 1.25 & - \\
\hline 22 & 15.3 & 1.49 & 0.1253 & -0.0925 & 1.25 & - \\
\hline 23 & 16.3 & 1.40 & 0.1632 & -0.1140 & 1.25 & -- \\
\hline 24 & 17.3 & 1.12 & 0.1304 & -0.0924 & 1.27 & -- \\
\hline 25 & 18.2 & 1.13 & 0.1477 & -0.0931 & 1.25 & - \\
\hline 26 & 19.1 & 1.09 & 0.1580 & -0.0951 & 1.25 & - \\
\hline 27 & 20.2 & 1.24 & 0.2211 & -0.1178 & 1.25 & -- \\
\hline
\end{tabular}




\begin{tabular}{|c|c|c|c|c|c|c||}
\hline \multicolumn{7}{|c||}{ Table B3. LS(1)-0417MOD, Clean, Re $=1.25 \times 10^{6}$} \\
\hline \hline RUN & $\mathrm{AOA}$ & $\mathrm{C}_{\mathrm{l}}$ & $\mathrm{C}_{\mathrm{dp}}$ & $\mathrm{C}_{\mathrm{m} 1 / 4}$ & $\operatorname{Re} \times 10^{-6}$ & $\mathrm{C}_{\mathrm{dw}}$ \\
\hline 28 & 22.2 & 1.27 & 0.2818 & -0.1347 & 1.24 & - \\
\hline 29 & 24.1 & 1.25 & 0.3185 & -0.1430 & 1.24 & - \\
\hline 30 & 26.1 & 1.20 & 0.3476 & -0.1463 & 1.23 & - \\
\hline 31 & 28.2 & 1.15 & 0.4052 & -0.1679 & 1.22 & - \\
\hline 32 & 30.1 & 1.16 & 0.4721 & -0.1919 & 1.22 & - \\
\hline 33 & 32.1 & 1.23 & $0.8115^{-}$ & -0.2802 & 1.23 & - \\
\hline 34 & 34.1 & 1.28 & 0.9128 & -0.3071 & 1.22 & - \\
\hline 35 & 35.9 & 1.31 & 0.9994 & -0.3306 & 1.22 & - \\
\hline 36 & 38.0 & 1.33 & 1.0845 & -0.3473 & 1.21 & - \\
\hline 37 & 40.0 & 1.35 & 1.1915 & -0.3777 & 1.21 & - \\
\hline & & & End of Table B3 & & \\
\hline \hline
\end{tabular}




\begin{tabular}{|c|c|c|c|c|c|c|}
\hline RUN & $\mathrm{AOA}$ & $\mathrm{C}_{1}$ & $\mathrm{C}_{\mathrm{dp}}$ & $\mathrm{C}_{\mathrm{m} / \mathrm{t}}$ & $\operatorname{Re} \times 10^{-6}$ & $\mathrm{C}_{\mathrm{dw}}$ \\
\hline 87 & -20.1 & -0.43 & 0.2707 & 0.0316 & 1.45 & - \\
\hline 86 & -18.0 & -0.38 & 0.2356 & 0.0268 & 1.46 & - \\
\hline 85 & -16.1 & -0.34 & 0.2063 & 0.0242 & 1.47 & - \\
\hline 84 & -14.2 & -0.83 & 0.0313 & -0.0367 & 1.48 & - \\
\hline 83 & -12.4 & -0.79 & 0.0008 & -0.0596 & 1.51 & 0.0535 \\
\hline 82 & -10.3 & -0.65 & -0.0006 & -0.0625 & 1.50 & 0.0312 \\
\hline 81 & -8.1 & -0.43 & -0.0020 & -0.0686 & 1.51 & 0.0191 \\
\hline 80 & -6.2 & -0.27 & -0.0041 & -0.0704 & 1.51 & 0.0163 \\
\hline 79 & -4.1 & -0.06 & -0.0046 & -0.0727 & 1.51 & 0.0124 \\
\hline 78 & -2.0 & 0.17 & -0.0031 & -0.0773 & 1.50 & 0.0116 \\
\hline 77 & -0.1 & 0.38 & -0.0008 & -0.0808 & 1.51 & 0.0110 \\
\hline 88 & -0.1 & 0.36 & 0.0006 & -0.0802 & 1.50 & 0.0109 \\
\hline 89 & 2.0 & 0.60 & 0.0058 & -0.0841 & 1.50 & 0.0109 \\
\hline 90 & 4.2 & 0.82 & 0.0129 & -0.0838 & 1.51 & 0.0123 \\
\hline 91 & 6.3 & 1.03 & 0.0200 & -0.0800 & 1.51 & 0.0131 \\
\hline 92 & 8.2 & 1.22 & 0.0238 & -0.0757 & 1.49 & 0.0156 \\
\hline 93 & 10.3 & 1.39 & 0.0306 & -0.0669 & 1.50 & 0.0211 \\
\hline 94 & 11.4 & 1.46 & 0.0360 & -0.0628 & 1.50 & 0.0210 \\
\hline 95 & 12.2 & 1.49 & 0.0414 & -0.0596 & 1.50 & 0.0277 \\
\hline 96 & 13.2 & 1.53 & 0.0483 & -0.0566 & 1.50 & 0.0283 \\
\hline 97 & 14.3 & 1.54 & 0.0641 & -0.0561 & 1.50 & 0.0434 \\
\hline 98 & 15.2 & 1.34 & 0.1508 & -0.1135 & 1.49 & - \\
\hline 99 & 16.2 & 1.07 & 0.1381 & -0.1088 & 1.50 & - \\
\hline 100 & 17.2 & 1.04 & 0.1549 & -0.1112 & 1.49 & $\ldots$ \\
\hline 101 & 18.2 & 1.03 & 0.1705 & -0.1118 & 1.48 & $\ldots$ \\
\hline \multicolumn{7}{|c|}{ End of Table B4 } \\
\hline
\end{tabular}




\begin{tabular}{|c|c|c|c|c|c|c|}
\hline \multicolumn{7}{|c|}{ Table B5. LS(1)-0417MOD, $k / c=0.0019, R e=0.75 \times 10^{6}$} \\
\hline RUN & $\mathrm{AOA}$ & $\mathrm{C}_{1}$ & $\mathrm{C}_{\mathrm{dp}}$ & $\mathrm{C}_{\mathrm{m} / \mathrm{t}}$ & $\operatorname{Re} \times 10^{-6}$ & $\mathrm{C}_{\mathrm{dw}}$ \\
\hline 260 & -20.1 & -0.50 & 0.2700 & 0.0430 & 0.75 & - \\
\hline 259 & -18.0 & -0.52 & 0.2405 & 0.0458 & 0.75 & - \\
\hline 258 & -16.2 & -0.57 & 0.2053 & 0.0435 & 0.75 & - \\
\hline 257 & -14.1 & -0.59 & 0.1412 & 0.0239 & 0.74 & - \\
\hline 256 & -12.1 & -0.63 & 0.0359 & -0.0260 & 0.74 & - \\
\hline 255 & -10.2 & -0.61 & 0.0002 & -0.0514 & 0.75 & 0.0454 \\
\hline 254 & -8.1 & -0.42 & -0.0031 & -0.0630 & 0.76 & 0.0241 \\
\hline 253 & -6.0 & -0.27 & -0.0040 & -0.0598 & 0.75 & 0.0219 \\
\hline 252 & -4.1 & -0.09 & -0.0017 & -0.0621 & 0.75 & 0.0177 \\
\hline 251 & -2.0 & 0.12 & -0.0013 & -0.0651 & 0.75 & 0.0163 \\
\hline 250 & -0.1 & 0.32 & 0.0009 & -0.0665 & 0.75 & 0.0174 \\
\hline 261 & -0.1 & 0.33 & 0.0007 & -0.0671 & 0.76 & 0.0163 \\
\hline 287 & -0.1 & 0.30 & 0.0035 & -0.0660 & 0.75 & 0.0168 \\
\hline 262 & 2.0 & 0.51 & 0.0076 & -0.0678 & 0.75 & 0.0178 \\
\hline 263 & 4.1 & 0.71 & 0.0149 & -0.0666 & 0.74 & 0.0187 \\
\hline 264 & 6.3 & 0.90 & 0.0260 & -0.0625 & 0.75 & 0.0223 \\
\hline 265 & 8.2 & 1.05 & 0.0327 & -0.0559 & 0.75 & 0.0281 \\
\hline 266 & 10.3 & 1.12 & 0.0431 & -0.0451 & 0.75 & 0.0504 \\
\hline 267 & 11.2 & 0.86 & 0.0925 & -0.0796 & 0.75 & - \\
\hline 268 & 12.0 & 0.82 & 0.1062 & -0.0822 & 0.75 & - \\
\hline 269 & 13.0 & 0.80 & 0.1235 & -0.0840 & 0.75 & - \\
\hline 270 & 14.1 & 0.79 & 0.1399 & -0.0874 & 0.75 & - \\
\hline 271 & 15.1 & 0.80 & 0.1600 & -0.0937 & 0.75 & - \\
\hline 272 & 16.2 & 0.80 & 0.1788 & -0.0971 & 0.75 & - \\
\hline 273 & 17.0 & 0.83 & 0.2019 & -0.1046 & 0.76 & - \\
\hline 274 & 18.0 & 0.83 & 0.2207 & -0.1084 & 0.75 & - \\
\hline 275 & 19.1 & 0.84 & 0.2441 & -0.1140 & 0.75 & - \\
\hline 276 & 20.1 & 0.87 & 0.2740 & -0.1234 & 0.75 & - \\
\hline
\end{tabular}




\begin{tabular}{|c|c|c|c|c|c|c||}
\hline \multicolumn{7}{|c|}{ Table B5. LS(1)-0417MOD, $k / c=0.0019, \operatorname{Re}=0.75 \times 10^{6}$} \\
\hline \hline RUN & AOA & $\mathrm{C}_{1}$ & $\mathrm{C}_{\mathrm{dp}}$ & $\mathrm{C}_{\mathrm{m} / 4}$ & $\operatorname{Re} \times 10^{-6}$ & $\mathrm{C}_{\mathrm{dw}}$ \\
\hline 277 & 22.2 & 0.94 & 0.3409 & -0.1458 & 0.76 & - \\
\hline 278 & 24.0 & 1.01 & 0.4212 & -0.1767 & 0.75 & - \\
\hline 279 & 26.1 & 1.07 & 0.5010 & -0.2018 & 0.75 & - \\
\hline 280 & 28.2 & 1.11 & 0.5774 & -0.2204 & 0.75 & - \\
\hline 281 & 30.0 & 1.15 & 0.6568 & -0.2419 & 0.74 & - \\
\hline 282 & 32.1 & 1.22 & 0.7598 & -0.2711 & 0.74 & - \\
\hline 283 & 33.9 & 1.29 & 0.8666 & -0.3059 & 0.74 & - \\
\hline 284 & 36.0 & 1.31 & 0.9562 & -0.3272 & 0.73 & - \\
\hline 285 & 38.0 & 1.35 & 1.0650 & -0.3597 & 0.73 & - \\
\hline 286 & 39.9 & 1.35 & 1.1361 & -0.3749 & 0.72 & - \\
\hline & & & End of Table B5 & & \\
\hline
\end{tabular}




\begin{tabular}{|c|c|c|c|c|c|c|}
\hline \multicolumn{7}{|c|}{ Table B6. LS(1)-0417MOD, $k / c=0.0019, R e=1.0 \times 10^{6}$} \\
\hline RUN & $\mathrm{AOA}$ & $\mathrm{C}_{1}$ & $\mathrm{C}_{\mathrm{dp}}$ & $\mathrm{C}_{\mathrm{m} / \mathrm{k}}$ & $\operatorname{Re} \times 10^{-6}$ & $\mathrm{C}_{\mathrm{dw}}$ \\
\hline 222 & -20.0 & -0.47 & 0.2742 & 0.0400 & 1.00 & - \\
\hline 221 & -17.9 & -0.53 & 0.2580 & 0.0498 & 1.00 & - \\
\hline 220 & -16.1 & -0.58 & 0.2225 & 0.0437 & 1.01 & - \\
\hline 219 & -14.1 & -0.61 & 0.1437 & 0.0122 & 1.01 & - \\
\hline 218 & -12.3 & -0.63 & 0.0282 & -0.0569 & 1.01 & 0.0689 \\
\hline 217 & -10.2 & -0.55 & 0.0112 & -0.0674 & 1.00 & 0.0335 \\
\hline 216 & -8.1 & -0.43 & 0.0037 & -0.0632 & 1.00 & 0.0246 \\
\hline 215 & -6.2 & -0.29 & -0.0007 & -0.0615 & 1.00 & 0.0217 \\
\hline 214 & -4.1 & -0.09 & -0.0019 & -0.0634 & 1.00 & 0.0184 \\
\hline 213 & -2.0 & 0.13 & -0.0011 & -0.0657 & 1.00 & 0.0169 \\
\hline 212 & -0.1 & 0.33 & 0.0012 & -0.0686 & 1.00 & 0.0166 \\
\hline 223 & -0.1 & 0.31 & 0.0015 & -0.0672 & 1.00 & 0.0169 \\
\hline 249 & -0.1 & 0.31 & 0.0020 & -0.0673 & 1.00 & 0.0169 \\
\hline 224 & 2.0 & 0.52 & 0.0074 & -0.0687 & 1.00 & 0.0156 \\
\hline 225 & 4.1 & 0.73 & 0.0132 & -0.0665 & 1.00 & 0.0190 \\
\hline 226 & 6.3 & 0.92 & 0.0216 & -0.0624 & 1.00 & 0.0219 \\
\hline 227 & 8.1 & 1.06 & 0.0260 & -0.0554 & 1.00 & 0.0273 \\
\hline 228 & 10.2 & 1.13 & 0.0377 & -0.0459 & 1.00 & 0.0452 \\
\hline 229 & 11.2 & 0.89 & 0.0972 & -0.0865 & 1.00 & - \\
\hline 230 & 12.0 & 0.87 & 0.1106 & -0.0879 & 1.01 & - \\
\hline 231 & 13.0 & 0.82 & 0.1230 & -0.0865 & 1.00 & - \\
\hline 232 & 14.0 & 0.80 & 0.1385 & -0.0871 & 1.01 & - \\
\hline 233 & 15.1 & 0.80 & 0.1580 & -0.0924 & 1.01 & - \\
\hline 234 & 16.1 & 0.83 & 0.1809 & -0.0994 & 1.00 & - \\
\hline 235 & 17.2 & 0.83 & 0.2014 & -0.1037 & 1.00 & - \\
\hline 236 & 18.2 & 0.85 & 0.2268 & -0.1114 & 1.00 & - \\
\hline 237 & 19.0 & 0.87 & 0.2510 & -0.1212 & 1.00 & - \\
\hline 238 & 20.1 & 0.89 & 0.2785 & -0.1290 & 1.00 & - \\
\hline
\end{tabular}




\begin{tabular}{||c|c|c|c|c|c|c||}
\hline \multicolumn{7}{|c|}{ Table B6. LS(1)-0417MOD, k/c $=0.0019, \operatorname{Re}=1.0 \times 10^{6}$} \\
\hline \hline RUN & AOA & $\mathrm{C}_{1}$ & $\mathrm{C}_{\mathrm{dp}}$ & $\mathrm{C}_{\mathrm{m} / \mathrm{h}}$ & $\operatorname{Re} \times 10^{-6}$ & $\mathrm{C}_{\mathrm{dw}}$ \\
\hline 239 & 22.2 & 0.94 & 0.3476 & -0.1523 & 1.00 & - \\
\hline 240 & 23.9 & 0.99 & 0.4113 & -0.1723 & 1.00 & - \\
\hline 241 & 26.0 & 1.03 & 0.4883 & -0.1945 & 1.00 & - \\
\hline 242 & 28.1 & 1.10 & 0.5695 & -0.2173 & 1.00 & - \\
\hline 243 & 30.0 & 1.16 & 0.6548 & -0.2429 & 0.99 & - \\
\hline 244 & 32.0 & 1.21 & 0.7547 & -0.2709 & 0.99 & - \\
\hline 245 & 34.1 & 1.28 & 0.8596 & -0.3007 & 0.98 & - \\
\hline 246 & 36.2 & 1.33 & 0.9708 & -0.3338 & 0.97 & - \\
\hline 247 & 37.9 & 1.35 & 1.0524 & -0.3518 & 0.99 & - \\
\hline 248 & 40.0 & 1.36 & 1.1427 & -0.3741 & 0.98 & - \\
\hline & & & End of Table B6 & & \\
\hline
\end{tabular}




\begin{tabular}{|c|c|c|c|c|c|c|}
\hline RUN & $\mathrm{AOA}$ & $\mathrm{C}_{1}$ & $\mathrm{C}_{\mathrm{dp}}$ & $\mathrm{C}_{\mathrm{m} / \mathrm{t}}$ & $\operatorname{Re} \times 10^{-6}$ & $\mathrm{C}_{\mathrm{dw}}$ \\
\hline 184 & -20.1 & -0.47 & 0.2704 & 0.0317 & 1.25 & - \\
\hline 183 & -18.0 & -0.53 & 0.2492 & 0.0373 & 1.25 & - \\
\hline 182 & -16.2 & -0.57 & 0.2092 & 0.0301 & 1.26 & - \\
\hline 181 & -14.1 & -0.60 & 0.1321 & 0.0023 & 1.25 & - \\
\hline 180 & -12.1 & -0.63 & 0.0228 & -0.0684 & 1.25 & 0.0588 \\
\hline 179 & -10.2 & -0.57 & 0.0135 & -0.0647 & 1.25 & 0.0337 \\
\hline 178 & -8.1 & -0.45 & 0.0039 & -0.0618 & 1.26 & 0.0246 \\
\hline 177 & -6.3 & -0.30 & -0.0009 & -0.0606 & 1.25 & 0.0228 \\
\hline 176 & -4.1 & -0.09 & -0.0022 & -0.0631 & 1.25 & 0.0174 \\
\hline 175 & -2.0 & 0.14 & -0.0018 & -0.0662 & 1.25 & 0.0171 \\
\hline 174 & -0.1 & 0.33 & 0.0007 & -0.0678 & 1.25 & 0.0165 \\
\hline 185 & -0.1 & 0.34 & 0.0007 & -0.0678 & 1.25 & 0.0165 \\
\hline 211 & -0.1 & 0.32 & 0.0013 & -0.0679 & 1.26 & 0.0161 \\
\hline 186 & 2.0 & 0.54 & 0.0062 & -0.0696 & 1.25 & 0.0163 \\
\hline 187 & 4.1 & 0.74 & 0.0141 & -0.0676 & 1.25 & 0.0190 \\
\hline 188 & 6.0 & 0.92 & 0.0174 & -0.0639 & 1.25 & 0.0207 \\
\hline 189 & 8.2 & 1.08 & 0.0263 & -0.0571 & 1.25 & 0.0284 \\
\hline 190 & 10.3 & 1.16 & 0.0375 & -0.0470 & 1.25 & 0.0515 \\
\hline 191 & 11.3 & 0.96 & 0.1016 & -0.0929 & 1.26 & - \\
\hline 192 & 12.0 & 0.87 & 0.1112 & -0.0886 & 1.25 & - \\
\hline 193 & 13.1 & 0.82 & 0.1240 & -0.0861 & 1.26 & - \\
\hline 194 & 14.1 & 0.82 & 0.1419 & -0.0890 & 1.25 & - \\
\hline 195 & 15.1 & 0.82 & 0.1613 & -0.0937 & 1.25 & - \\
\hline 196 & 16.2 & 0.83 & 0.1810 & -0.0981 & 1.26 & - \\
\hline 197 & 17.2 & 0.85 & 0.2054 & -0.1053 & 1.26 & - \\
\hline 198 & 18.0 & 0.86 & 0.2243 & -0.1104 & 1.25 & - \\
\hline 199 & 19.1 & 0.89 & 0.2546 & -0.1227 & 1.27 & - \\
\hline 200 & 20.1 & 0.91 & 0.2815 & -0.1319 & 1.25 & - \\
\hline
\end{tabular}




\begin{tabular}{|c|c|c|c|c|c|c||}
\hline \multicolumn{7}{|c|}{ Table B7. LS(1)-0417MOD, k/c $=0.0019, \operatorname{Re}=1.25 \times 10^{6}$} \\
\hline \hline RUN & AOA & $\mathrm{C}_{1}$ & $\mathrm{C}_{\mathrm{dp}}$ & $\mathrm{C}_{\mathrm{m} / 4}$ & $\operatorname{Re} \times 10^{-6}$ & $\mathrm{C}_{\mathrm{dw}}$ \\
\hline 201 & 22.2 & 0.97 & 0.3539 & -0.1567 & 1.26 & - \\
\hline 202 & 24.0 & 1.00 & 0.4154 & -0.1757 & 1.25 & - \\
\hline 203 & 26.1 & 1.05 & 0.4883 & -0.1962 & 1.24 & - \\
\hline 204 & 28.2 & 1.11 & 0.5772 & -0.2216 & 1.25 & - \\
\hline 205 & 30.0 & 1.16 & 0.6537 & -0.2442 & 1.25 & - \\
\hline 206 & 32.1 & 1.22 & 0.7502 & -0.2693 & 1.23 & - \\
\hline 207 & 34.2 & 1.29 & 0.8619 & -0.3017 & 1.22 & - \\
\hline 208 & 36.0 & 1.32 & 0.9514 & -0.3271 & 1.21 & - \\
\hline 209 & 38.0 & 1.36 & 1.0557 & -0.3562 & 1.19 & - \\
\hline 210 & 39.8 & 1.36 & 1.1323 & -0.3747 & 1.17 & - \\
\hline & & & End of Table B7 & & \\
\hline \hline
\end{tabular}




\begin{tabular}{|c|c|c|c|c|c|c|}
\hline \multicolumn{7}{|c|}{ Table B8. LS(1)-0417MOD, $k / c=0.0019, R e=1.5 \times 10^{6}$} \\
\hline RUN & $\mathrm{AOA}$ & $\mathrm{C}_{\mathrm{l}}$ & $\mathrm{C}_{\mathrm{dp}}$ & $\mathrm{C}_{\mathrm{m} / \mathrm{k}}$ & $\operatorname{Re} \times 10^{-6}$ & $\mathrm{C}_{\mathrm{dw}}$ \\
\hline 151 & -20.2 & -0.43 & 0.2502 & 0.0191 & 1.41 & - \\
\hline 150 & -18.1 & -0.45 & 0.2206 & 0.0232 & 1.43 & - \\
\hline 149 & -16.1 & -0.47 & 0.1890 & 0.0217 & 1.44 & - \\
\hline 148 & -14.2 & -0.53 & 0.1319 & 0.0045 & 1.46 & - \\
\hline 147 & -12.2 & -0.61 & 0.0109 & -0.0679 & 1.49 & 0.0618 \\
\hline 146 & -10.3 & -0.56 & 0.0038 & -0.0662 & 1.49 & 0.0353 \\
\hline 145 & -8.1 & -0.44 & -0.0017 & -0.0606 & 1.51 & 0.0238 \\
\hline 144 & -6.0 & -0.30 & -0.0048 & -0.0605 & 1.50 & 0.0220 \\
\hline 143 & -4.1 & -0.08 & -0.0022 & -0.0625 & 1.51 & 0.0171 \\
\hline 142 & -2.2 & 0.13 & -0.0018 & -0.0660 & 1.50 & 0.0162 \\
\hline 141 & -0.1 & 0.32 & 0.0017 & -0.0679 & 1.51 & 0.0160 \\
\hline 152 & -0.1 & 0.35 & 0.0001 & -0.0686 & 1.50 & 0.0165 \\
\hline 153 & 2.0 & 0.54 & 0.0082 & -0.0697 & 1.50 & 0.0155 \\
\hline 154 & 4.2 & 0.74 & 0.0164 & -0.0692 & 1.50 & 0.0178 \\
\hline 155 & 6.1 & 0.93 & 0.0203 & -0.0655 & 1.50 & 0.0211 \\
\hline 156 & 8.2 & 1.08 & 0.0293 & -0.0585 & 1.50 & 0.0276 \\
\hline 157 & 10.3 & 1.16 & 0.0390 & -0.0480 & 1.49 & 0.0482 \\
\hline 158 & 11.1 & 0.92 & 0.1034 & -0.0941 & 1.47 & - \\
\hline 159 & 12.1 & 0.82 & 0.1128 & -0.0867 & 1.47 & - \\
\hline 160 & 13.1 & 0.80 & 0.1291 & -0.0883 & 1.47 & - \\
\hline 161 & 14.2 & 0.80 & 0.1446 & -0.0899 & 1.46 & - \\
\hline 162 & 15.1 & 0.81 & 0.1625 & -0.0946 & 1.46 & - \\
\hline 163 & 16.1 & 0.80 & 0.1804 & -0.0984 & 1.44 & - \\
\hline 164 & 17.1 & 0.82 & 0.2025 & -0.1052 & 1.44 & - \\
\hline 165 & 18.1 & 0.83 & 0.2244 & -0.1113 & 1.43 & - \\
\hline & & & End of & & & \\
\hline
\end{tabular}




\section{Steady State \\ Pressure Distributions LS(1)-0417MOD \\ $\operatorname{Re}=0.75$ million}




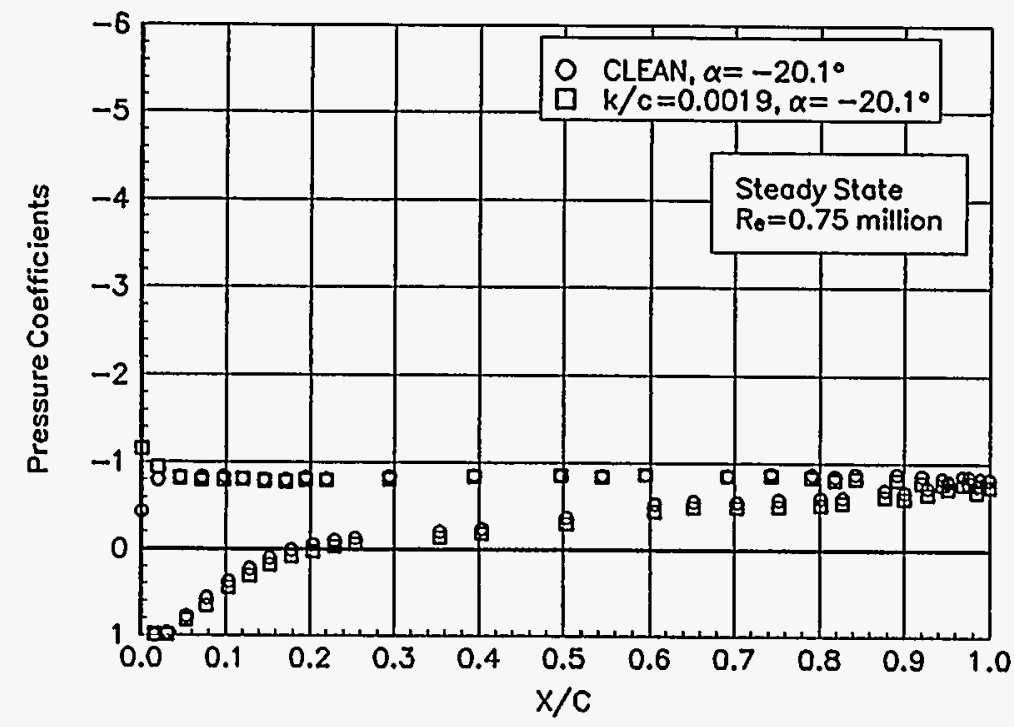

Figure B1. $a=-20.1^{\circ}$

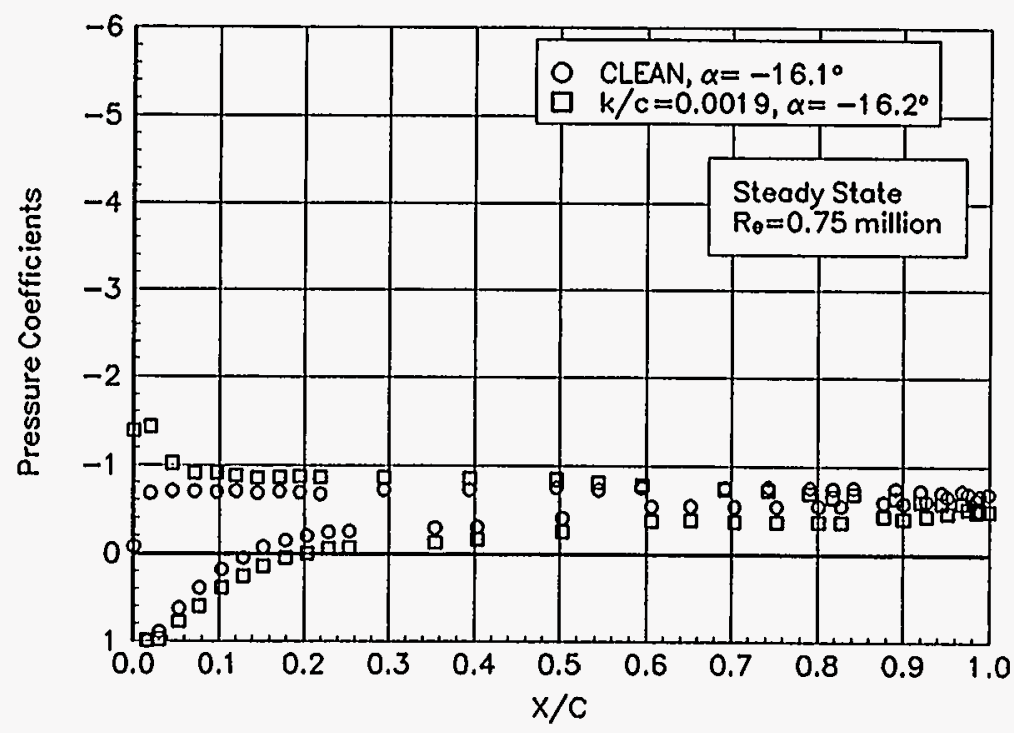

Figure B3. $a=-16.1^{\circ}$

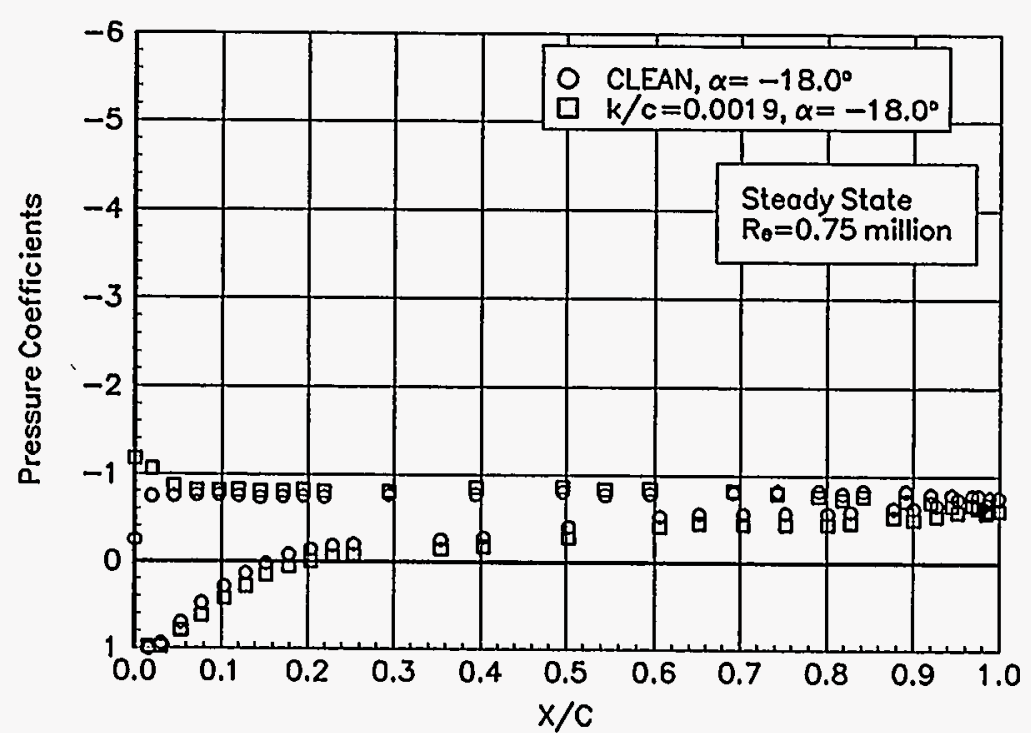

Figure B2. $a=-18.0^{\circ}$

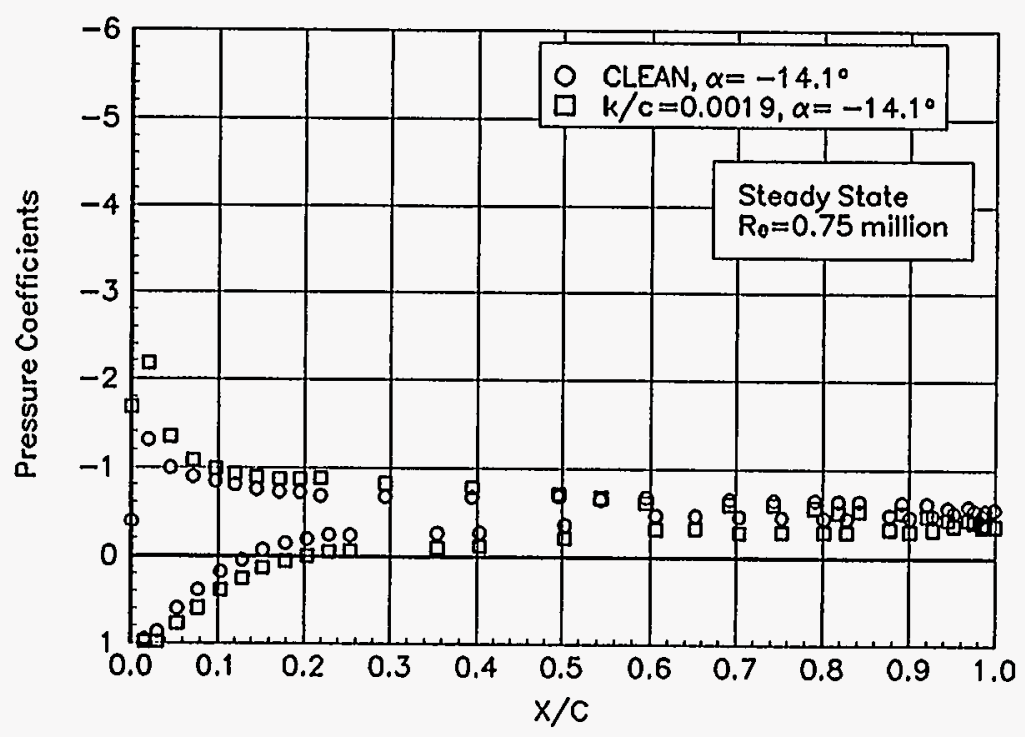

Figure B4. $a=-14.1^{\circ}$ 


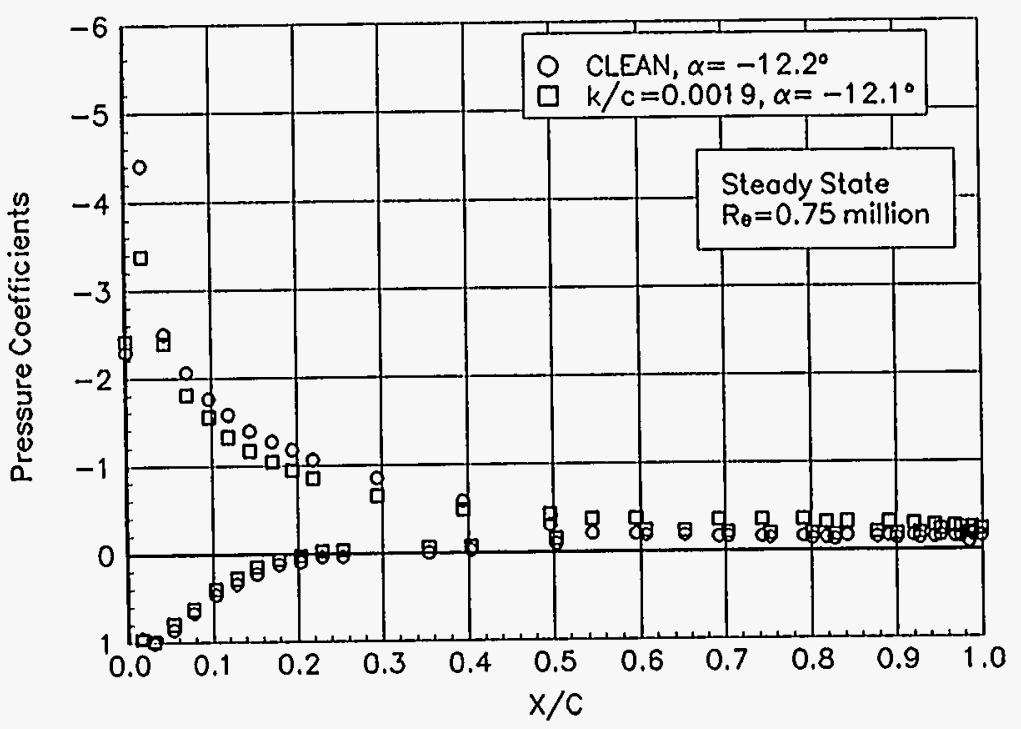

Figure B5. $a=-12.2^{\circ}$

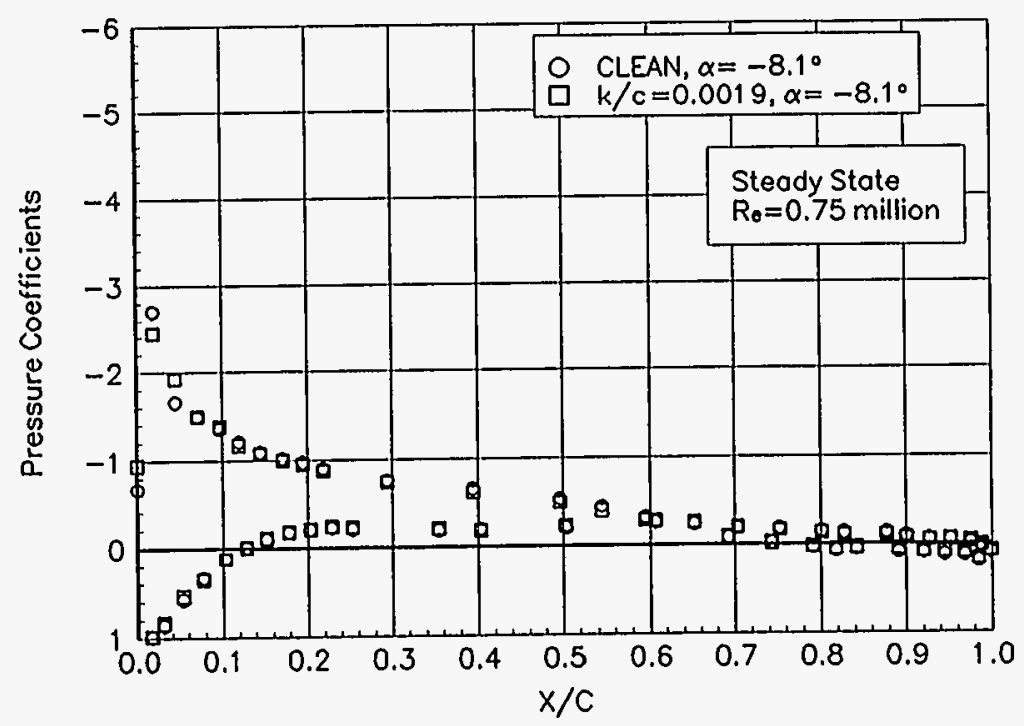

Figure B7. $a=-8.1^{\circ}$

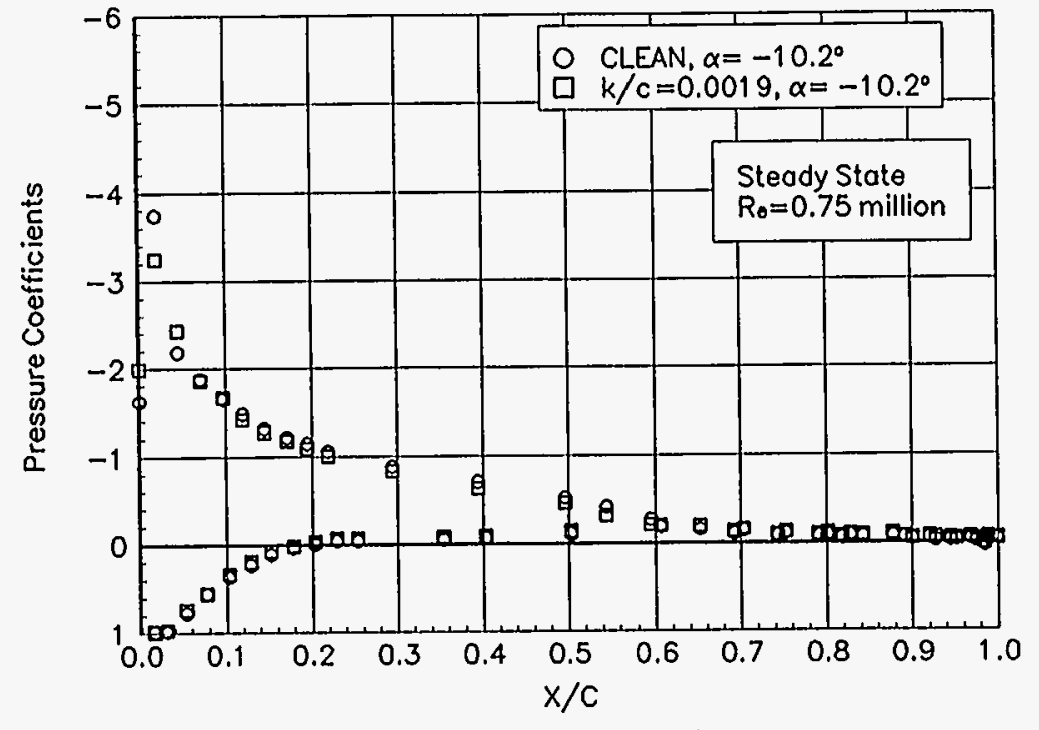

Figure B6. $a=-10.2^{\circ}$

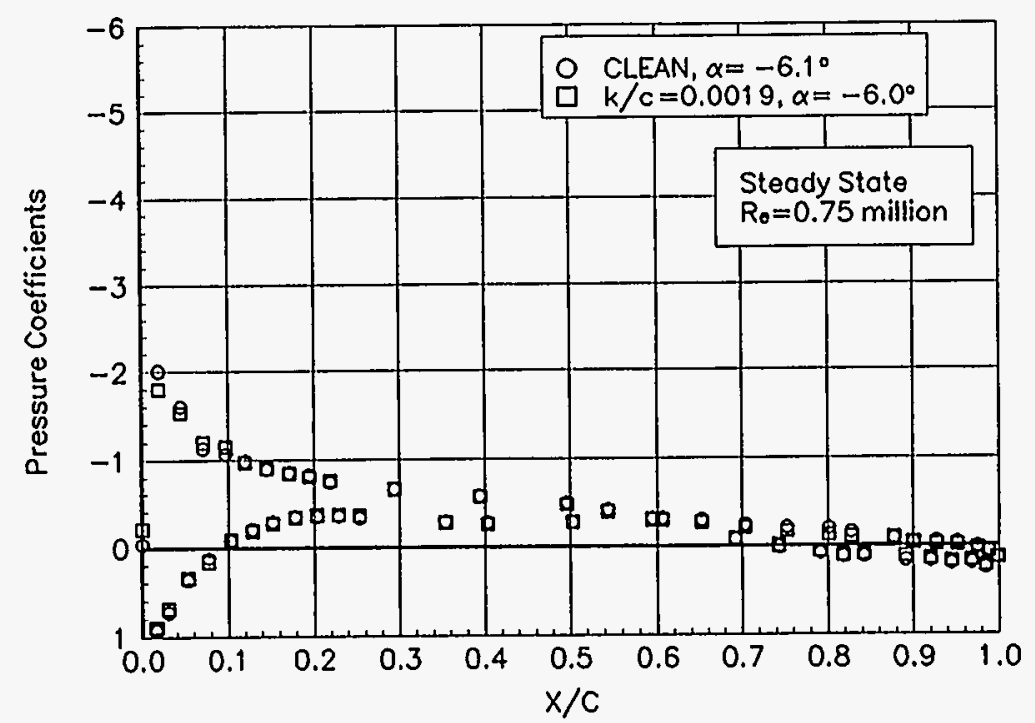

Figure B8. $a=-6.1^{\circ}$ 


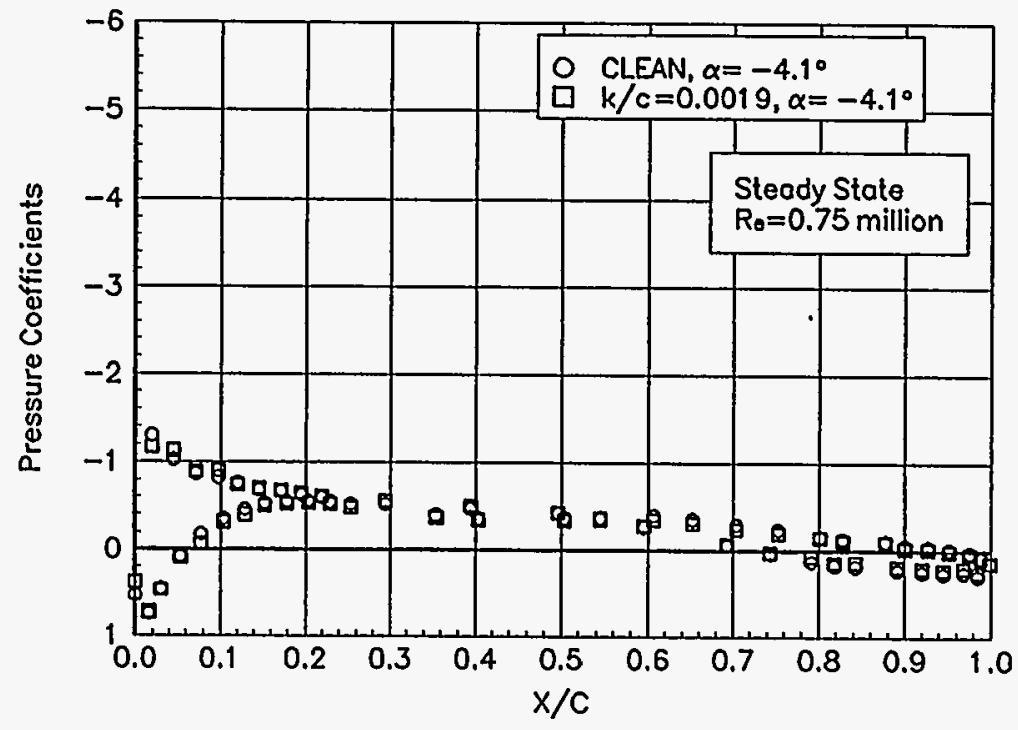

Figure B9. $a=-4.1^{\circ}$

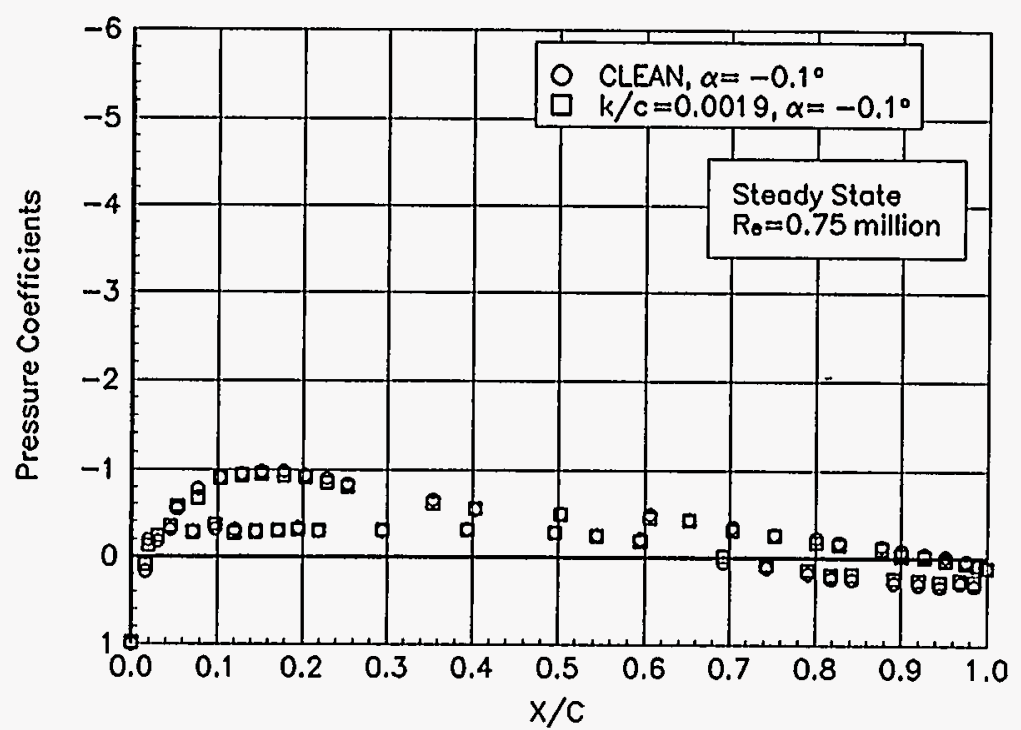

Figure B11. $a=-0.1^{\circ}$

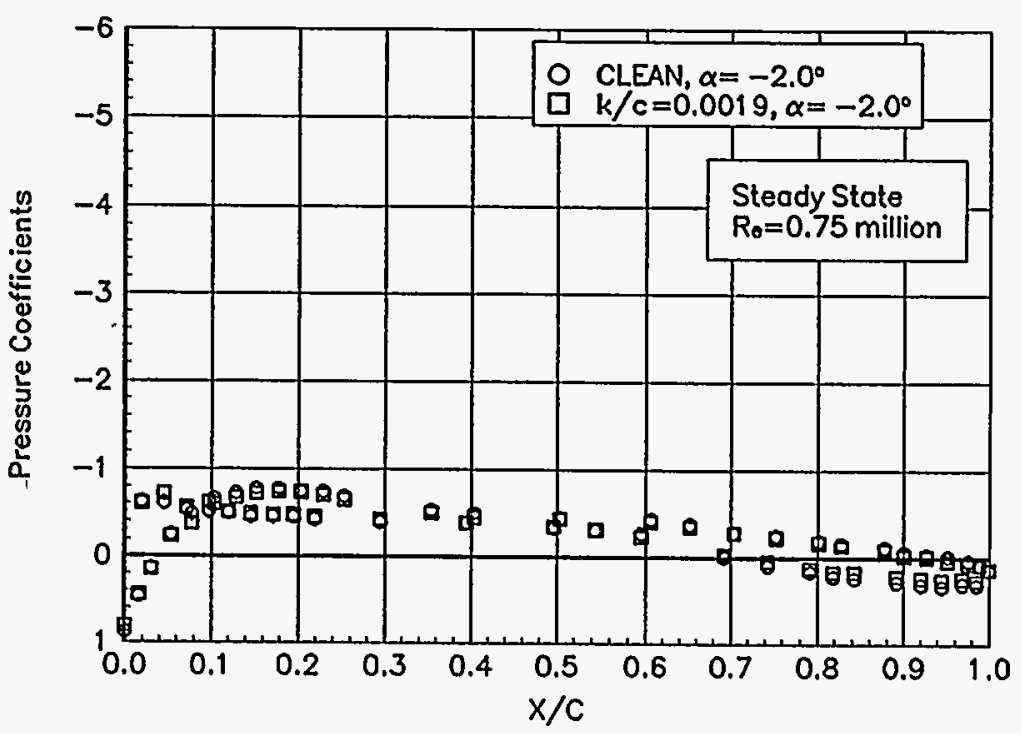

Figure B10. $a=-2.0^{\circ}$

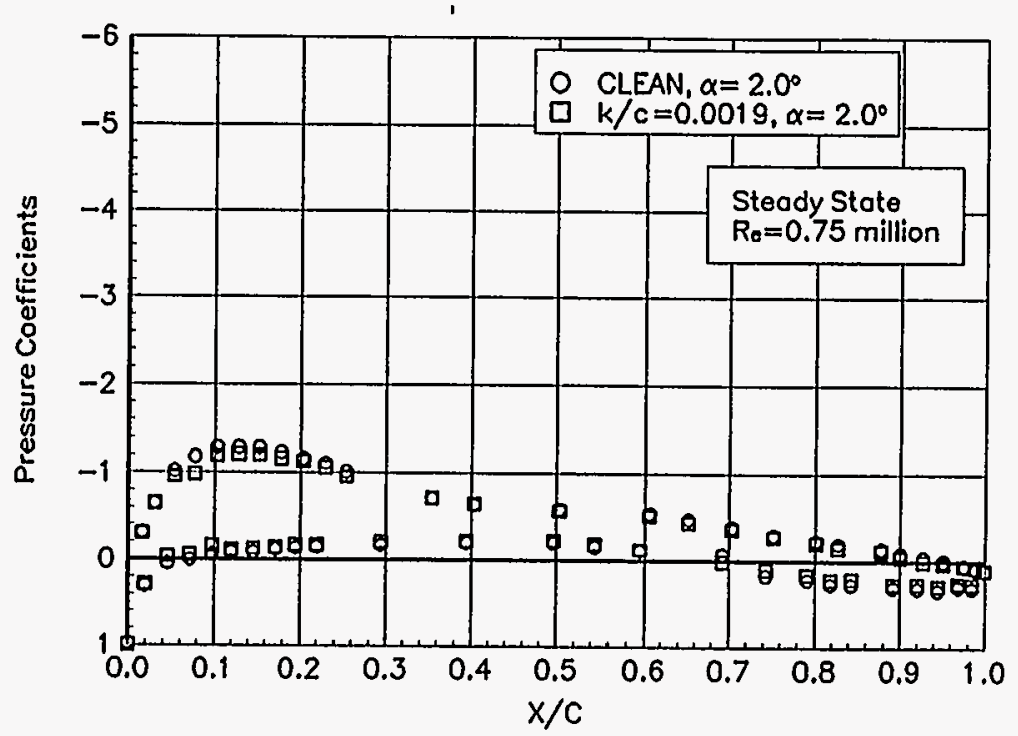

Figure B12. $a=2.0^{\circ}$ 


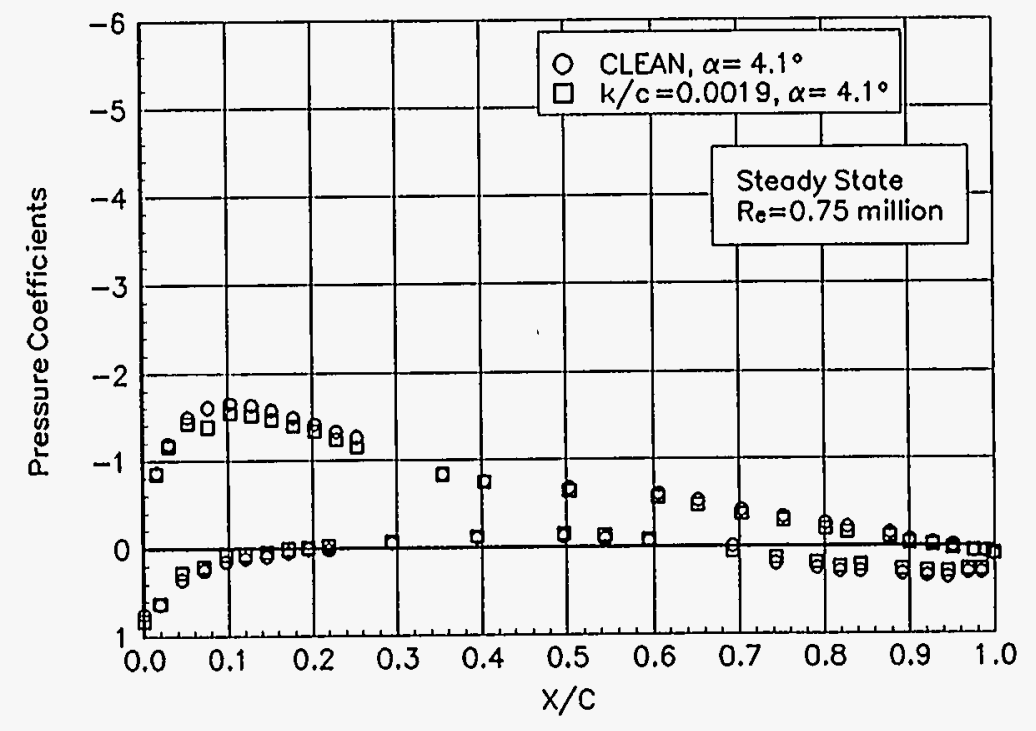

Figure B13. $a=4.1^{\circ}$

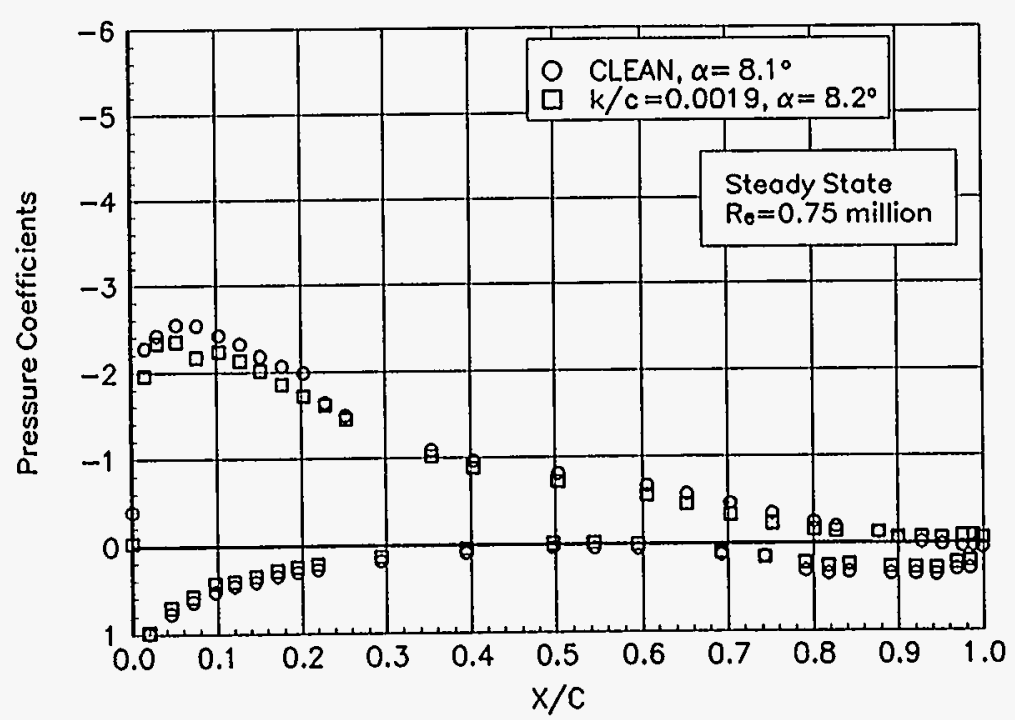

Figure B15. $a=8.1^{\circ}$

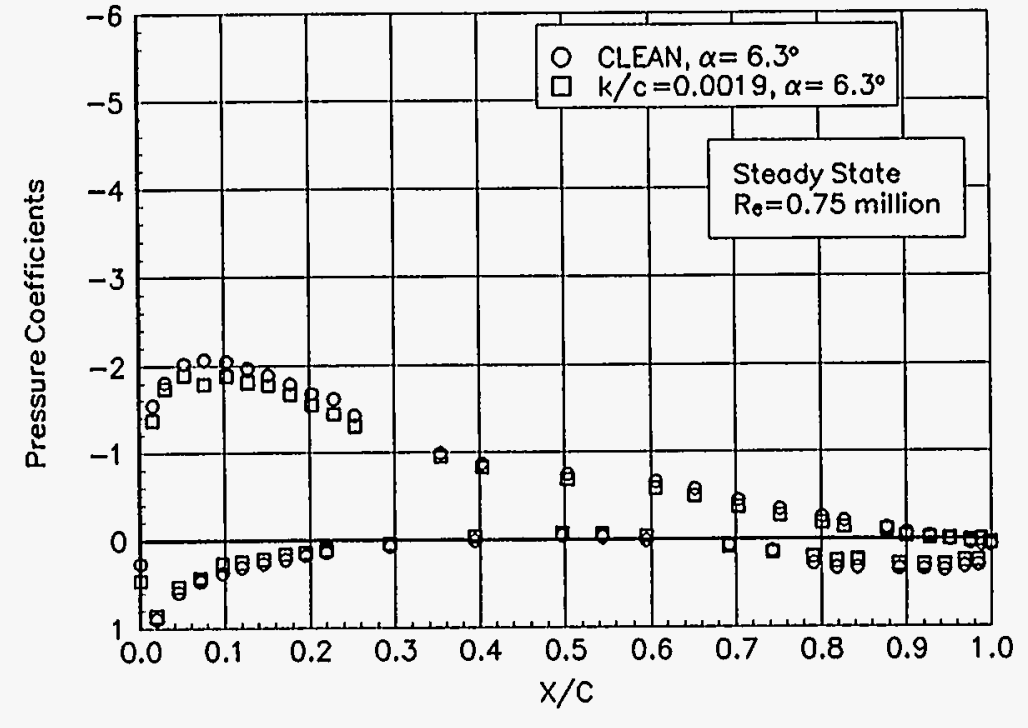

Figure B14. $a=6.3^{\circ}$

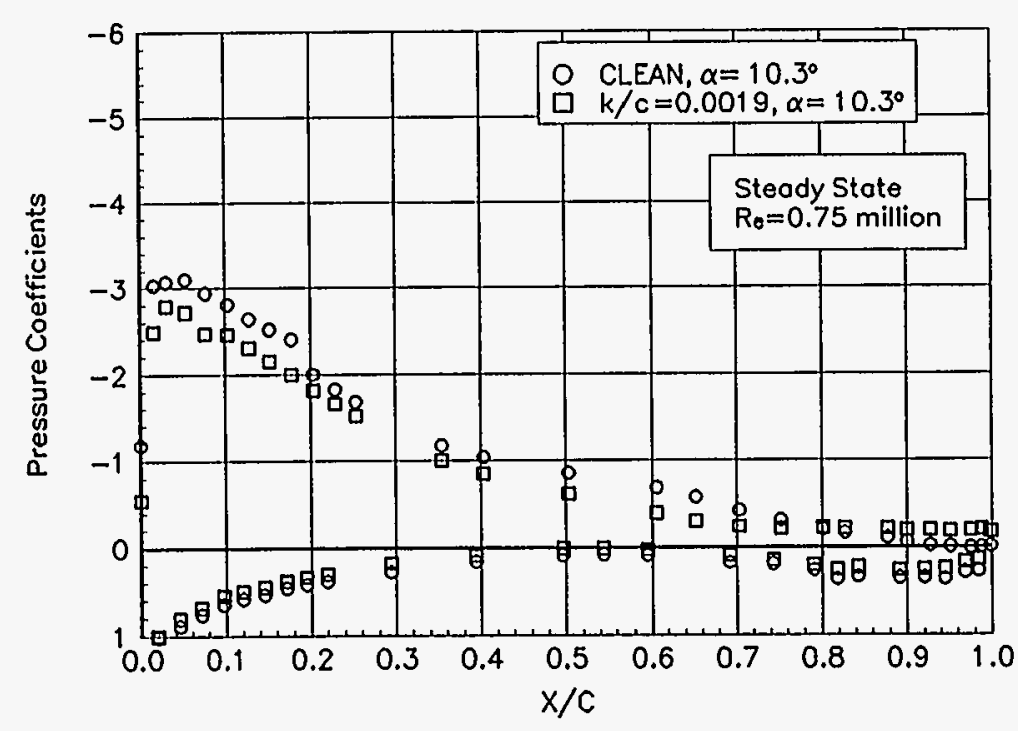

Figure B16. $a=10.3^{\circ}$ 


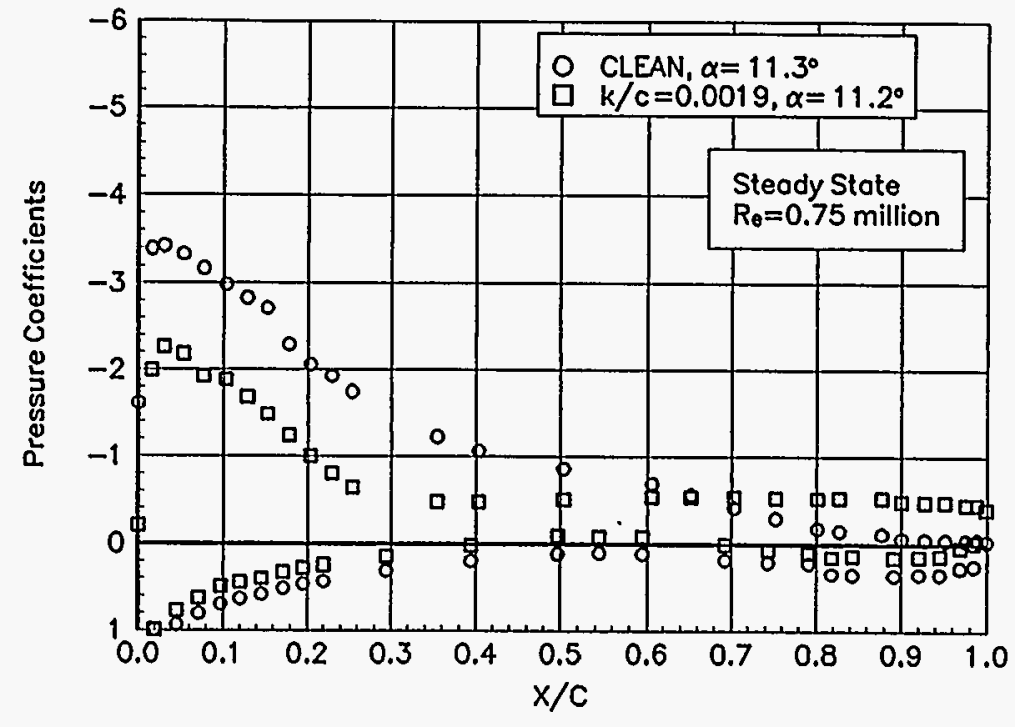

Figure B17. $a=11.3^{\circ}$

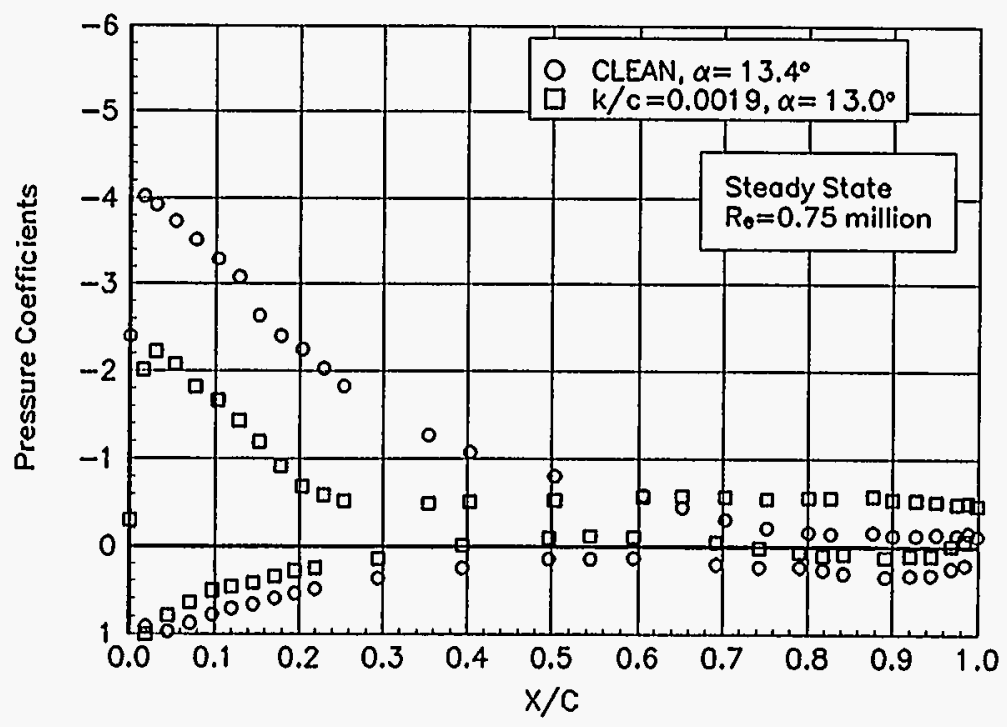

Figure B19. $a=13.4^{\circ}$

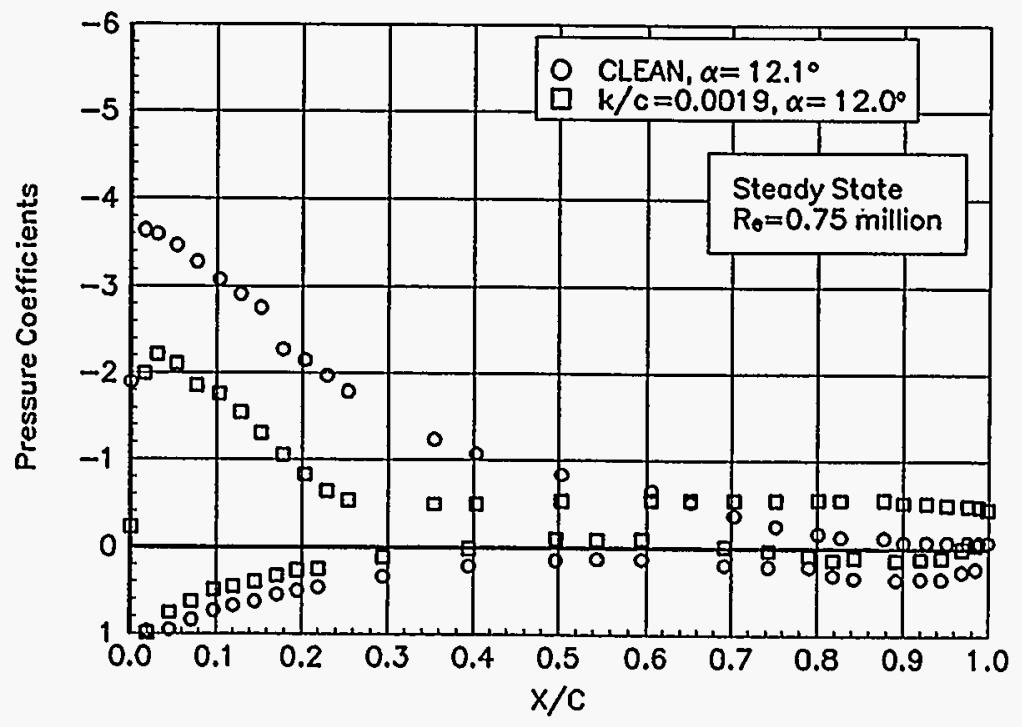

Figure B18. $\alpha=12.1^{\circ}$

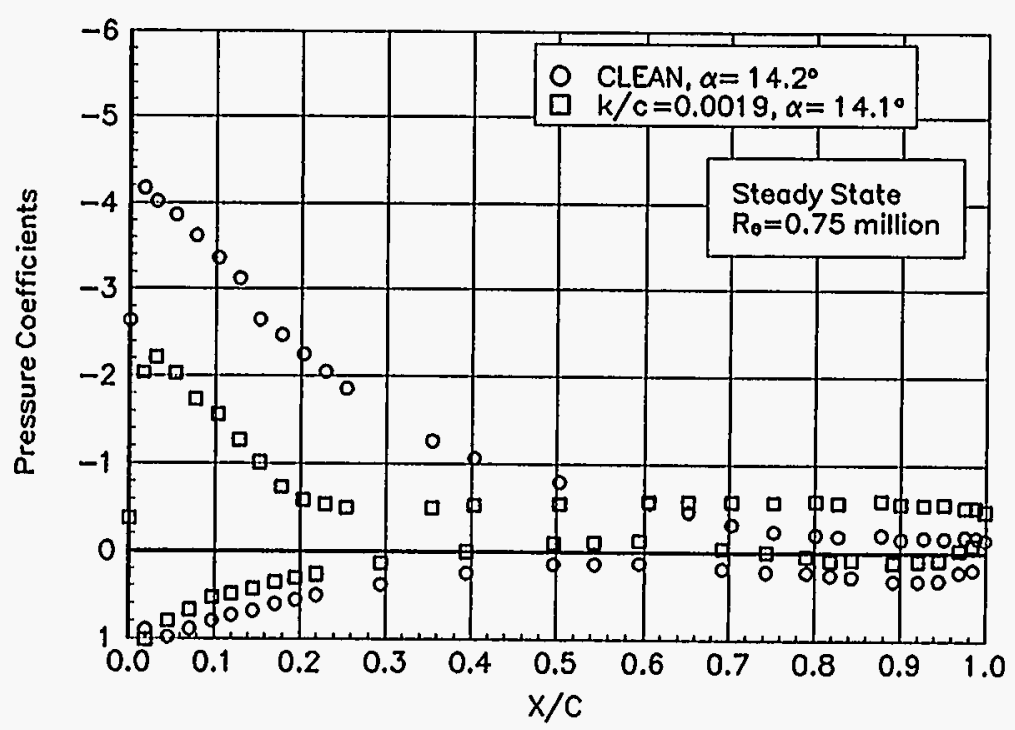

Figure B20. $a=14.2^{\circ}$ 


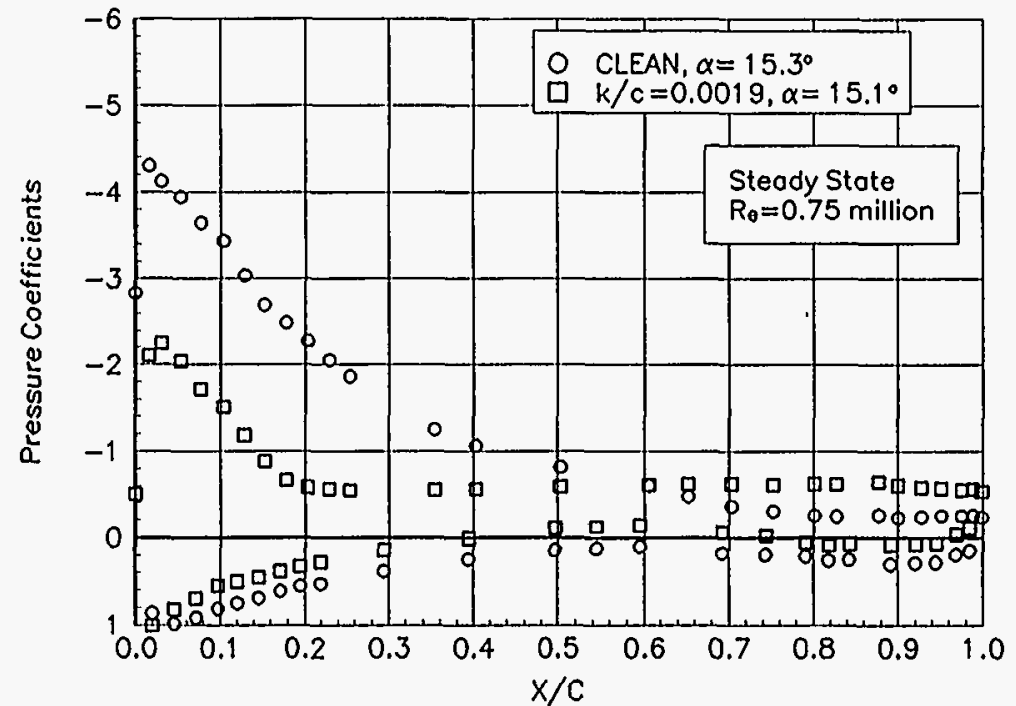

Figure B21. $a=15.3^{\circ}$

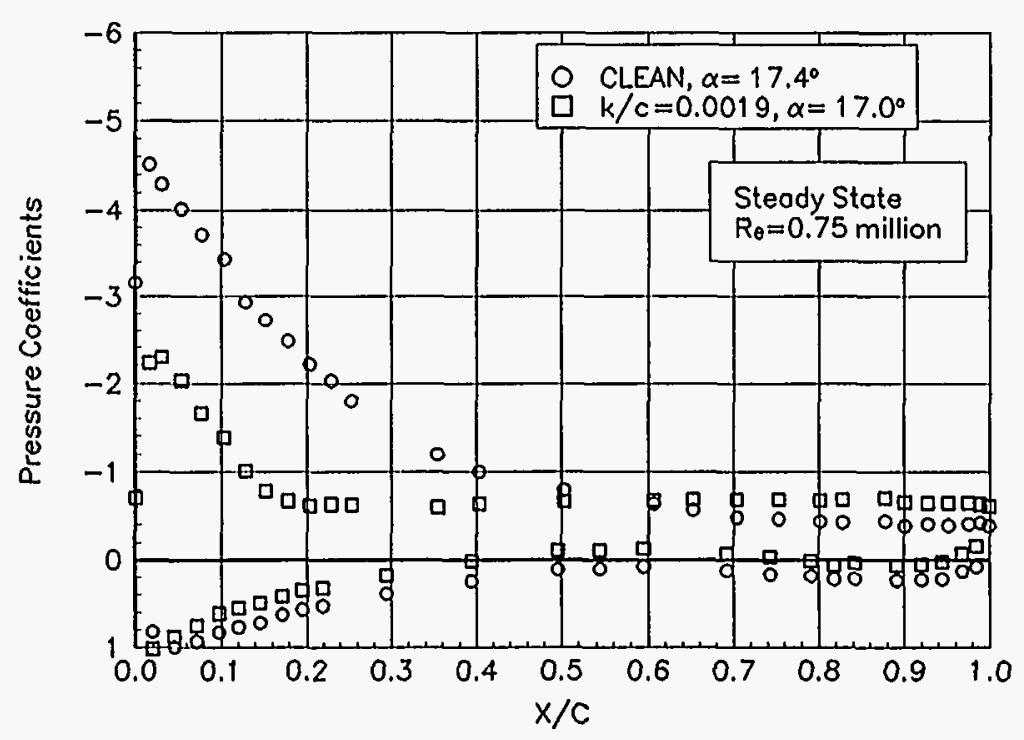

Figure B23. $a=17.4^{\circ}$

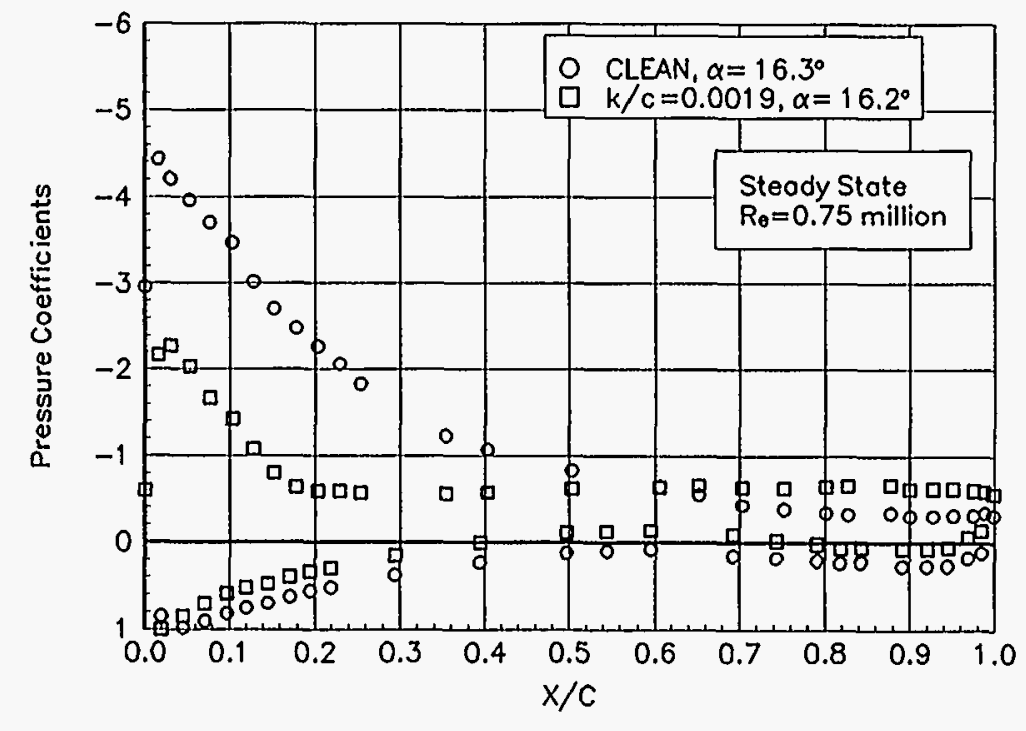

Figure B22. $a=16.3^{\circ}$

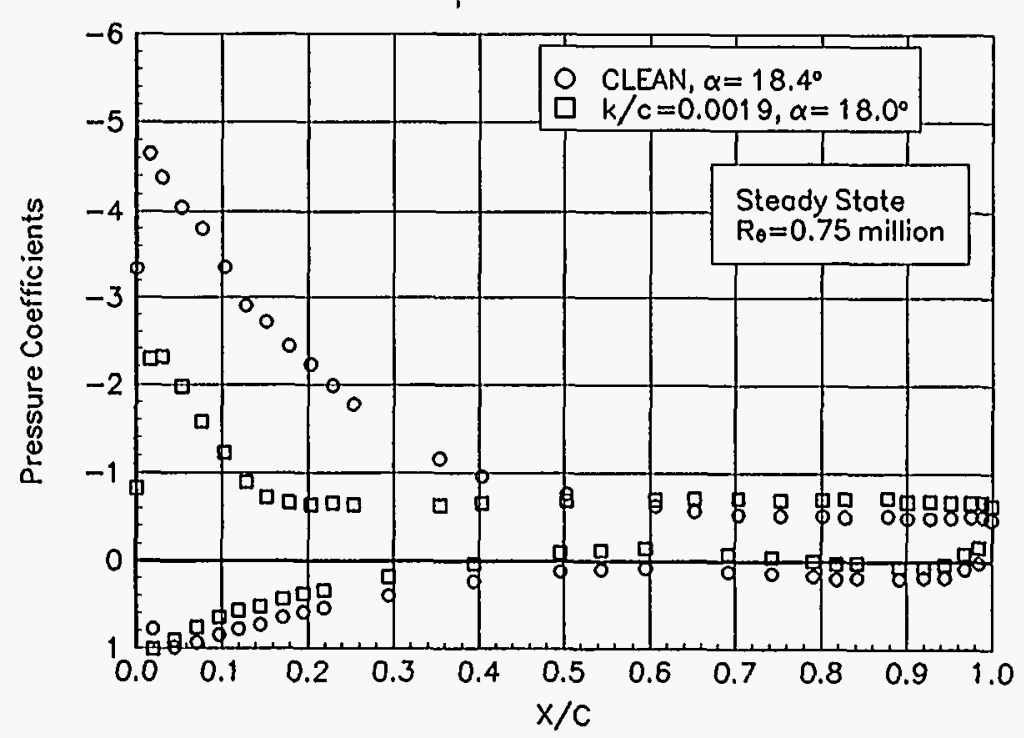

Figure B24. $a=18.4^{\circ}$ 


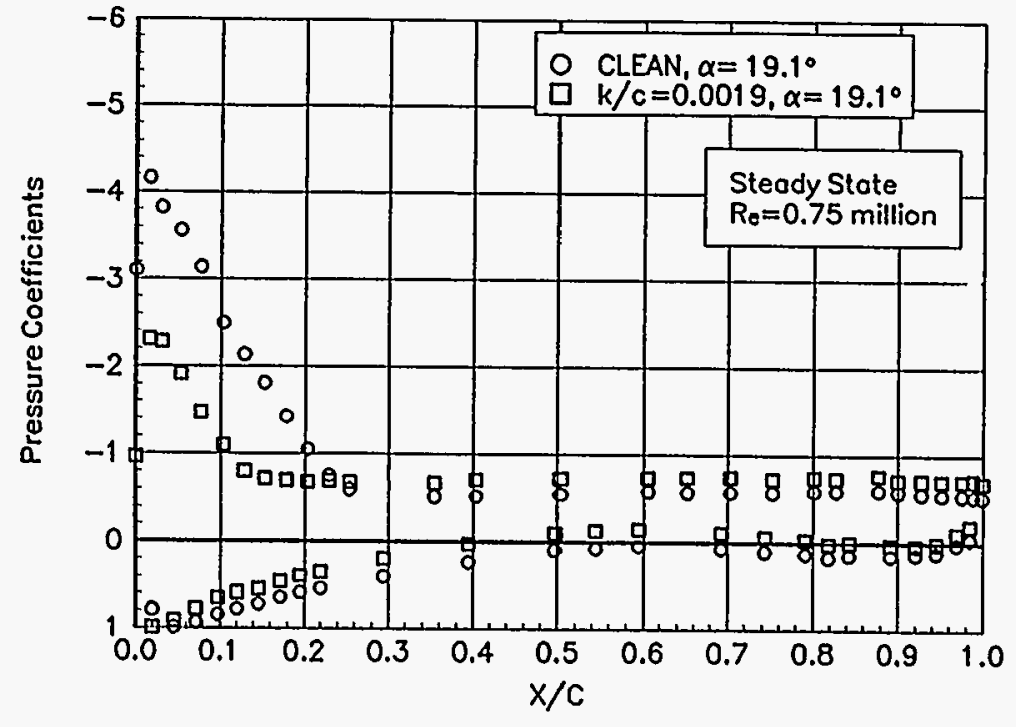

Figure B25. $a=19.1^{\circ}$

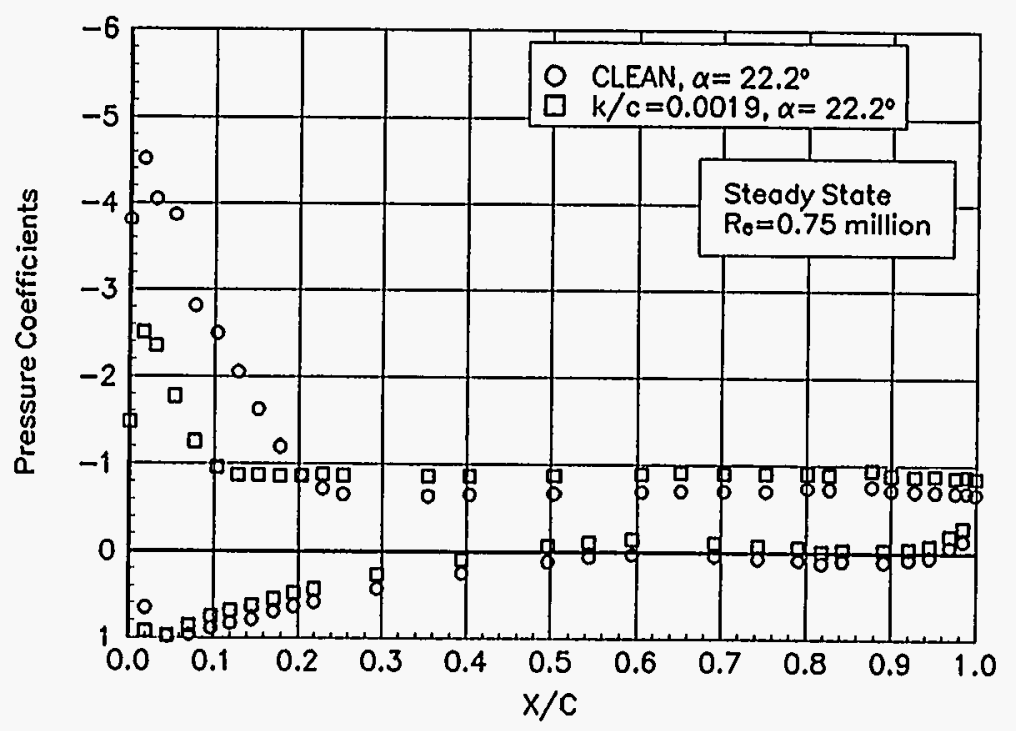

Figure B27. $a=22.2^{\circ}$

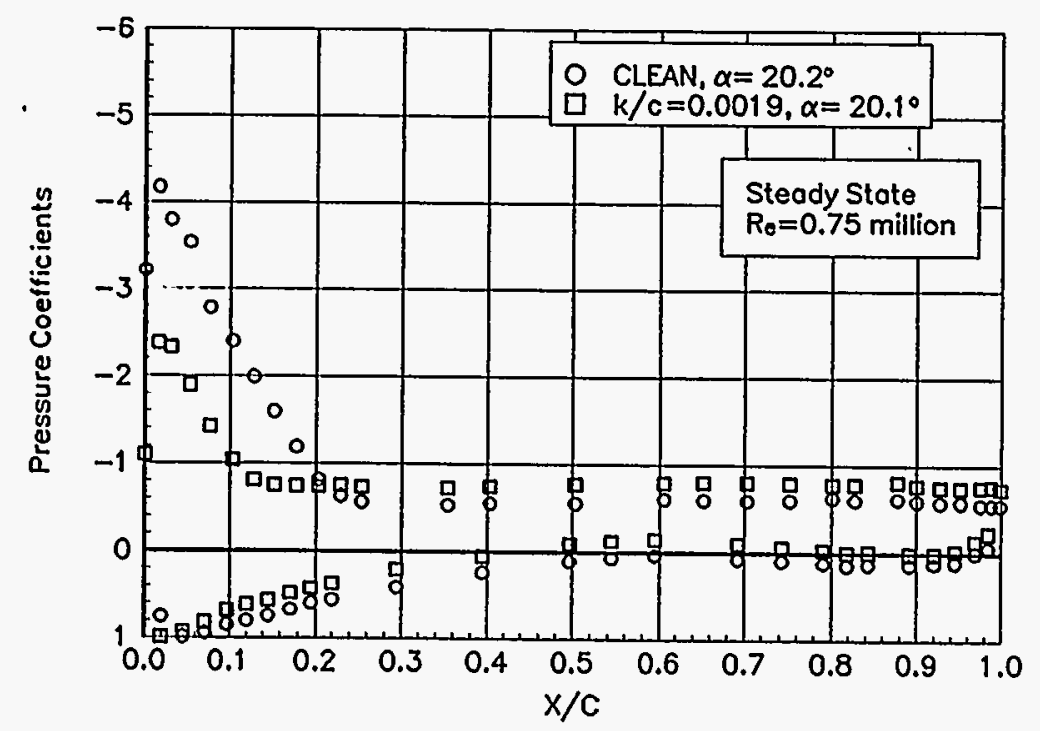

Figure B26. $a=20.2^{\circ}$

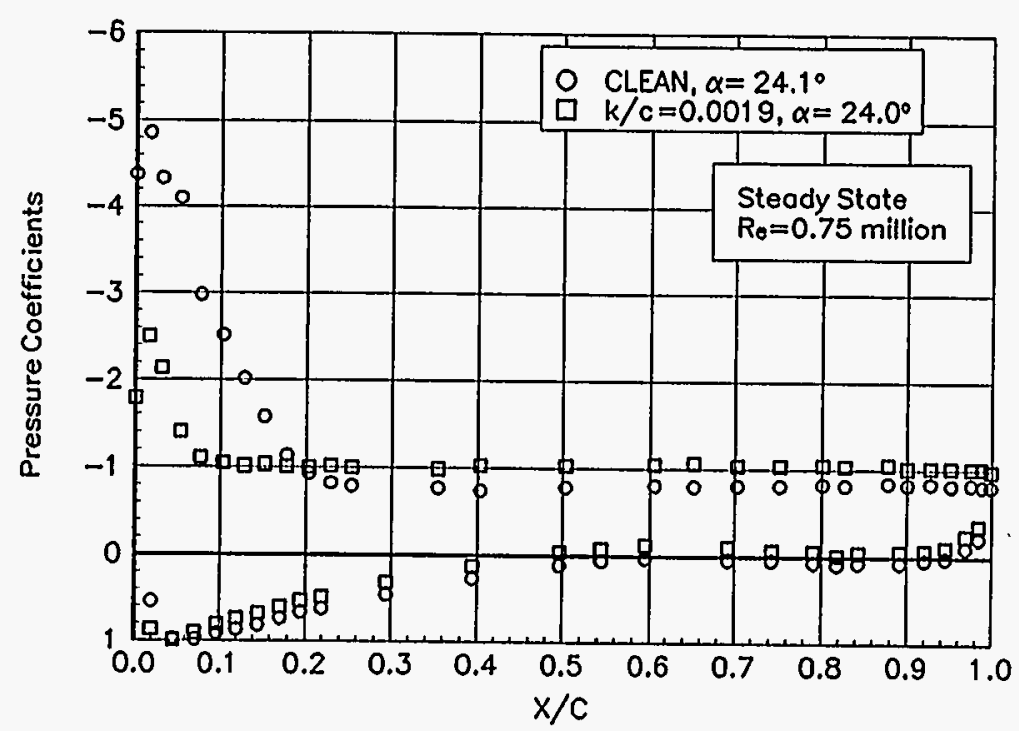

Figure B28. $a=24.1^{\circ}$ 


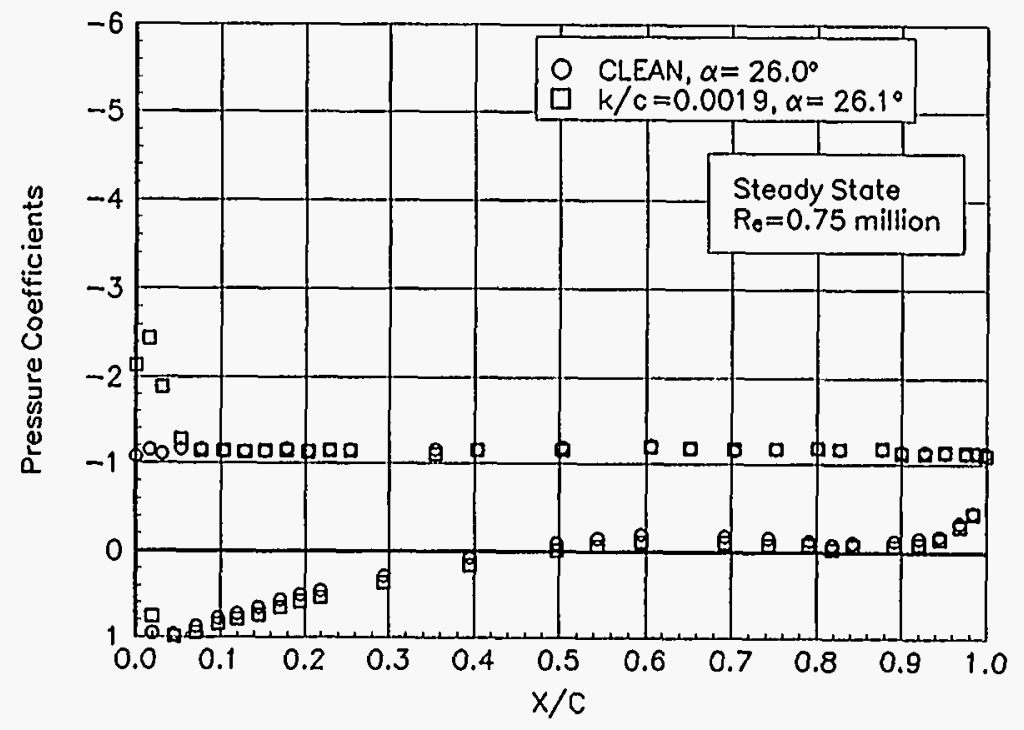

Figure B29. $a=26.0^{\circ}$

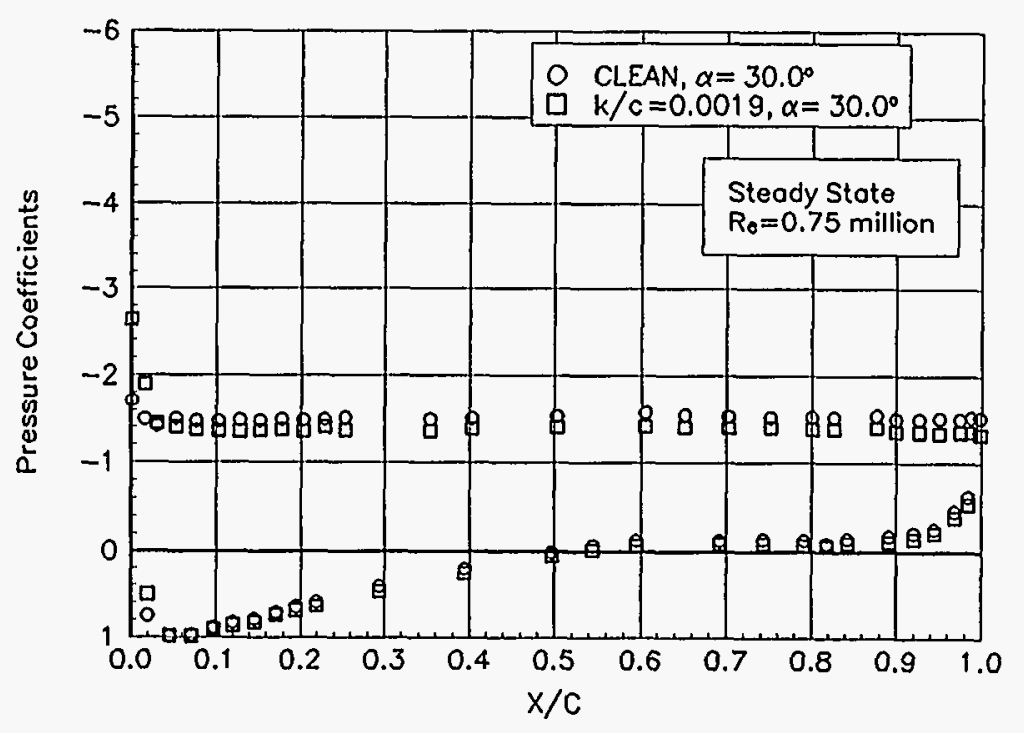

Figure B31. $a=30.0^{\circ}$

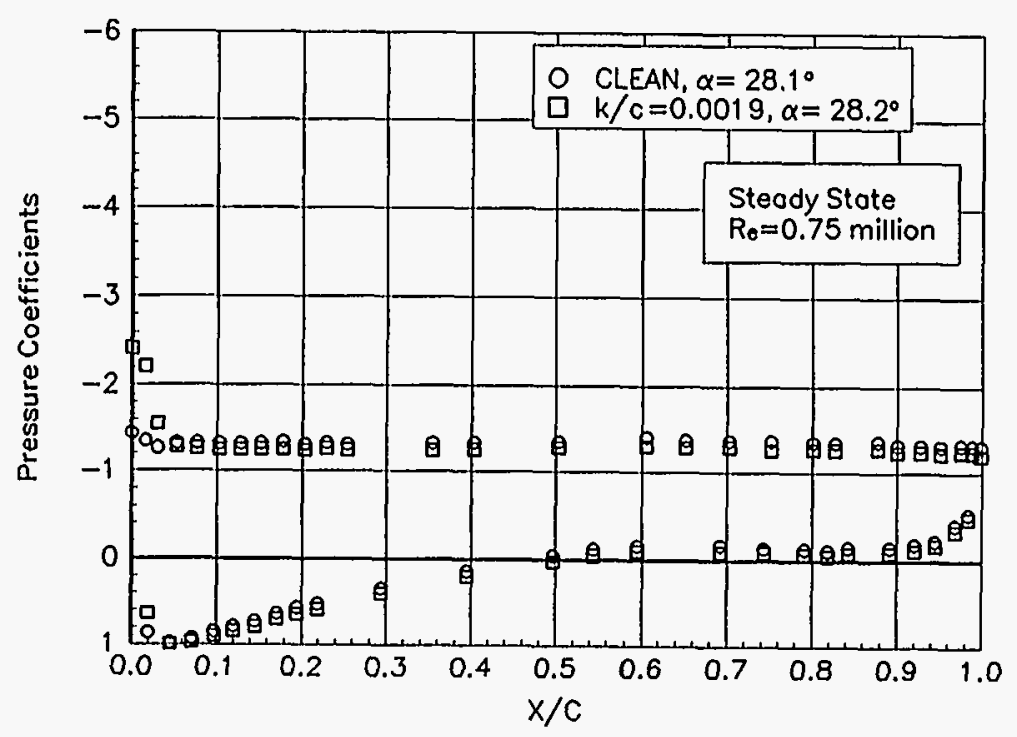

Figure B30. $a=28.1^{\circ}$

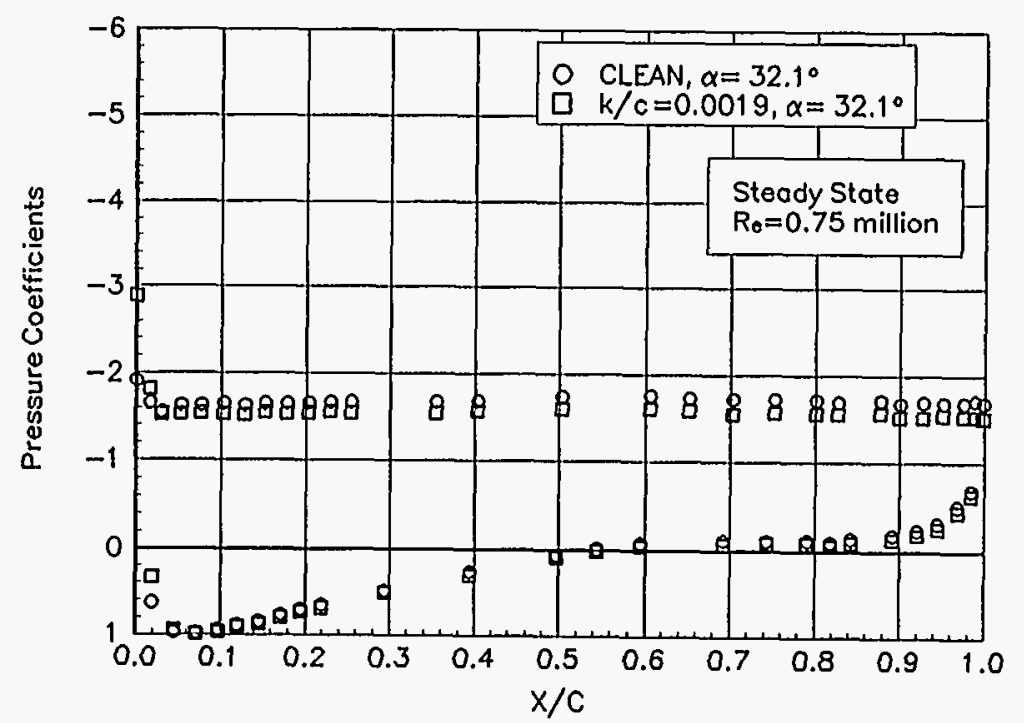

Figure B32. $a=32.1^{\circ}$ 


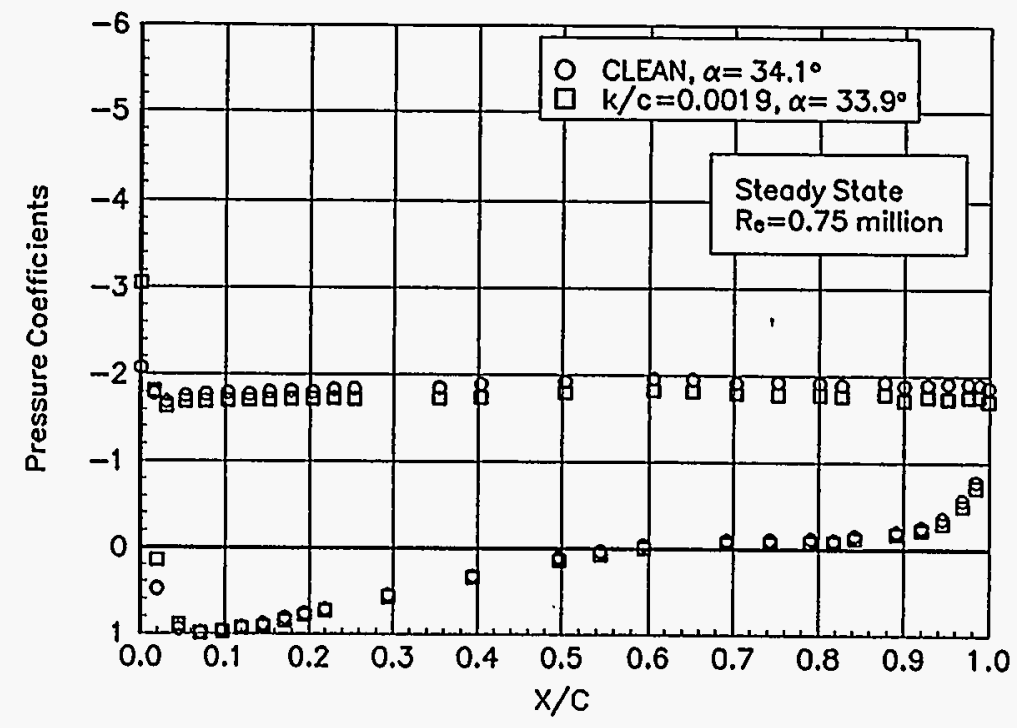

Figure B33. $\alpha=34.1^{\circ}$

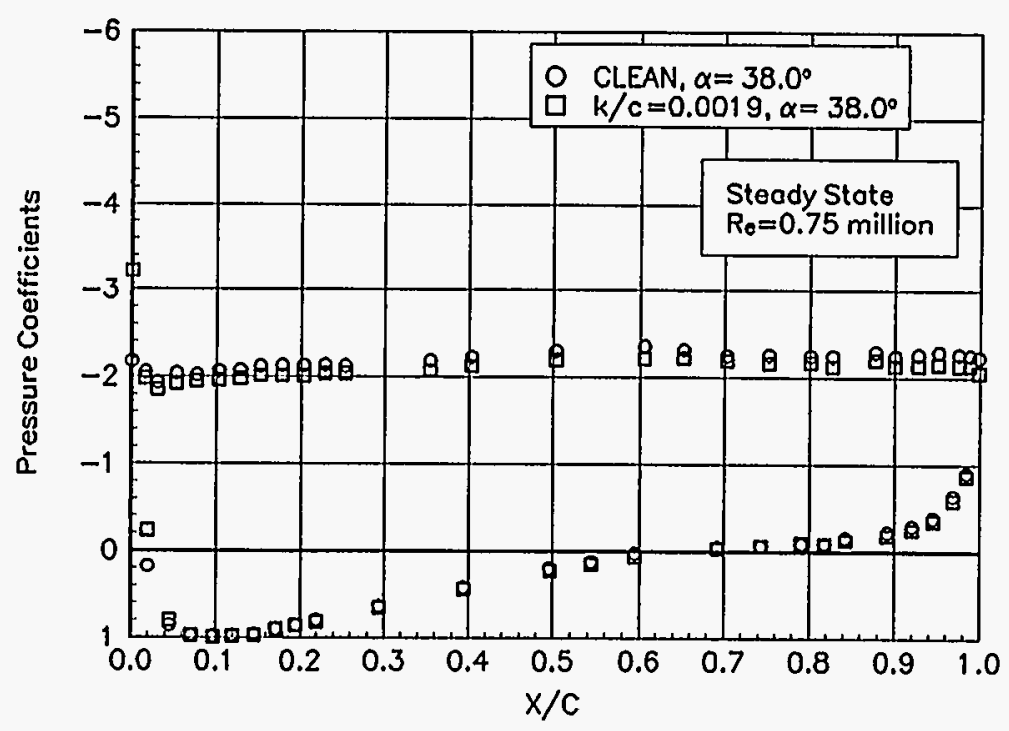

Figure B35. $a=38.0^{\circ}$

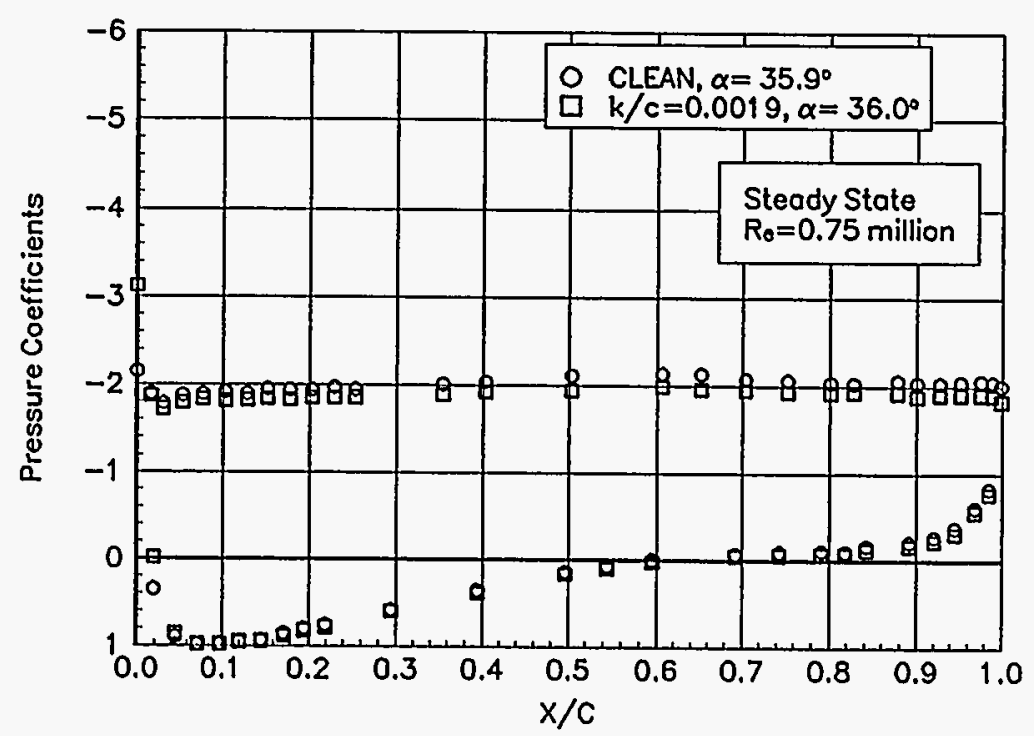

Figure B34. $a=35.9^{\circ}$

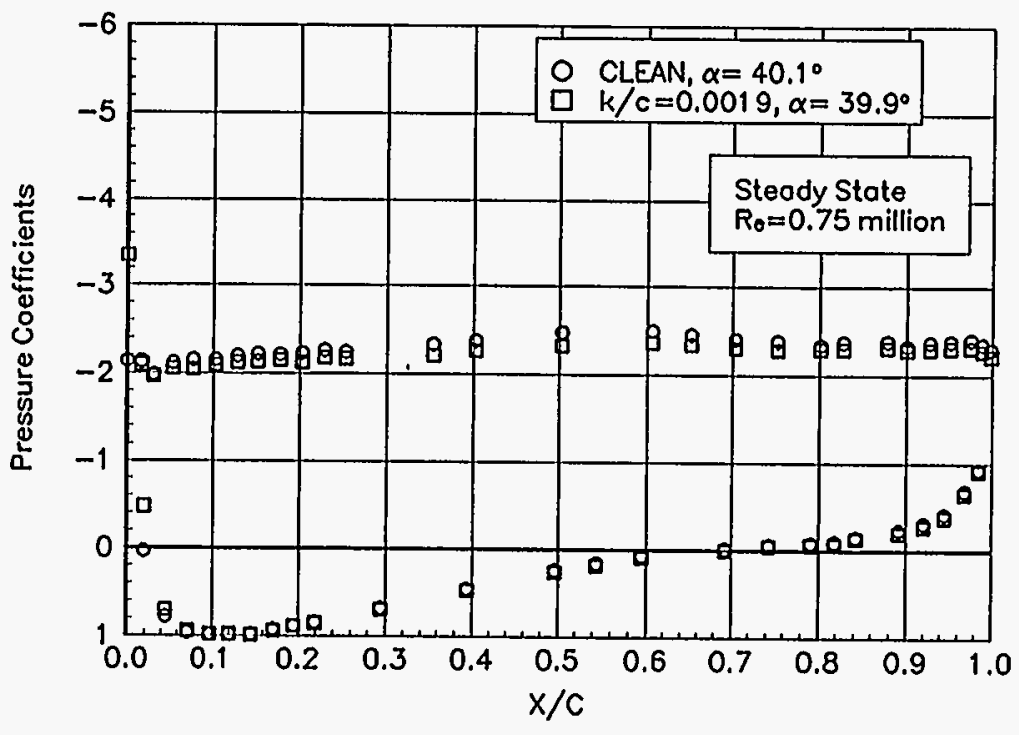

Figure B36. $a=40.1^{\circ}$ 


\section{Steady State \\ Pressure Distributions \\ LS(1)-0417MOD \\ $\operatorname{Re}=1$ million}




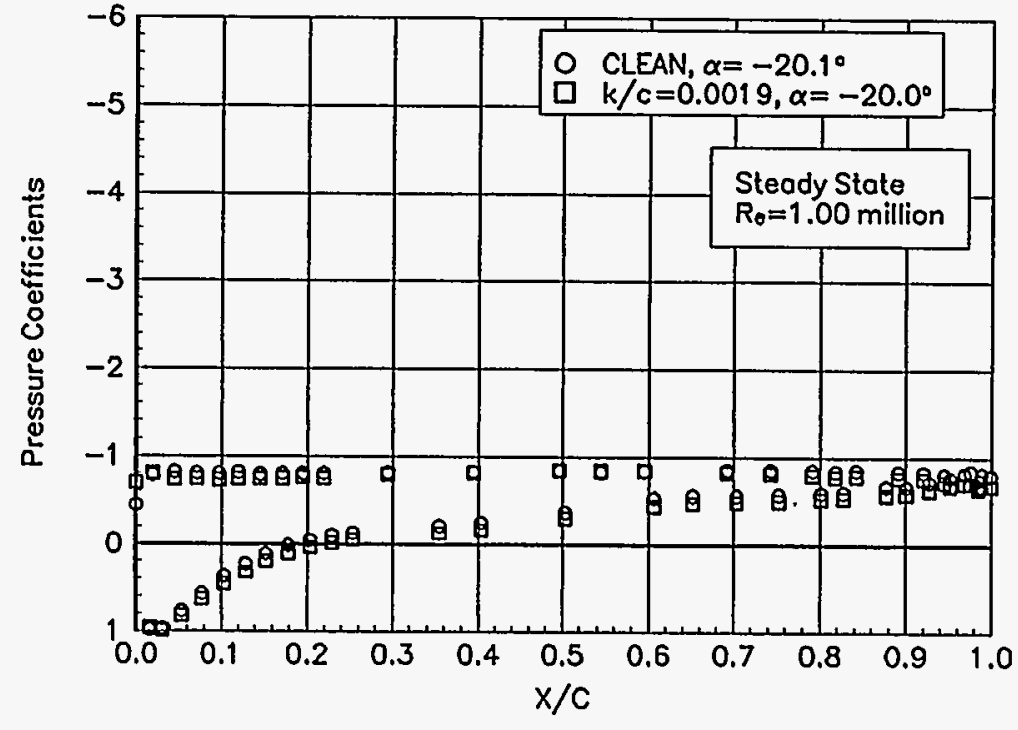

Figure B37. $a=-20.1^{\circ}$

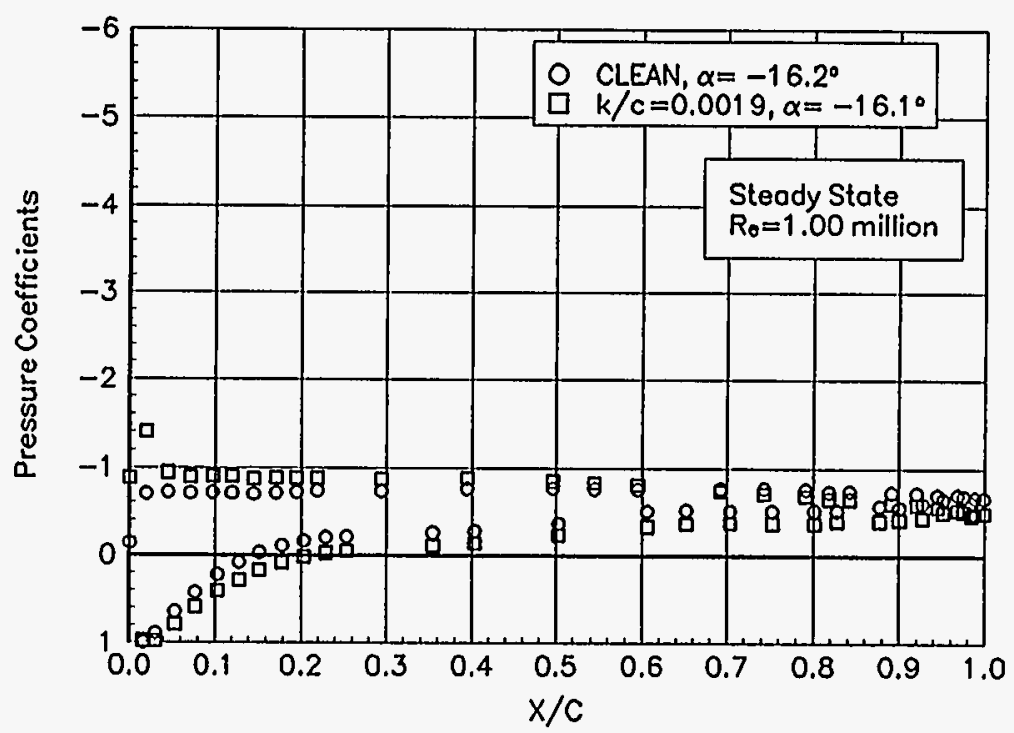

Figure B39. $a=-16.2^{\circ}$

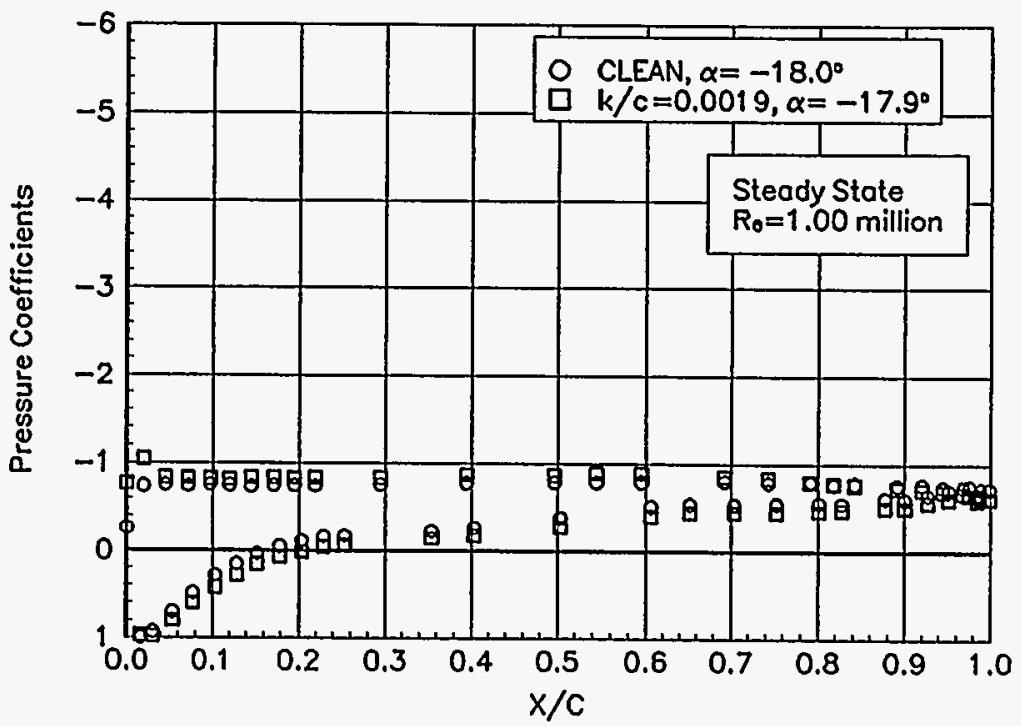

Figure B38. $a=-18.0^{\circ}$

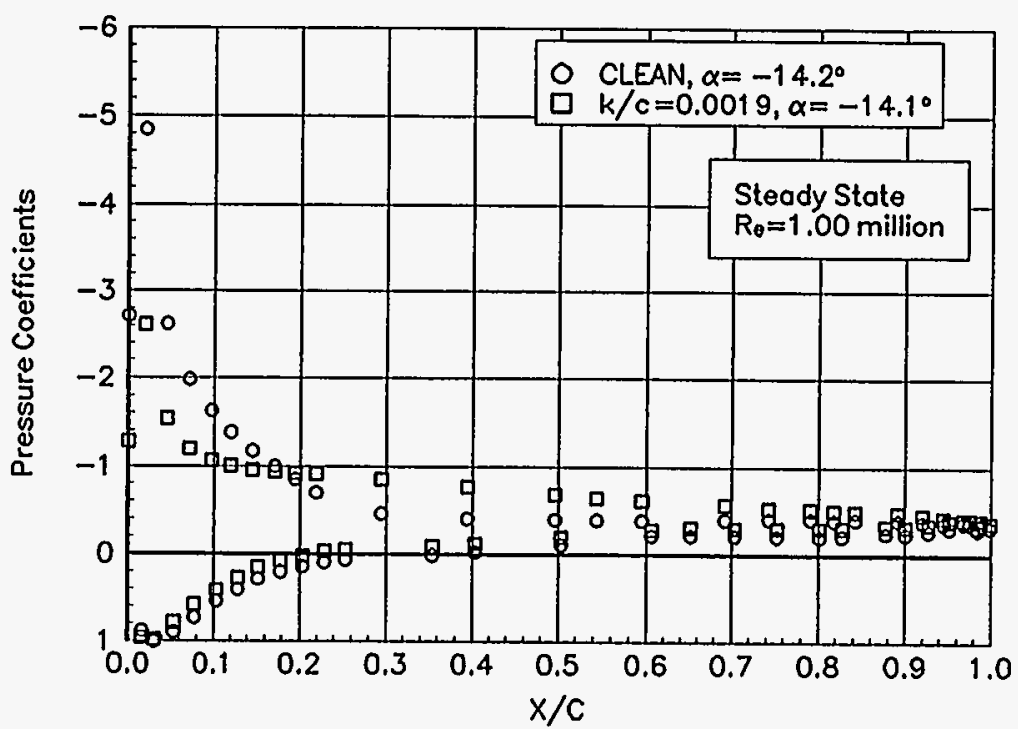

Figure B40. $a=-14.2^{\circ}$ 

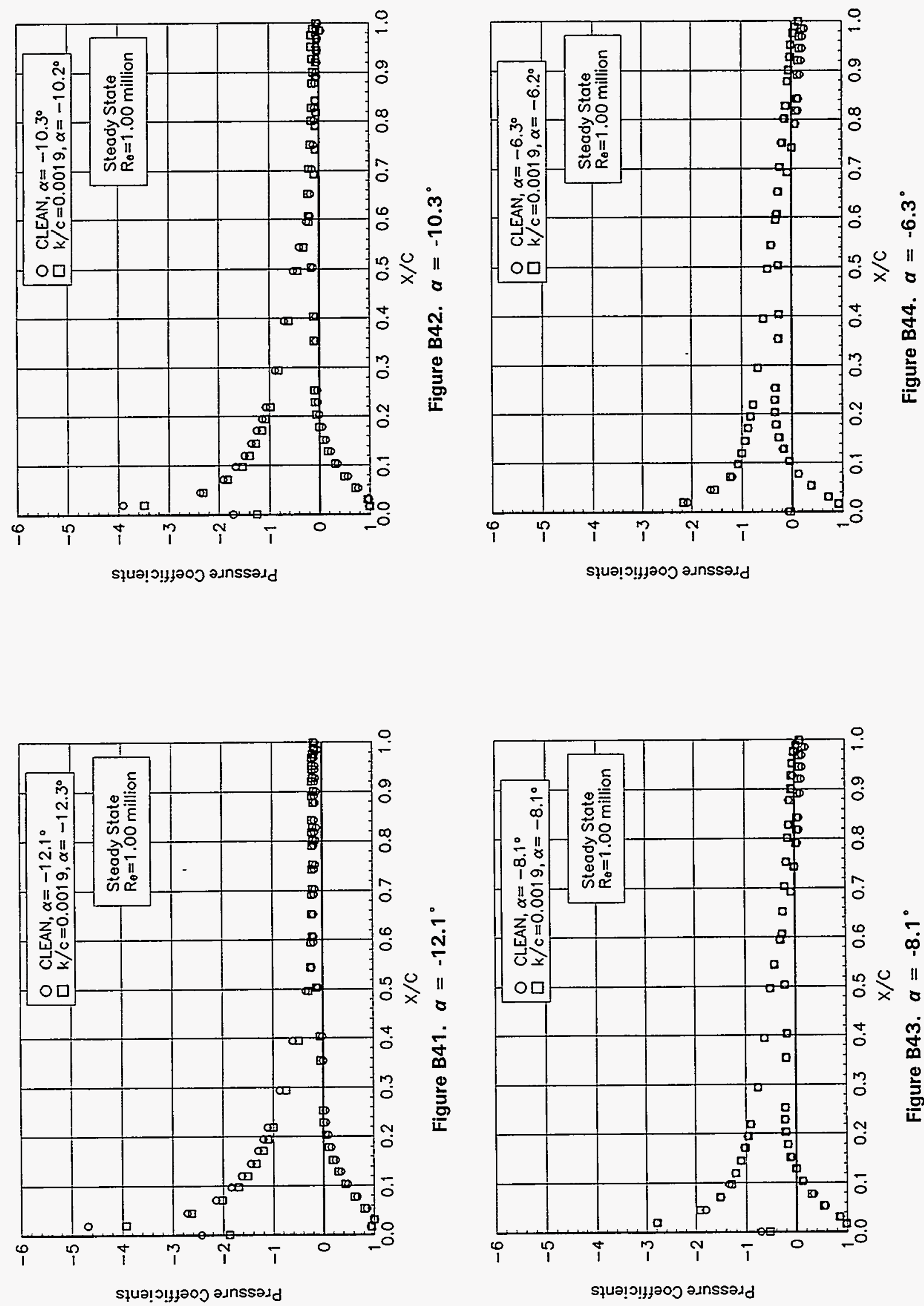

ผै

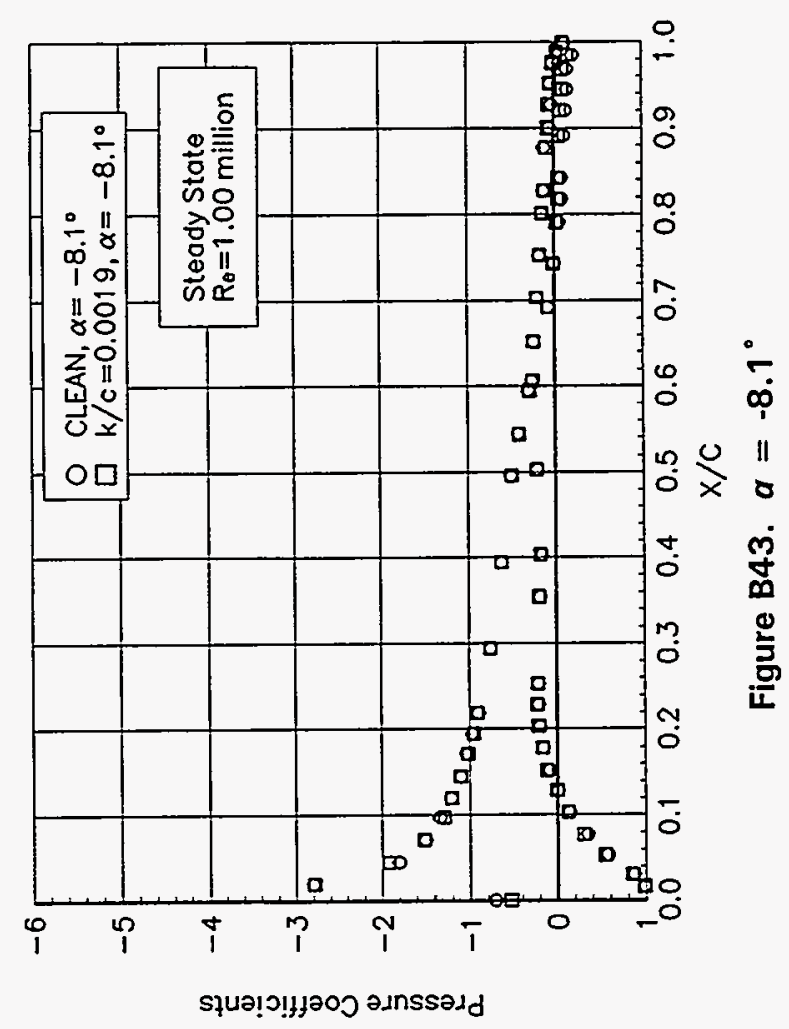




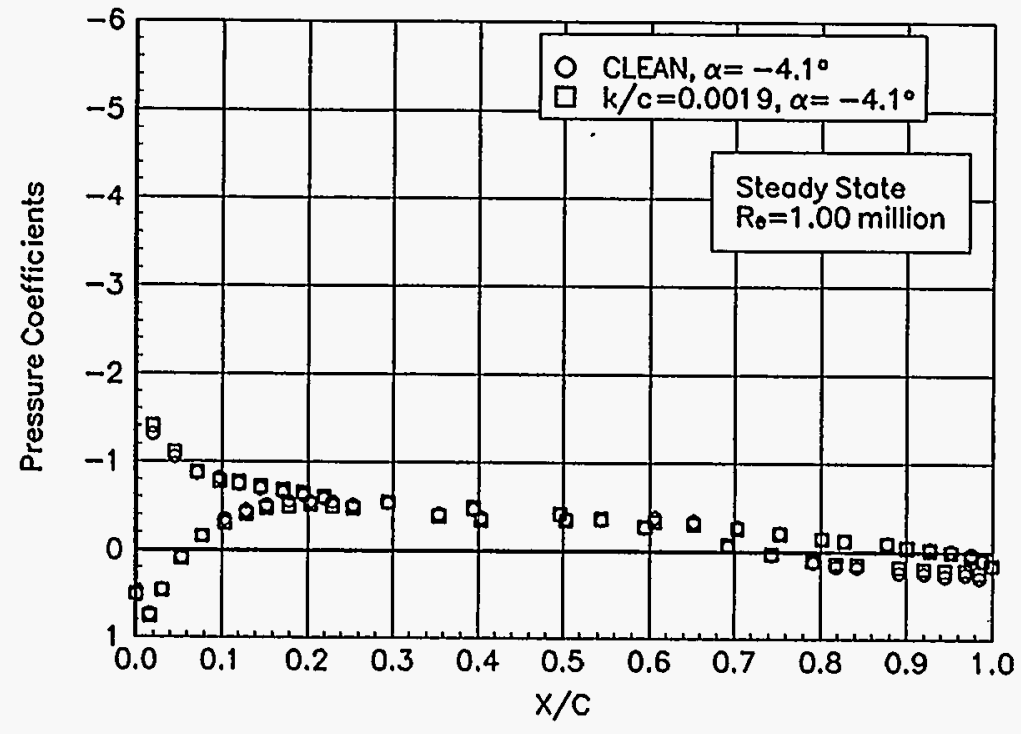

Figure B45. $a=-4.1^{\circ}$

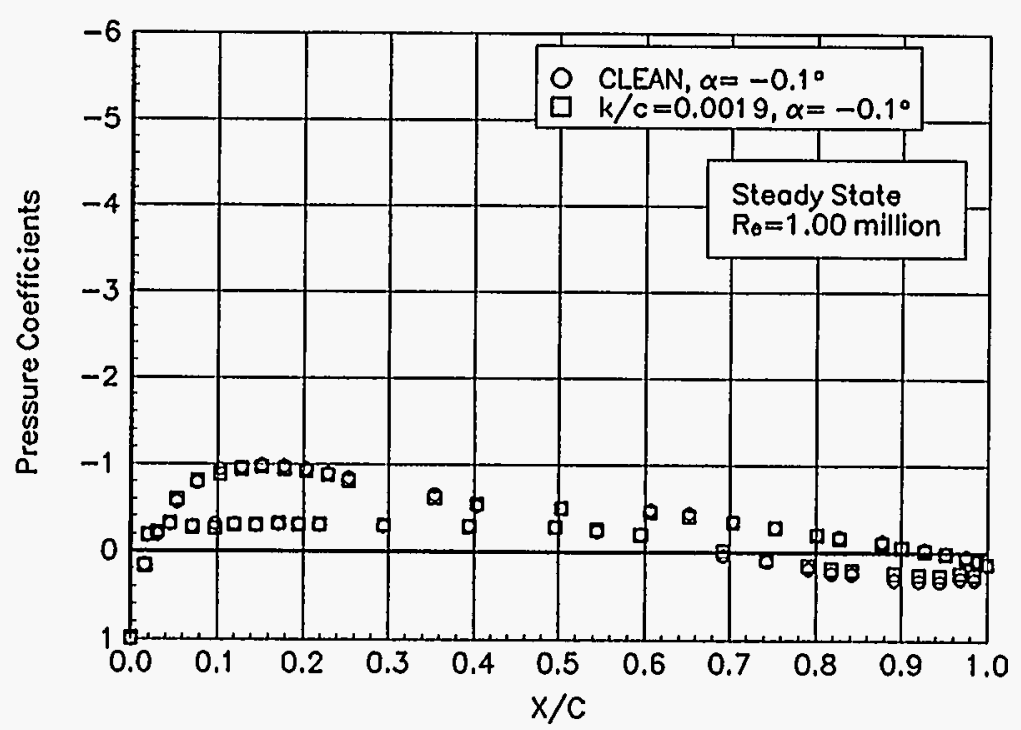

Figure B47. $a=-0.1$

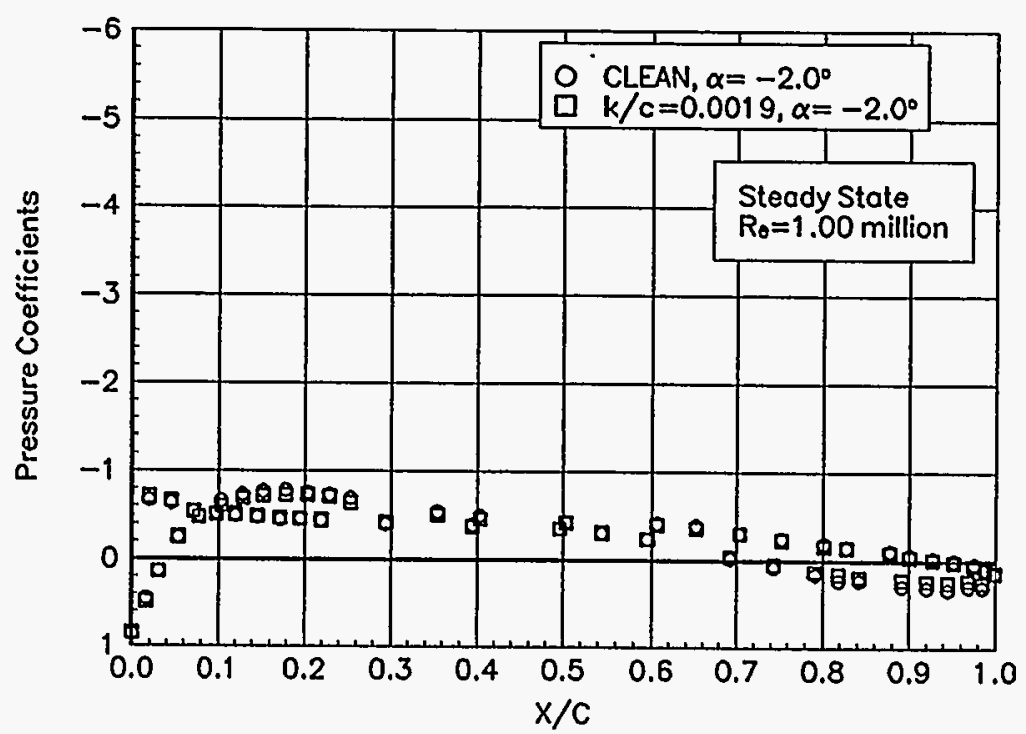

Figure B46. $a=-2.0^{\circ}$

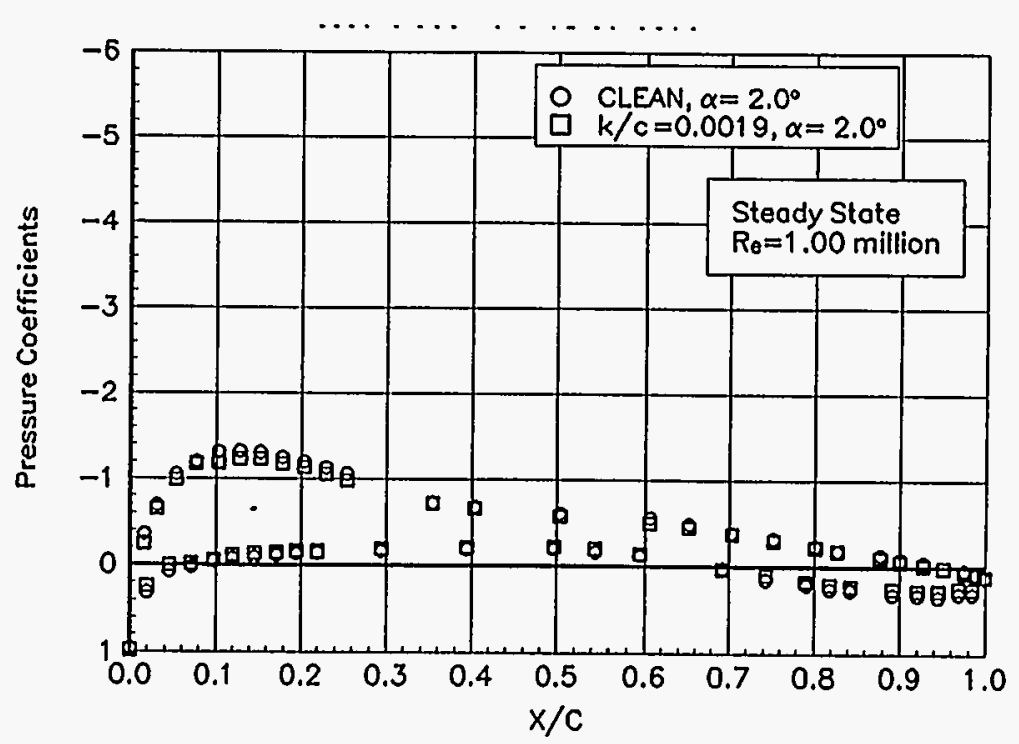

Figure B48. $a=2.0^{\circ}$ 


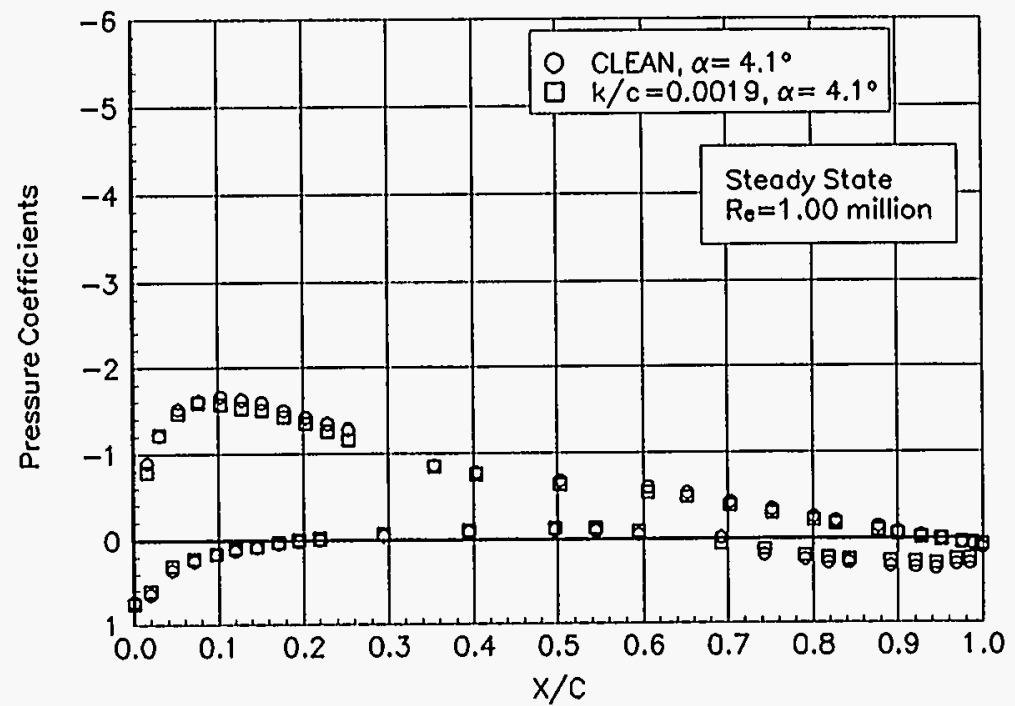

Figure B49. $a=4.1^{\circ}$

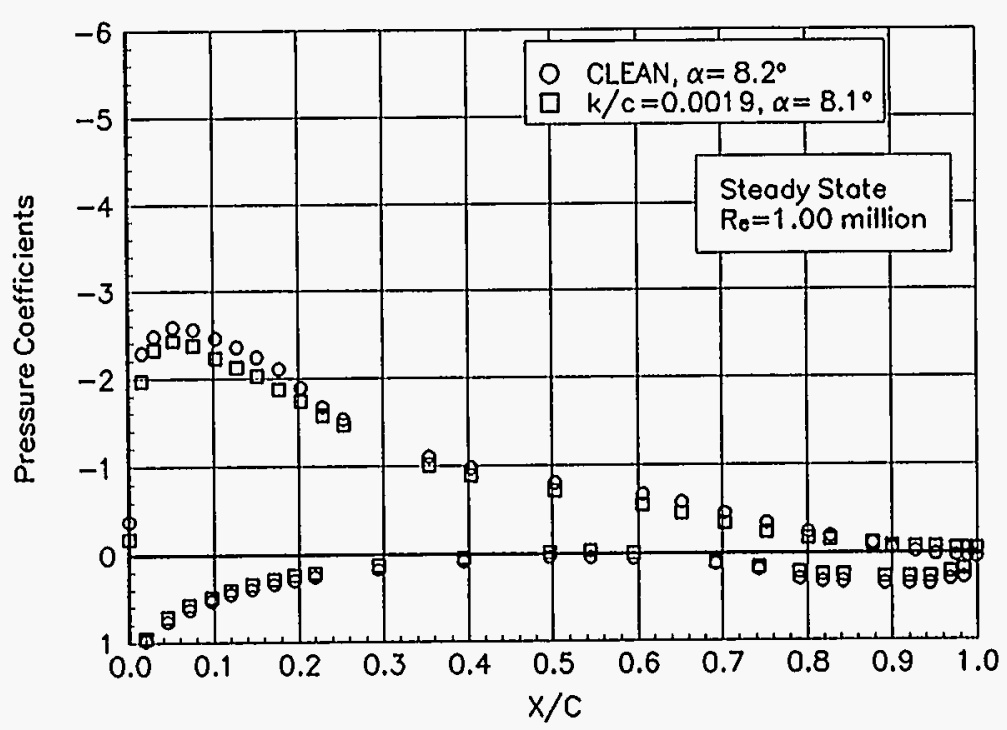

Figure B51. $a=8.2^{\circ}$

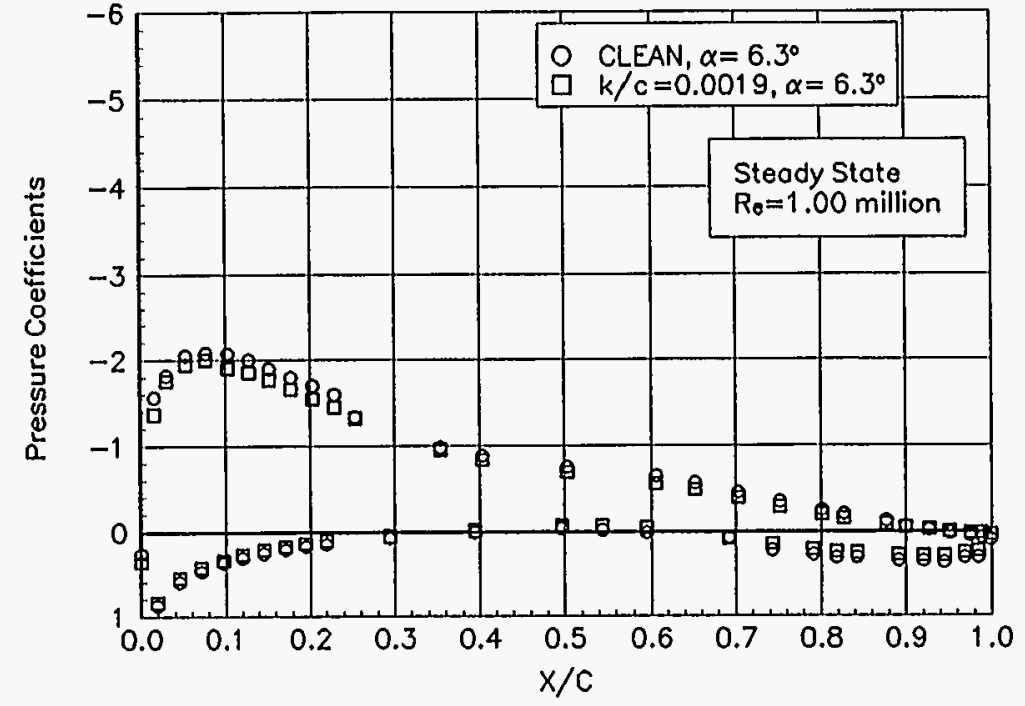

Figure B50. $a=6.3^{\circ}$

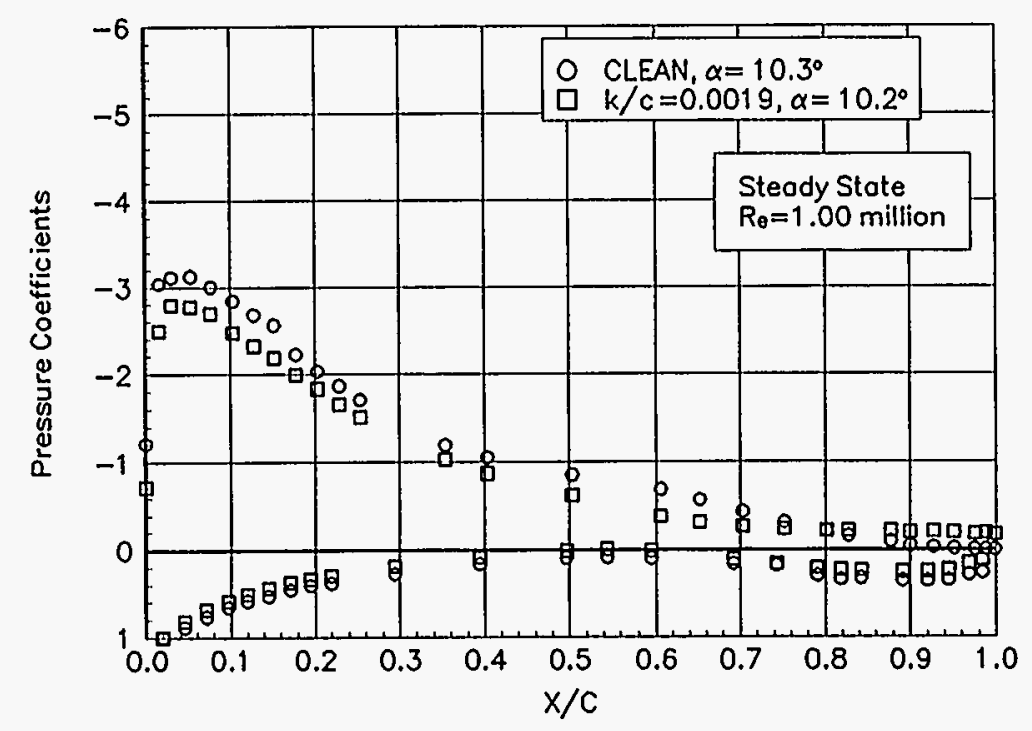

Figure B52. $a=10.3^{\circ}$ 


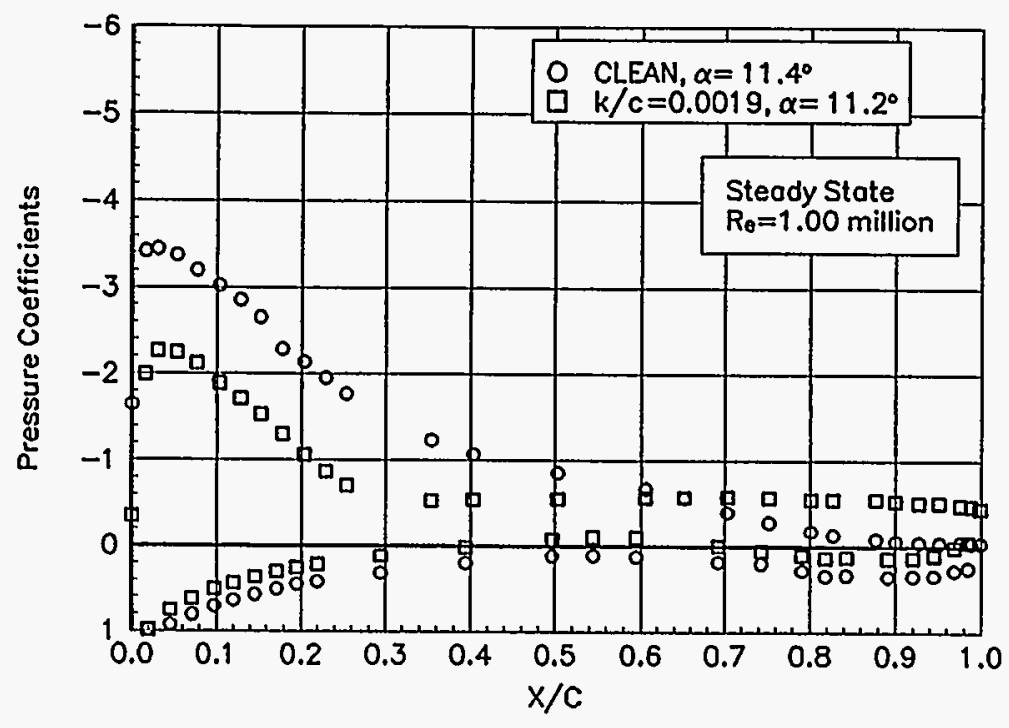

Figure B53. $a=11.4^{\circ}$

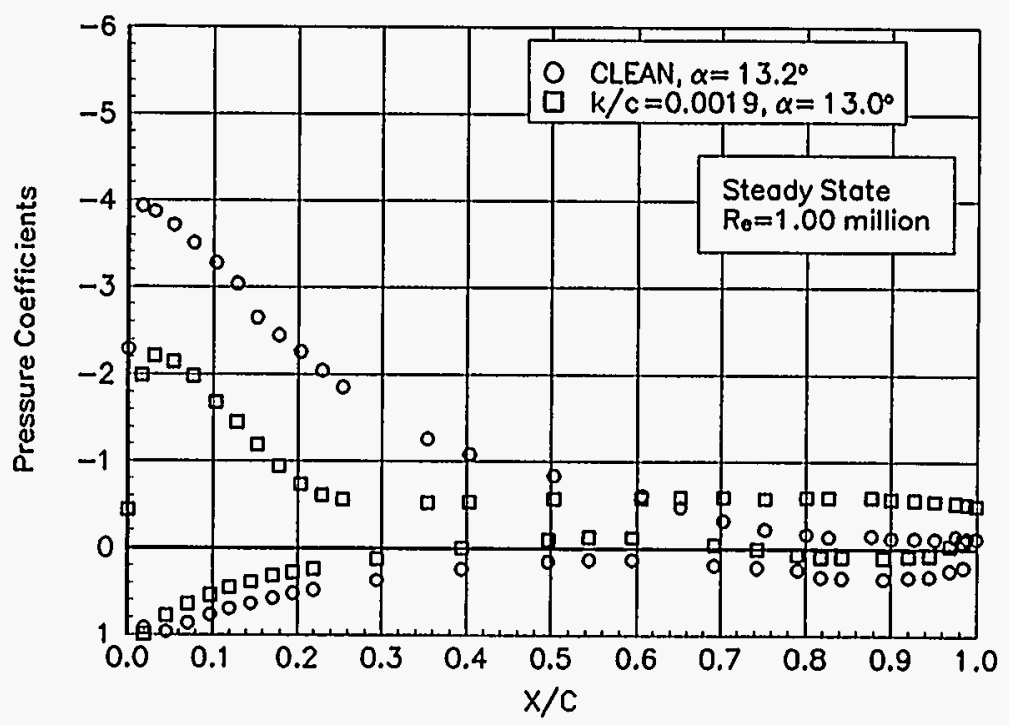

Figure B55. $a=13.2^{\circ}$

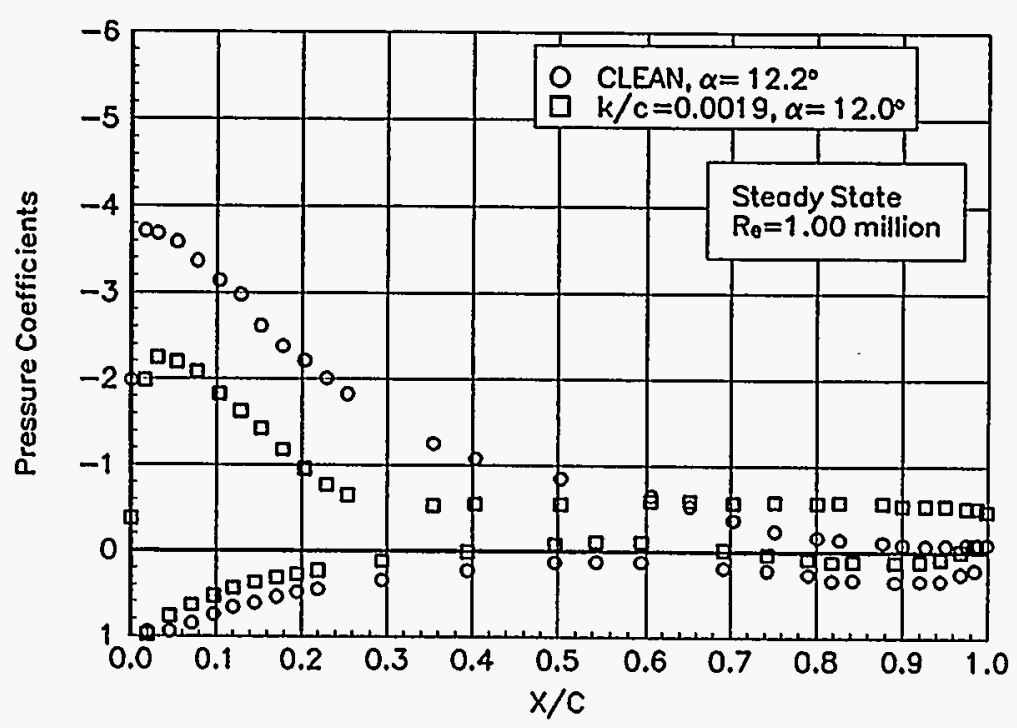

Figure B54. $a=12.2^{\circ}$

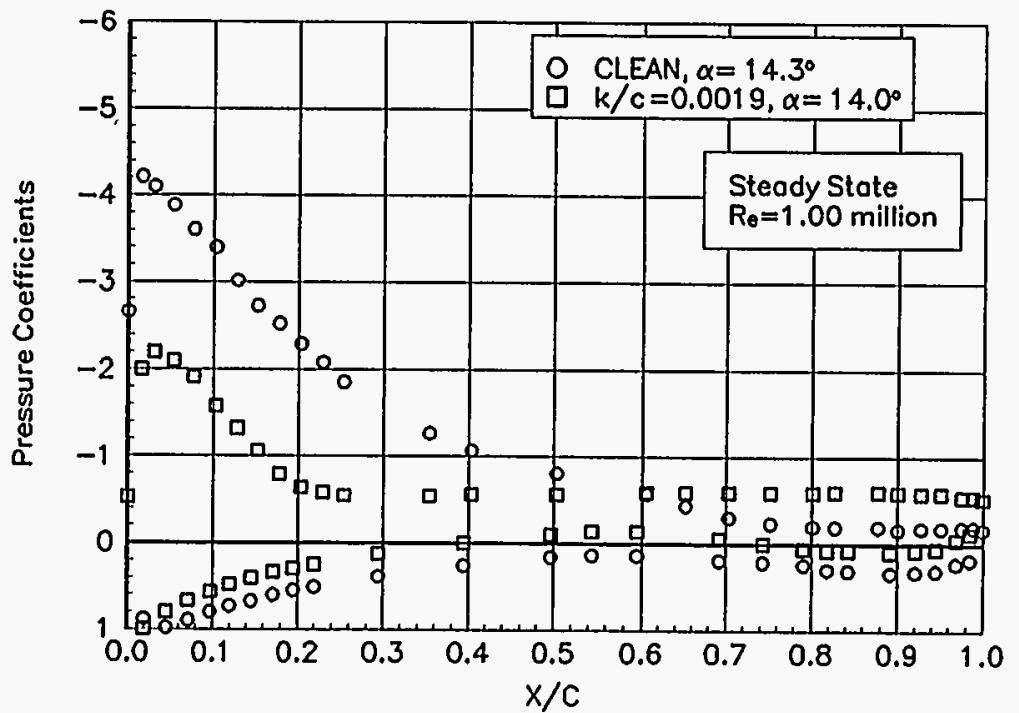

Figure B56. $a=14.3^{\circ}$ 


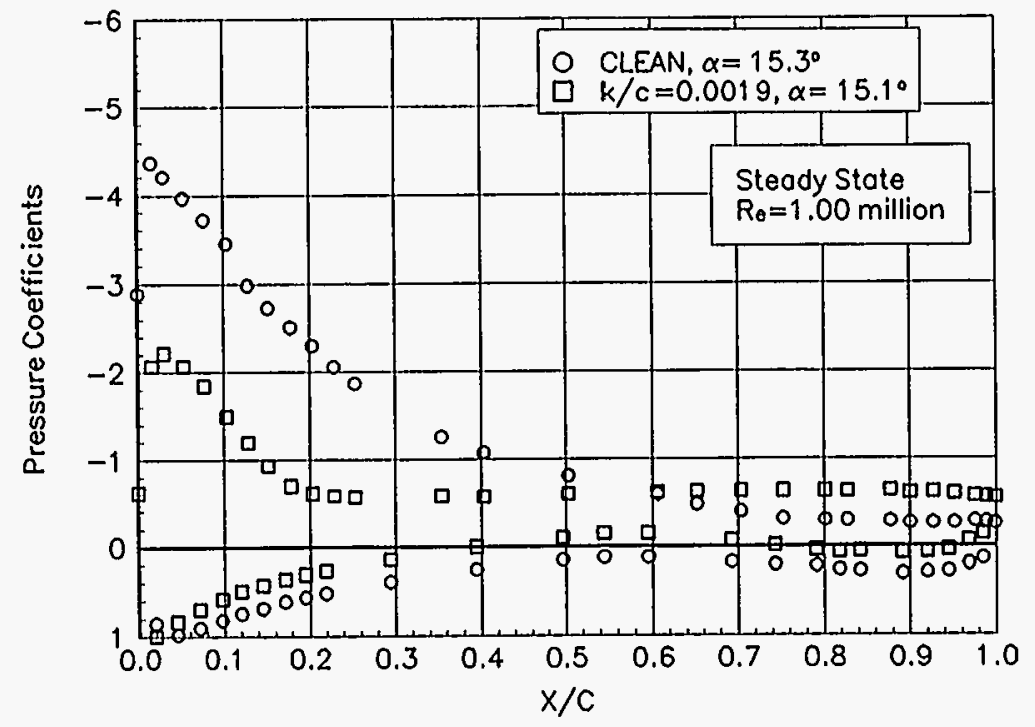

Figure B57. $a=15.3^{\circ}$

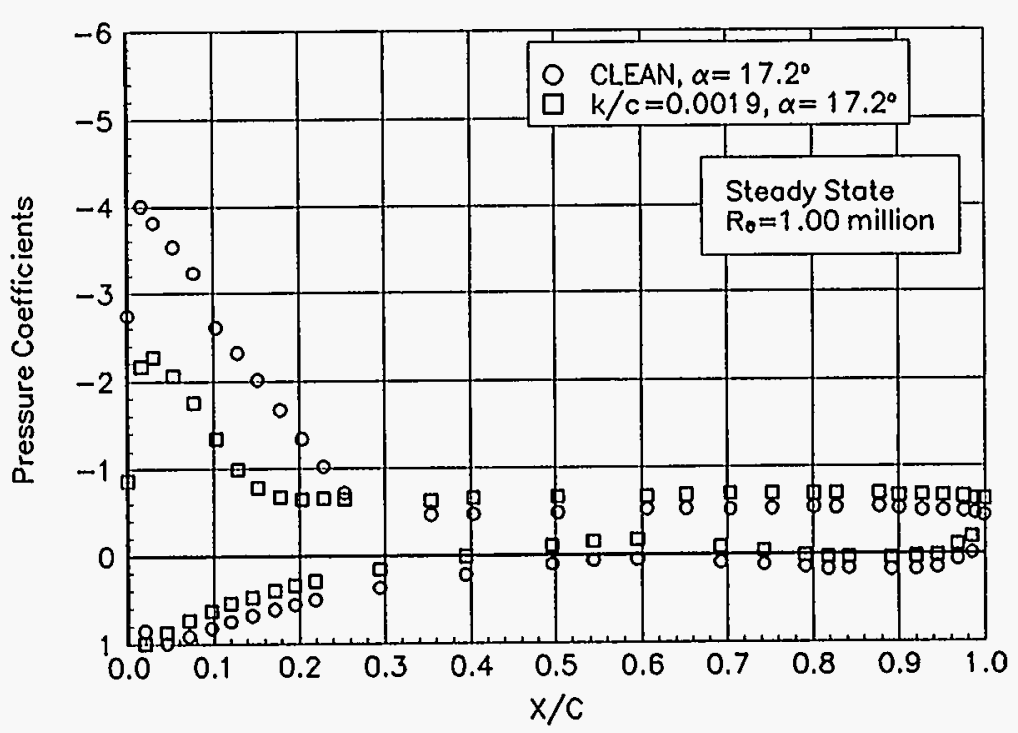

Figure B59. $a=17.2^{\circ}$

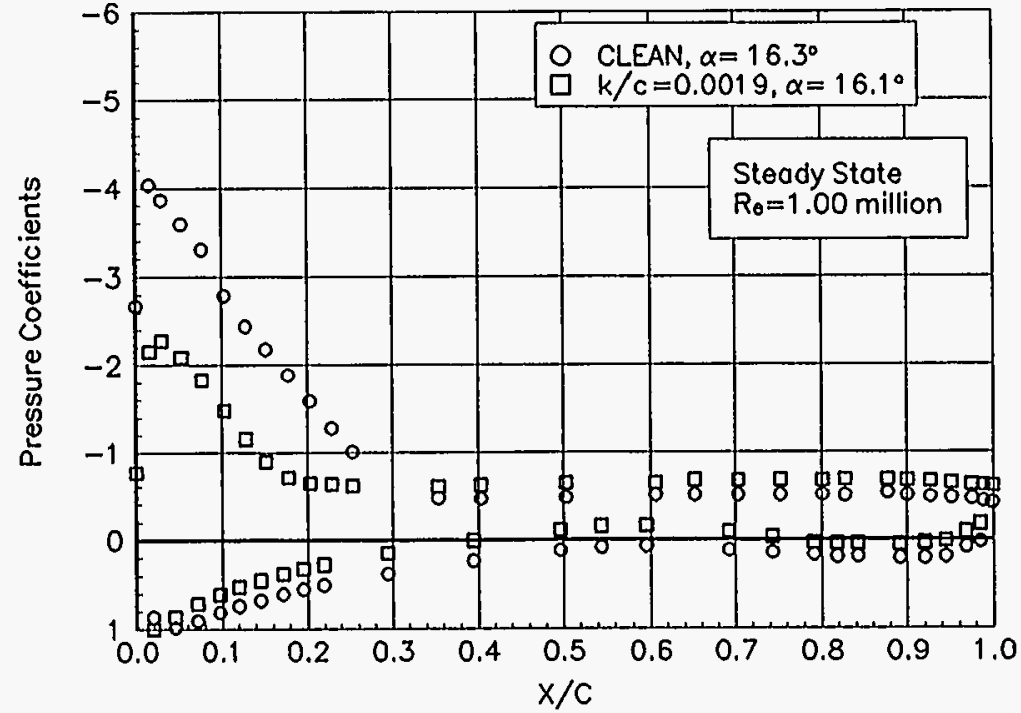

Figure B58. $a=16.3^{\circ}$

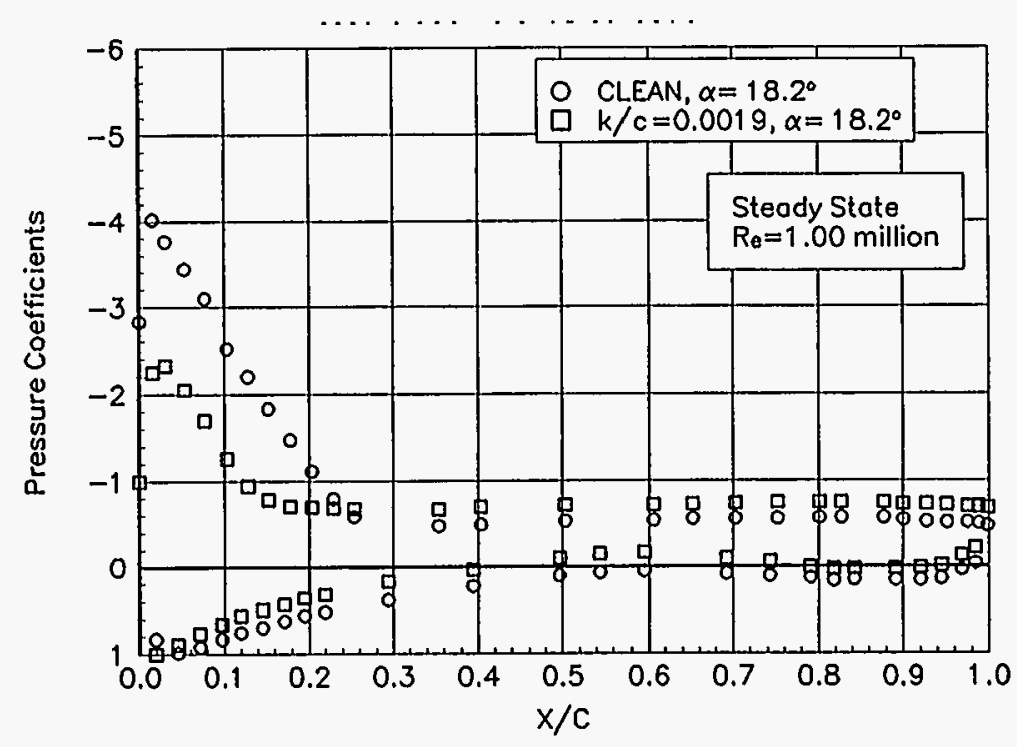

Figure B60. $a=18.2^{\circ}$ 


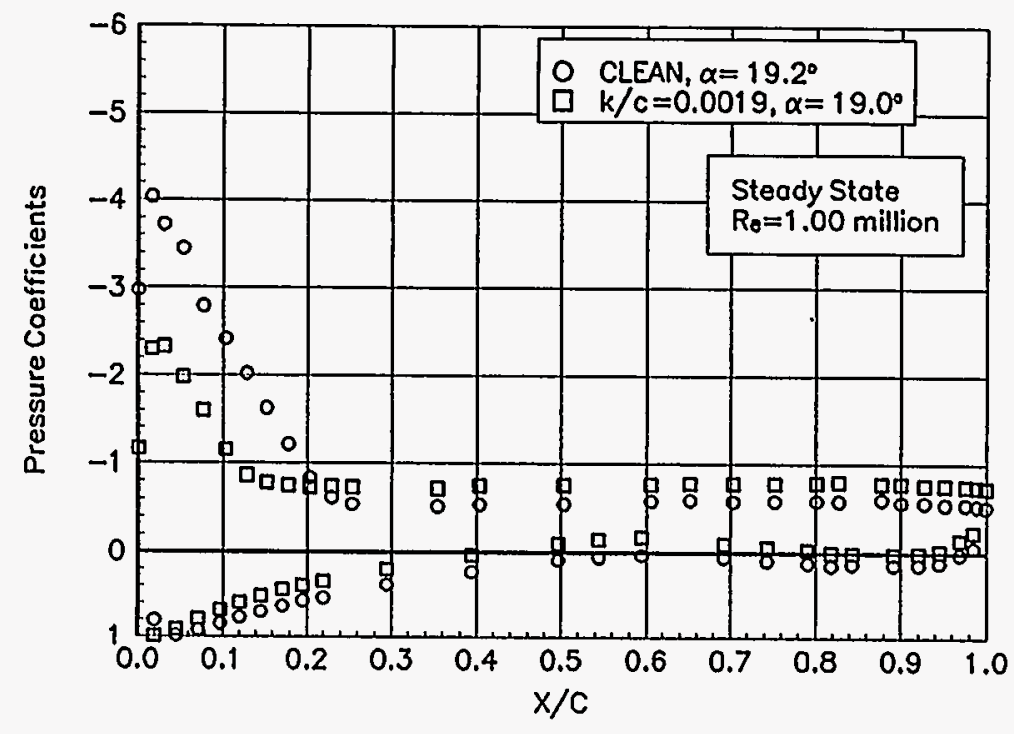

Figure B61. $a=19.2^{\circ}$

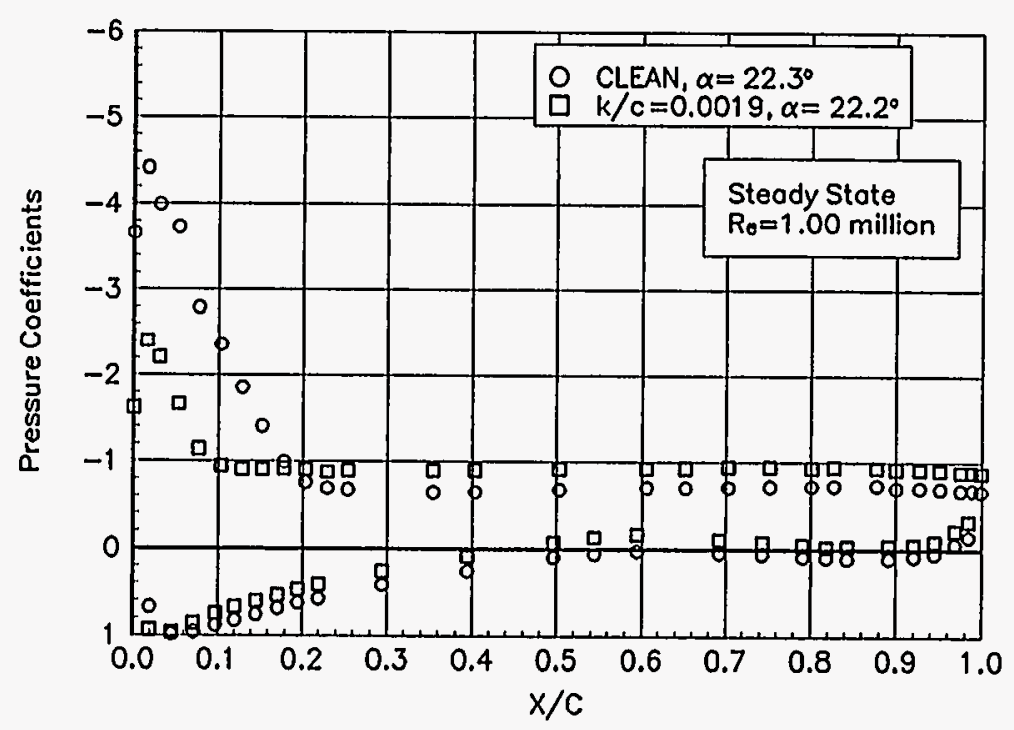

Figure B63. $a=22.3^{\circ}$

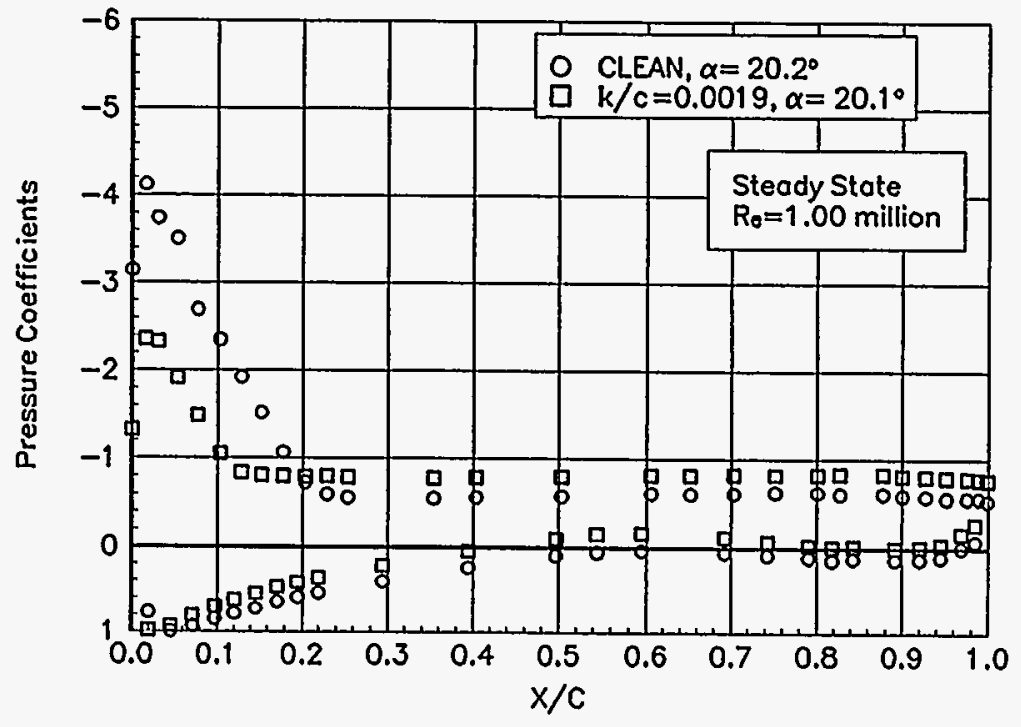

Figure B62. $a=20.2^{\circ}$

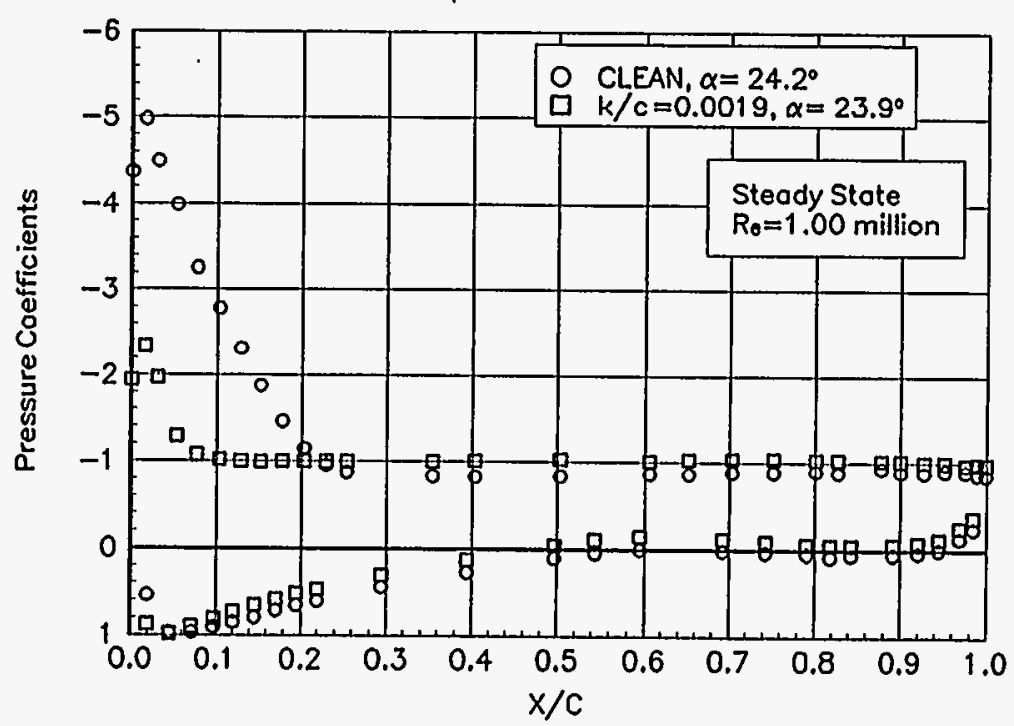

Figure B64. $a=24.2^{\circ}$ 


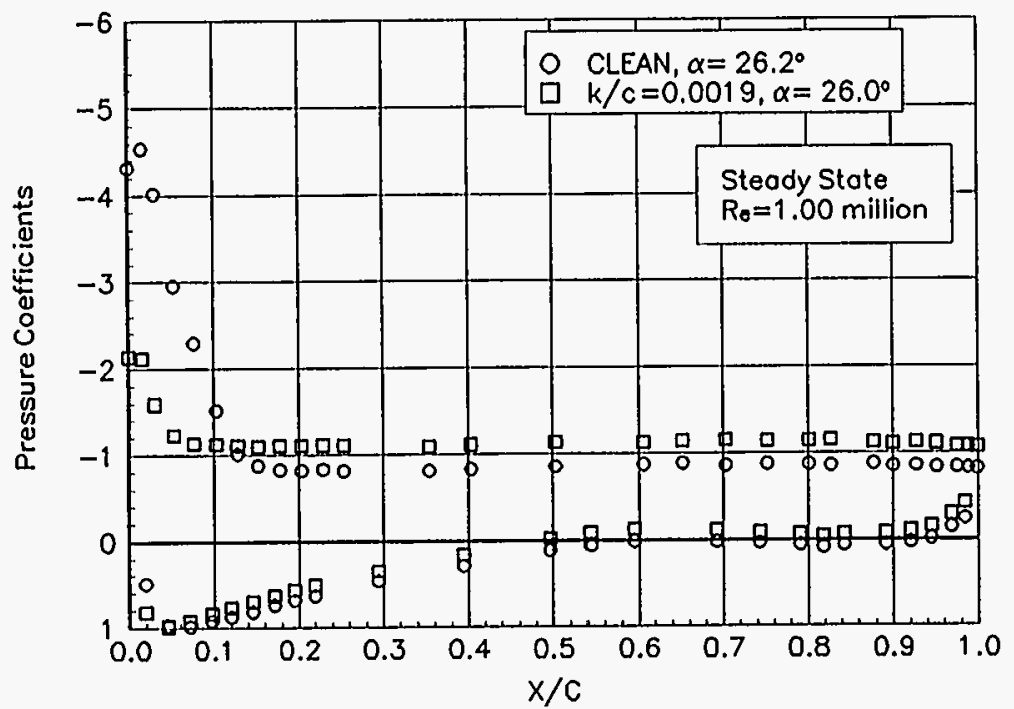

Figure B65. $a=26.2^{\circ}$

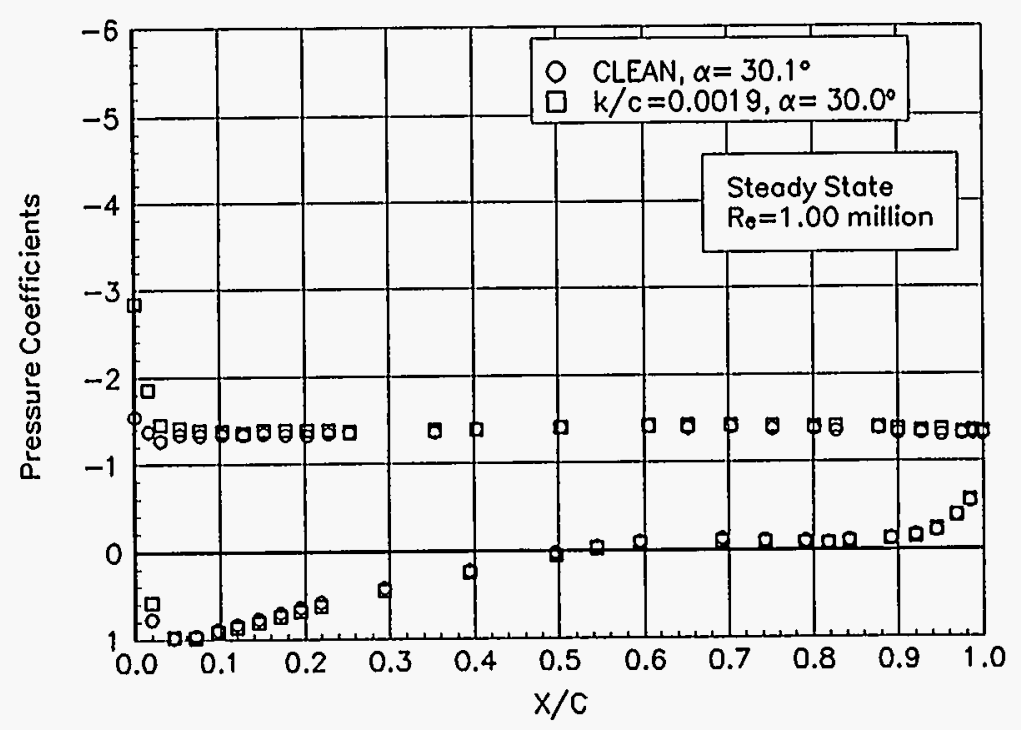

Figure B67. $a=30.1^{\circ}$

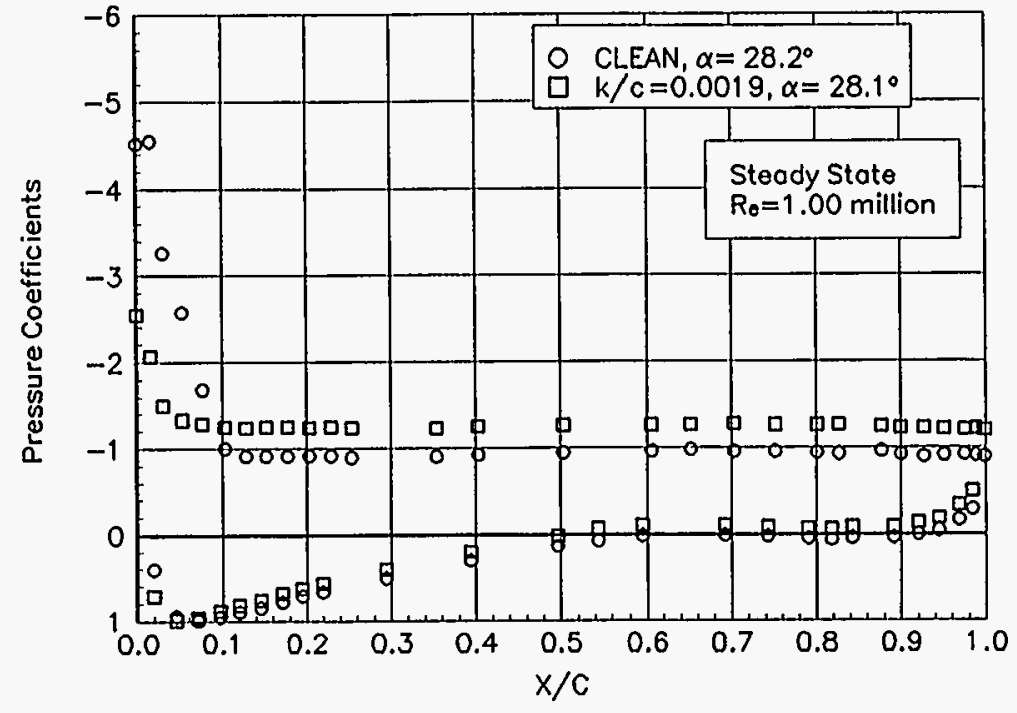

Figure B66. $a=28.2^{\circ}$

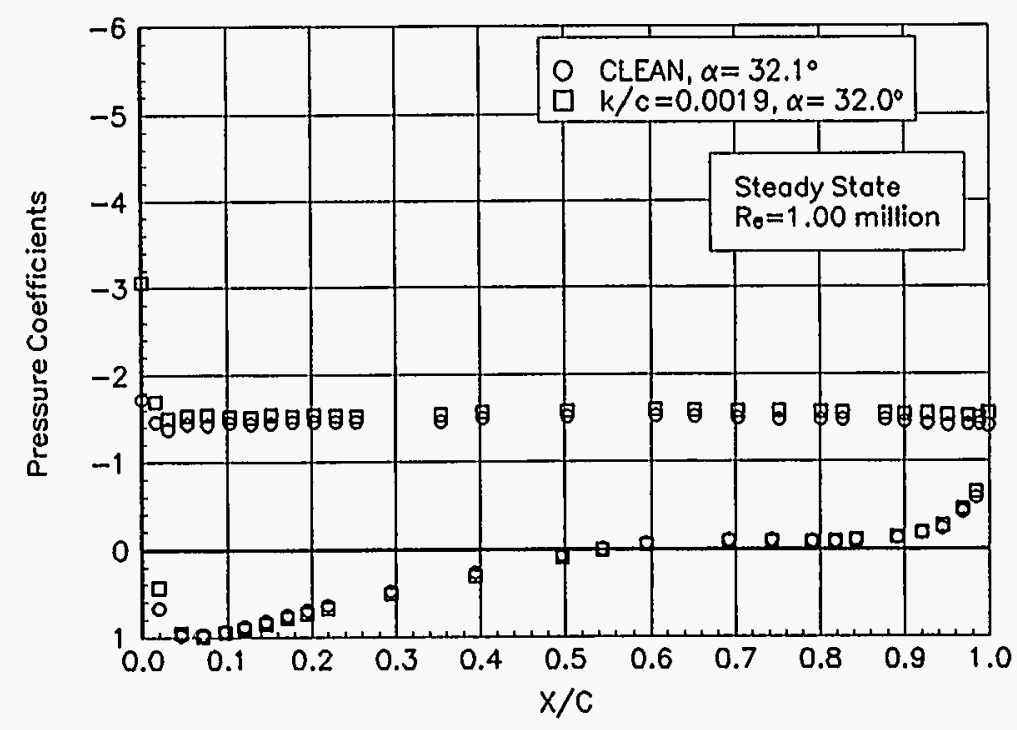

Figure B68. $a=32.1^{\circ}$ 
Pressure Coefficients

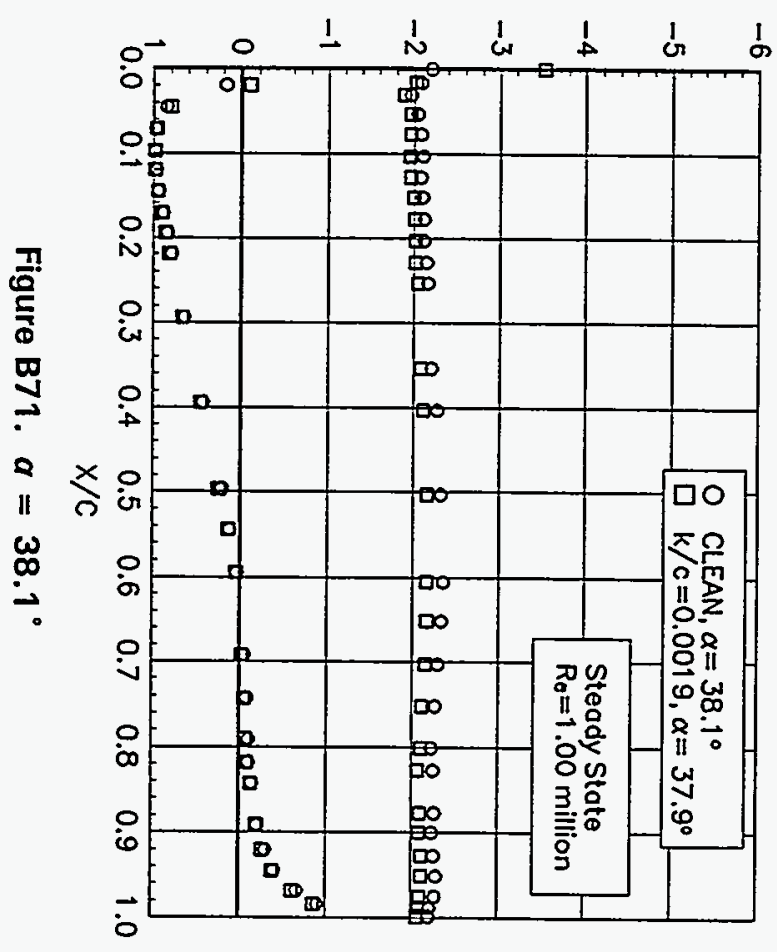

Pressure Coefficients

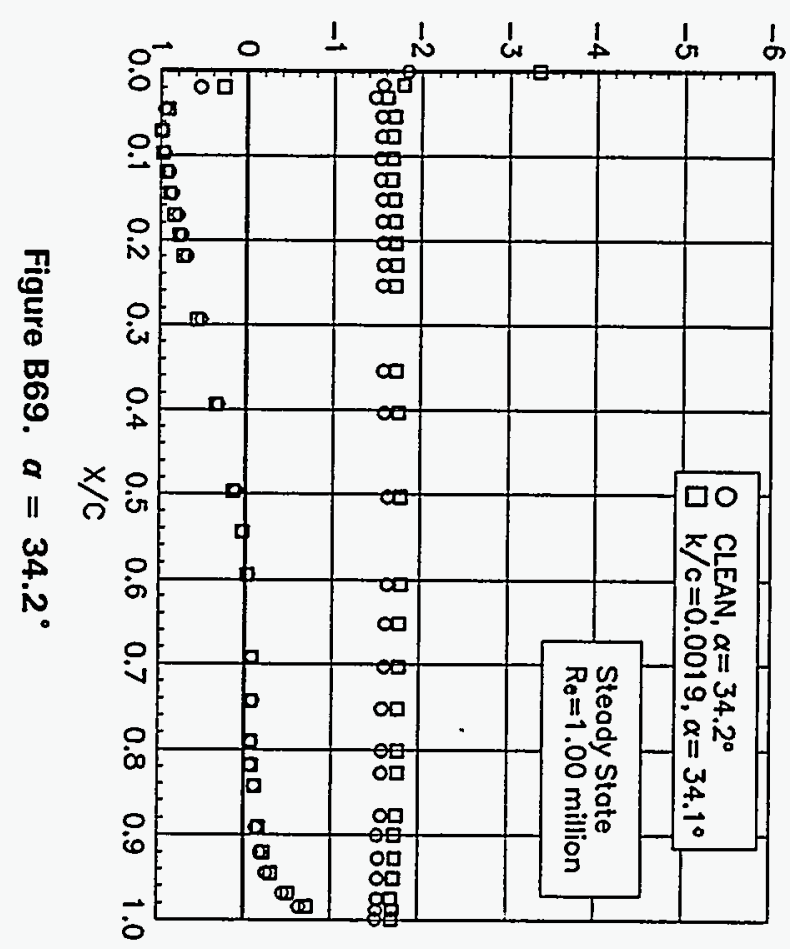

$\underset{\omega}{\omega}$
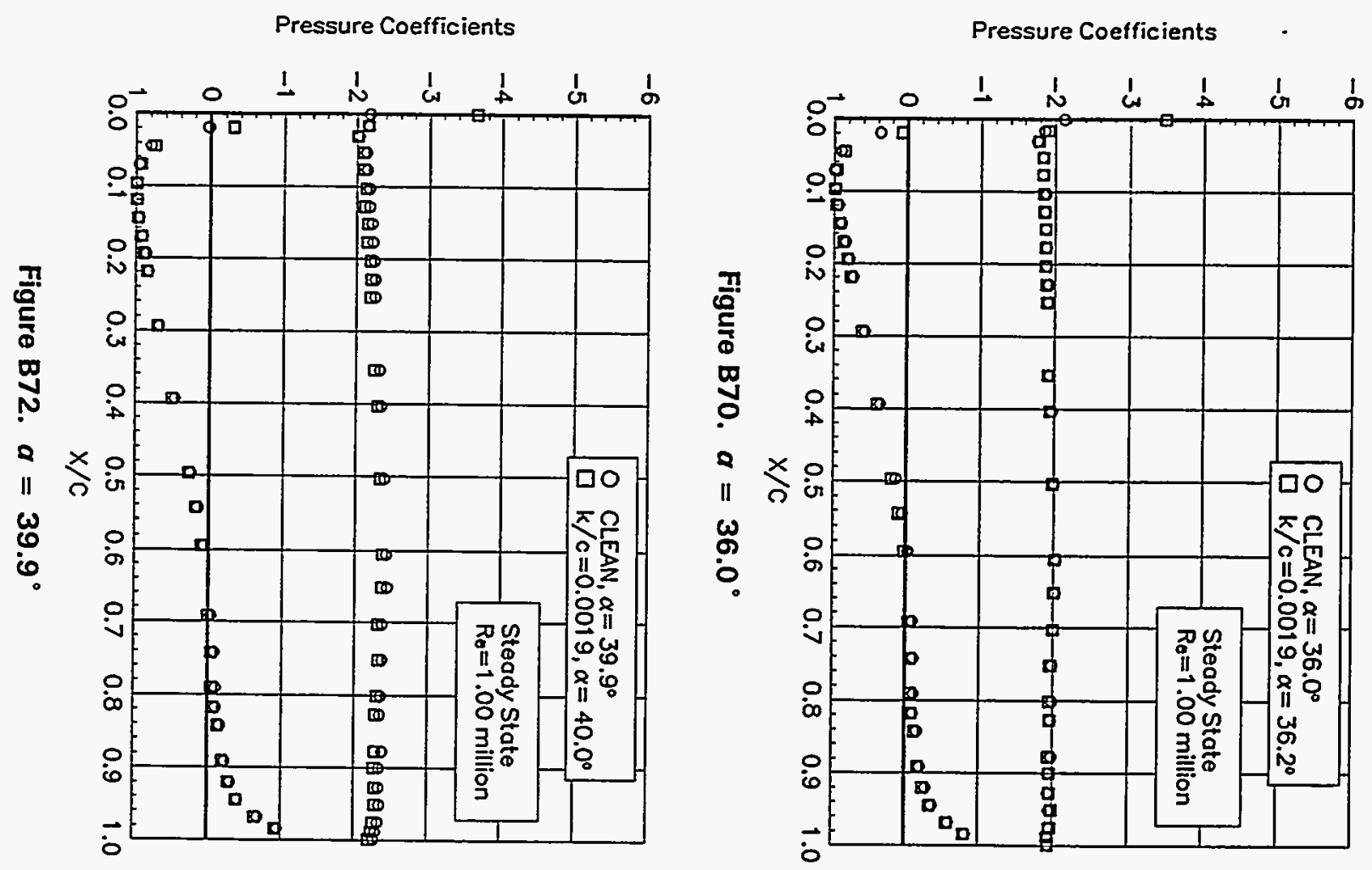


\section{Steady State \\ Pressure Distributions LS(1)-0417MOD}

$$
\operatorname{Re}=1.25 \text { million }
$$




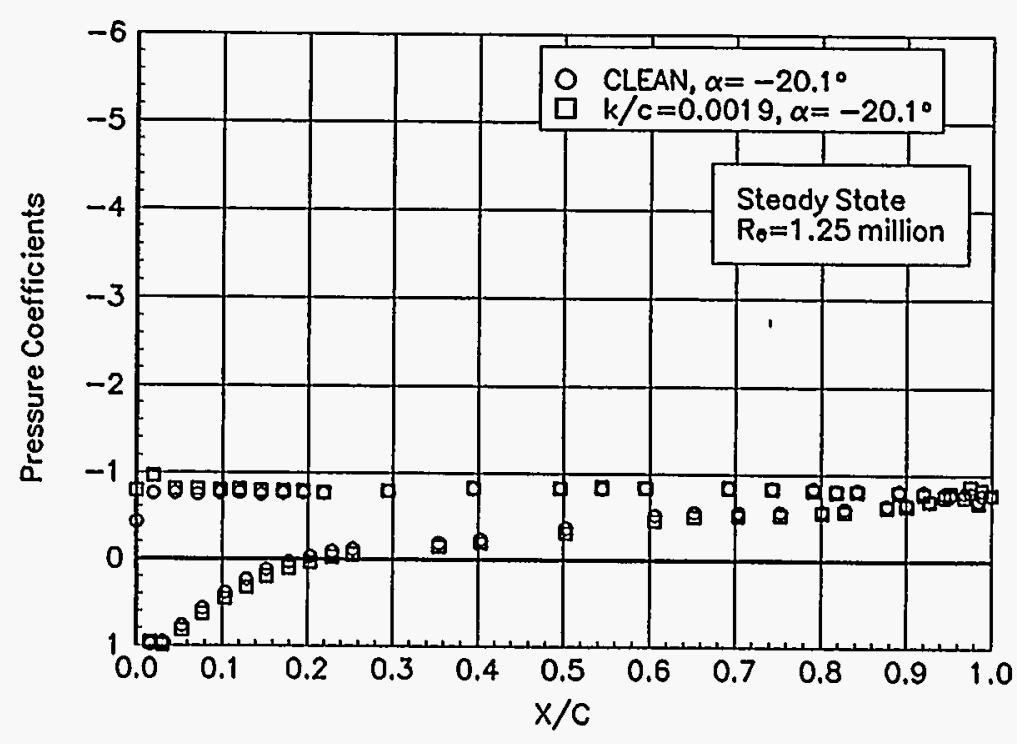

Figure B73. $a=-20.1^{\circ}$

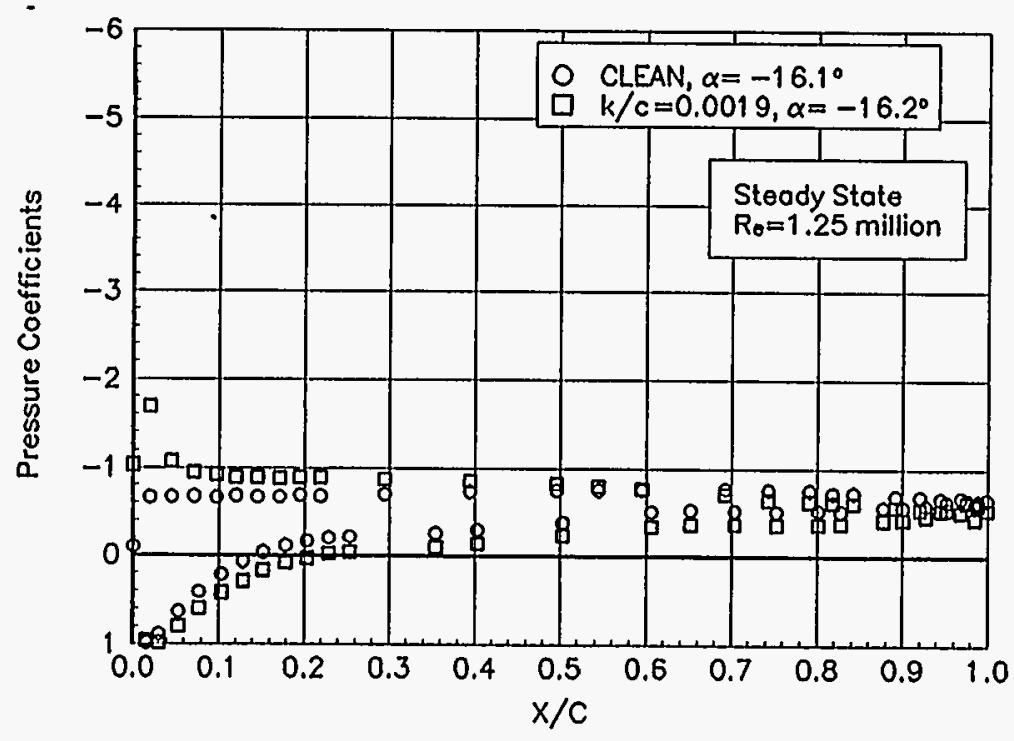

Figure B75. $a=-16.1^{\circ}$

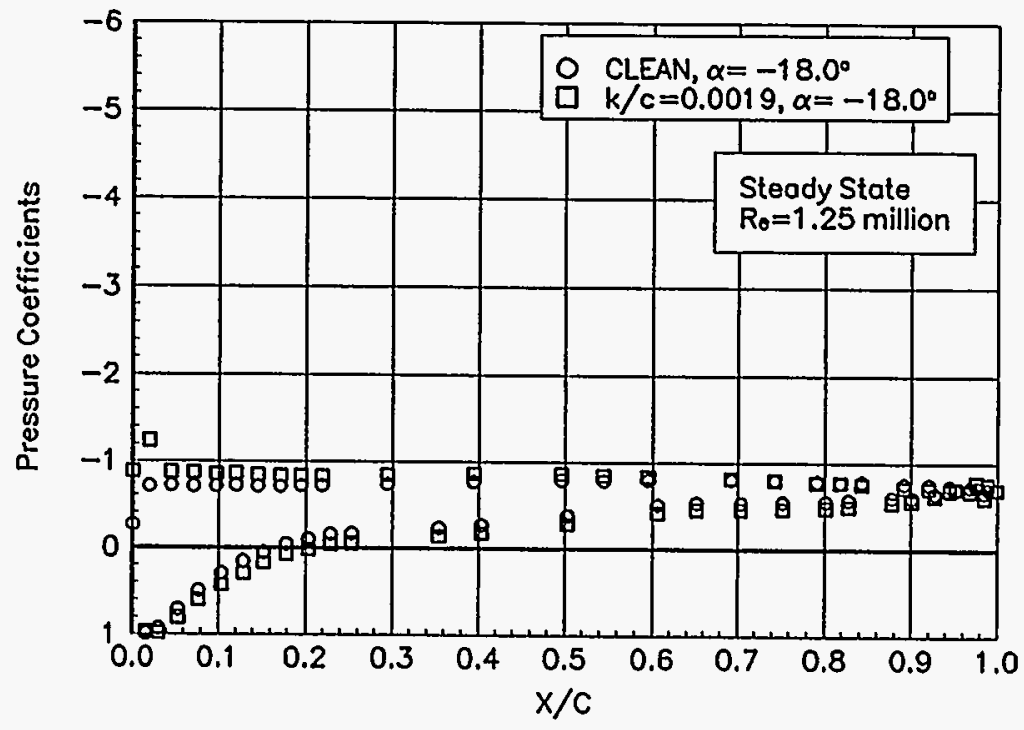

Figure B74. $a=-18.0^{\circ}$

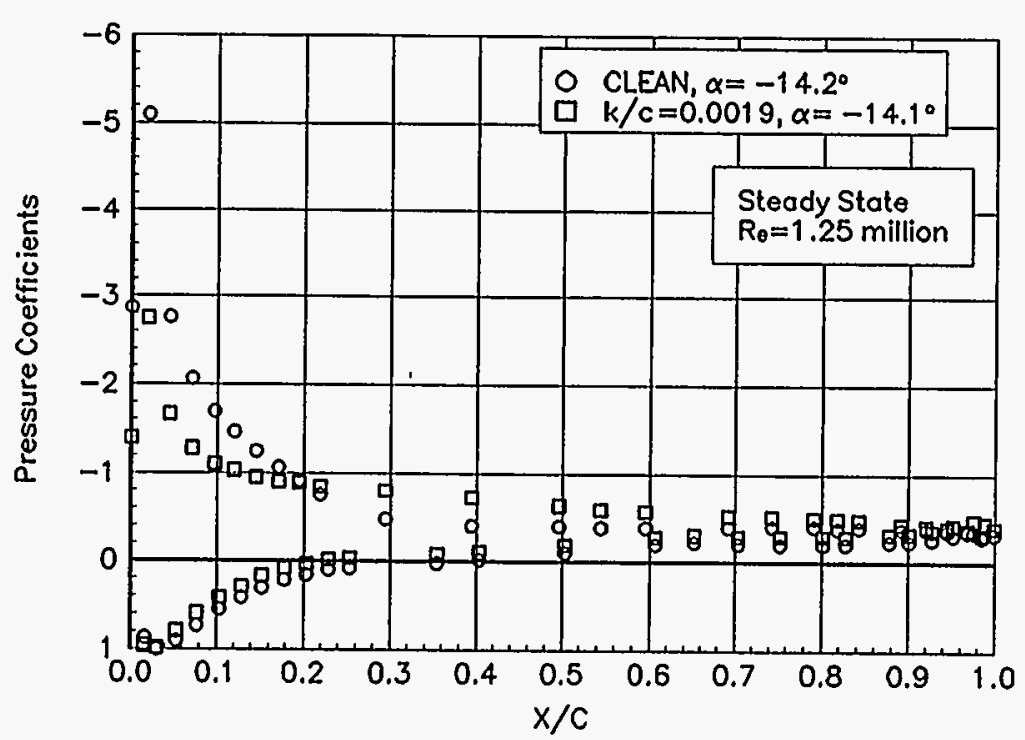

Figure B76. $a=-14.2^{\circ}$ 

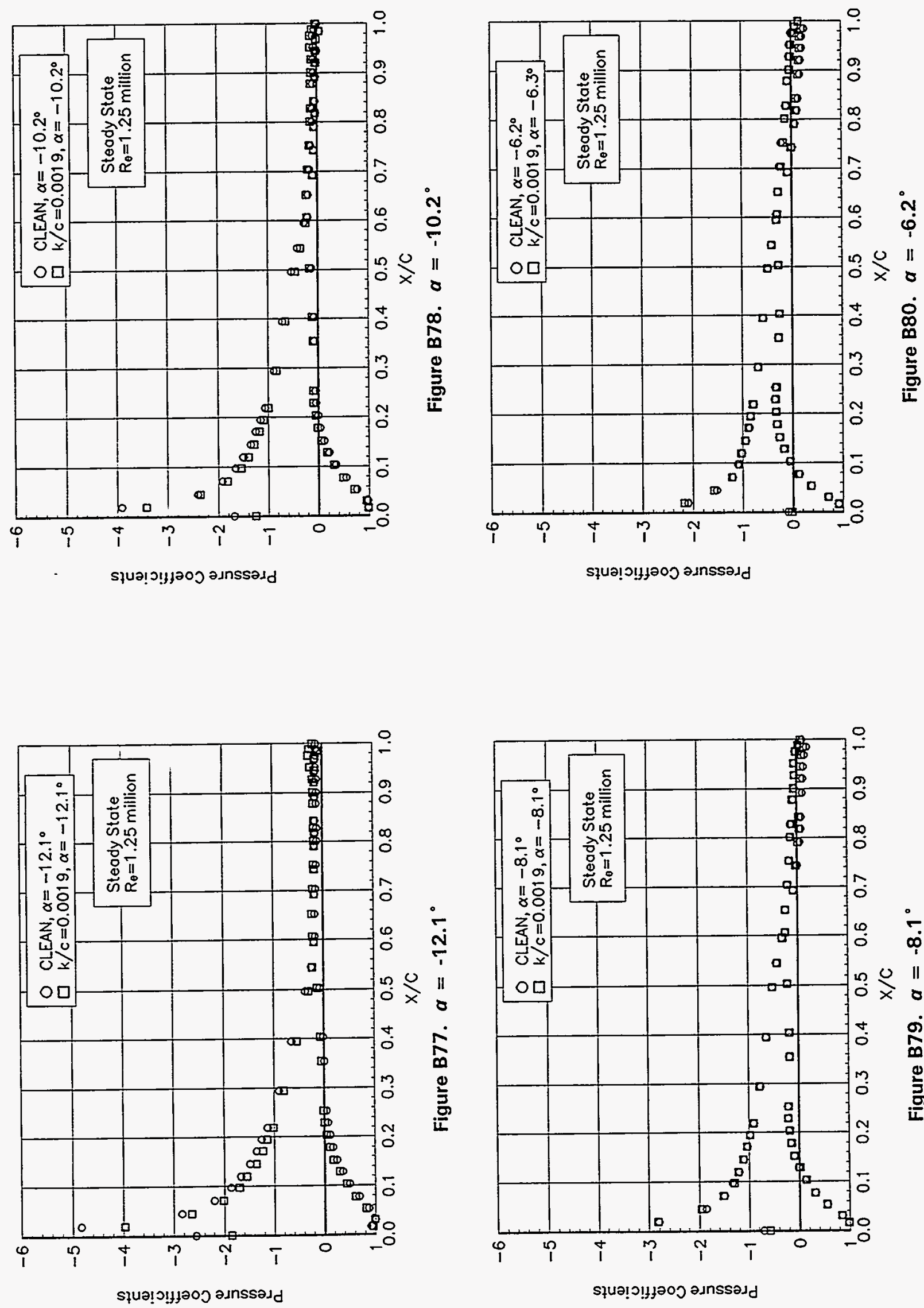

番 


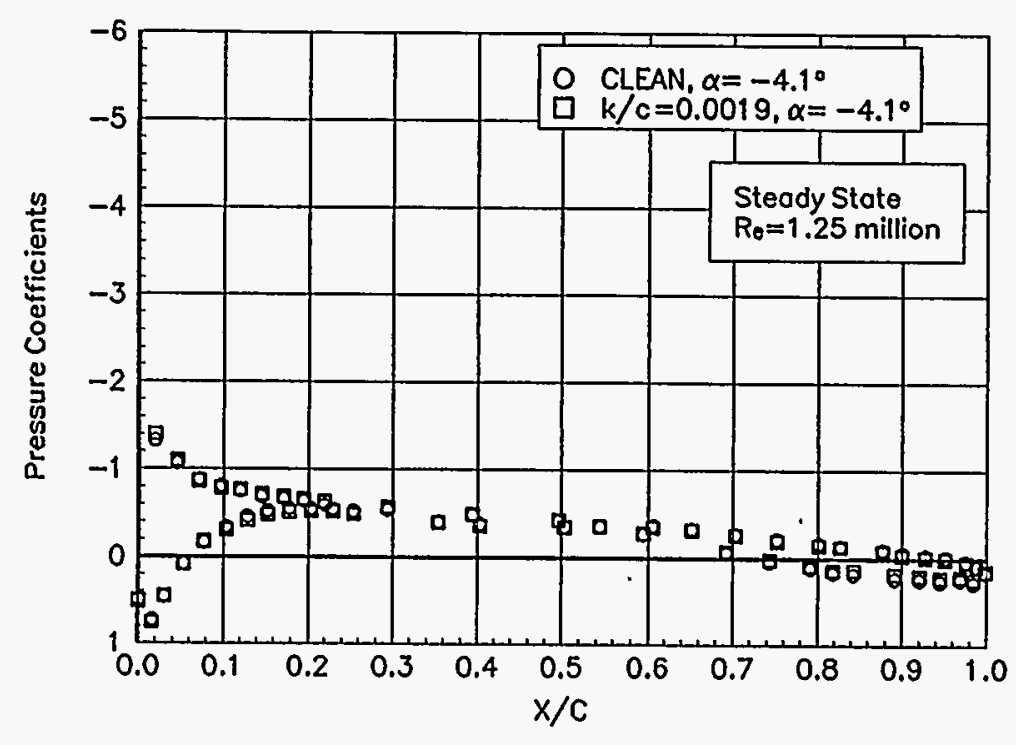

Figure B81. $a=-4.1^{\circ}$

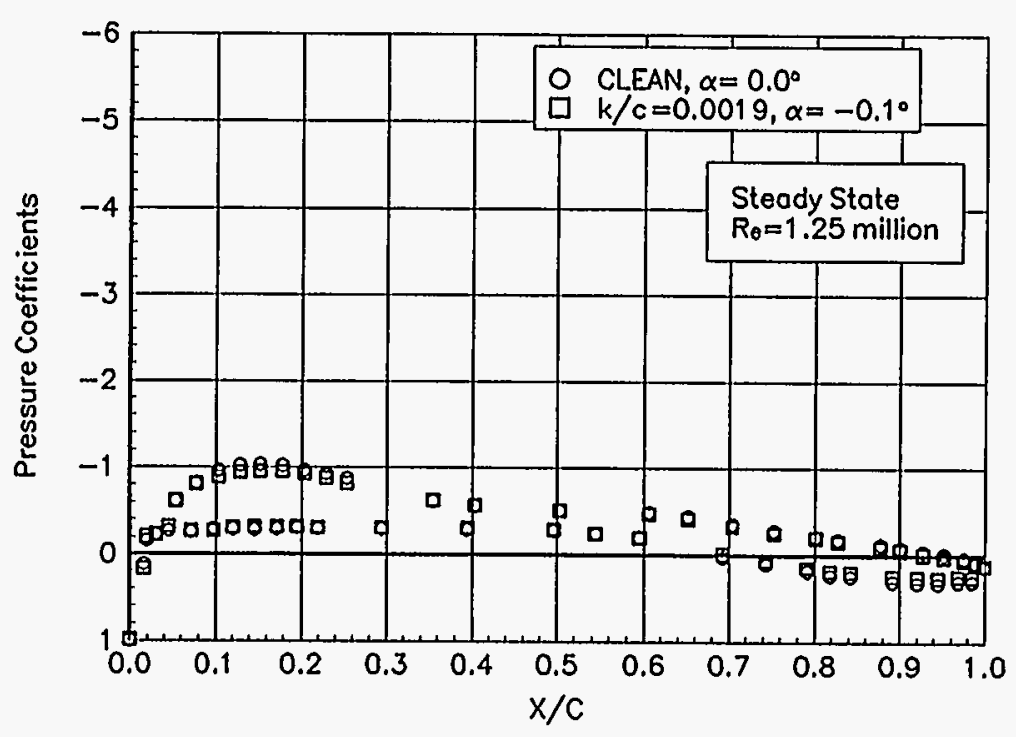

Figure B83. $a=0.0^{\circ}$

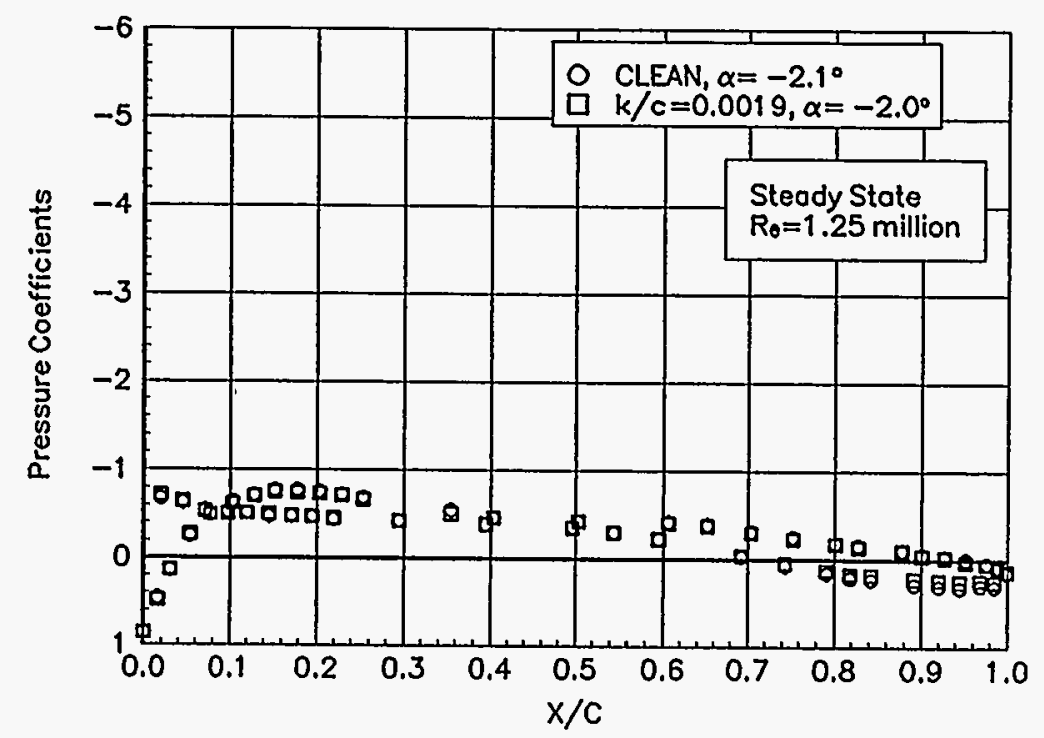

Figure B82. $a=-2.1^{\circ}$

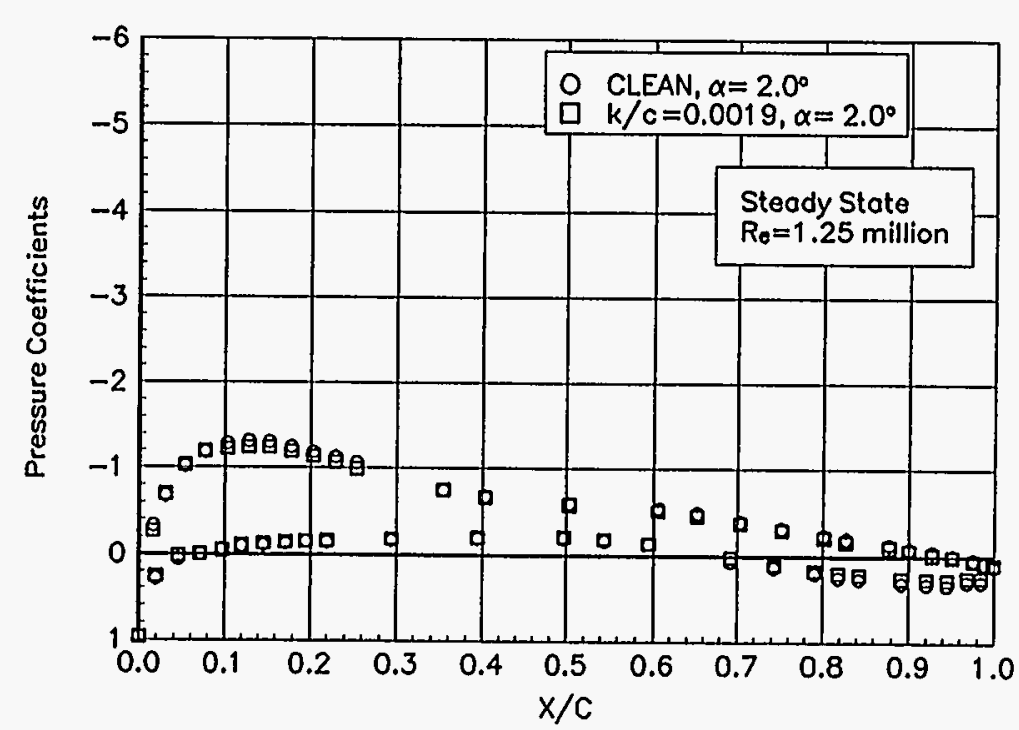

Figure B84. $a=2.0^{\circ}$ 


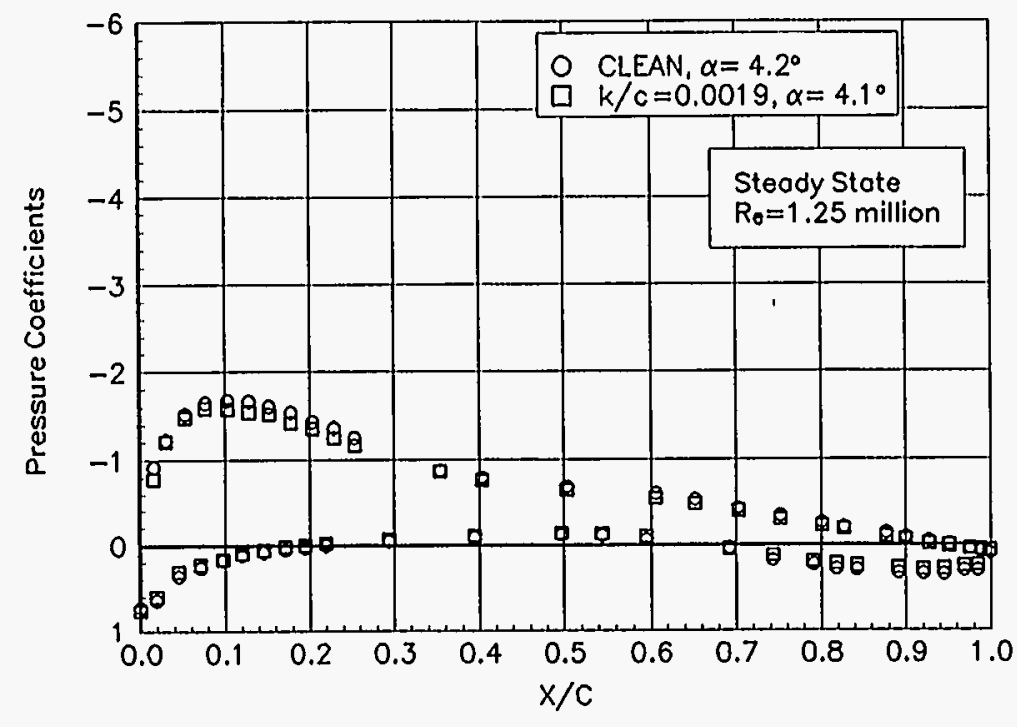

Figure B85. $\alpha=4.2^{\circ}$

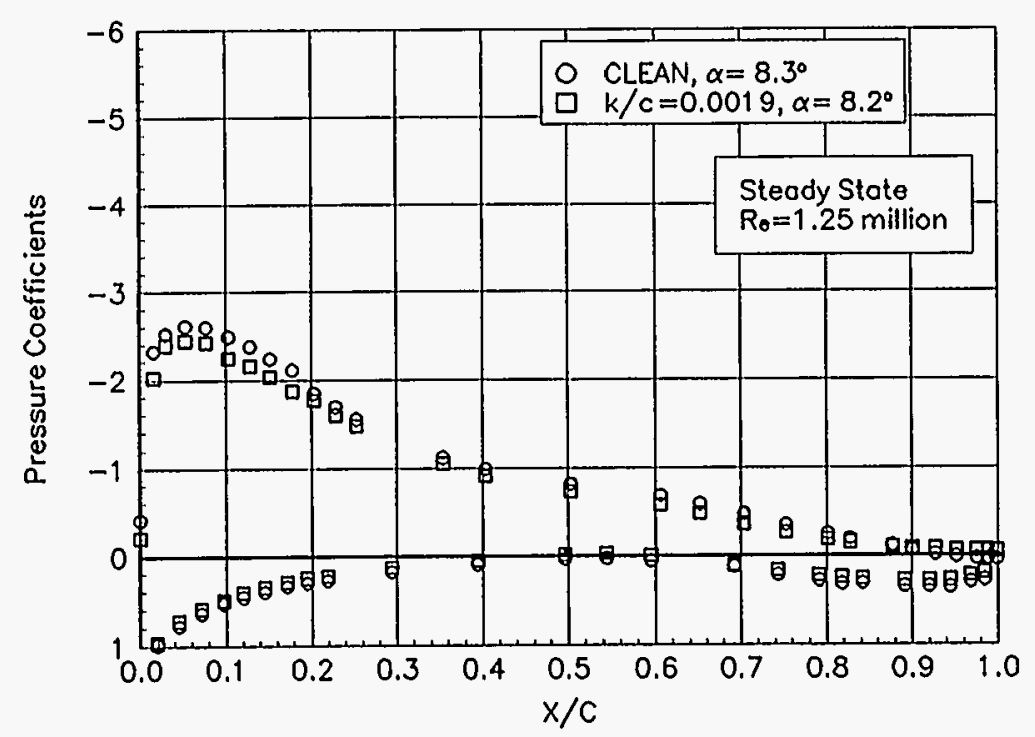

Figure B87. $a=8.3^{\circ}$

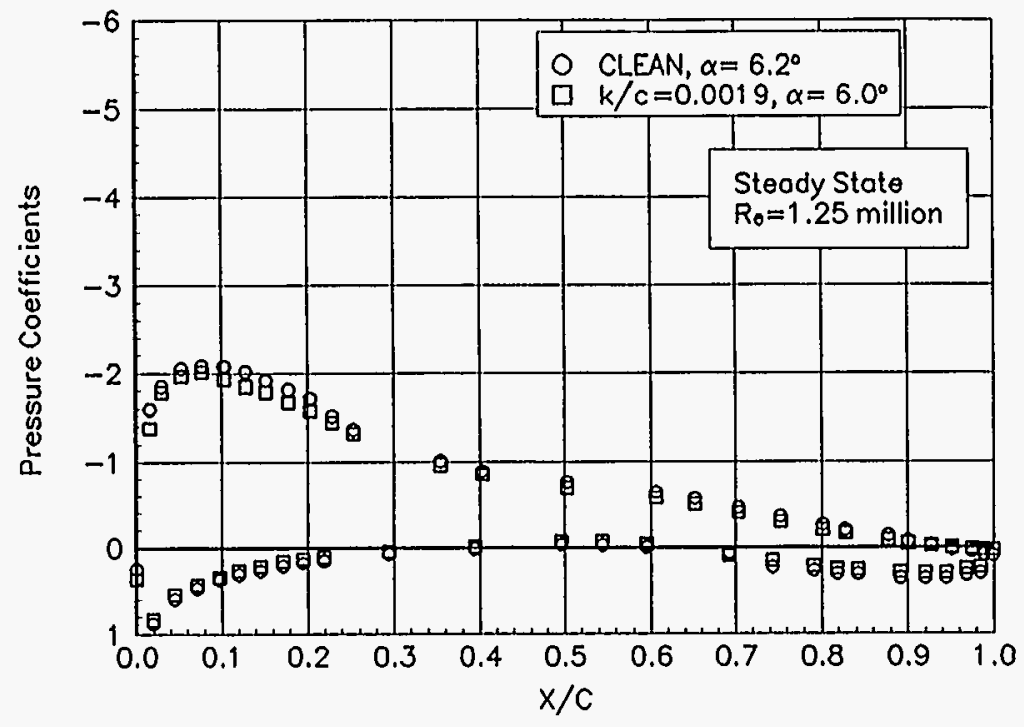

Figure B86. $a=6.2^{\circ}$

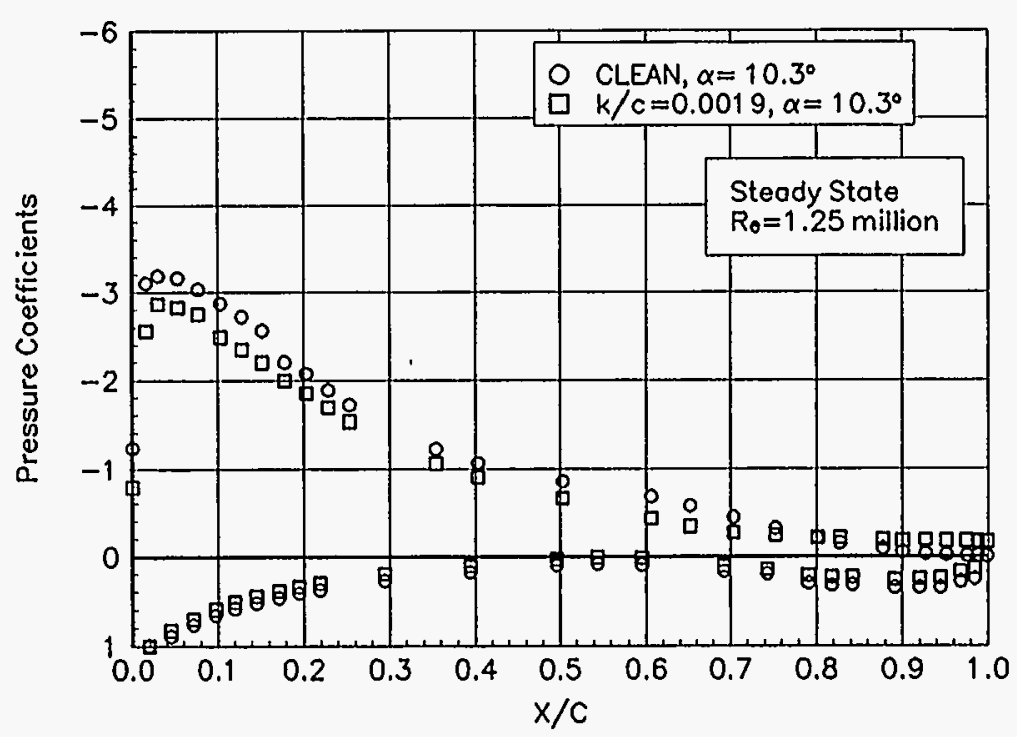

Figure B88. $a=10.3^{\circ}$ 


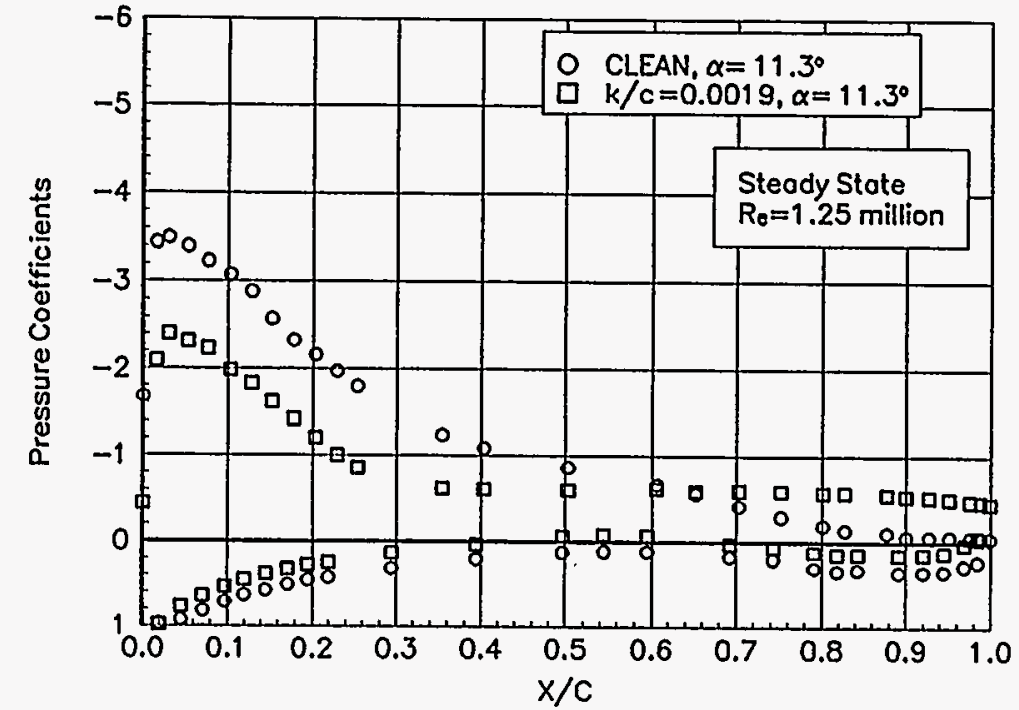

Figure B89, $a=11.3^{\circ}$

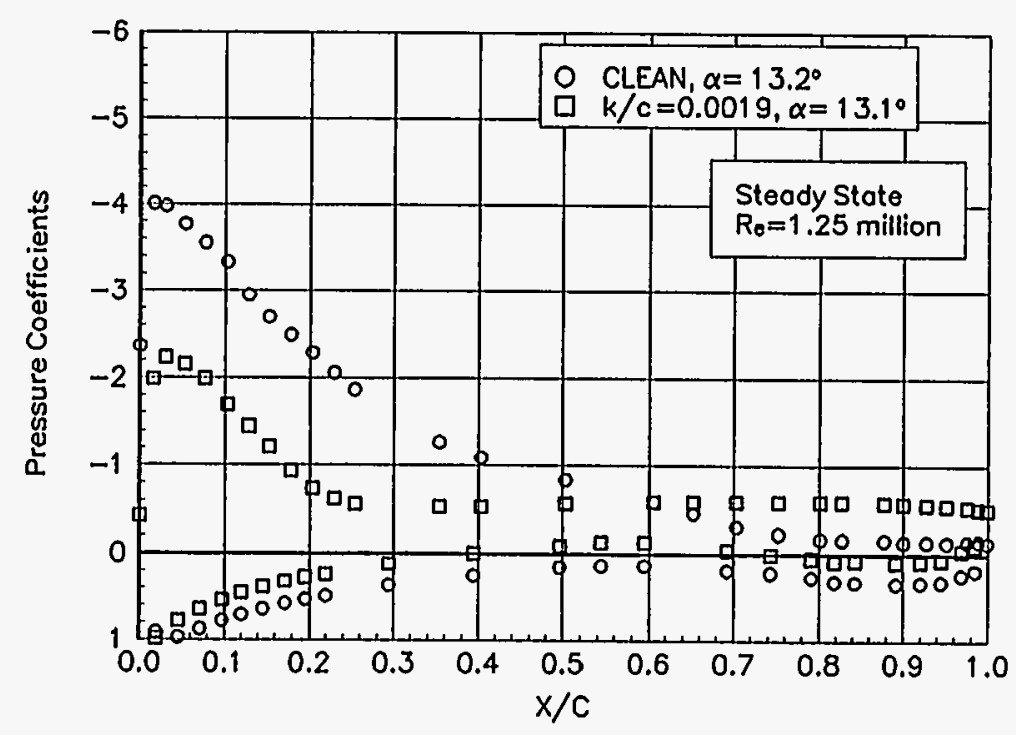

Figure B91. $a=13.2^{\circ}$

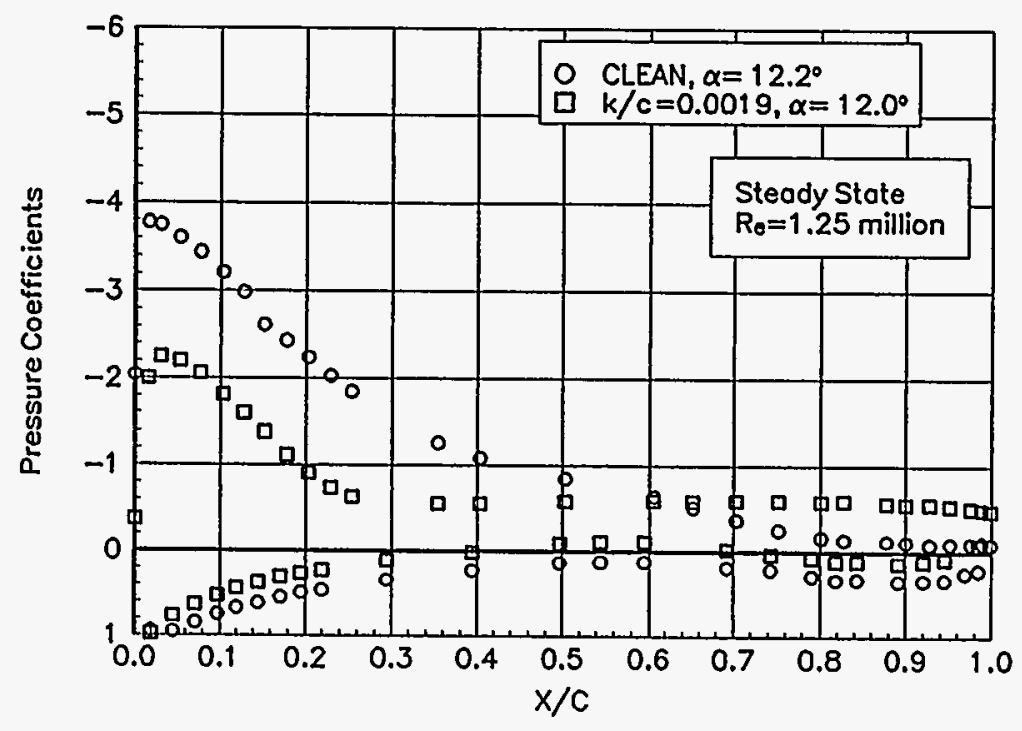

Figure B90. $a=12.2^{\circ}$

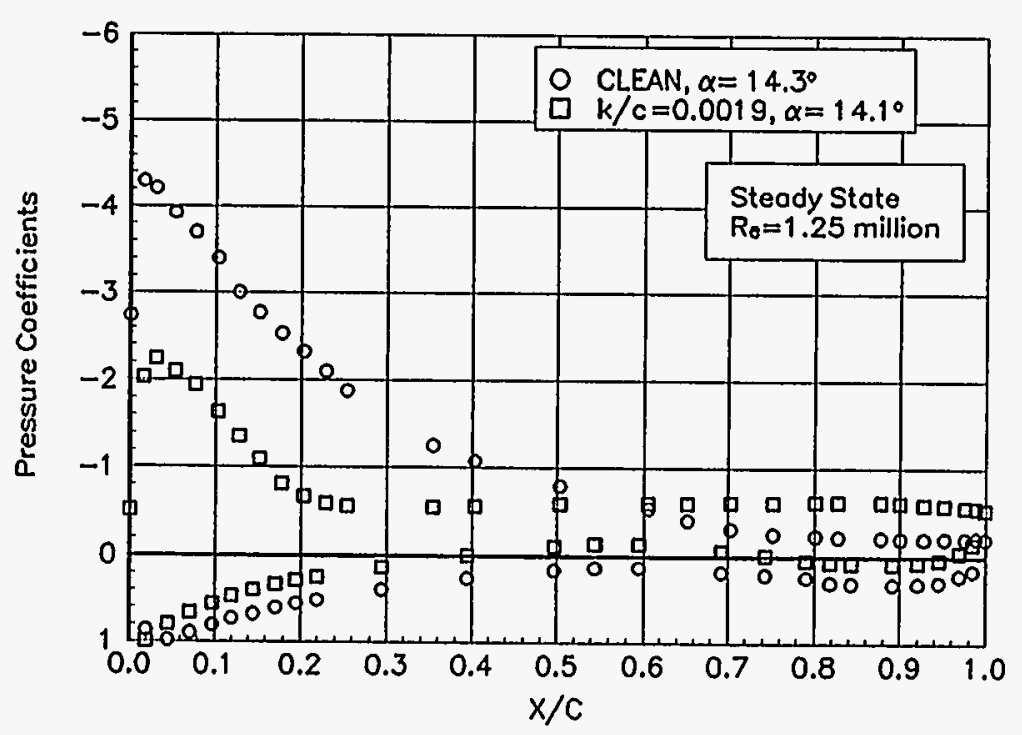

Figure B92. $a=14.3^{\circ}$ 


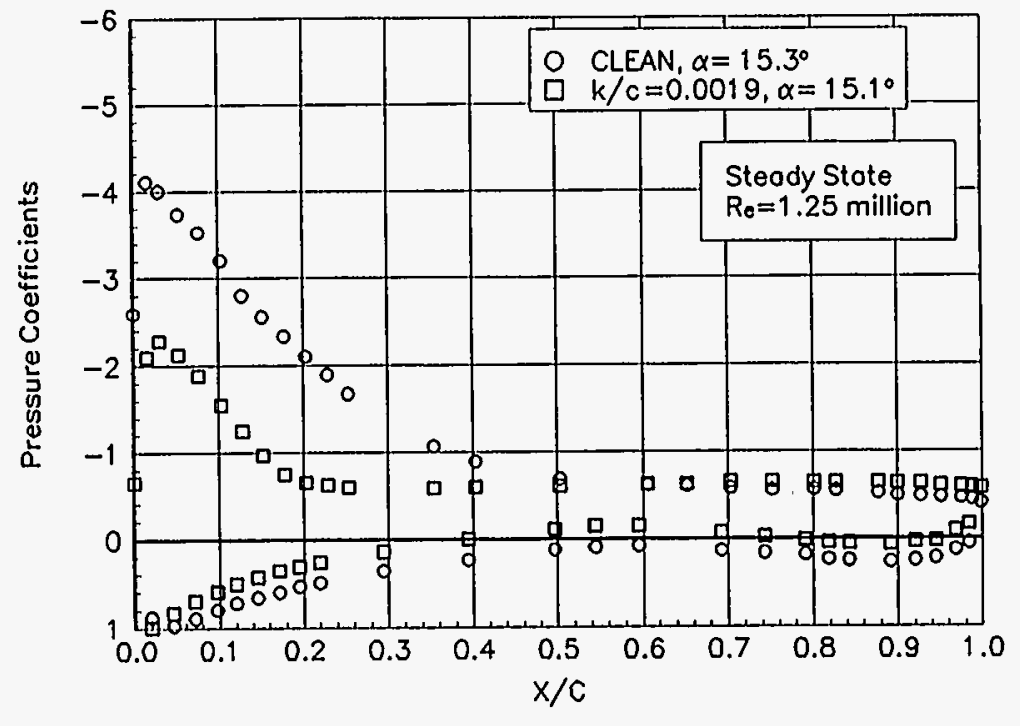

Figure B93. $a=15.3^{\circ}$

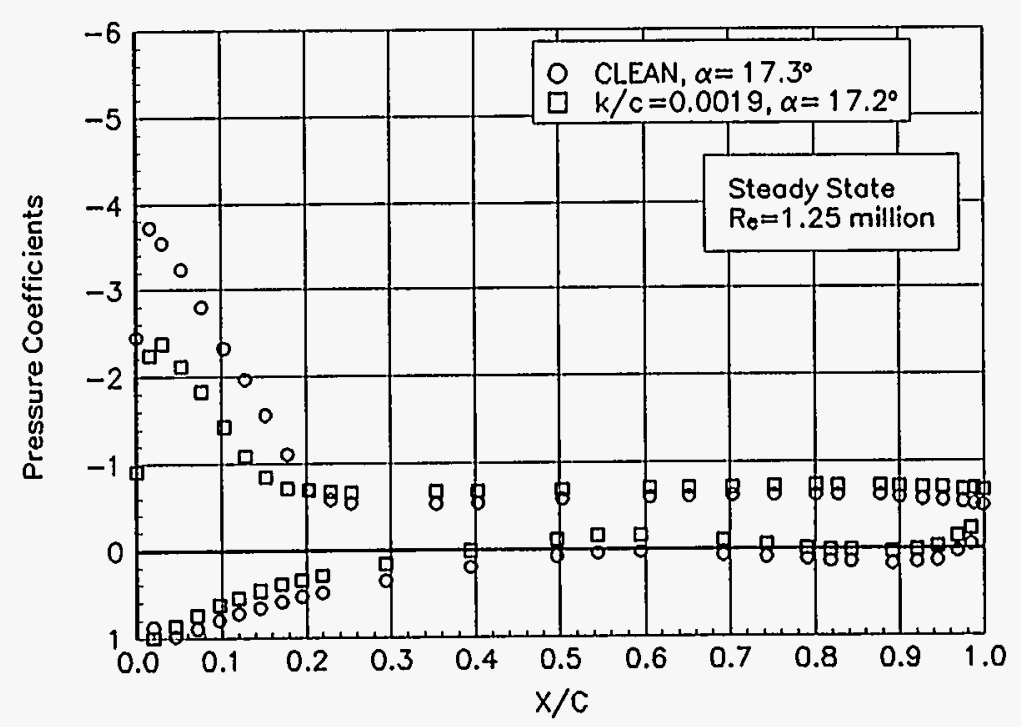

Figure B95. $a=17.3^{\circ}$

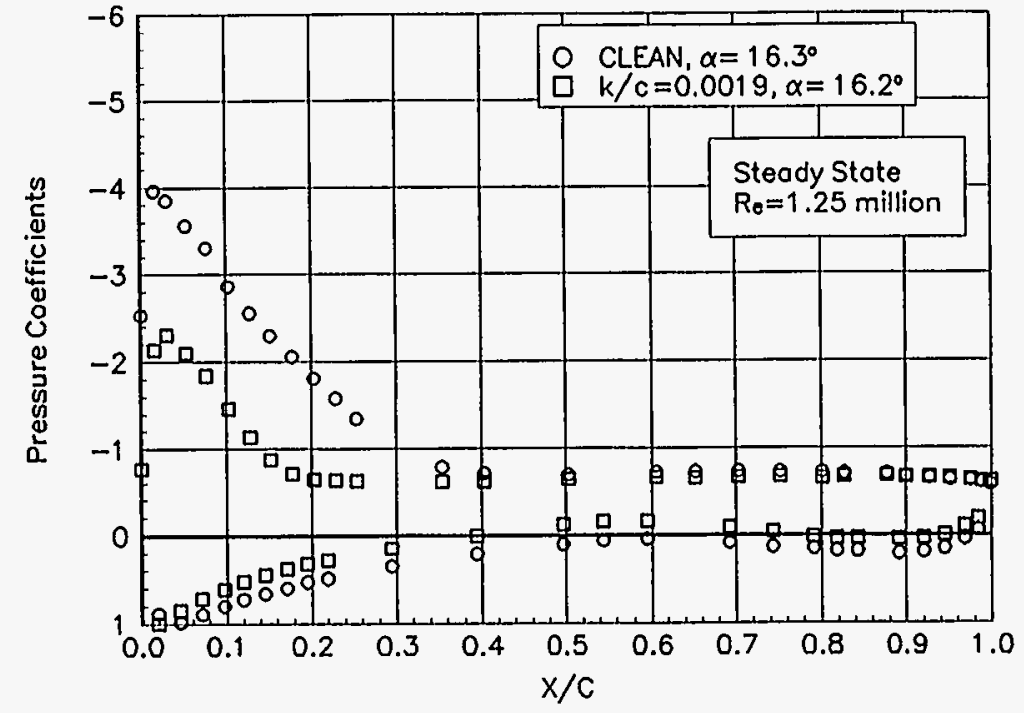

Figure B94. $a=16.3^{\circ}$

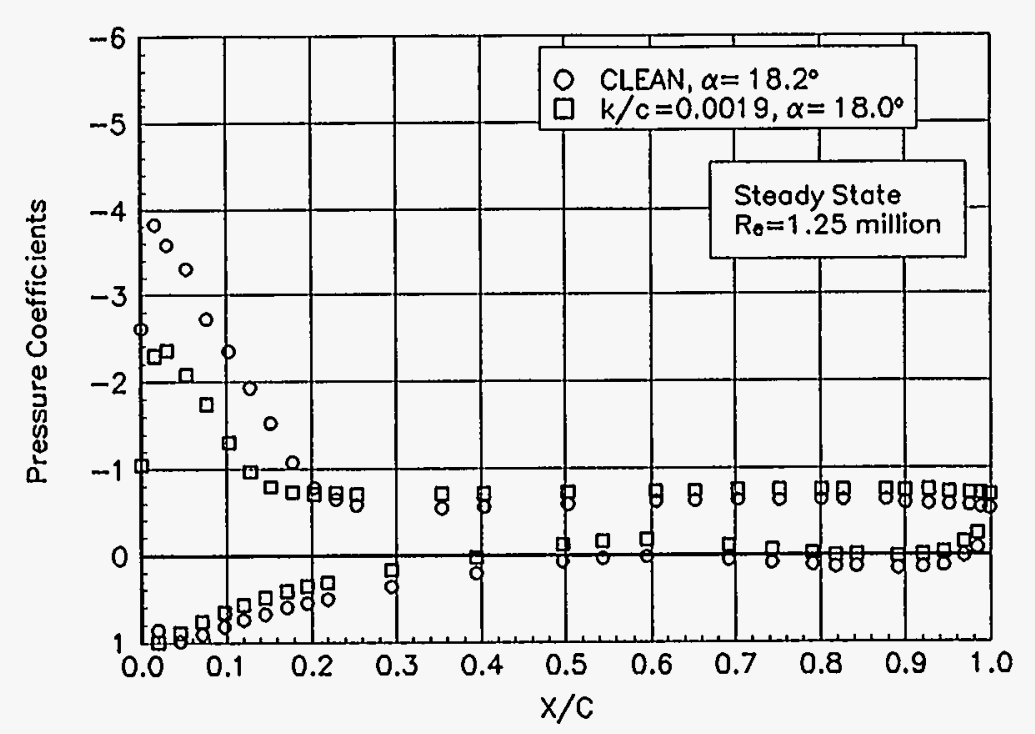

Figure B96. $a=18.2^{\circ}$ 


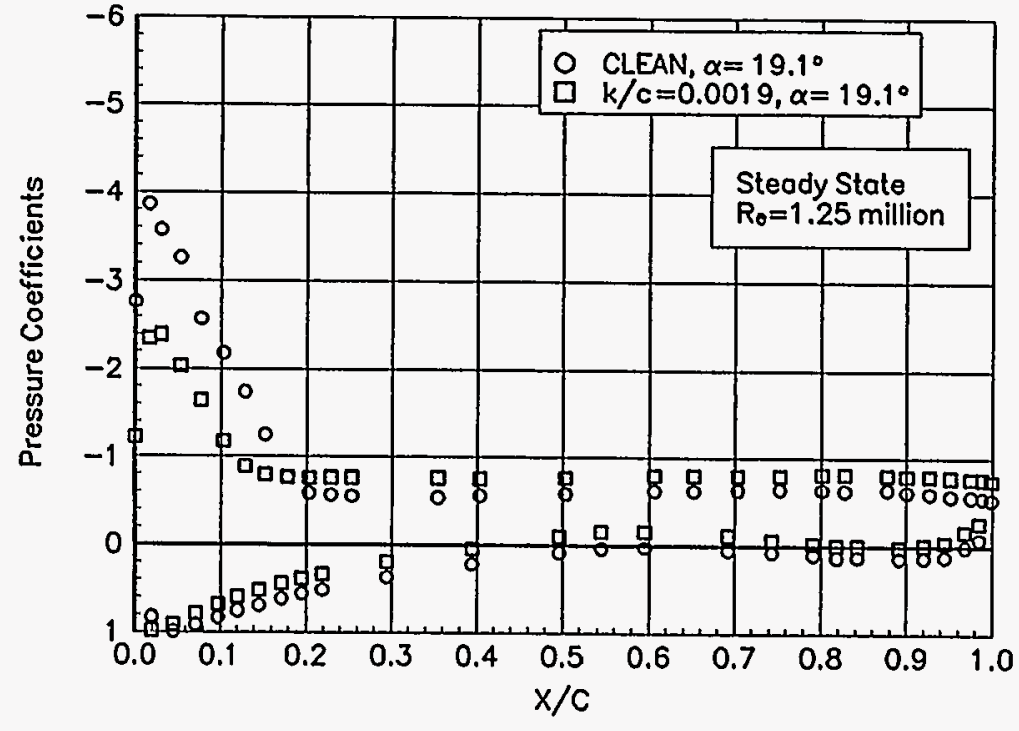

Figure B97. $a=19.1^{\circ}$

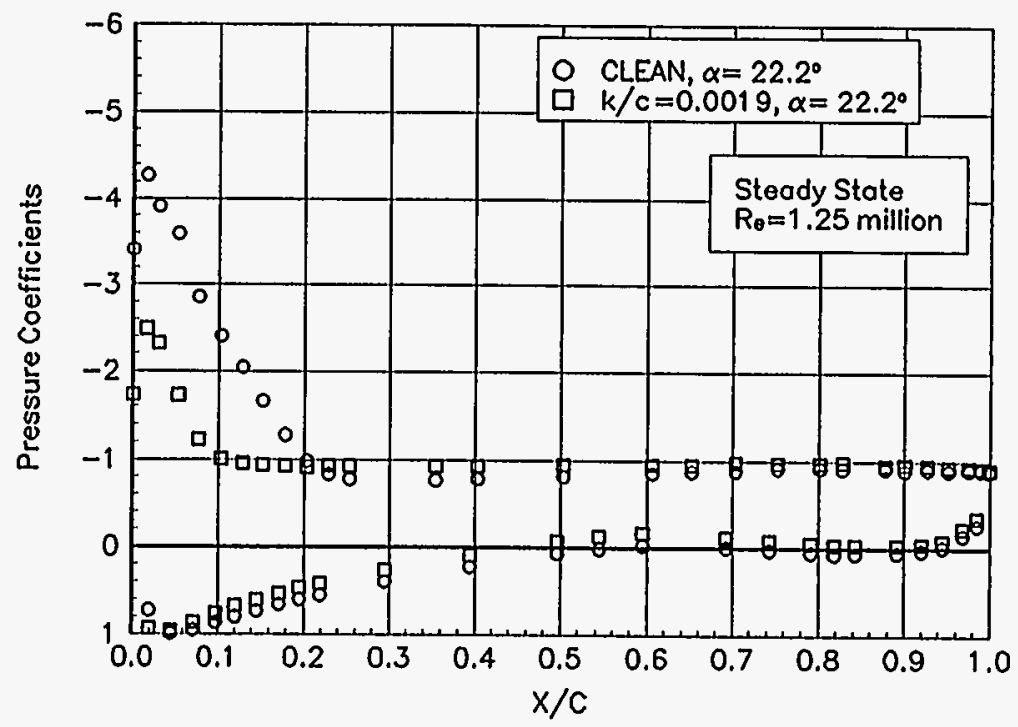

Figure B99. $a=22.2^{\circ}$

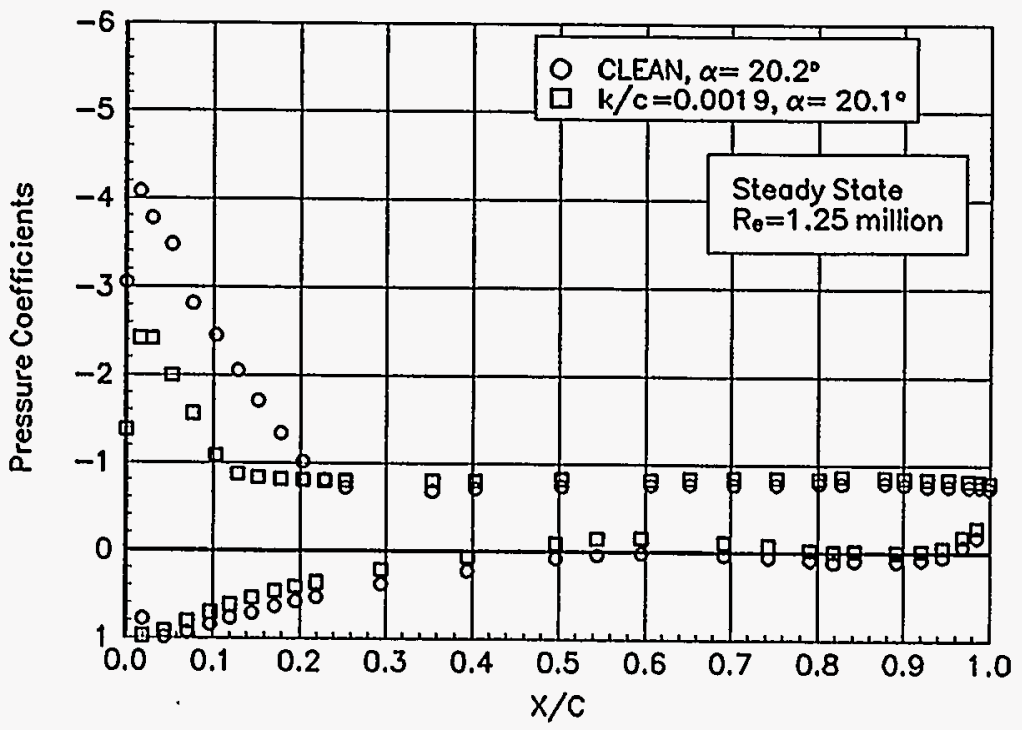

Figure B98. $\alpha=20.2^{\circ}$

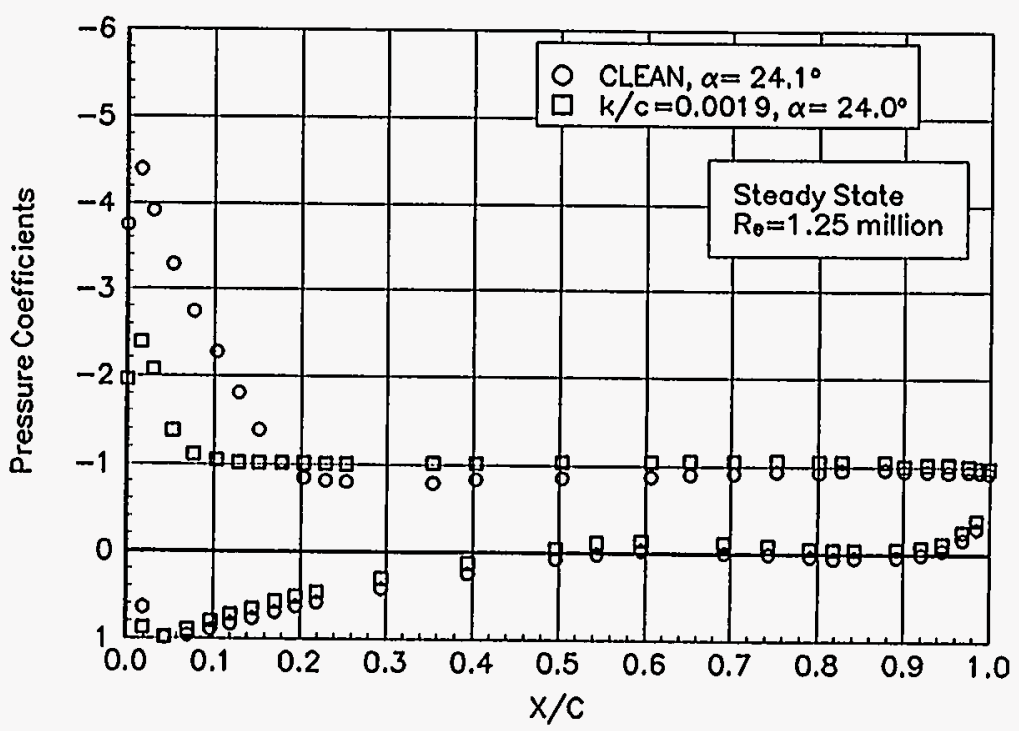

Figure B100. $\alpha=24.1^{\circ}$ 

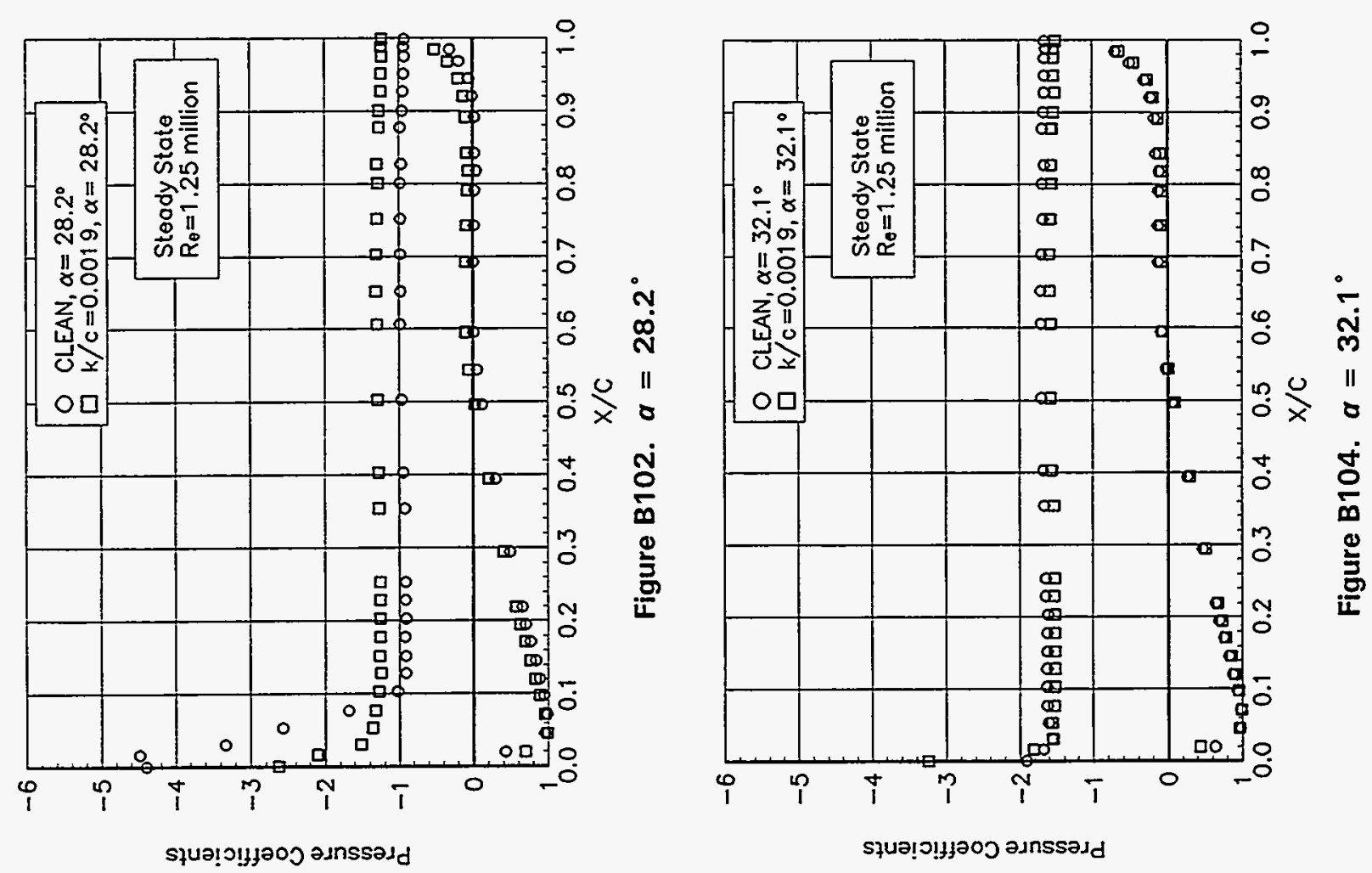

嘿
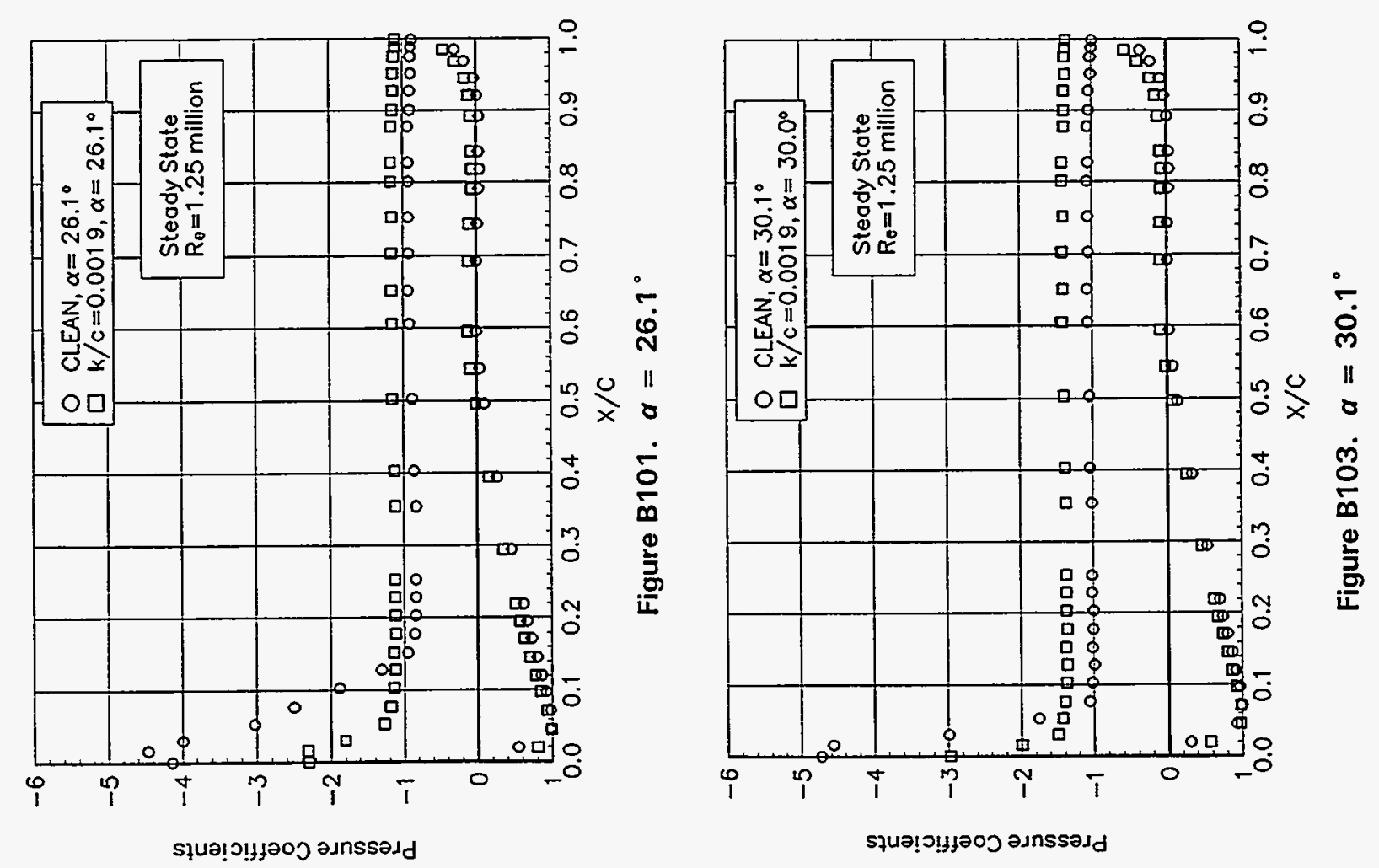


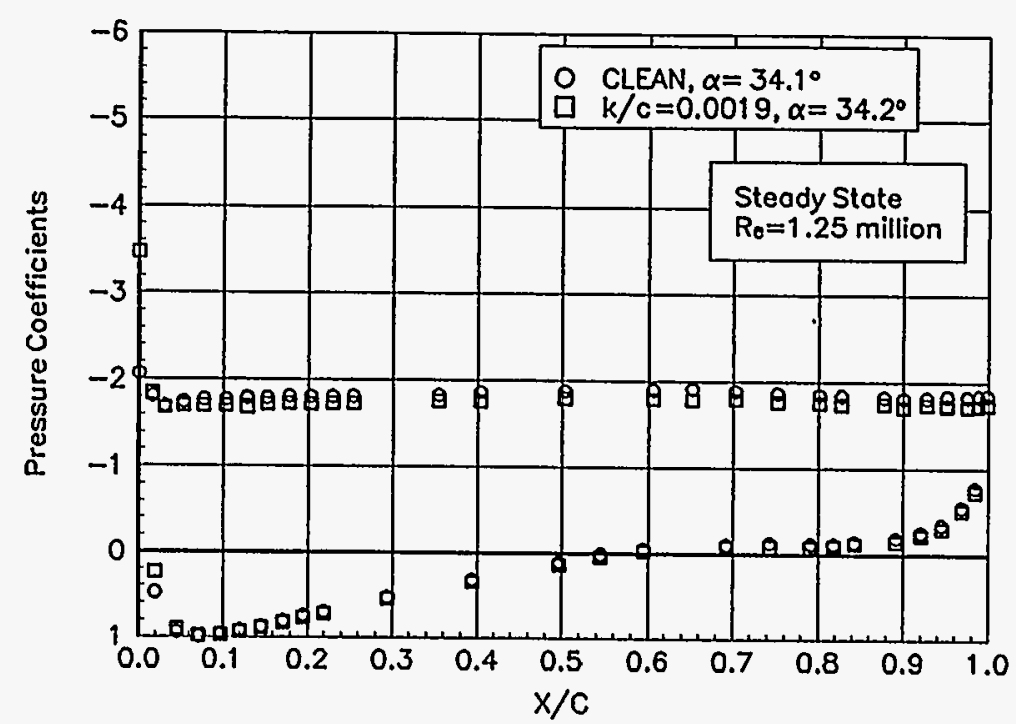

Figure B105. $a=34.1^{\circ}$

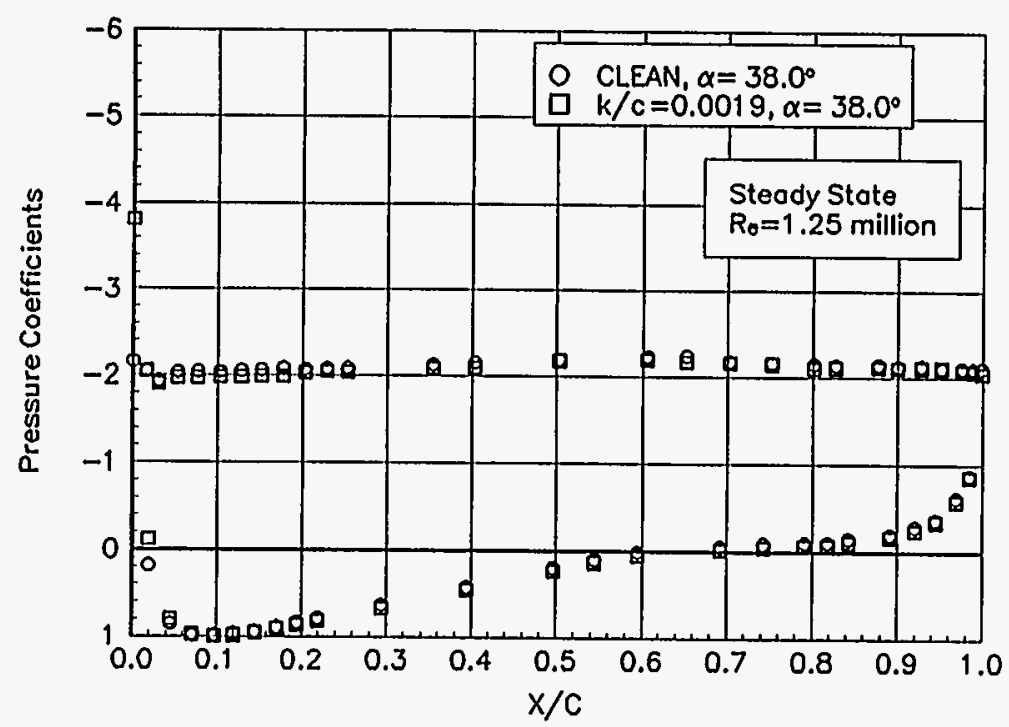

Figure B107. $a=38.0^{\circ}$

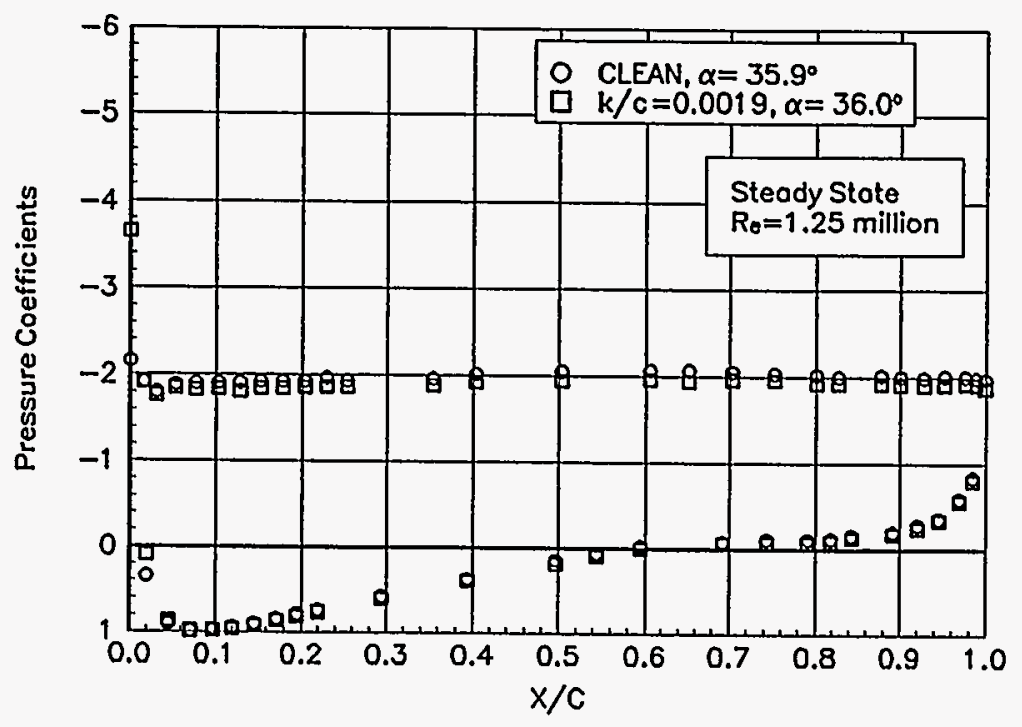

Figure B106. $a=35.9^{\circ}$

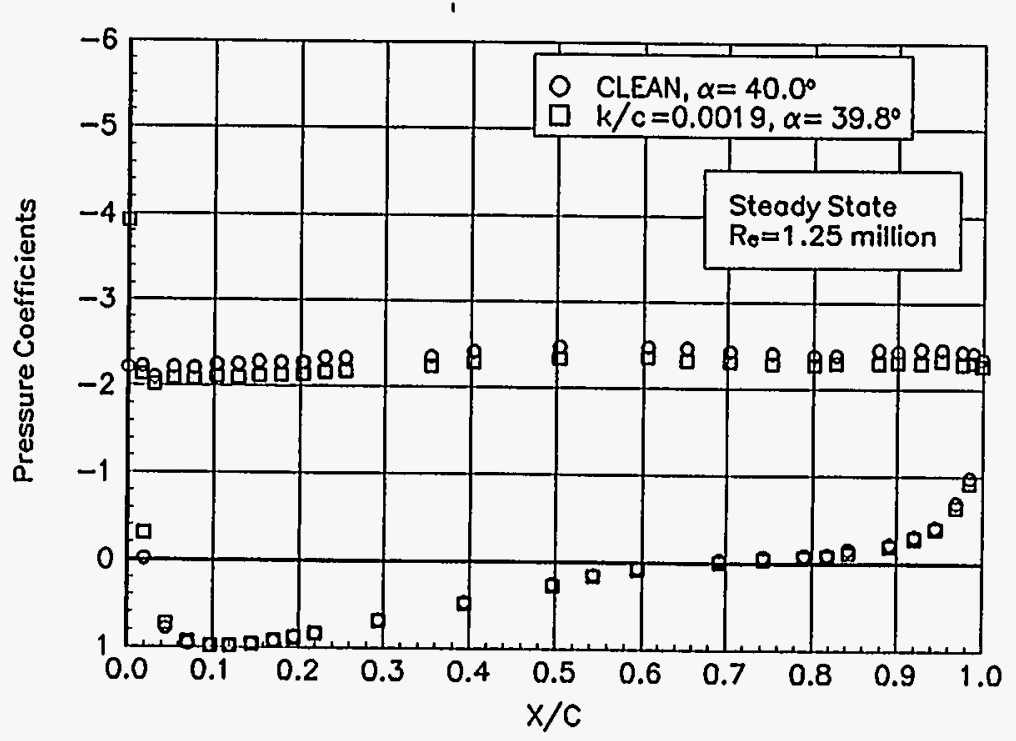

Figure B108. $a=40.0^{\circ}$ 


\section{Steady State \\ Pressure Distributions \\ LS(1)-0417MOD \\ $\operatorname{Re}=1.5$ million}




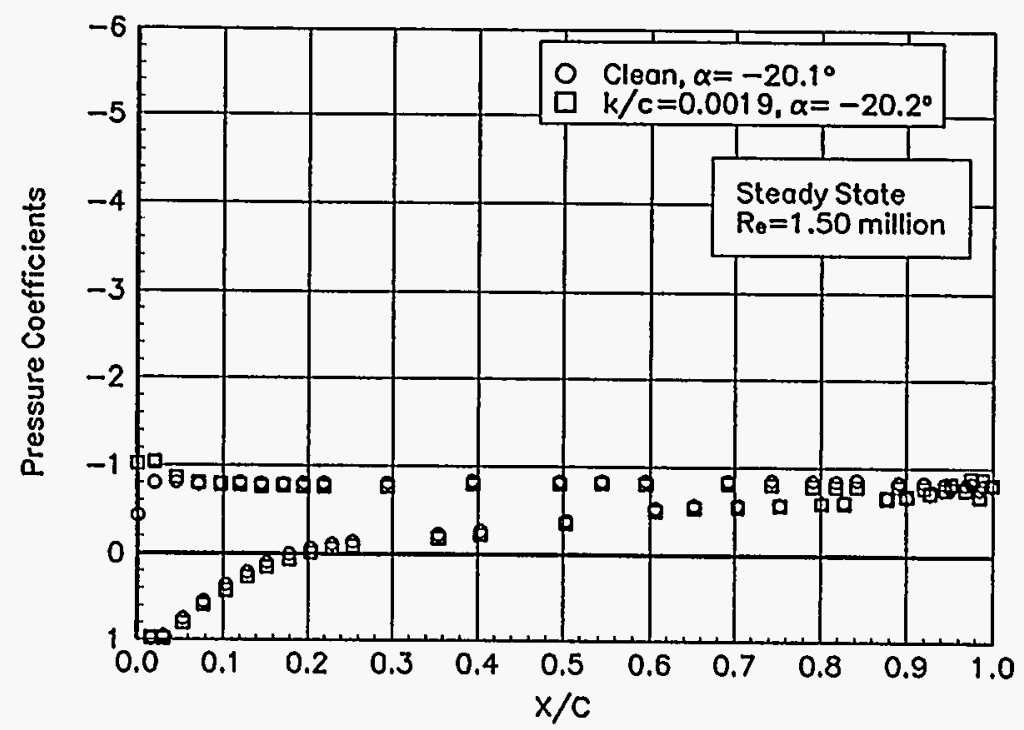

Figure B109. $a=-20.1^{\circ}$

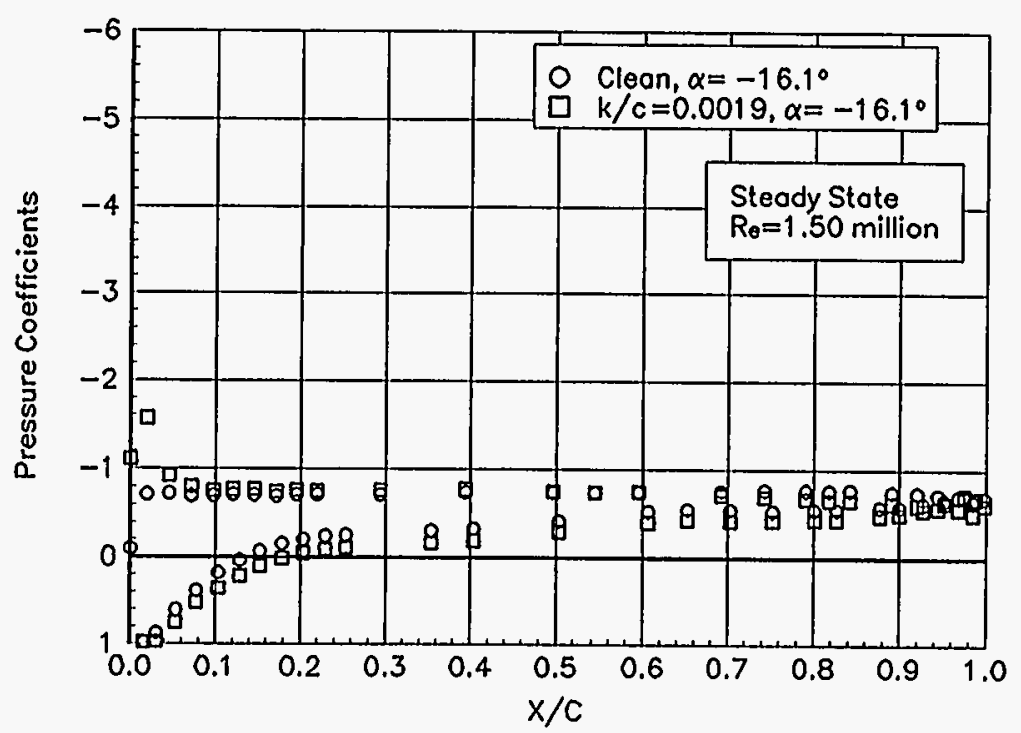

Figure B111. $a=-16.1^{\circ}$

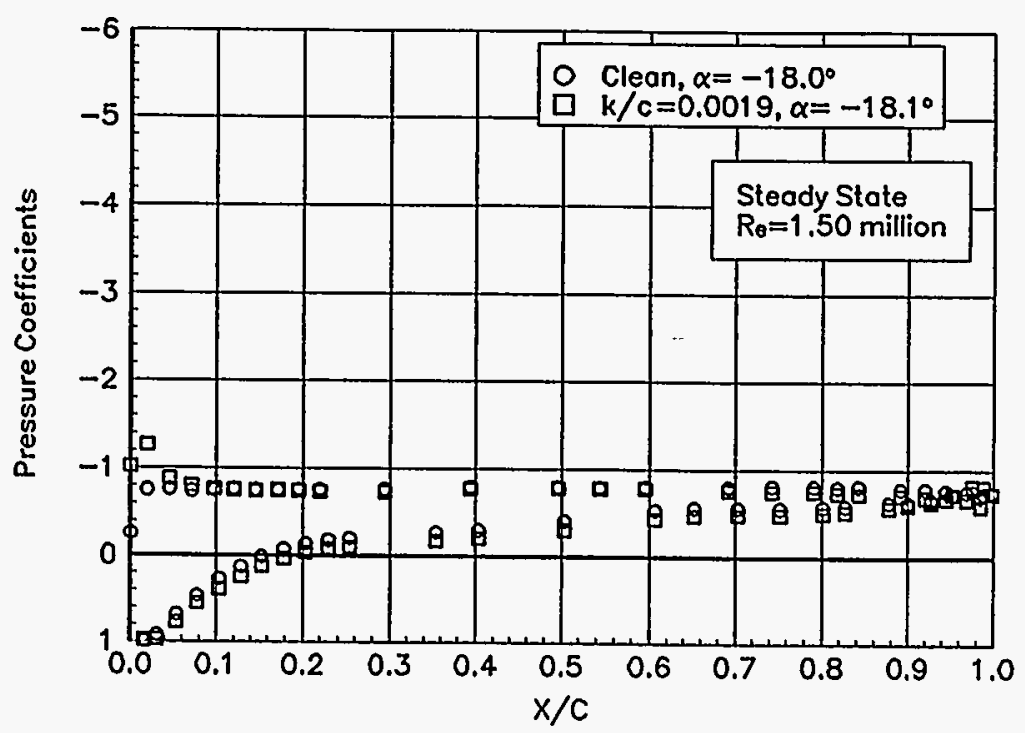

Figure B110. $a=-18.0^{\circ}$

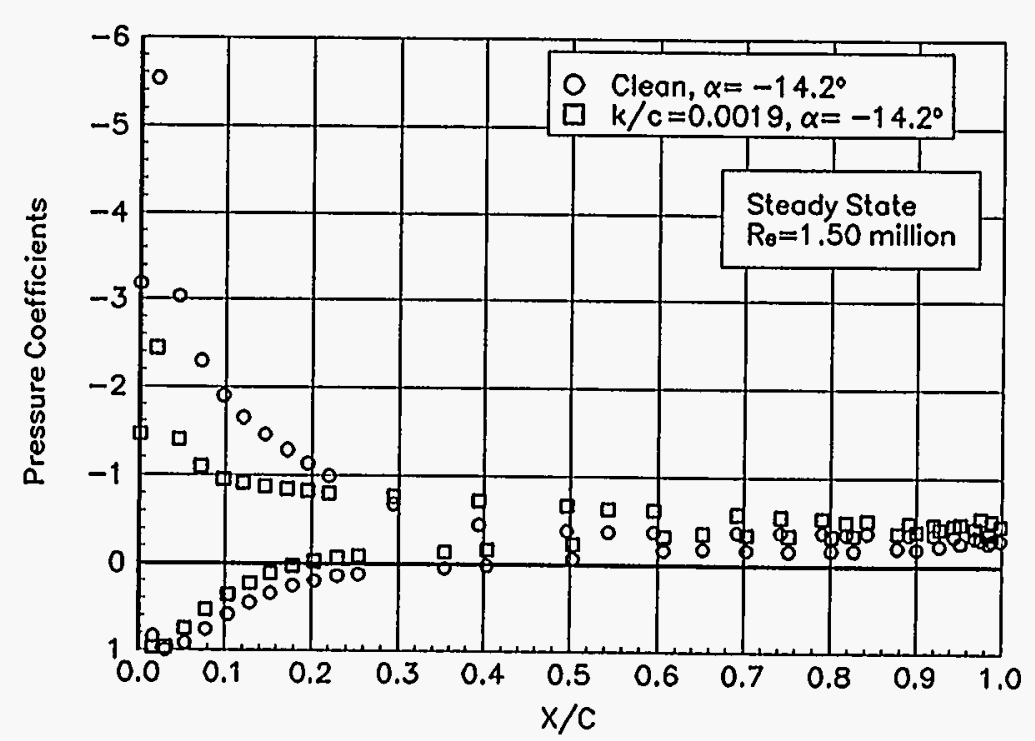

Figure B112. $\alpha=-14.2^{\circ}$ 

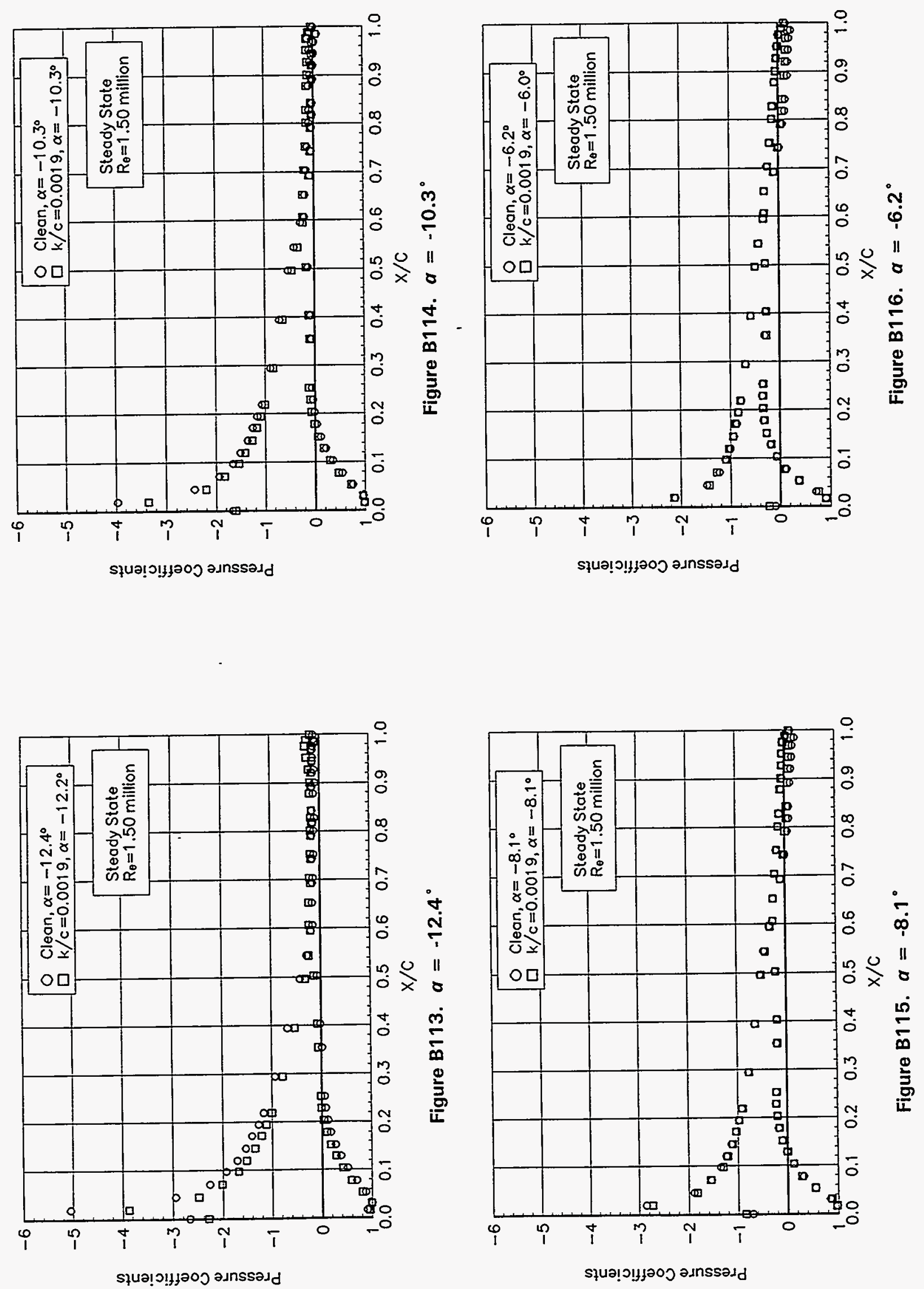


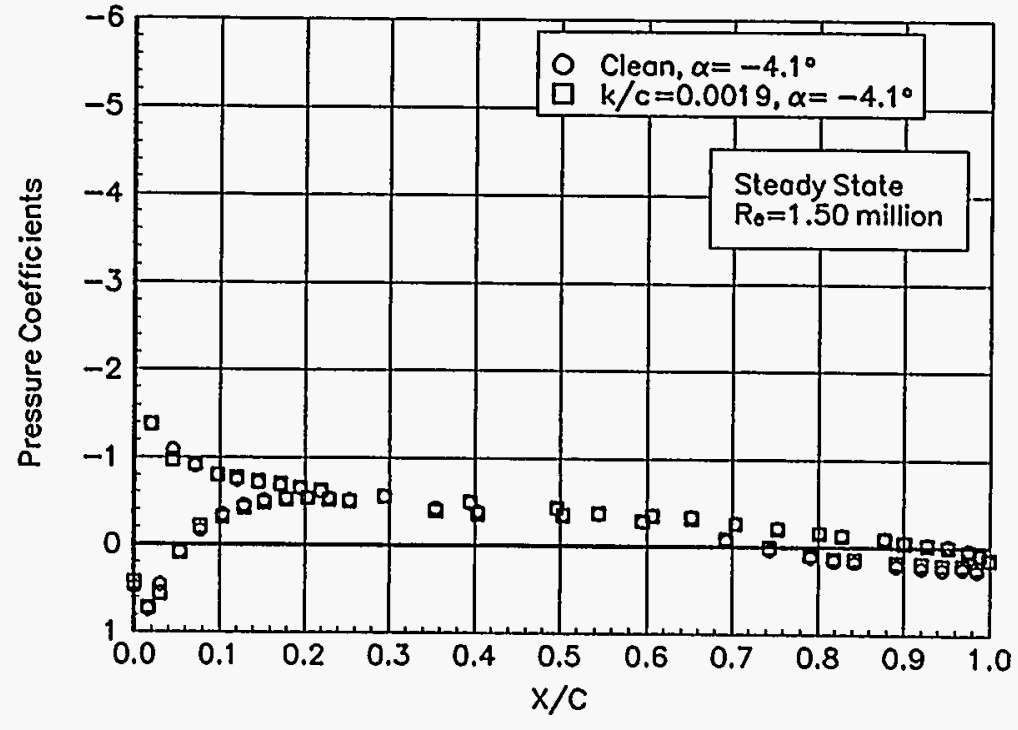

Figure B117. $\alpha=-4.1^{\circ}$

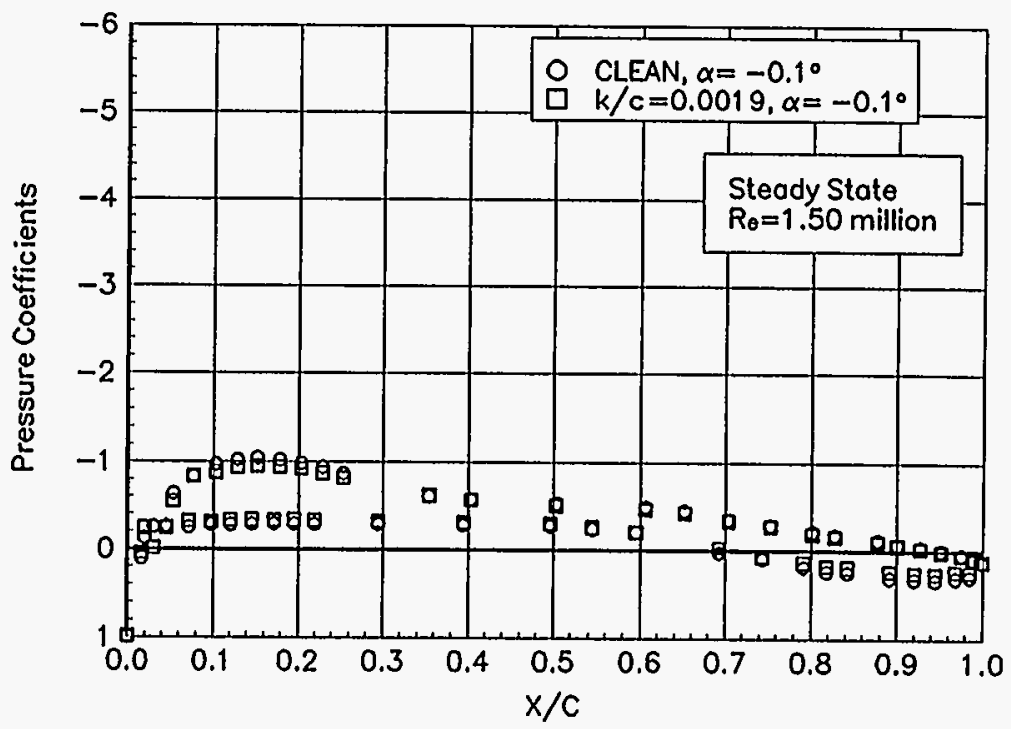

Figure B119. $a=-0.1^{\circ}$

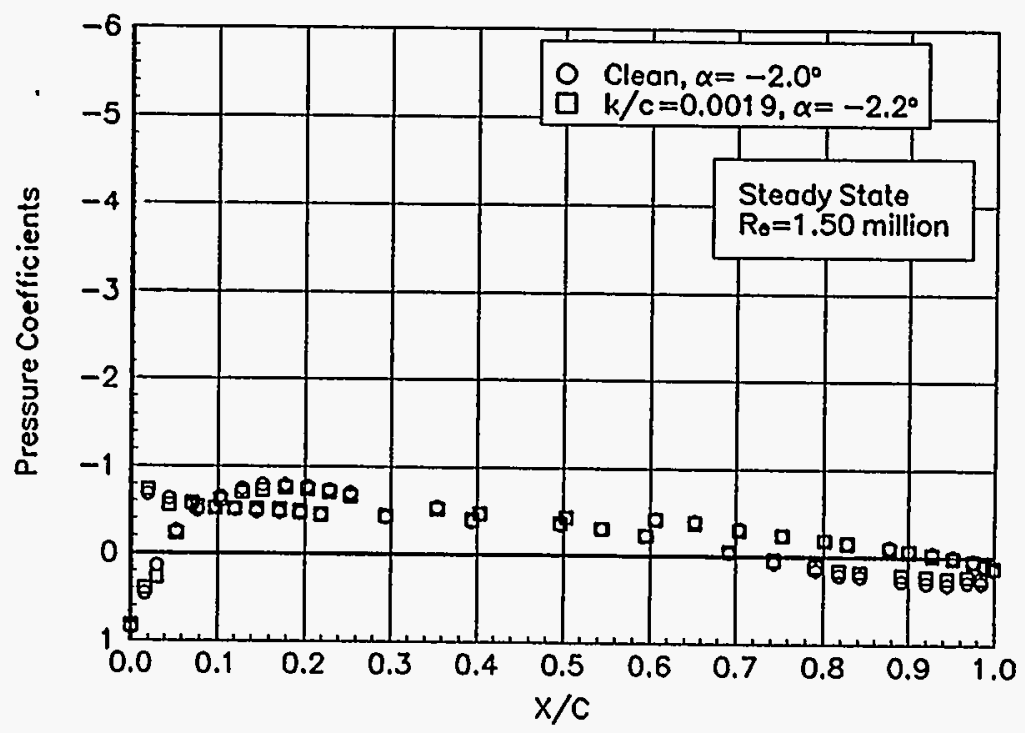

Figure B118. $a=-2.0^{\circ}$

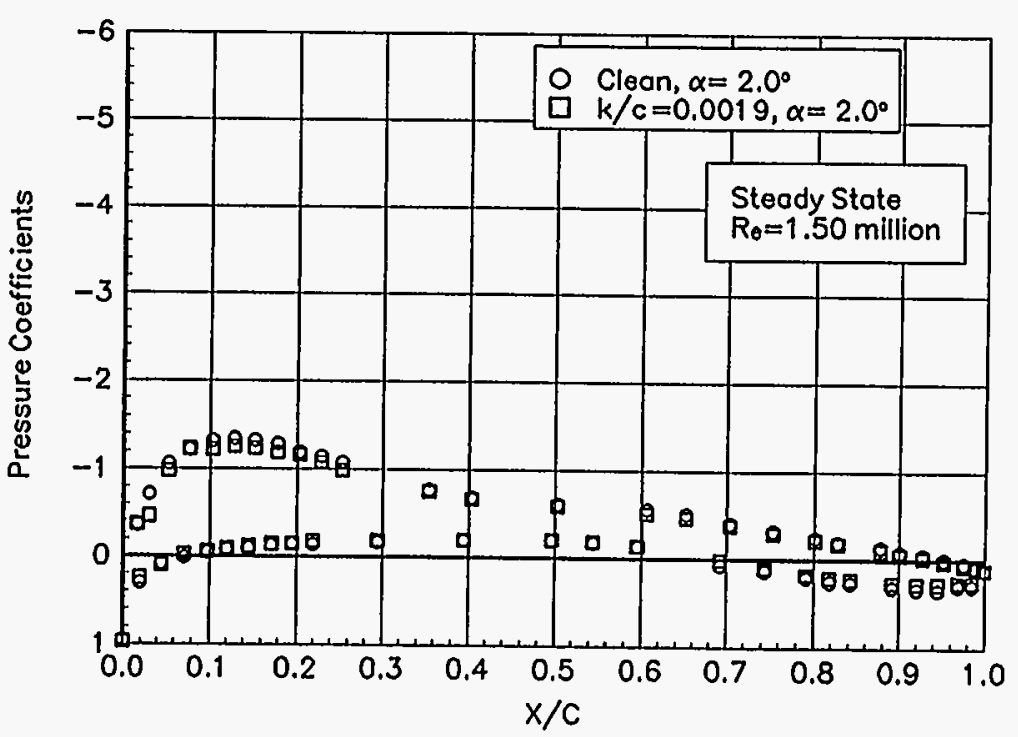

Figure B120. $a=2.0^{\circ}$ 

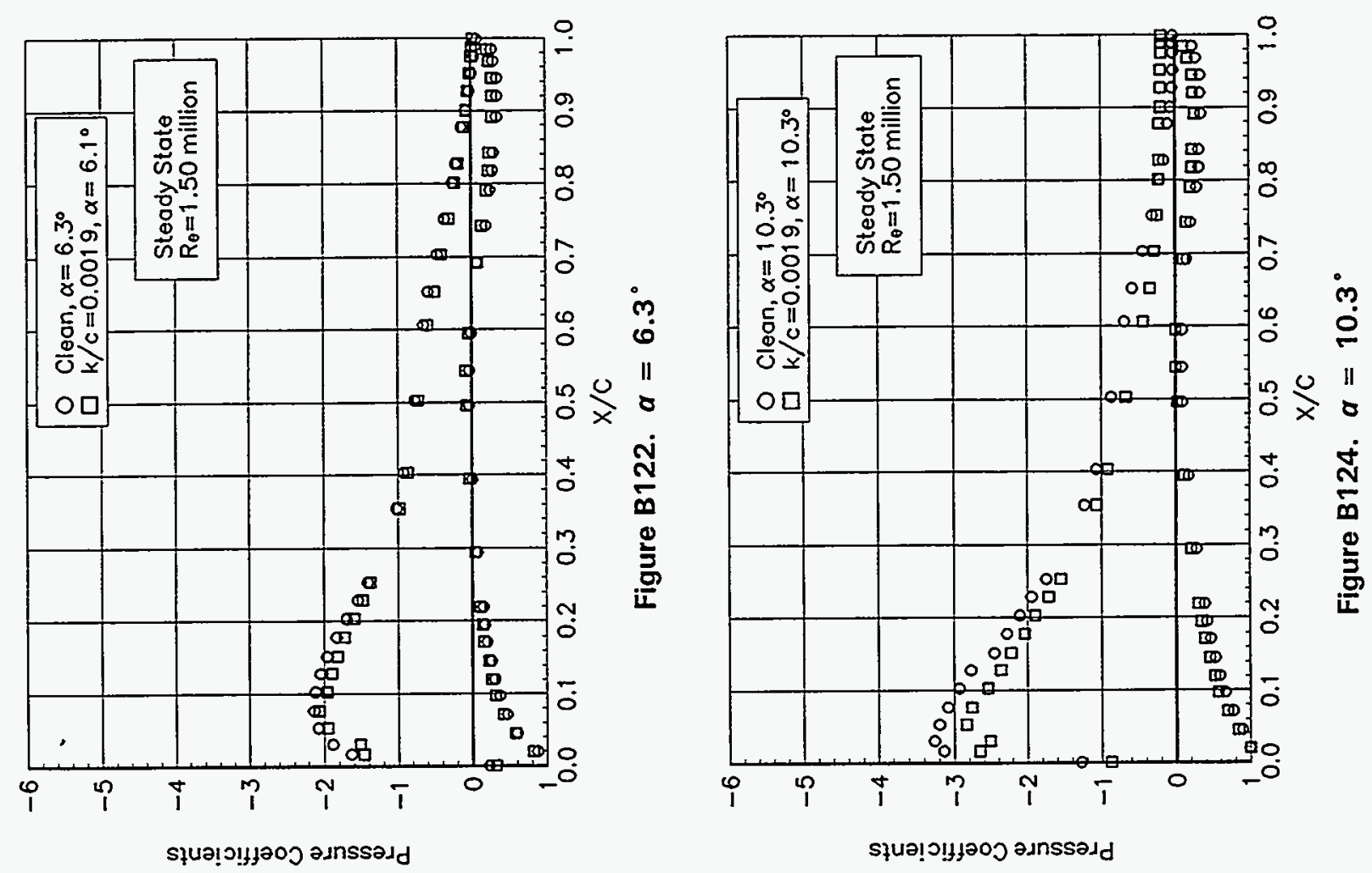

กิ

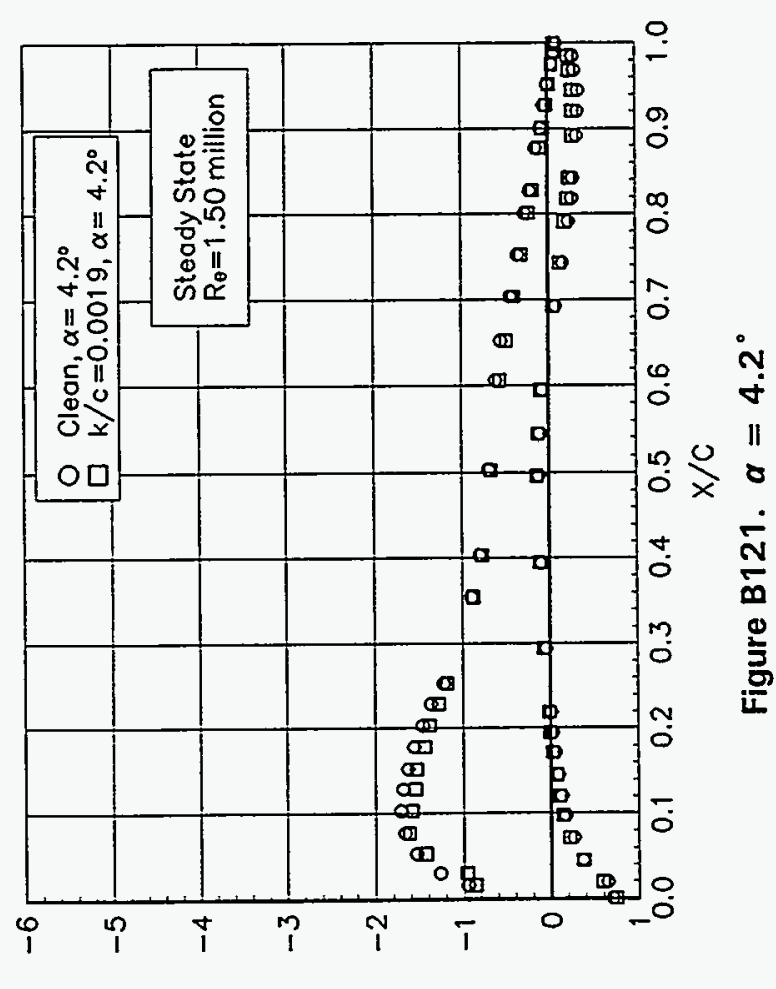

słนว!ฺ!

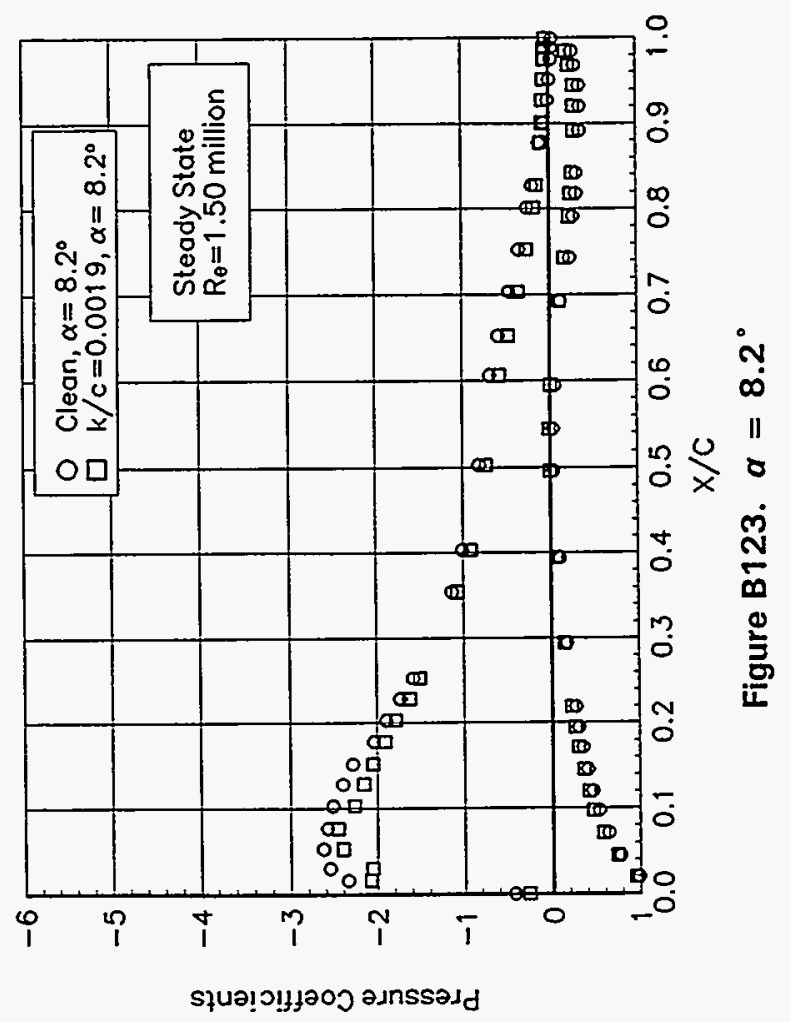




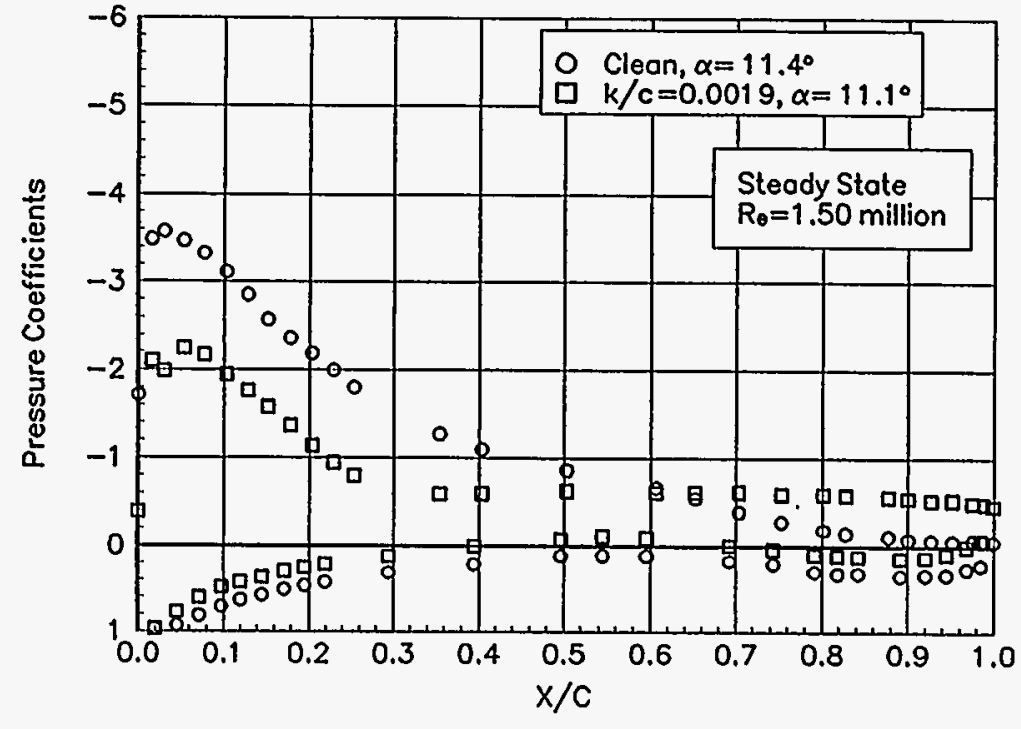

Figure B125. $a=11.4^{\circ}$

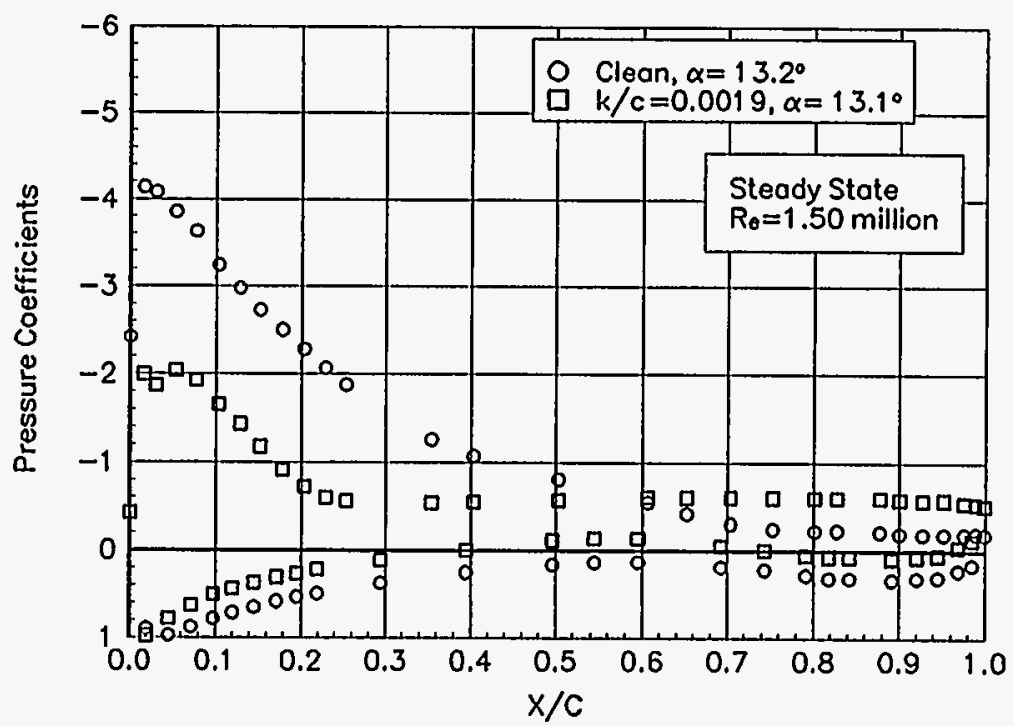

Figure B127. $a=13.2^{\circ}$

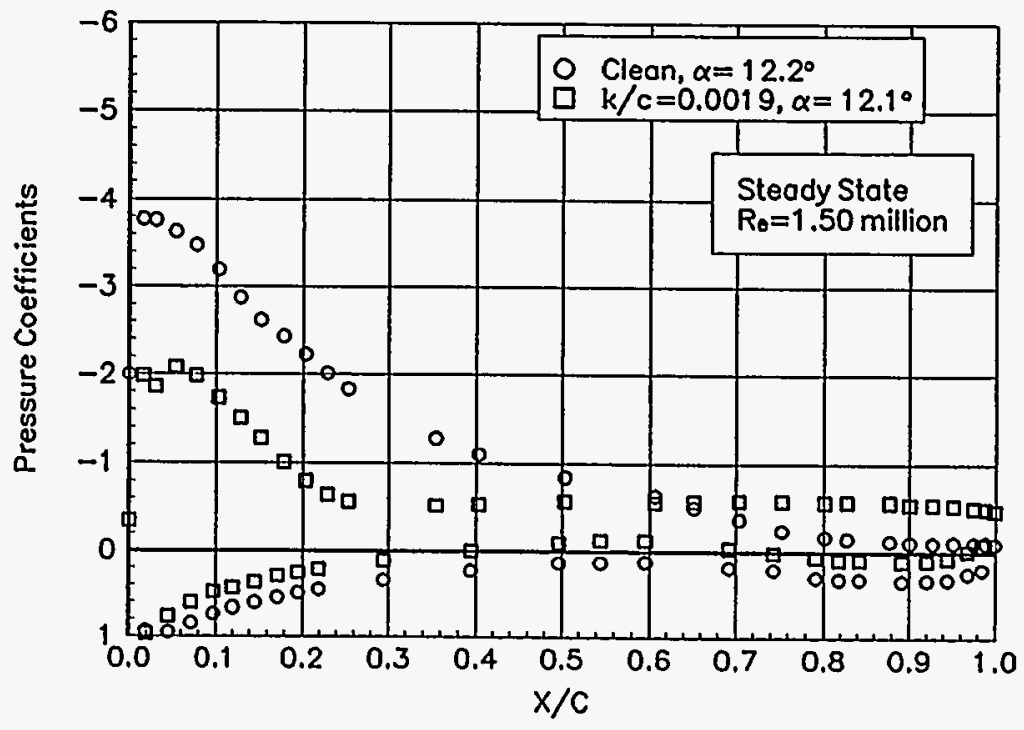

Figure B126. $a=12.2^{\circ}$

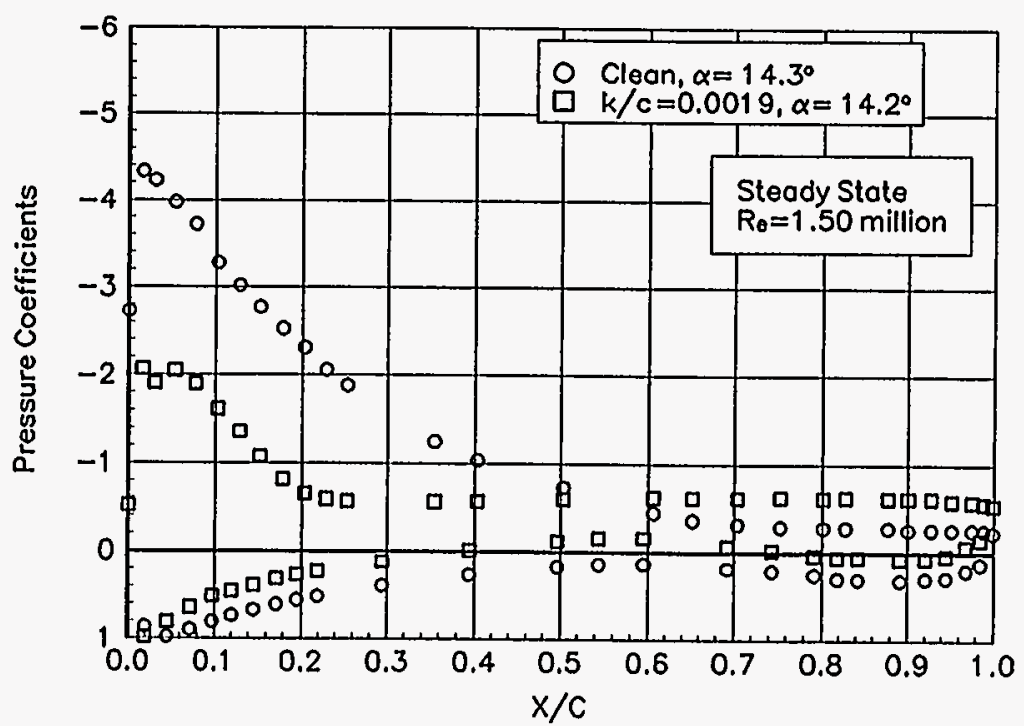

Figure B128. $a=14.3^{\circ}$ 
Pressure Coefficients

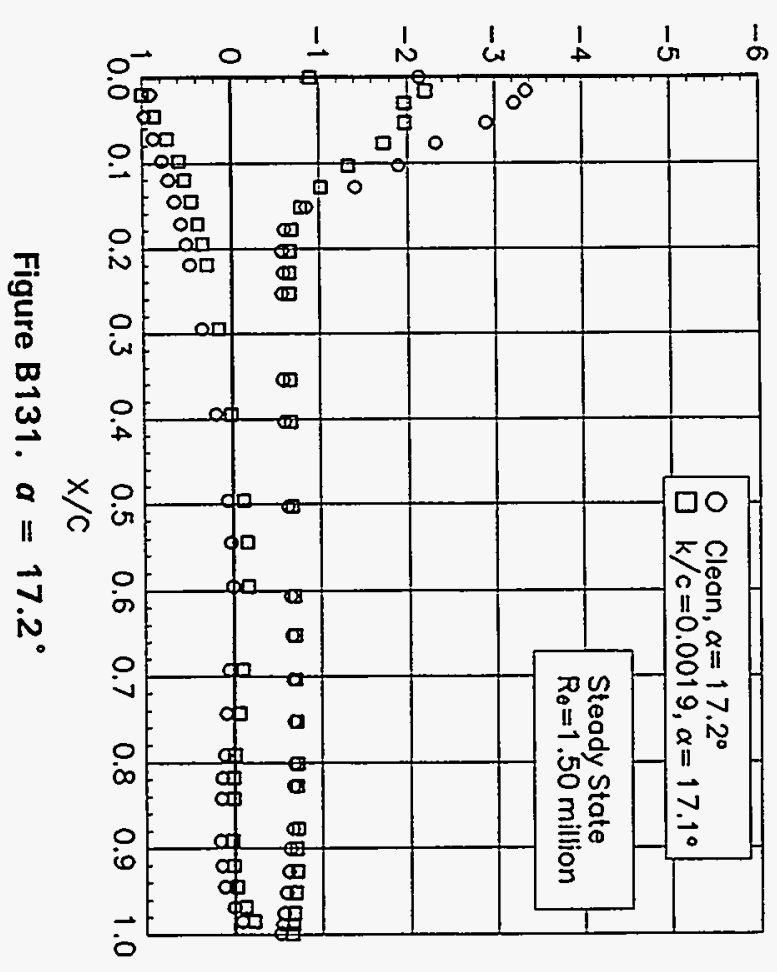

od
on
Pressure Coefficients

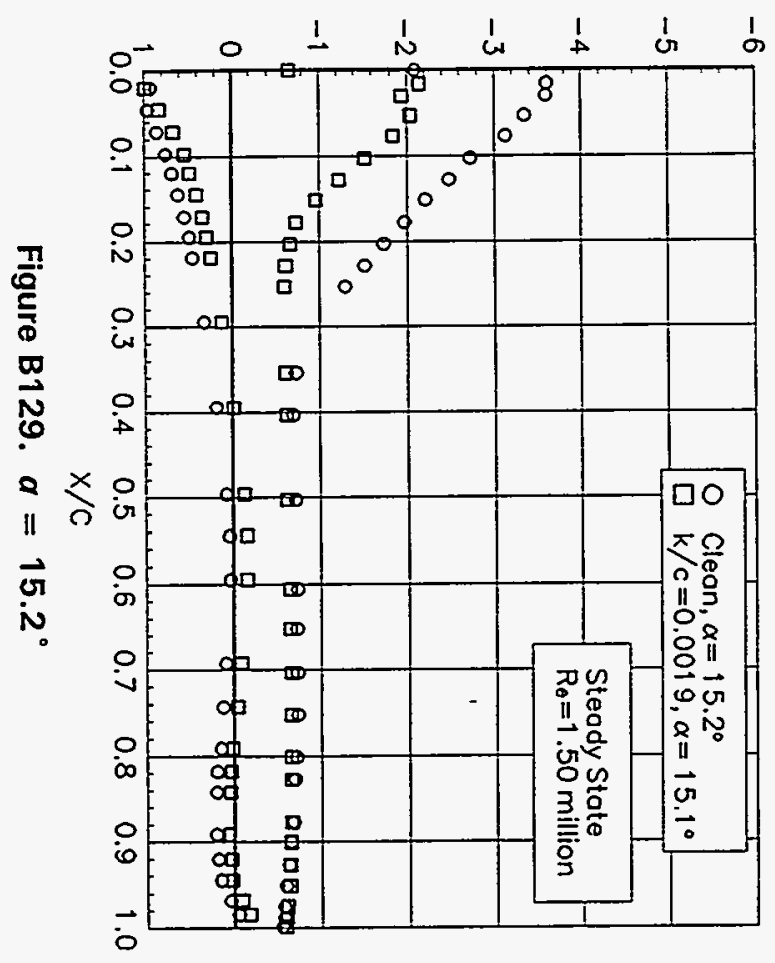

Pressure Coefficients

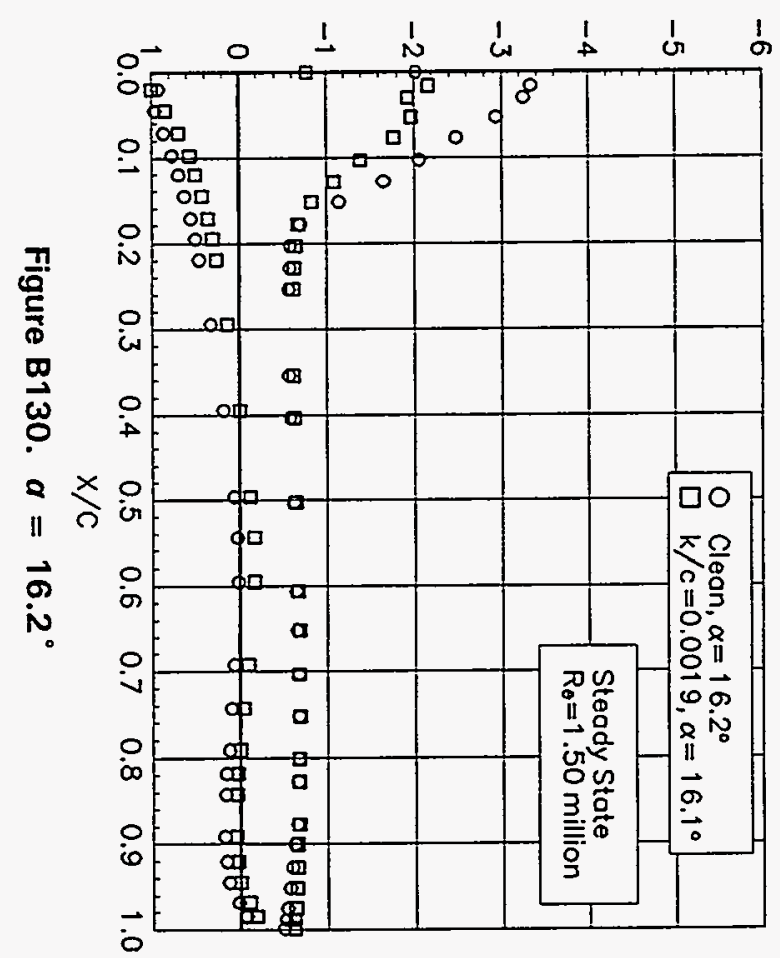




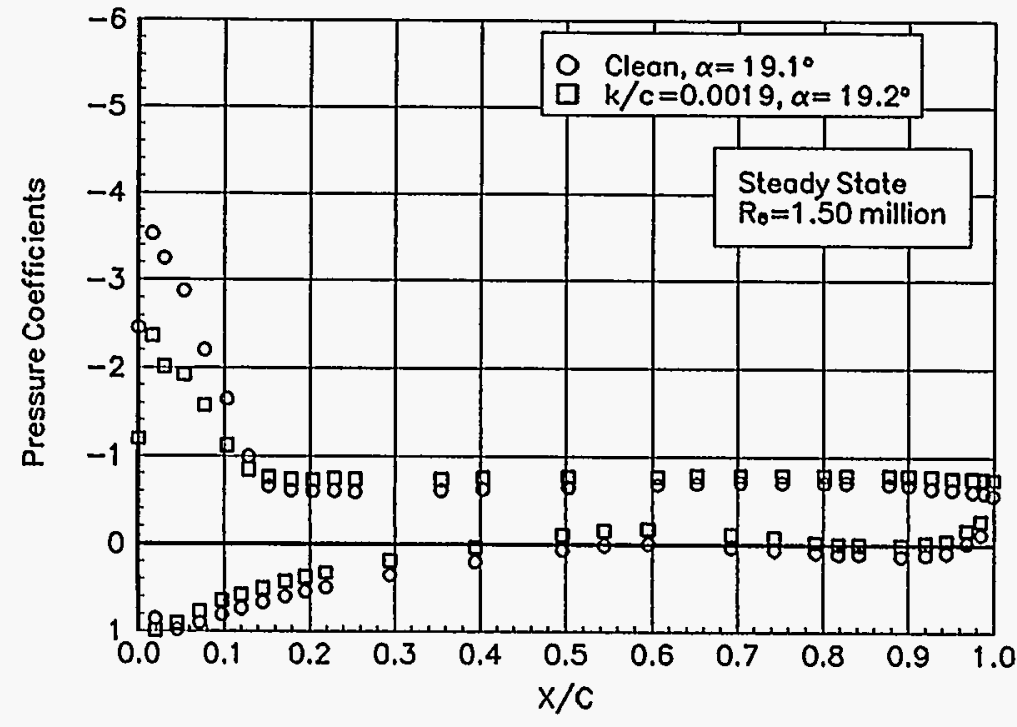

Figure B133. $a=19.1^{\circ}$

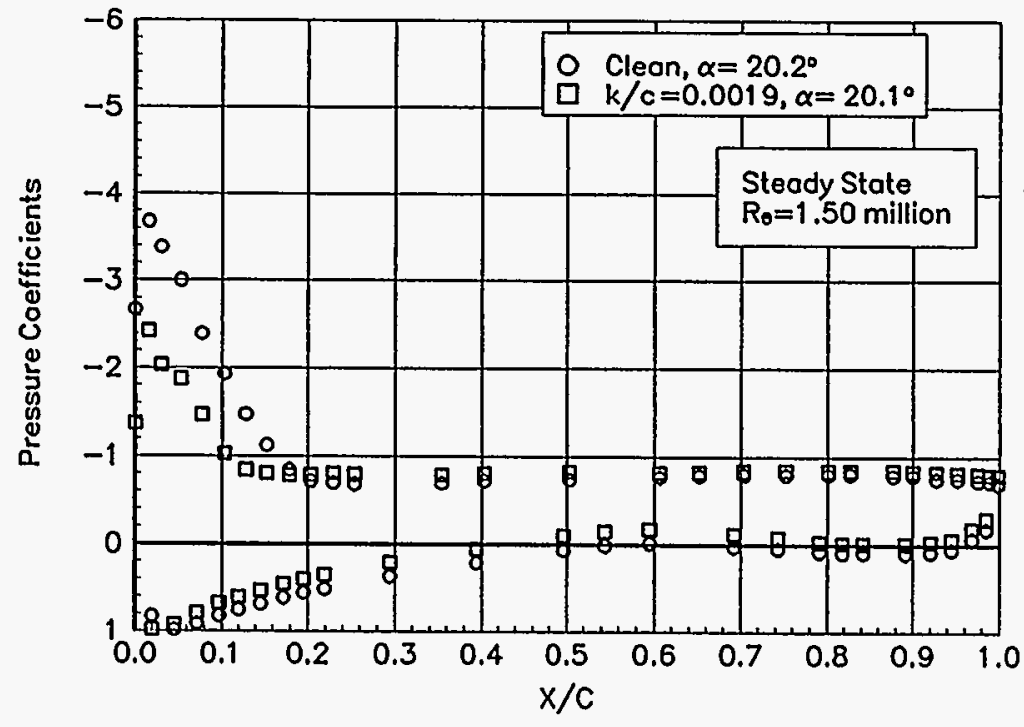

Figure B134. $a=20.2^{\circ}$ 

Appendix C: Unsteady Integrated Coefficients 


\section{List of Figures}

\section{Page}

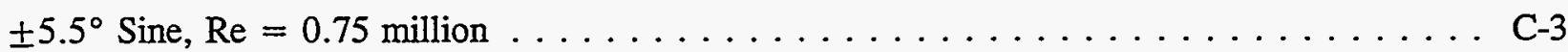

$\pm 5.5^{\circ}$ Sine, $\mathrm{Re}=1$ million $\ldots \ldots \ldots \ldots \ldots \ldots \ldots \ldots \ldots \ldots \ldots$

$\pm 5.5^{\circ}$ Sine $\mathrm{Re}=1.25$ million $\ldots \ldots \ldots \ldots \ldots \ldots \ldots \ldots \ldots \ldots \ldots \ldots \ldots$

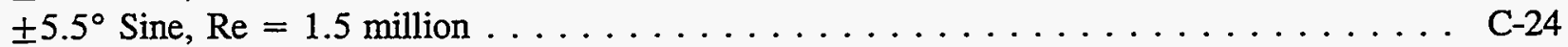

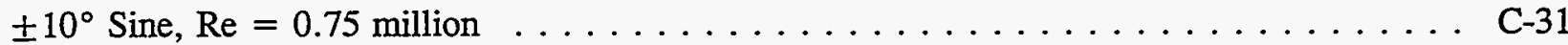

$\pm 10^{\circ}$ Sine $\operatorname{Re}=1$ million $\ldots \ldots \ldots \ldots \ldots \ldots \ldots \ldots \ldots \ldots \ldots \ldots$

$\pm 10^{\circ}$ Sine $\operatorname{Re}=1.25$ million $\ldots \ldots \ldots \ldots \ldots \ldots \ldots \ldots \ldots \ldots \ldots \ldots$

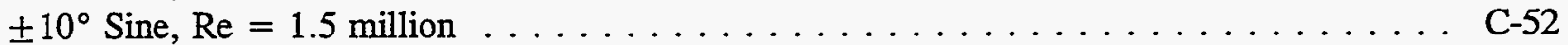




\section{Unsteady Airfoil Characteristics \\ $\pm 5.5^{\circ}$ Sine, $\operatorname{Re}=0.75$ million}



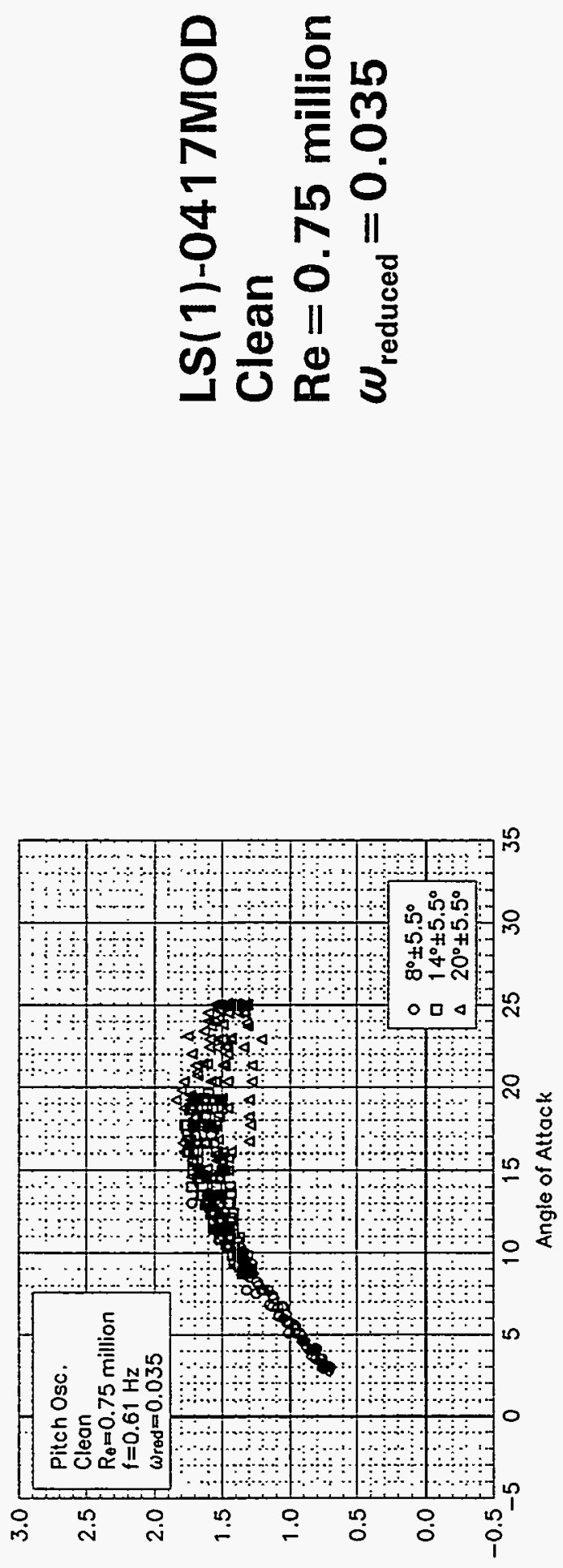

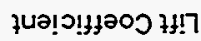

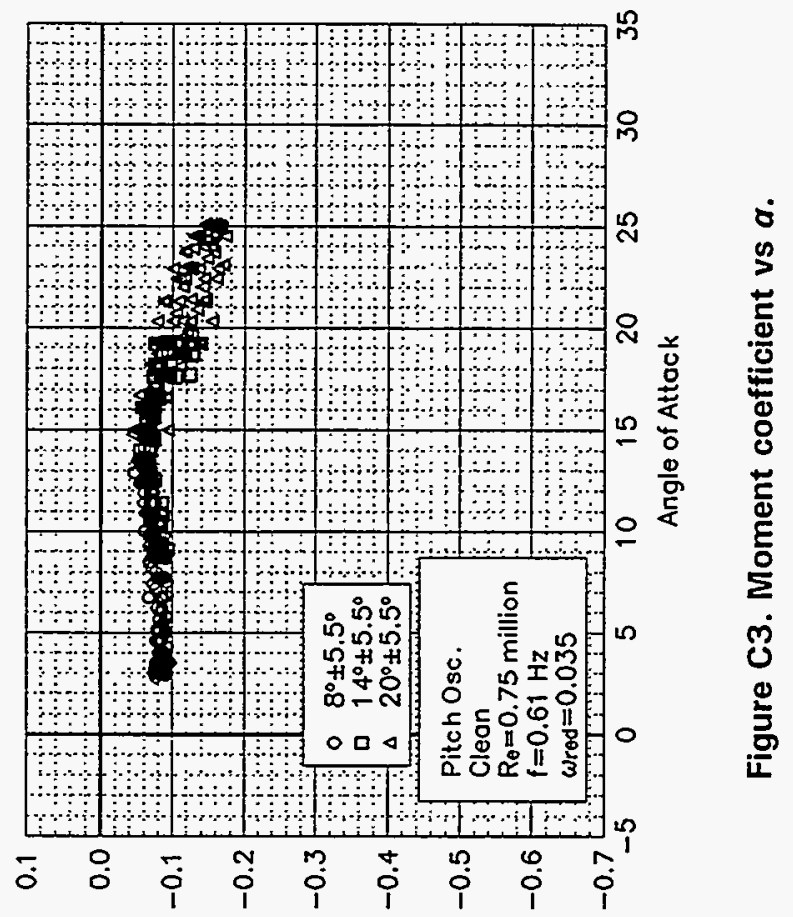

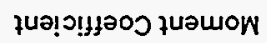

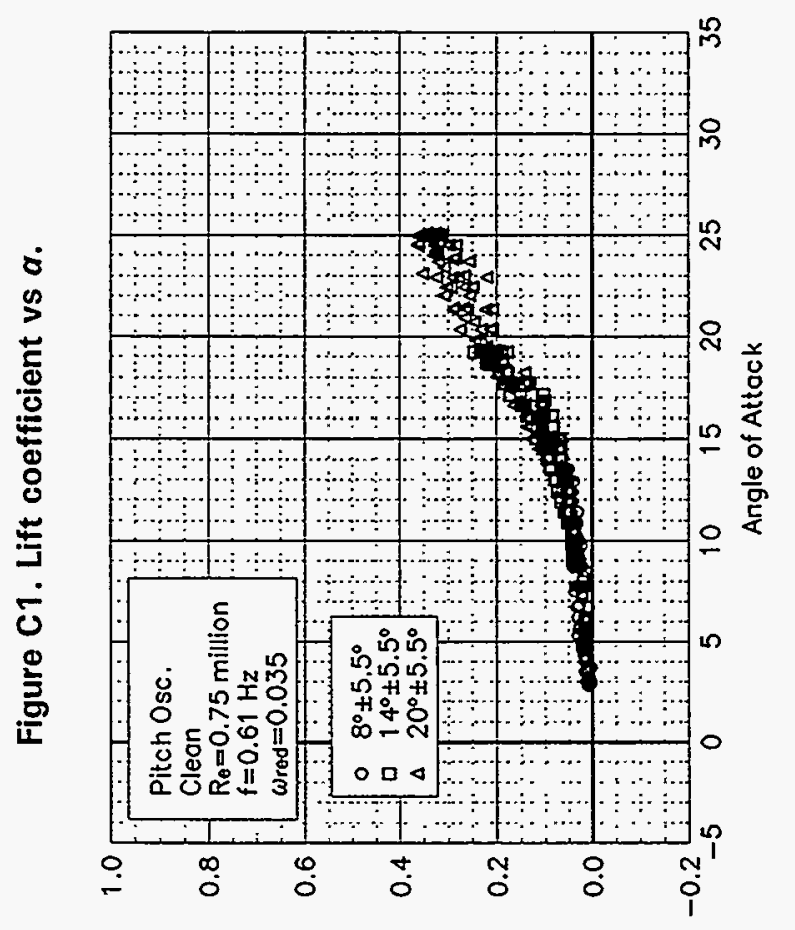

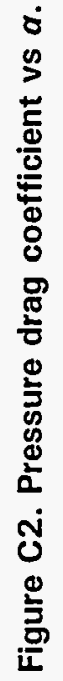

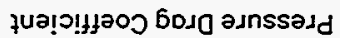



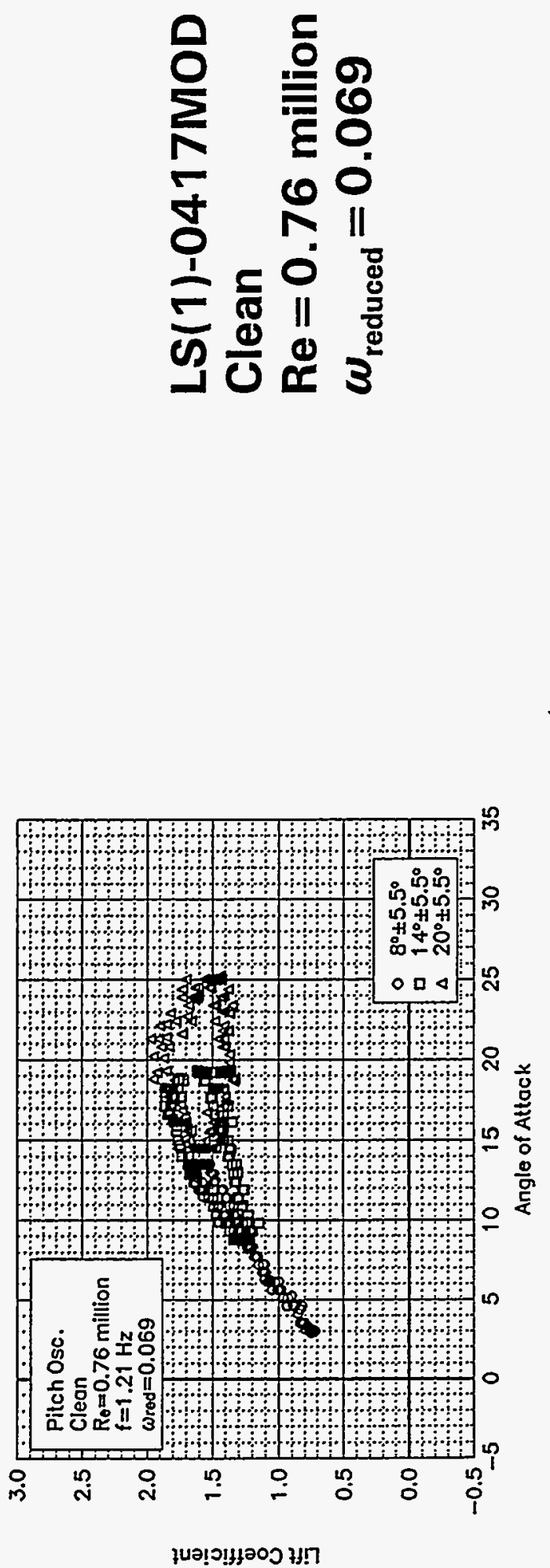

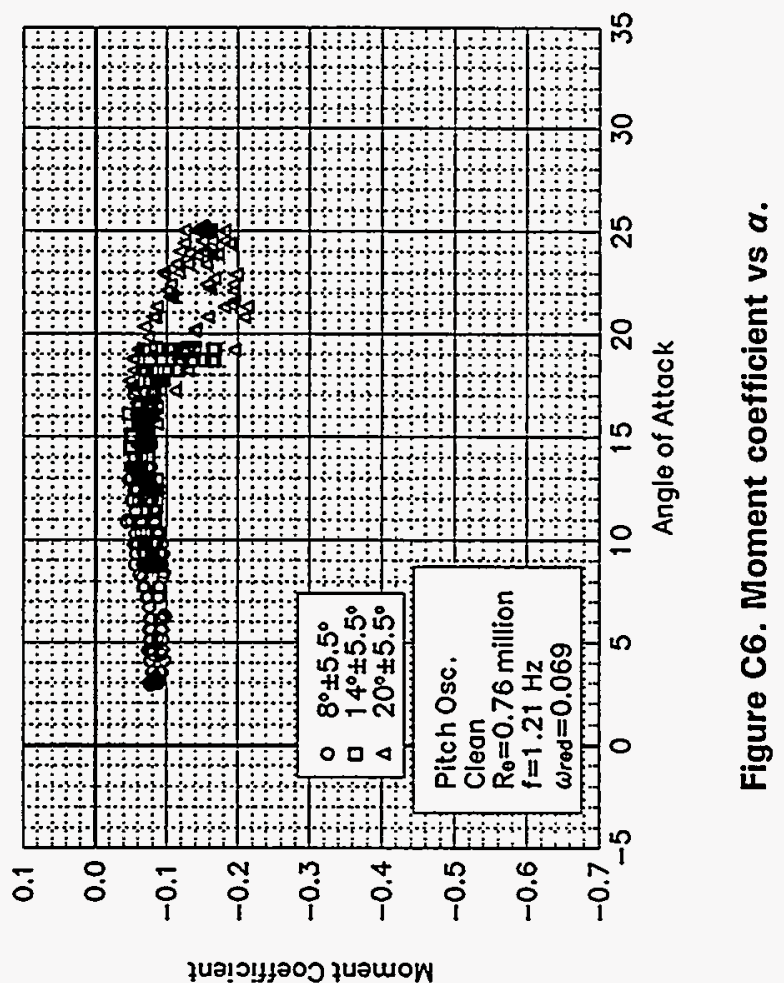

ช

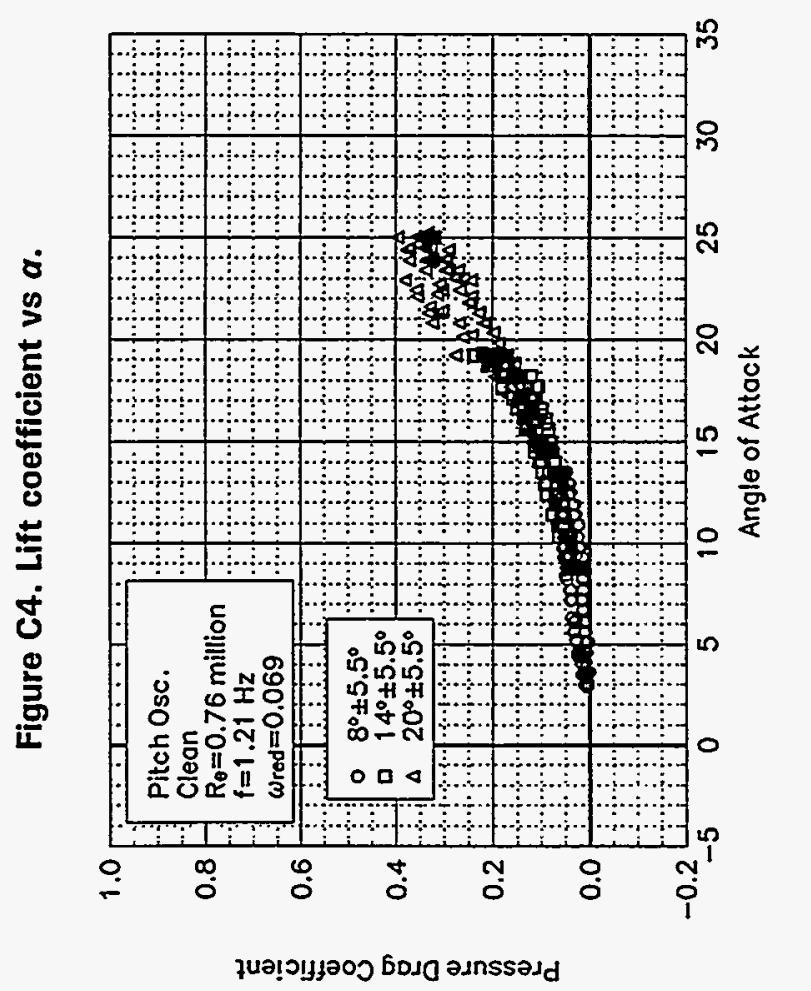

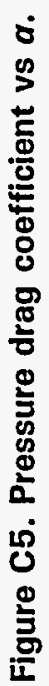



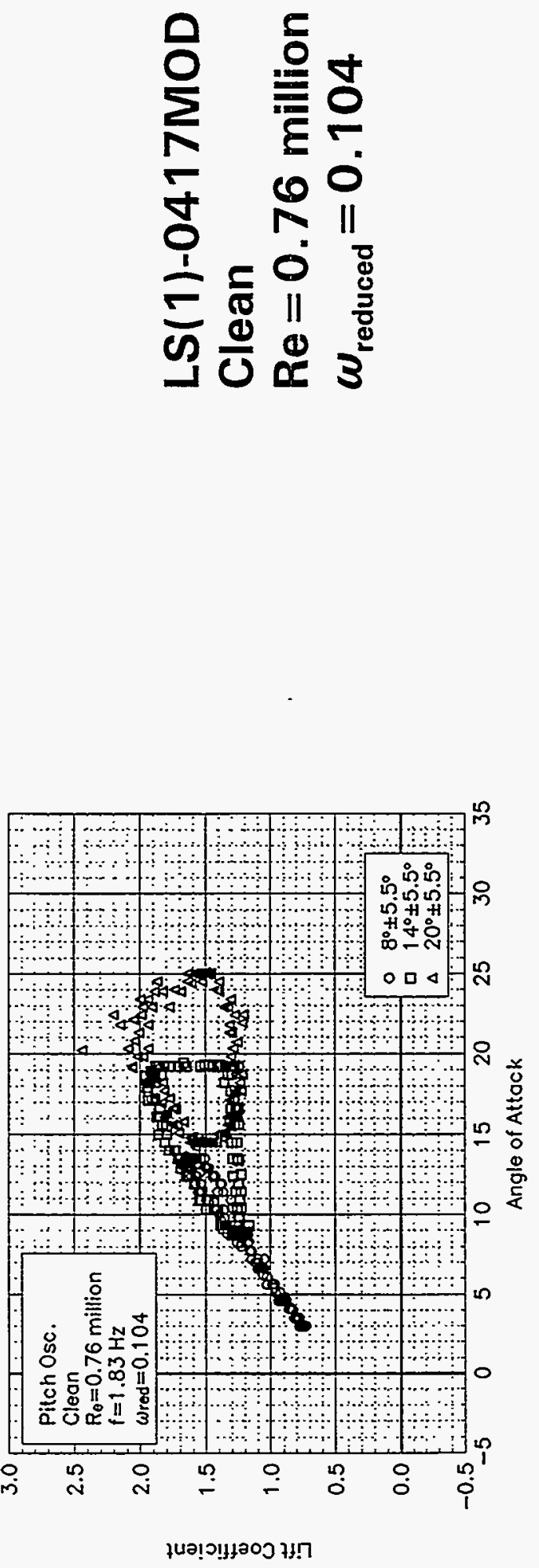

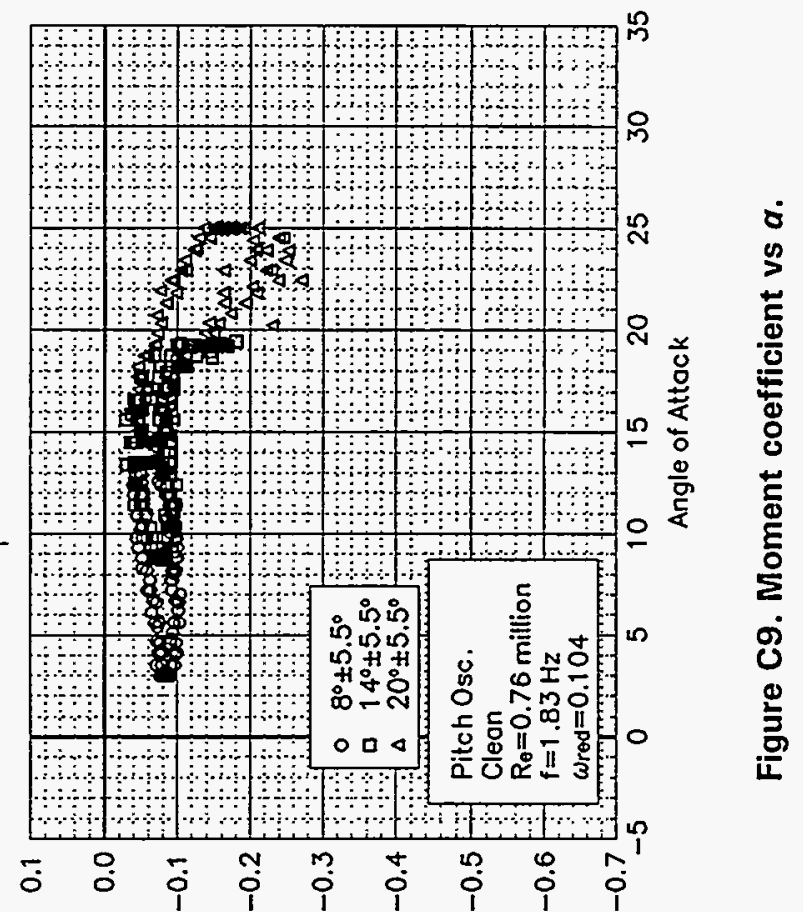

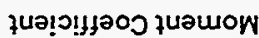

ú

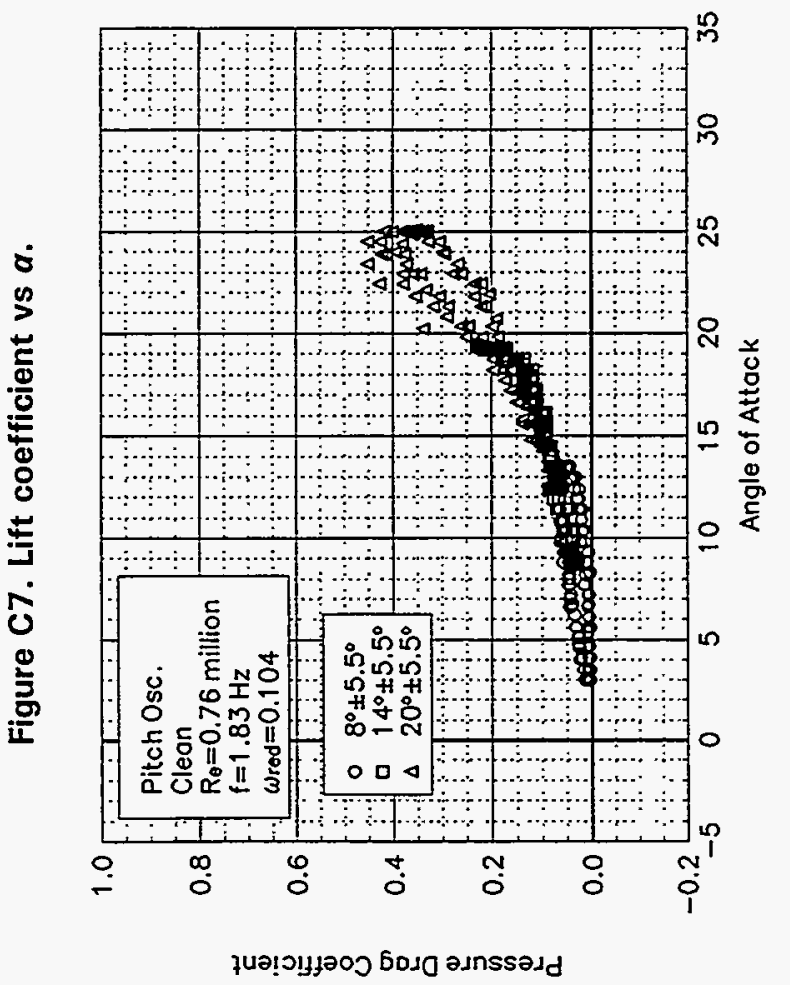

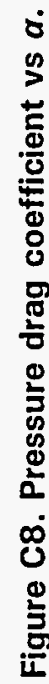



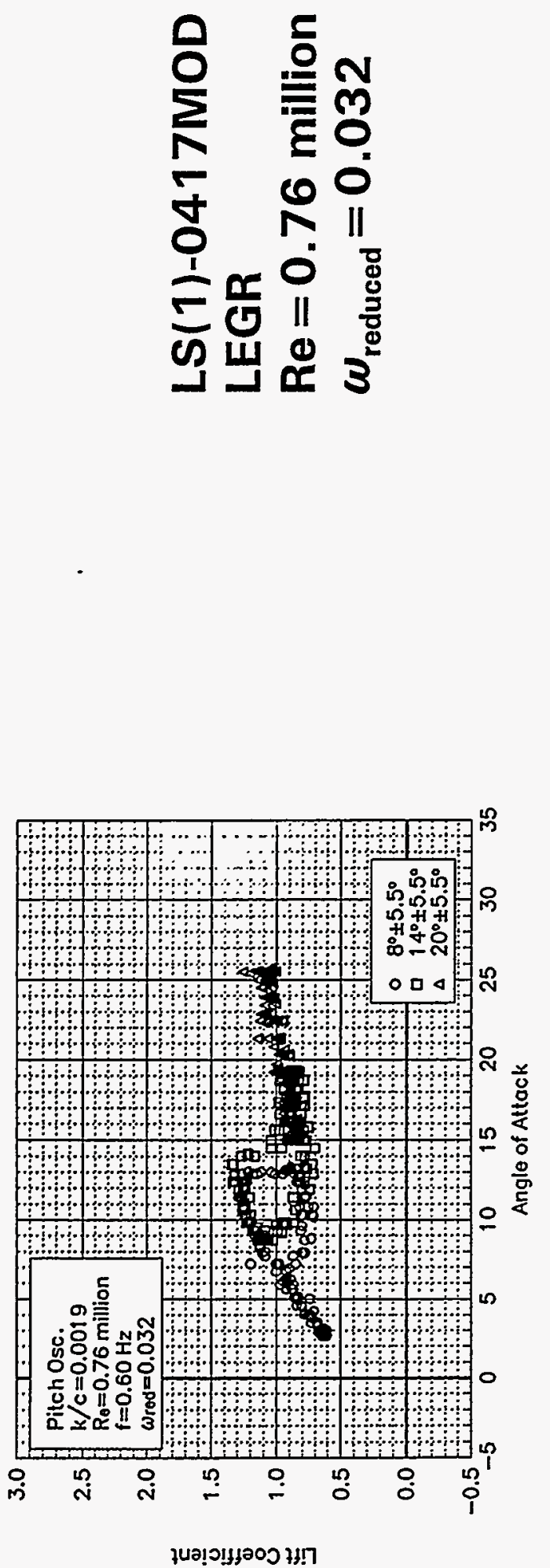

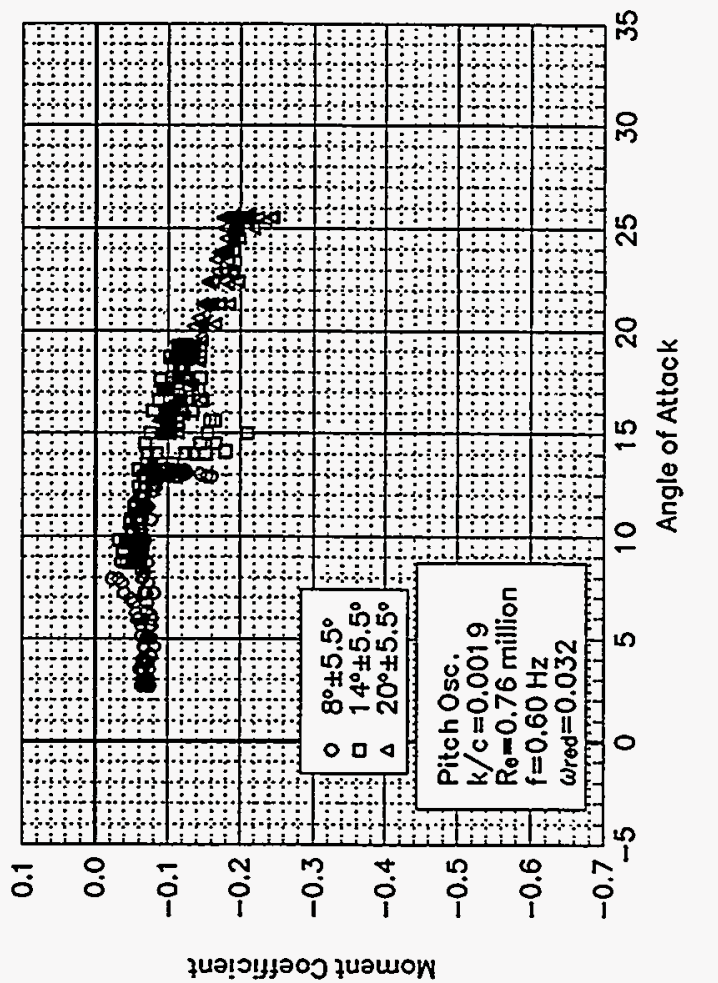

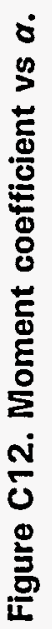

U

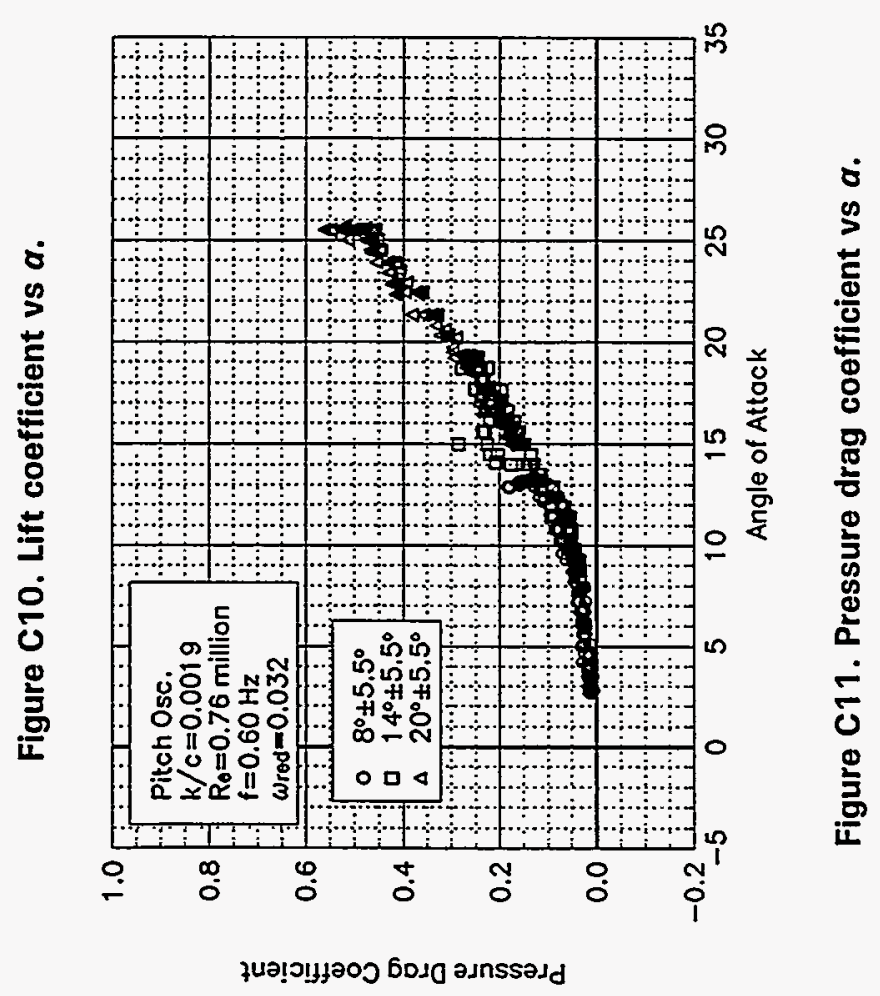




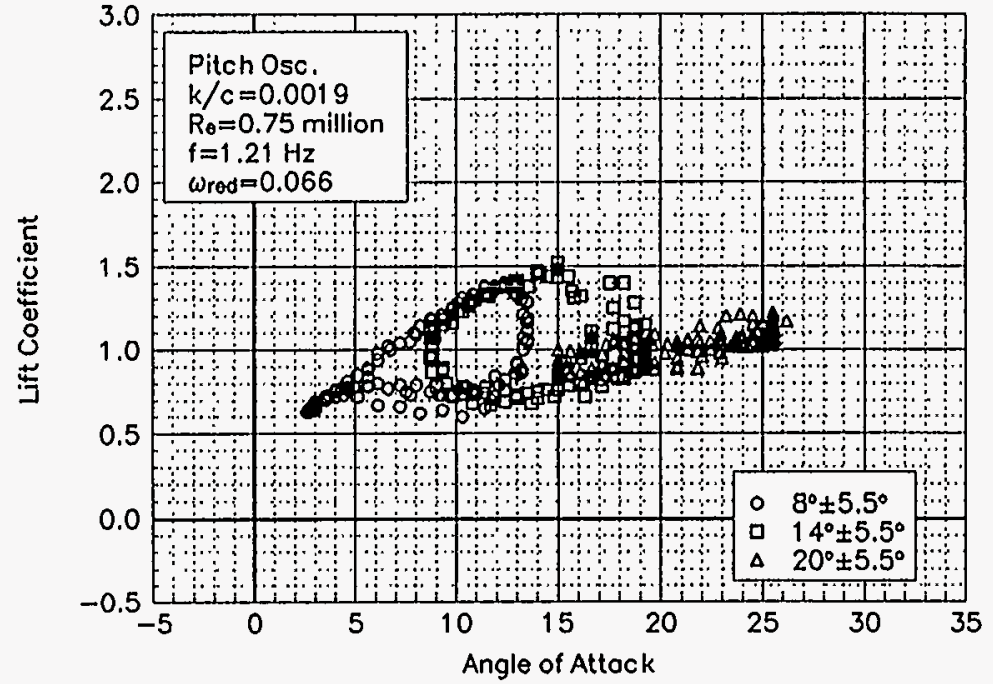

Figure C13. Lift coefficient vs $a$.

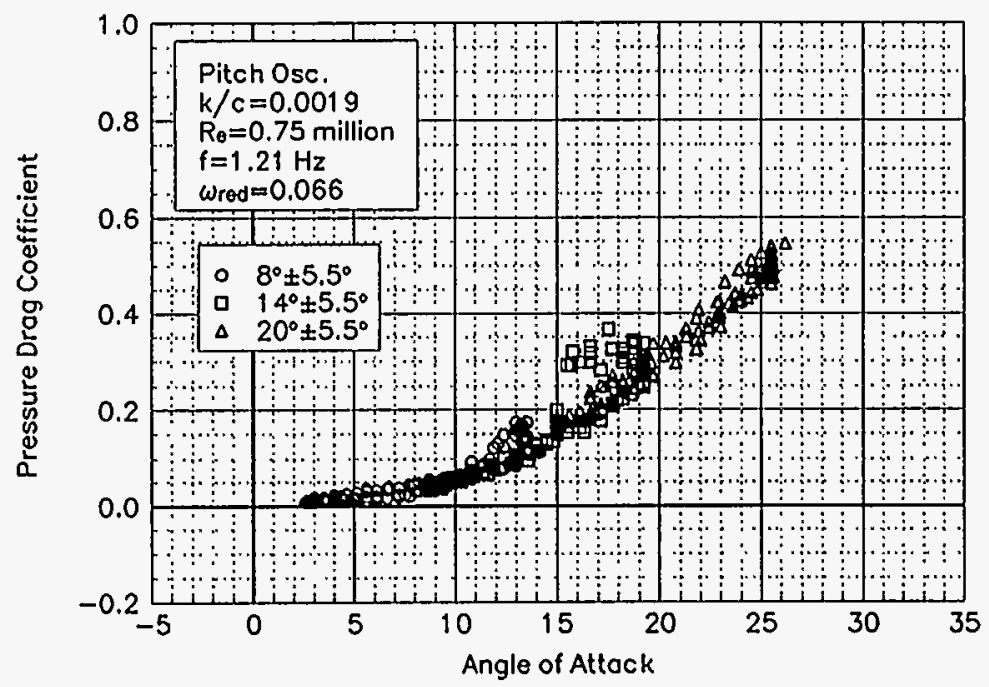

Figure C14. Pressure drag coefficient vs $a$.

\section{LS(1)-0417MOD LEGR \\ $\mathrm{Re}=0.75$ million \\ $\omega_{\text {reduced }}=0.066$}

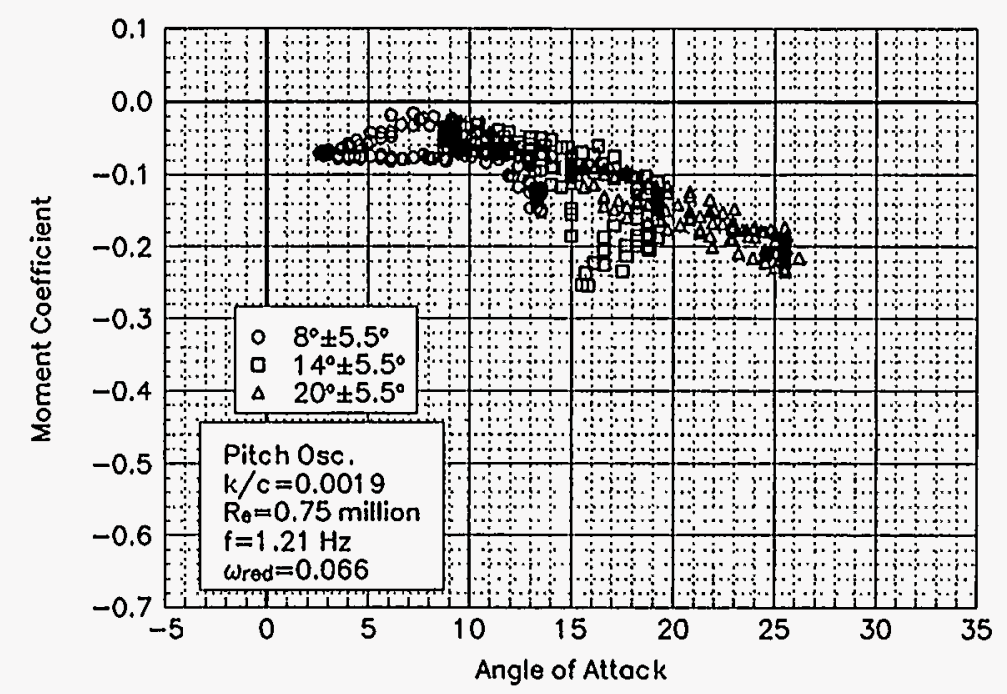

Figure C15. Moment coefficient vs $a$. 

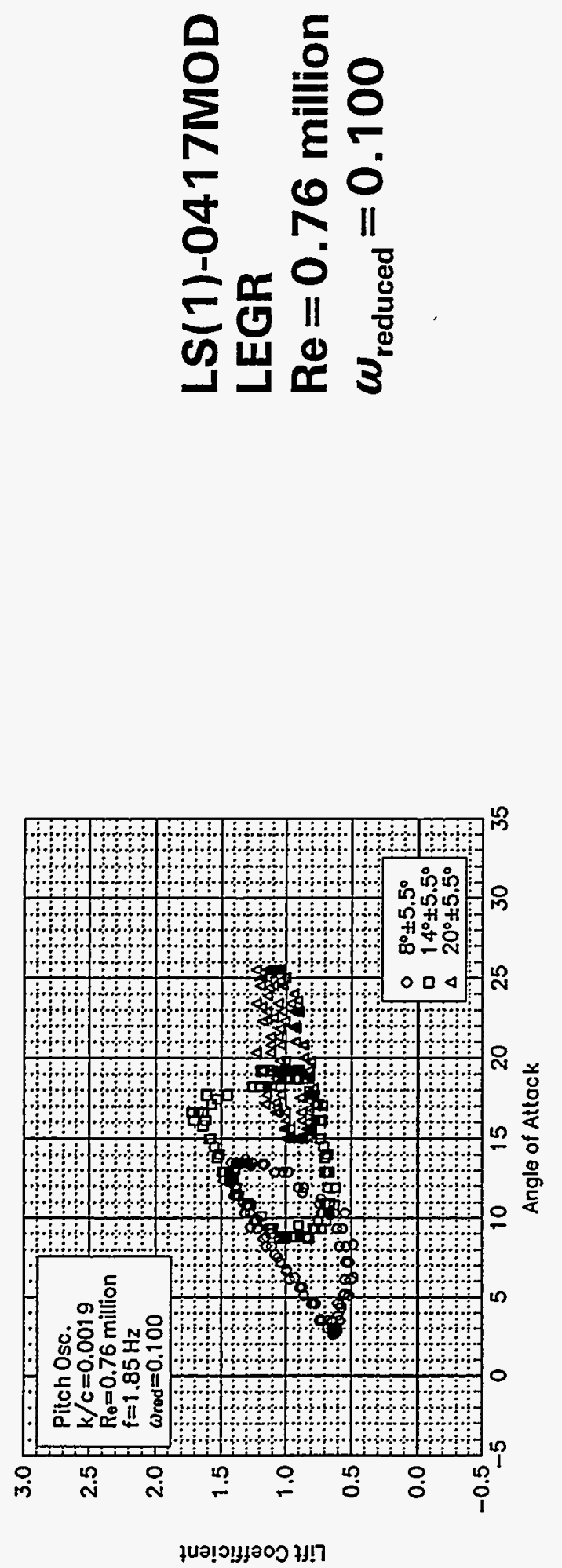

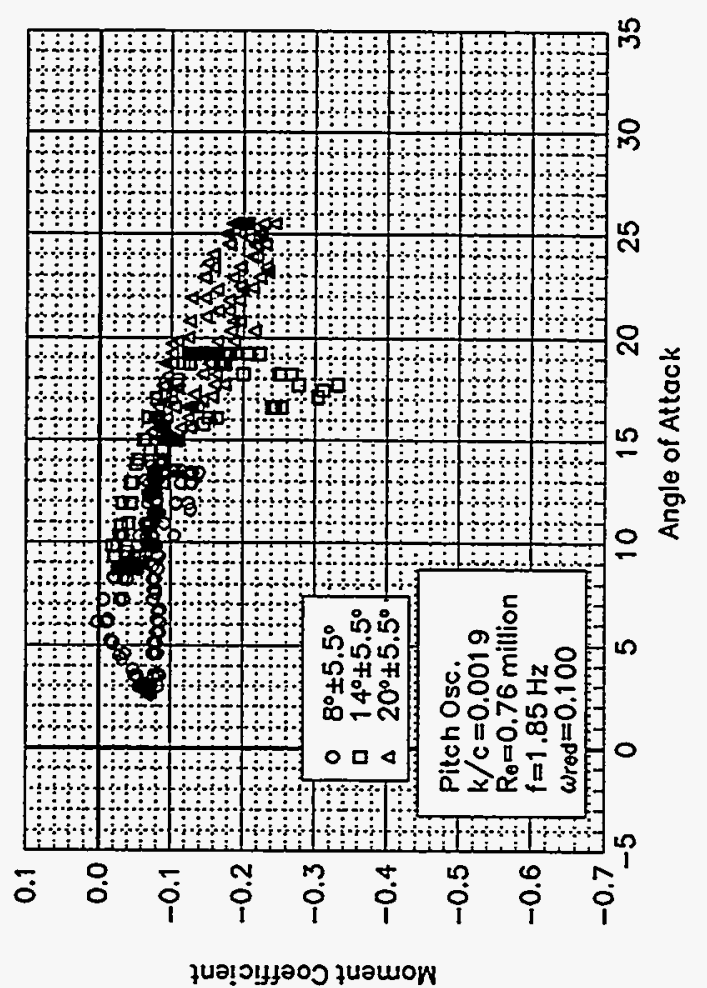

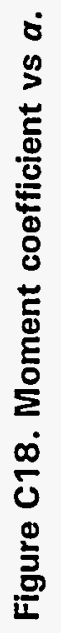

i

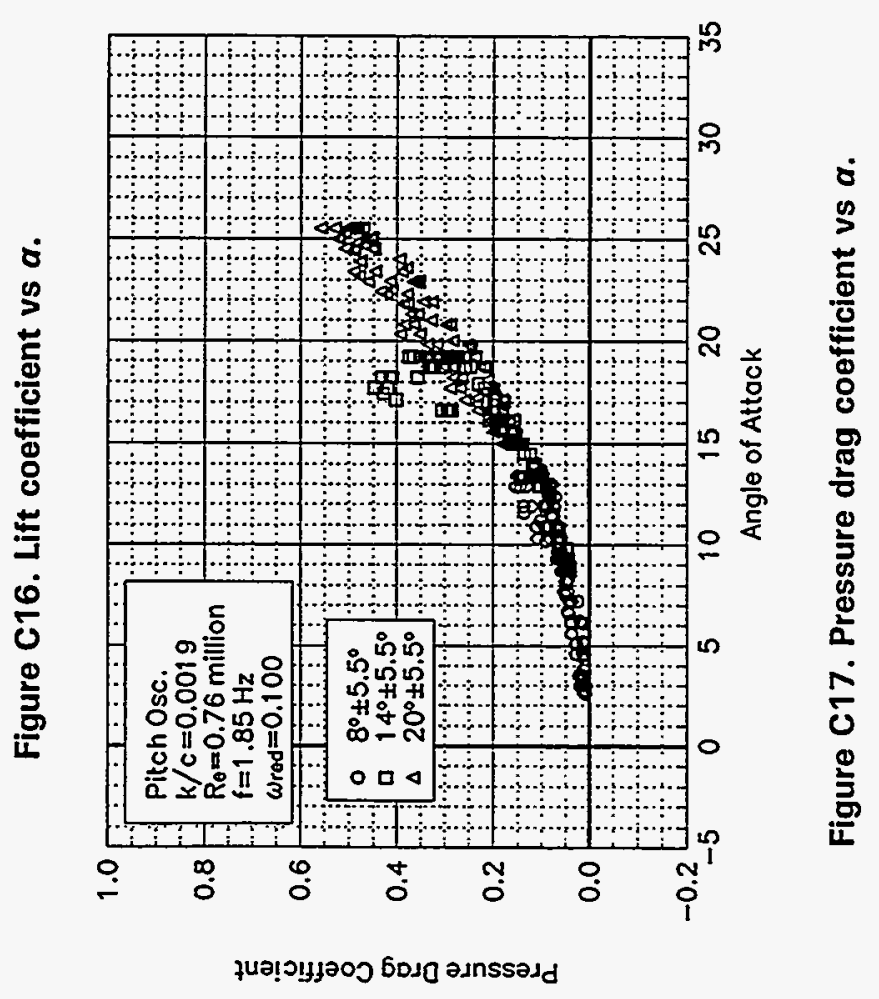




\section{Unsteady Airfoil Characteristics}

$\pm 5.5^{\circ}$ Sine, $\operatorname{Re}=1$ million 

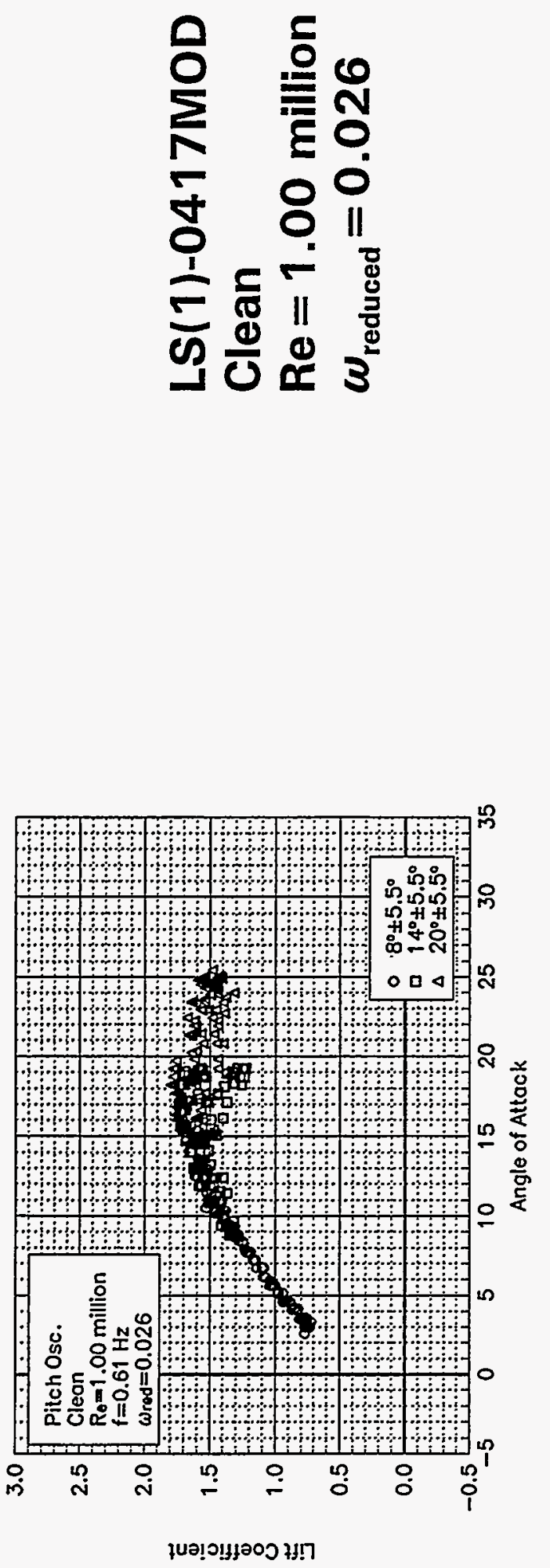

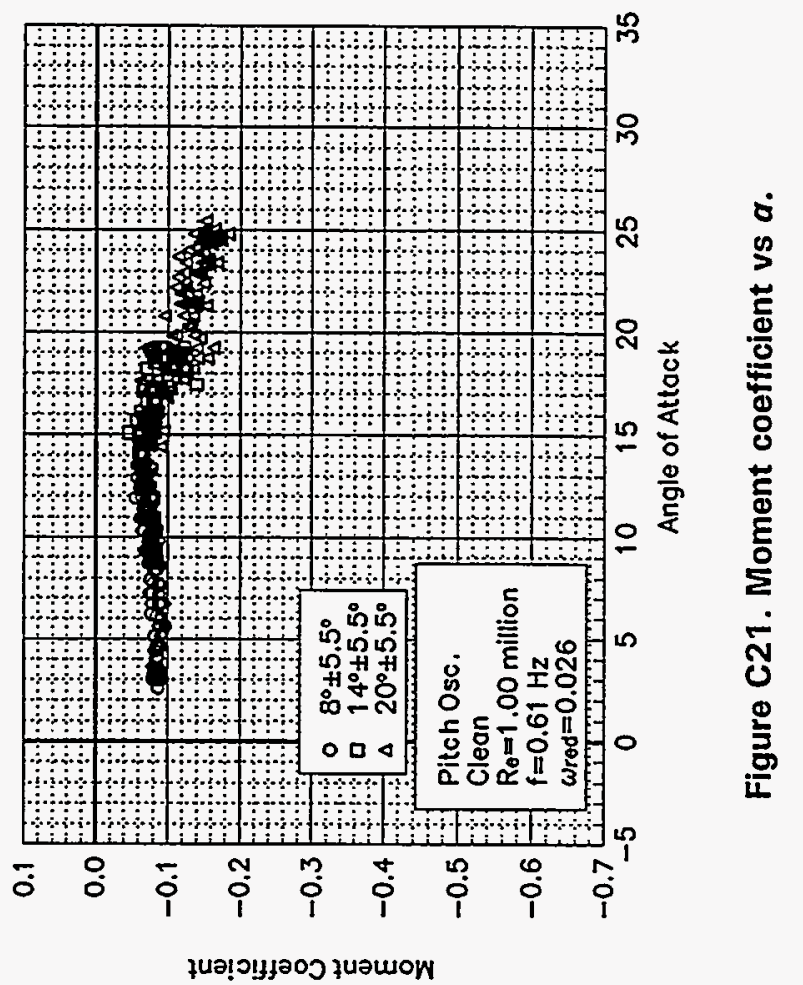

$\overline{0}$

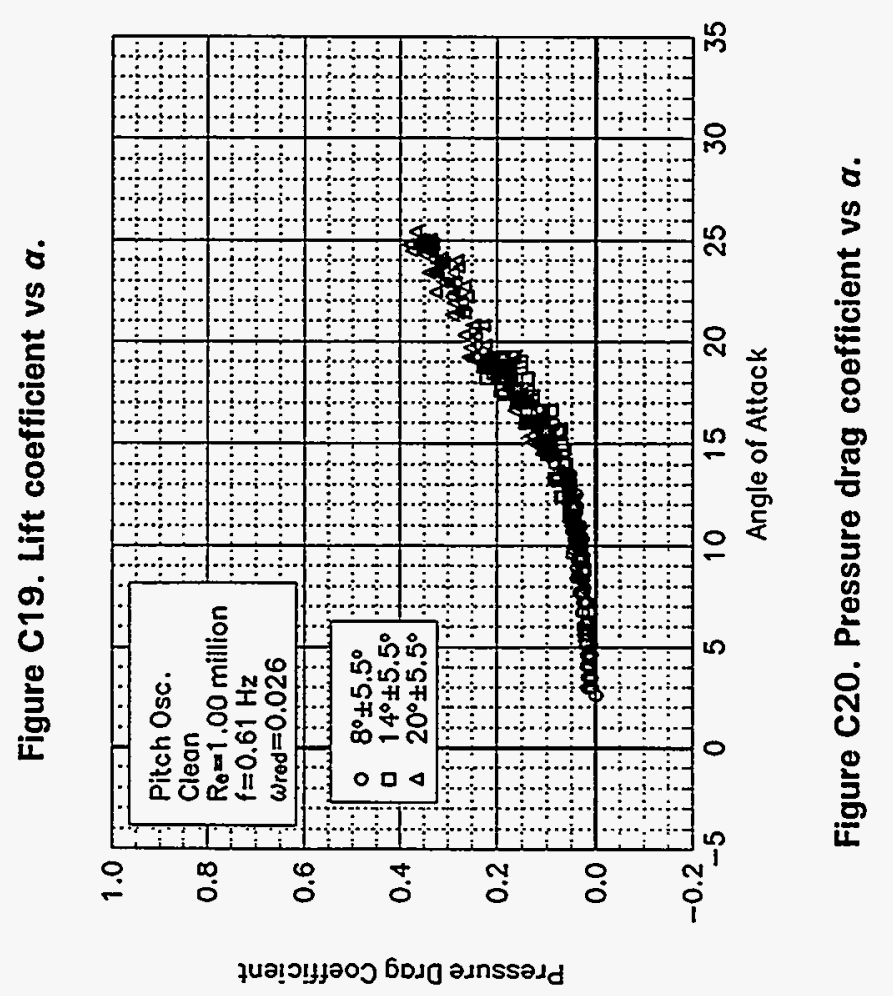




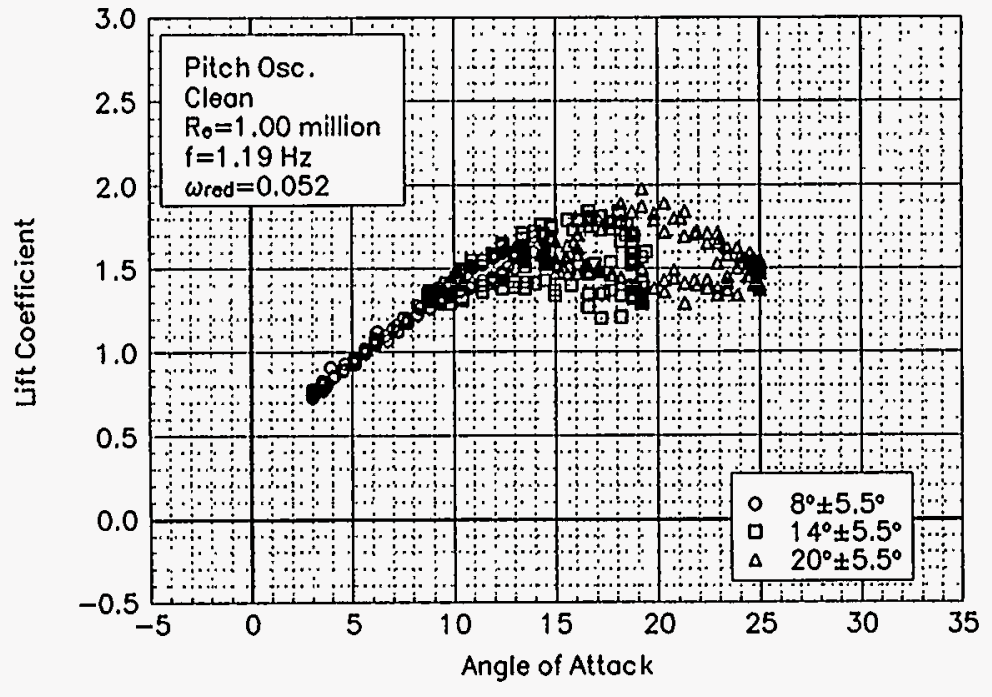

Figure C22. Lift coefficient vs $a$.

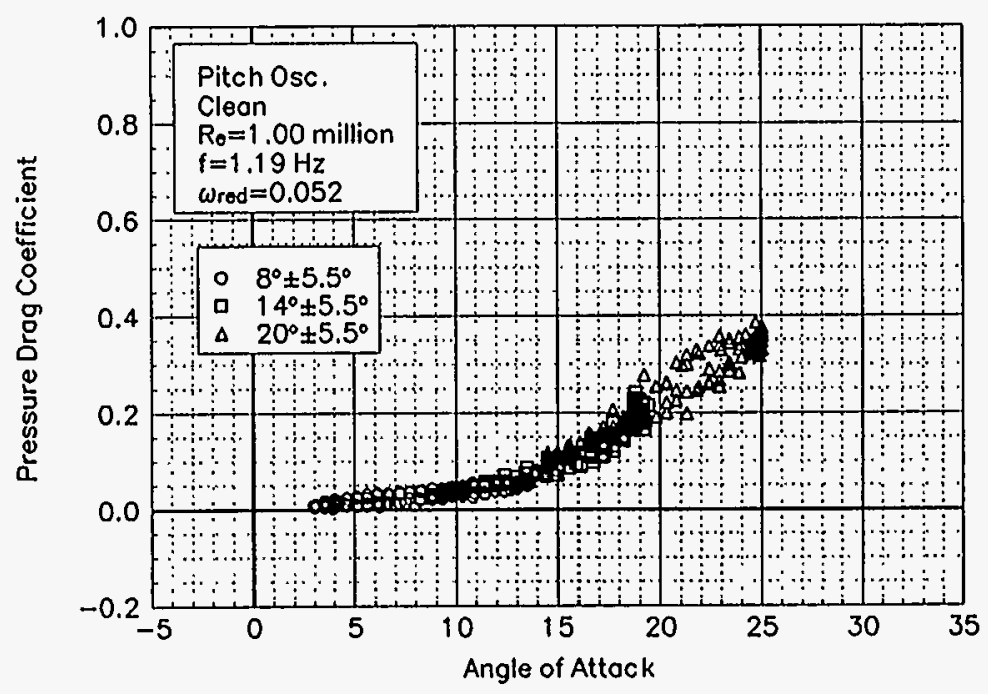

Figure C23. Pressure drag coefficient vs $a$.

\section{LS(1)-0417MOD Clean \\ $\mathrm{Re}=1.00$ million \\ $\omega_{\text {reduced }}=0.052$}

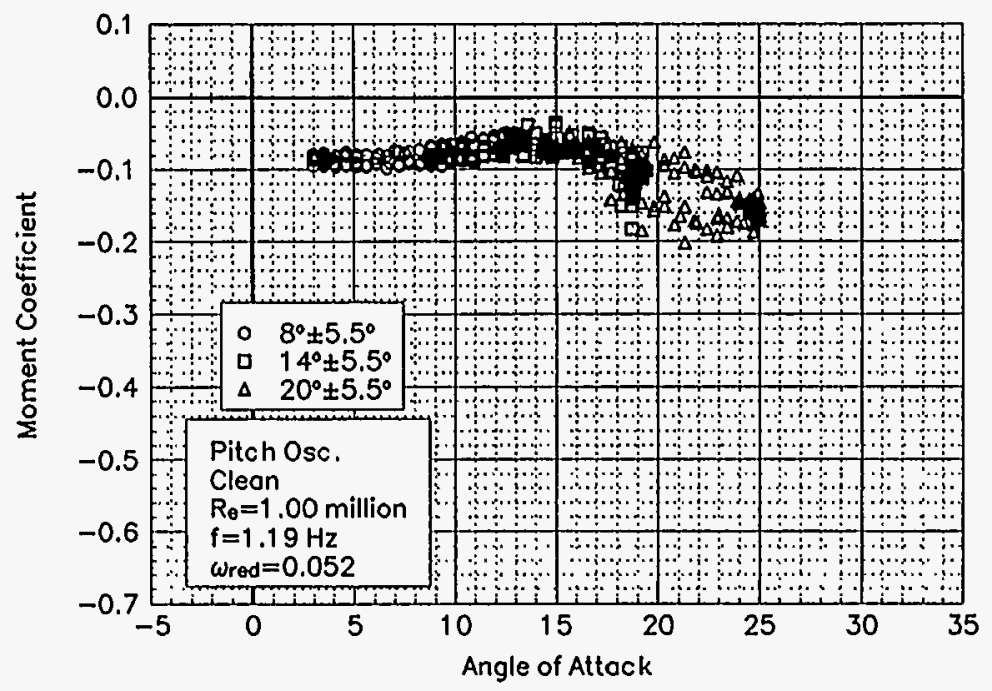

Figure C24. Moment coefficient vs $a$. 

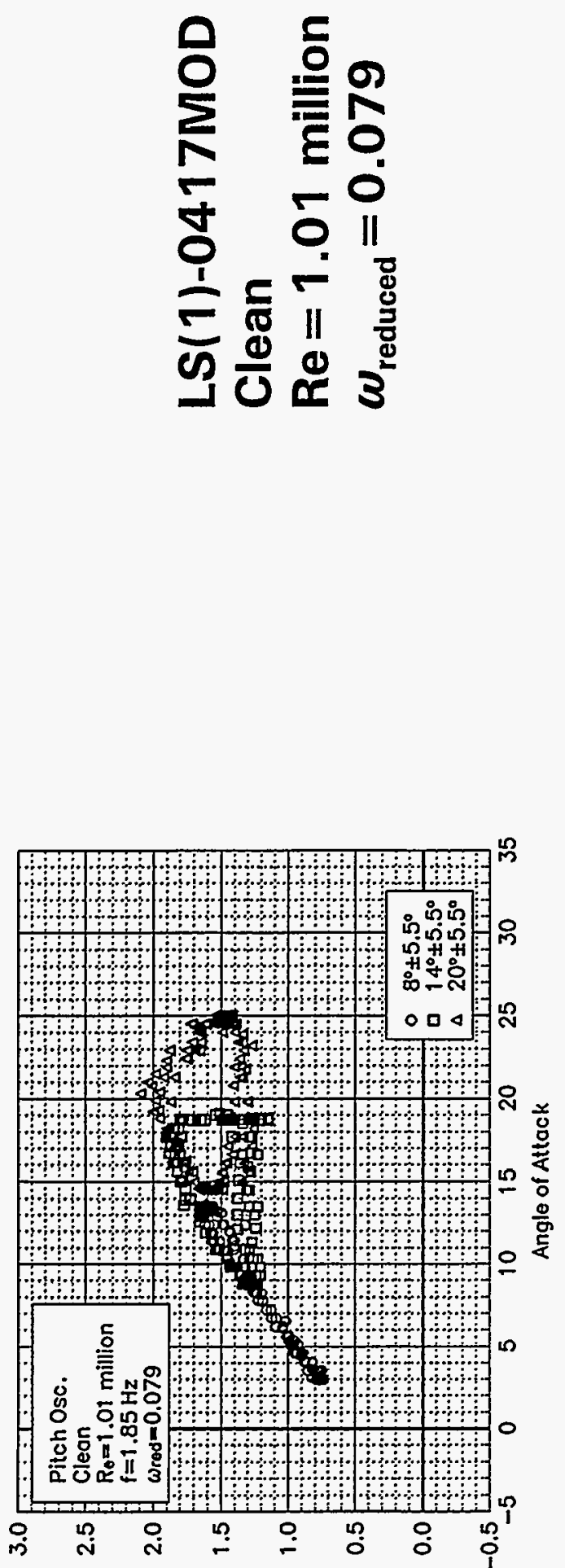

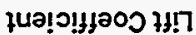

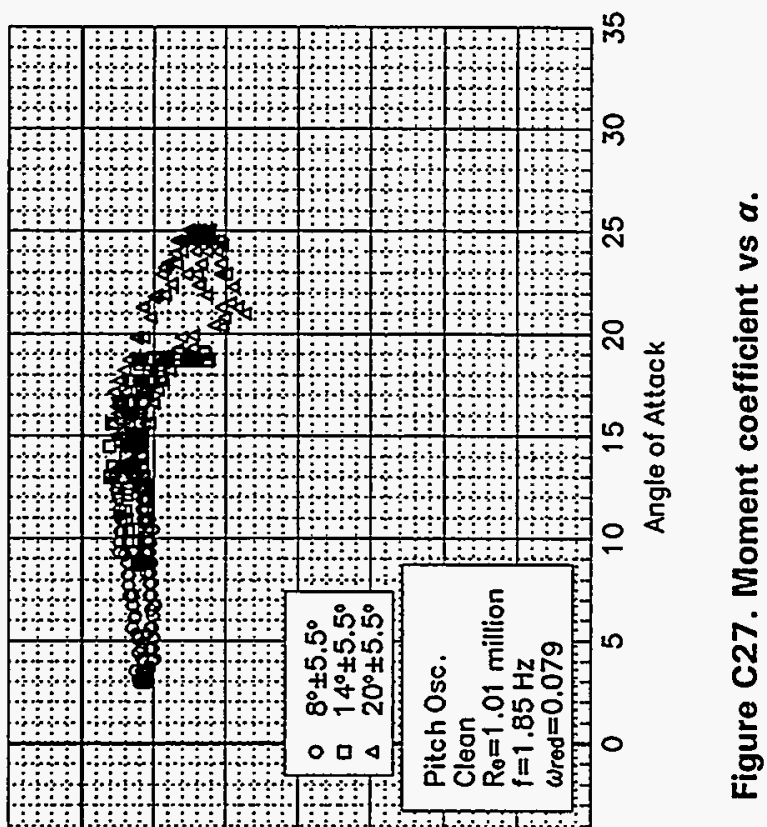

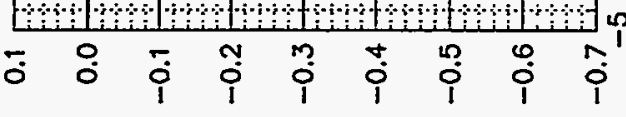

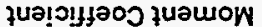

$\frac{m}{0}$

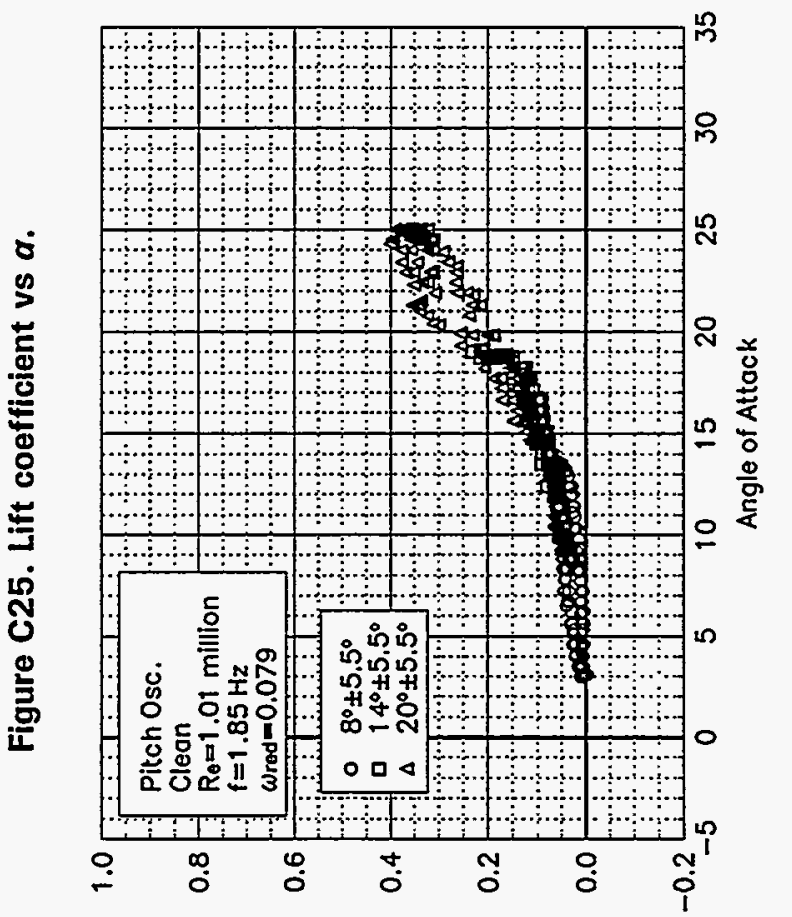

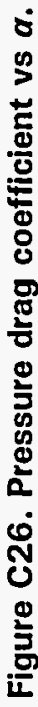

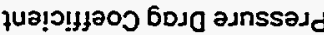



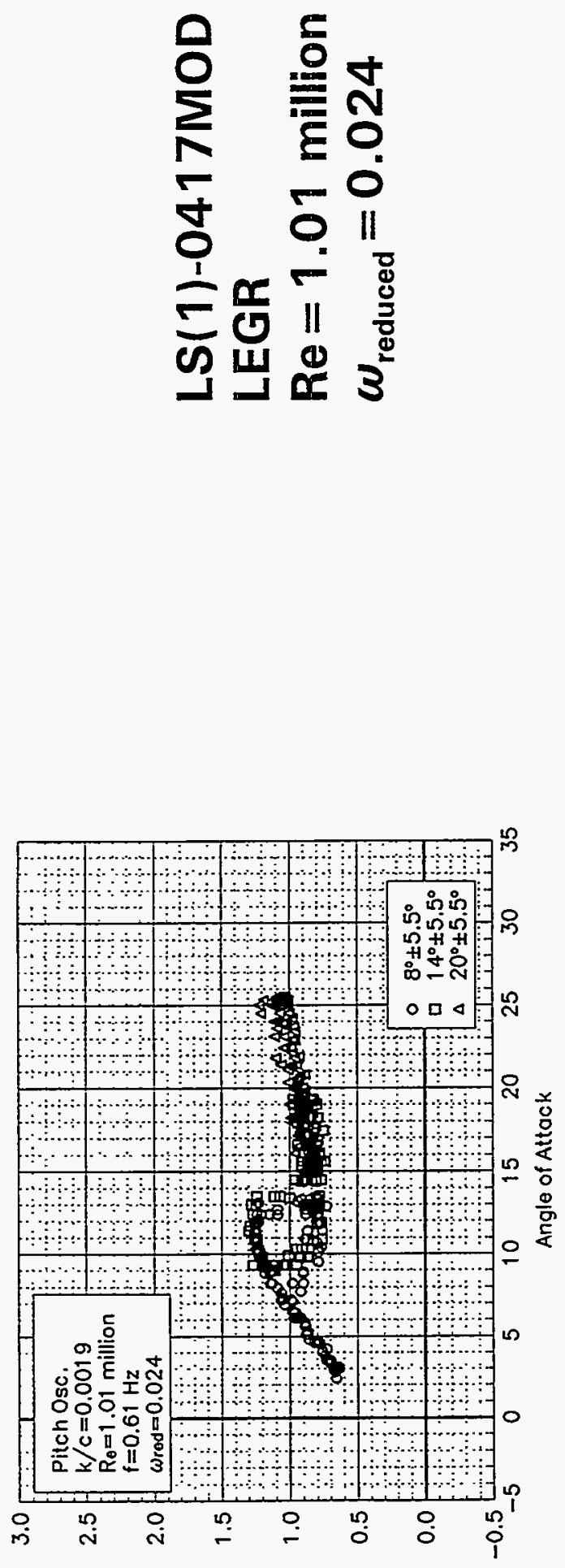

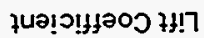

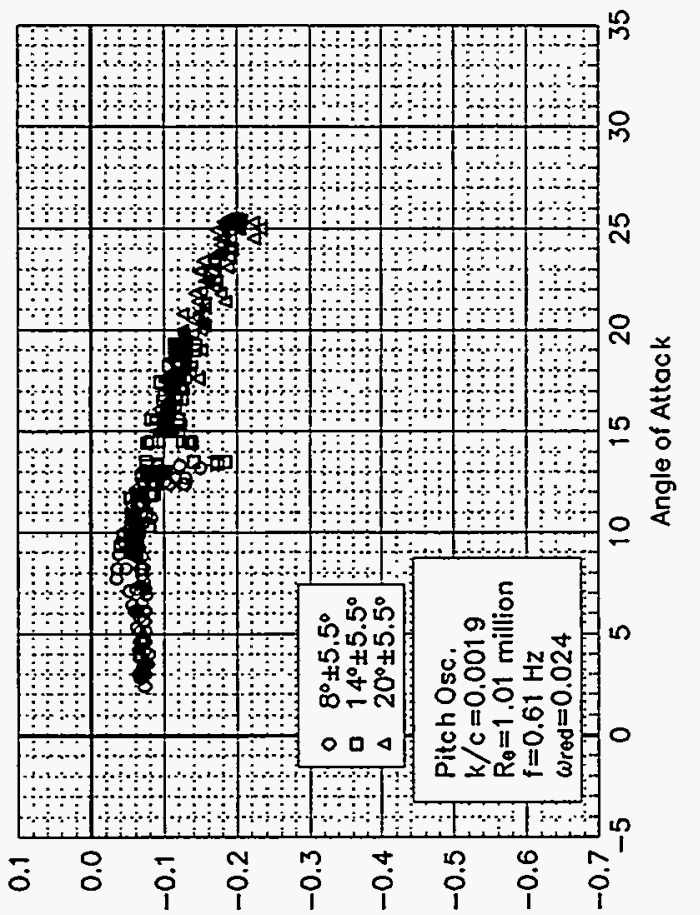

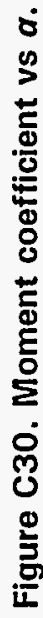

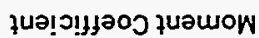

$\frac{ \pm}{0}$

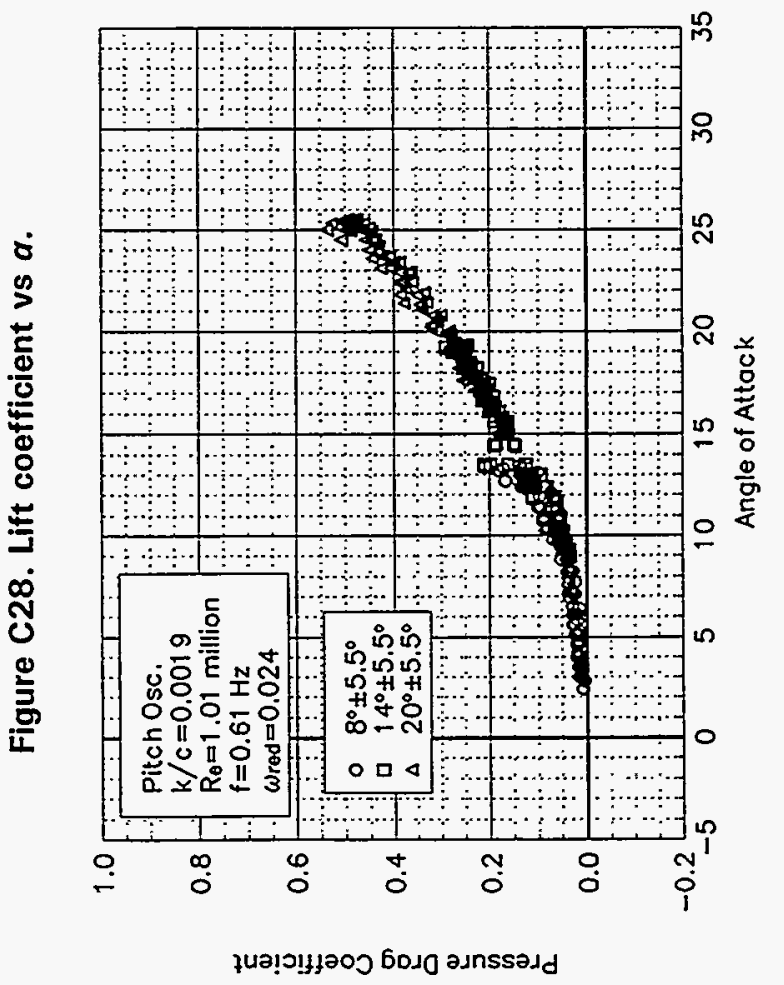

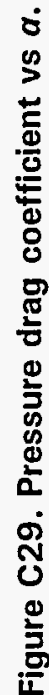



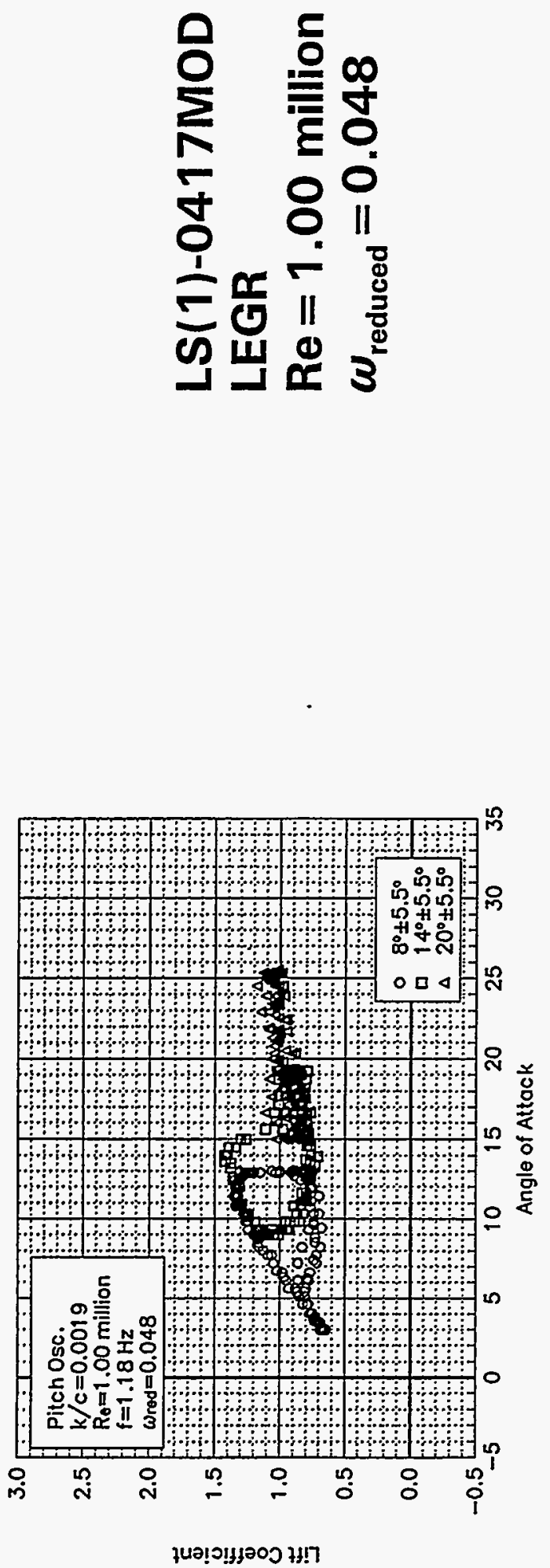

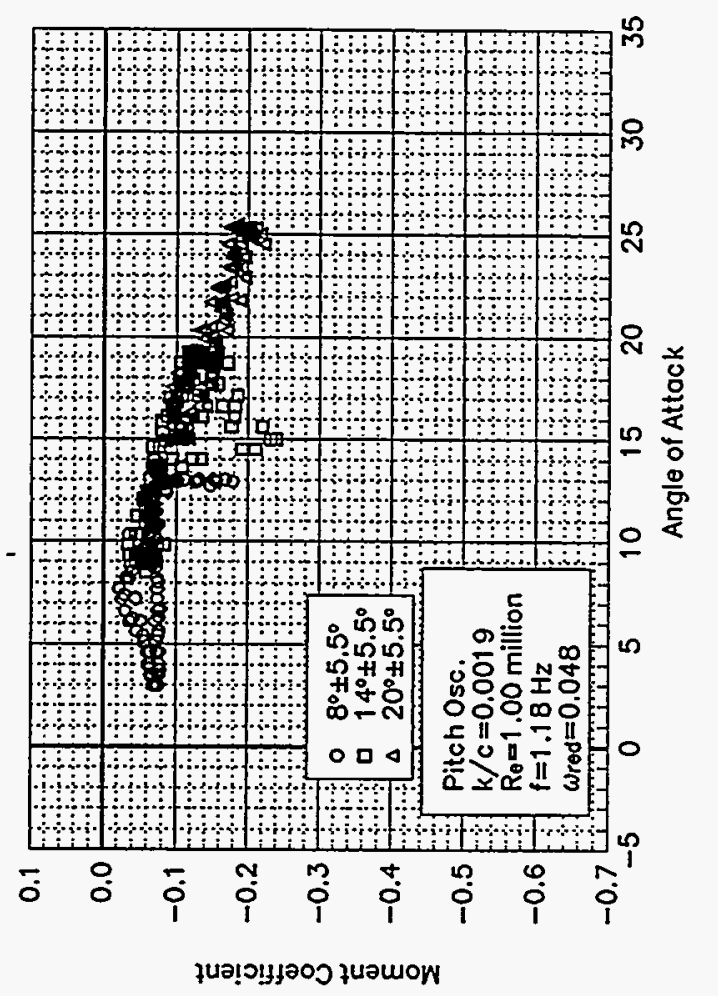

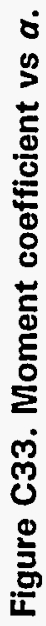

$\frac{n}{0}$

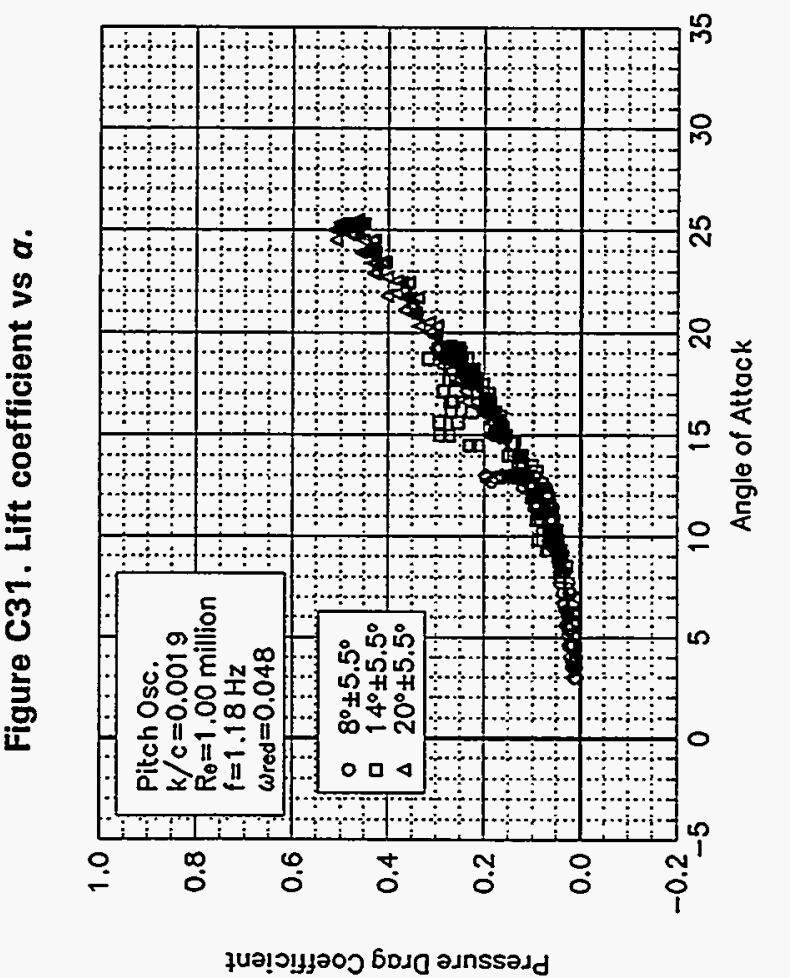

O 

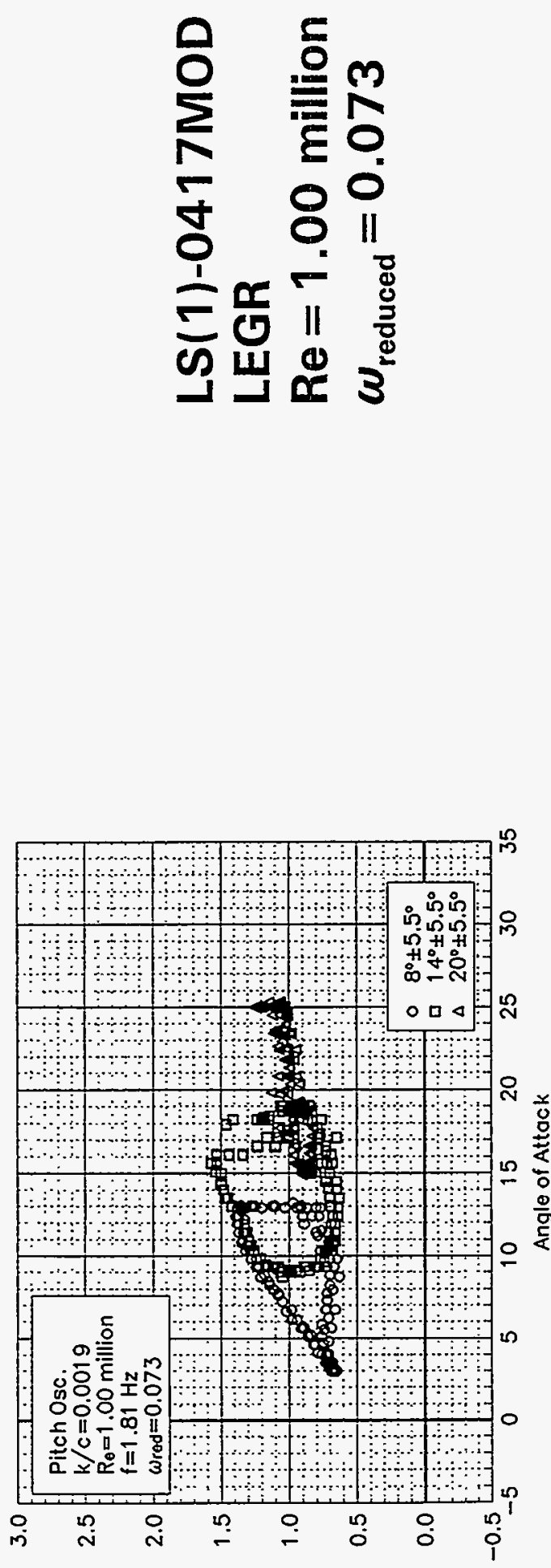

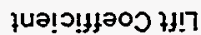

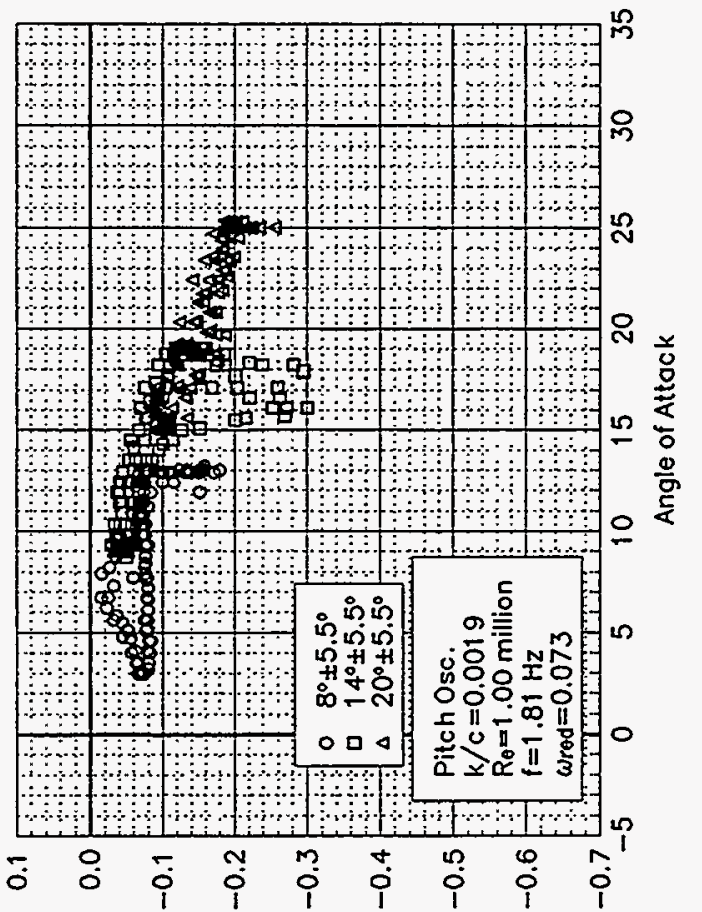

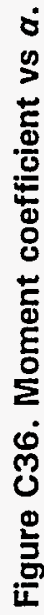

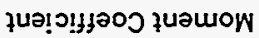

$\frac{6}{0}$

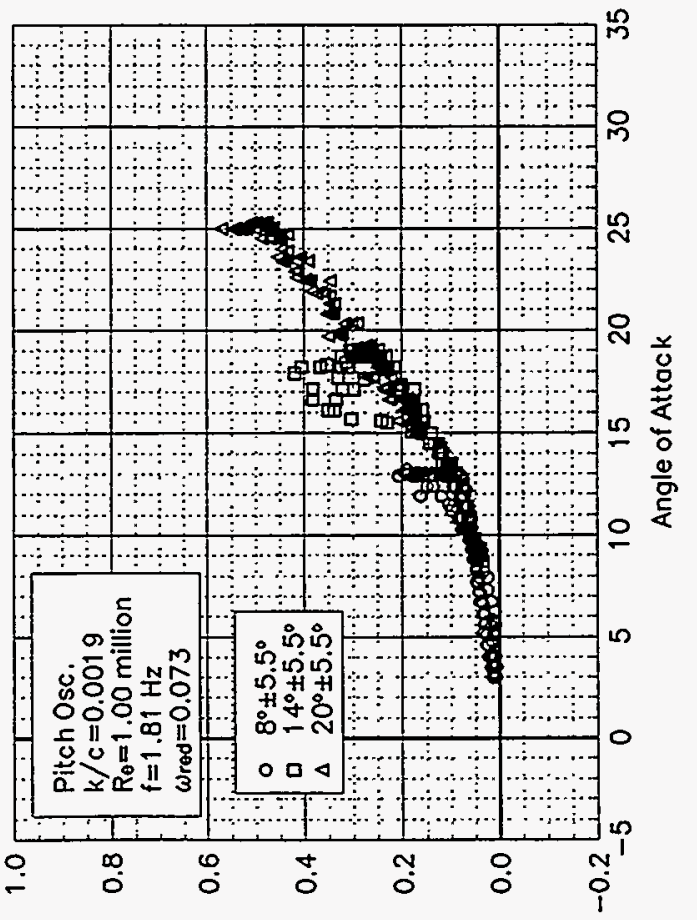

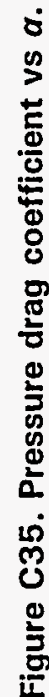

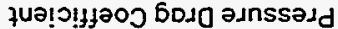




\section{Unsteady Airfoil Characteristics \\ $\pm 5.5^{\circ}$ Sine, $\operatorname{Re}=1.25$ million}



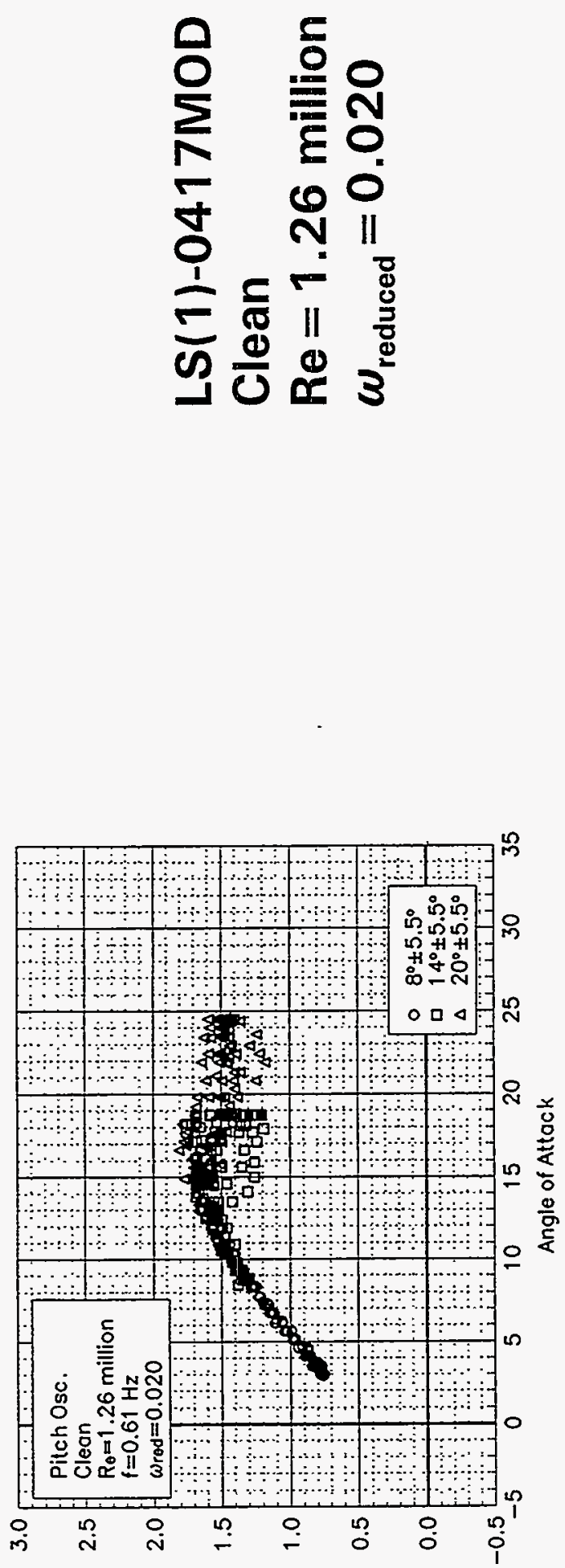

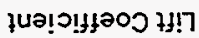

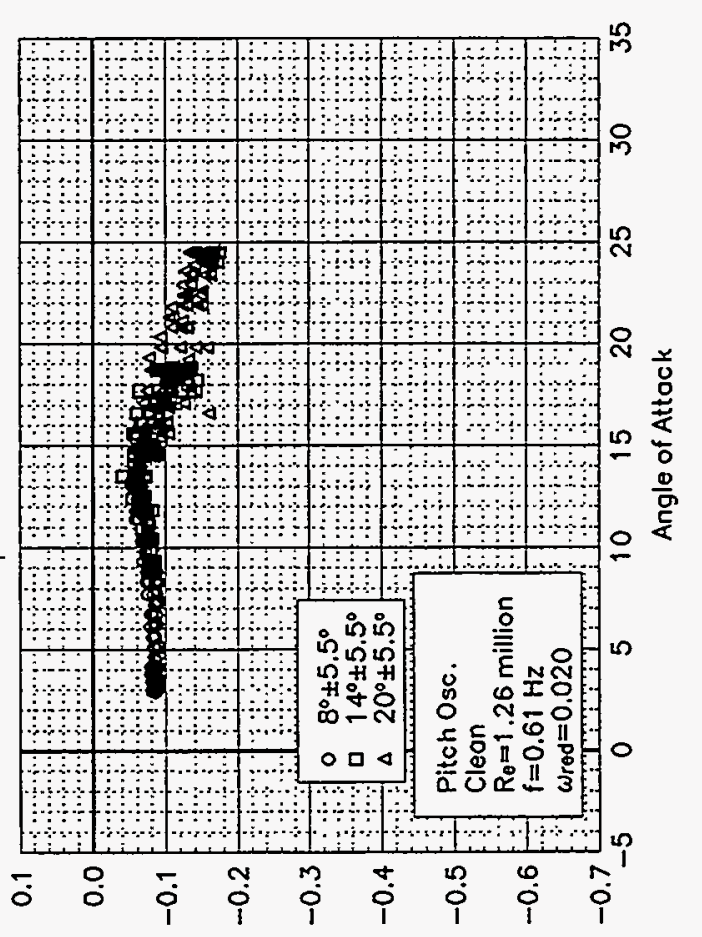

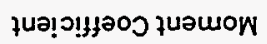

$\frac{\infty}{u}$

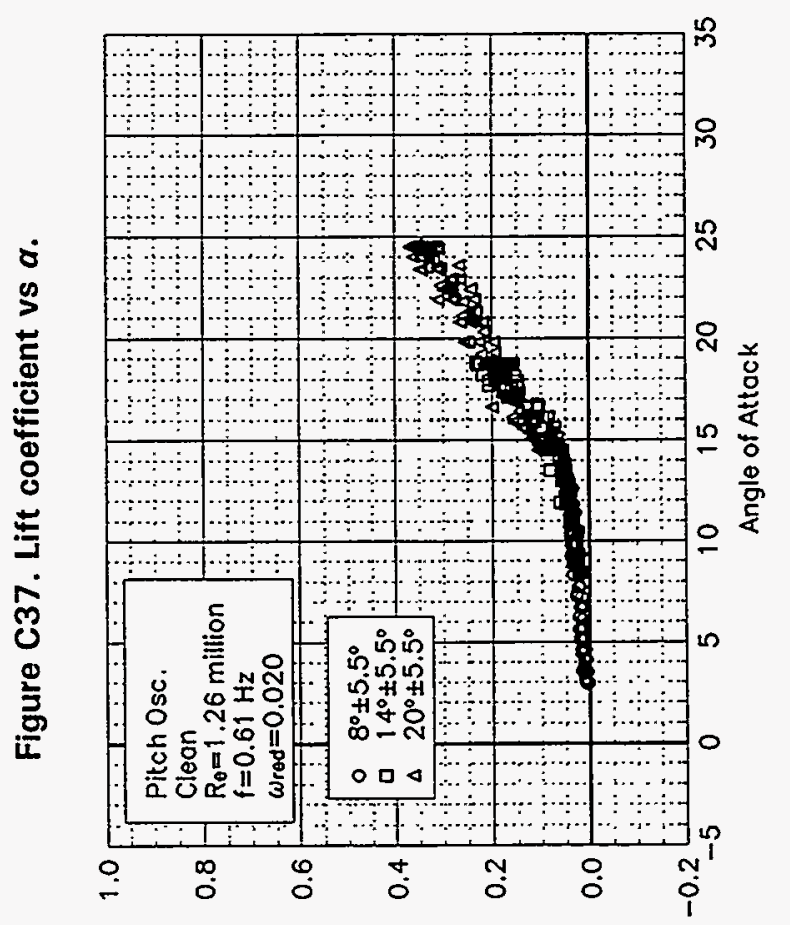

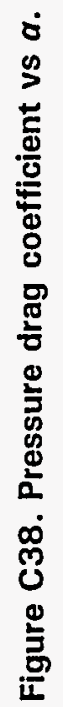

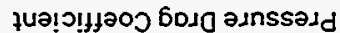



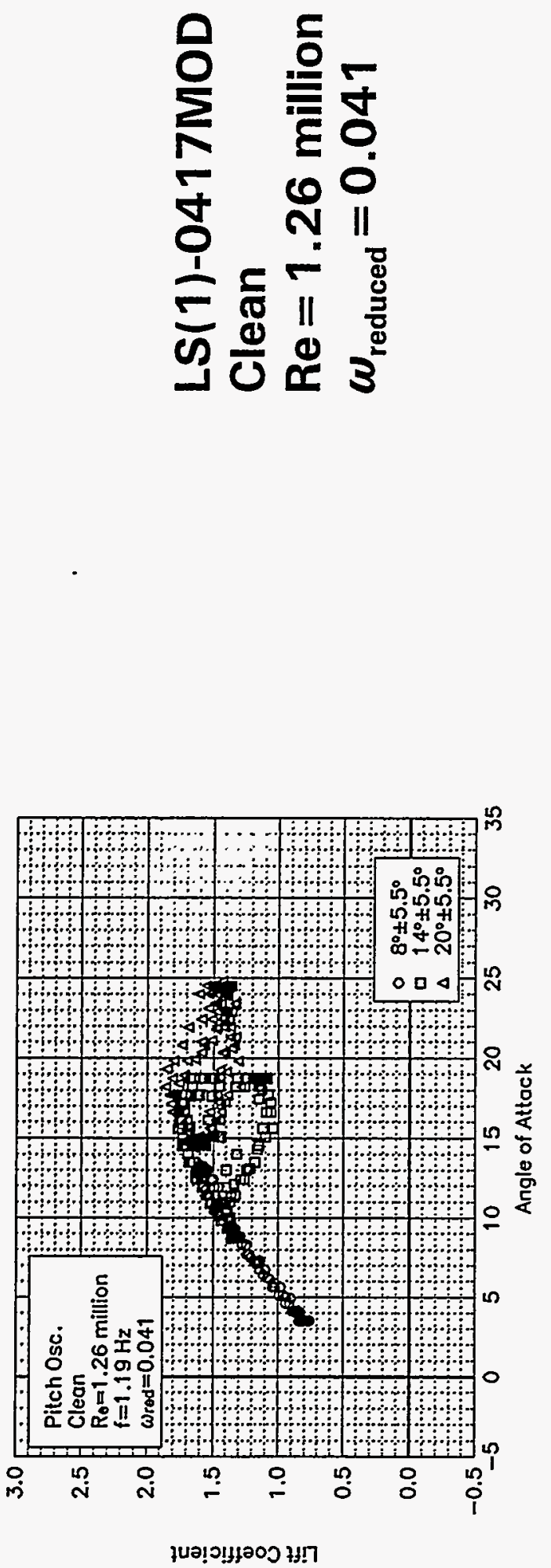

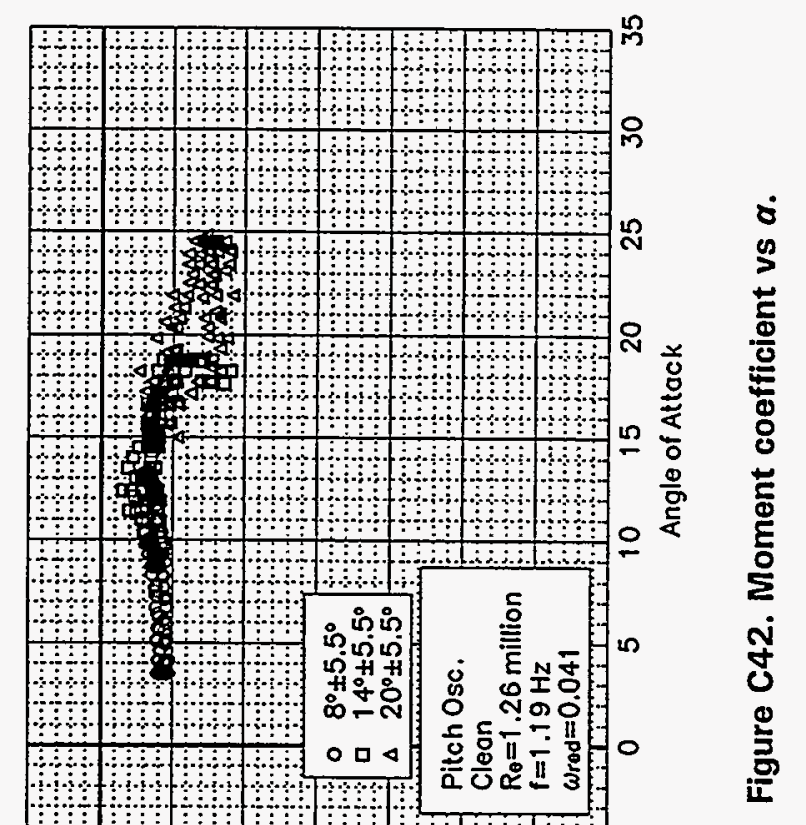

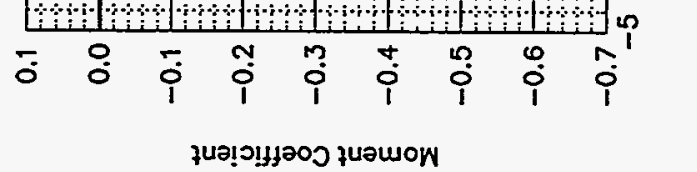

i

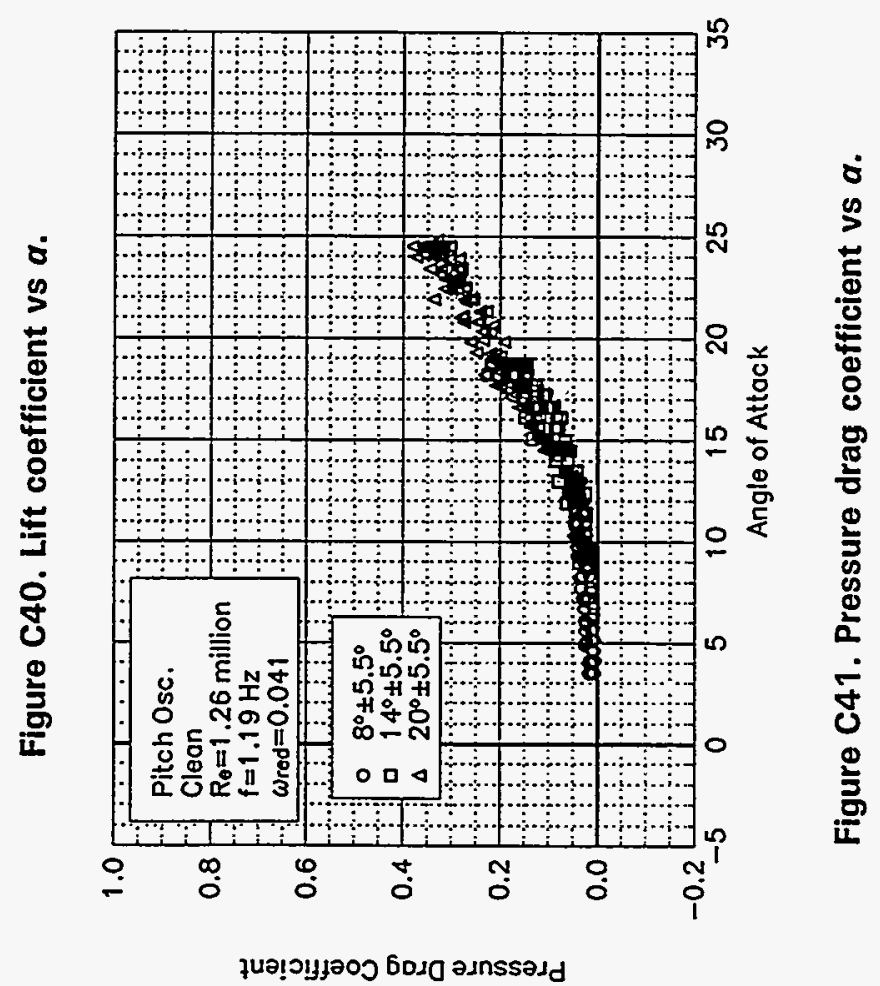


Pressure Drag Coefficient
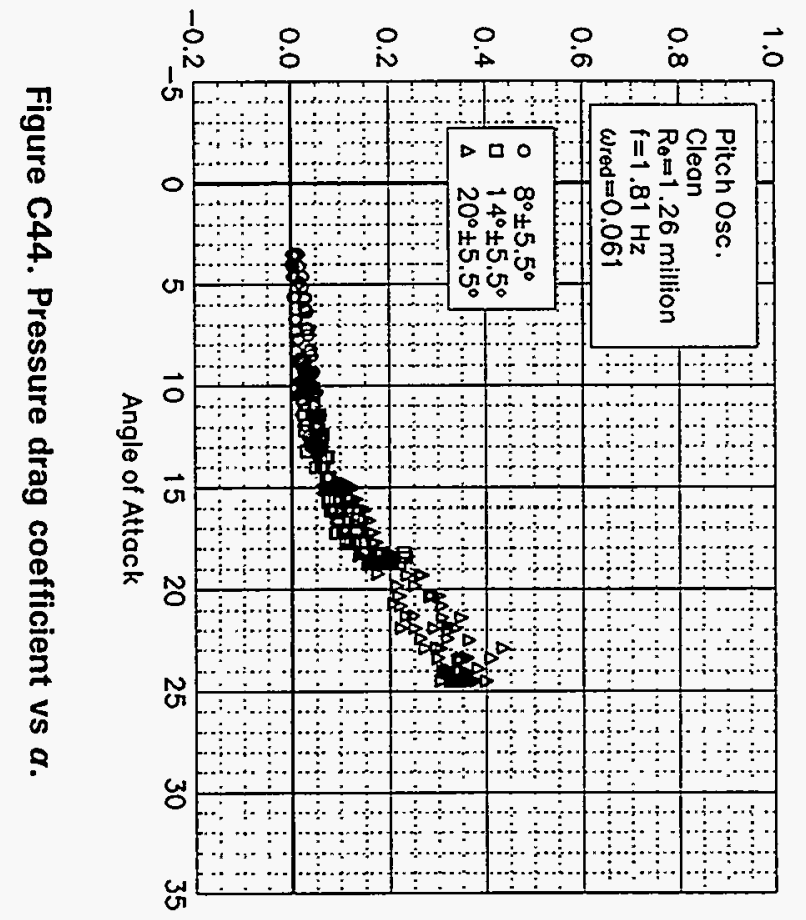

Lift Coefficient

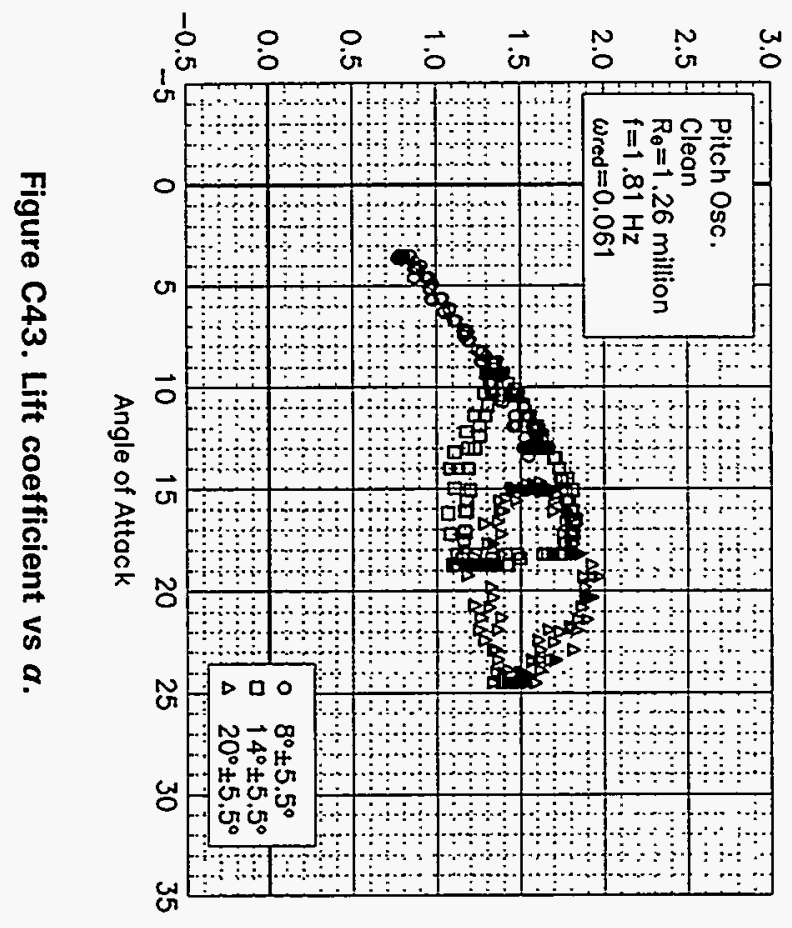

ثิ
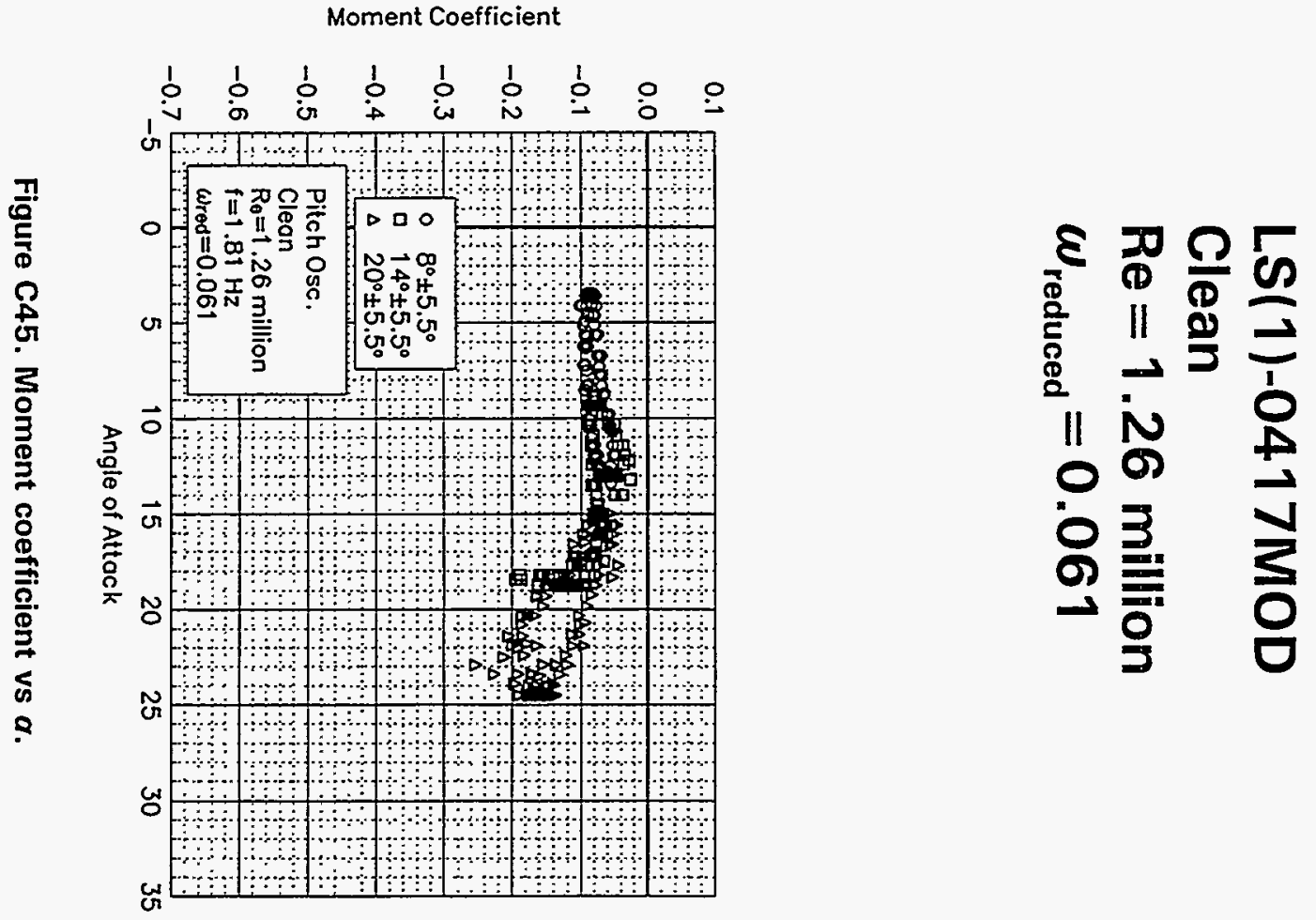

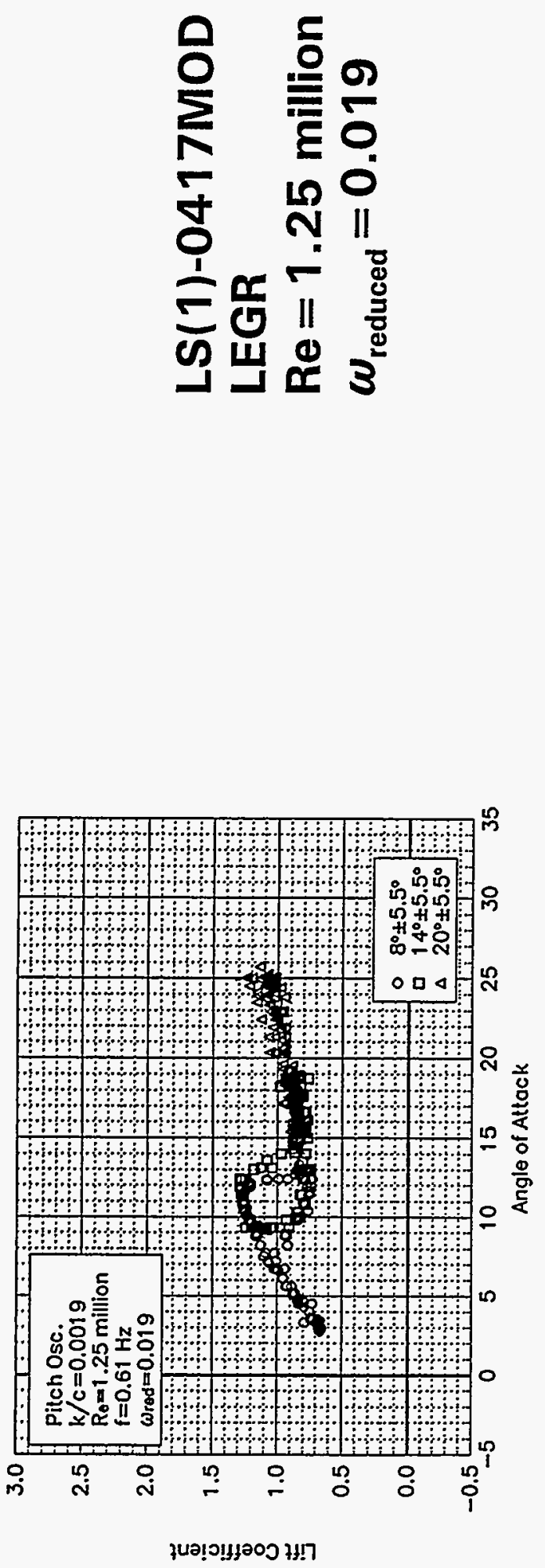

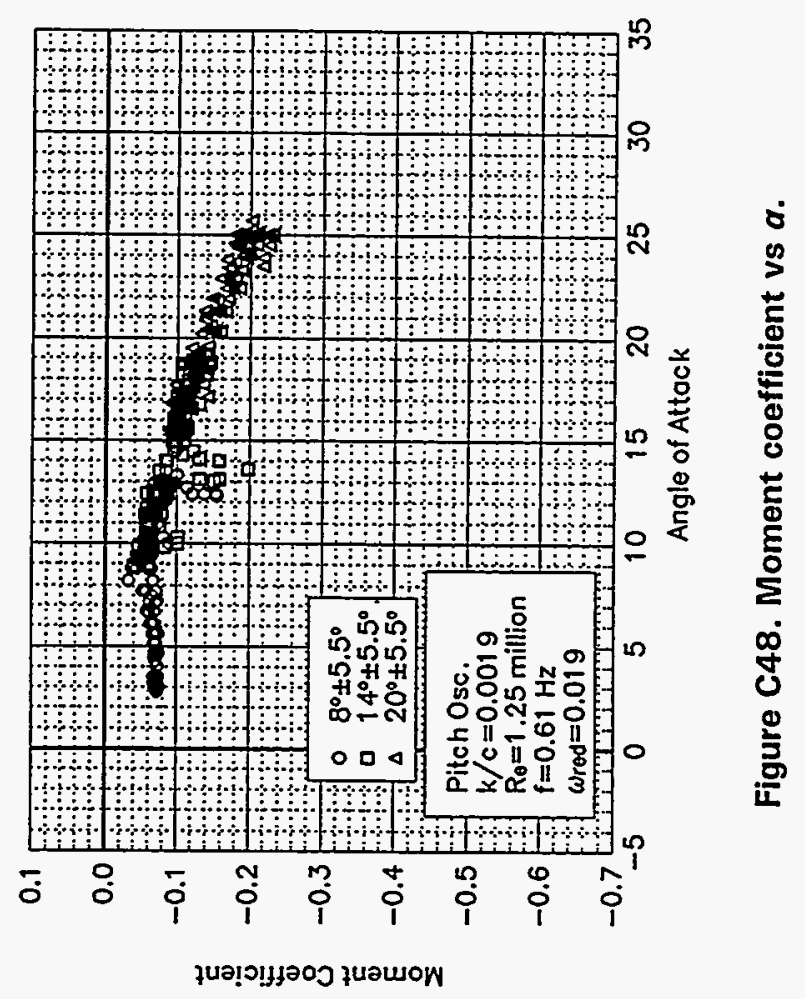

ริ

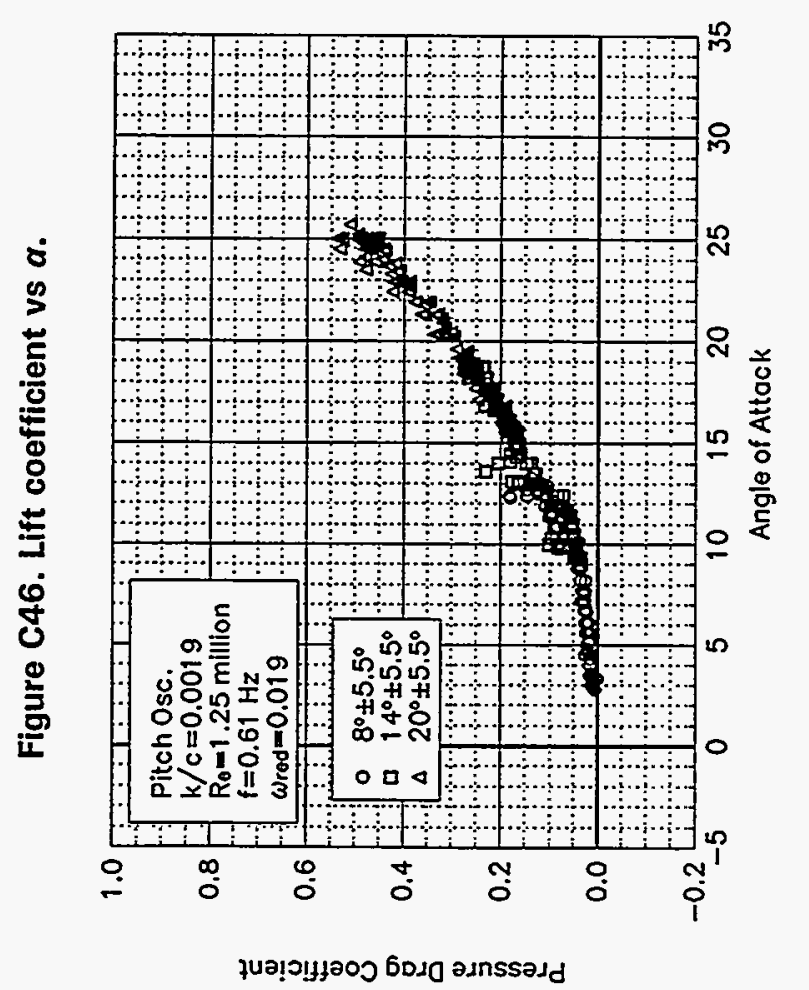

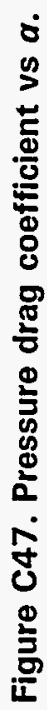



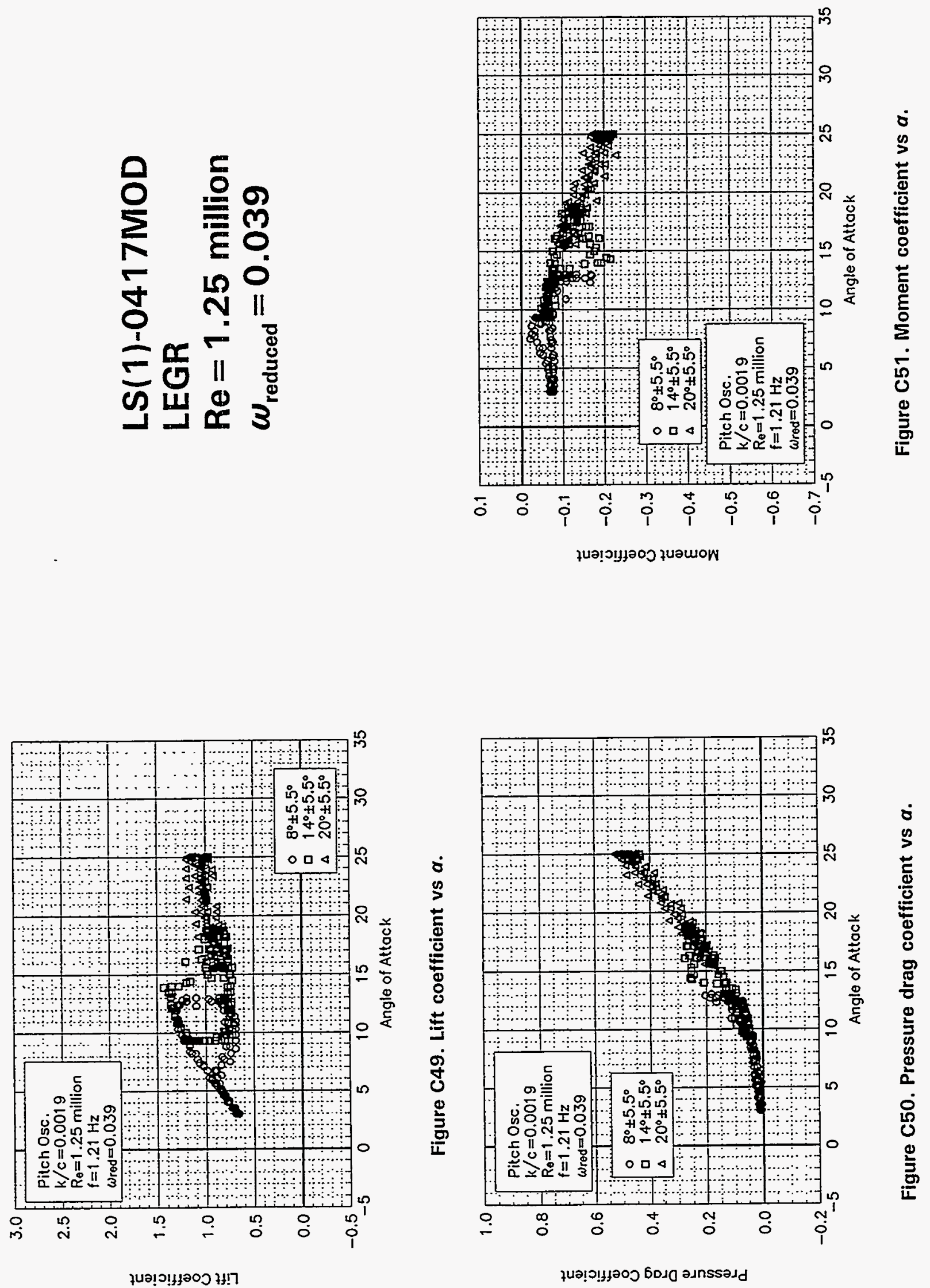

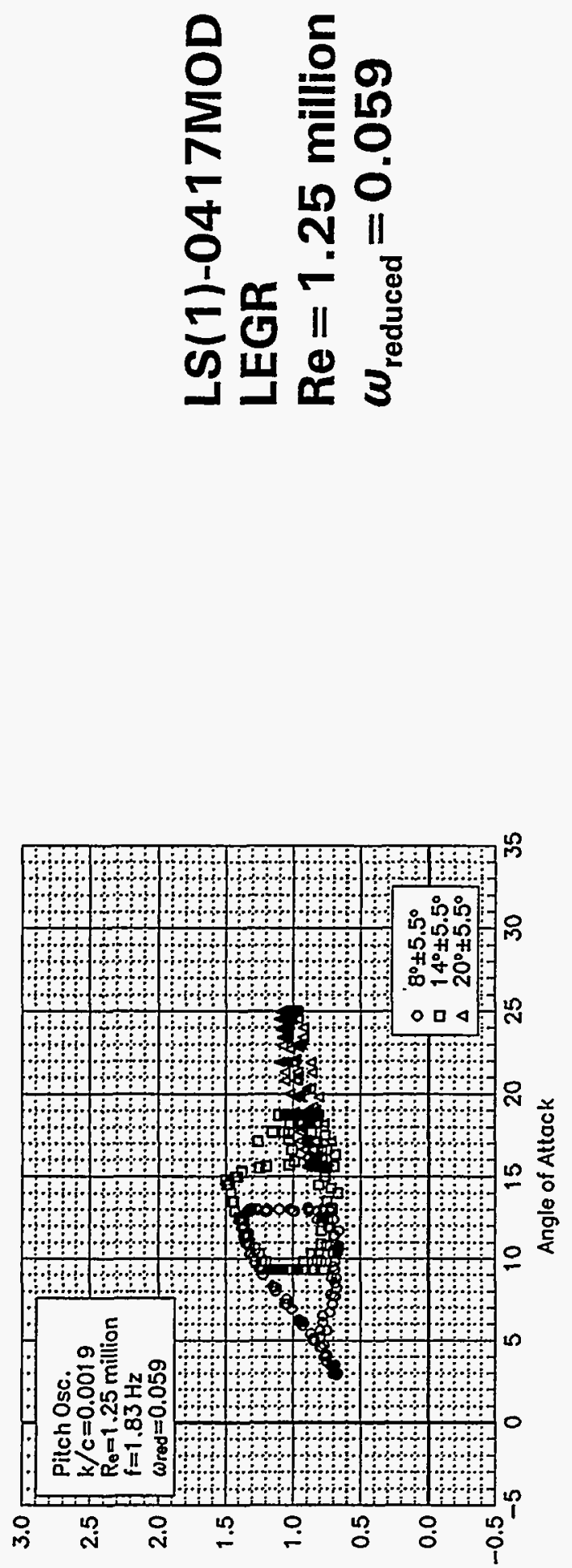

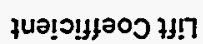

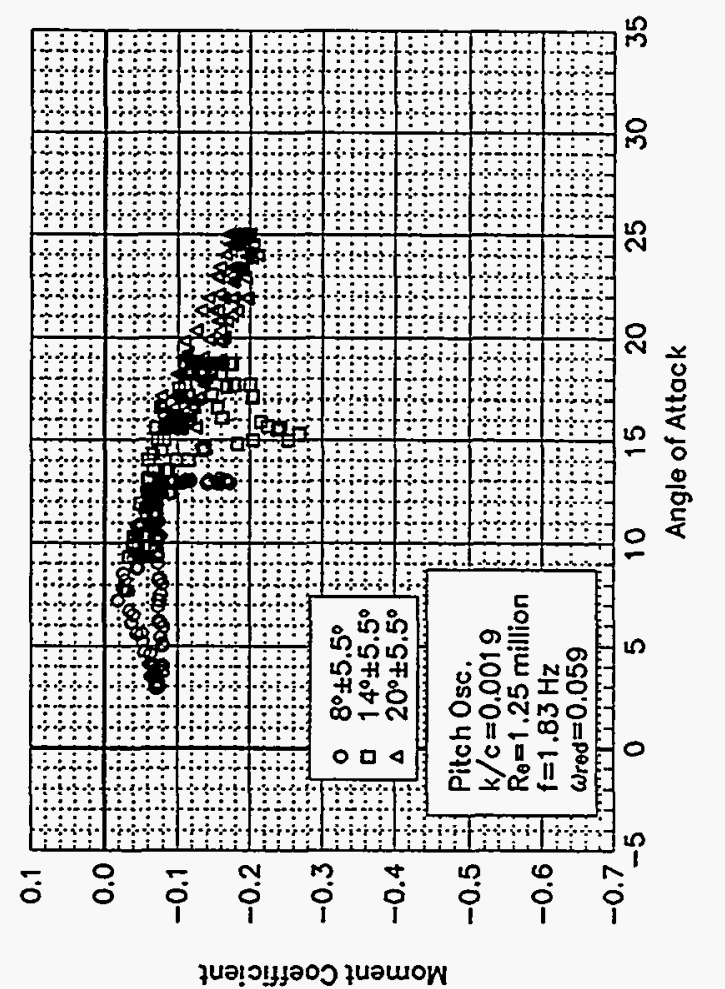

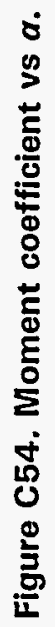

ֻั)

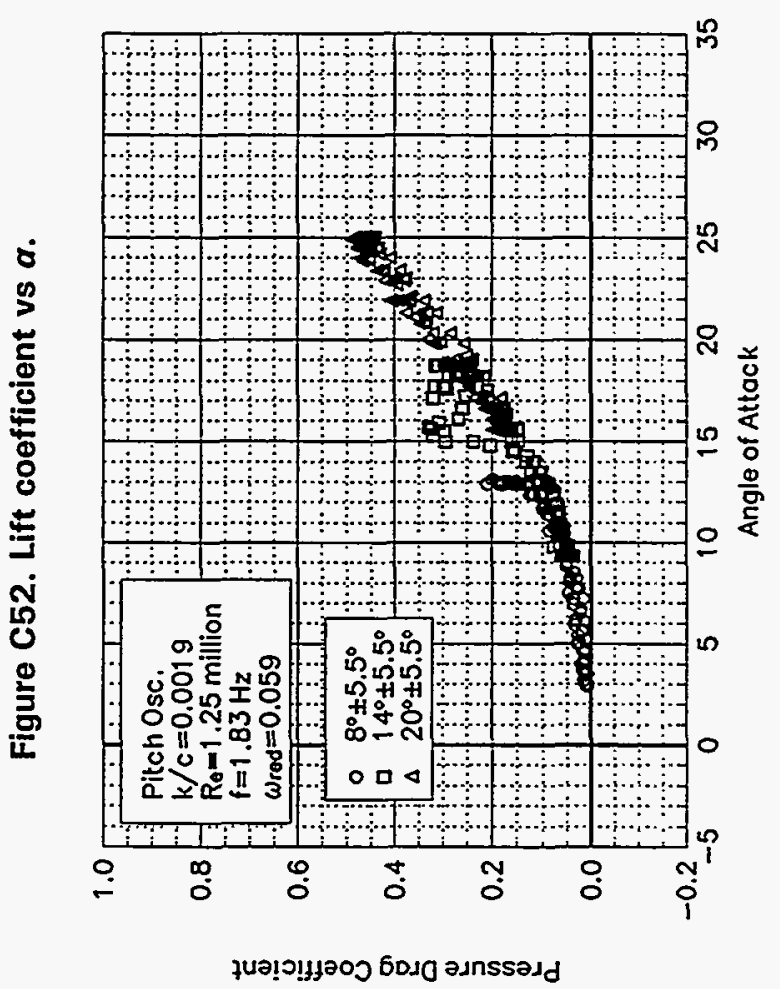

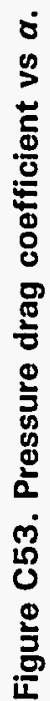




\section{Unsteady Airfoil Characteristics}

$$
\pm 5.5^{\circ} \text { Sine, } \operatorname{Re}=1.5 \text { million }
$$



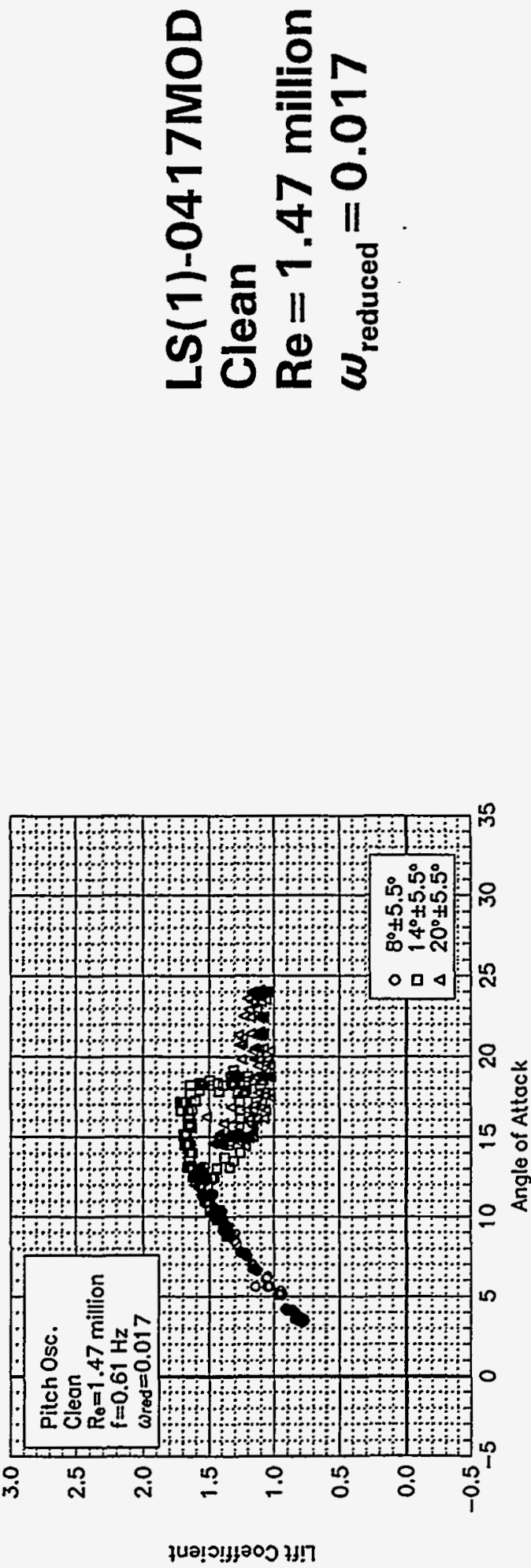

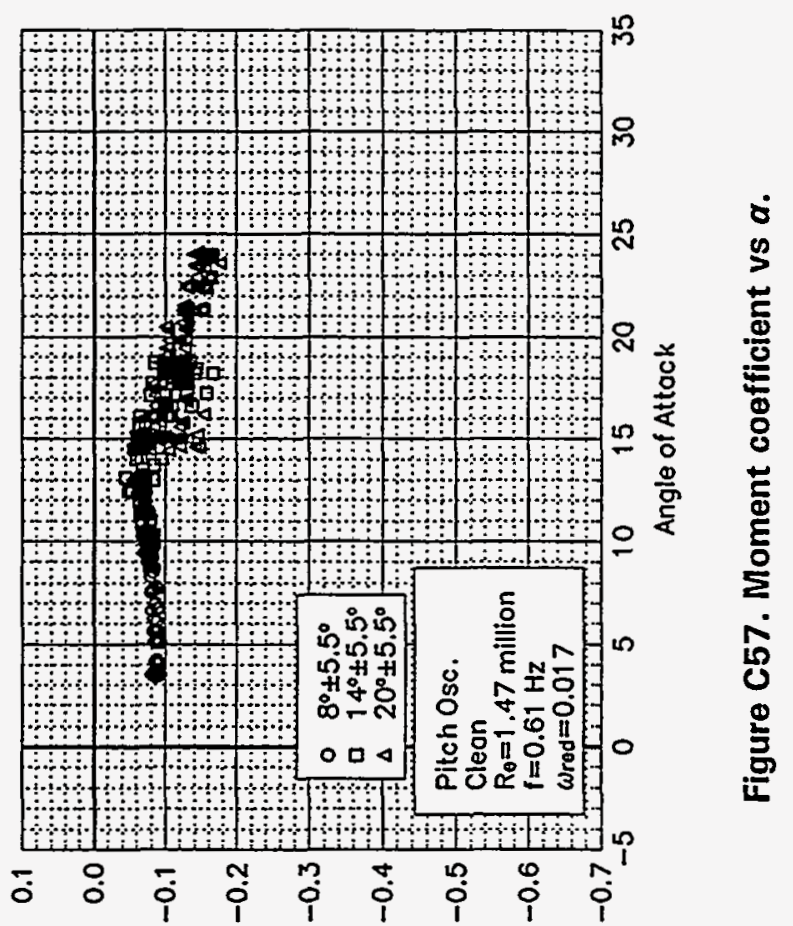

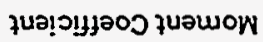

0

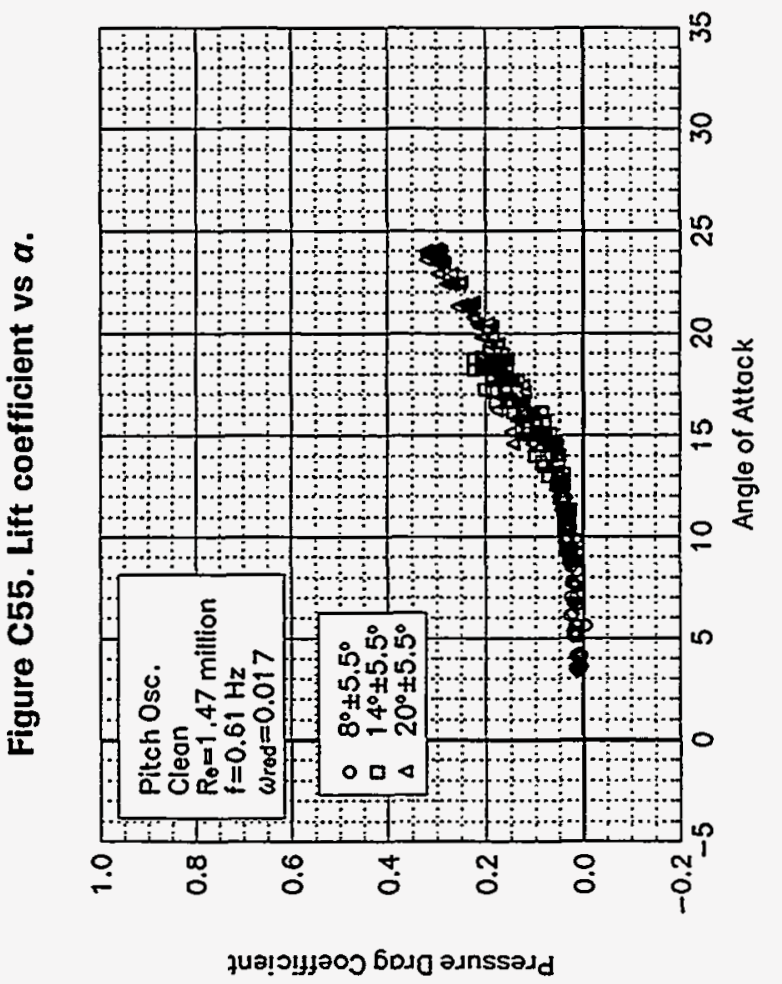

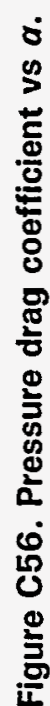



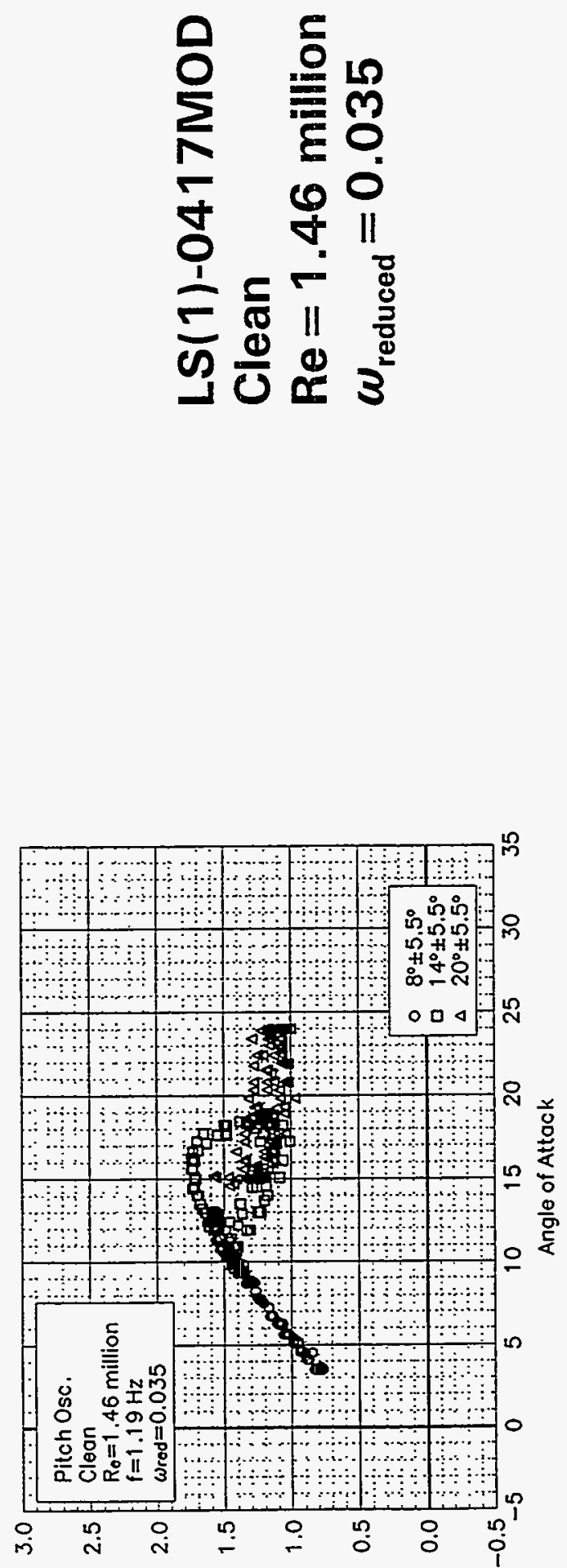

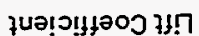

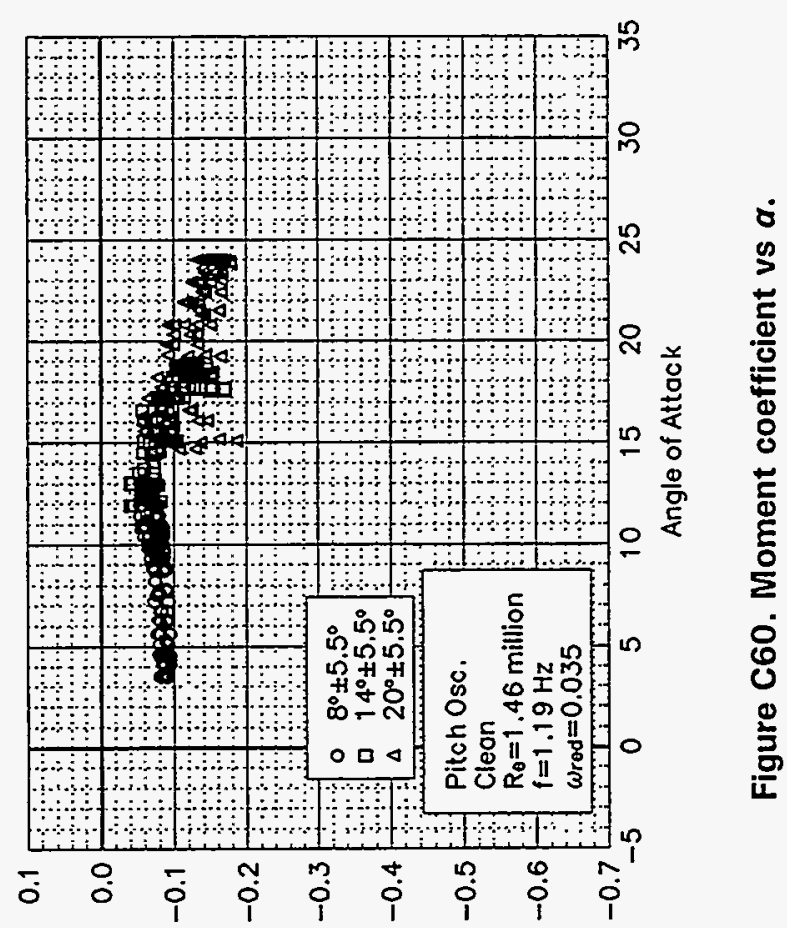

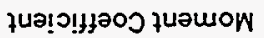

نั

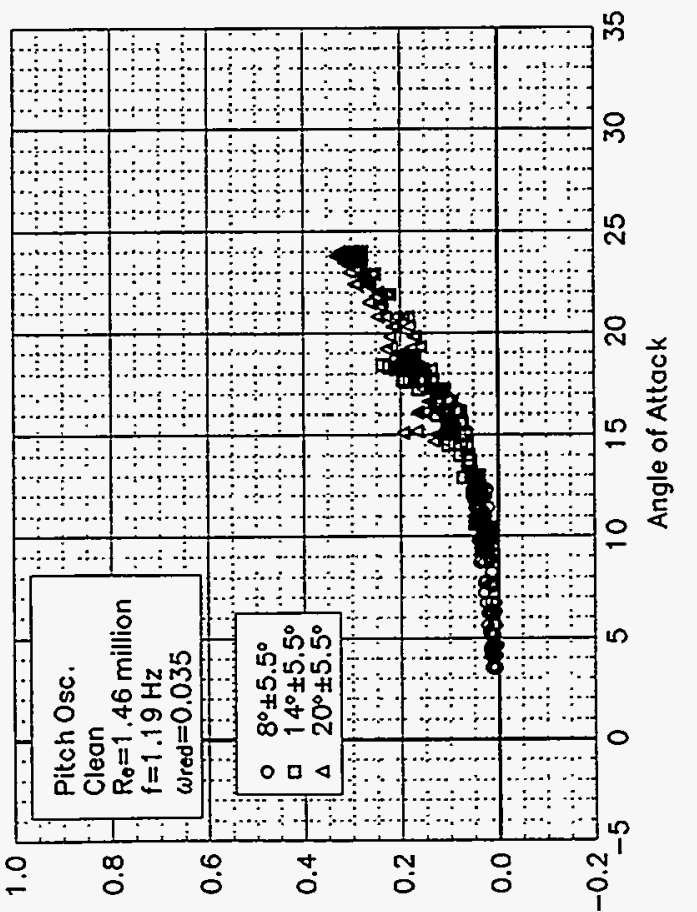

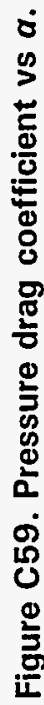



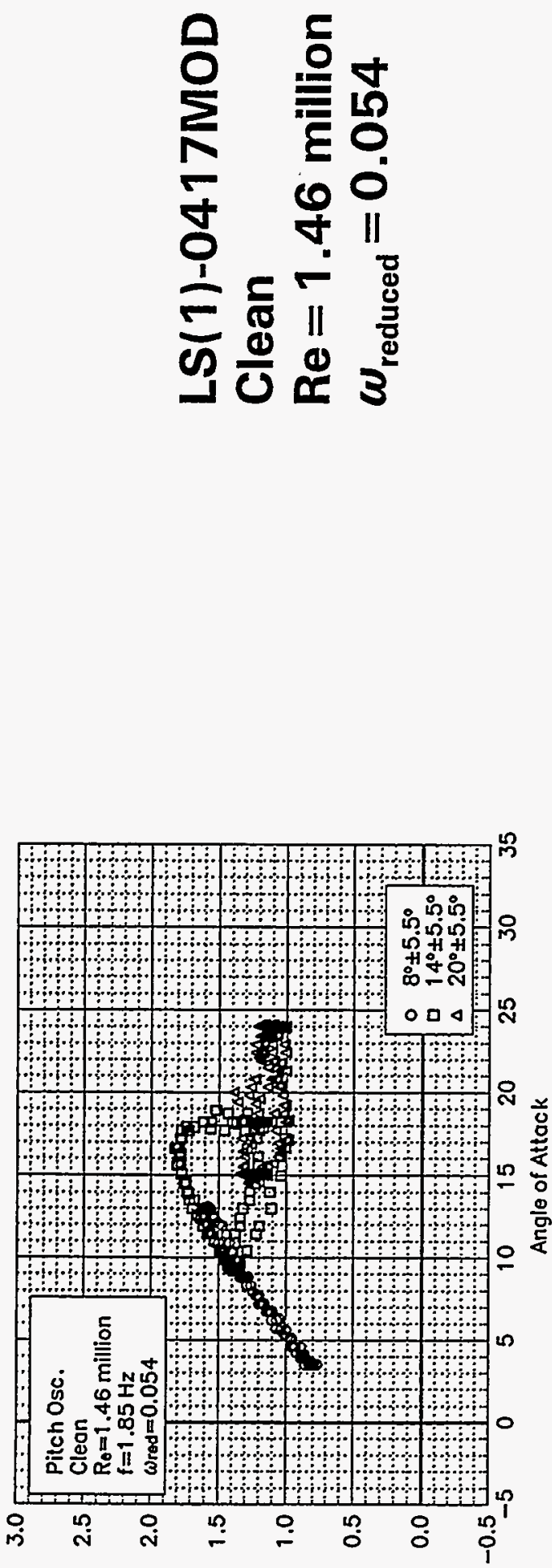

นบอ!ว!มยว०ว มย!า

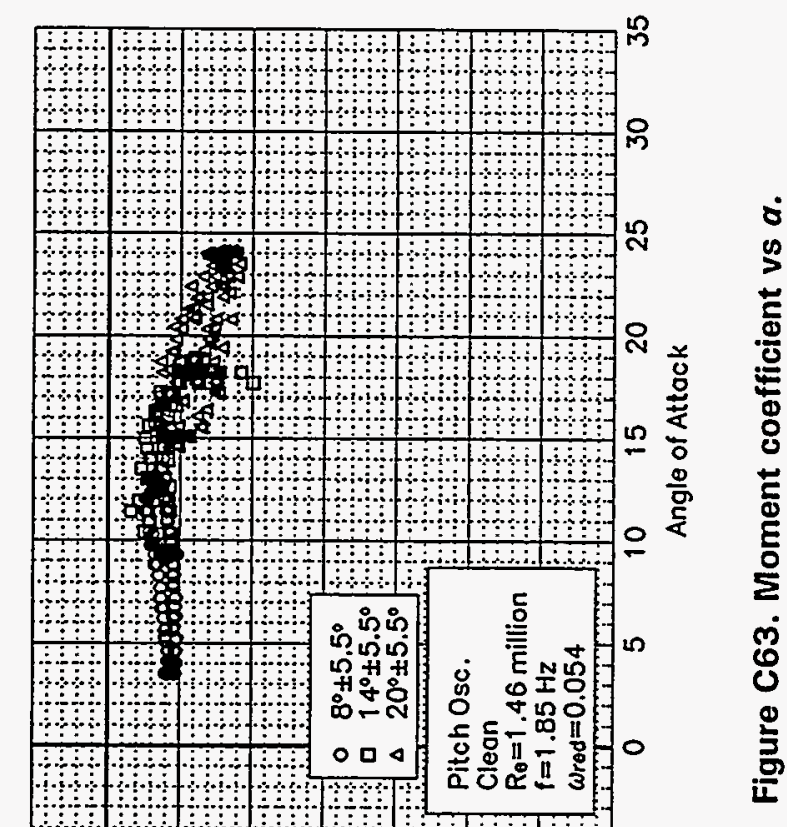

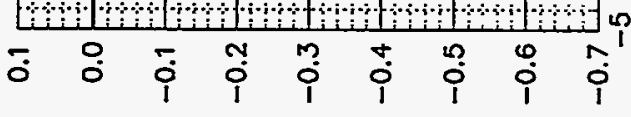

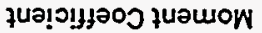

กิ

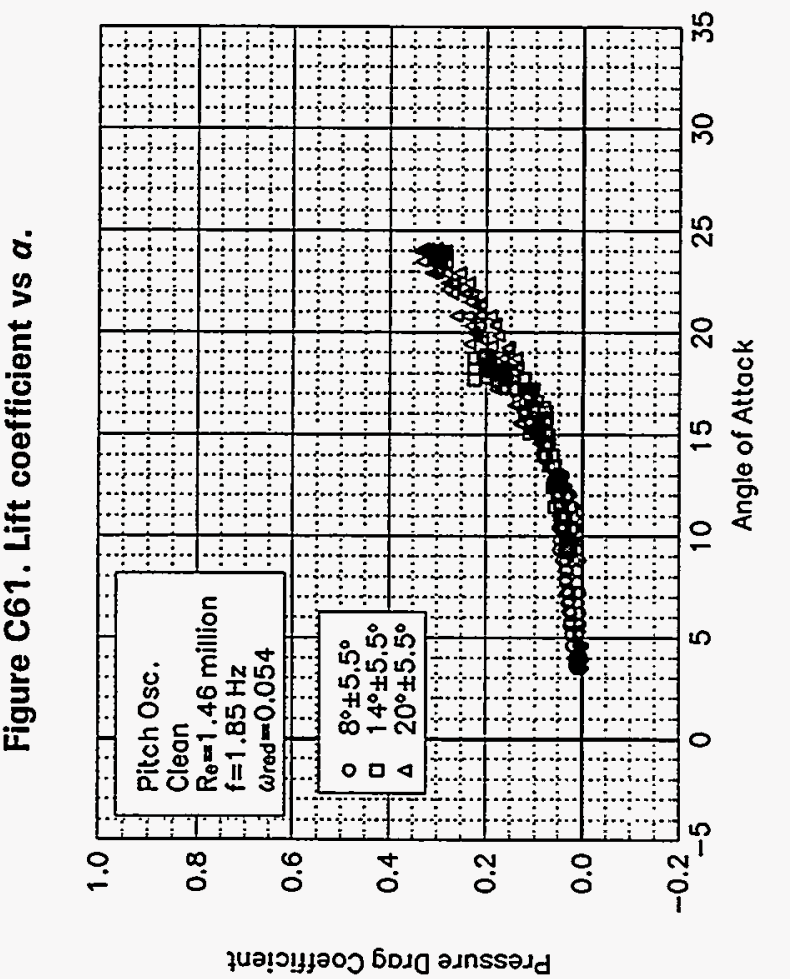

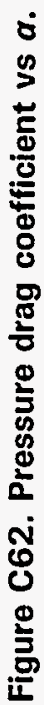


Pressure Drag Coefficient

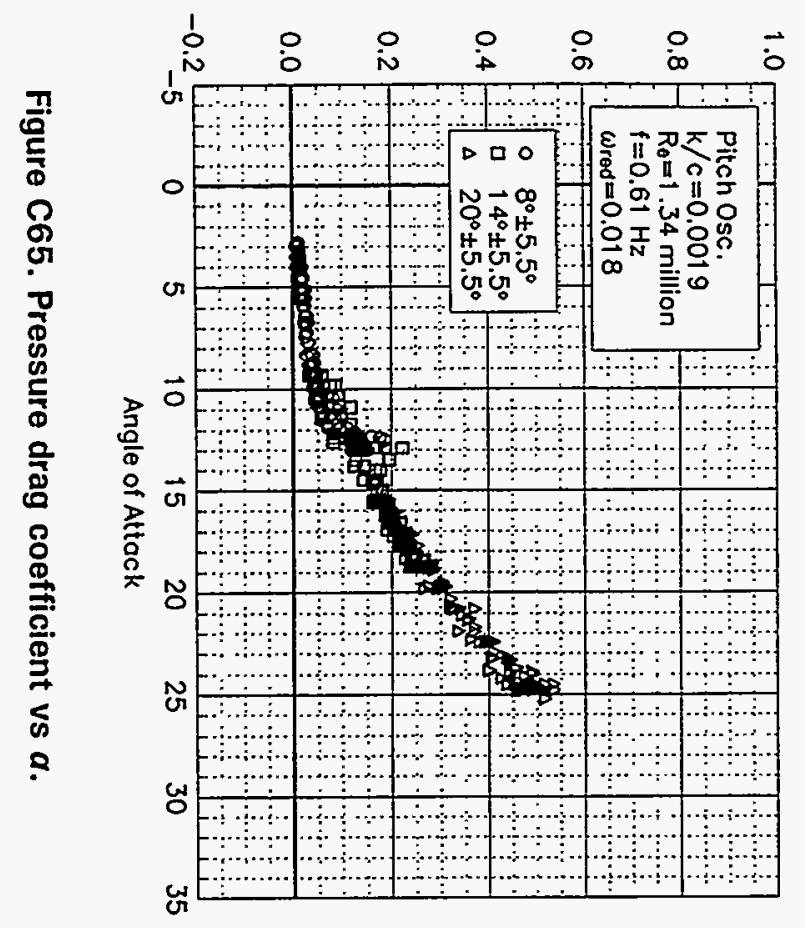

Lift Coefficient

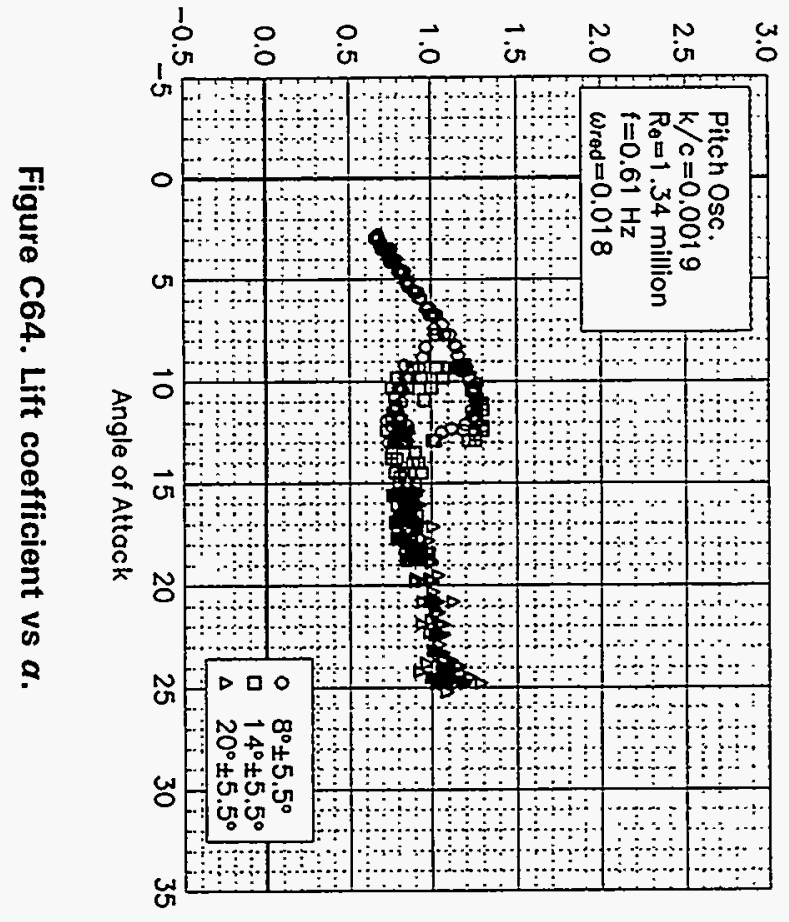

$\stackrel{\infty}{N}$
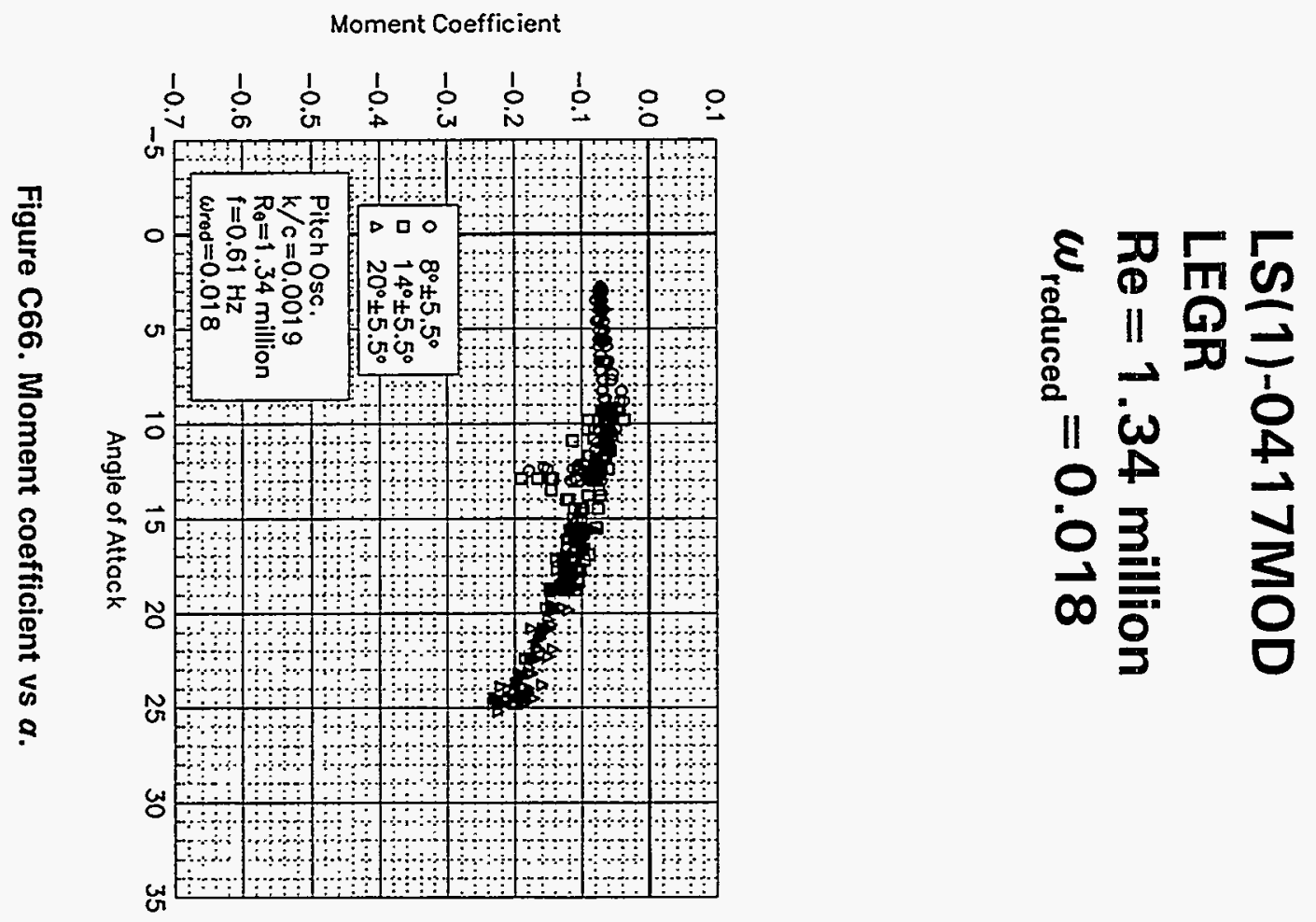


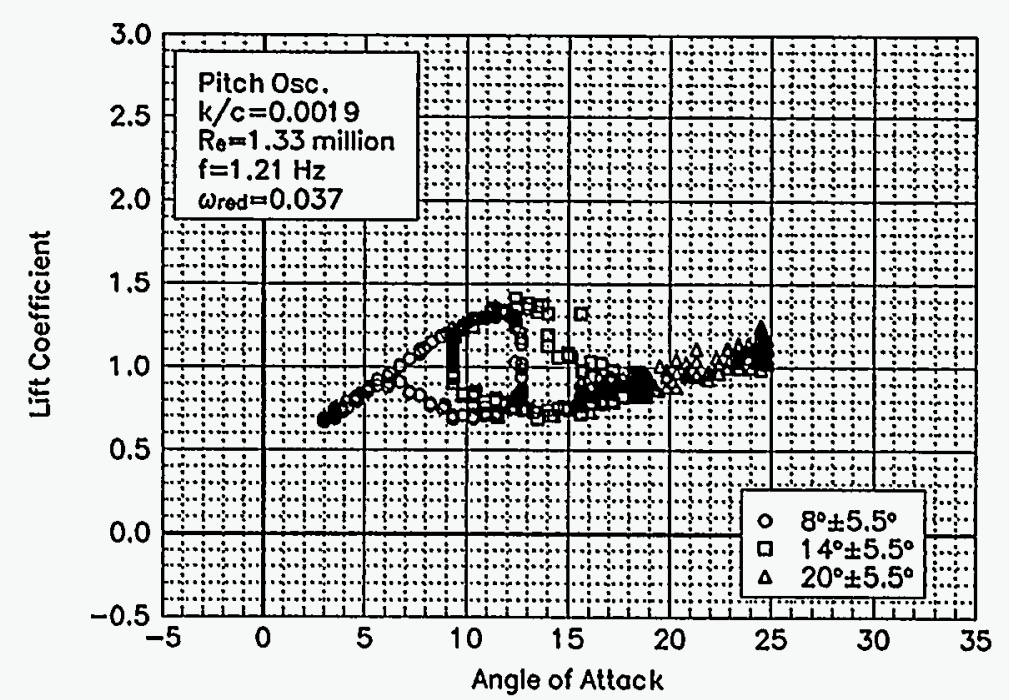

Figure C67. Lift coefficient vs $\boldsymbol{a}$.

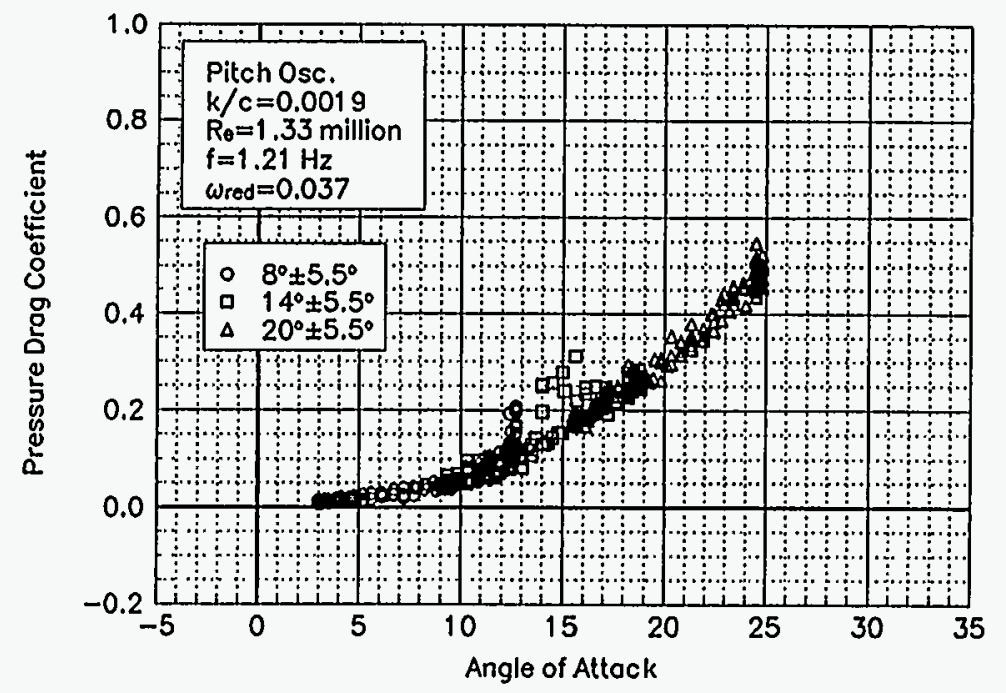

Figure C68. Pressure drag coefficient vs $a$.

\section{LS(1)-0417MOD LEGR \\ $\operatorname{Re}=1.33$ million \\ $\omega_{\text {reduced }}=0.037$}

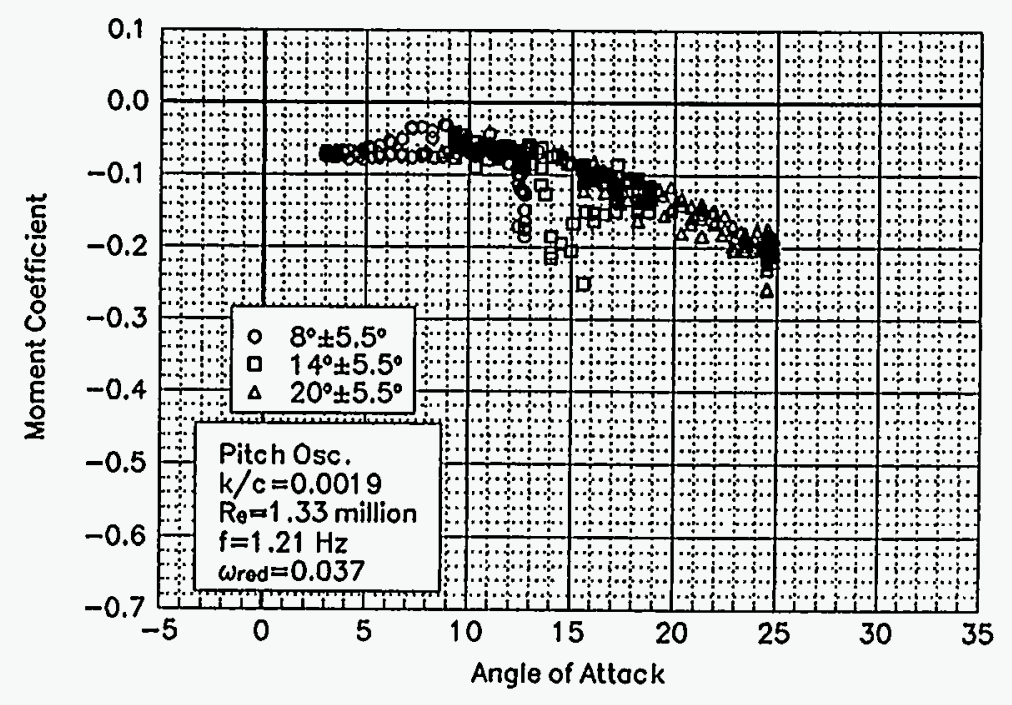

Figure C69. Moment coefficient vs $a$. 

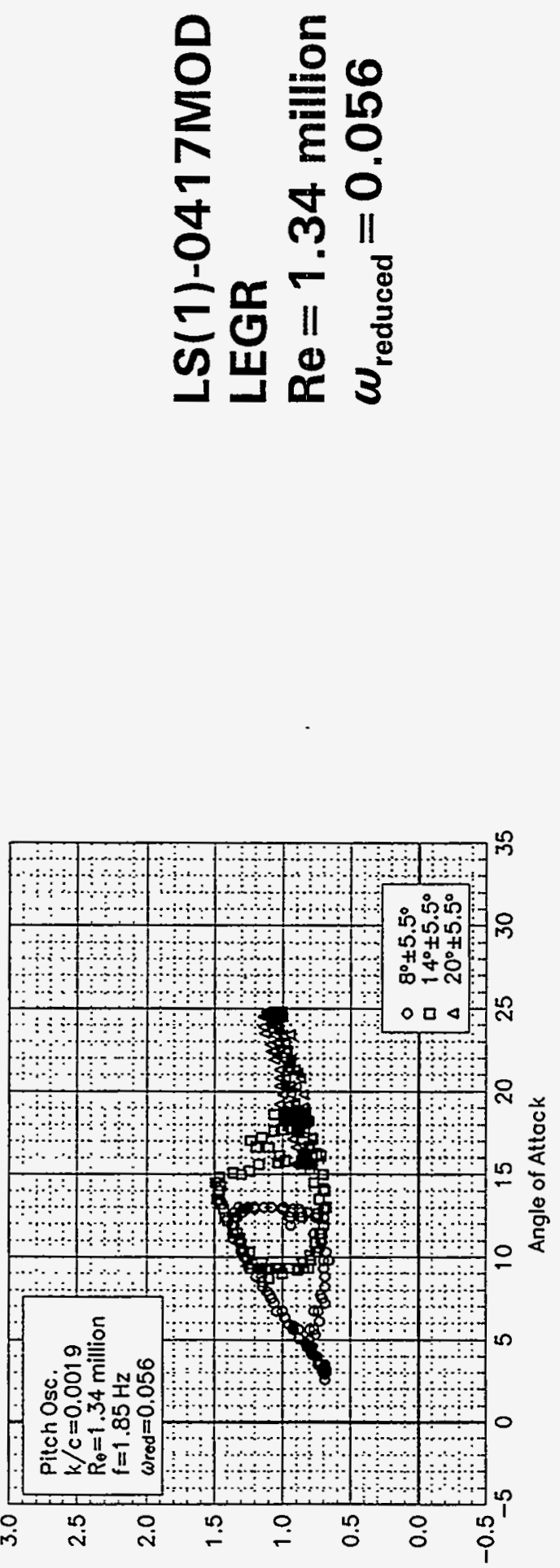

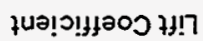

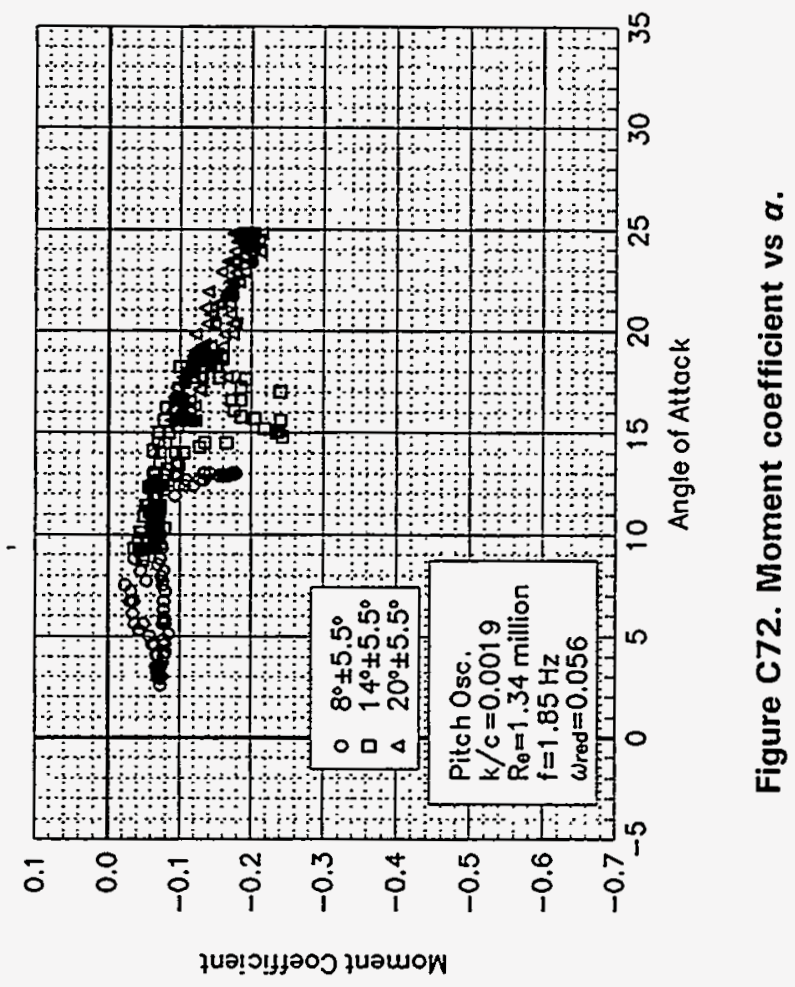

i

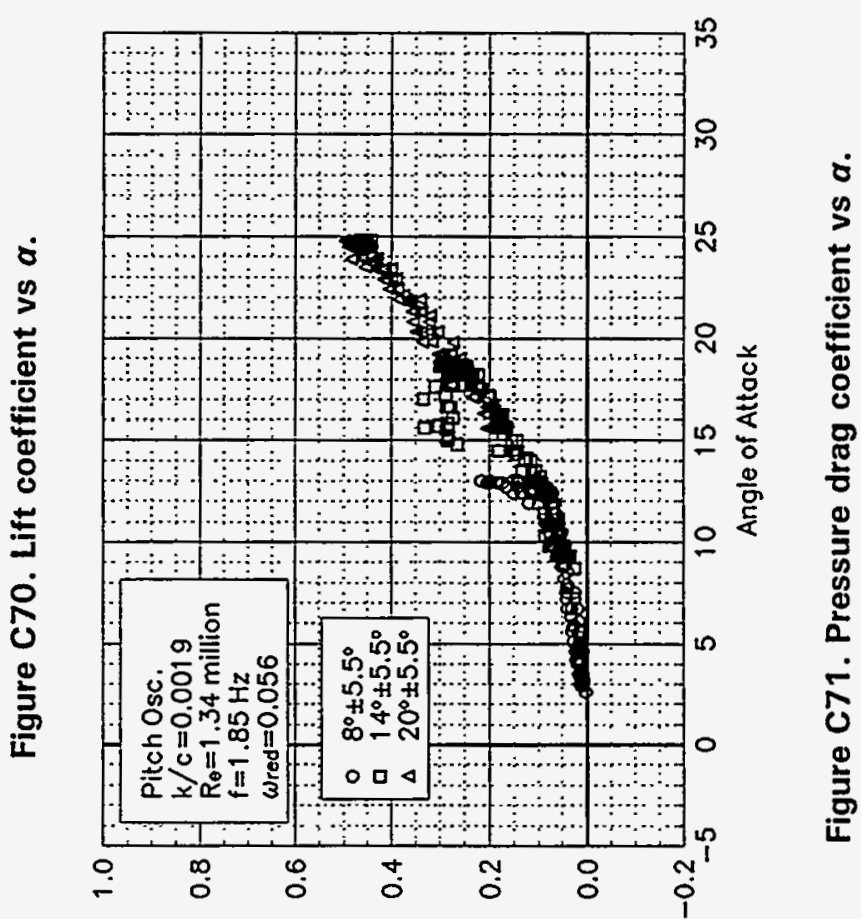

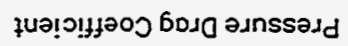




\section{Unsteady Airfoil Characteristics \\ $\pm 10^{\circ}$ Sine, $\operatorname{Re}=0.75$ million}



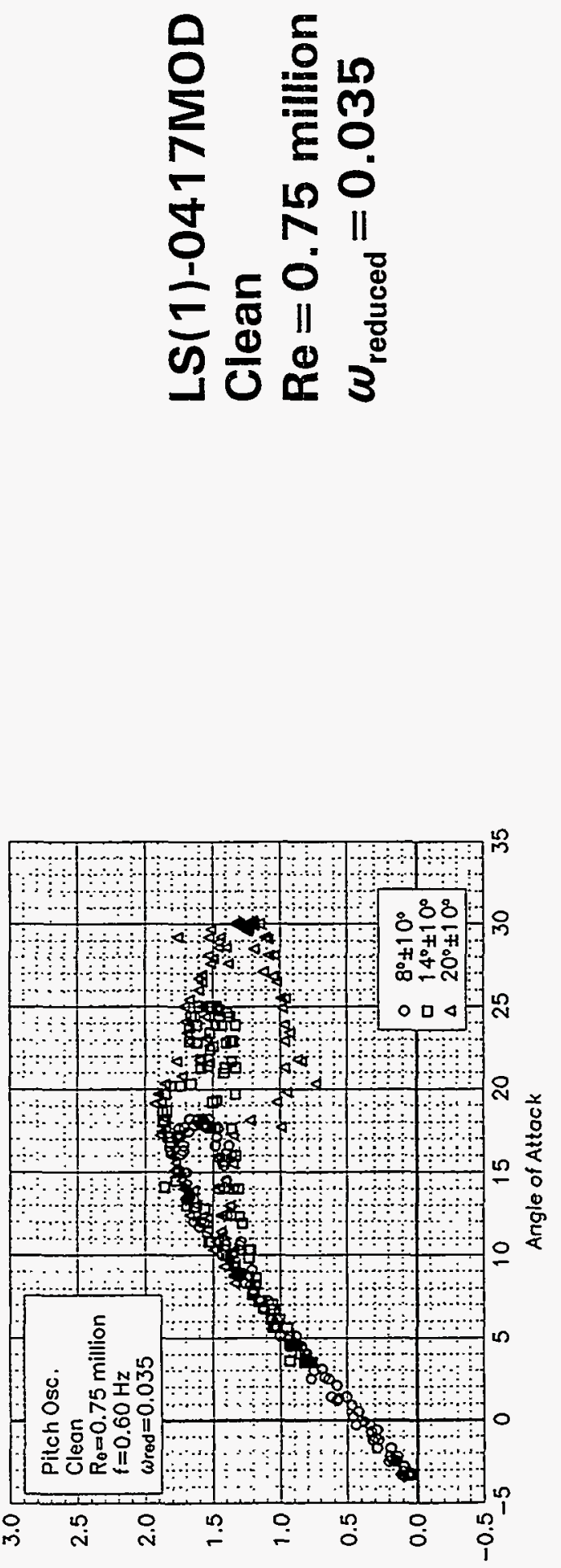

ұนว!ว!ม\}วัว ห!า

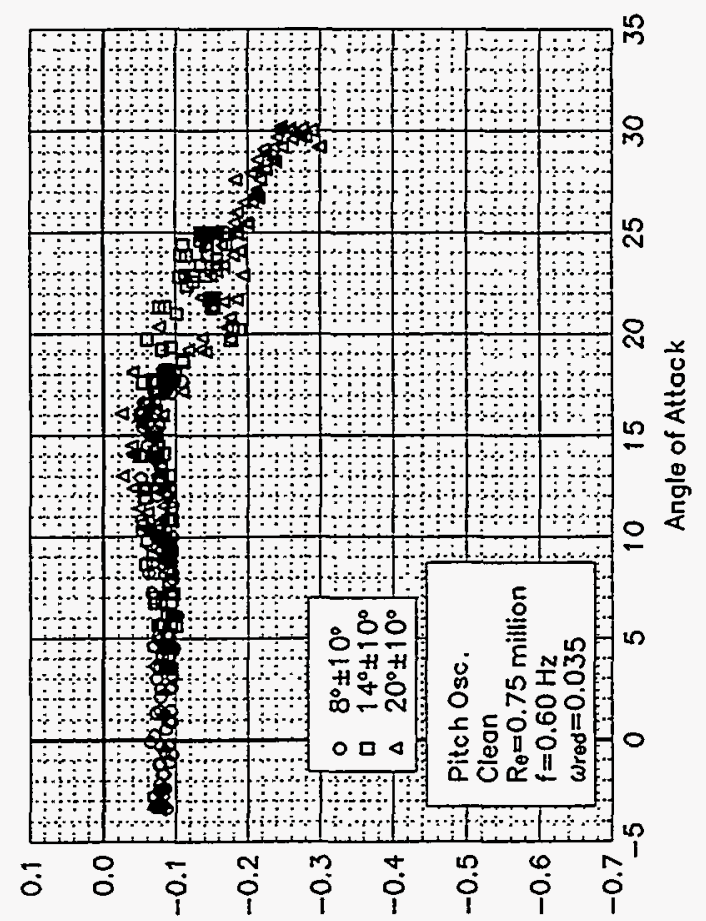

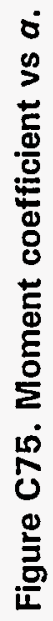

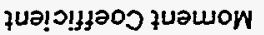

กิ

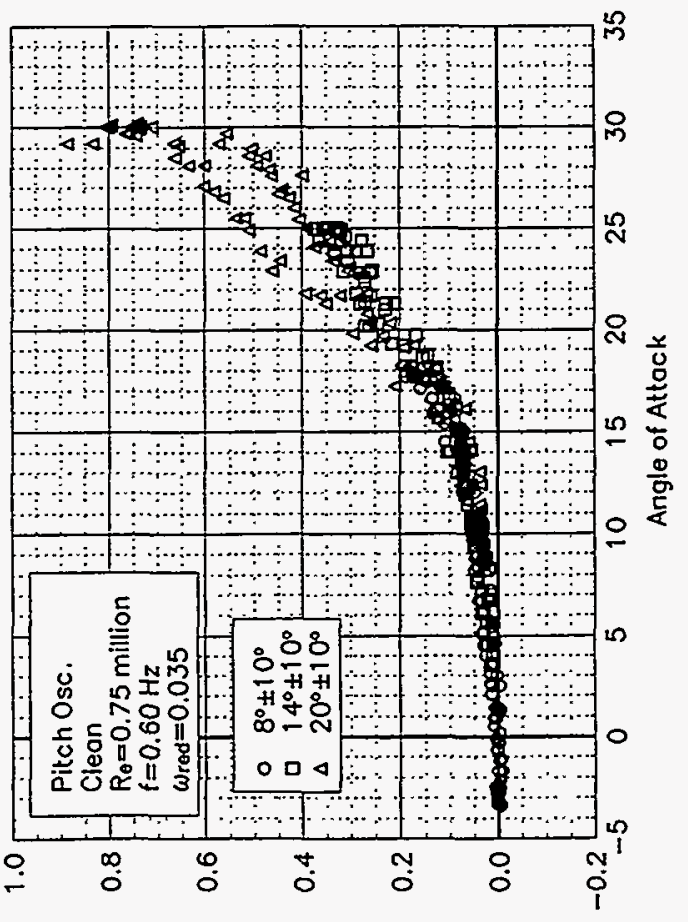

 

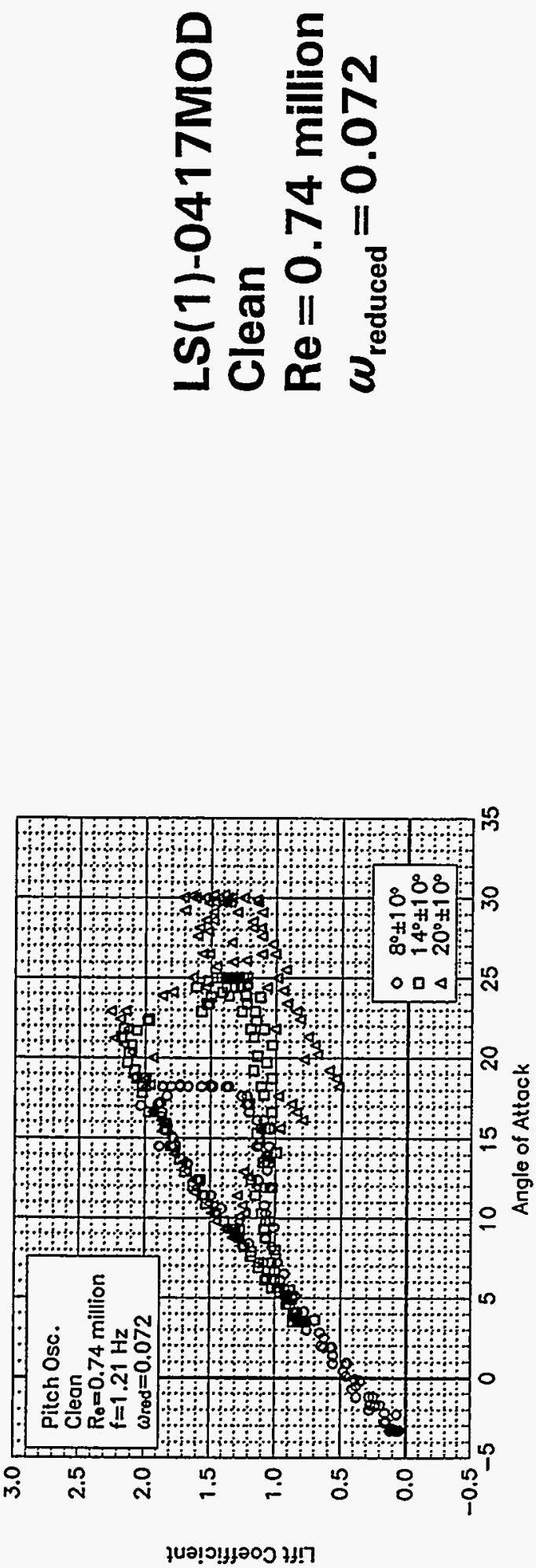

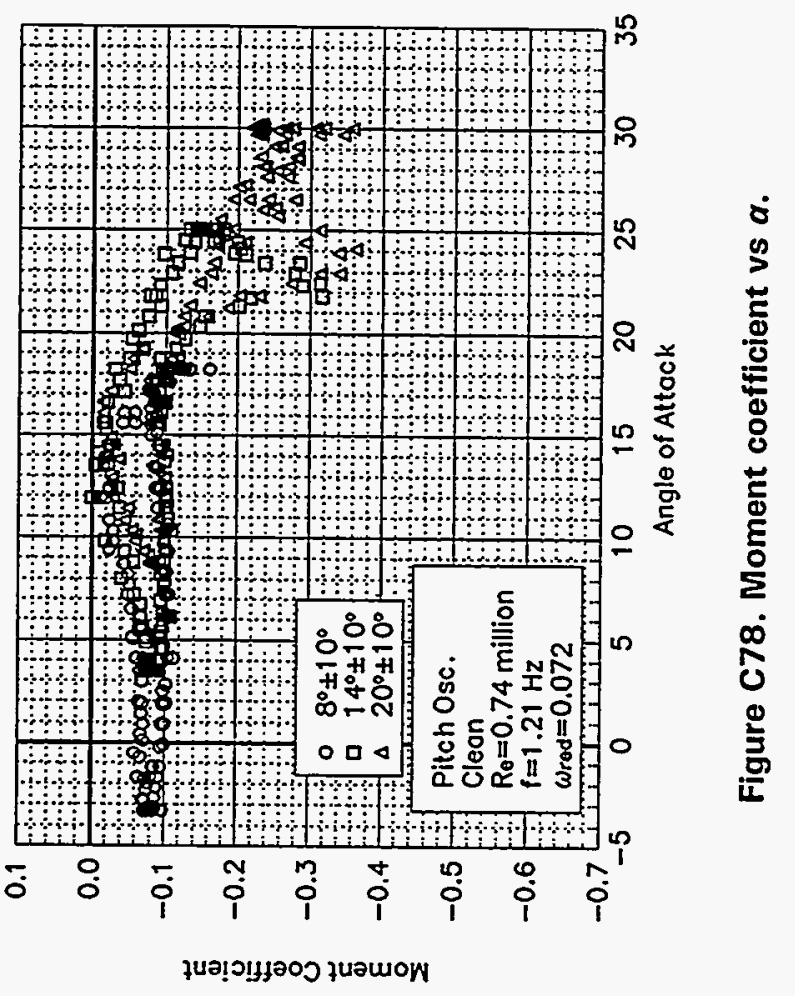

ì

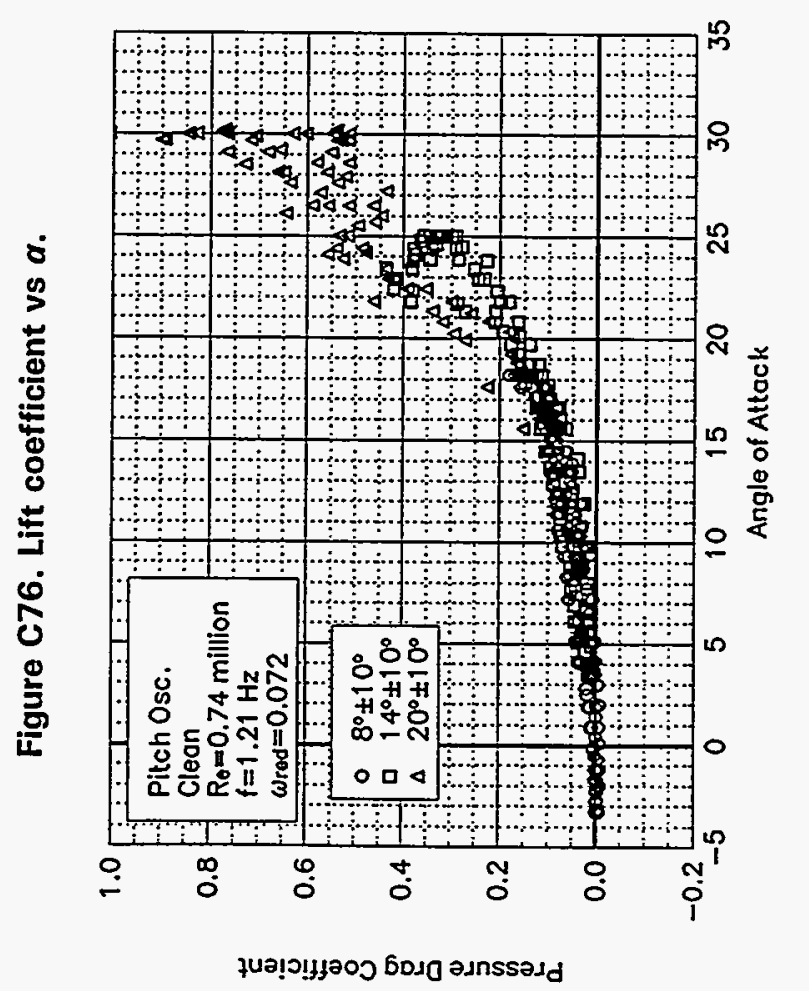



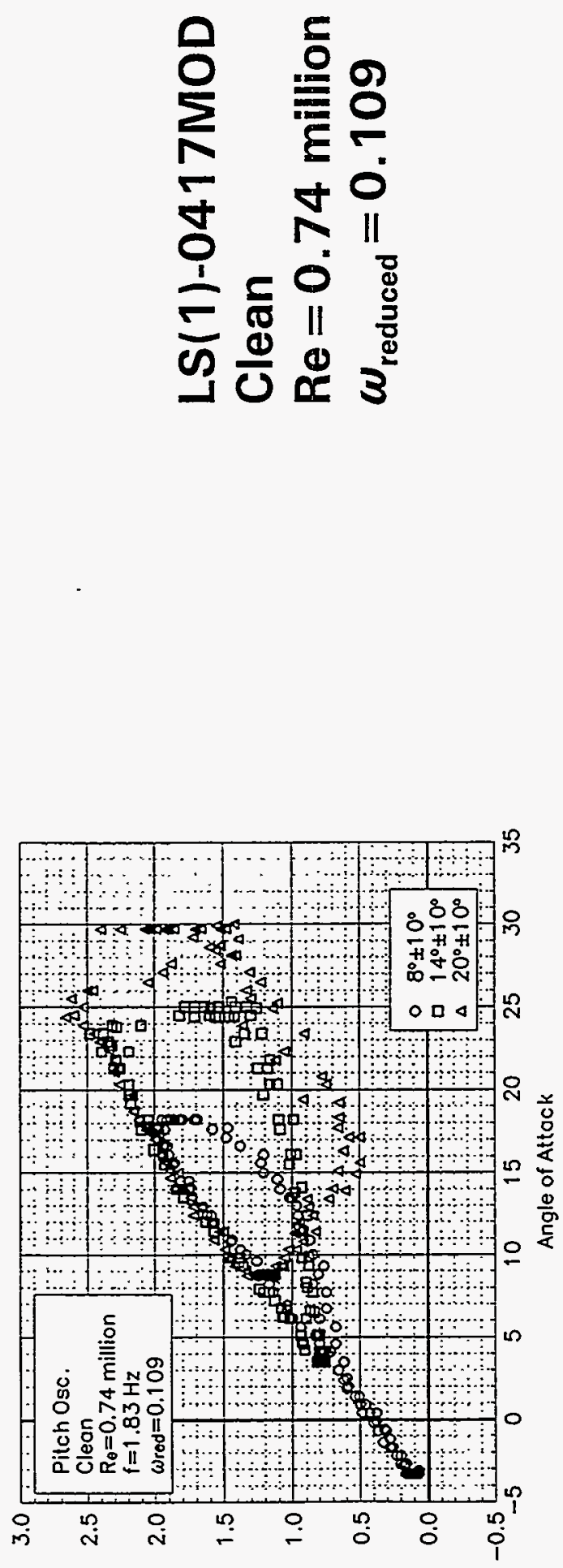

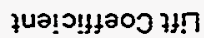

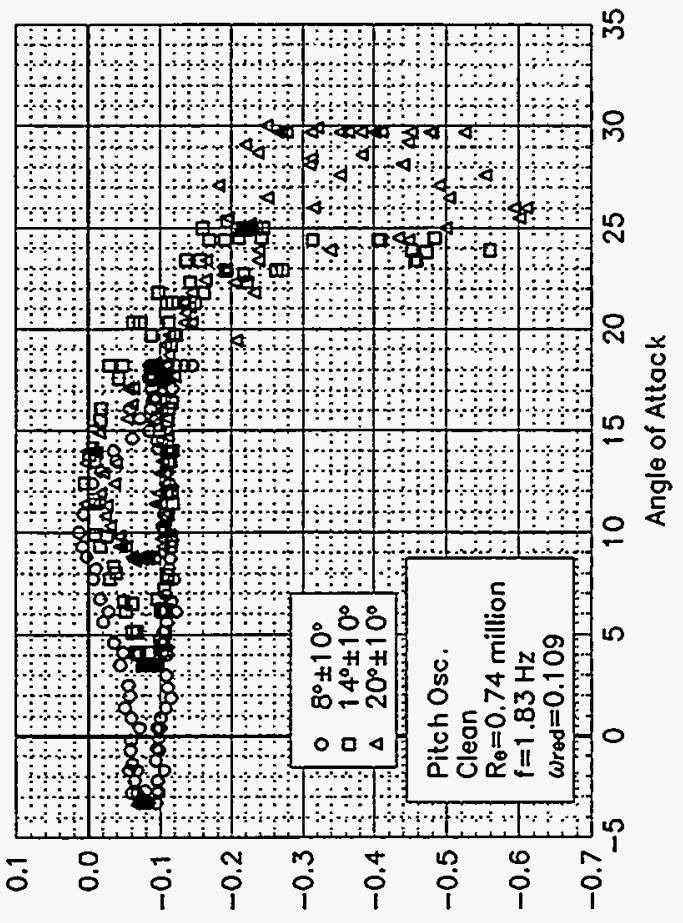

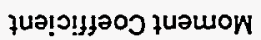

$\dot{j}$

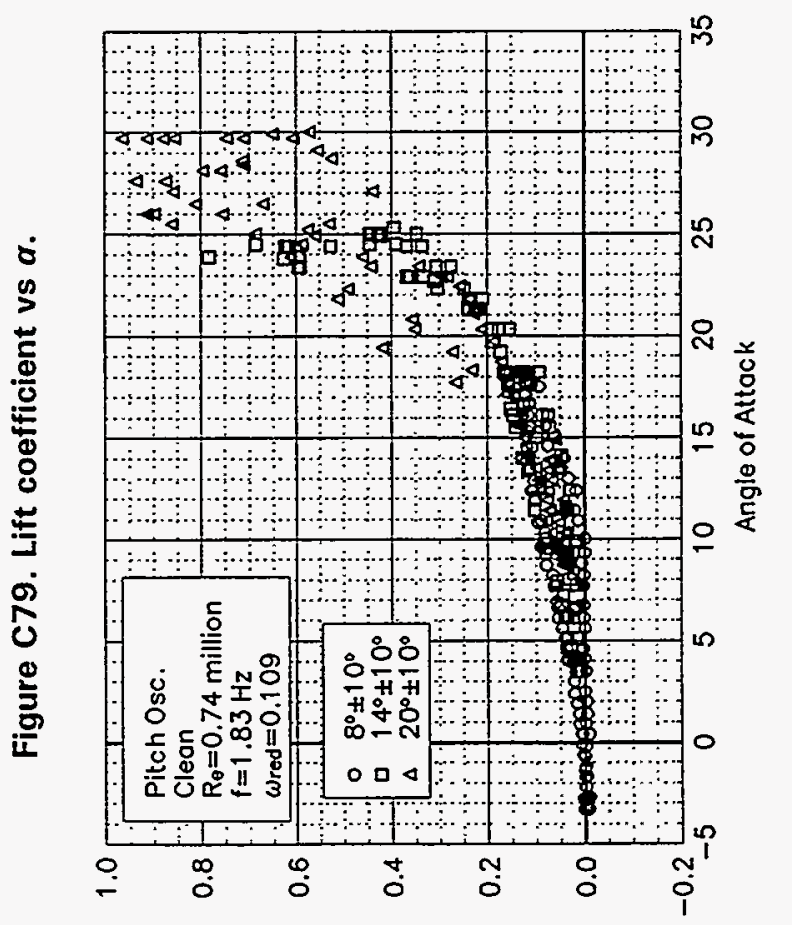



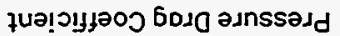




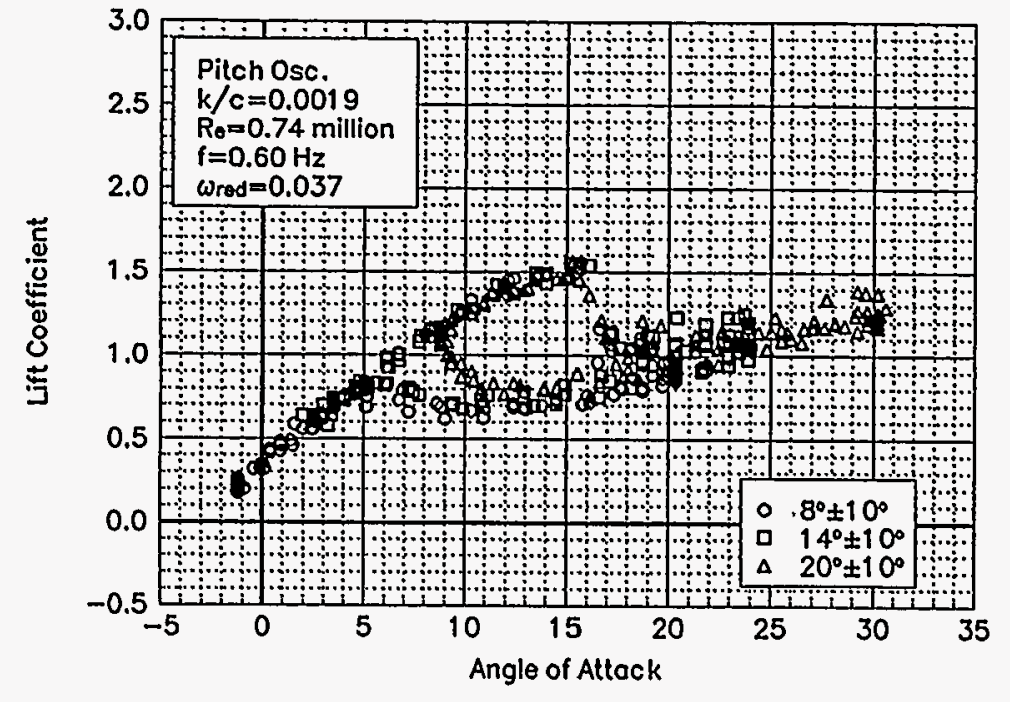

Figure C82. Lift coefficient vs $a$.

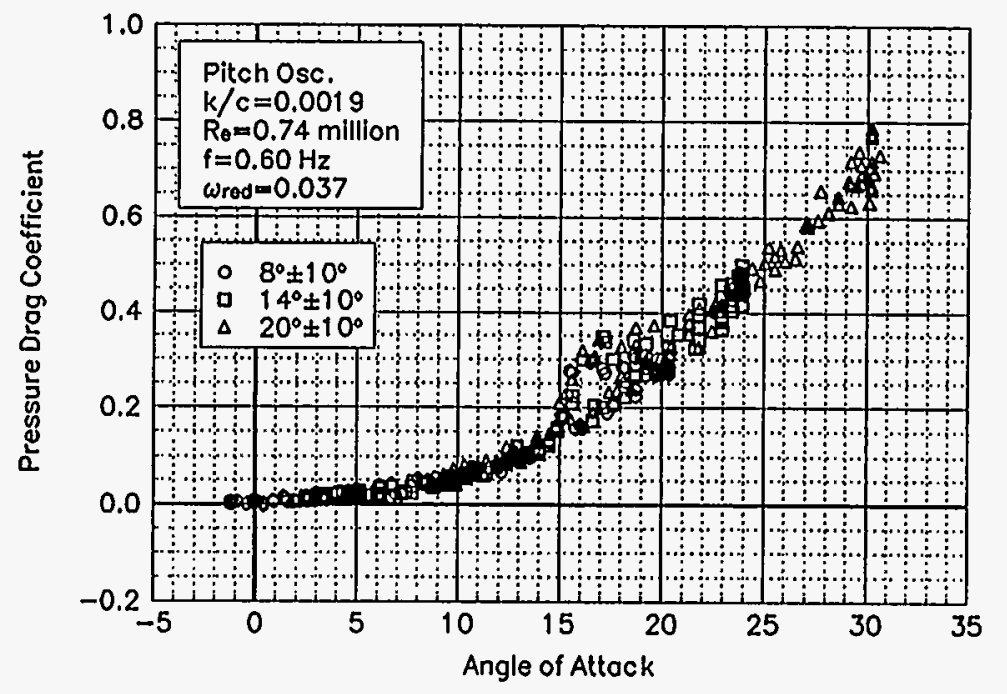

Figure C83. Pressure drag coefficient vs $a$.

\section{LS(1)-0417MOD LEGR \\ $\operatorname{Re}=\mathbf{0 . 7 4}$ million \\ $\omega_{\text {reduced }}=0.037$}

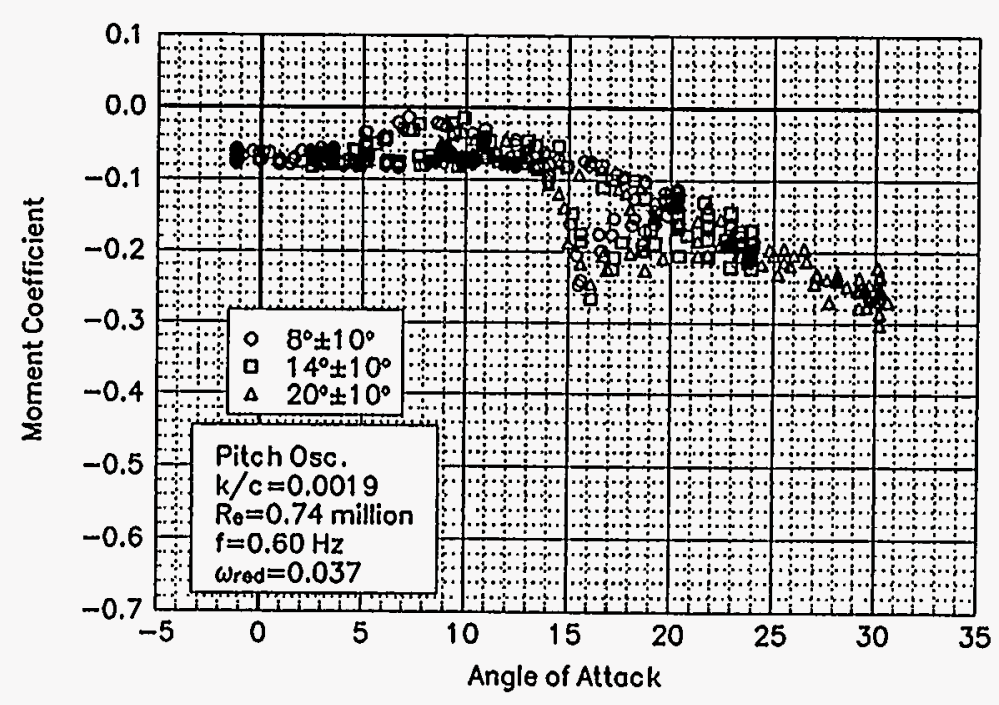

Figure C84. Moment coefficient vs $a$. 

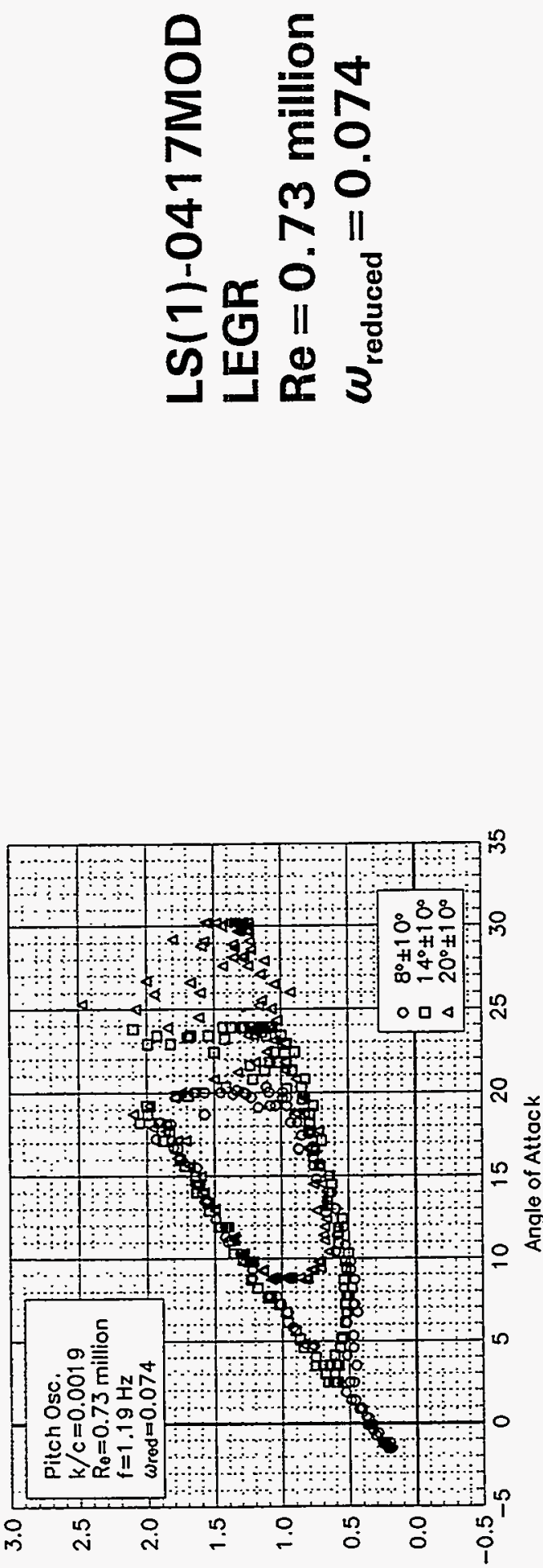

วนข!ว!มฆคว ม!!า

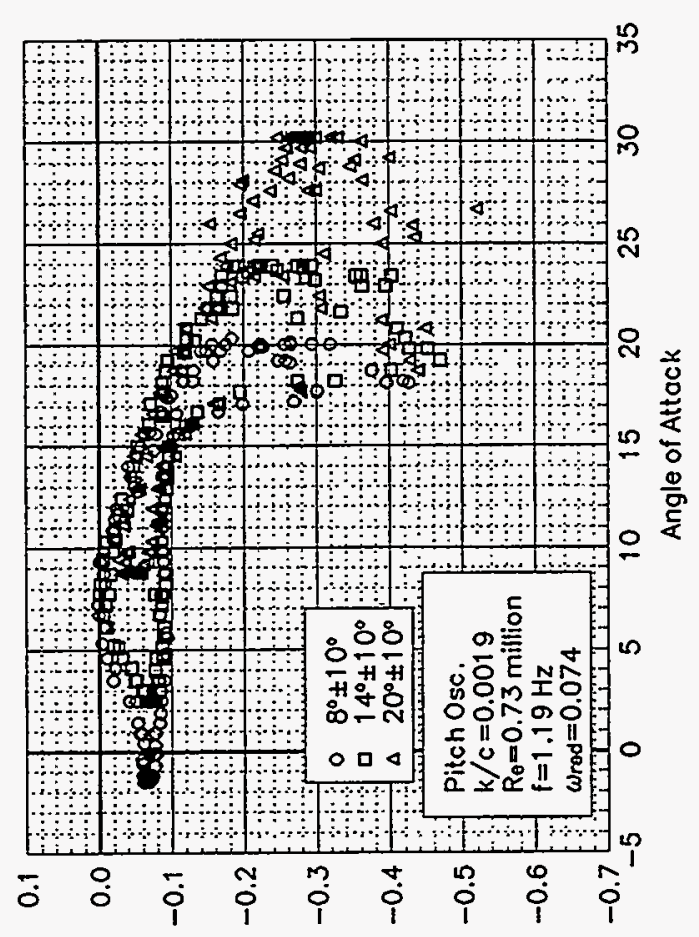

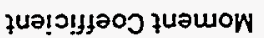

b
u

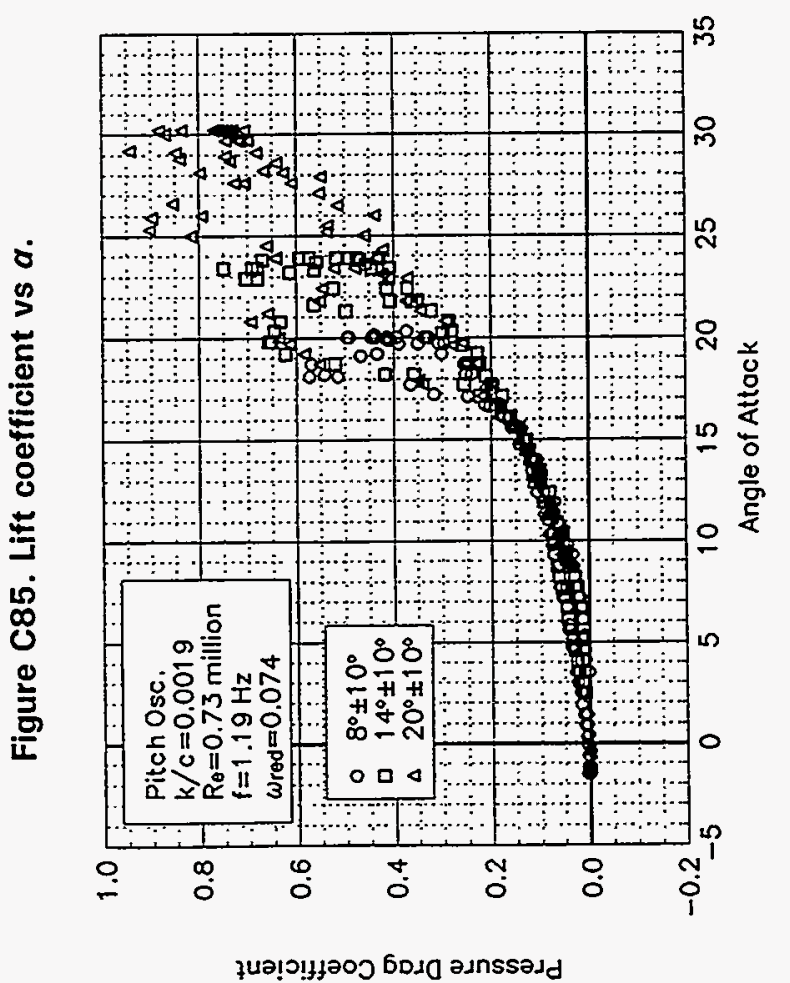

ن 

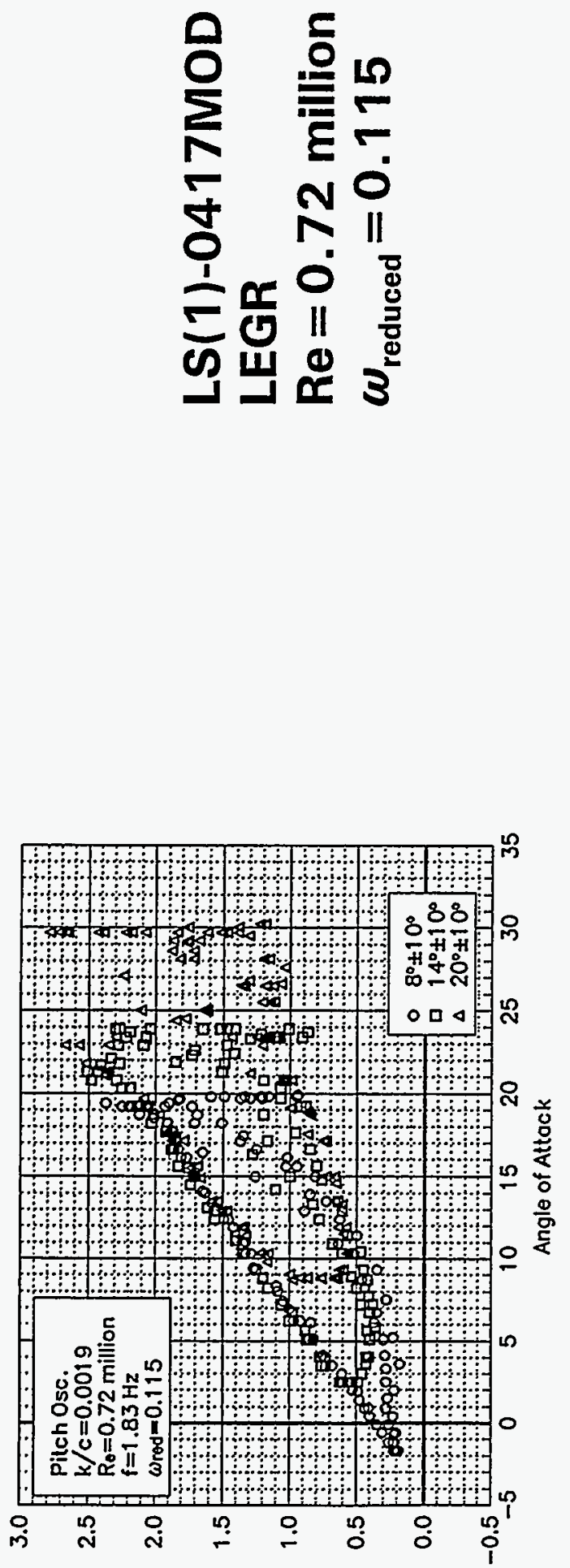

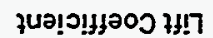

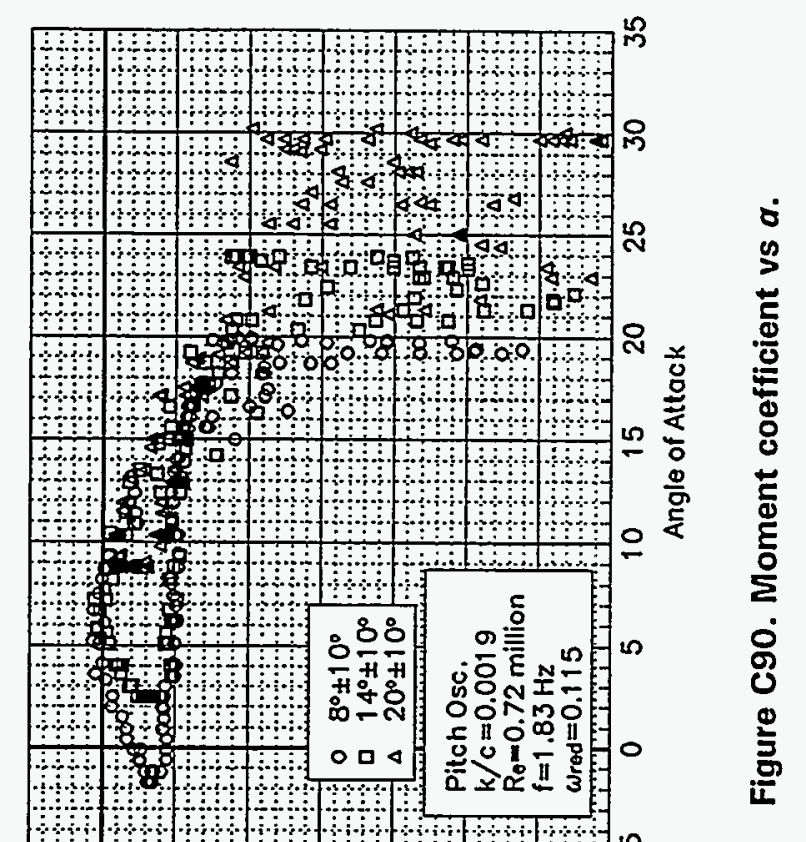

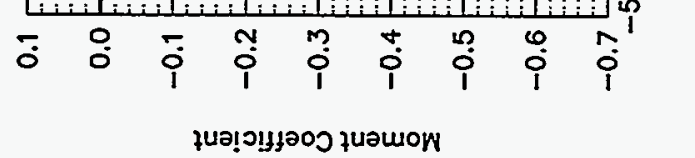

仓

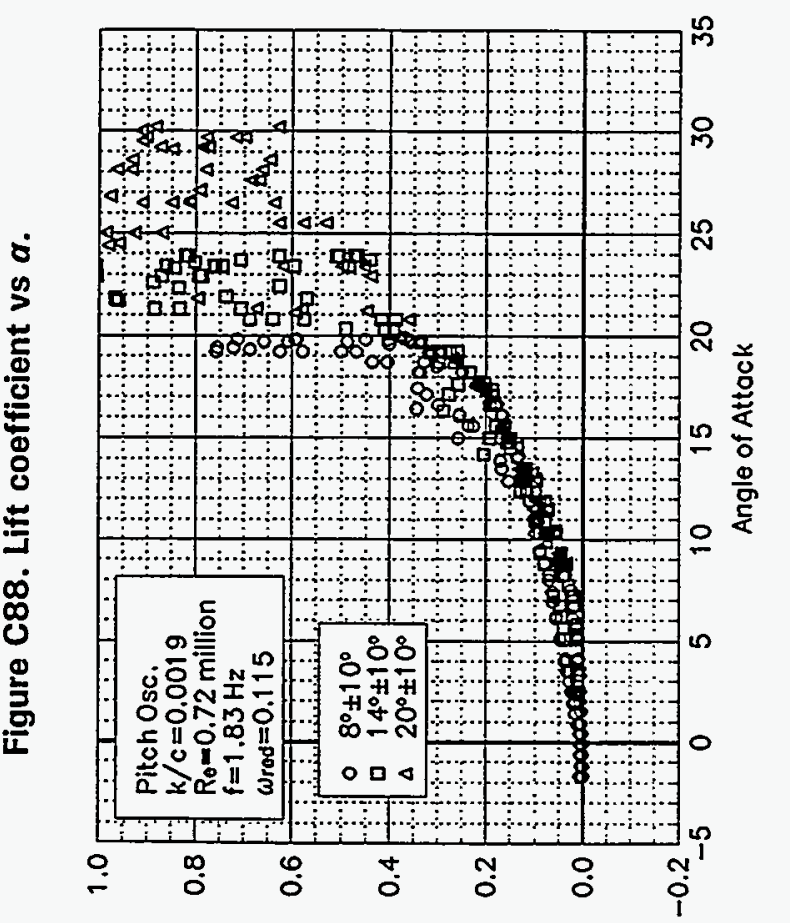

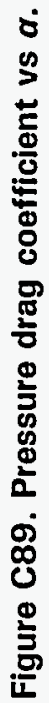




\section{Unsteady Airfoil Characteristics}

$\pm 10^{\circ}$ Sine, $\operatorname{Re}=1$ million 

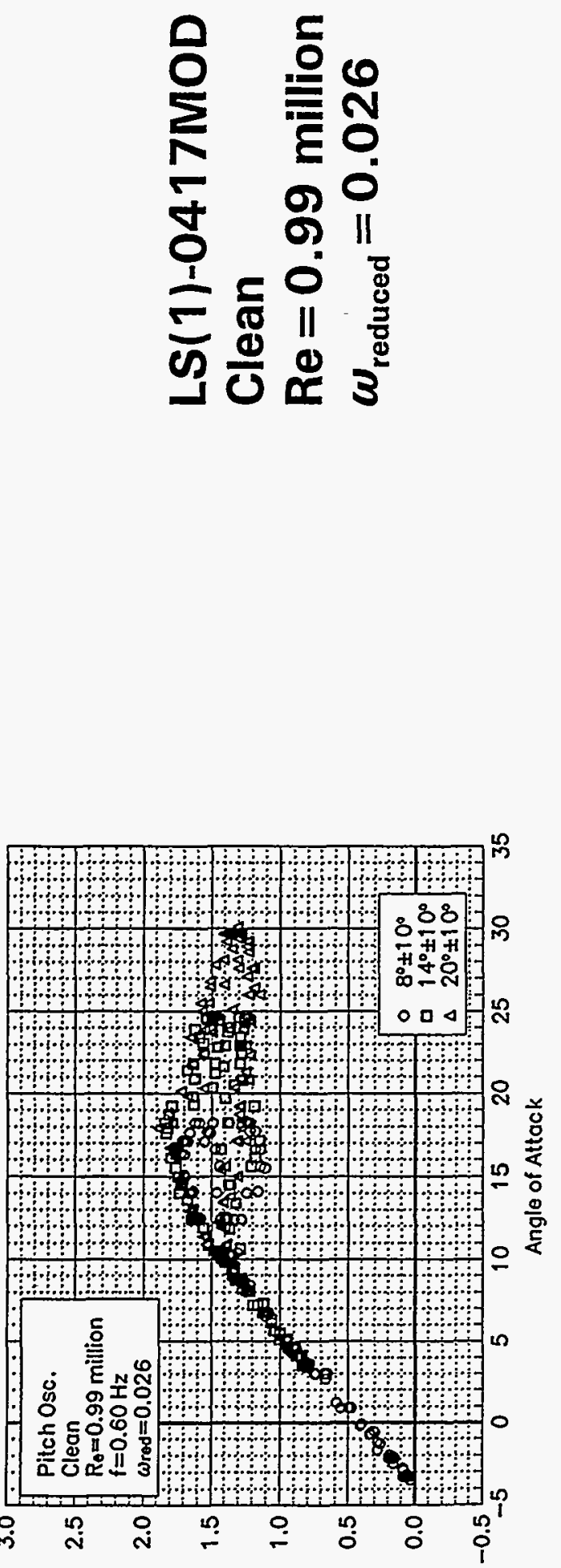

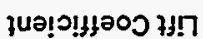

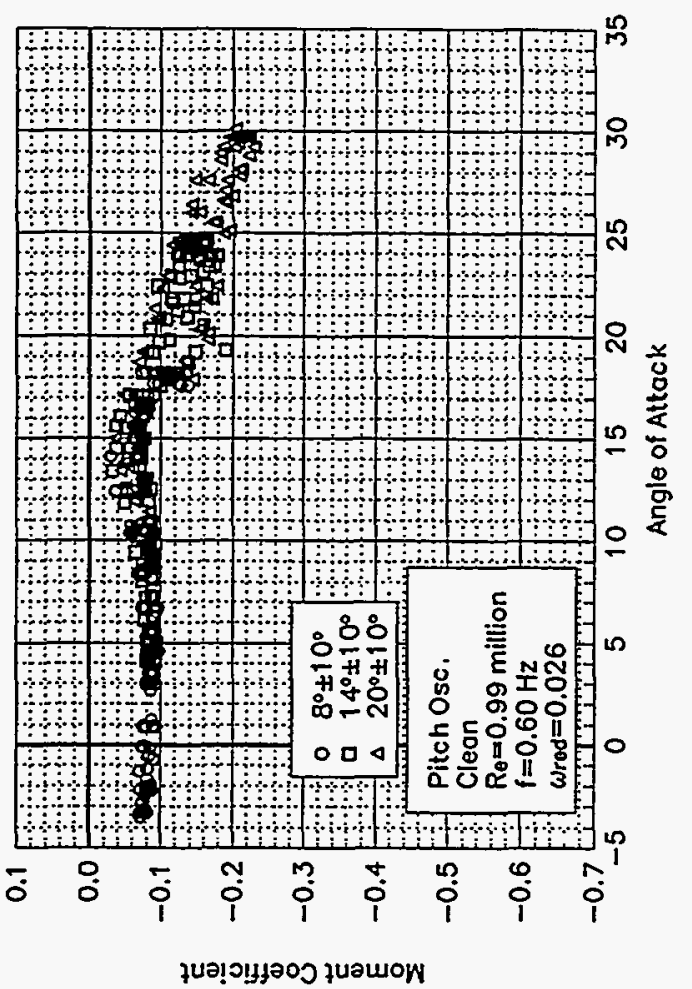

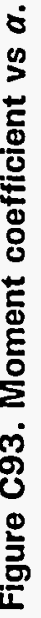

ì

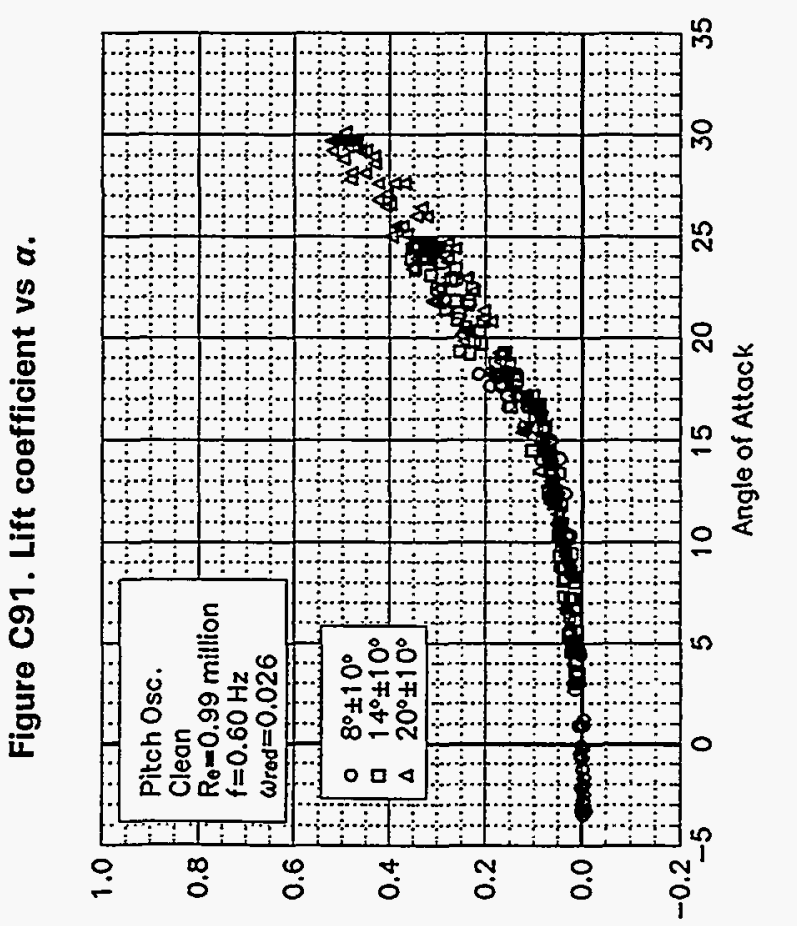

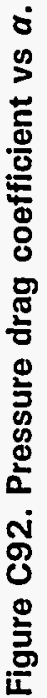

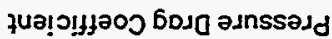



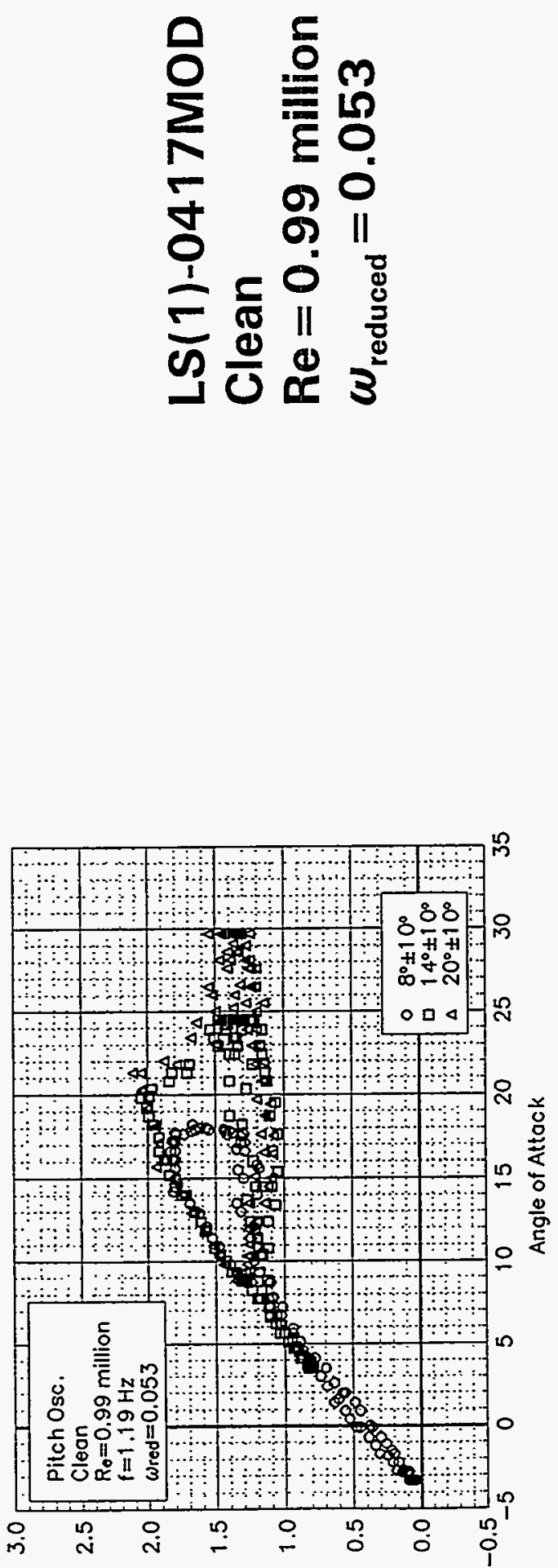

ในจ!ว!มฆอว วมก

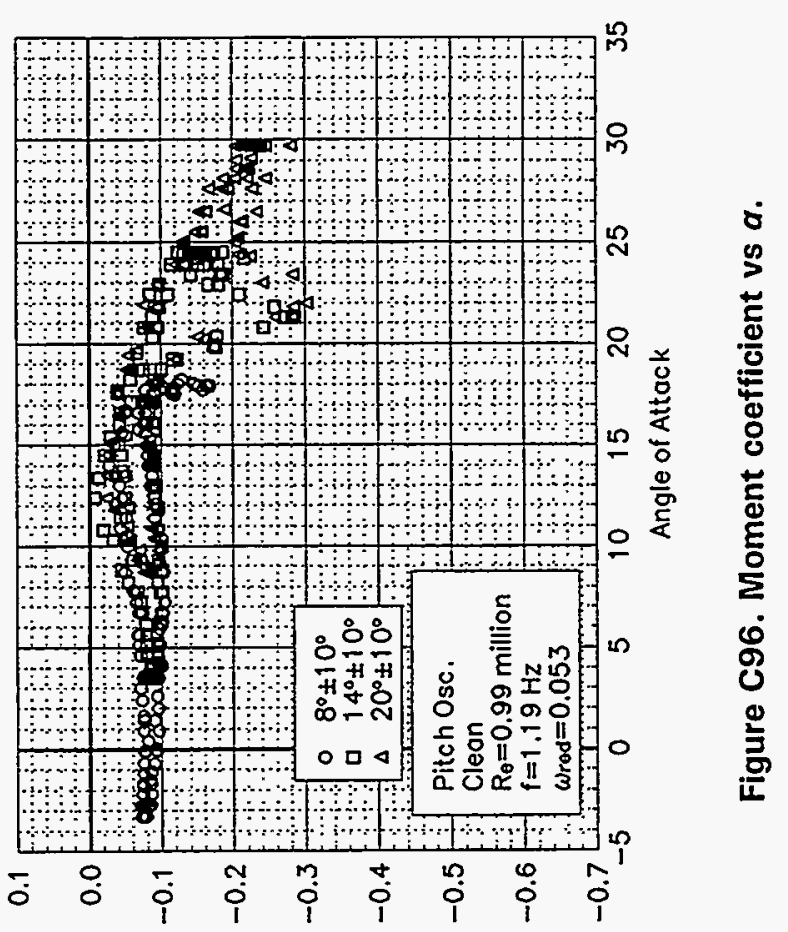

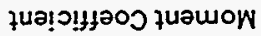

ช

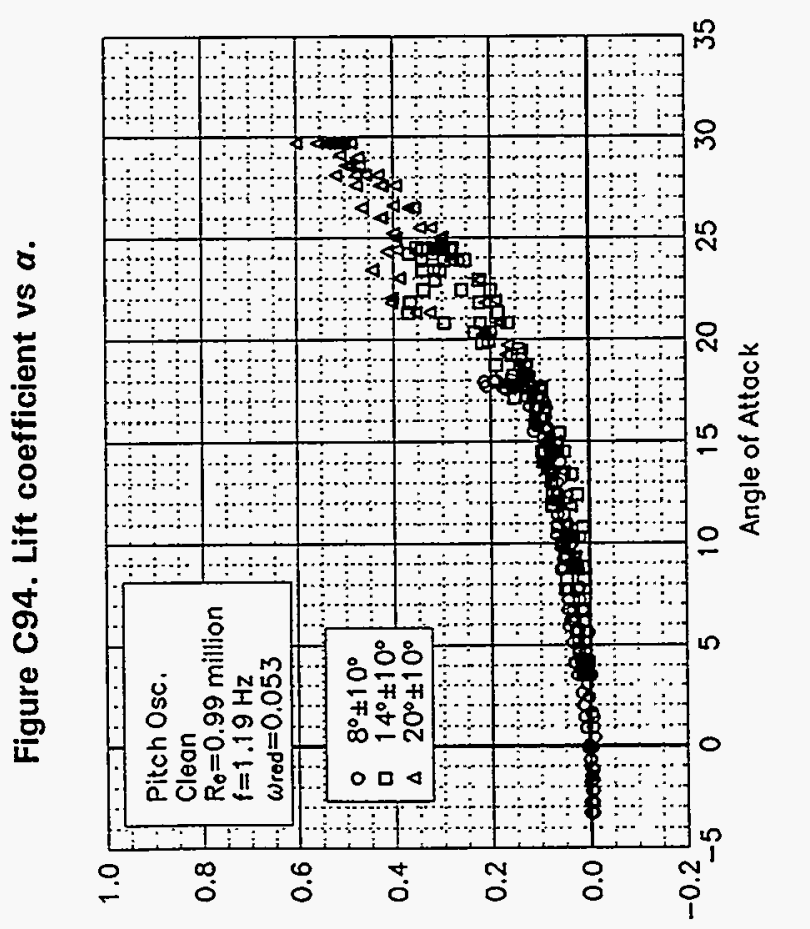

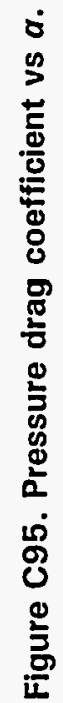


Pressure Drag Coefficient

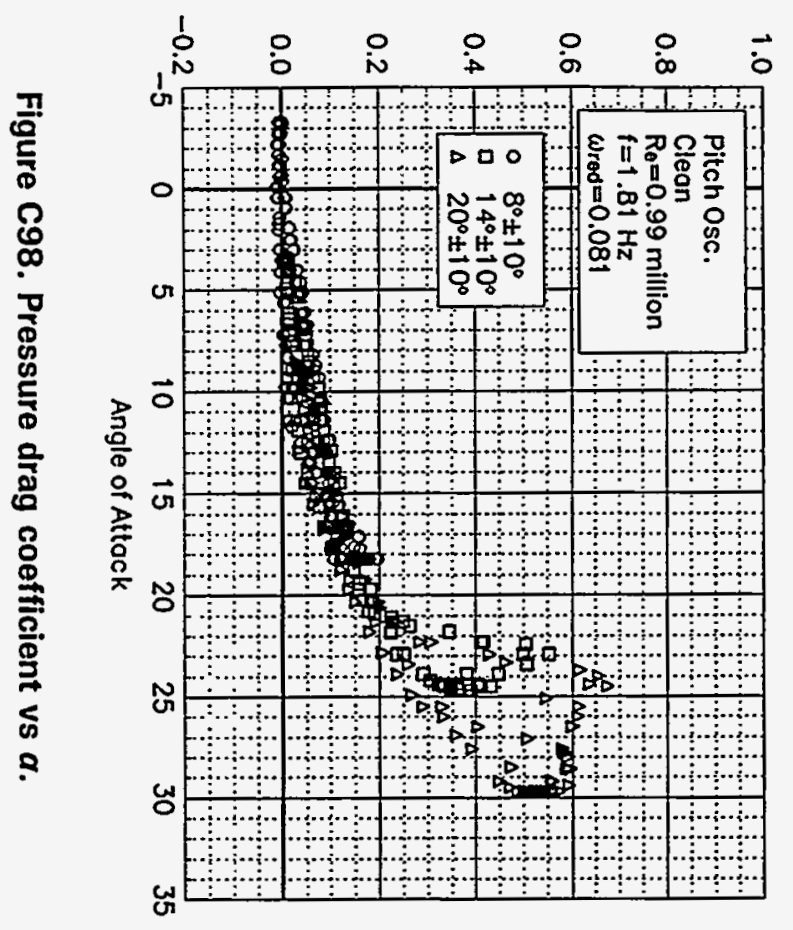

Lift Coefficient

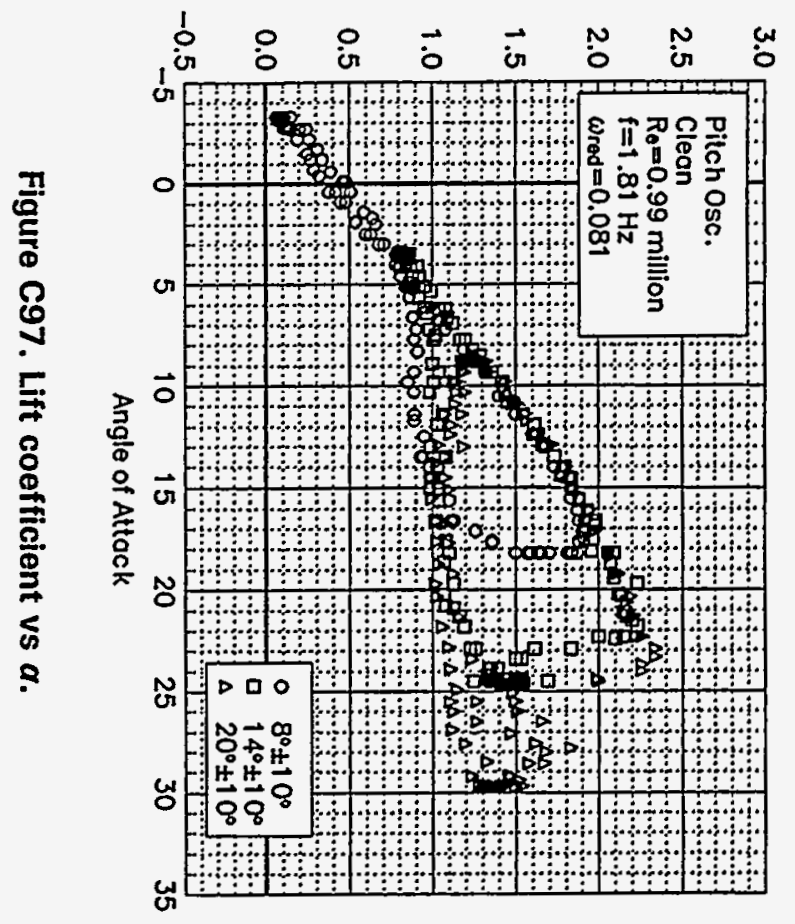

$£$

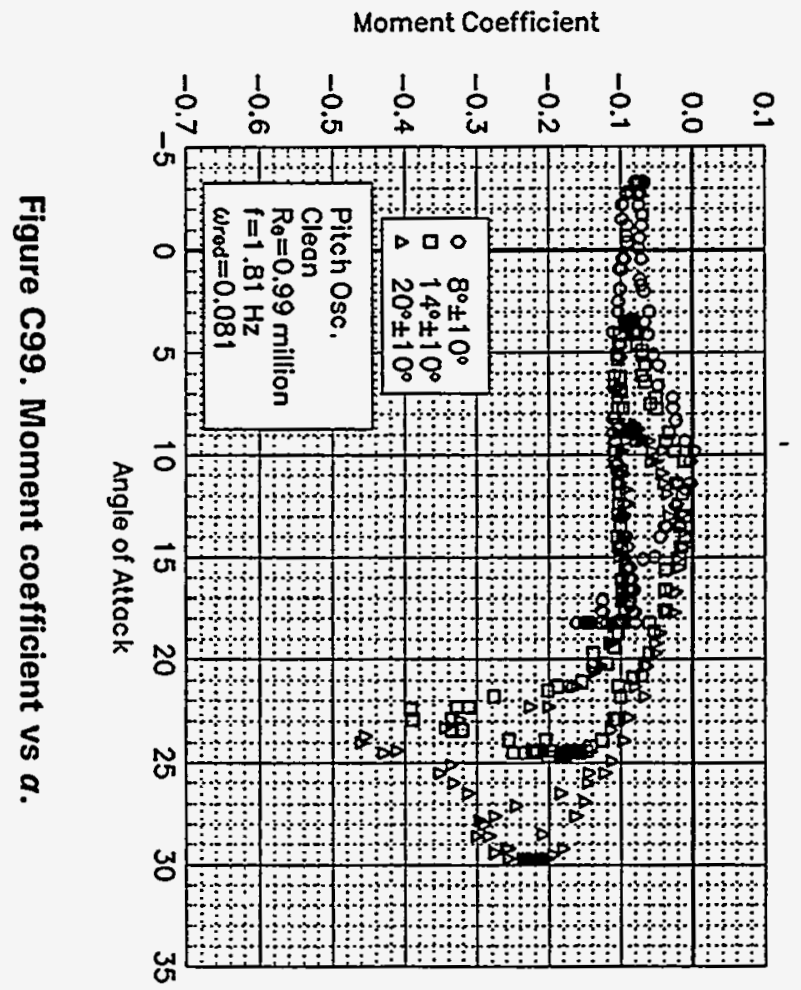

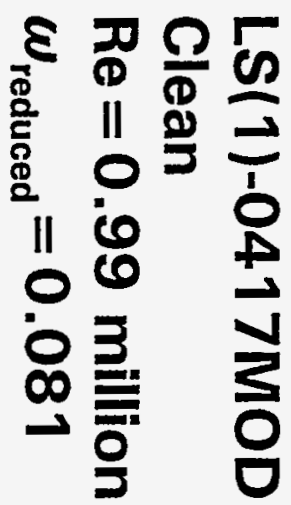



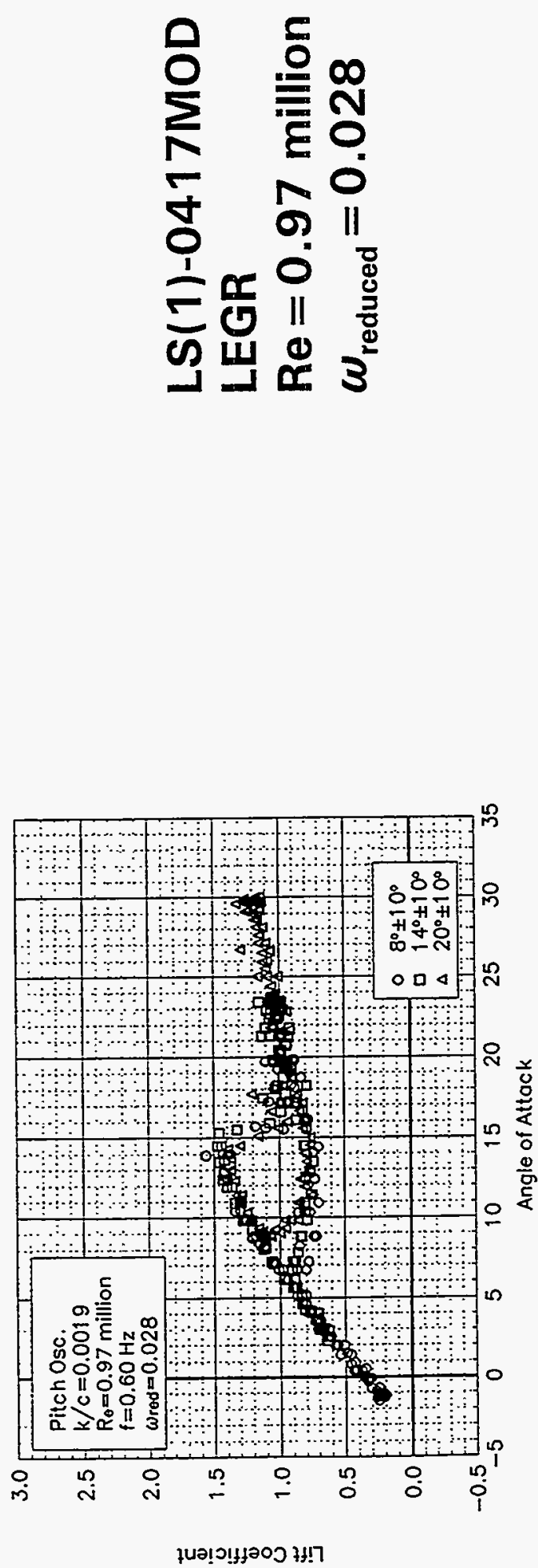

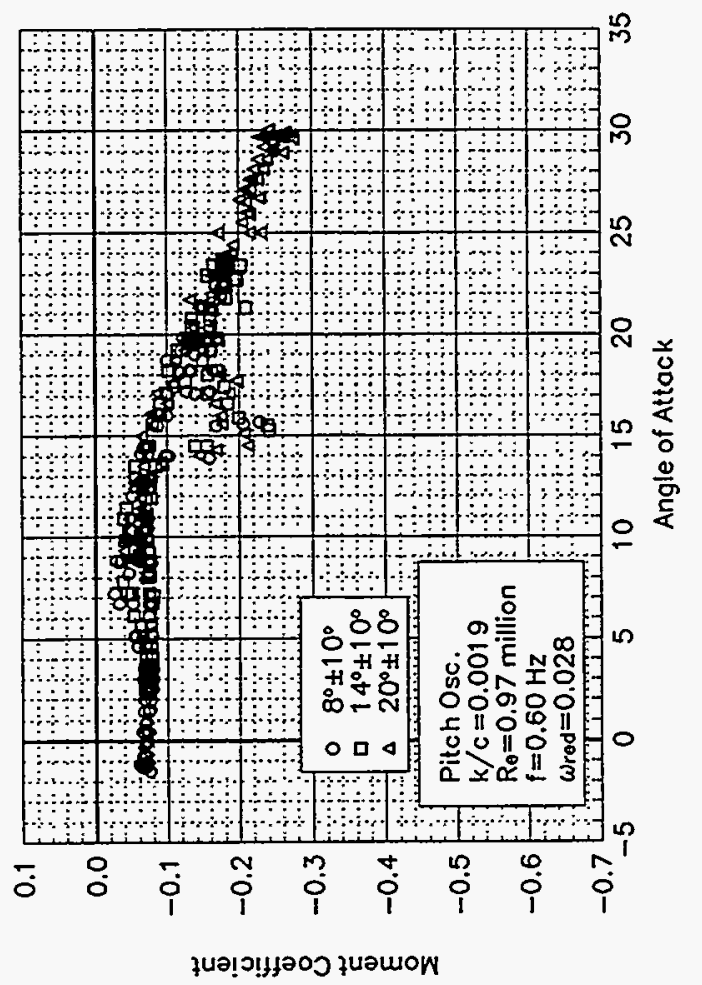

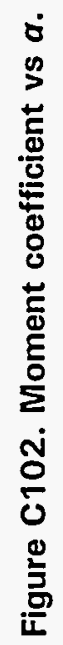

广

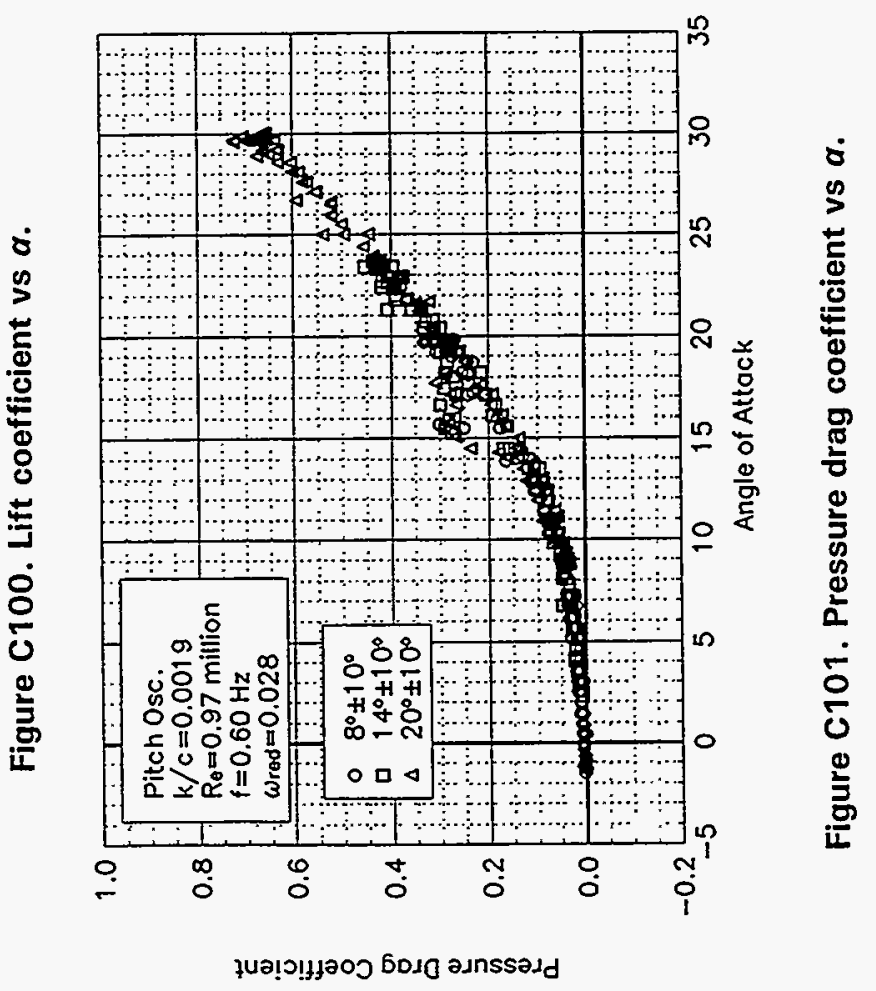



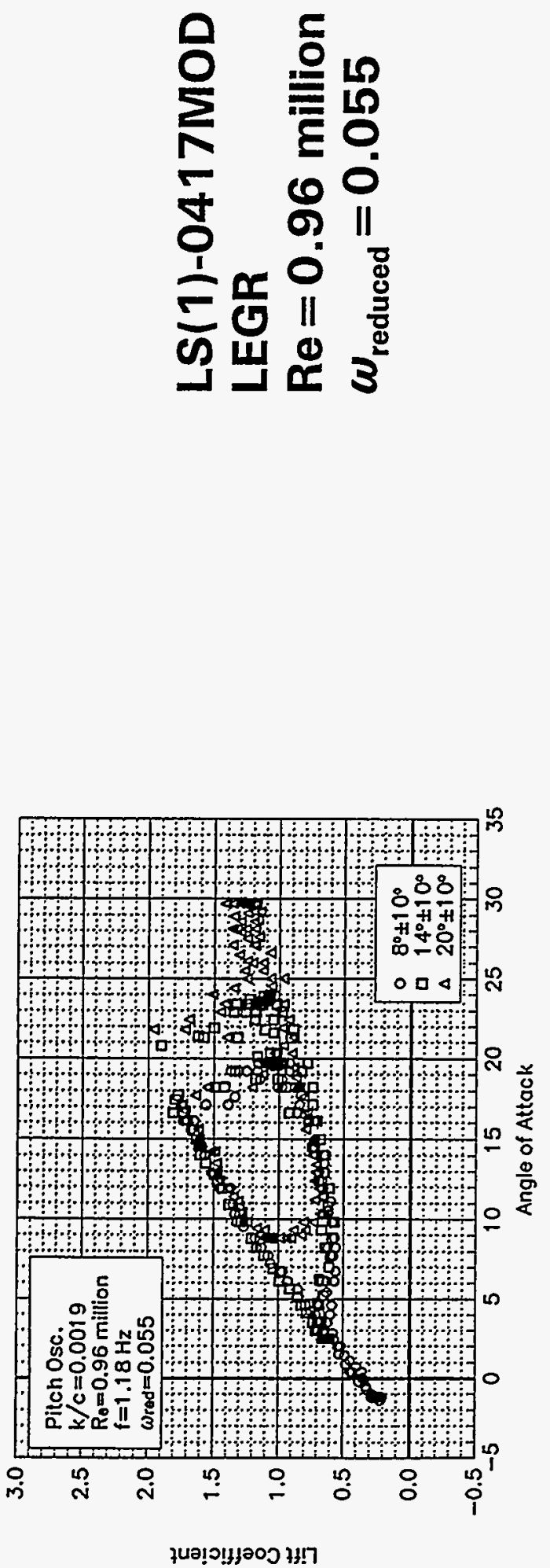

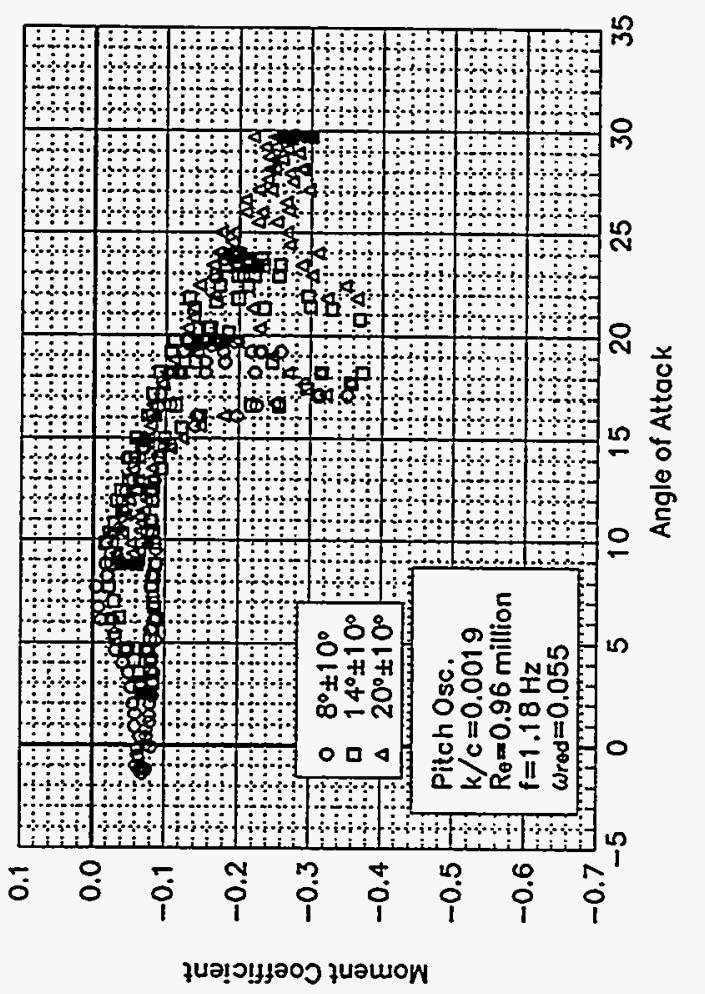

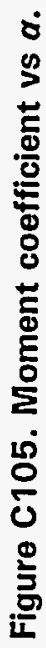

đ̊

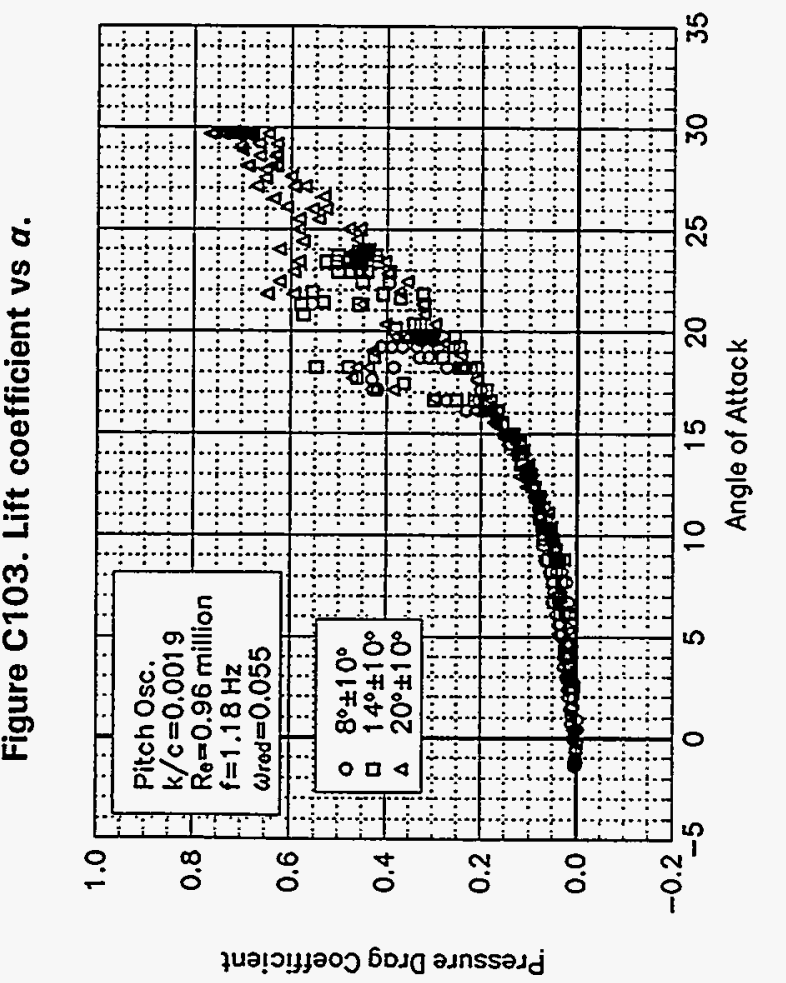

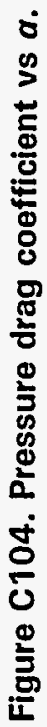



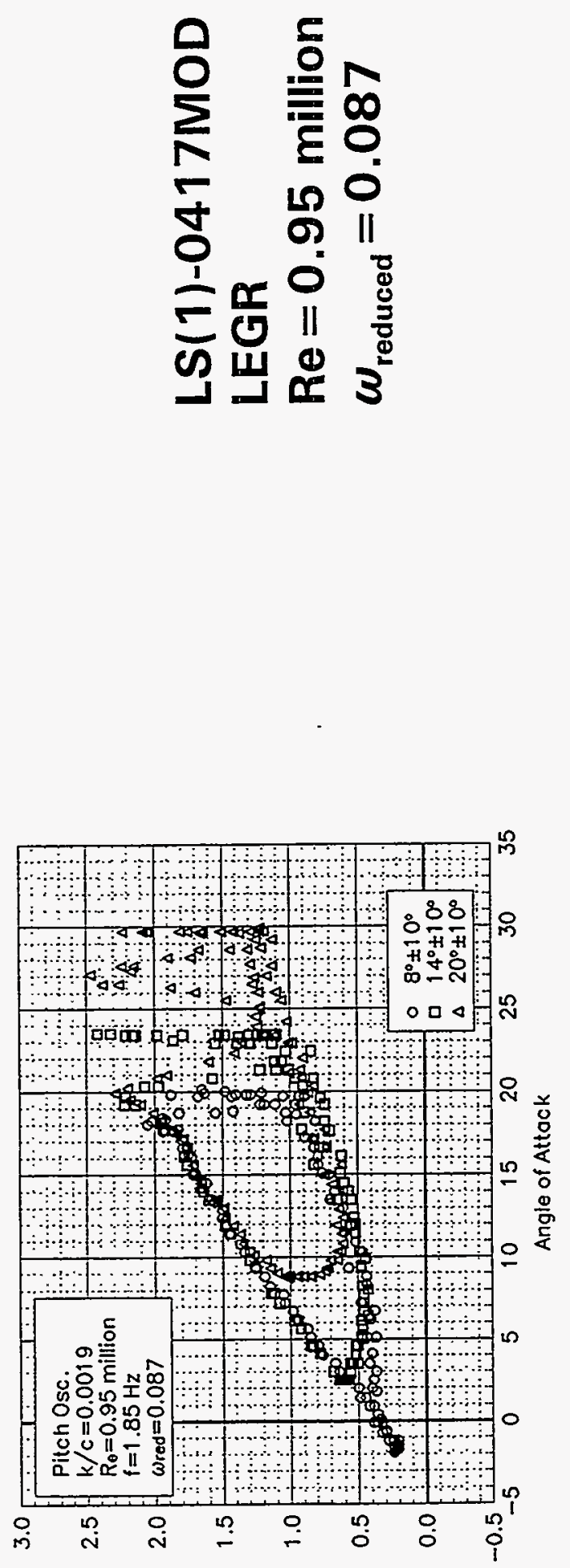

\}นจ!ว!น\}วัว หม!

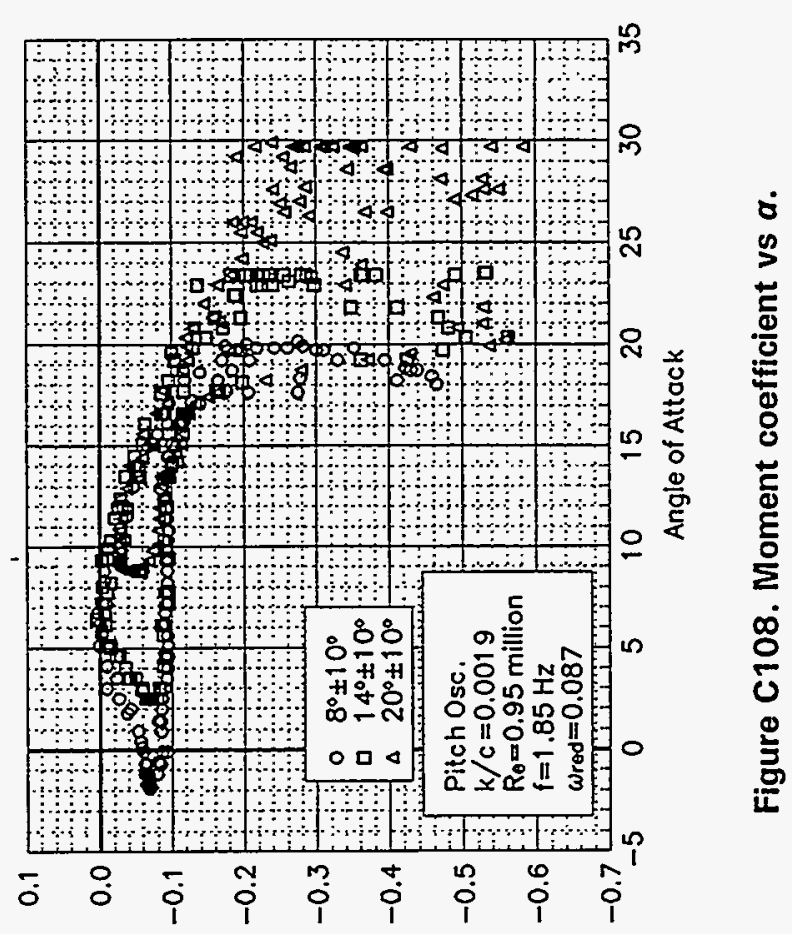

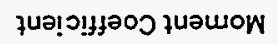

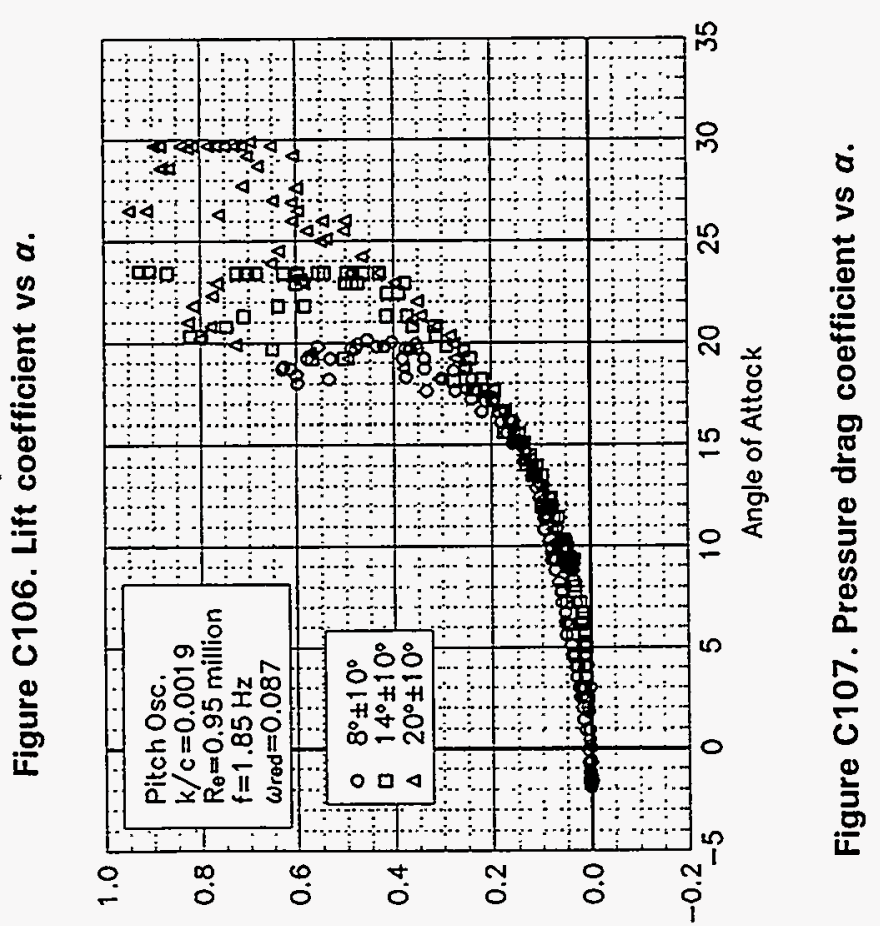

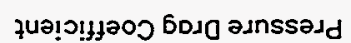




\section{Unsteady Airfoil Characteristics}

\section{$\pm 10^{\circ}$ Sine, $\operatorname{Re}=1.25$ million}




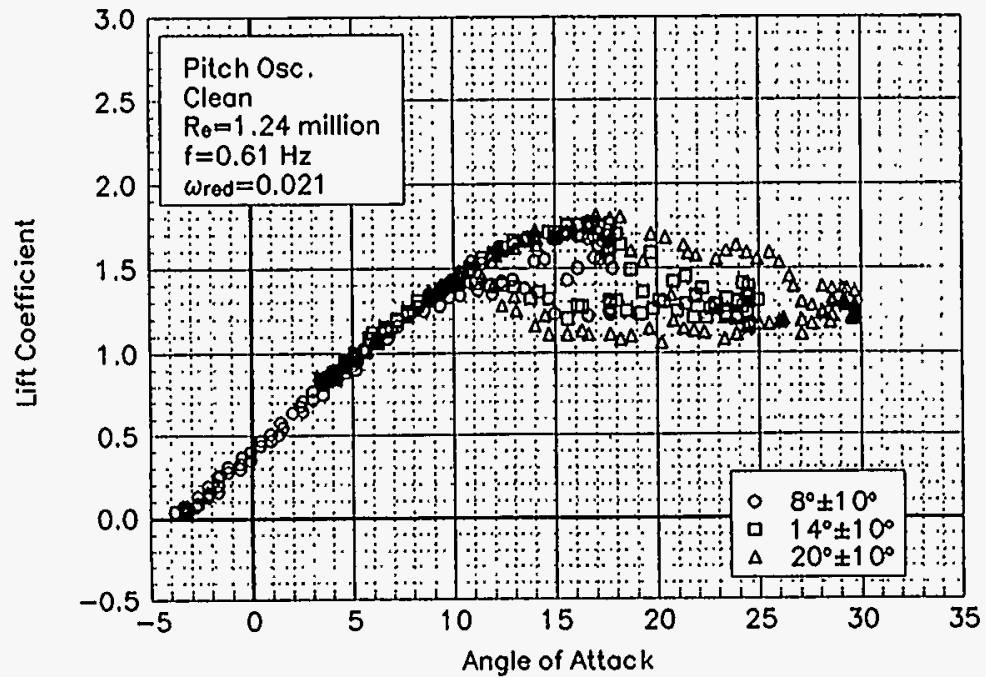

Figure C109. Lift coefficient vs $a$.

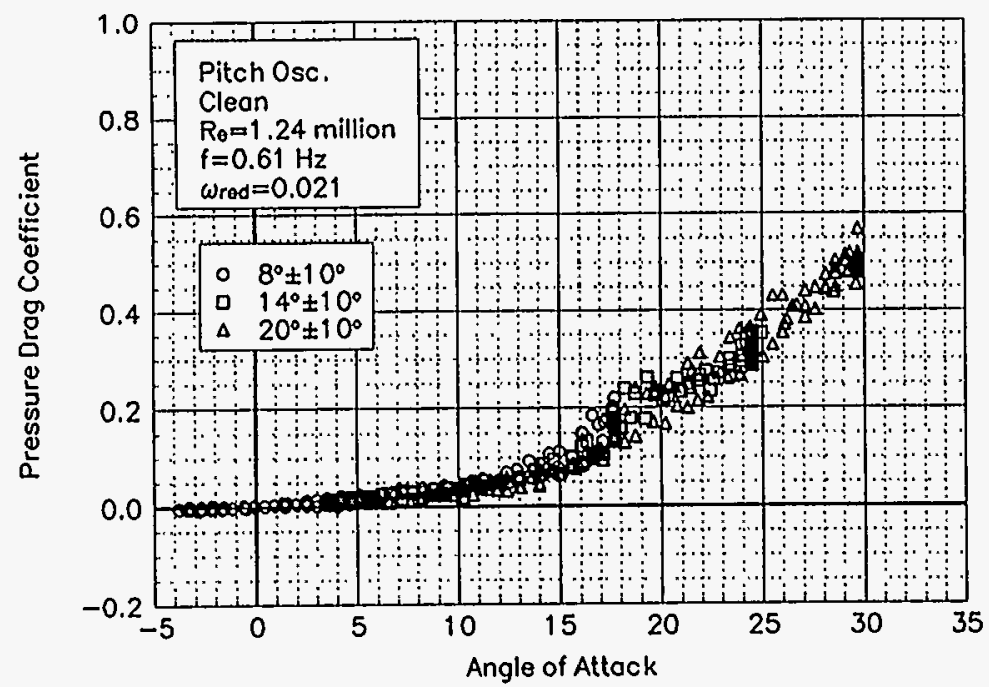

Figure $\mathrm{C} 110$. Pressure drag coefficient vs $a$.

\section{LS(1)-0417MOD Clean \\ $\operatorname{Re}=1.24$ million \\ $\omega_{\text {reduced }}=0.021$}

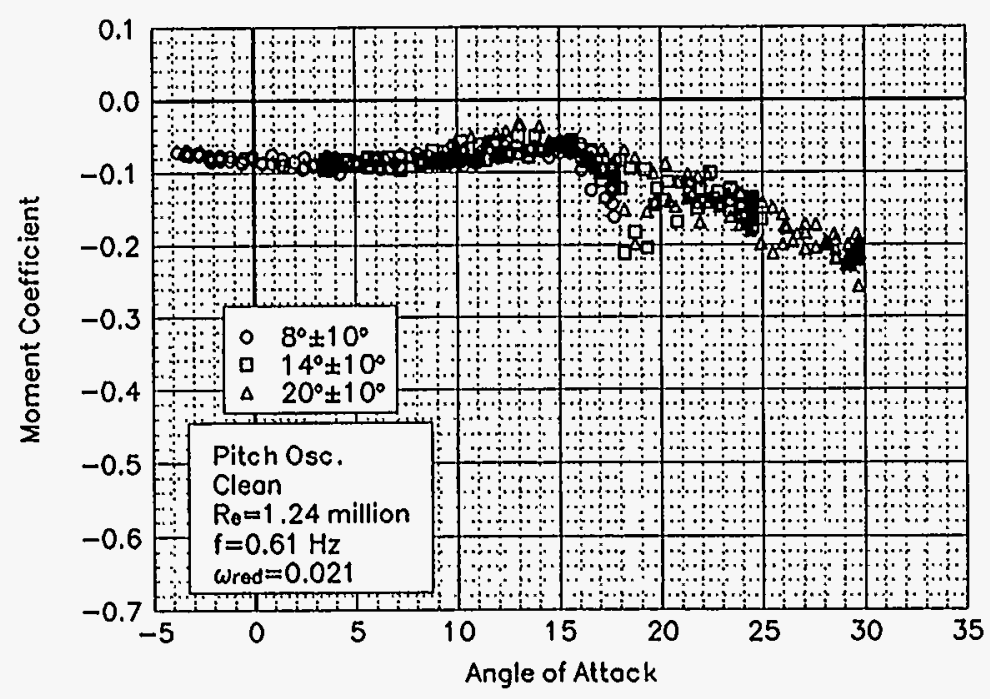

Figure C111. Moment coefficient vs $a$. 

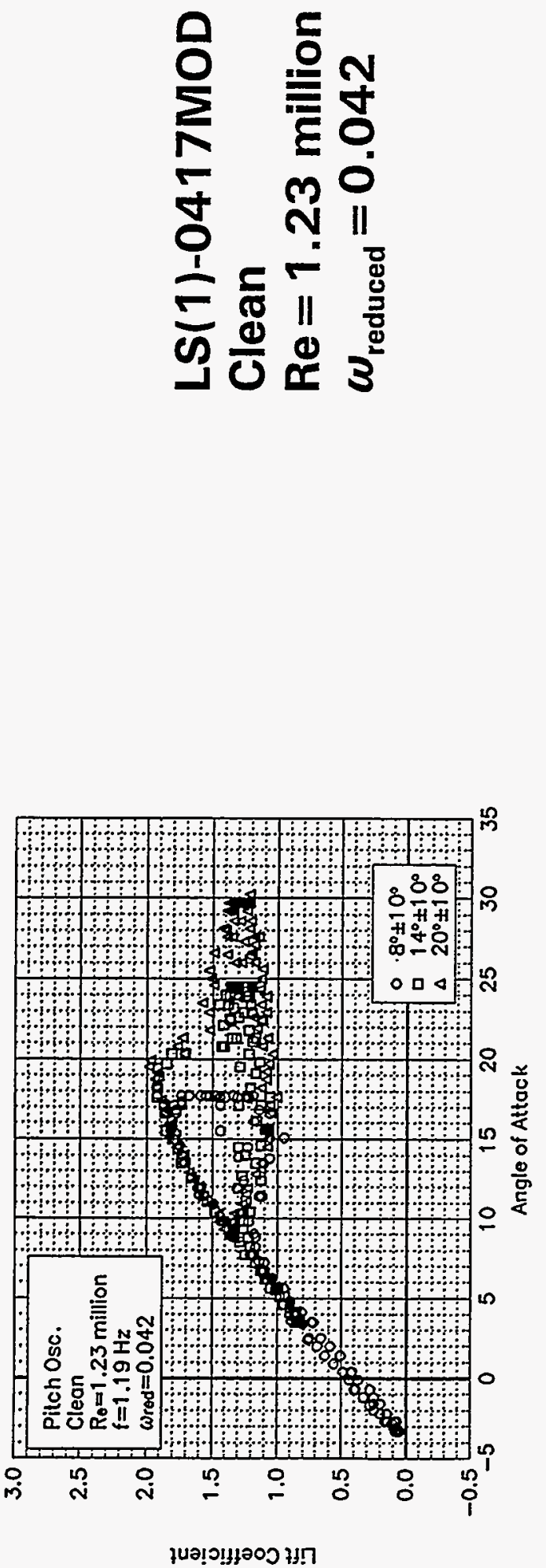

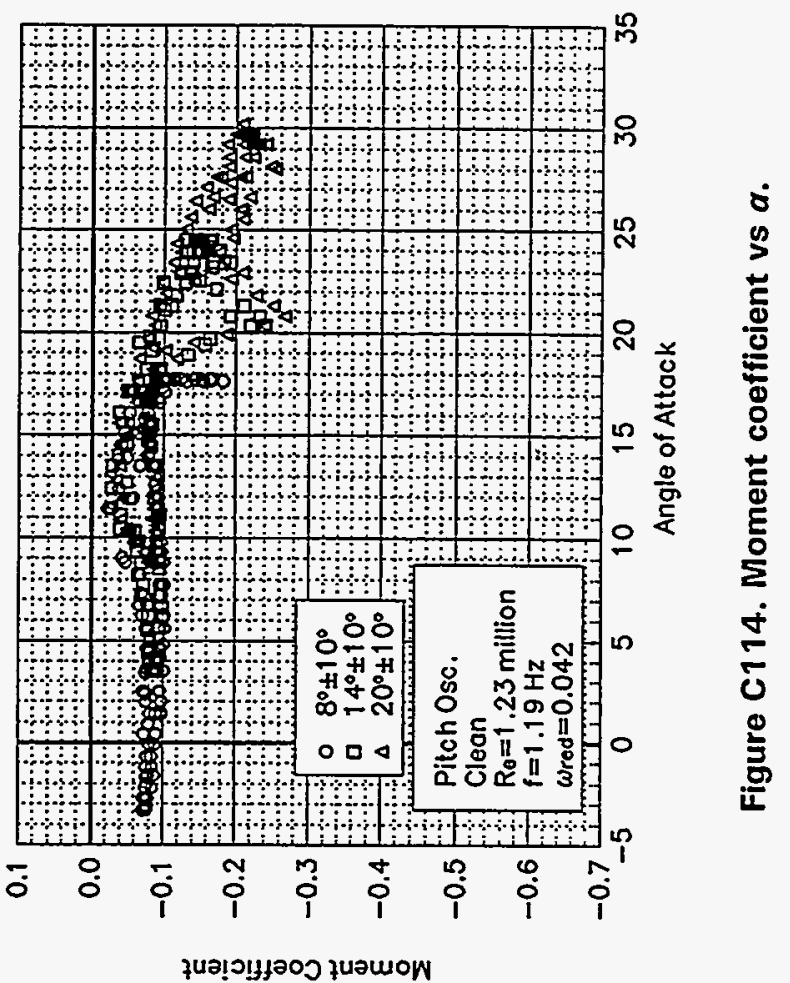

于

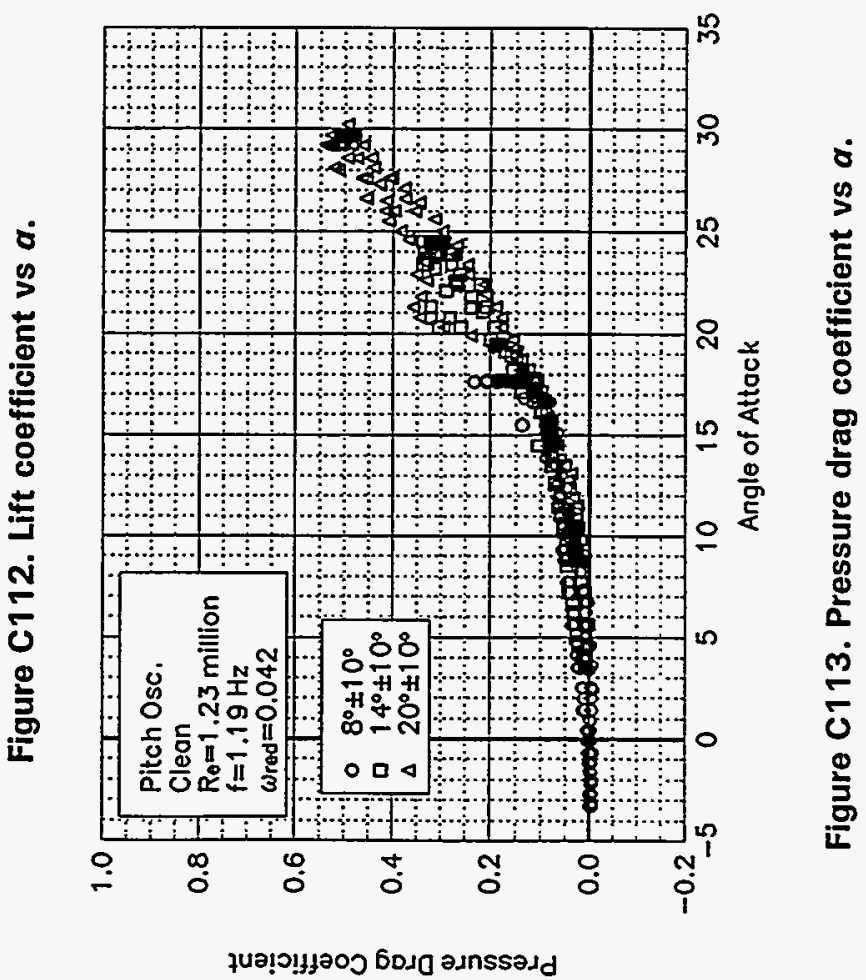



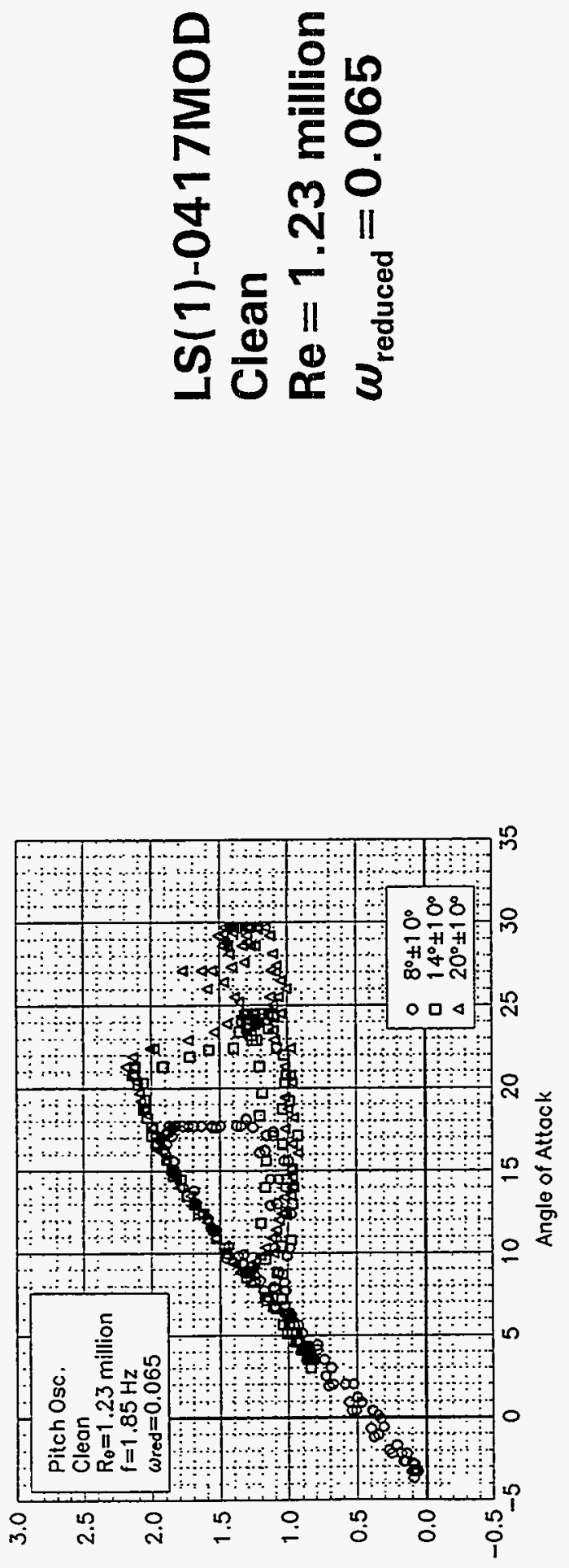

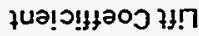

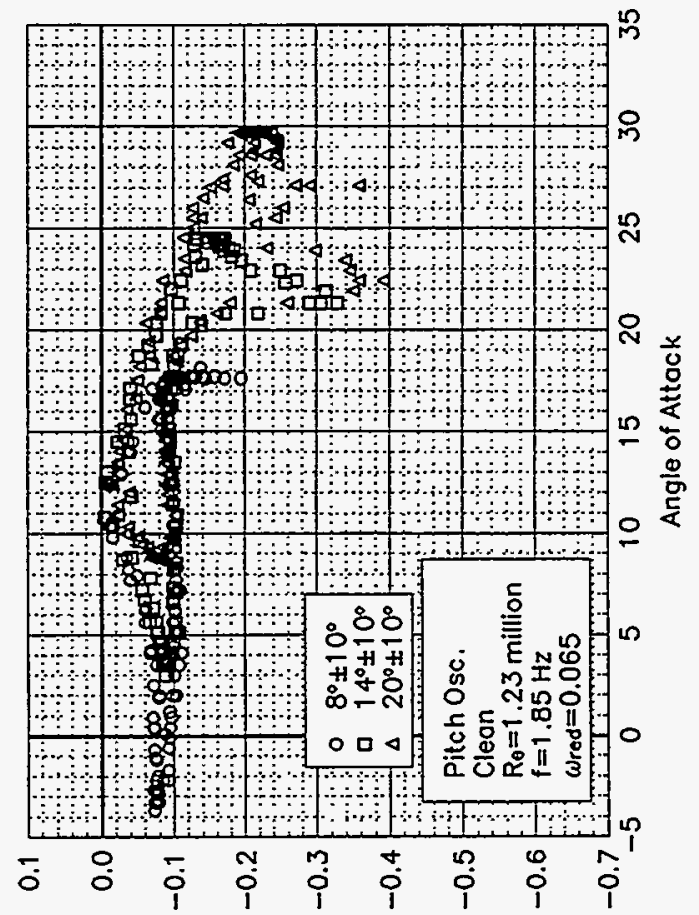

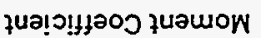

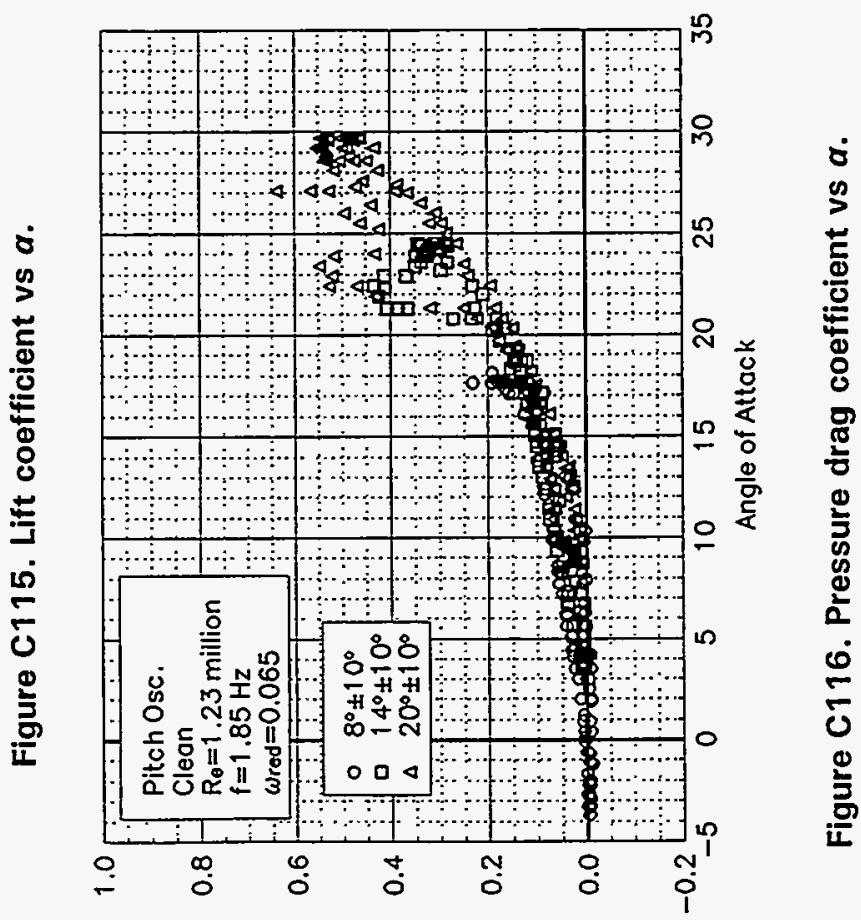

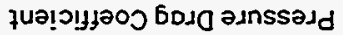



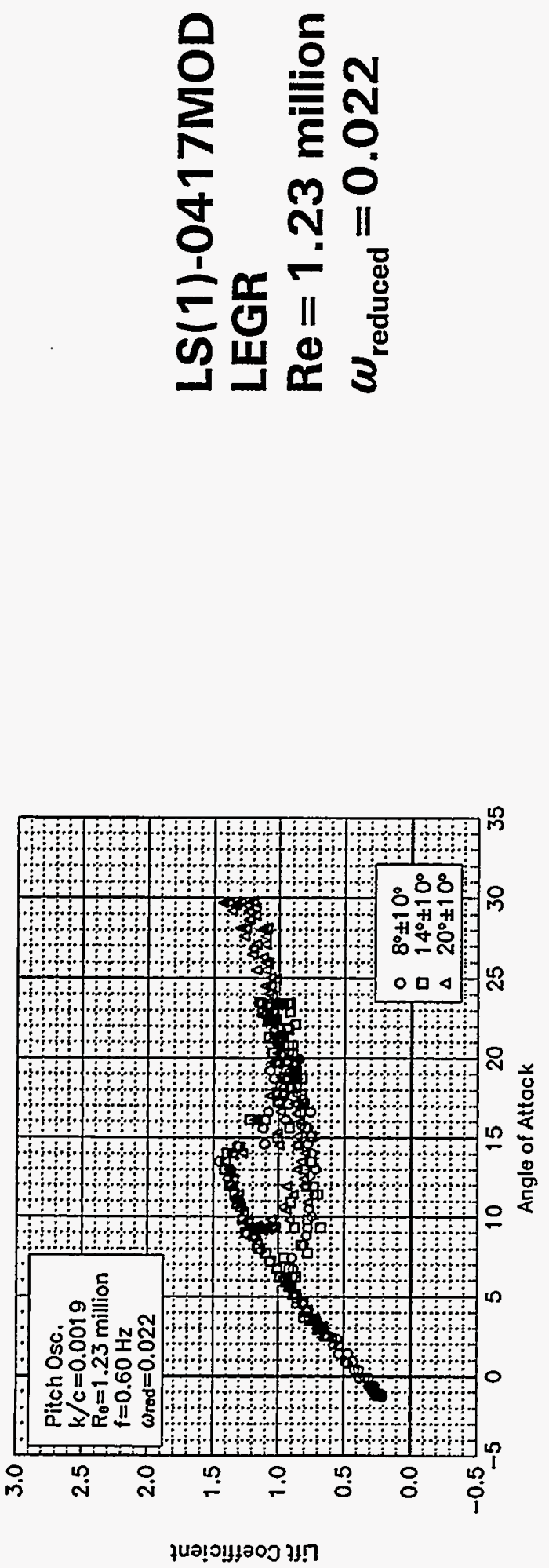

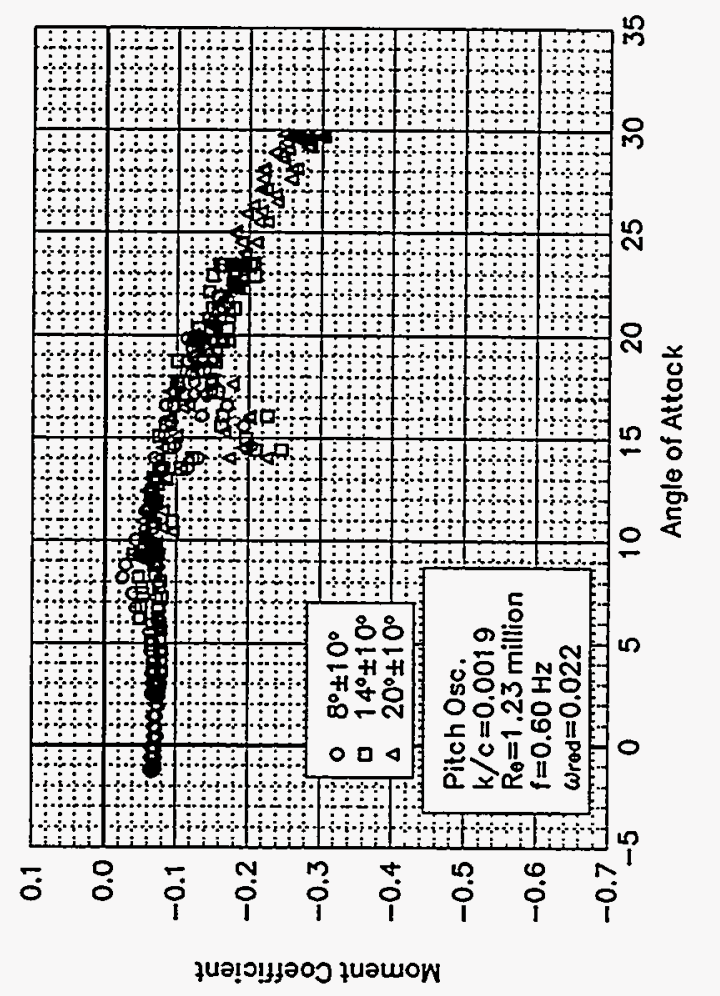

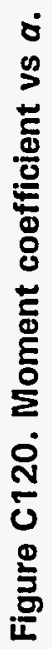

g

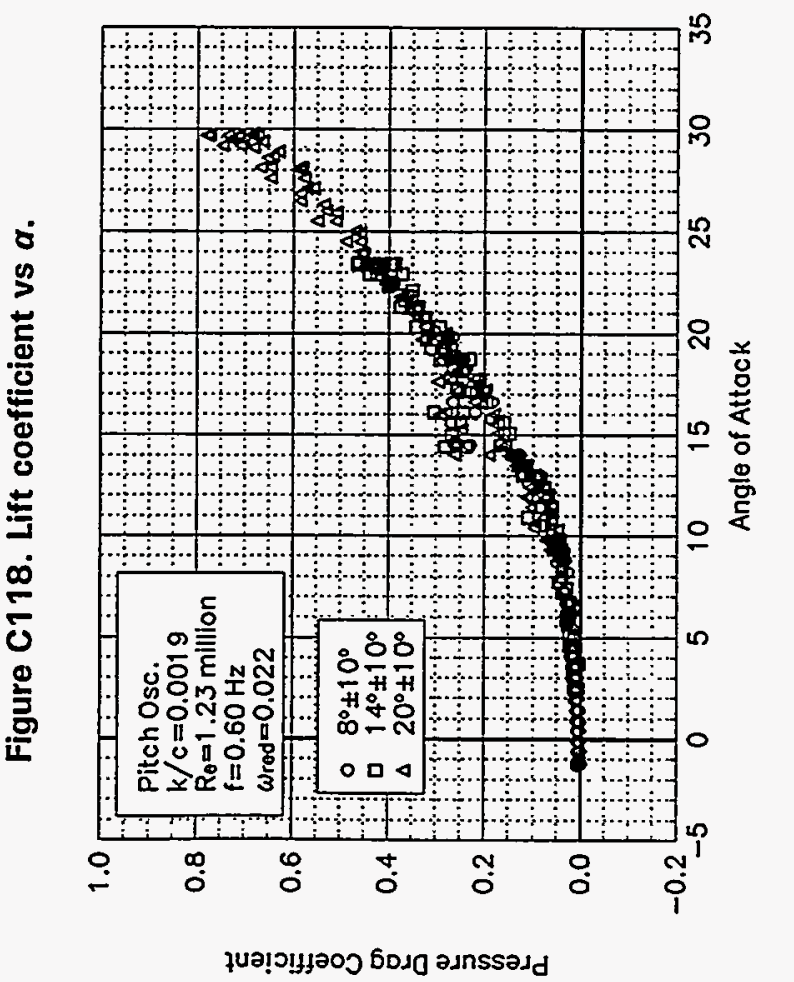



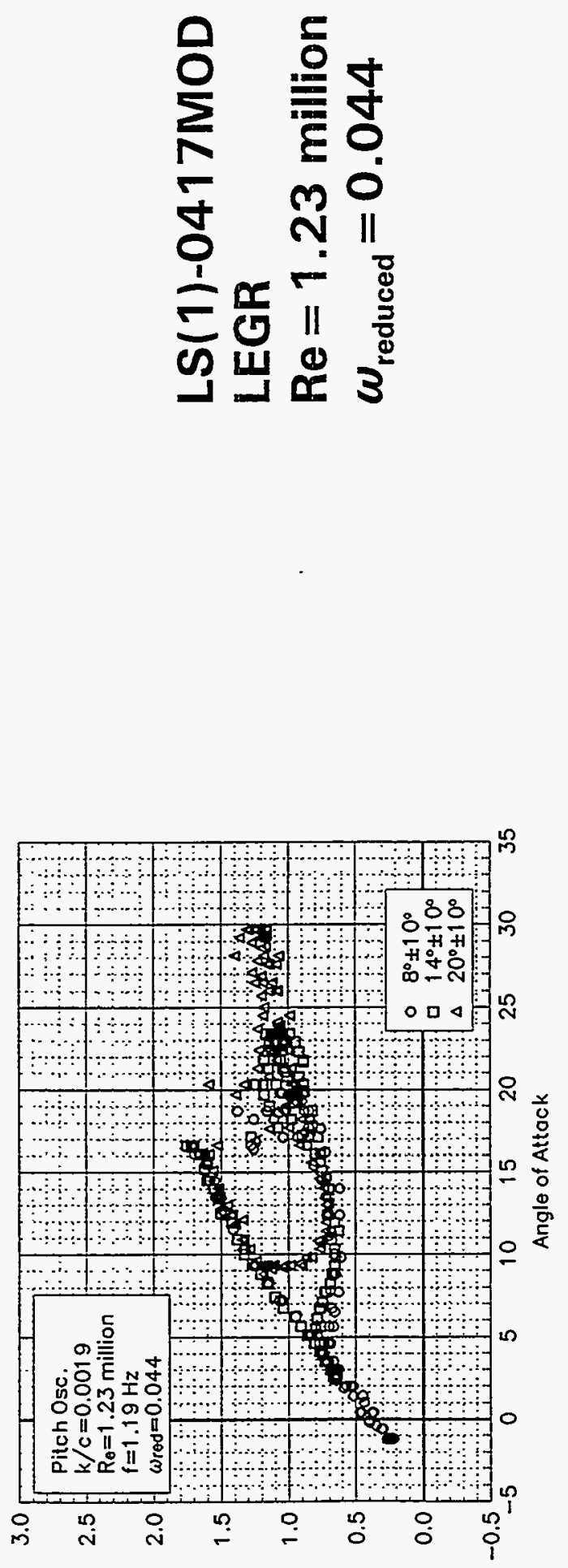

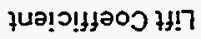

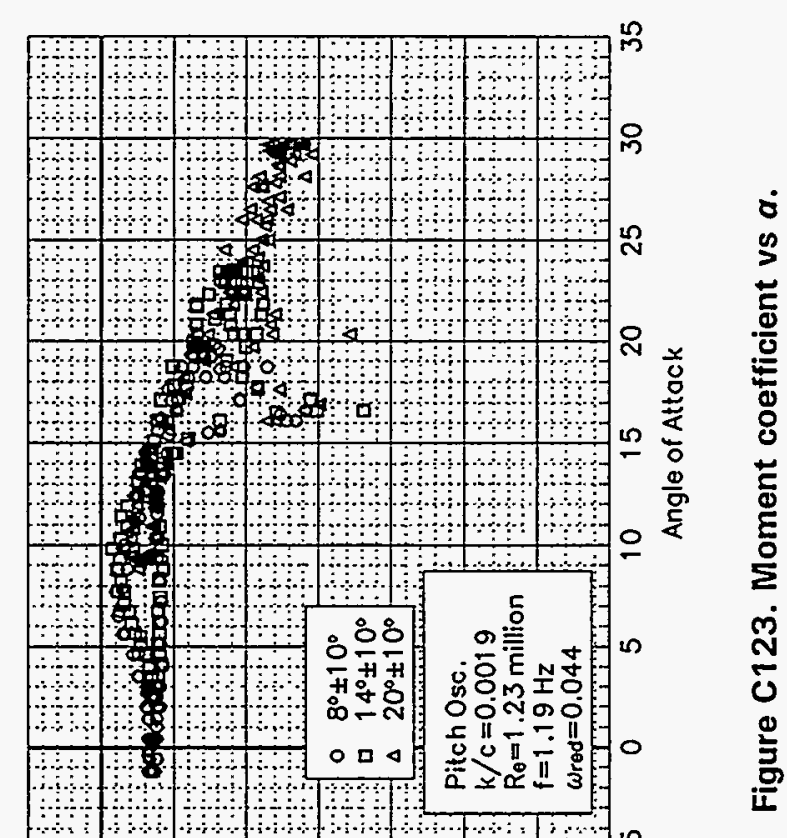

ن

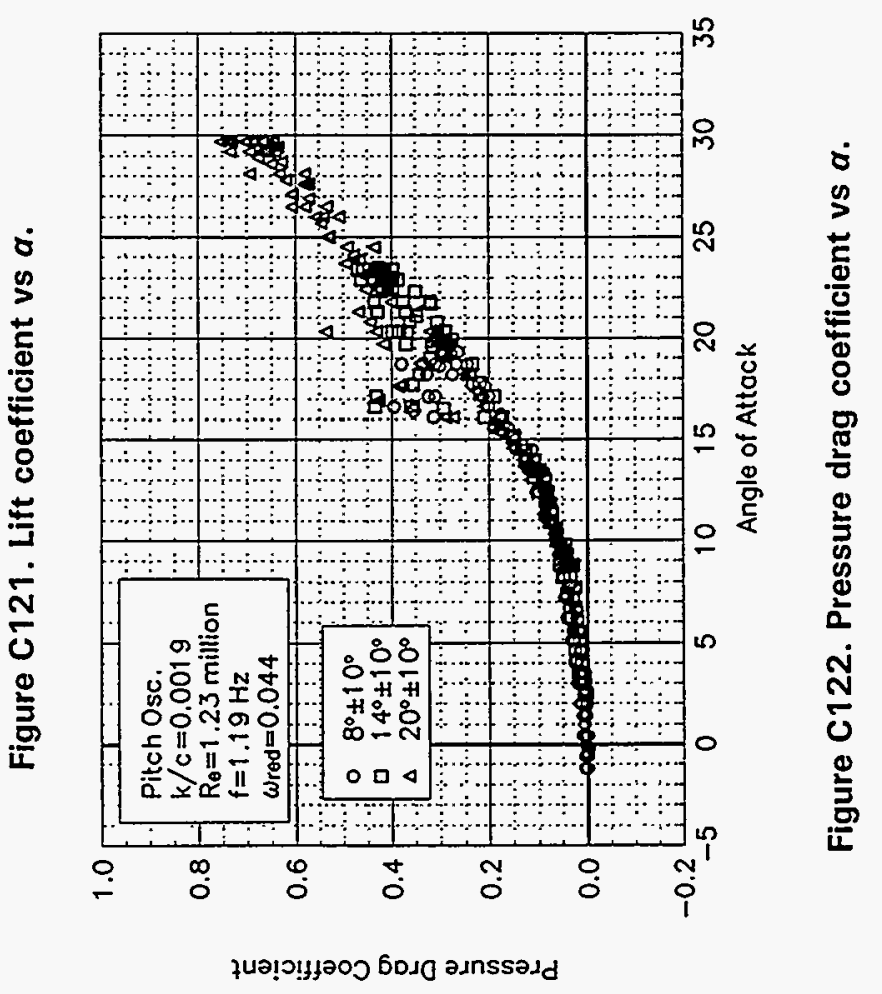



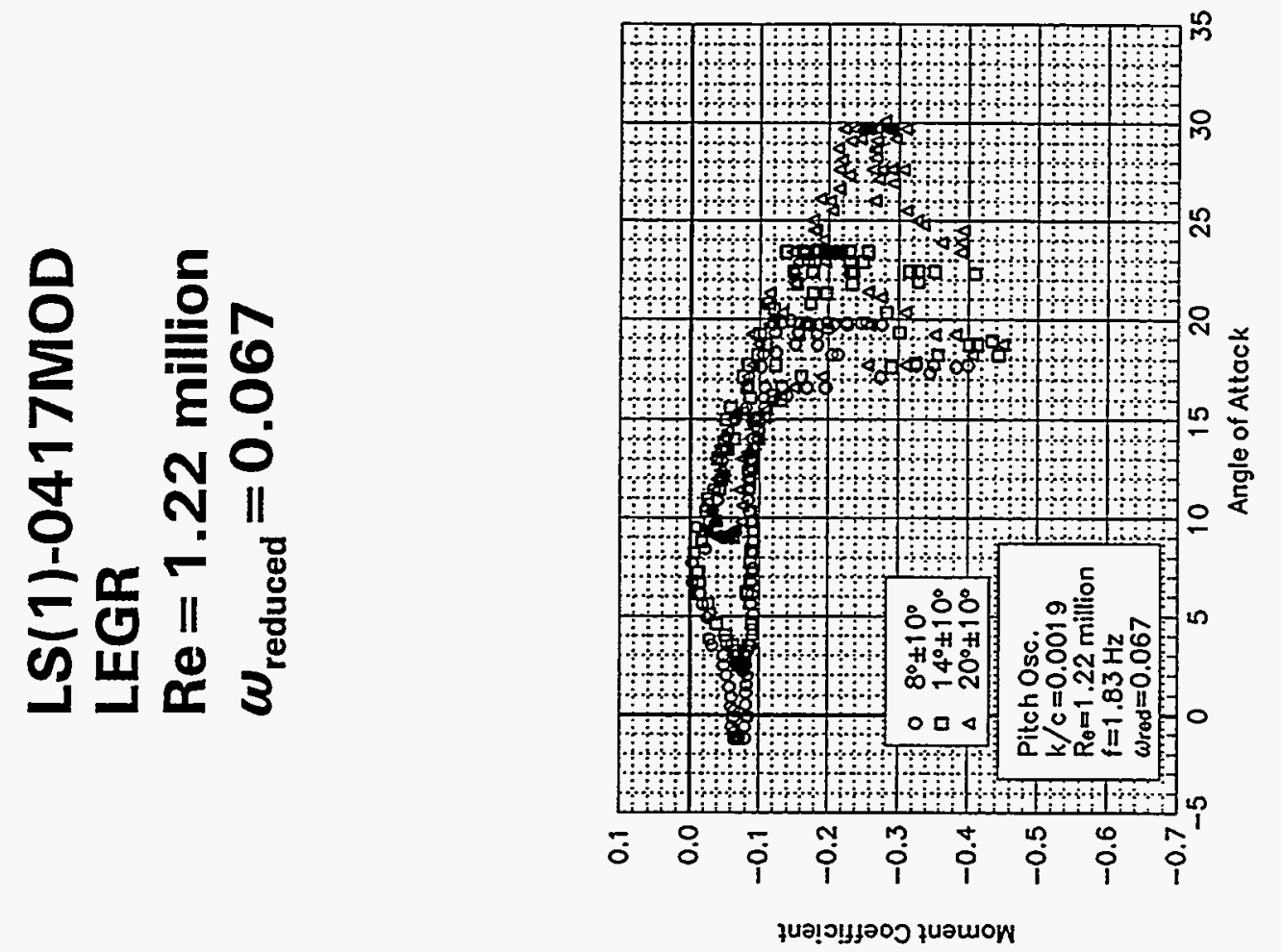

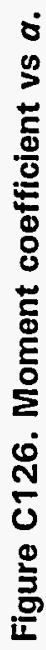
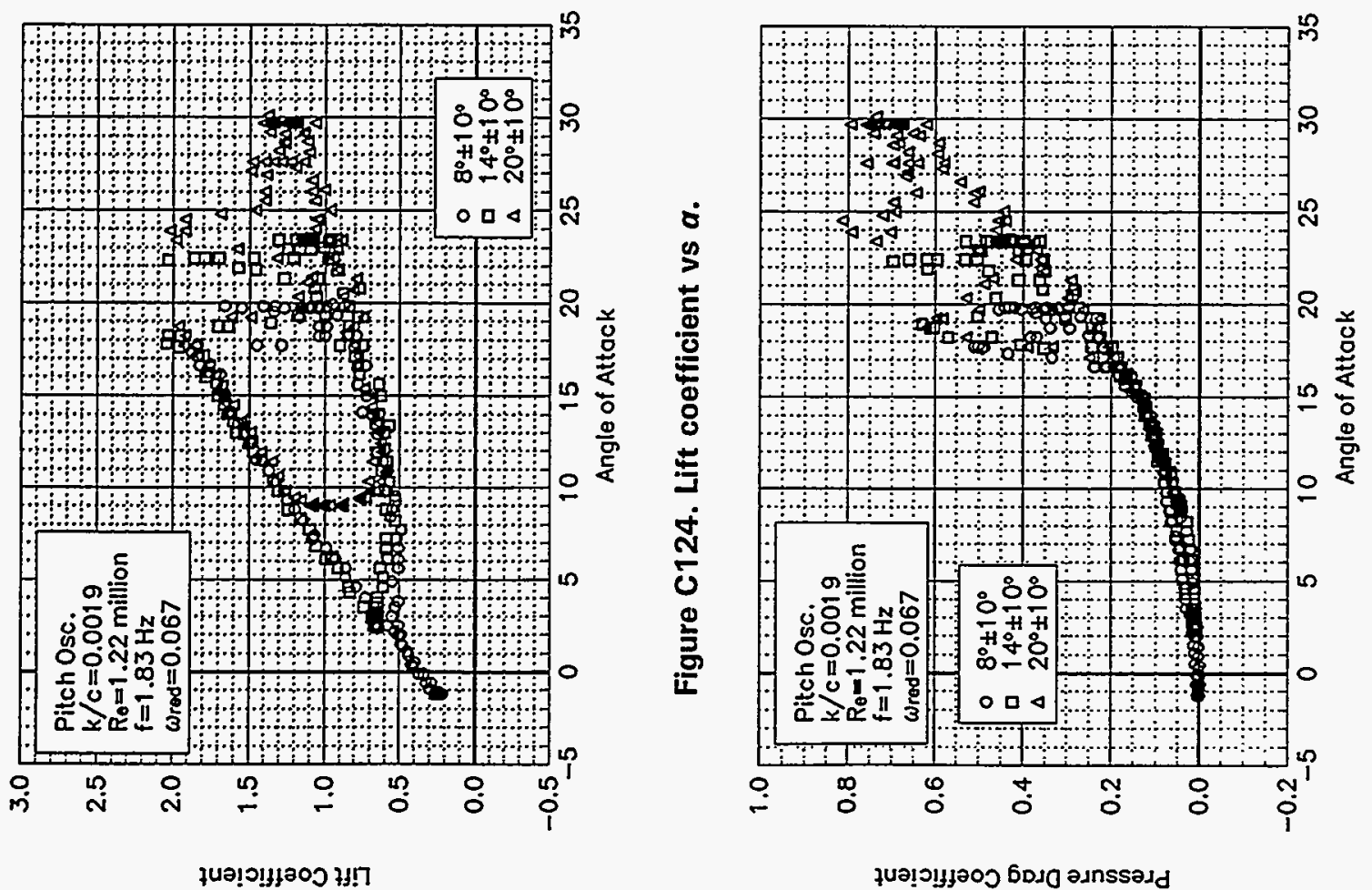

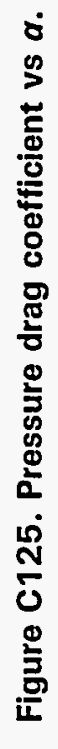

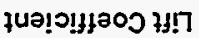




\section{Unsteady Airfoil Characteristics \\ $\pm 10^{\circ}$ Sine, $\operatorname{Re}=1.5$ million}



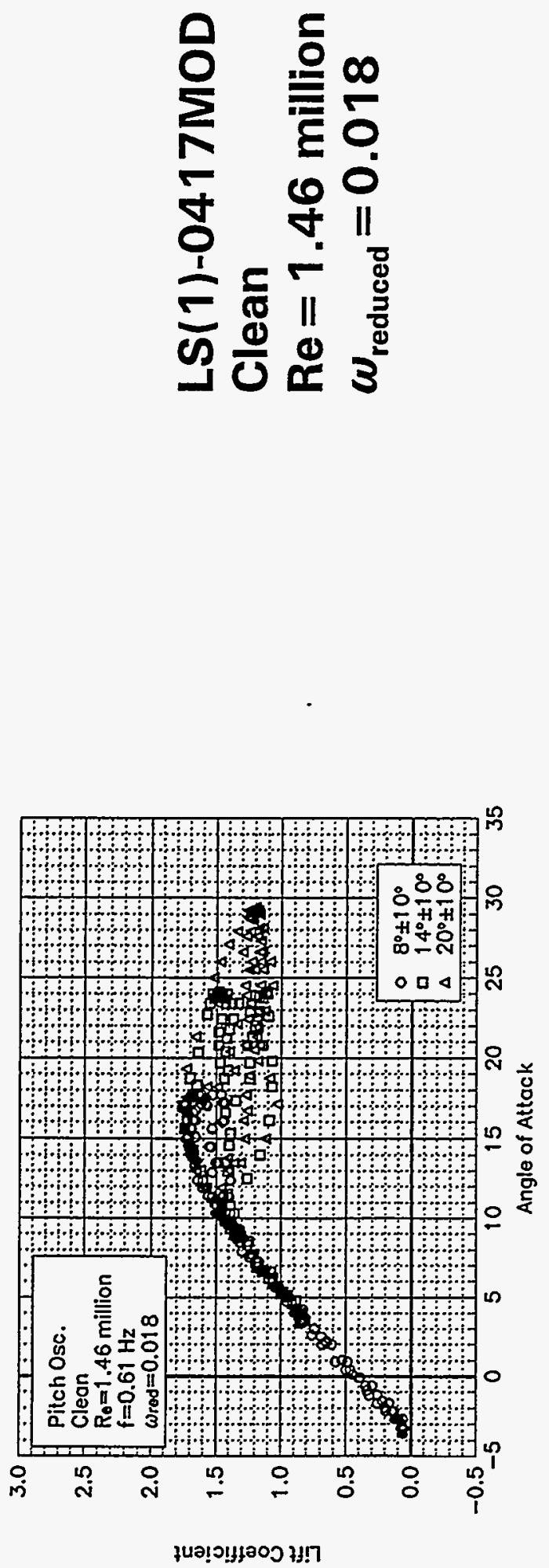

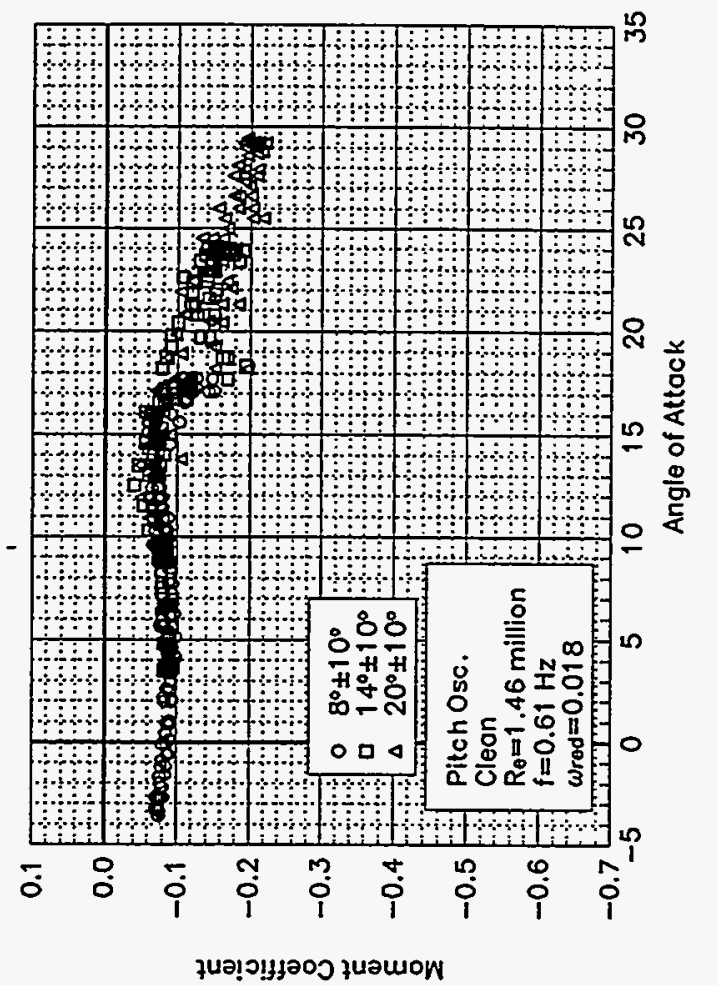

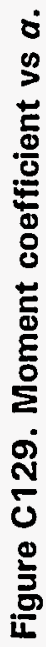

$n$
ñ

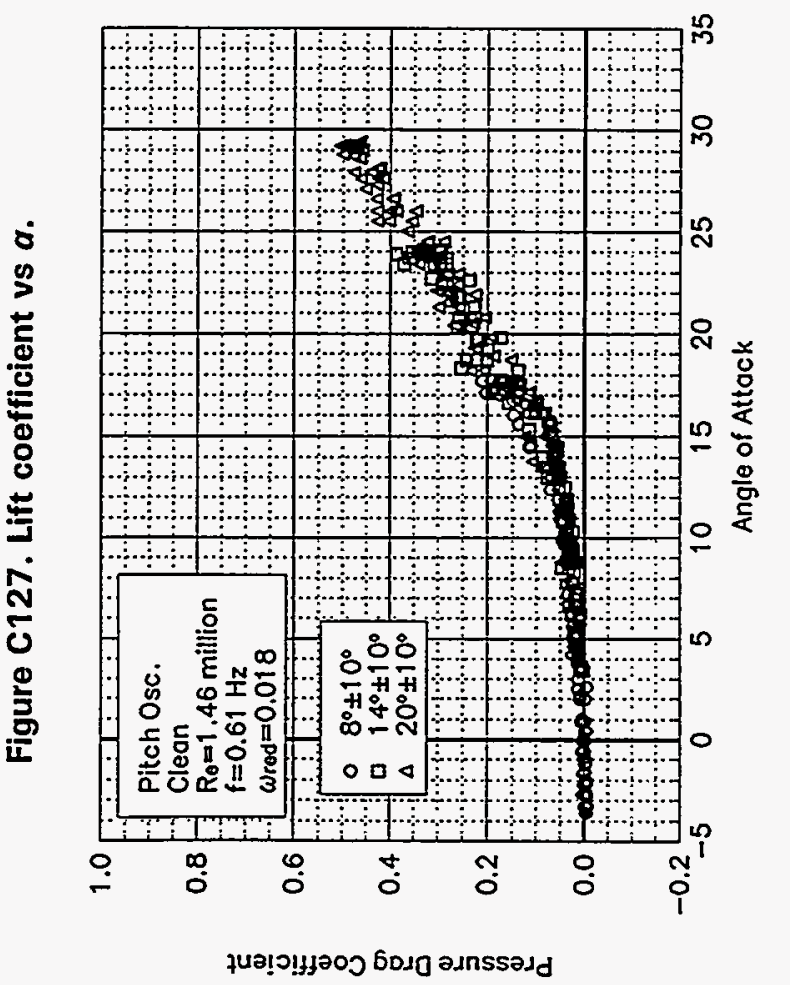

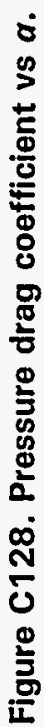



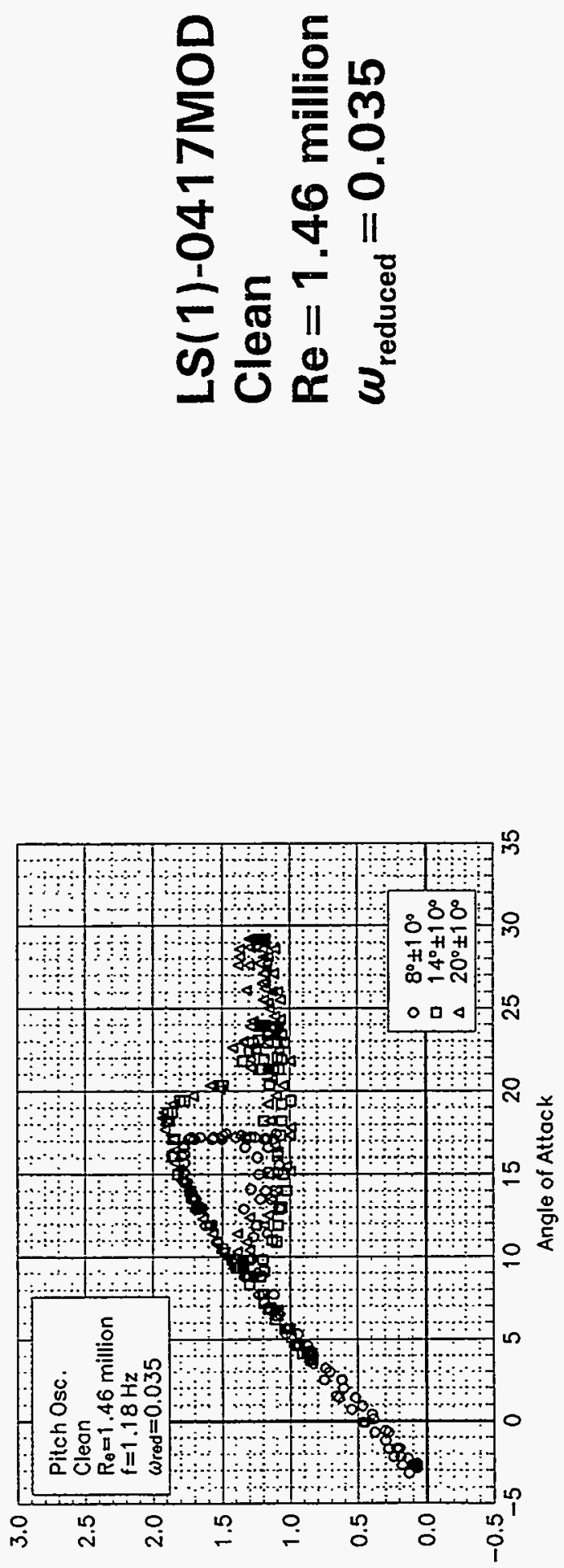

ไนว!ว!\}\}əัว 7$\} ! 7$

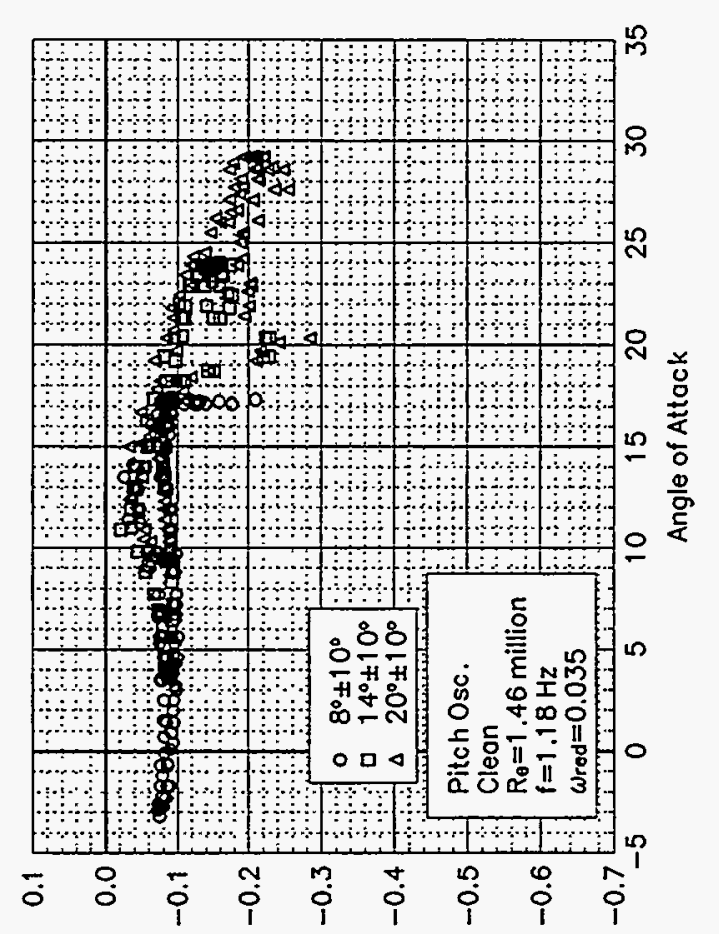

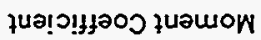

苦

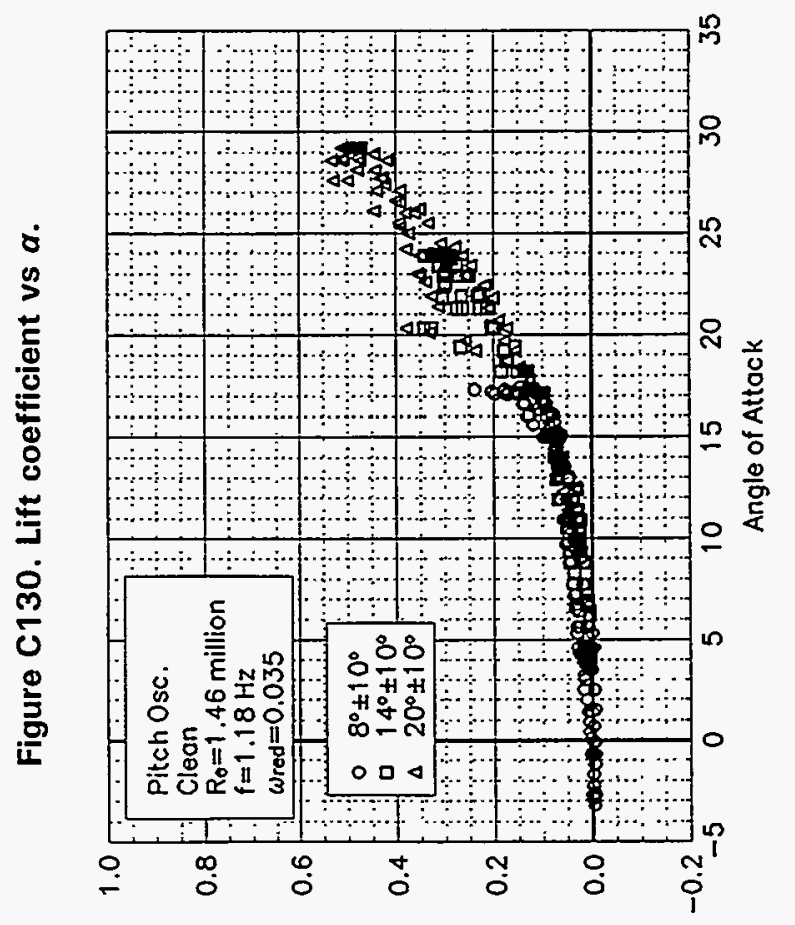

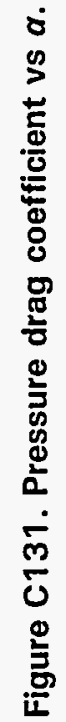

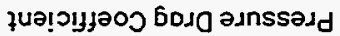




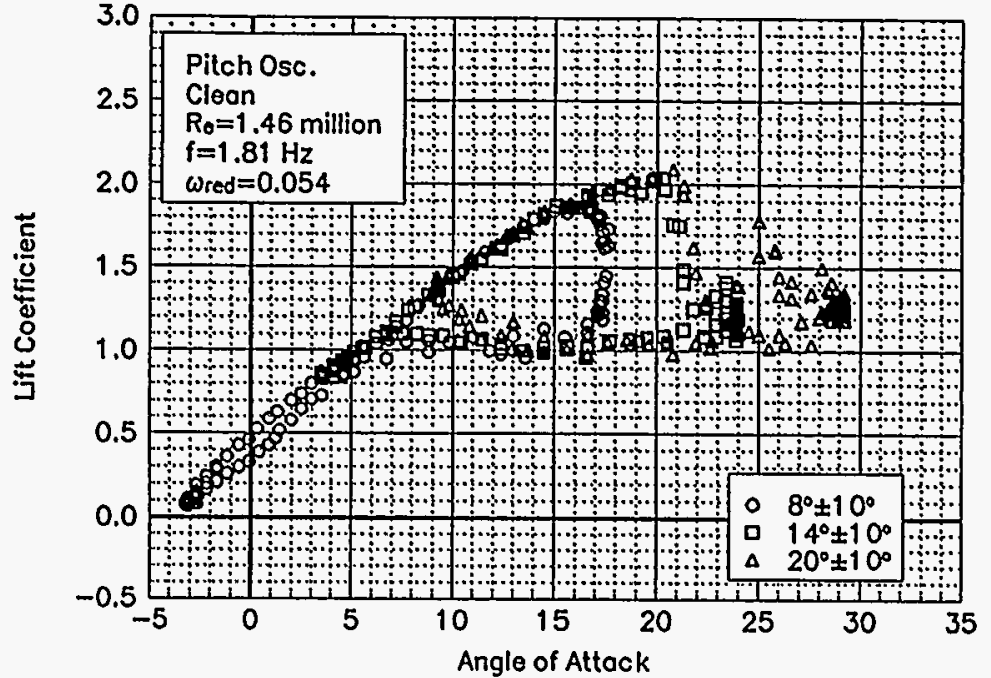

Figure C133. Lift coefficient vs $a$.

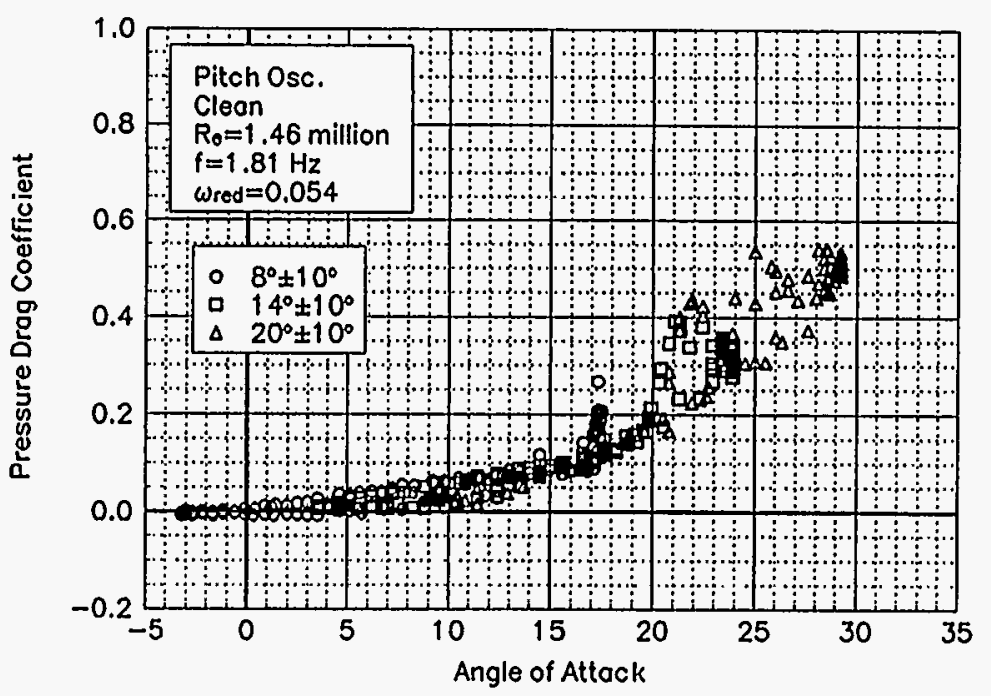

Figure C134. Pressure drag coefficient vs $a$.

\section{LS(1)-0417MOD Clean \\ $\operatorname{Re}=1.46$ million \\ $\omega_{\text {reduced }}=0.054$}

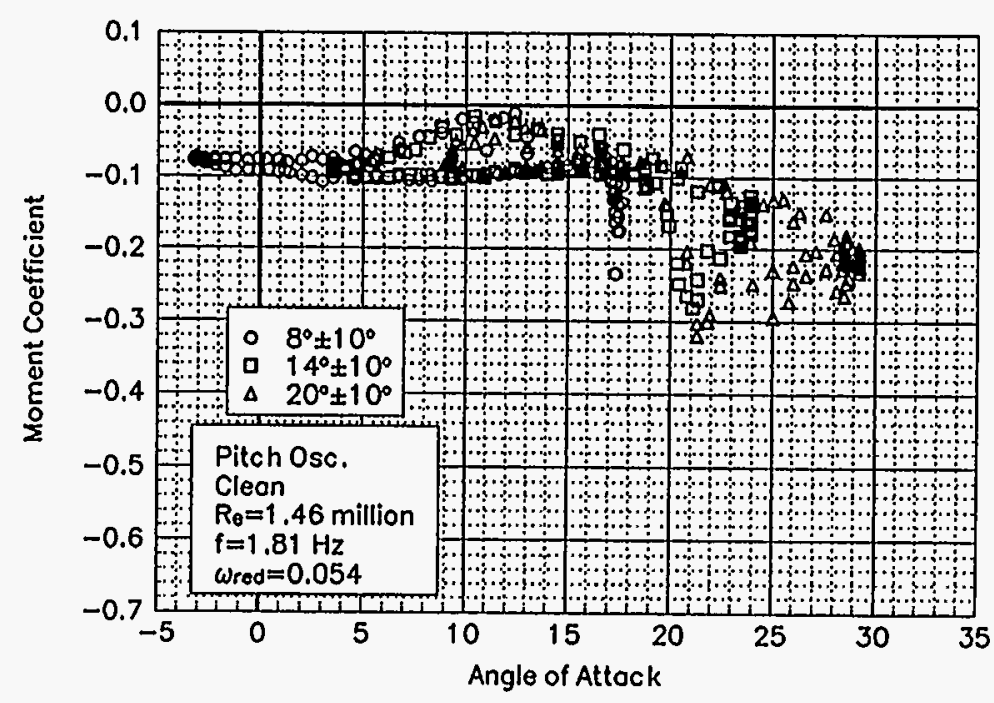

Figure C135. Moment coefficient vs $a$. 

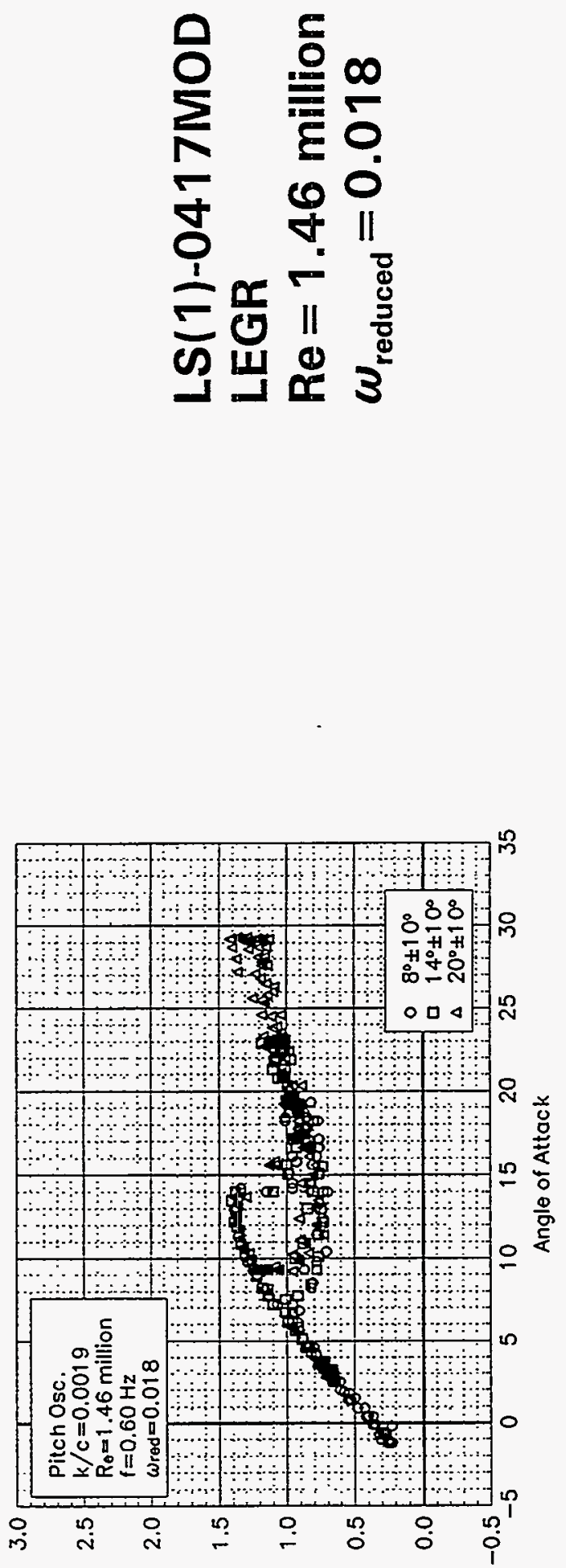

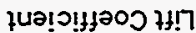

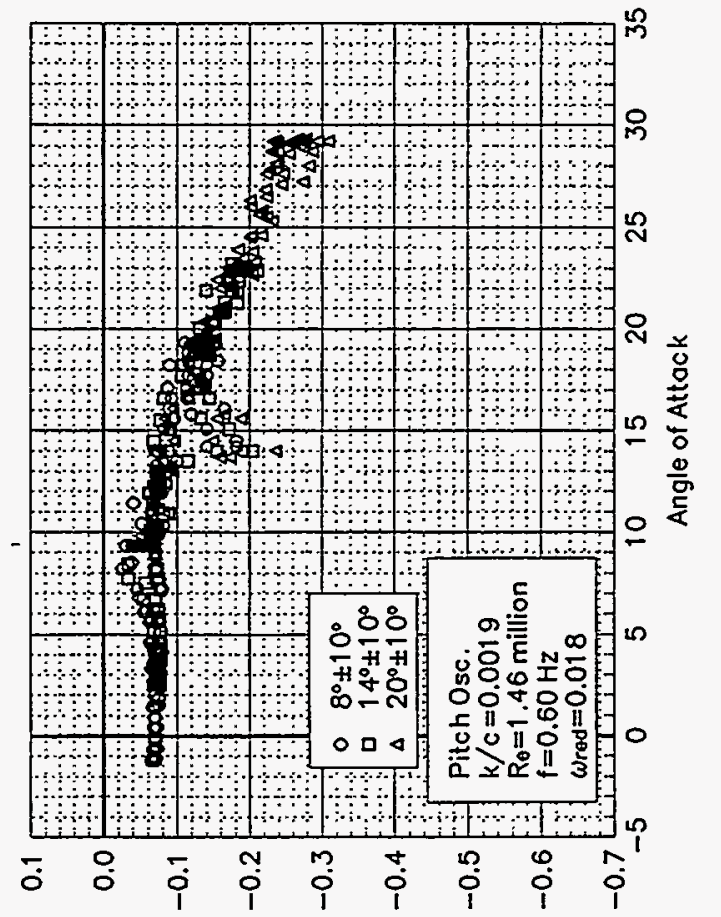

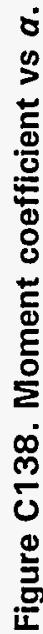

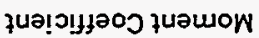

号

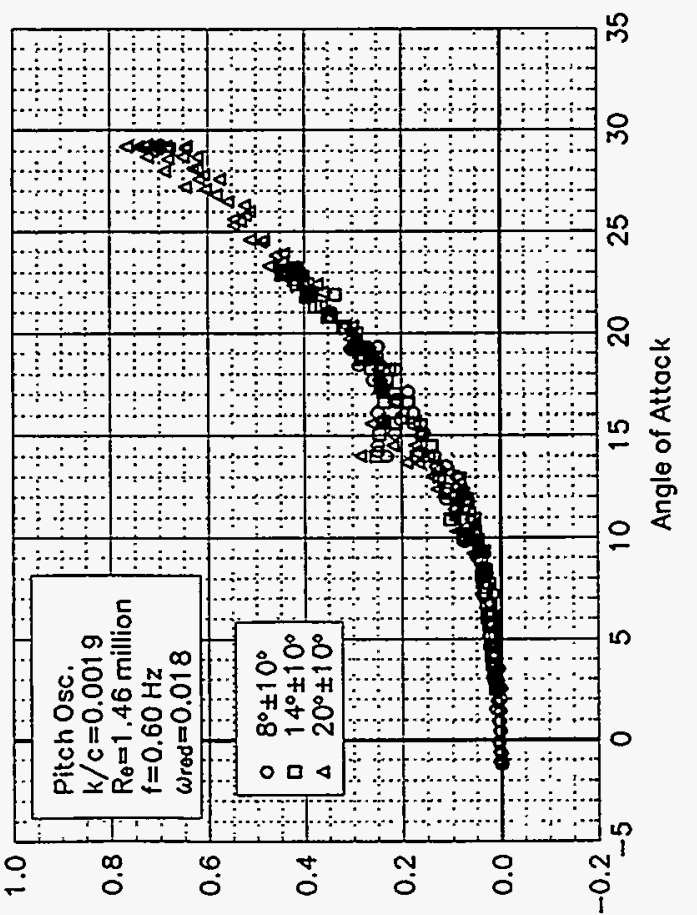

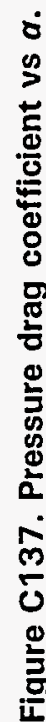

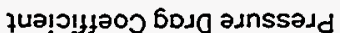



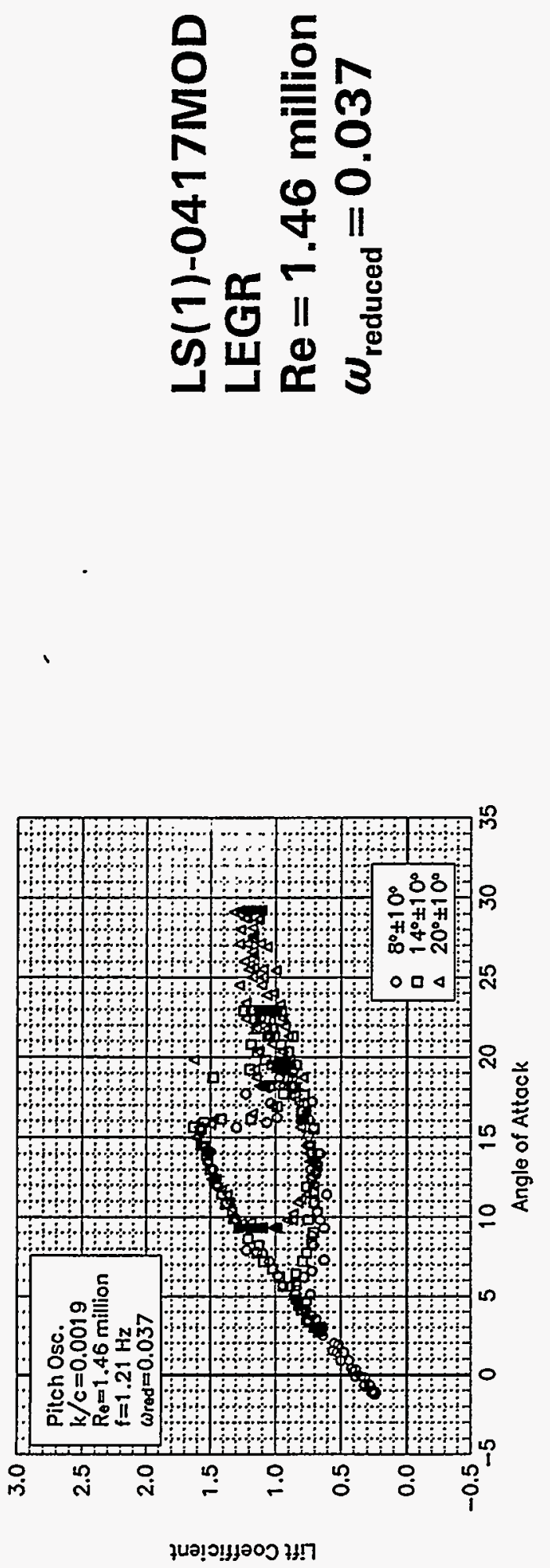

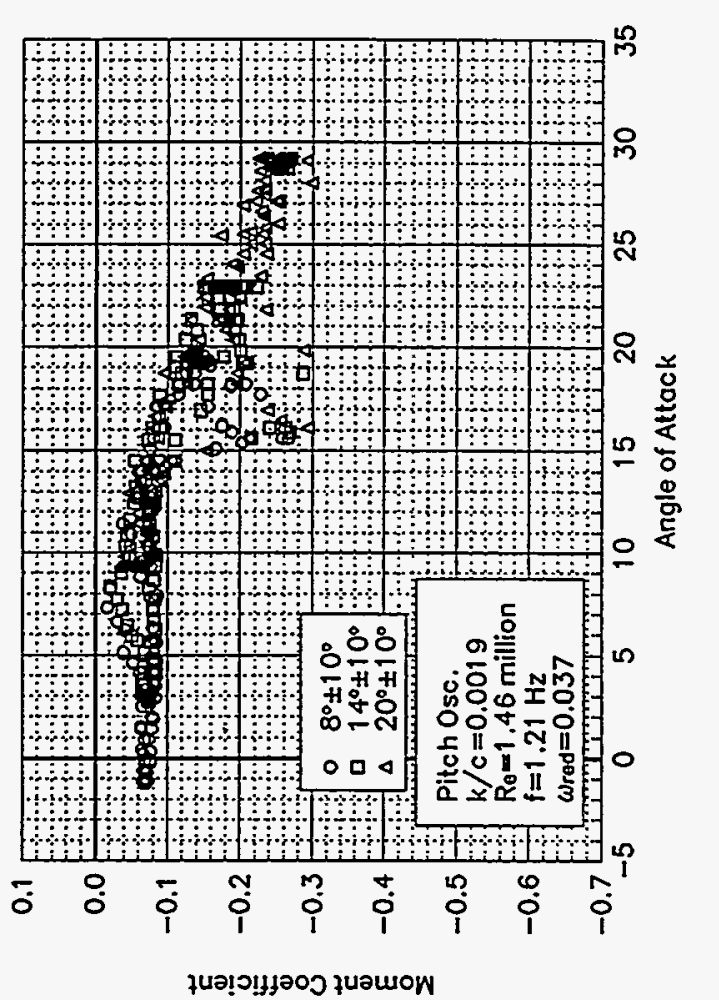

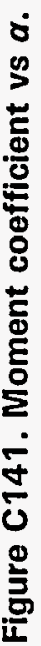

5

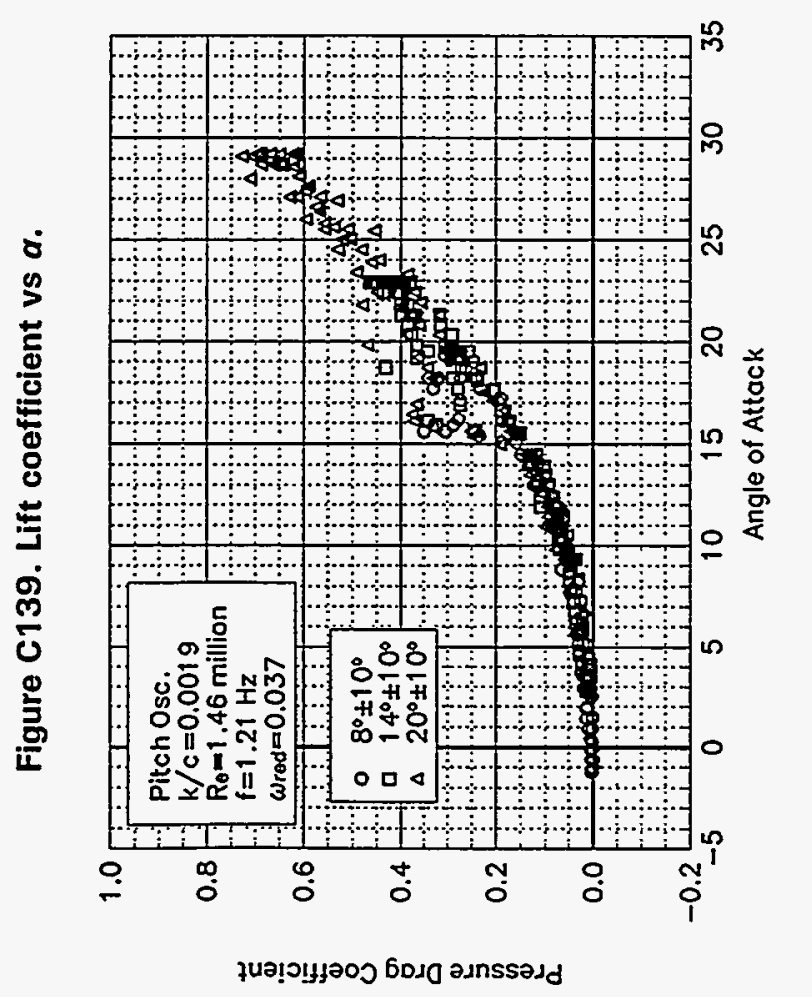

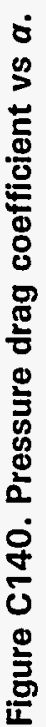



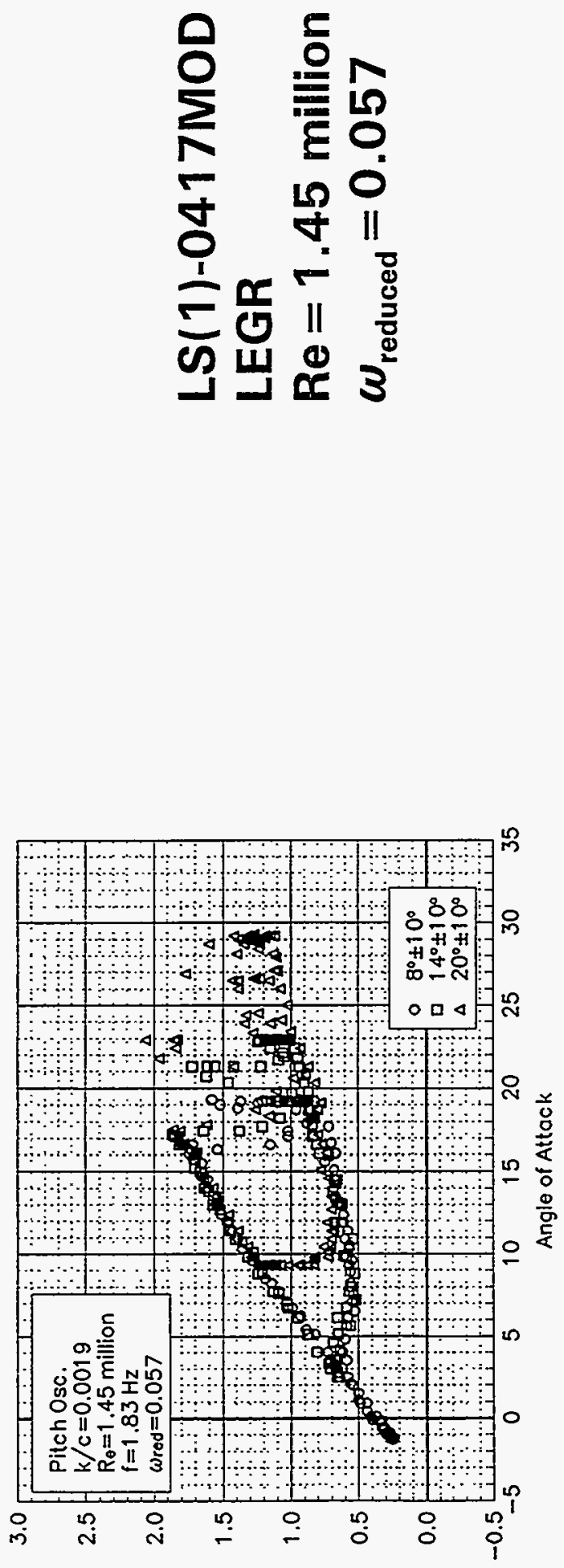

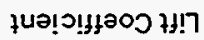

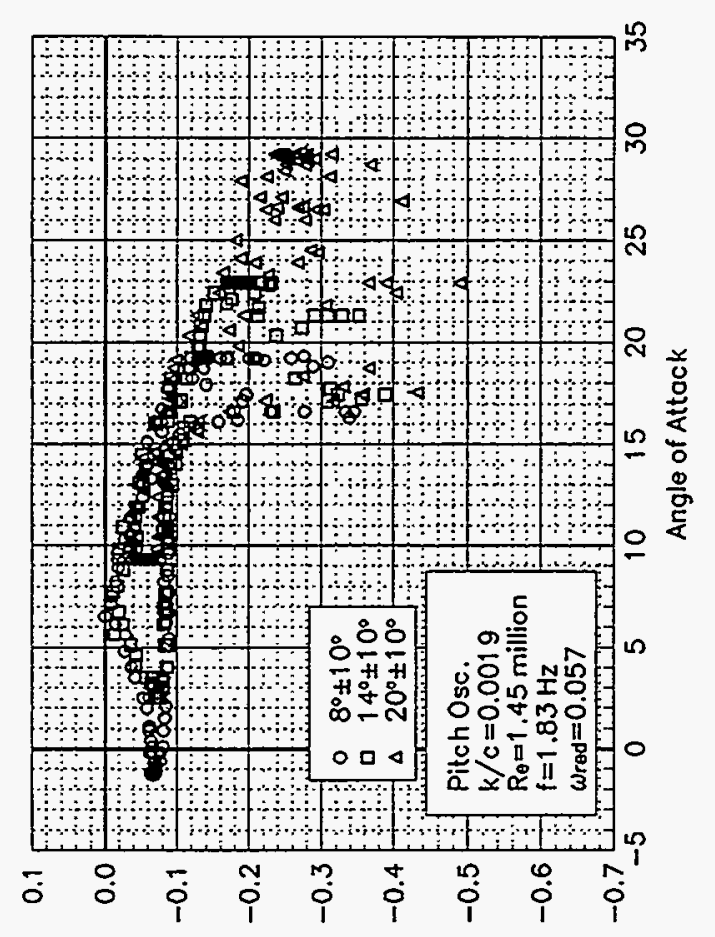

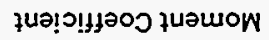

ن

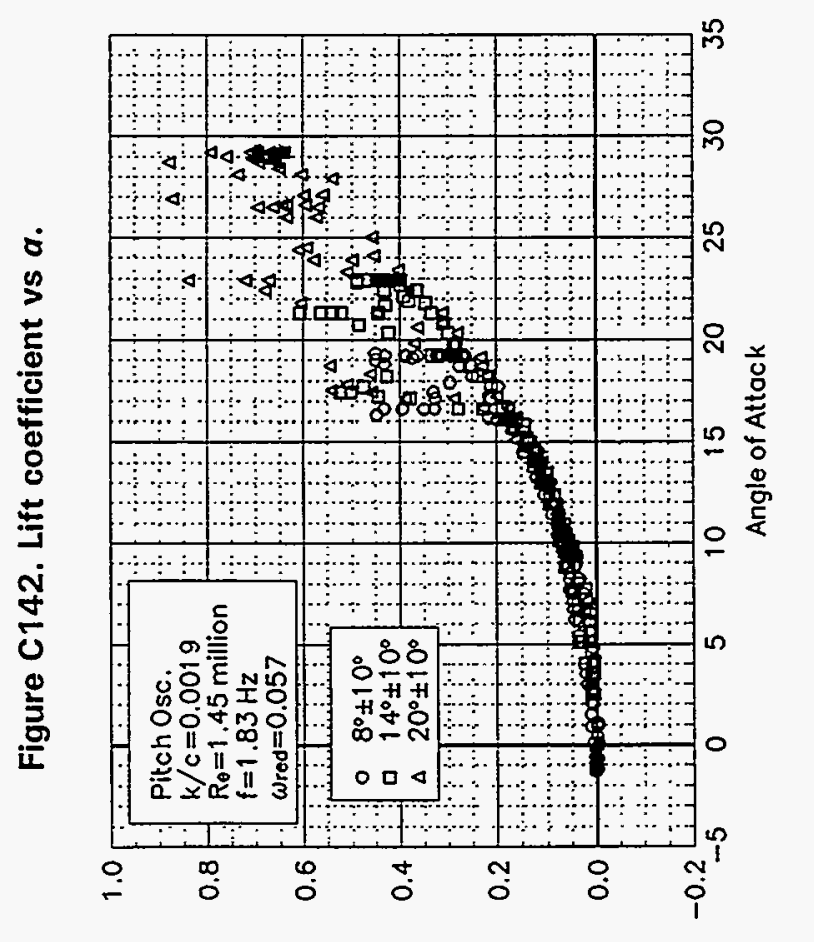

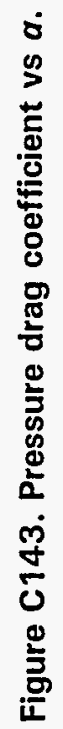
fua!ว! 


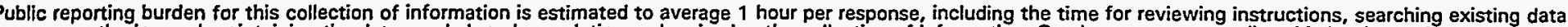

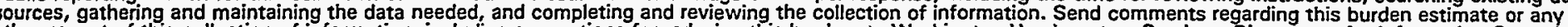

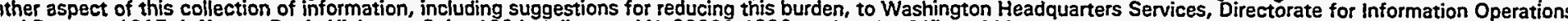

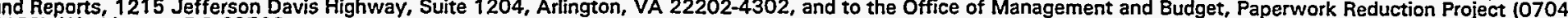
1188), Washington, DC 20503.

I.

\section{REPORT DATE}

January 1996
3. REPORT TYPE AND DATES COVERED Subcontract Report
H. TITLE AND SUBTITLE

Effects of Grit Roughness and Pitch Oscillations on the LS(1)-0417MOD Airfoil
5. FUNDING NUMBERS

C:

TA: WE619030
J. M. Janiszewska, R. Reuss Ramsay, M. J. Hoffmann, G. M. Gregorek

\section{TA: WE619030}

8. PERFORMING ORGANIZATION REPORT NUMBER

\section{PERFORMING ORGANIZ
Dr. Gerald Gregorek}

The Ohio State University

Aero \& Astronautical Research

2300 West Case Road

Columbus, Ohio 43220

(614) 292-5491

1. SPONSORING/MONITORING AGENCY NAME(S) AND ADDRESS(ES)

National Renewable Energy Laboratory

1617 Cole Blvd.

Golden, CO 80401-3393

10. SPONSORING/MONITORING AGENCY REPORT NUMBER

TP-442-7819

DE96000528

1. SUPPLEMENTARY NOTES

NREL Technical Monitor: C. P. Butterfield

2a. DISTRIBUTION/AVAILABILITY STATEMENT

National Technical Information Service

U.S. Department of Commerce

5285 Port Royal Road

Springfield, VA 22161 12b. DISTRIBUTION CODE

UC-1211

\section{ABSTRACT (Maximum 200 words)}

Horizontal axis wind turbine rotors experience unsteady aerodynamics due to wind shear when the rotor is yawed, when rotor blades pass through the support tower wake, and when the wind is gusting. An understanding of this unsteady behavior is necessary to assist in the calculations of rotor performance and loads. The rotors also experience performance degradation caused by surface roughness. These surface irregularities are due to the accumulation of insect debris, ice, and/or the aging process. Wind tunnel studies that examine both the steady and unsteady behavior of airfoils can help define pertinent flow phenomena, and the resultant data can be used to validate analytical computer codes.

An LS(1)-0417MOD airfoil model was tested in The Ohio State University Aeronautical and Astronautical Research Laboratory (OSU/AARL) $3 \times 5$ subsonic wind tunnel $(3 \times 5)$ under steady flow and stationary model conditions, as well as with the model undergoing pitch oscillations. To study the possible extent of performance loss due to surface roughness, a standard grit pattern (LEGR) was used to simulate leading edge contamination. After baseline cases were completed, the LEGR was applied for both steady state and model pitch oscillation cases. The Reynolds numbers for steady state conditions were $0.75,1,1.25$, and 1.5 million, while the angle of attack ranged from $-20^{\circ}$ to $+40^{\circ}$. With the model undergoing pitch oscillations, data were acquired at Reynolds numbers of $0.75,1,1.25$, and 1.5 million, at frequencies of $0.6,1.2$, and $1.8 \mathrm{~Hz}$. Two sine wave forcing functions were used, $\pm 5.5^{\circ}$ and $\pm 10^{\circ}$, at mean angles of attack of $8^{\circ}, 14^{\circ}$, and $20^{\circ}$. For purposes herein, any reference to unsteady conditions means the airfoil model was in pitch oscillation about the quarter chord.

7. SUBJECT TERMS

wind energy; horizontal-axis wind turbine; wind tunnel test data; wind turbine airfoil
15. NUMBER OF PAGES

16. PRICE CODE

20. LIMITATION OF ABSTRACT

UL

\author{
7. SECURITY CLASSIFICATION \\ OF REPORT \\ Unclassified
}

18. SECURITY CLASSIFICATION
OF THIS PAGE
Unclassified

19. SECURITY CLASSIFICATION OF ABSTRACT Unclassified 
